Fina1 Report

Security Assessment of Power Systems

Inc1uding Energy Storage

and with the

Integration of Wind Energy

Volume I

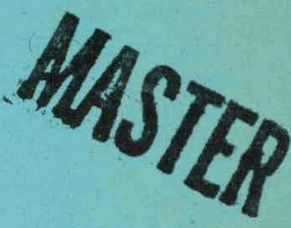

Do NoT

Microfilm Cover

Digital Transient Simulation Effort

Consulting Agreement No. 1

\title{
Performed by
}

Power Math Associates, Inc.

Tempe, Arizona

Dr. P. M. Anderson

Principal Investigator

June 30,1982

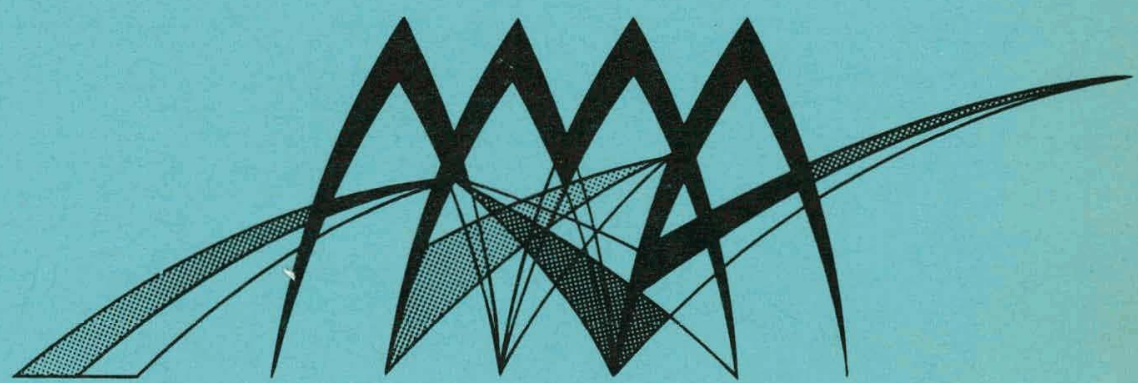




\section{DISCLAIMER}

This report was prepared as an account of work sponsored by an agency of the United States Government. Neither the United States Government nor any agency Thereof, nor any of their employees, makes any warranty, express or implied, or assumes any legal liability or responsibility for the accuracy, completeness, or usefulness of any information, apparatus, product, or process disclosed, or represents that its use would not infringe privately owned rights. Reference herein to any specific commercial product, process, or service by trade name, trademark, manufacturer, or otherwise does not necessarily constitute or imply its endorsement, recommendation, or favoring by the United States Government or any agency thereof. The views and opinions of authors expressed herein do not necessarily state or reflect those of the United States Government or any agency thereof. 


\section{DISCLAIMER}

Portions of this document may be illegible in electronic image products. Images are produced from the best available original document. 
DOE/ET/29100--21

DE82 021063

Final Report
Security Assessment of Power Systems
Including Energy Storage
and with the
Integration of Wind Energy

Volume I

DOE Contract EC-77-S-02-4206

Purdue University

Digital Transient Simulation Effort

Consulting Agreement No. 1

\title{
Performed by
}

\author{
Power Math Associates, Inc. \\ Tempe, Arizona
}

Dr. P. M. Anderson

Principal Investigator

June 30,1982

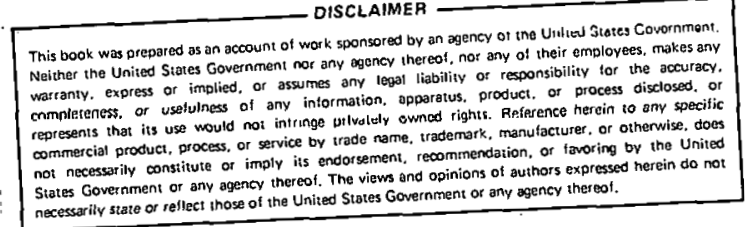


THIS PAGE

WAS INTENTIONALLY

LEFT BLANK 
Final Report

Digital Transient Simulation Effort

Tab1e of Contents

Page No.

1.0 Overview of Digital Simulation Effort . . . . . . . . . 1

1.1 Host Program Selection . . . . . . . . . . . . 1

1.2 Analysis of the Purdue MOD-2 Mode1 . . . . . . . . 2

1.2.1 The Mechanical System ............. 3

1.2.2 The Electrical System .............. 3

2.0 Digital Mode1ing of Synchronous Machines. . . . . . . . . 11

2.1 Basic Concepts of Machine Modeling for Stability . . . . 11

2.1.1 Synchronous Machine Saturation. . . . . . . 12

2.1 .2 Test Problem. . . . . . . . . . . . 15

2.2 F1ux Linkage Mode1 Representation. . . . . . . . . 16

2.2.1 Saturation of the F1ux Linkage Mode1. . . . . . 16

2.2.2 Simulation Results for the Flux Linkage Mode1 . . 17

2.3 E' Mode1 Representation ............. 19

2.3.1 Saturation of the E' Mode1.......... 20

2.3.2 Simulation Results for the E' Mode1. . . . . . 20

2.4 Simplified Saturation of the F1ux Linkage Mode1. . . . 23

2.5 Simp1ified Saturation of the E' Mode1 ......... 23

2.6 Conc1usions.................... 26

3.0 EPRI Stability Program Simulation . . . . . . . . . . . 27

3.1 Digital Mode1 of the Wind Turbine Generator. . . . . . 27

3.2 Wind Mode1.................... 34 
3.3 Modular Modeling for Digital Simulation. . . . . . . 41

3.4 ETMSTAB Simulation of the Wind Generator . . . . . . 48

4.0 Conclusions . . . . . . . . . . . . . . . . . 61

References........................ 63

Appendix A. Generator Simulation Results with Complete

Saturation for a $10 \%$ Step Change in $T_{m}$. . . . . . 67

Appendix B. Generator Simulation Results with Complete

Eaturation for a $5 \pi$ step Cliange in EFD. . . . . . . 111

Appendix C. Generator Simulation Results for the Flux

Linkage Model Comparing Fu11 Saturation to

Partial Saturation with Constant $\mathrm{L}_{\mathrm{MD}}$ and $\mathrm{L}_{\mathrm{MQ}} \cdot$. . . 155

Appendix D. Generator Simulation Results Comparing F1ux

Linkage and E'" Mode1s with the E' Mode1

Only Partialiy Saturated. . . . . . . . . . 177

Appendix E. Statistical Analysis of Differences in

Generator Simulation Kesults. . . . . . . . 199

Appendix F. Modffled ETMSTAB Subroutines. . . . . . . . . 257 
Figure 1.1 Block Diagram of MOD-2 Mechanical System. . . . . . . . . . 4 Figure 1.2 Block Diagram of EPRI Program Generator System Component Definitions. . . . . . . . . . 5

Figure 1.3 Block Diagram of the E' Mode1. . . . . . . . . . . 9

Figure 1.4 Block Diagram of the Flux Linkage Mode1 . . . . . . . . 10

Figure 2.1 Typical d-axis Open Circuit Saturation Curve. . . . . . 13

Figure 3.1 Block Diagram of the Digital MOD-2 Mode1. . . . . . . . 28

Figure 3.2 Power Coefficient as a Function of Gama

for Pitch Angles of (top to bottom) 0-36 degrees

in 4 degree increments. . . . . . . . . . . . . 30

Figure 3.3 Wind Turbine Output Power vs Wind Velocity at

Rated Blade Angular Velocity, Pitch Angles

(top to bottom) of $0,4,8,12,16$ and 20 degrees..... 31

Figure 3.4 Wind Turbine Torque-Speed Characteristic,

Pitch Angles of $0-36$ in 4 degree increments........ 32

Figure 3.5 Wind Turbine Power-Speed Characteristic,

Pitch Angles of $0-36$ in 4 degree increments...... . 33

Figure $3.6 \quad$ Block Diagram of Wind Mode1 . . . . . . . . . . . . 36

Figure 3.7 Wind Model Simulation with $V_{W B}=30 \mathrm{mi} / \mathrm{h}(44 \mathrm{ft} / \mathrm{s}) . . . . .39$ 
Figure 3.8 Wind Model Simulation with $V_{W B}=30 \mathrm{mi} / \mathrm{h}(44 \mathrm{ft} / \mathrm{s})$

(a) Random Noise with $\Delta \omega=0.5$;

(b) Random Noise with $\Delta \omega=0.5$, Ramp with $M A X R=10 \mathrm{mi} / \mathrm{h}$,

$T_{1 R}=5 s, T_{2 R}=10 \mathrm{~s}$, and Gust $w i$ th $M A X G=10 \mathrm{mi} / \mathrm{h}$,

$\mathrm{T}_{\mathrm{G}}=5 \mathrm{~s}, \mathrm{~T}_{1 \mathrm{G}}=15 \mathrm{~s} . . . . . . . . . . . . . . .440$

Figure 3.9 Histogram of Random Noise Component with

$\Delta \omega=2.0 \mathrm{rad} / \mathrm{s} . . . . . . . . . . . . . . . . . . .42$

Figure 3.10 Digital Implementation of the Notch Filter. . . . . . . 45

Figtre 3.11 Nine Bus Test System; Top: Impedance Diagram,

Bottom: Initial Conditions................ 49

Figure 3.12 Wind Turbine Yerformanuc for Cage FTol. . . . . . . . . . . 50

Figure 3.13 Wind Turbine Performance for Case WT02. . . . . . . . . . 51

Figure 3.14 Wind Turbine Performance for Case WT03. . . . . . . . . 52

Figure 3.15. Wind Turbine Performance for Case HTO4. . . . . . . . . 53

Figure 3,16 Wind Turbine Performance for Case WTO5........... . 54

Figure 3.17 Wind Turbinè Perfurwanoc for Case WT06. . . . . . . . . . 55

Figure 3.18 Wind Turbine Performance for Case WT07............ 56

Figure 3.19 Wiud Turbine Performance for Case WTU8. . . . . . . . 57

Figure 3.20 Wind Turbine Performance for Case TT09. . . . . . . . . 58

Figure 3.21 Wind Turbine Performance for Case WT10. . . . . . . . . 59

Fignre A.1.a $T_{m}$ vs time in seconds, flux 1inkage mode1 (a),

step change in $T_{m}$, satnrated $(*)$ and unsaturated response 68

Figure A.1.b $T_{m}$ vs time in seconds, $E$ !' $\operatorname{mode1}(b)$,

step change in $T_{m}$, saturated (*) and unsaturated response . 69

Figure A.2.a E $E_{F D}$ vs time in seconds, flax 1inkage mode1 (a),

step change in $T_{m}$, saturated (*) and unsaturated response 70 
Figure A.2.b $E_{F D}$ vs time in seconds, E'' mode1 (b), step change in $T_{m}$, saturated $(*)$ and unsaturated response 41

Figure A.3.a $V_{t}$ vs time in seconds, flux 1inkage mode1 (a),

step change in $T_{m}$, saturated $(*)$ and unsaturated response .72

Figure A.3.b $V_{t}$ vs time in seconds, E' model (b),

step change in $T_{m}$, saturated $(*)$ and unsaturated response 73

Figure A.4.a $I_{a}$ vs time in seconds, flux linkage model (a),

step change in $T_{m}$, saturated $\left(^{*}\right)$ and unsaturated response .74

Figure A.4.b $I_{a}$ vs time in seconds, E' model (b),

step change in $T_{m}$, saturated (*) and unsaturated response. 75

Figure A.5.a $T_{e}$ vs time in seconds, flux linkage model (a),

step change in $T_{m}$, saturated (*) and unsaturated response 76

Figure A.5.b $T_{e}$ vs time in seconds, E' model (b),

step change in $T_{m}$, saturated $(*)$ and unsaturated response, 77

Figure A.6.a $\Delta \omega$ vs time in seconds, flux 1 inkage model (a),

step change in $T_{m}$, saturated $(*)$ and unsaturated response. 78

Figure A.6.b $\Delta \omega$ vs time in seconds, E' mode1 (b),

step change in $T_{m}$, saturated (*) and unsaturated response 79

Figure A.7.a $\delta$ vs time in seconds, flux linkage model (a),

step change in $T_{m}$, saturated $(*)$ and unsaturated response 80

Figure $A, 7 . b$ ' 6 s time ini seconds, E' $\operatorname{mode} 1$ (b),

step change in $T_{m}$, saturated (*) and unsaturated response 81

Figure A.8.8 $S_{g d} v s$ time in seconds, flux 1 inkage model (a),

step change in $T_{m}$, saturated (*) and unsaturated response, 82

Figure A.8.b $S_{g d} v s$ time in seconds, E' mode1 (b),

step change in $T_{m}$, saturated $(*)$ and unsaturated response 48 
Figure A.9.a AD vs time in seconds, flux 1 inkage mode1 (a), step change in $T_{m}$, saturated (*) and unsaturated response. 84

Figure A.9.b $\psi_{\mathrm{AD}} \mathrm{vs}$ time in seconds, E' model (b), step change in $T_{m}$, saturated (*) and unsaturated response. 85

Figure A.10.a $\psi_{d}$ vs time in seconds, flux 1 inkage mode1 (a), step change iti $T_{m}$, saturated (*) and unsaturated response 46

Figure A.10.b $\Psi_{d}$ vs time in seconds, E' $\operatorname{model}(\mathrm{b})$, step change in $T_{m}$, saturated (*) and unsaturated response .87

Figure A.11.a $\psi_{F}$ vs time in seconds, f1ux linkage mode1 (a), step change in $T_{m}$, saturated (*) and unsaturated response . 88

Figure A.11.b $\psi_{F}$ vs time in seconds, E' mode1 (b), step change in $T_{m}$, saturated (*) and unsaturated response. 89

Figure A.12.a $\psi_{\text {kd }}$ vs time in seconds, flux linkage model (a), step change in $T_{m}$, saturated (*) and unsaturated response . 90

Figure A.12.b $\psi_{\text {kd }}$ vs time in seconds, E' model (b), step change in $T_{m}$, saturated $(*)$ and unsaturated response. 91

Figure A.13.ü $I_{d}$ Ps time in seconds, flnx linkago modol (a), step change in $T_{m}$, saturated (*) and unsaturated response 92

Figure A.13.b. Id vs time in seconds, E' mode1 (b), step change in $T_{m}$, saturated $(*)$ and unșuturated response, 93

Figure A.14, a If vs time in sernnis, f1ux 1inkage modol (a), step change in $T_{m}$, saturated (*) and unsaturated response - 94

Figure A.14.b If $I_{f}$ time in seconds, E' mode1 (b), step change in $T_{m}$, saturated (*) and unsaturated response 95

Figure A.15.a $I_{\mathrm{kd}}$ vs time in seconds, E' mode1 (b), step change in $T_{m}$, saturated (*) and nosaturated response. 96 
Figure A.15.b $I_{k d} v s$ time in seconds, E' $\operatorname{mode1}(b)$,

step change in $T_{m}$, saturated $\left(^{*}\right)$ and unsaturated response.

Figure A.16.a $S_{g p}$ vs time in seconds, flux linkage model (a),

step change in $T_{m}$, saturated $(*)$ and unsaturated response. 98

Figure A.16.b $S_{g p}$ vs time in seconds, E' mode1 (b),

step change in $T_{m}$, saturated $(*)$ and unsaturated response 99

Figure A.17.a $\psi_{A Q}$ vs time in seconds, flux linkage mode1 (a),

step change in $T_{m}$, saturated (*) and unsaturated response. 100

Figure A.17.b $\psi_{A Q}$ vs time in seconds, E' mode1 (b),

step change in $T_{m}$, saturated (*) and unsaturated response. 101

Figure A.18.a $\Psi_{q}$ vs time in seconds, f1ux linkage model (a),

step change in $T_{m}$, saturated (*) and unsaturated response 102

Figure A.18.b $\psi_{q}$ vs time in seconds, E' model (b),

step change in $T_{m}$, saturated (*) and unsaturated response. 103

Figure A.19.a $\psi_{k q}$ vs time in seconds, flux linkage model (a),

step change in $T_{m}$, saturated (*) and unsaturated response. 104

Figure A.19.b $\psi_{k q}$ vs time in seconds, E' model (b),

step change in $T_{m}$, saturated (*) and unsaturated response 105

Figure A.20.a $I_{q}$ vs time in seconds, flux 1inkage mode1 (a),

step change in $T_{m}$, saturated (*) and unsaturated response. 106

Figure A.20.b $I_{q}$ vs time in seconds, E' model (b),

step change in $T_{m}$, saturated $(*)$ and unsaturated response 107

Figure A.21.a $I_{k q}$ vs time in seconds, flux linkage model (a),

step change in $T_{m}$, saturated (*) and unsaturated response. 108

Figure A.21.b $I_{k q}$ vs time in seconds, E' mode1 (b),

step change in $T_{m}$, saturated (*) and unsaturated response. 109 
Figure B.1.a $T_{m}$ vs time in seconds, flux linkage model (a), step change in EFT, saturated (*) and unsaturated response. 112

Figure B.1.b $T_{m}$ vs time in seconds, E' model (b), step change in EFD, saturated (*) and unsaturated response. 113

Figure B.2.a EFD vs time in seconds, f1ux 1inkage mode1 (a), step change in EFD, saturated (*) and unsaturated response. 114

Figure B.2.b E FD s time in seconds, E' model (b), step change in EFD, saturated (*) and unsaturated resnonse. 115

Figure B.3.a $V_{t}$ vs time in seconds. flnx linkage mode1 (a), step change in EFD, saturated (*) and unsaturated response. 116

Figure B.3.b $V_{t}$ vs time in seconds, $E^{\prime \prime} \operatorname{model}(b)$, step change in EFD, saturated (*) and unsaturated response. 117

Figure B.4.a I vs time in seconds, flux 1 inkage mode1 (a), step change in EFD, saturated (*) and unsaturated response. 118

Figure B.4.b $I_{a}$ vs time in seconds, E' 'mode1 (b), step change in EFD, saturated (*) and unsaturated responec. 119 Figure R.5.2 $T_{e}$ ys tithe in coconds, flux linkage model (a), step change in EFD, saturated (*) and unsaturated response, 120

Figure B.5.b $T_{e}$ vs time in seconds. E' 'mode1 (b), step change in EFD, saturated (*) and unsaturated response. 121

Figute B.6.a $\Delta \omega$ vs time in seconds, flux linkage model (a), step change in EFD, saturated (*) and unsaturated rosponse. 122

Figure B.6.b $\Delta \omega$ vs time in seconds, E' model (b), step change in EFD, saturated (*) and unsaturated response. 123

Figure B.7.a $\delta$ vs time in seconds, flux 1inkage model (a), step change in EFD, saturated (*) and unsaturated response. 124 
Figure B.7.b $\delta$ vs time ini seconds, E'" model (b),

step change in EFD, saturated (*) and unsaturated response. 125

Figure B.8.a $S_{g d} v s$ time in seconds, flux linkage model (a),

step change in EFD, saturated (*) and unsaturated response. 126

Figure B.8.b $S_{g d}$ s time in seconds, E' mode1 (b),

step change in EFD, saturated (*) and unsaturated response. 127

Figure B.9.a $\psi_{A D} v s$ time in seconds, f1ux linkage mode1 (a),

step change in EFD, saturated (*) and unsaturated response. 128

Figure B.9.b $\psi_{\mathrm{AD}} \mathrm{vs}$ time in seconds, E' $\operatorname{mode1}(\mathrm{b})$,

step change in EFD, saturated (*) and unsaturated response. 129

Figure B.10.a $\psi_{d}$ vs time in seconds, flux linkage model (a),

step change in EFD, saturated (*) and unsaturated response. 130

Figure B.10.b $\psi_{d}$ vs time in seconds, E'' model (b),

step change in EFD, saturated (*) and unsaturated response. 131

Figure B.11.a $\psi_{F}$ vs time in seconds, f1ux 1 inkage model (a),

step change in EFD, saturated (*) and unsaturated response. 132

Figure B.11.b $\psi_{F}$ vs time in seconds, E' model (b),

step change in EFD, saturated (*) and unsaturated response. 133

Figure B.12.a $\psi_{k d} \nabla s$ time in seconds, flux 1 inkage mode1 (a),

stcp change in EFD, saturated (*) and unsaturated response. 134

Figure B.12.b $\psi_{k d} v s$ time in seconds, E' $\operatorname{mode1}(b)$,

step change in EFD, saturated (*) and unsaturated response. 135

Figure B.13.a $I_{d}$ vs time in seconds, flux linkage mode1 (a),

step change in EFD, saturated (*) and unsaturated response. 136

Figure B.13.b $I_{d}$ vs time in seconds, E' mode1 (b),

step change in EFD, saturated (*) and unsaturated response. 137 
Figure B.14.a $I_{f}$ vs time in seconds, f1ux 1 inkage mode1 (a), step change in EFD, saturated (*) and unsaturated response. 138

Figure B.14.b If vs time in seconds, E' $\operatorname{mode1}(\mathrm{b})$, step change in EFD, saturated (*) and unsaturated response. 139

Figure B.15.a $I_{k d} v s$ time in seconds, E' mode1 (b), step change in EFD, saturated (*) and unsaturated response. 140

Figure B.15.b $I_{k d}$ vs time in seconds, E' mode1 (b), step change in EFD, saturated (*) and unsaturated response. 141

Figure B.16.a $S_{g p}$ vs time in seconds, flux 11nkage mode1 (a), step change in EFD, saturated (*) and unsaturated rosponse. 142

Figure B.16.b $s_{\text {gP }}$ vs time in seconds, E' model (b), step change in EFD, saturated (*) and unsaturated response. 143

Figure B.17.a $\psi_{A Q}$ vs time in seconds, flux linkage model (a), step change in EFD, saturated (*) and unsaturated response. 144

Figure B.17.b $\psi_{A Q}$ vs time in seconds, $E^{\prime \prime} \operatorname{mode1}(\mathrm{b})$, step change in EFD, saturated (*) and unsaturated respunse. 145

Figure B.18.a $\psi_{q}$ vs time in seconds, f1ux linkage model (a), step chänge in EFD, saturatod (*) and unsaturated response. 146

Figure B.18.b $\Psi_{q}$ vs time in seconds, E'" model (b), ctop change in EFD, saturated (*) and unsaturated response. 147

Figure B.19.a $\psi_{\mathrm{kq}}$ vs time in seconds, flux linkage model (a), step change in EFD; saturated (*) and nusaturated response. 148

Figure R.19.b $\psi_{k q}$ vs time in seconds, E' $\operatorname{mode1}(\mathrm{b})$, step change in EFD, saturated (*) and unsaturated response. 149 Figure B.20.a $I_{q}$ vs time in seconds, f1ux 1inkage mode1 (a), step change in EFD, saturated (*) and unsaturated response. 150 
Figure B.20.b $I_{q}$ vs time in seconds, E' mode1 (b), step change in EFD, saturated (*) and unsaturated response. 151

Figure B.21.a $I_{k q}$ vs time in seconds, f1ux 1 inkage mode1 (a), step change in EFD, saturated (*) and unsaturated response. 152

Figure B.21.b $I_{k q}$ vs time in seconds, E' mode1 (b), step change in EFD, saturated (*) and unsaturated response. 153

Figure C.1 $T_{m}$ vs time in seconds, Simplified F1ux Linkage Mode1, Top: 10\% Change in $\mathrm{T}_{\mathrm{m}}$, Bottom: 5\% Change in $\mathrm{E}_{\mathrm{FD}} . . . . .156$ Figure C.2 E FD time in seconds, Simplified F1ux Linkage Mode1, Top: 10\% Change in $\mathrm{T}_{\mathrm{m}}$, Bottom: $5 \%$ Change in $\mathrm{E}_{\mathrm{FD}} . . . . .157$ Figure C.3 $V_{t}$ vs time in seconds, Simplified F1ux Linkage Mode1, Top: 10\% Change in $T_{m}$, Bottom: 5\% Change in $E_{F D} \cdot . . . .158$ Figure C.4 $I_{a}$ vs time in seconds, Simplified Flux Linkage Model, Top: 10\% Change in $\mathrm{T}_{\mathrm{m}}$, Bottom: 5\% Change in $\mathrm{E}_{\mathrm{FD}} \cdot . . . .159$ Figure C.5 $T_{e}$ s time in seconds, Simplified F1nx Linkage Mode1, Top: 10\% Change in $\mathrm{T}_{\mathrm{m}}$, Bottom: $5 \%$ Change in $\mathrm{E}_{\mathrm{FD}} . . . . .160$ Figure C.6 $\Delta \omega$ vs time in seconds, Simplified F1ux Linkage Model, Top: $10 \%$ Change in $T_{m}$, Bottom: 5\% Change in $E_{F D} . . . . .161$

Figure C.7 $\delta$ vs time in seconds, Simp1ified F1ux Linkage Mode1, Top: 10\% Change in $\mathrm{T}_{\mathrm{m}}$, Bottom: 5\% Change in $\mathrm{E}_{\mathrm{FD}} . . . . .162$ Figure C. $8 \quad S_{\text {GD }}$ vs time in seconds, Simplified F1ux Linkage Mode1, Top: 10\% Change in $\mathrm{T}_{\mathrm{m}}$, Bottom: $5 \%$ Change in $\mathrm{E}_{\mathrm{FU}}, \ldots ., ., 163$ Figure C.9 $\psi_{\text {AD }}$ vs time in seconds, Simplified Flüx Liukago Model, Top: $10 \%$ Change in $\mathrm{T}_{\mathrm{m}}$. Bottom: 5\% Change in $\mathrm{E}_{\mathrm{FD}}$..... 164 Figure C.10 $\psi_{d}$ vs time in seconds, Simplified Flux Linkage Mode1, Top: 10\% Change in $\mathrm{T}_{\mathrm{m}}$, Bottom: 5\% Chauge in $\mathrm{E}_{\mathrm{FD}} . . . . .165$ 
Figure C.11 $\psi_{F}$ vs time in seconds, Simplified F1ux Linkage liodel,

Top: 10\% Change in $\mathrm{T}_{\mathrm{m}}$, Bottom: 5\% Change in $\mathrm{E}_{\mathrm{FD}} . . . . .166$

Figure C.12 $\psi_{\text {kd }}$ vs time in seconds, Simplified Flux Linkage Model,

Top: $10 \%$ Change in $\mathrm{T}_{\mathrm{m}}$, Bottom: $5 \%$ Change in $\mathrm{E}_{\mathrm{FD}} . . . . .167$

Figure C.13 I I vs time in seconds, Simplified F1ux Linkage Model,

Top: 10\% Change in $\mathrm{T}_{\mathrm{m}}$, Bottom: 5\% Change in $\mathrm{E}_{\mathrm{FD}} . . . . .168$

Figure C.14 I $I_{F}$ s time in seconds, Simplified F1nx Linkage Mode1,

Top: 10\% Change in $T_{m}$, Bottom: 5\% Changc in EFD . . . . 169

Figure C.15 I $I_{\text {kd }}$ vs time in seconds, Simplified F1ux Linkage Model.

Top: 10\% Change in $T_{m}$, Bottom: 5\% Change in $E_{F D}$. . . . 170

Figure C.16 $S_{G q}$ vs time in seconds, Simplified F1ur Linkage Mode1,

Top: 10\% Change in $\mathrm{T}_{\mathrm{m}}$, Bottom: $5 \%$ Change in $\mathrm{E}_{\mathrm{FD}} . . . . .171$

Figure C.17 $\Psi_{A Q}$ vs time in seconds. Simplified Flux Linkage Mode1,

Top: $10 \%$ Change in $\mathrm{T}_{\mathrm{m}}$, Bottom: 5\% Change in $\mathrm{E}_{\mathrm{FD}} . . . . .172$

Figure C.18 $\psi_{q}$ vs time in seconds, Simplified Flux Linkage Model,

Tup: 10\% Change in $\mathrm{T}_{\mathrm{m}}$, Bottom: 5\% Change in $\mathrm{E}_{\mathrm{FD}} . . . .173$

Figure C.19 $\psi_{\text {kq }}$ vs time in seconds, Simplified Flux Linkago Mode1,

Top: 10m Change in $\mathrm{T}_{\mathrm{m}}$, Bottom: 5\% Change in $\mathrm{E}_{\mathrm{FD}}$. . . . . 174

Figure C.20 $I_{q}$ vs.time in seconds, Simp1ified F1ux Linkage Mode1,

Top: $10 \%$ Change in $\mathrm{T}_{\mathrm{m}}$, Bottom: $5 \%$ Change in $\mathrm{E}_{\mathrm{FD}} . . . . .175$

Figure C.21 $I_{\mathrm{kq}}$ vs time in seconds, Simplified F1ux. Linkage Mode1,

Top: 10\% Change in $\mathrm{T}_{\mathrm{m}}$. Bottom: $5 \%$ Change in $\mathrm{E}_{\mathrm{FD}} . . . .176$

Figure D.1 $T_{m}$ vs time in seconds, Simplified E'" Model,

Top: $10 \%$ Change in $\mathrm{T}_{\mathrm{m}}$, Rottom: $5 \%$ Chunge in $\mathrm{E}_{\mathrm{FD}}$..... 178

Figure D.2 EFD $\mathrm{E}_{\mathrm{s}}$ time in seconds, Simplified E'" Mode1,

Top: 10\% Change in $\mathrm{T}_{\mathrm{m}}$, Bottom: 5\% Change in $\mathrm{E}_{\mathrm{FD}}$..... 179 
Figure D.3 $\quad V_{t}$ vs time in seconds, Simplified E' Mode1,

Top: $10 \%$ Change in $\mathrm{T}_{\mathrm{m}}$, Bottom: $5 \%$ Change in $\mathrm{E}_{\mathrm{FD}}$. . . . 180

Figure D.4 $I_{a}$ vs time in seconds, Simplified E'.' Mode1,

Top: 10\% Change in $\mathrm{T}_{\mathrm{m}}$, Bottom: 5\% Change in $\mathrm{E}_{\mathrm{FD}}$..... 181

Figure D.5 Te vs time in seconds, Simplified E''Mode1,

Top: 10\% Change in $\mathrm{T}_{\mathrm{m}}$, Bottom: $5 \%$ Change in $\mathrm{E}_{\mathrm{FD}} \cdot . . . .182$

Figure D.6 .. $\Delta \omega$ vs time in seconds, Simplified E'' Model,

Top: $10 \%$ Change in $\mathrm{T}_{\mathrm{m}}$, Bottom: $5 \%$ Change in $\mathrm{E}_{\mathrm{FD}} \cdot \ldots . . \therefore 183$

Figure D.7 $\delta$ vs time in seconds, Simplified E'' Mode1,

Top: 10\% Change in $\mathrm{T}_{\mathrm{m}}$, Bottom: 5\% Change in $\mathrm{E}_{\mathrm{FD}}$. . . . . 184

Figure D.8 $S_{G D}$ vs time in seconds, Simplified E''Mode1,

Top: 10\% Change in $T_{m}$, Bottom: 5\% Change in $E_{F D} \cdot . . . .185$

Figure D.9 $\psi_{\text {AD }}$ vs time in seconds, Simplified E'" Mode1,

Top: 10\% Change in $T_{m}$. Bottom: 5\% Change in $E_{F D}$. . . . 186

Figure D.10 $\psi_{\mathrm{d}}$ vs time in seconds, Simplified E' Mode1,

Top: 10\% Change in $T_{m}$, Bottom: 5\% Change in $E_{F D}$..... 187

Figure D.11 $\psi_{F}$ vs time in seconds, Simplified E'' Mode1,

Top: $10 \%$ Change in $T_{m}$, Bottom: $5 \%$ Change in $E_{F D} \cdot . . . .188$

Figure D.12 $\psi_{k d}$ vs time in seconds, Simplified E'" Model,

Top: $10 \%$ Change in $T_{m}$, Bottom: $5 \%$ Change in $E_{F D} . . . . .189$

Figure D.13 $I_{d}$ vs time in seconds, Simplified E' Mode1,

Top: 10\% Change in $\mathrm{T}_{\mathrm{m}}$, Bottom: 5\% Change in $\mathrm{E}_{\mathrm{FD}}$..... 190

Figure D.14 I $I_{F}$ vs time in seconds, Simplified E' Mode1,

Top: 10\% Change in $\mathrm{T}_{\mathrm{m}}$, Bottom: 5\% Change in $\mathrm{E}_{\mathrm{FD}}$..... 191

Figure D.15 $I_{k d}$ vs time in seconds, Simp1ified E' Mode1,

Top: 10\% Change in $\mathrm{T}_{\mathrm{m}}$, Bottom: 5\% Change in $\mathrm{E}_{\mathrm{FD}} . . . . .192$ 
Figure D.16 $S_{G Q}$ vs time in seconds, Simp1ified E'' Mode1,

Top: 10\% Change in $\mathrm{T}_{\mathrm{m}}$, Bottom: 5\% Change in $\mathrm{E}_{\mathrm{FD}} . . . . .193$

Figure D.17 $\Psi_{A Q}$ vs time in seconds, Simplified E' Model,

Top: 10\% Change in $T_{m}$, Bottom: $5 \%$ Change in $E_{F D}$. . . . 194

Figure D.18 $\psi_{\mathrm{q}}$ vs time in seconds, Simplified E' Model,

Top: $10 \%$ Change in $T_{m}$, Bottom: $5 \%$ Change in $E_{F D}$..... 195

Figure D.19 $\psi_{\mathrm{kq}}$ vs time in seconds, Simplified E'" Model,

Top: 10\% Change in $T_{m}$, Bottom: 5\% Change in $E_{F D} . . . . .196$

Figure D.20 $I_{q}$ vs time in seçonds. Simplified $E$ "' Modul,

Tup: 10\% Change in $T_{m}$, Bottom: 5\% Change in $E_{F D}$. . . . 197

Figure D.21 $I_{k q}$ vs time in seconds, Simplified E" Mode1,

Top: 10\% Change in $\mathrm{T}_{\mathrm{m}}$, Bottom: 5\% Change in $\mathrm{E}_{\mathrm{FD}} . . . . .198$

Figure E.1.a.1 Statistical P1ots of EA-EB for a $T_{m}$ Disturbance,

Data for $\mathrm{T}_{\mathrm{e}}$...................... 206

Figure E.1.a.2 Statistical P1ots of EA-EB for a $T_{m}$ Disturbance,

Data for $\Delta \omega . . . . . . . . . . . . . . . . . . . .207$

Figure E.1.a.3 Statistical Plots of EA-EB for a $T_{m}$ Disturbance,

Data for 8..................... 208

Figure E.1.a.4 Statistical Plots of EA-EB for a $T_{m}$ Disturbance,

Data for $v_{t}$..................... 209

Figure E.1.b.1 Statistica1 P1ots of EA-EB for a $E_{\text {FD Disturbance. }}$

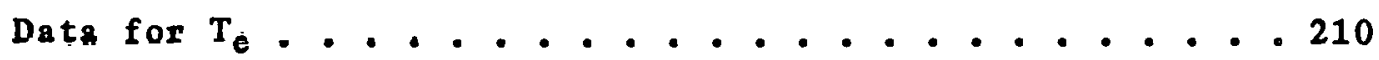

Figure E.1.b.2 Statistical P1ots of EA-EB for a $E_{F D}$ Disturbanco,

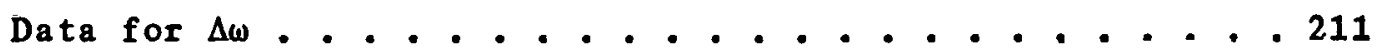

Figure E.1.b.3 Statistical P1ots of EA-EB for a $E_{F D}$ Disturbance,

Data for 8...................... 212

$x v i$ 
Figure E.1.b.4 Statistical P1ots of EA-EB for a $E_{F D}$ Disturbance,

Data for $v_{t}$. . . . . . . . . . . . . . . 213

Figure E.2.a.1 Statistical P1ots of A-B for a Tm Disturbance,

Data for $\mathrm{T}_{\mathrm{e}}$..................... 216

Figure E.2.a.2 Statistical P1ots of A-B for a Tm Disturbance,

Data for $\Delta \omega . . . . . . . . . . . . . . . . .217$

Figure E.2.a.3 Statistical P1ots of A-B for a Tm Disturbance,

Data for 8........................ 218

Figure E.2.a.4 Statistical Plots of A-B for a Tm Disturbance,

Data for $v_{t}$. . . . . . . . . . . . . . 219

Figure E.2.b.1 Statistical P1ots of A-B for a $E_{F D}$ Disturbance,

Data for $\mathrm{T}_{\mathrm{e}}$...................... 220

Figure E.2.b.2 Statistical P1ots of A-B for a $E_{F D}$ Distarbance,

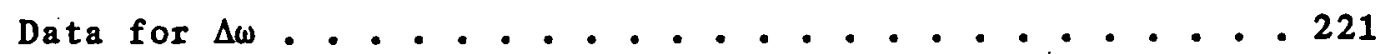

Figure E.2.b.3 Statistical P1ots of A-B for a $E_{F D}$ Disturbance,

Data for 6...................... 222

Figure E.2.b.4 Statistical P1ots of A-B for a $E_{F D}$ Disturbance,

Data for $v_{t}$. . . . . . . . . . . . . . . 223

Figure E.3.a.1 Statistical P1ots of A-EA for a $T_{m}$ Disturbance,

Data for $\mathrm{T}_{\mathrm{e}}$.................... 226

Figure E.3.a.2 Statistical P1ots of A-EA for a $T_{m}$ Disturbance,

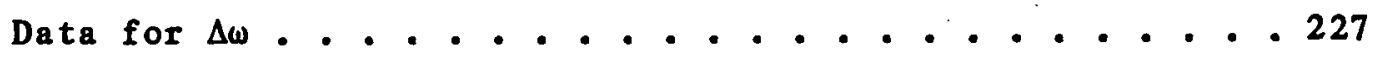

Figure E.3.a.3 Statistical P1ots of A-EA for a $T_{m}$ Disturbance,

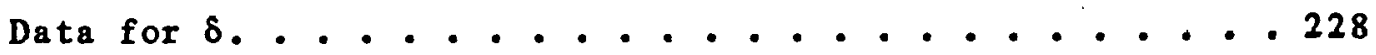

Figure E.3.a.4 Statistical P1ots of A-EA for a $T_{m}$ Disturbance,

Data for $v_{t}$..................... 229 
Figure E.3.b.1 Statistical P1ots of A-EA for a EFD Disturbance,

Data for $\mathrm{T}_{\mathrm{e}}$..................... 230

Figure E.3.b.2 Statistical Plots of A-EA for a $E_{F D}$ Disturbance,

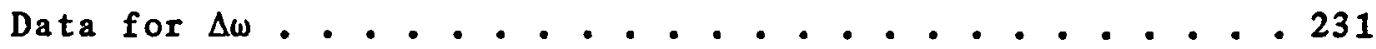

Figure E.3.b.3 Statistical Plots of A-EA for a EFD Disturbance,

Data for 6....................... 232

Figure E.3.b.4 Statistical P1ots of A-EA for a EFD Disturbance,

Data for $v_{t}$..................... 233

Figure E.4.a.1 Statistioal Plots of A-C for a $T_{m}$ Disturbanoe,

Data for $\mathrm{T}_{\mathrm{e}}$..................... 236

Figure E.4.a.2 Statistical Plots of A-C for a $T_{m}$ Disturbance,

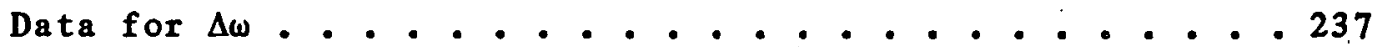

Figure E.4.a.3 Statistical Plots of A-C for a $T_{m}$ Disturbance.

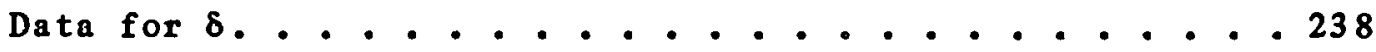

Figure E.4.a.4 Statistical P1ots of A-C for a $T_{m}$ Distrabance,

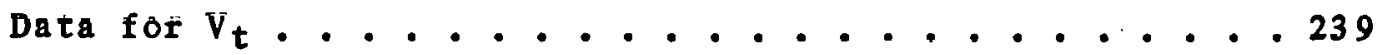

Figure E.4.b.1 Statistical P1ots of A-C for a EFD Disturbance.

Data for $\mathrm{T}_{\mathrm{e}}$. . . . . . . . . . . . . . . 240

Figure E.4.b.2 Statistical P1ots of A-C for a $E_{F D}$ Disturbance,

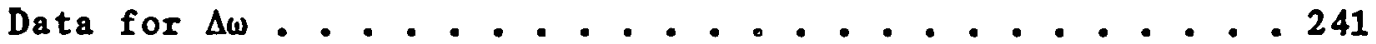

Figure E.4.b.3 Statistical P1ots of A-C for a EFD Disturbance.

Data for 8. . . . . . . . . . . . . . . 242

Figure E.4.b.4 3tatietioa1 P1ots of A-C for a EF Disturbance,

Data for $\mathrm{v}_{t}$. . . . . . . . . . . . . . . 243

Figure E.5.a.1 Statistical P1ots of A-D for a $T_{m}$ Disturbance.

Data for $\mathrm{T}_{\mathrm{e}}$. . . . . . . . . . . . . . . 246 
Figure E.5.a.2 Statistical Plots of A-D for a $T_{m}$ Disturbance,

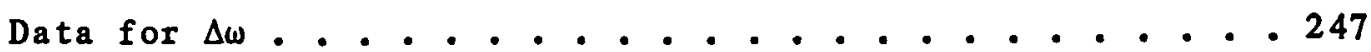

Figure E.5.a.3 Statistical Plots of A-D for a $T_{m}$ Disturbance,

Data for 8.................... 248

Figure E.5.a.4 Statistical Plots of A-D for a $T_{m}$ Disturbance,

Data for $v_{t}$. . . . . . . . . . . . . . . 249

Figure E.5.b.1 Statistical Plots of A-D for a $E_{F D}$ Disturbance,

Data for $\mathrm{T}_{\mathrm{e}}$. . . . . . . . . . . . . . 250

Figure E.5.b.2 Statistical Plots of A-D for a $E_{F D}$ Disturbance,

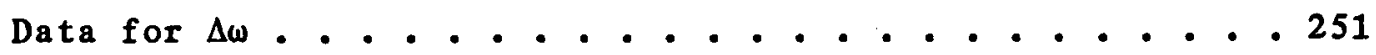

Figure E.5.b.3 Statistical P1ots of A-D for a EFD Disturbance,

Data for 8..................... 252

Figure E.5.b.4 Statistical P1ots of A-D for a $E_{F D}$ Disturbance,

Data for $v_{t}$..................... . 253 
THIS PAGE

WAS INTENTIONALLY

LEFT BLANK 
LIST OF TABLES

Page

Table 1.1 F1ax Linkage Form of Machine Equations. . . . . . . 7

Table 1.2 E' Form of Machine Equations . . . . . . . . . 8

Table 2.1 Flux Linkage Model Parameters............. 16

Tab1e 2.2 Machine Inductance Dependence on $L_{A D}$ and $L_{A Q}$ for

the E'"Mode1.................... 22

Table 2.3 Machine Time Constants and Gains for the E'" Mode1... 23

Tab1e 2.4 Sensitivity of Mode1 Parameters to Saturation . . . 25

Table 3.1 Statistics of Random Noise Component of Wind,

Computed for $N=50, \Delta \omega=2.0 \ldots . . . . . . . . .441$

Tab1e 3.2 Wind Turbine Governor Parameters. . . . . . . . . . 46

Table $3.3 \quad$ Special Mode1 Parameters. . . . . . . . . . . 47

Tab1e 3.4 Summary of Compater Runs of the Nine Bus System . . . 48

Table E.1 Coding of Simulation Runs . . . . . . . . . . . 202

Table E.2 Comparison Sets for Statistical Analysis. . . . . . 203

Tab1e E.3a Statistical Analysis of the Difference between F1ux

Linkage and E"' Modo13, Unsaturatcd Casc,

Step Change in $\mathrm{T}_{\mathrm{m}}$.................. 214

Table E.3b Statistical Analysis of the Difference between F1ux

Linkage and E" Mode1s, Unsaturated Case,

Step Change in $\mathrm{E}_{\mathrm{FD}} . . . . . . . . . . . . . .215$

Tab1e E.4a Statistical Analysis of the Difference between F1ux

Linkage and E' Models, Complete Saturation,

Step Change in $T_{m}$............ . . . . . 224 
Table E.4b Statistical Analysis of the Difference between F1ux

Linkage and E' Mode1s, Complete Saturation,

Step Change in $\mathrm{E}_{\mathrm{FD}} . . . . . . . . . . . . . . .225$

Tab1e E.5a Statistical Analysis of the Difference between

the Saturated (A) and Unsaturated (EA) F1ux

Linkage Mode1, Step Change in $\mathrm{T}_{\mathrm{m}}$. . . . . . . . 234

Tab1e E.5b Statistical Analysis of the Difference between

the Saturated (A) and Unsaturated (EA) F1ux

Linkage Móde1, Step Change in $\mathrm{E}_{\mathrm{fO}}$. . . . . . . . 235

Table E.6a Statistical Analysis of the Difference between

the F1ux Linkage Model when Fully Saturated and

Partia11y Saturated, Step Change in $\mathrm{T}_{\mathrm{m}}$....... 244

Table E.6b Statistical Analysis of the Difference between

F1ux Linkage Model when Fu11y Saturated and

Partially Saturated, Step Change in $\mathrm{E}_{\mathrm{FD}}$. . . . . . 245

Tab1e E.7a Statistical Analysis of the Difference between

the F1ux Linkage (Saturated) Mode1 and the E' Mode1

with Partial Saturation, Step Change in $\mathrm{T}_{\mathrm{m}} \cdot$. . . . 254

Table E.7b Statistical Analysis of the Difference between

F1ux Linkage (Saturated) Mode1 and the E'" Mode1

Wth Partial Saturatiun, Step Change in $\mathrm{E}_{\mathrm{FD}} . . . . .255$ 


\subsection{OVERVIEW OF THE DIGITAL SIMULATION EFFORT}

The purpose of the PMA effort has been to adapt the MOD-2 simulation mode1s, developed by Purdue University, for implementation on a digital transient stability program. This has involved several problems: selection of an appropriate host program, examination of the host program interface, analysis of the Purdue analog models for digital implementation, Fortran coding of the model equations, installation and debugging on the host program, and final model verification.

\section{$\underline{1,1}$ Host Program Selection}

Our initial selection of the host stability code was the EPRI Diagnostic Program (DP), developed by Boeing Compater Services from a production stability codes $[1,2]$. There were several factors favoring use of the DP as a host program. The DP was developed as a modular test program, designed with complete indpendence of component models [1]. The DP was also well documented [2], both in terms of it's performance accuracy, but also in terms of the exact steps required to implement new models. These are important considerations. Adding new code to an already large simnlation is difficult. The added code segments must not only be correct, bat must not interact with existing code in any way except as intended. This requires careful data management and coding precautions.

The DP was perceived to be a convenient solution because of its modular design, its unusually detailed documentation, and the availability of instruction manals for code modification. These manuals were carefully followed in the early stages of the work to set np the appropriate table modifications for our intended code additions. 
By mid-1981 new code developments in progress made the DP effort obsolete. EPRI had initiated, as part of RP 1208, a 'modular modeling package' to be implemented as part of a new Extended Transient-Midterm Stability Program (ETMSTAB). The older Transient Midtern Stability Program is itself a well documented, widely used program, developed by EPRI as RP 745 [3]. The extension of this original work by RP 1208 is not yet completed, but the modular feature was such an important development that it was clearly to our advantage in the present project to take advantage of these new features. EPRI and their contractor, BCS, agreed to our use of the new code, and provided assistance in our implementation of needed code revisions.

The modular modeling package permits the modeler to construct new component models by the concatenation of basic building blocks. This is similar to widely used continuous system modeling codes, suoh as CSMP or ACSL. The model building blocks available in the 1208 code provided all structures needed for the Purdue MOD-2 model except for the random number generator, which BCS provided.

\subsection{Analysis of the Purdue MOD-2 Mode1}

The Purdue MOD-2 model consists of the following subsystems:

1. wind mode1

2. b1ade dynamics

3. shaft dynamics

4. pitch control

5. generator mode1 
The first four of these models may be considered the mechanical system and the generator model is the MOD-2 electrical system. We will discuss each system separately.

1.2.1 The Mechanical System. The mechanical system is shown in block diagram form in Figure 1.1. To implement this mechanical system into the existing code required a matching of subsystems already existing in ETMSTAB. These subsystem definitions are shown in Figure 1.2. ETMSTAB defines Generation System Components, such as SWING, TURBINE, and GOVERNOR to which the wind model must conform. To introduce the new mechanical model of the wind system requires the definition of new GOVERNOR and TURBINE blocks. The TURBINE block was constructed from linear components al ready defined in the modolar modeling package. The wind GOVERNOR block required the creation of new nonlinear components for blade dynamics and the addition of a randon number generator to allow specification of a random wind component as prescribed by Wasynczuk, et a1 [4]. The remainder of the wind mechanical system is as defined by Krause, et a1 [5,6]. Implementation required the revision of ETMSTAB subroutines APRINT, EVALG, GENEQT, INPUT, PREgOV, PRgOVH, and TSSTP, modified versions of which are given in the Appendix F.

1.2.2. The Electrical System. The electrical system requiring the greatest effort was an adaptation of the MACHINE block of Figure 1.2 for the generator model specified by references 5 and 6 , as documented thoroughly by private comminucation [7]. Since our original host program was the DP, a substantial effort was required to improve on the 


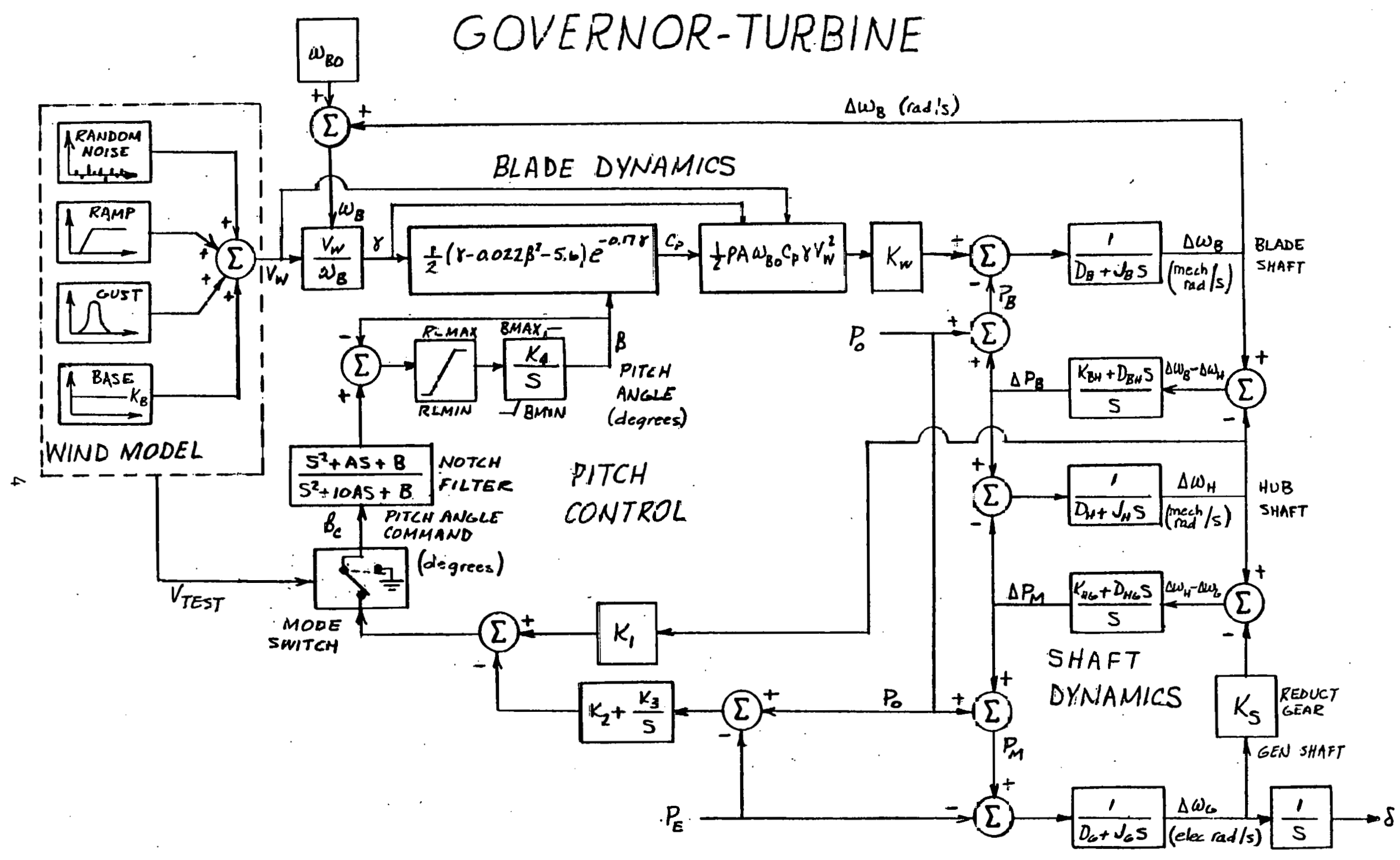

Figure 1.1 Block Diagram of MOD-2 Mechanical Systen. 


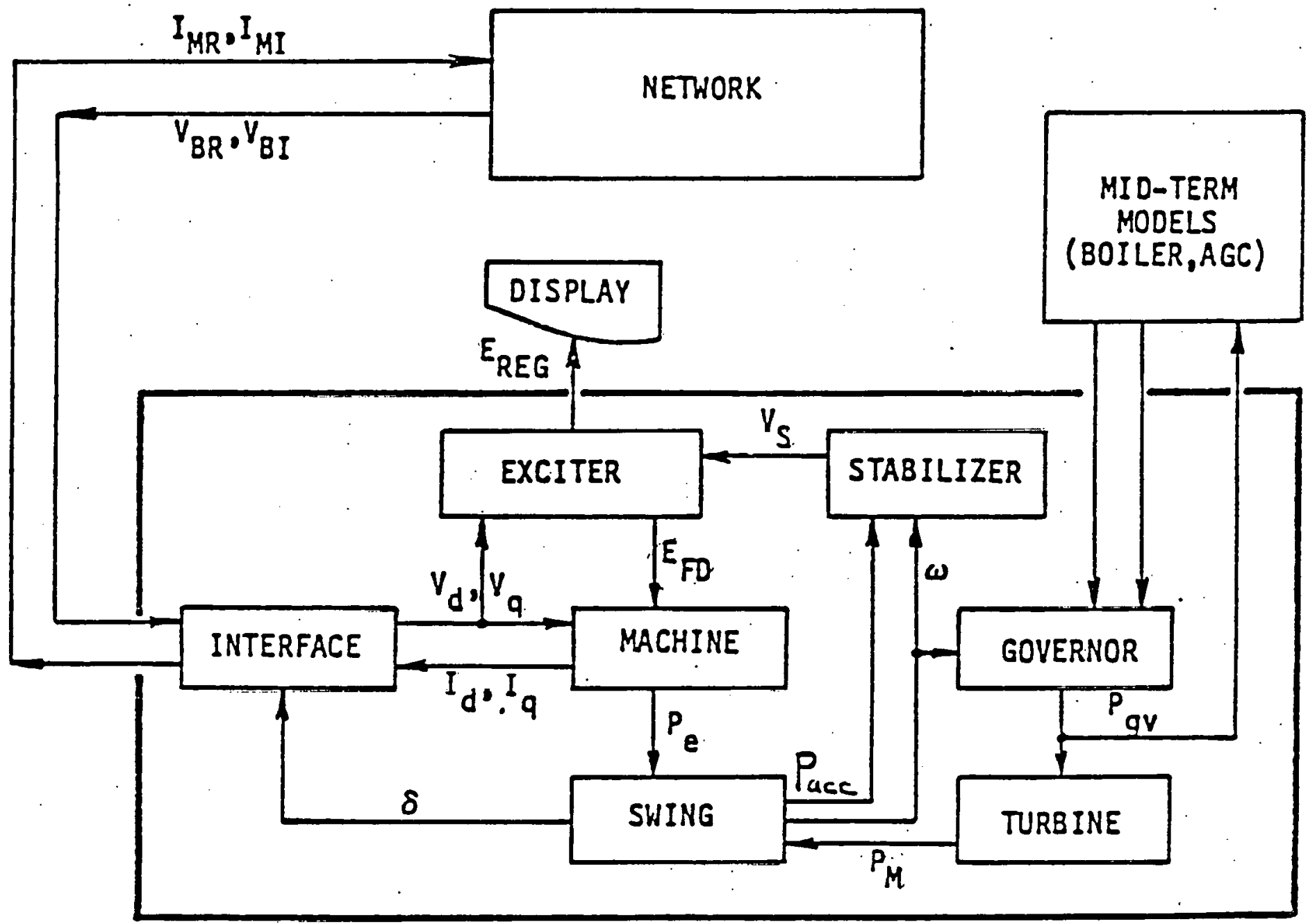

Figure 1.2 Block Diagram of EPRI Program Generator System Component Definitions. 
rather simple model provided in the host program. The equations provided by Purdue for the machine were adequate and complete, but indicated a more complex machine than that available in the DP. The linear portions of the model are simple and direct to implement, but considerable effort was spent on examining the best form for the equations so that saturation could be accurately and economically computed for each step in the digital solution.

Two forms of the machine equations were studied:

(1) using $E_{q}^{\prime}, E_{d}^{\prime}$, and $\psi_{k d}$ as steates

(2) using $\psi_{\mathrm{F}}, \psi_{\mathrm{kd}}$, and $\psi_{\mathrm{kq}}$ as states.

We shall refer to these models as the $E^{\prime \prime}$ model and the flux 1 inkage model throughout the balance of this report.

The 1inear equations for each mode1 are disp1ayed in Tables 1.1 and 1.2. The $E^{\prime \prime}$ form of machine equation is similar to the structure usually employed in transient stability programs. Many forms of the equations are available, some with currents as inputs and some with voltages. In our testing, we used the form illustrated in Figure 1.3 .

The flux linkage model, described fully in references 7 and 8 , has the form shown in Figure 1.4. This form has certain advantages over the E' mode1, as will be shown later. Our work consisted of comparing thase models for ease nf implementation and for arontarg of representation using simplified forms of saturation computation. 
Tab1e 1.1 F1ux Linkage Form of Machine Equations [5,6]

\section{Differential Equations}

$$
\begin{aligned}
& \frac{\mathrm{d} \psi_{\mathrm{F}}}{\mathrm{dt}}=\frac{\mathrm{r}_{\mathrm{F}} \mathrm{L}_{\mathrm{MD}}}{\ell_{\mathrm{F}}} \frac{\psi_{\mathrm{d}}}{\ell_{\mathrm{a}}}-\mathrm{r}_{\mathrm{F}}\left(1-\frac{\mathrm{L}_{\mathrm{MD}}}{\ell_{\mathrm{F}}}\right) \frac{\psi_{\mathrm{F}}}{\ell_{\mathrm{F}}}+\mathrm{r}_{\mathrm{F}} \frac{\mathrm{L}_{\mathrm{MD}}}{\ell_{\mathrm{F}}} \frac{\psi_{\mathrm{kd}}}{\ell_{\mathrm{kd}}}+\frac{\mathrm{r}_{\mathrm{F}}}{\mathrm{L}_{\mathrm{ADO}}} \mathrm{E}_{\mathrm{FD}} \\
& \frac{\mathrm{d} \psi_{\mathrm{kd}}}{\mathrm{d} \mathrm{t}}=\mathrm{r}_{\mathrm{kd}} \frac{\mathrm{L}_{\mathrm{MD}}}{\ell_{\mathrm{kd}}} \frac{\psi_{\mathrm{d}}}{\ell_{\mathrm{a}}}+\mathrm{r}_{\mathrm{kd}} \frac{\mathrm{L}_{\mathrm{MD}}}{\ell_{\mathrm{kd}}} \frac{\psi_{\mathrm{F}}}{\ell_{\mathrm{F}}}-\mathrm{r}_{\mathrm{kd}}\left(1-\frac{\mathrm{L}_{\mathrm{MD}}}{\ell_{\mathrm{kd}}}\right) \frac{\psi_{\mathrm{kd}}}{\ell_{\mathrm{kd}}} \\
& \frac{\mathrm{d} \psi_{\mathrm{kq}}}{\mathrm{d} \mathrm{t}}=\mathrm{r}_{\mathrm{kq}} \frac{\mathrm{L}_{\mathrm{MQ}}}{\ell_{\mathrm{kq}}} \frac{\psi_{\mathrm{q}}}{\ell_{\mathrm{a}}}-\mathrm{r}_{\mathrm{kq}}\left(1-\frac{\mathrm{L}_{\mathrm{MQ}}}{\ell_{\mathrm{kq}}}\right) \frac{\psi_{\mathrm{kq}}}{\ell_{\mathrm{kq}}}
\end{aligned}
$$

\section{Algebraic Equations}

$$
\begin{aligned}
& \psi_{\mathrm{d}}=\frac{1}{\frac{r_{\mathrm{a}}}{\ell_{\mathrm{a}}}\left(1-\frac{\mathrm{L}_{\mathrm{MD}}}{\ell_{\mathrm{a}}}\right)}\left(\mathrm{r}_{\mathrm{a}} \frac{\mathbf{L}_{\mathrm{MD}}}{\ell_{\mathrm{a}}} \frac{\psi_{\mathrm{F}}}{\ell_{\mathrm{F}}}+\mathrm{r}_{\mathrm{a}} \frac{\mathrm{L}_{\mathrm{MD}}}{\ell_{\mathrm{a}}} \frac{\psi_{\mathrm{kd}}}{\ell_{\mathrm{kd}}}-\omega \psi_{\mathrm{q}}-\mathrm{v}_{\mathrm{d}}\right) \\
& \psi_{\mathrm{q}}=\frac{1}{\frac{r_{\mathrm{a}}}{l_{\mathrm{a}}}\left(1-\frac{\mathrm{L}_{\mathrm{MQ}}}{\ell_{\mathrm{a}}}\right)}\left(\mathrm{r}_{\mathrm{a}} \frac{\mathrm{L}_{\mathrm{MQ}}}{l_{\mathrm{a}}} \frac{\psi_{\mathrm{kq}}}{\ell_{\mathrm{kq}}}+\omega \psi_{\mathrm{d}}-\mathrm{v}_{\mathrm{q}}\right) \\
& T_{e}=I_{q} \psi_{d}-I_{a} \psi_{q}
\end{aligned}
$$

\section{Constants}

$$
\begin{array}{ll}
1 / \mathrm{L}_{\mathrm{MD}}=1 / \mathrm{L}_{\mathrm{AD}}+1 / \ell_{\mathrm{q}}+1 / \ell_{\mathrm{F}}+1 / \ell_{\mathrm{kd}} & \mathrm{T}_{\mathrm{F}}=\ell_{\mathrm{F}} / \mathrm{r}_{\mathrm{F}} \\
1 / \mathrm{L}_{\mathrm{MQ}}=1 / \mathrm{L}_{\mathrm{AQ}}+1 / \ell_{\mathrm{a}}+1 / \ell_{\mathrm{kq}} & \mathrm{T}_{\mathbf{k d}}=\ell_{\mathbf{k d}} / \mathbf{r}_{\mathbf{k d}} \\
& \mathrm{T}_{\mathbf{k q}}=\ell_{\mathbf{k q}} / \mathbf{r}_{\mathbf{k q}}
\end{array}
$$




\section{Differential Equations}

$$
\begin{aligned}
& T_{d o}^{\prime} \frac{d E_{q}^{\prime}}{d t}=\frac{L_{A D}}{L_{A D 0}} E_{F D}-\left(1+K_{d}\right) E_{q}^{\prime}+K_{d} \Psi_{k d}+x_{k d} I_{d} \\
& T_{q o}^{\prime \prime} \frac{d E_{d}^{\prime \prime}}{d t}=-E_{d}^{\prime \prime}-\left(x_{q}-x_{q}^{\prime \prime}\right) I_{q} \\
& T_{d o}^{\prime \prime} \frac{d \Psi_{k d}}{d t}=-\Psi_{k d}+E_{q}^{\prime}+\left(x_{d}^{\prime}-x_{\ell}\right) I_{d}
\end{aligned}
$$

\section{Algebraic Constraints}

$$
\begin{array}{ll}
E_{q}^{\prime \prime}=K_{1} E_{q}^{\prime}+K_{2} \psi_{k d} & V_{d}=E_{d}^{\prime \prime}-I_{q} X_{q}^{\prime \prime}-I_{d} r \\
T_{e}=E_{q}^{\prime \prime} I_{q}+E_{d}^{\prime \prime} I_{d} & V_{q}=E_{q}^{\prime \prime}-I_{q} r+I_{d} X_{d}^{\prime \prime}
\end{array}
$$

\section{Derived Constants}

$$
\begin{aligned}
& K_{d}=\frac{\left(L_{d}-L_{d}^{\prime}\right)\left(L_{d}^{\prime}-L_{d}^{\prime \prime}\right)}{\left(L_{d}^{\prime}-l_{a}\right)^{2}} \\
& \mathrm{~T}_{\mathrm{d}_{0}}^{\prime}=\frac{\mathrm{L}_{\mathrm{AD}}+\ell_{\mathrm{F}}}{\mathrm{T}_{\mathrm{F}}} \\
& \mathrm{K}_{1}=\frac{\mathrm{L}_{\mathrm{d}}^{\prime}-\ell_{\mathrm{a}}}{L_{\mathrm{d}}^{\prime}-\ell_{\mathrm{a}}} \\
& K^{2}=1-K_{1} \\
& T_{d o}^{\prime \prime}=\frac{1}{r_{k d}}\left(\ell_{k d}+L_{A D}-\frac{L_{A D^{2}}}{L A D^{+} l_{G}}\right) \\
& x_{x d}=\frac{\left(L_{d}-L_{d}^{\prime}\right)\left(L_{d}^{\prime \prime}-\ell_{a}\right)}{L_{d}^{\prime}-\ell_{a}} \\
& \mathrm{~T}_{\mathrm{q}}^{\prime \prime}=\frac{\mathrm{L}_{\mathrm{AR}}+\ell_{\mathrm{kq}}}{\mathrm{r}_{\mathrm{kq}}}
\end{aligned}
$$




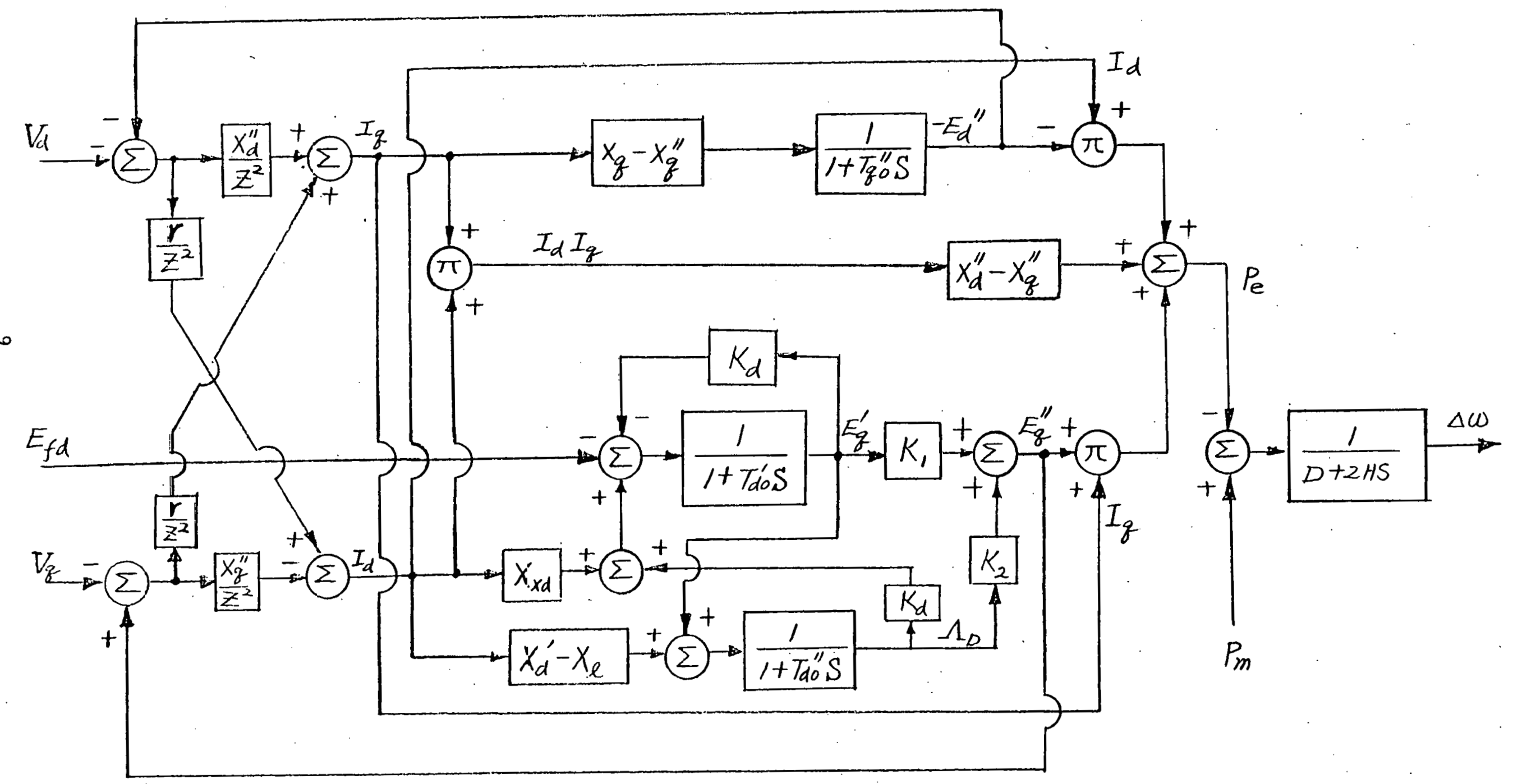

Figure 1.3 Block Diagram of the E' Mode1. 


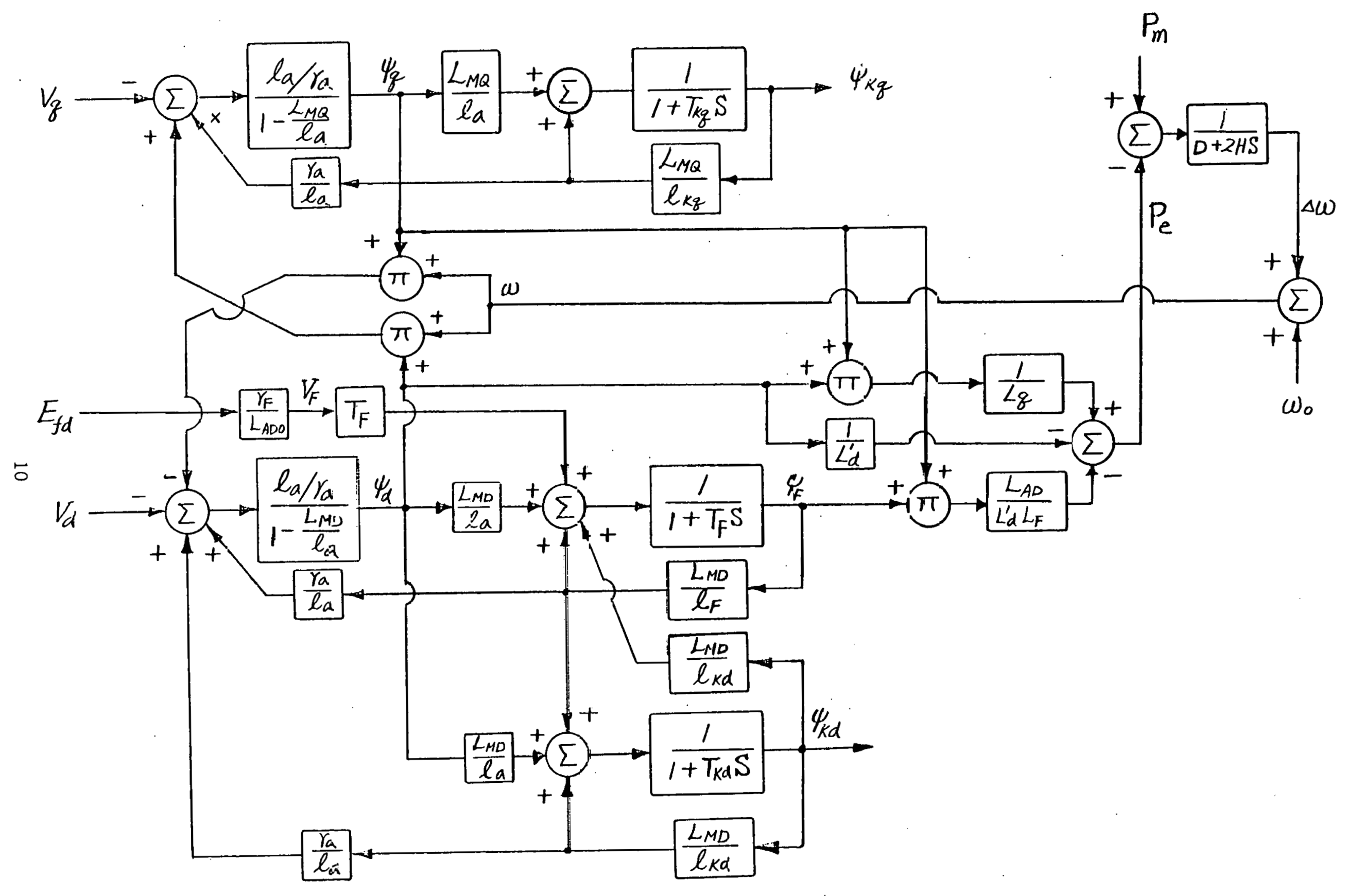

Figure 1.4 Block Diagram of the Flux Linkage Mode1 


\subsection{DIGITAL MODELING OF SYNCHRONOUS MACHINES}

This section presents an analysis of synchronous machine equations, with particular emphasis on numerical solution. The basic machine model is that used by Purdue for their simulation of the MOD-2 generation [5,6]. This model ignores the derivative (p) terms and assumes constant generator angular velocity. These assumptions are consistent with current theory on synchronous machine modeling that neglect stator transients [9-14]. Our treatment follows these published assumptions, except for our adherence to the international standard conventions for describing synchronous machines [15].

\subsection{Basic Concepts of Machine Mode1ing for Stability Studies}

Power system transient stability involves the interaction of rotating machines of similar inertias following a severe disturbance that canses the displacement of one or more machines. The oscillations that follow the disturbance are poorly damped and usually have frequencies of oscillation of below 5 hertz. Machine models must faithfully describe synchronous generator behavior in this restricted bandwidth.

Another requirement of the generator model is the need for compatubility with the models that represent the balance of the power system. Since network transients are very fast with respect to electromechanical transients, the network is solved algebraically in transient stability studies. Since derivative $\left(p_{\psi}\right)$ terms are neglected in the networks, they should also be neglected in the stator of the machine. In studies made for this project the stator transients were neglected throughout. 
Because stator transients are neglected and only balanced disturbances are assumed, an artificial method of simulating the fault damping due to dc offset must be provided. This is usually done as shown in Figures 3 and 4 by the introduction of a speed feedback term (D) in the accelerating torque calculation.

2.1.1 Synchronous Machine Saturation. Saturation is an important nonlinearity that must be included in the modeling of synchronous machines. Our approach to modeling saturation 18 presulted briefly to provide background information for the results that follow.

We make the basic assumtion that saturation in the $d$ and q axes is uncoupled and can be treated separately. This is not really true, since saturation of one axis affects the other axis through the torque equation. Some modelers combine the fluxes in a Euclidean way to compute a total flux, which is used as the basis for saturation [16]. Others treat the saturation in the two axes separately, as we do here. The 'best' method is considered a subject for research beyond the scupe of our work.

Consider the d-axis saturation curve shown in Figure 2.1, where we plot the flux 1inkage $A D$ vs the current flowing through $L_{A D}$. We assume tho loakage inductances axe constant and that on1y $L_{A D}$ saturates. Note that saturation starts to have an effect at a threshold value $A$ and increases in some nonlinear, monotonic manner for values of flux 1 inkage greater than the threshold.

Now define the saturation function

$$
\mathrm{S}_{\mathrm{GD}}=\frac{\Delta \mathrm{I}_{\mathrm{M}}}{\mathrm{I}_{\mathrm{MO}}}
$$




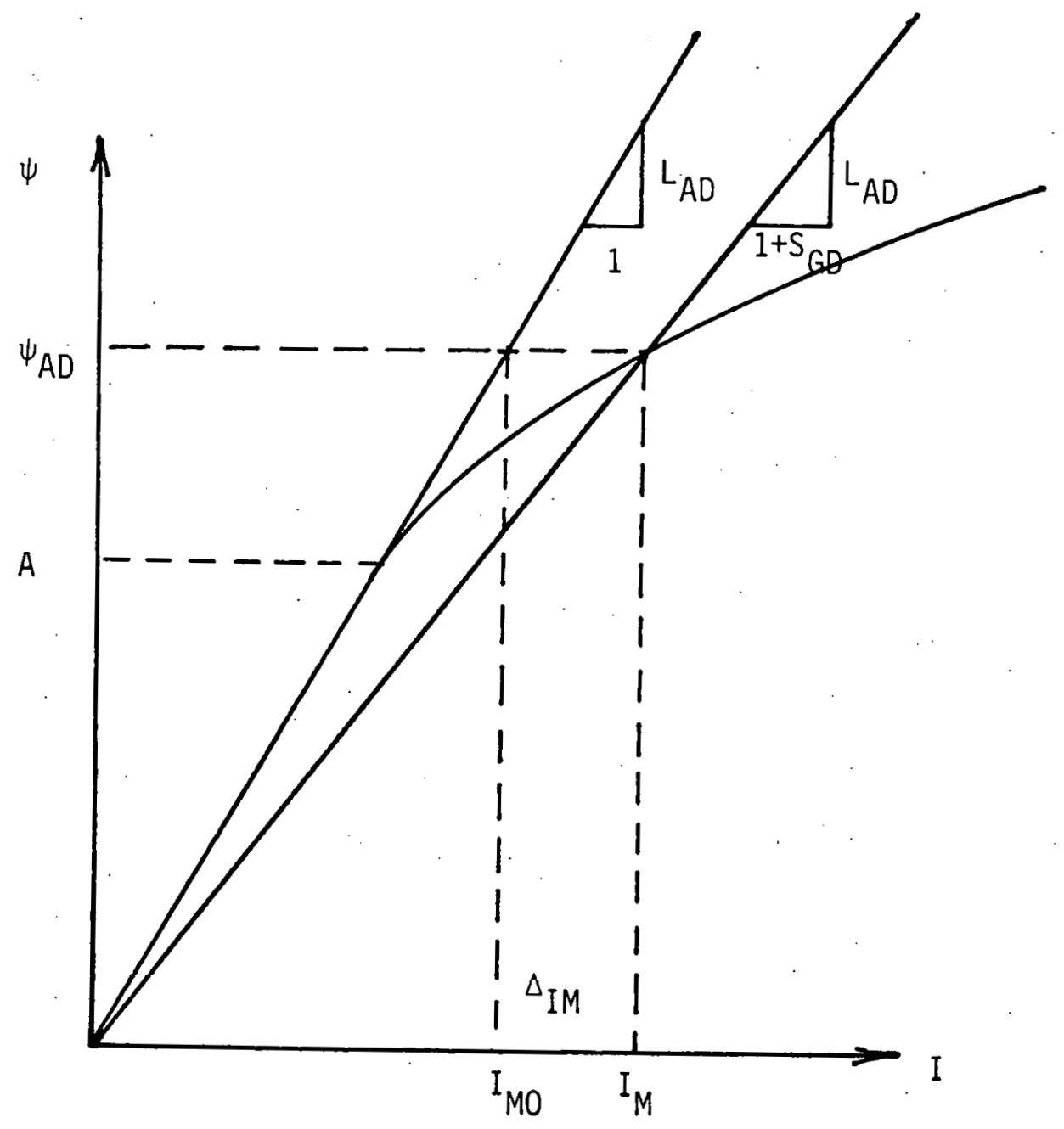

Figure 2.1 Typical d-axis Open Circuit Saturation Curve 
Then $\Delta \mathrm{I}_{\mathrm{M}}=\mathrm{S}_{\mathrm{GD}} \mathrm{I}_{\mathrm{M}}$ or

$$
\Delta \mathbf{I}_{M}=\frac{\mathbf{S}_{\mathrm{GD}} \psi_{\mathrm{AD}}}{\mathbf{L}_{\mathrm{AD}}}
$$

The saturation function $S_{G D}$ is usually approximated by either a quadratic or exponential function. For example, let

$$
\mathbf{S}_{\mathbf{G D}}=\left\{\begin{array}{cc}
\frac{\mathrm{B}\left(\psi_{\mathrm{AD}}-\mathrm{A}\right)^{2}}{\psi_{\mathrm{AD}}} & \psi_{\mathrm{AU}}>\mathrm{A} \\
& \\
0 & \psi_{\mathrm{AD}}<\mathrm{A}
\end{array}\right.
$$

Then, we may compute

$$
\begin{aligned}
& \psi_{A D}=L_{A D} I_{M O}=L_{A D}\left(I_{M}-\Delta I_{M}\right) \\
& =\mathrm{L}_{\mathrm{AD}} \mathbf{I}_{\mathrm{M}}-\mathrm{S}_{\mathrm{GD}} \psi_{\mathrm{AD}}
\end{aligned}
$$

or

$$
\psi_{A D}=\frac{L_{A D}}{1+s_{G D}} I_{M}
$$

Equation (2.4) says that, in terms of the total current $I_{M}$ flowing through the nonlinear inductance $L_{A D}$, the total flux linkage $\Psi_{A D}$ behaves as if $L_{A D}$ were replaced by a smaller inductance $L_{A D} /\left(1+S_{G D}\right)$. This smaller inductance is the slope of the $\psi$ vS I line passing through the operating point, as shown in Figure 2.1 . Thus, if $S_{G D}$ is computed by a formula such as (2.3), L $L_{A D}$ may be modified as required to continually reflect the saturation of the d axis. We treat the q axis similarly, modifying $L_{A Q}$ by a similar saturation function $S_{G Q}$. 
In the digital solution of the differential equations, the computation at each time step is complicated by the implicit nature of the nonlinear equations. Thus, flux linkages may be known (at the completion of a time step) from which currents may be compated. But flux linkages are nonlinear functions of currents and saturation, and are therefore functions of the saturated flux linkages. We solve this problem by computing saturation functions $S_{G D}$ and $S_{G Q}$ at the end of each time step explicitly and then use these saturations for the next time step. We assume that this introduces negligible error since the time steps are small and the changes in $S_{G}$ are smooth and slowly varying.

2.1.2 Test Problem. To test simulation results we devise a system consisting of a single machine connected through a transmission line to an infinite bus. We excite the system by making step changes in the mechanical torque $T_{M}$ or the excitation voltage $E_{F D}$. The observed results are plotted and compared.

Details of the one machine system are given in Anderson and Fouad [8], Chapter 5, for both analog and digital simulations. Here, our machine model is simplified, as discussed previously, but the line constants and initial conditions as given in xeference 5 . The initial conditions are rated load at rated power factor with 1.0 per unit voltage at the infinite bus. This requires high initial machine voltage with heavy saturation, and provides a good test of saturated vs unsaturated conditions.

Data for the test machine are values taken from [8]. These values were uscd for our comparison studies so that results could be benchmarked against known solutions. 


\subsection{F1ux Linkage Mode1 Representation}

The flux linkage model simulated in our tests is exactly that used by Purdae, and is described by the equations of Table 1.1. A block diagram of the mode1 is shown in Figure 1.4. Our simulation did not neglect the $\Delta \omega$ terms, a fact that we realized only after the plotting was completed. The simulation would have been improved, according to we11 established theory, had we neglected this term [12].

2.2.1 Saturation of the F1ux Linkage Mode1. As noted in Figure 1.4, the only terms that are functions of saturation are the inductances $\mathrm{L}_{\mathrm{AD}}$, $L_{A Q}, L_{M D}$, and $L_{M Q}$. Saturation functions were computed at each time step and revised values used for the succeding time step. The relationship betwen the model parameters and the saturating inductances is shown in Tab1e 2.1. Using the relationships of Table 2.1 we may compate the

\section{Tab1e 2.1 F1ux Linkage Mode1 Parameters}

Parameter

$\mathbf{L}_{\text {MID }}$

$\mathbf{L}_{\mathbf{M Q}}$

$$
\begin{aligned}
& \text { Dependence on } L_{A D} \text { or } L_{A Q} \\
& \frac{1}{1 / L_{A D}+1 / l_{Q}+1 / l_{F}+1 / l_{k d}}
\end{aligned}
$$

1

$$
1 / L_{A Q}+1 / \ell_{a}+1 / \ell_{k n}
$$

sensitivity of $L_{M D}$ and $L_{M Q}$ to changes in $L_{A D}$ and $L_{A Q}$ by taking the total differential. 


$$
\begin{aligned}
& \Delta \mathrm{L}_{\mathrm{MD}}= \frac{\partial \mathrm{L}_{\mathrm{MD}}}{\partial \mathrm{L}_{\mathrm{AD}}} \Delta \mathrm{L}_{\mathrm{AD}}=\frac{\mathrm{L}_{\mathrm{MDO}}^{2}}{\mathrm{~L}_{\mathrm{ADO}}^{2}} \Delta \mathrm{L}_{\mathrm{AD}} \\
& \Delta \mathrm{L}_{\mathrm{MQ}}=\frac{\partial \mathrm{L}_{M Q}}{\partial \mathrm{L}_{\mathrm{AQ}}} \Delta \mathrm{L}_{\mathrm{AQ}}=\frac{\mathrm{L}_{\mathrm{MQO}}^{2}}{\mathrm{~L}_{\mathrm{AQO}}^{2}} \Delta \mathrm{L}_{\mathrm{AQ}}
\end{aligned}
$$

where the zero subscript refers to the unsaturated value. Then we may compate

$$
\mathrm{L}_{\mathrm{MD}}=\mathrm{L}_{\mathrm{MDO}}-\frac{\mathrm{L}_{\mathrm{MDO}}^{2} \mathrm{~S}_{\mathrm{GD}}}{\mathrm{L}_{\mathrm{ADO}}\left(1+\mathrm{S}_{\mathrm{GD}}\right)}
$$

with a similar result for $L_{M Q}$. Computing the percent change in $L_{M D}$ at fu11 rated load operation, we find that $\mathrm{L}_{\mathrm{MD}}$ varies 1 ess than $1 \%$. Thus $L_{M D}$ and $L_{M Q}$ are rather insensitive to changes in saturation. This is fortunate since these parameters are often treated as constants, such as in potentiometer settings on the analog computer.

2.2.2 Simulation Results for the Flux Linkage Mode1. Simulated results for the flux linkage model are presented in Appendices $A$ and $B$, whére they are arranged for comparison with the $E^{\prime \prime}$ mode1. Appendix A. presents the reus1ts due to a $10 \%$ increase in mechanical torque $T_{M}$ with constant excitation. Appendix B shows the effect of a 5\% increase in $\mathrm{E}_{\mathrm{FD}}$ with constant mechanical torque. All variables are plotted twice, once over the $0-2.5 \mathrm{~s}$ range and once for $0-25.0 \mathrm{~s}$. The two plots show the different time constants of the responses effectively.

A step change in either $E_{F D}$ or $T_{m}$ prodaces an oscillating response, the frequency of which depends on the machine parameters, the inertia 
constant of the rotating shaft, and the machine loading. Since the simulated disturbances are relative small we can estimate the frequency of oscillation by examining a 1 inear machine mode1 [8, Chap. 5]. Thus we write, in the s domain,

$$
\begin{aligned}
& s E_{q}^{\prime}=-\left(1 / K_{3} \tau_{d_{0}}\right) E_{q}^{\prime}-\left(K_{4} / \tau_{d_{0}}\right) \delta+\left(1 / \tau_{d_{0}}\right) E_{F D} \\
& \text { s } \omega=-\left(K_{2} / \tau_{j}\right) E_{q}^{\prime}-\left(K_{1} / \tau_{j}\right) \delta+\left(1 / \tau_{j}\right) T_{m} \\
& s \delta=\omega_{B} \omega
\end{aligned}
$$

Solving for $\omega$, we have

$$
\omega=\frac{-K_{2} s E_{F D}}{\tau_{j} \text { do }_{0} \phi(s)}+\frac{\left(1+K_{3} \tau d_{0} s\right) s T_{m}}{K_{3}{ }_{j} \tau d_{0} \phi(s)}
$$

where $\phi(s)$ is the characteristic equation

$$
\phi(s)=s^{3}+\left(1 / K_{3} d_{0}\right) s^{2}+\left(\omega_{B} K_{1} / \tau_{j}\right) s+\frac{\omega_{B}\left(K_{1} K_{4}-K_{2} K_{3}\right)}{K_{3} K_{4} \tau{ }_{j} d_{0}}
$$

For the machine and condition simulated, we have the constants [8],

$$
\begin{array}{ll}
\mathrm{K}_{1}=1.4479 & \mathrm{~K}_{4}=1.8050 \\
\mathrm{~K}_{2}=1.3174 & \tau_{\mathrm{do}}=5.9 \mathrm{~s} \\
\mathrm{~K}_{3}=0.3072 & \tau_{\mathrm{j}}=4.74 \mathrm{~s}
\end{array}
$$

Substituting into (2.10) we compute 


$$
\begin{aligned}
\phi(s) & =s^{3}+0.5517 s^{2}+115.1735 s+53.6848 \\
& =(s+0.4663)(s+0.0427 \pm j 10.7300) \\
& =(s+0.4663)\left(s^{2}+0.0854 s+10.7301\right)
\end{aligned}
$$

The response will be greatly underdamped and will oscillated at a frequency of $10.7 \mathrm{rad} / \mathrm{s}$ or about $1.7 \mathrm{~Hz}$ (period of oscillation $0.58 \mathrm{~s}$ ). The damping ratio is computed to be 0.0044 .

Oscillations of almost exactly $1.7 \mathrm{~Hz}$ are observed in nearly all plots. The step change in $T_{m}$ excites this mode of oscillation markedy, with nearly all variables showing this characteristic oscillation. Oniy the terminal voltage fails to show a strong oscillation.

When excited by a step change in $E_{F D}$, the oscillatory behavior is present, but to a lesser degree. Indeed, many variables exhibit almost a first order response. The speed is oscillatory, however, as predicted by $(2.9)$.

The effect of saturation is clearly evident in all variables plotted in Appendices A and B. For stability simulations, the most important variables are $T_{e}$ and $\omega$, since these variables reflect the ability of the machine to maintain synchronism. It is interesting to note that these variables are hardly affected by saturation at all.

The network interaction is also important, and this is best illustrated by examining $V_{t}$ and $I_{a} \cdot V_{t}$ is greatiy affected by saturation, largely because this machine has no exciter. The terminal current is different for the saturated case with a step in $E_{F D}$ because the excitation change is less effective in producing more reactive power in the saturated condition. 


\subsection{E' Mode1 Representation}

The $E^{\prime \prime}$ model is important to study carefully since this mode1, or very similar models, are in common use in digital stability simulations. All of the current generation of large scale simulations employ models of similar structure to the E' model, using currents or voltages as states in preference to flux 1 inkages.

The response of this model to changes in $T_{m}$ and $E_{F D}$ are displayed in Appendices $A$ and $B$, respectively. The displays are arranged for ease of comparison with the flus liukage mudel aud the results are observed to be nearly identical. This is to be expected since exactly the same assumptions are made in each model and only tho ohoice of state variables is different. The method of treating saturation, however, is greatly different.

2.3.1 Saturation of the E'I Mode1. In the f1ux 1inkage mode1, saturation is easily introduced by replacing $L_{A D}$ by $L_{A D} /\left(1+S_{G D}\right)$ at every time step, with similar treatment in the $q$ axis. Since $\dot{L}_{A D}$ and $L_{A Q}$ appear in very few terms of the equations, this modification is simple and direct. None of the time constants in the flux 1 inkage model vary with saturation.

For the E' model, the inclusion of saturation is much more complex. Almost every inductance and time constant in this model is a function of $L_{A D}$ or $L_{A Q}$. This means that nearly every 'constant' term in every equation must be modified at each time step in the dynamic solution. (Refer to Table 1.2 to review these equations). The dependence of inductances, time constants, and gains on $L_{A D}$ and $L_{A Q}$ is shown in Tables 2.2 and 2.3 . 
Our approach to the $E^{\prime \prime}$ model is to recompute the parameters of Tables 2.2 and 2.3 at each time step in the digital solution. This gives assurance that saturation is treated correctly and the result is seen to be almost exactly the same as for the flux linakge model.

2.3.2 Simulation Results for the E'I Mode1. An examination of Appendices $A$ and $B$ show that the two models perform almost identically. Any visual comparison of the two simulations leads one to the conclusion that the models are very similar in performance.

In order to provide a quantitative comparison, the computed stepby-step results were subtracted to give a difference for each variable as a function of time. We then analyzed this difference variable statistically, using 126 data points from the time domain simulation. A statistical comparison of these differences is given in Appendix E, where several cases are compared against the saturated flux 1 inkage mode1. Tab1e E4 and Figure E2 show results of the comparison between the saturated flux 1 inkage and $E$ ' mode1. All error measures are very sma11 and indicate a satisfactory model comparison. This fact merely confirms the visual comparison in Appendices $A$ and $B$, but does so quantitative1y.

An outside bound on saturation error is provided by a comparison between saturated and unsaturated mode1s, shown in Figure E3 and Table E5 .

\subsection{Simplified Saturation of the F1ux Linkage Mode1}

Simulation results of the f1nx linkage model with a simplified saturation is shown in Appendix C. The simplified saturation makes use 


\section{Tab1e 2.2 Machine Inductance Dependence on $\mathrm{L}_{\mathrm{AD}}$ and $\mathrm{L}_{\mathrm{AQ}}$ for the E'' model}

$$
\begin{aligned}
& L_{d}^{d}=x_{d} \quad L_{A D}+\ell_{a}-\frac{L_{A D}^{2}}{L_{A D}+\ell_{F}} \\
& \mathbf{L} \cdot \mathbf{d}=\mathbf{x}^{\prime} \mathbf{d} \quad \mathbf{L}_{\mathrm{AD}}+\ell_{\mathbf{a}}-\frac{\mathrm{L}_{\mathrm{AD}}^{2}\left(\ell_{\mathrm{F}}+\ell_{\mathrm{kd}}\right)}{\ell_{\mathrm{F}} \ell_{\mathrm{kd}}+\mathrm{L}_{\mathrm{AD}}\left(\ell_{\mathrm{F}}+\ell_{\mathrm{kd}}\right)}=\frac{\ell_{\mathbf{a}}}{\ell_{\mathrm{a}}-\mathrm{L}_{\mathrm{MD}}}
\end{aligned}
$$

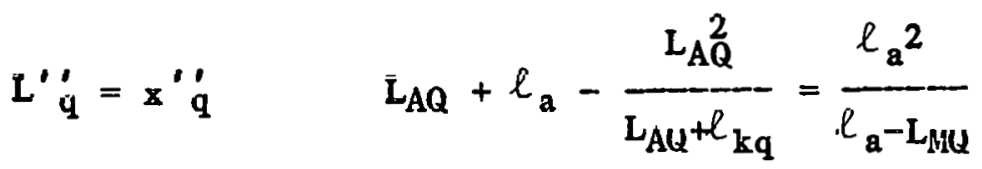

$$
\begin{aligned}
& \mathrm{L}_{\mathrm{MD}} \quad \frac{1}{1 / \mathrm{L}_{\mathrm{AD}}+1 / \ell_{\mathrm{a}}+1 / \ell_{\mathrm{F}}+1 / \ell_{\mathrm{Kd}}}
\end{aligned}
$$

$\mathrm{L}_{\mathrm{MQ}} \quad \frac{1}{1 / \mathrm{L}_{\mathrm{AQ}}+1 / 1 / \ell_{\mathrm{g}}+1 / \ell_{\mathrm{kq}}}$

$\begin{array}{ll}x_{x d} & \frac{\left(L_{d}-L_{d}^{\prime}\right)\left(L^{\prime} l_{d}\right)}{L_{d}^{\prime}-l_{a}} \\ z^{2} & r^{2}+x^{\prime}{ }^{\prime} x^{\prime}{ }_{q}^{q}\end{array}$


Table 2.3 Machine Time Constants and Gain Constants for the E' Model

$\mathrm{T}_{\mathrm{d} o}^{\prime}$

$\left(\mathrm{L}_{\mathrm{AD}}+\ell_{\mathrm{F}}\right) / \mathrm{TF}$

$T^{\prime}$ ḋo

$\frac{\mathrm{L}_{\mathrm{AD}}+\ell_{\mathrm{kd}}-\mathrm{L}_{\mathrm{kD}} /\left(\mathrm{L}_{\mathrm{AD}}+\ell_{\mathrm{F}}\right)}{\mathrm{r}_{\mathrm{kd}}}$

$\mathrm{T}^{\prime \prime}$ qo

$\left(\mathrm{L}_{\mathrm{AQ}}+\ell_{\mathrm{kq}}\right) / \mathrm{r}_{\mathrm{kq}}$

$\mathrm{k}_{1}$

$L^{\prime}{ }_{d}^{\prime}-l_{a}$

$L_{\dot{d}}^{\prime}-l_{a}$

$\mathrm{K}_{2}$

$1-\mathrm{K}_{1}$

$\mathbf{K}_{\mathbf{d}}$

$$
\frac{\left(L_{d}-L_{d}^{\prime}\right)\left(L_{d}^{\prime}-L^{\prime}{ }_{d}^{\prime}\right)}{\left(L_{d}^{\prime}-\ell_{a}\right)^{2}}
$$


of the fact that, from equation (2.7). L LD varies only slightly with saturation. This suggests that the simulation might hold $L_{M D}, L_{M Q}, L_{A D}$, and $\mathrm{L}_{A Q}$ constant, but still modify $\psi_{A D}$ and $\psi_{A Q}$ using the same saturation function. This is the way saturation is usually applied in the analog computer.

The results of this simplified saturation model are disappointing, as shown in Appendix $C$. The statistical analysis of Appendix $E$ shows that the simplified model has almost the same error as the unsaturated case.

This approach was not pursued further to determine the reasons for the observed results. The digital simulation of the flux linkage mode1 with complete saturation is so simple that there is 1ittle need for a reduction in complexity.

\subsection{Simplified Saturation of the E'' Mode1}

An analysis of the parameters for the E' model suggest that it may not be necessray to saturate every term in Tables 2.2 and 2.3 in order to get satisfactory results. Compatation of the total differentiais of al1 inductances, time constants, and gains shows that most of these parameters are relative1y insensitive to saturation. We explore this concept further in an attempt to identify a simpler saturation model.

Table 2.4 summarizes the sensitivity of the E' model parameters to changes in $\mathrm{L}_{\mathrm{AD}}$ and $\mathrm{L}_{\mathrm{AQ}}$ and gives the percent change between saturated and unsaturated values at full load. On1y five parameters, marked by an astorisk in Table 2.4, show any marked variation due to saturation. This suggests that a satisfactory model might be devised where only these five parameters are treated for saturation. 
The results of the simplified saturation, modifiying only the five parameters, is given in Appendix D. The simulations plotted would appear to have only one quantity plotted, but actually show two plots:

Table 2.4 Sensitivity of Model Parameters to Saturation

\begin{tabular}{|c|c|c|}
\hline Parameter & Saturation Dependence & \% Change \\
\hline $\mathrm{L}_{\mathrm{d}}$ & $\mathrm{L}_{\mathrm{do}}-\frac{\mathrm{S}_{\mathrm{GD}} \mathrm{L}_{\mathrm{ADO}}}{1+\mathrm{S}_{\mathrm{GD}}}$ & $-21 . *$ \\
\hline $\mathbf{L}_{\mathrm{d}}^{\prime}$ & $\mathrm{L}_{\dot{d} \mathrm{o}}^{\prime}-\frac{\mathrm{s}_{\mathrm{GD}} \mathrm{L}_{\mathrm{ADO}}}{1+\mathrm{s}_{\mathrm{GD}}}\left(\frac{\ell_{\mathrm{F}}}{\ell_{\mathrm{F}^{+}+\mathrm{L}_{\mathrm{ADO}}}}\right)$ & -1.55 \\
\hline$L_{d}^{\prime \prime}$ & $L^{\prime}{ }_{d o}-\frac{S_{G D} L_{A D O}}{1+S_{G D}}\left(\frac{L^{\prime}{ }_{d o}-\ell_{\mathrm{a}}^{\prime}}{L_{A D O}}{ }^{2}\right.$ & -0.35 \\
\hline$x_{x d}$ & $x_{x d 0}-\frac{s_{G D} L_{A D O}}{1+s_{G D}} \frac{d x_{x d}}{d L_{A D}}$ & -27 \\
\hline $\mathrm{L}_{\mathbf{q}}$ & $L_{q 0}-\frac{S_{G Q} L_{A Q O}}{1+S_{G Q}}$ & $-20.7 *$ \\
\hline$L^{\prime \prime} q$ & $L^{\prime}{ }_{q 0}-\frac{s_{G Q} L_{A Q O}}{1+s_{G Q}} \frac{\ell_{k q}}{l_{k q}+L_{A Q O}}$ & -0.65 \\
\hline $\mathrm{T}_{\text {do }}^{\prime}$ & $\mathrm{T}^{\prime}$ doo $^{\prime}-\frac{\mathrm{S}_{\mathrm{GD}_{\mathrm{ADO}}}}{\left(1+\mathrm{S}_{\mathrm{GD}}\right) \mathrm{r}_{\mathrm{F}}}$ & $-20.3 *$ \\
\hline$T^{\prime}$ do & $T_{\text {doo }}^{\prime \prime}-\frac{S_{G D} L_{A D 0}}{1+S_{G D}} \frac{d T^{\prime \prime} d_{0}}{d L_{A D}}$ & -1.39 \\
\hline$T^{\prime \prime}$ qgo & $\mathrm{T}_{\text {qOO }}^{\prime \prime}-\frac{\mathrm{S}_{\mathrm{GQ}} \mathrm{L}_{\mathrm{AQO}}}{1+\mathrm{S}_{\mathrm{GQ}}} \frac{\mathrm{dT}^{\prime \prime}{ }_{\mathrm{qO}}^{\prime}}{\mathrm{d} \mathrm{L}_{\mathrm{AQ}}}$ & -0.01 \\
\hline $\mathbf{r}_{1}$ & $\mathrm{~K}_{10}-\frac{\mathrm{s}_{\mathrm{GD}} \mathrm{L}_{\mathrm{ADO}}}{1+\mathrm{s}_{\mathrm{GD}}} \quad \frac{\mathrm{dK}_{1}}{\mathrm{dL}_{\mathrm{AD}}}$ & 3.9 \\
\hline
\end{tabular}


the fully saturated flux linkage model and the simplified E' model. The results are obviously almost identical.

A statisticaly analysis of the simplified E'" model is given in Appendix E. The errors analyzed compared favorably with those of the fu11y saturated $\mathrm{E}^{\prime \prime}$ mode1.

\title{
2.6 Conclusions
}

Three forms of simulation model have been shown to provide almost identical results when modified to include the effect of saturation. Those are:

\author{
Mode1 A F1ux Linkage Mode1, fully saturated \\ Mode1 B E'' Mode1, fully saturated \\ Mode1 D E' Mode1, with simplified saturation
}

The usual industry practice is to use some form of Mode1 D, saturating only inductances. Our analysis shows that certain gains as well as $T_{d o}^{\prime}$ should also be treated for the effect of saturation.

The flux linkage model should be examined further. for its suitability as a digital model for stability. This model is simpler than morle1s of the $E^{\prime \prime}$ type and are easier to satarate. The time constants are really constant for this model and the number of gain parameters is sma11. We recommend this model for serious considerations in the futnre. 


\subsection{EPRI STABILITY PROGRAM SIMULATION}

3.1 Digita1 Mode1 of the Wind Turbine Generator

The purpose of this task is to provide a digital implementation of the Purdue MOD-2 Wind Turbine Generator Model for ase on the EPRI Transient Mid-Term Stability Program (ETMSTAB). The Purdue Model is wel1 documented in published references [4-6] and private communications [7]. A block diagram summarizing the component models and their interconnection, modified for digital simulation, is shown in Figure 3.1. The blade dynamics are approximated by the nonlinear functions

$$
\begin{aligned}
\gamma & =\frac{V_{W}}{\omega_{B}} \\
C_{p} & =\frac{1}{2}\left(\gamma-0.022 \beta^{2}-5.6\right) e^{-0.17 \gamma} \\
P_{W} & =\frac{1}{2} \rho A C_{p} V_{W}{ }^{3} \\
& \simeq \frac{1}{2} \rho A \omega_{B 0} C_{p} \gamma V_{W}^{2}
\end{aligned}
$$

$$
\text { where } \begin{aligned}
V_{W} & =\text { wind velocity in } \mathrm{mi} / \mathrm{h} \\
\omega_{B} & =\text { blade angular velocity in mech rad/s } \\
\gamma & =\text { tip speed ratio in }(\mathrm{mi} / \mathrm{h}) /(\mathrm{rad} / \mathrm{s}) \\
\beta & =\text { blade pitch angle, degrees } \\
C_{p} & =\text { power coefficient (dimensionless) } \\
\rho & =\text { air density in } 1 \mathrm{bf} / \mathrm{ft}^{3} \\
A & =\text { blade impact area in } \mathrm{ft}^{2}
\end{aligned}
$$




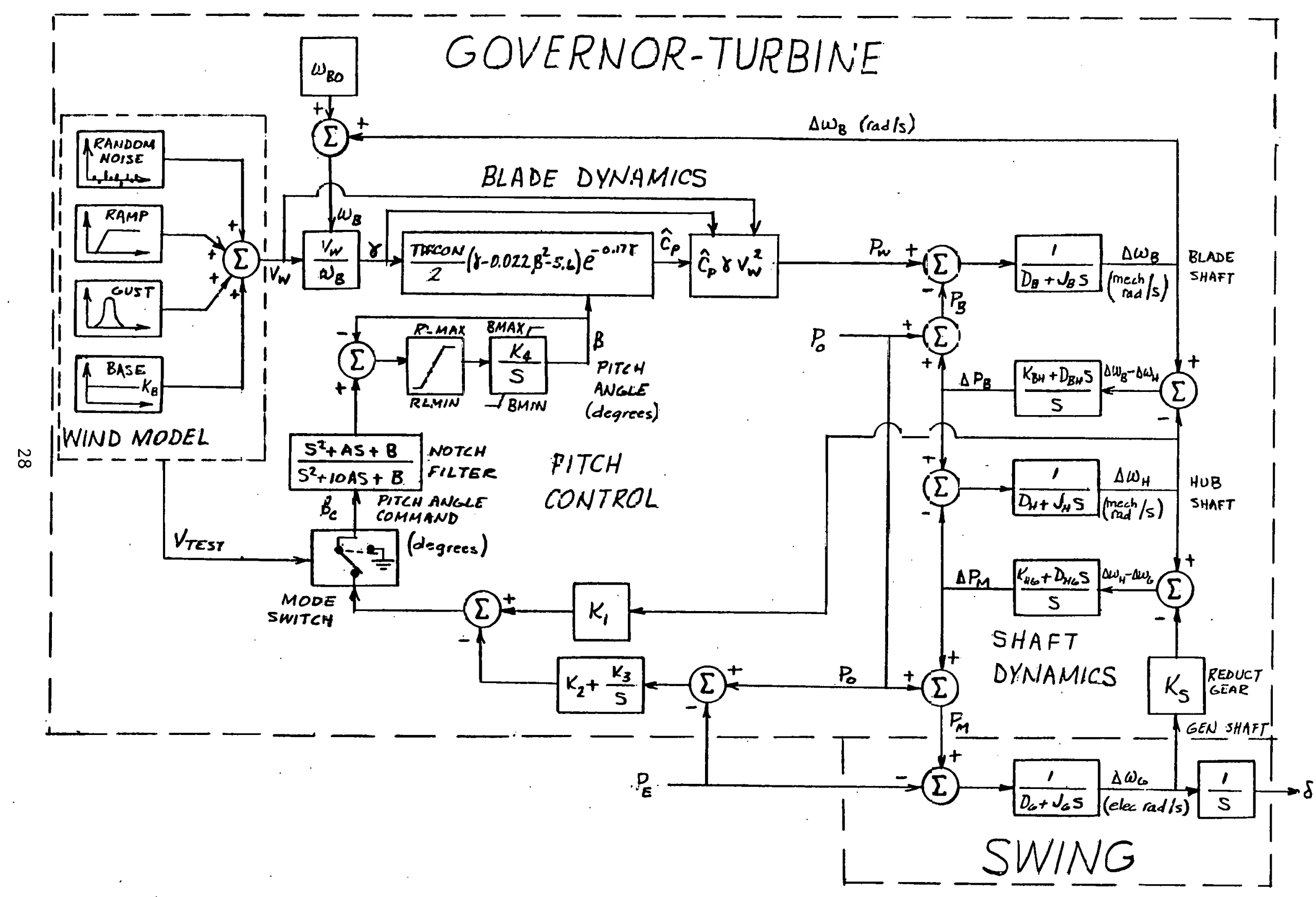

Figure 3.1 B1ock Diagram of the Digita1 MOD-2 Hode1 
Function (3.2) was not available in the ETMSTAB modular mode1ing package and was therefore constructed as a special module.

The Purdue Modelers devised the approximate expression (3.2) for the power coefficient $C_{p}$ as a nonlinear function of blade pitch angle, $\beta$, and tip speed ratio, $\gamma$. This function is shown in Figure 3.2. In the digital simulation, it was found convenient to multiply this function by the forward $100 p$ gain TWCON equal to $6.151 \times 10^{-6}$. This constant converts the turbine outpat torque in joules to per unit, normalized on the ETMSTAB base of 100 MVA, with all forward loop constants collected into the one value, as noted in Figure 3.1 .

The blade output power as a function of wind velocity is shown in Figure 3.3, which is a plot of the $P_{W}$ vs $V_{W}$ of Figure 3.1 at rated blade speed and for various pitch angles. It is noted that these characteristic curves level off at wind velocities of $45-50 \mathrm{mi} / \mathrm{h}$.

The b1ade torque-speed characteristic is of interest in power generation, since this characteristic works against the torque-speed characteristic of the load to determine frequency regulation or governing. The MOD-2 torque-speed characteristic varies with wind velocity, with two characteristic curves given in Figare 3.4. (Note that the two plots of Fignre 3.4 have different vertical scales.) We are interested in these plots only in the neighborhood of rated speed $(1.848 \mathrm{rad} / \mathrm{s})$. In this region, the torque characteristic is nearly f1at, with a small negative slope.

The turbine power v8. speed characteristic is shown in Figure 3.5 , where again we focus our attention in the region near $1.848 \mathrm{rad} / \mathrm{s}$. Here the slope is observed to be definitely positive for sma11 b1ade angles and corresponding high power output. Onr simulation of the wiud turbine 


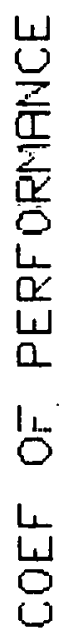

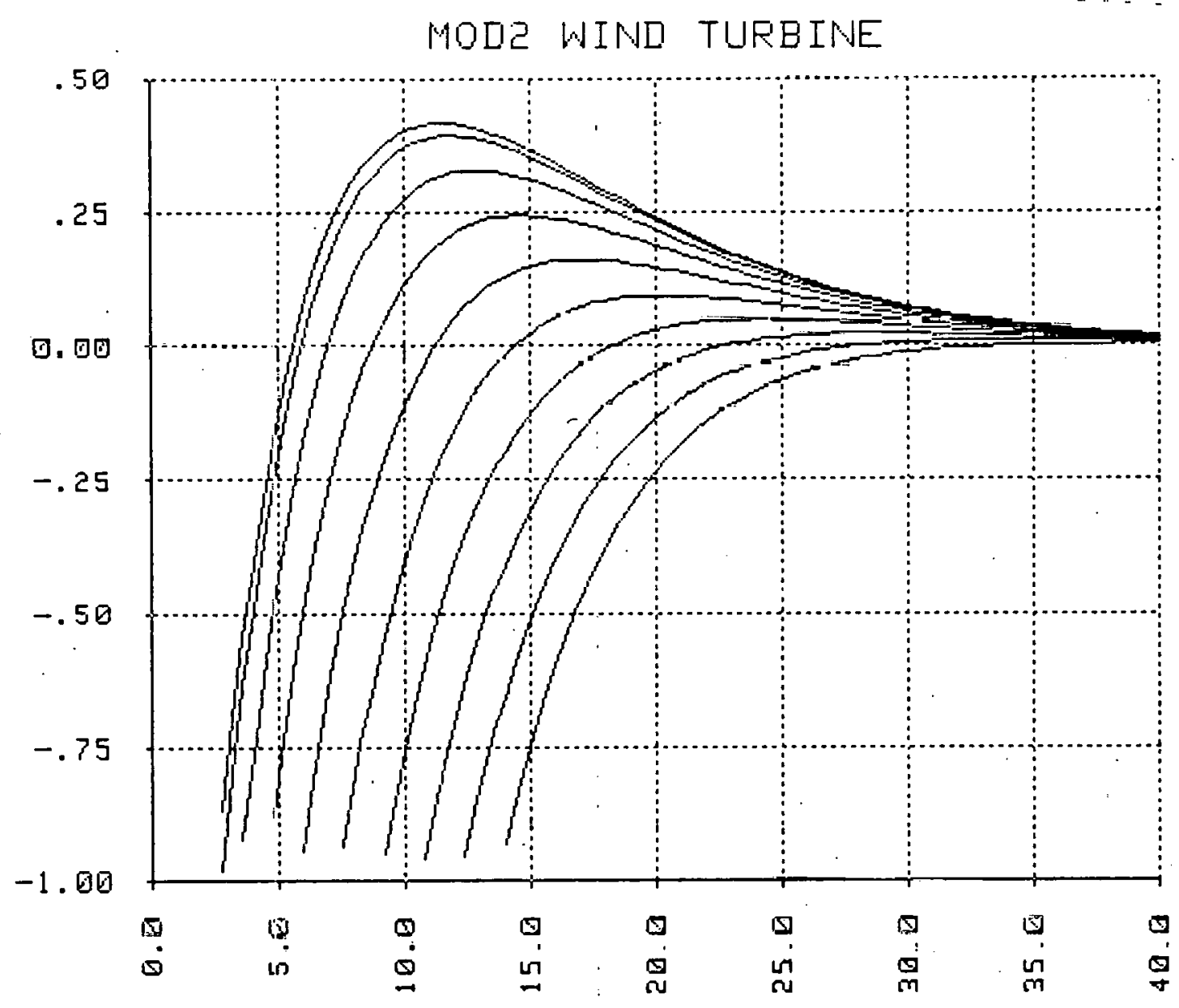

GAMMA

Figure 3.2 Powor Cuefficient as Fnotion of Gamma

for Pitch Angles of (top to bottom) 0-36 degrees

in 4 degree increments 


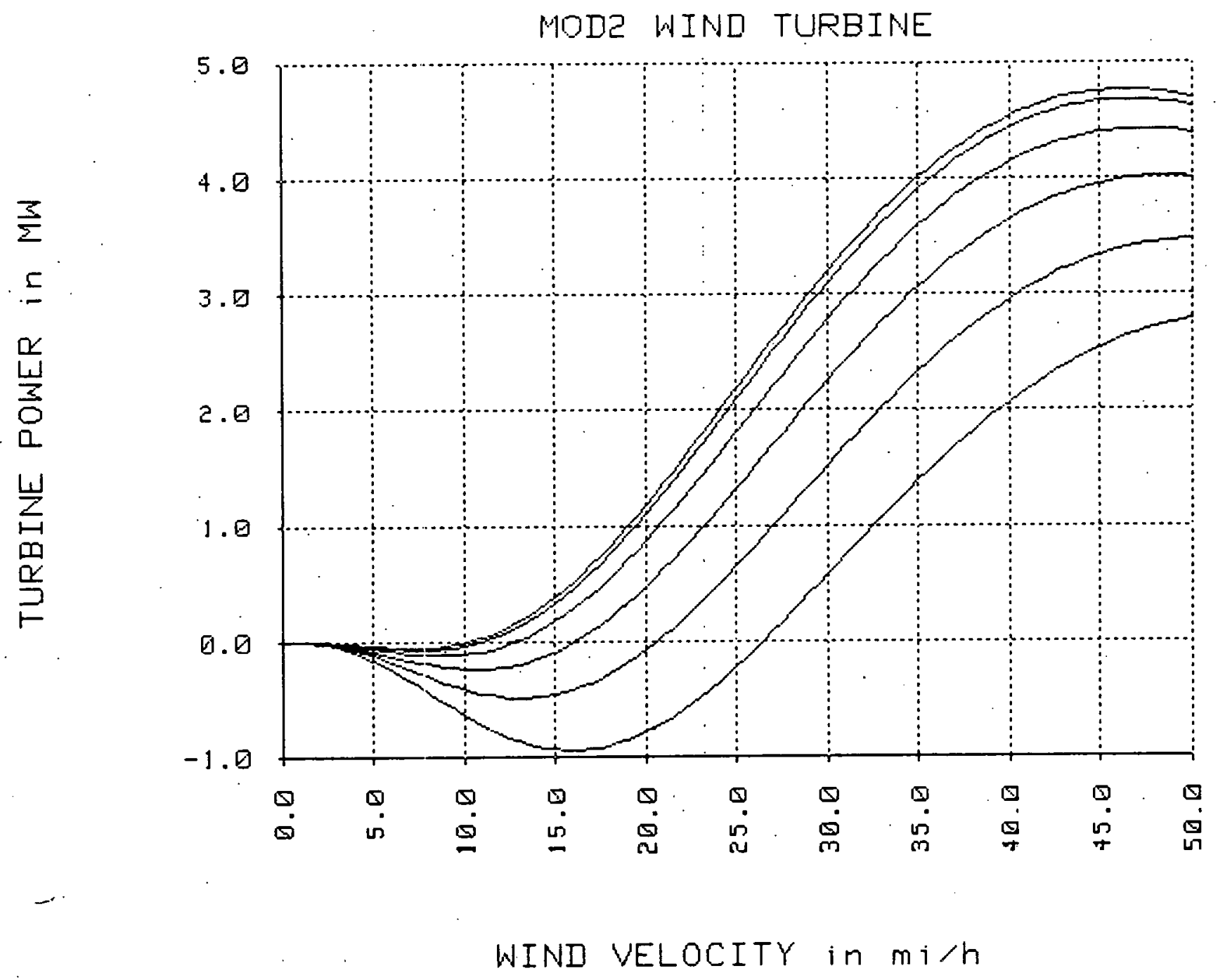

Figure 3.3 Wind Turbine Output Power vs Wind Velocity at Rated Blade Angular Velocity, Pitch Angles (top to bottom) of $0,4,8,12,16$ and 20 degrees 


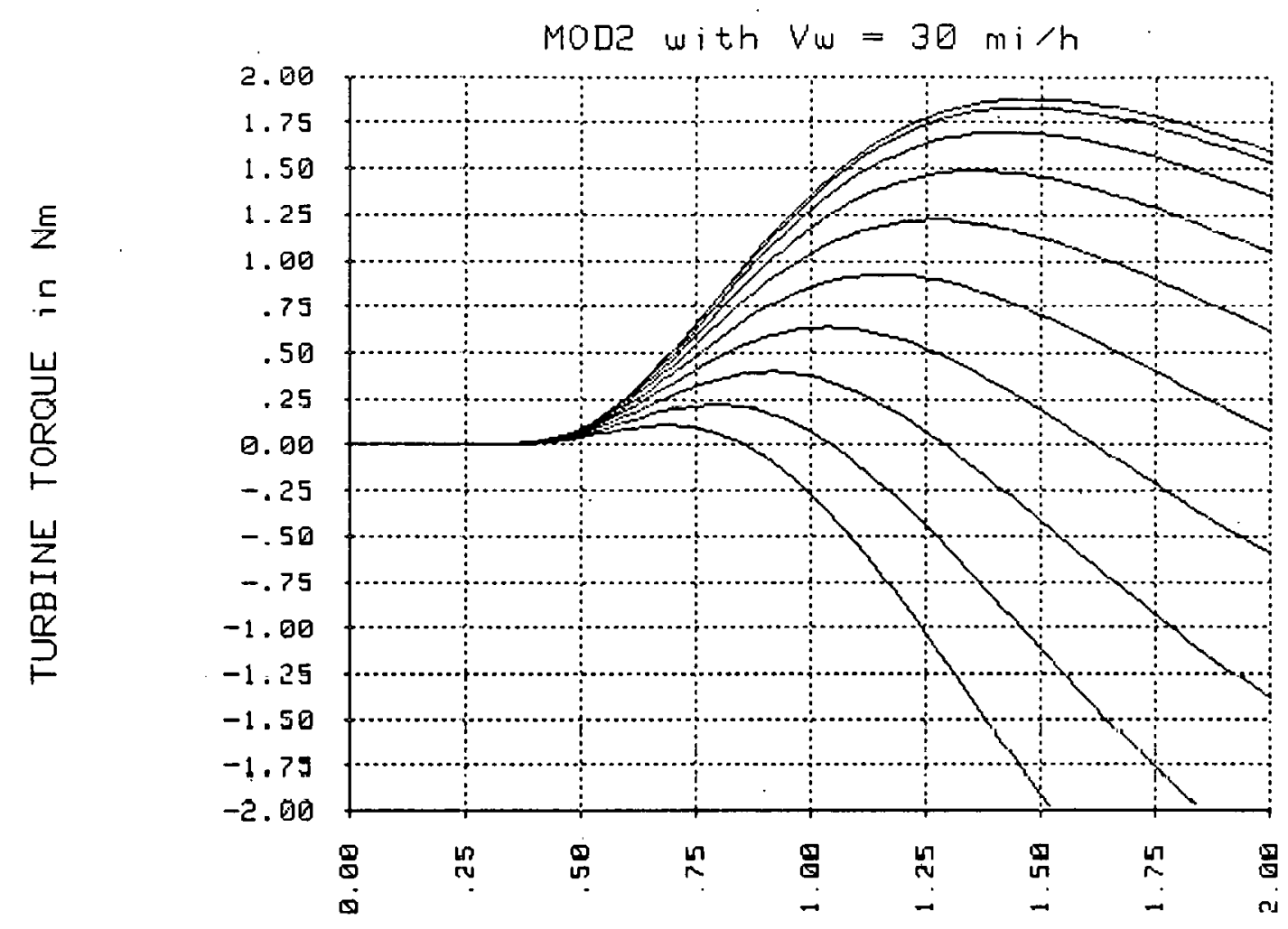

BLADE ANGULAR VELOCITY in $\mathrm{rad} / \mathrm{s}$

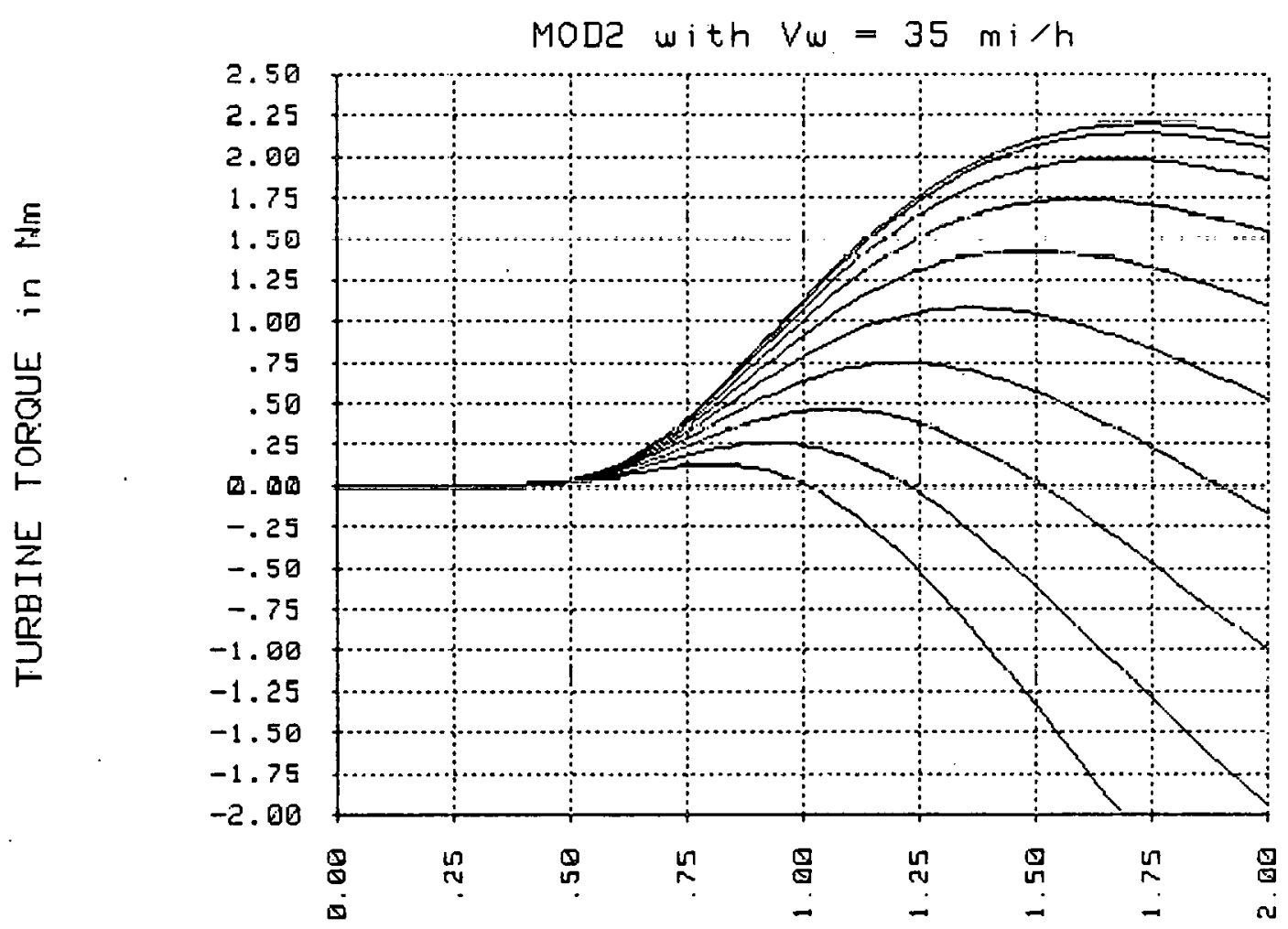

BLADE ANGULAR VELOCITY in radrs

Figure 3.4 Wind Turbine Torque-Speed Characteristic,

Pitch Angles of 0-36 in 4 degree increments 


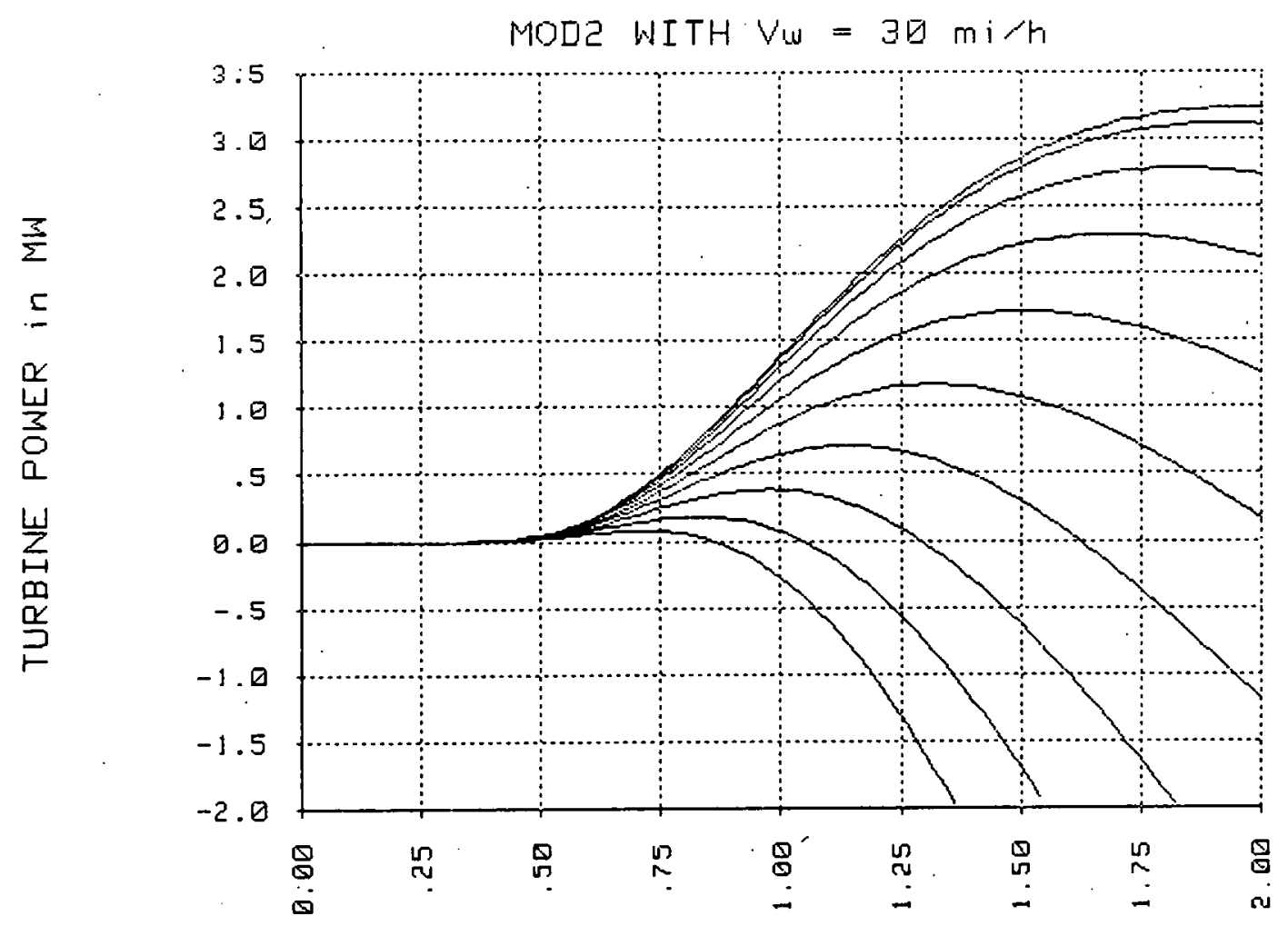

BLADE ANGULAR VELOCITY in $\mathrm{rad} / \mathrm{s}$

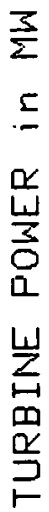

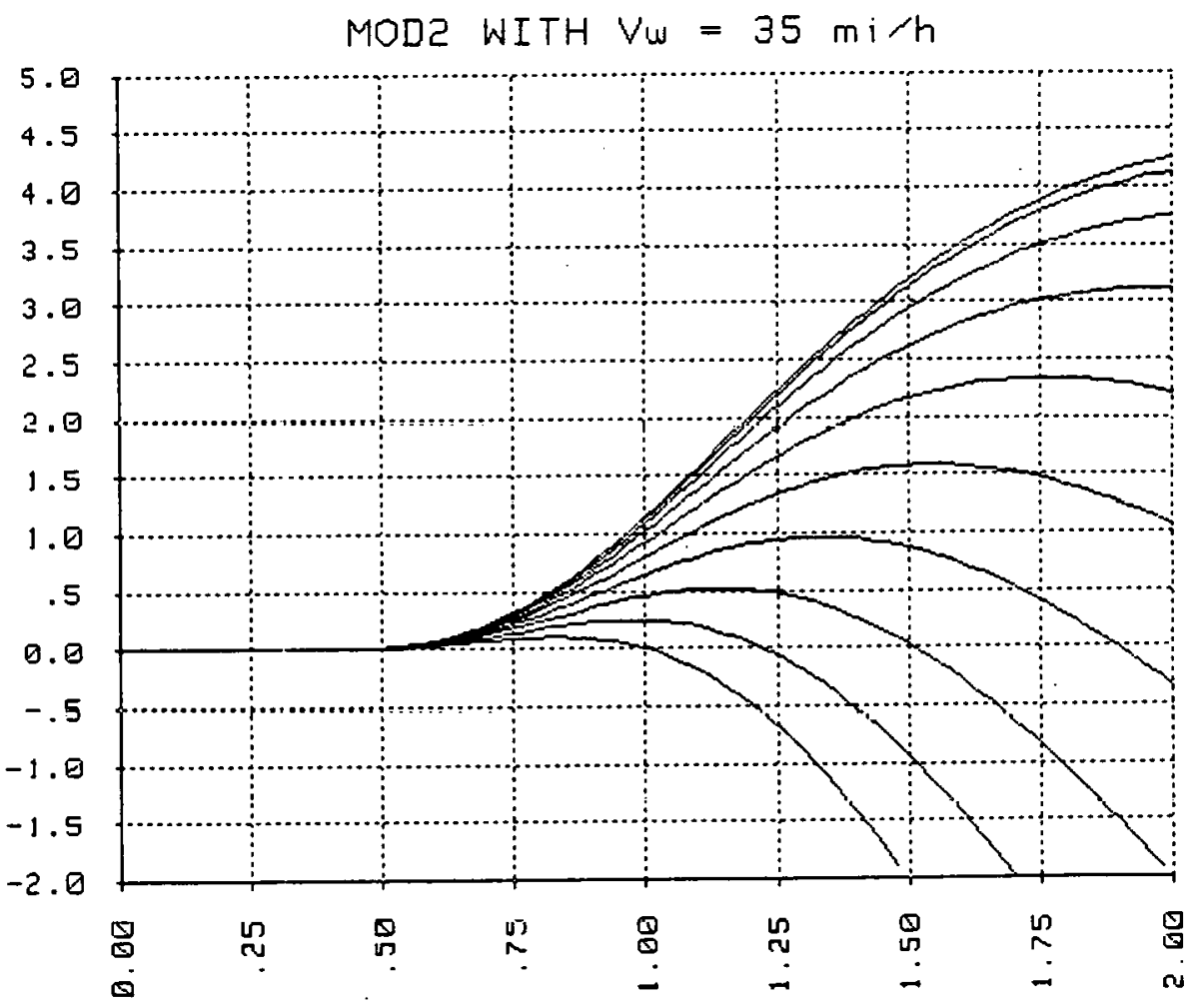

BLADE ANGLLLR VELOCITY in radrs

Figure 3.5 Wind Turbine Power-Speed Characteristic,

Pitch Angles of $0-36$ in 4 degree increments 
system verified that the open-10op system is marginally unstable for a base wind of $35 \mathrm{mi} / \mathrm{h}$ and a scheduled power of $2.55 \mathrm{HW}$. This point is just barely in the positive slope region.

The pitch control system shown in Figure 3.1 , provides integral control of errors in hub speed or generated power, with a notch filter introdaced to reduce oscillations of twice the rotational frequency, arising from wind shear phenomena, blade teetering and nacelle yaw [17]. Appropriate limiting of both pitch angle and rate-of-change are incorporated. A mode switch is devised to remove the pitch angle control when the average wind speed is below a nominal cut-off velocity. A11 the pitch control components, except the mode switch, are simulated using modeling modules normally available in ETMSTAB. The mode switch module is constructed according to the prescribed logic, and is added to the modeling package.

The shaft dynamics model is a straightforward implementation of a linear rotating shaft with three masses, corresponding to the b1ade, hub, and generator shafts.

All the foregoing model components are discossed in greacer derail in Section 3.3 .

\subsection{Wind Marie.1.}

The wind model is one feature that is unique to the wind turbinegenerator system and is not required for other generator systems in the stability program. A model is required that can properly simulate the spatial effect of wind behavior, including gusting, rapid (ramp) changes, and background noise. Obviously no wind model is available in existing stability programs and must be created as a special modeling module. 
The wind model chosen for this simalation is a four-component model, shown graphically in Figure 3.6 , and defined by the equation

$$
V_{W}=V_{W B}+V_{W G}+V_{W R}+V_{W N}
$$

where

$V_{W B}=$ base wind velocity, $\mathrm{mi} / \mathrm{h}$

$V_{W G}=$ gust wind component, mi/h

$V_{\text {WR }}=$ ramp wind component, mi/h

$V_{W N}=$ noise $w$ ind component, $\mathrm{mi} / \mathrm{h}$

These four components provide a reasonable flexibility for the study of one or a group of wind generators.

The base wind velocity component is described by the equation

$\mathrm{V}_{\mathrm{WB}}=\mathrm{K}_{\mathrm{B}} \quad \mathrm{mi} / \mathbf{h}$

where $K_{B}$ is a constant. This component is always assumed to be present in studies where the wind generator is required to be in service.

The gust wind velocity component is described by the equation

$V_{W G}= \begin{cases}0 & t<T_{1 G} \\ V_{C o s} & T_{1 G}<t<T_{1 G}+T_{G} \mathrm{mi} / \mathrm{h} \\ 0 & t>T_{1 G}+T_{G}\end{cases}$

where

$$
\begin{aligned}
& V_{C O S}=\left(\text { MAXG/2) }\left\{1-\cos 2 \pi\left[\left(t / T_{G}\right)-\left(T_{1 G} / T_{G}\right)\right]\right\}\right. \\
& T_{G}=\text { gust period in } \\
& T_{1 G}=\text { gust starting } t i m e \text { in } \\
& \text { MAXG }=\text { gust peak in mi/h } \\
& t \quad=\text { time ins }
\end{aligned}
$$


WIND MODEL
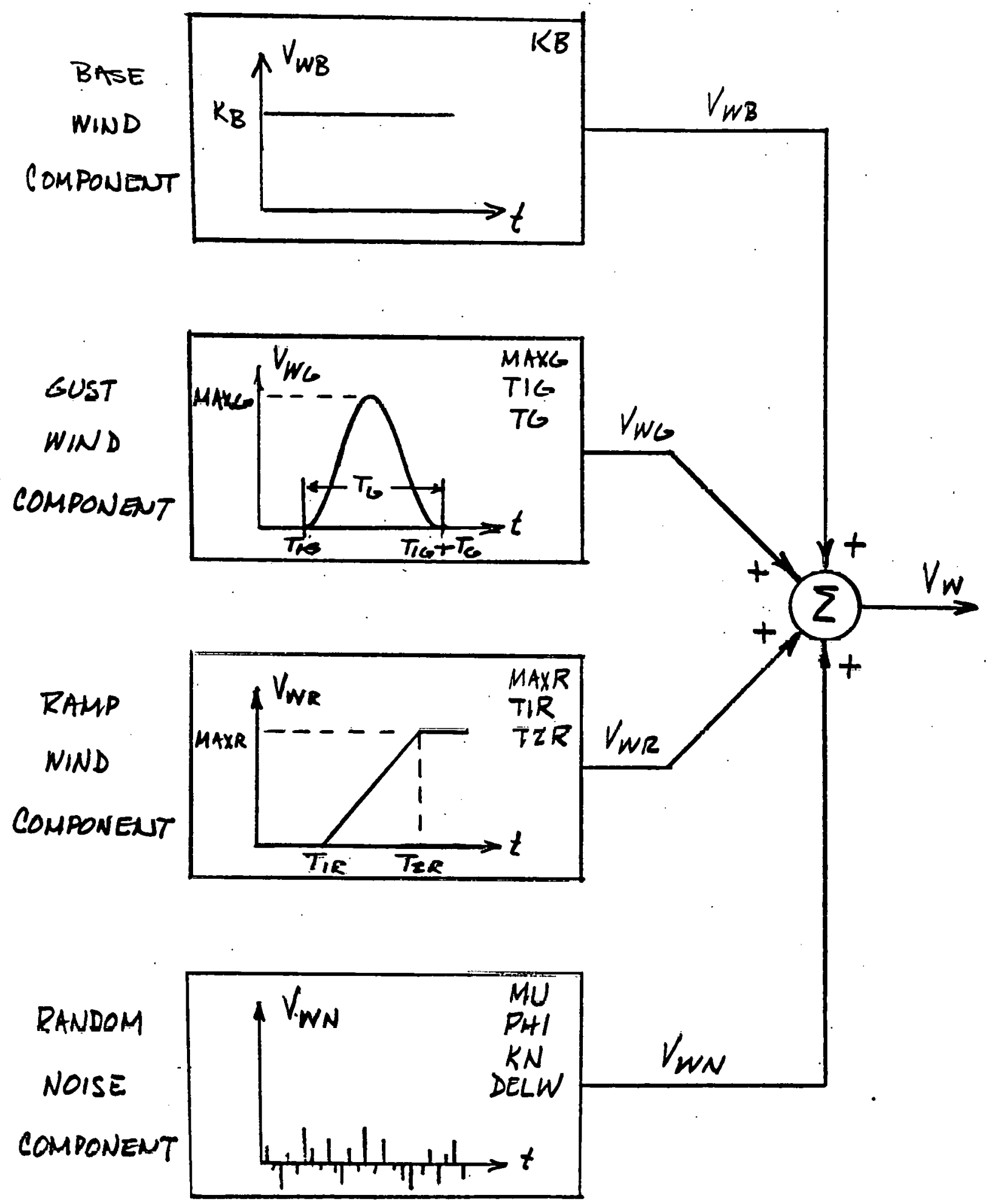

Figure 3.6 Block Diagram of Wind Model 
This is the usual 1-cosine gust used in wind studies by others [18], and is considered an essential component of wind velocity for dynamic studies.

The ramp wind velocity component is described by the equation

$$
V_{W R}= \begin{cases}0 & t<T_{1 R} \\ V_{\text {ramp }} & T_{1 R}<t<T_{2 R} \quad \mathrm{mi} / \mathrm{h} \\ 0 & t>T_{2 R}\end{cases}
$$

where

$$
\begin{aligned}
& V_{\text {ramp }}=\operatorname{MAXR}\left[1-\left(t-T_{2 R}\right) /\left(T_{1} R^{-} T_{2 R}\right)\right] \mathrm{mi} / \mathrm{h} \\
& \operatorname{MAXR}=\text { ramp maximum in mi/h } \\
& T_{1 R}=\text { ramp start time in } s \\
& T_{2 R}=\text { ramp max time in } s
\end{aligned}
$$

and where $T_{2 R}>T_{1 R}$. This functions may be used to approximate a step change, by setting $T_{2 R}$ only slightly greater than $T_{1 R}$, or a slowly increasing wind velocity to study ramp tracking. For negative values of MAXR, ramps of negative slopes could be studied.

The final wind velocity component is the random noise component, where we define

$$
V_{W N}=2 \sum_{i=1}^{N}\left[S_{V}\left(\omega_{i}\right) \Delta \omega\right]^{1 / 2} \cos \left(\omega_{i} t+\phi_{i}\right), t<0
$$

where

$$
\begin{aligned}
\omega_{i}= & (i-1 / 2) \Delta \omega \\
\phi_{i}= & \text { a random variable with uniform probability density on the } \\
& \text { interval o to } 2 \pi
\end{aligned}
$$


and the function $S_{V}\left(\omega_{i}\right)$ is the spectral density function defined by Vaicaitis, et al [19] by the equation

$$
S_{V}\left(\omega_{i}\right)=\frac{2 \mathrm{~K}_{N} F^{2}\left|\omega_{i}\right|}{\pi^{2}\left[1+\left(F \omega_{i} / \mu \pi\right)^{2}\right]^{4 / 3}}
$$

where $\quad K_{N}=$ surface drag coefficient $=0.004$

$$
\begin{aligned}
F & =\text { turbulance scale, ft }=2000 \\
\mu & =\text { mean speed of wind at reference height, ft/s } \\
& =29.33(30 \mathrm{mi} / \mathrm{h})
\end{aligned}
$$

Various studies have shown that values of $\mathrm{N}=50$ and $\Delta \omega=0.5-2.0 \mathrm{rad} / \mathrm{s}$ provide results of excellent accuracy.

Simnlation results for the wind model are shown in Figures 3.7 and 3.8. Fignre 3.7 shows a wind condition with a base component $V_{W B}$ of 30 mi/h (44 ft/s) with ramp and gnst components superimposed in (a) and (b) respectively. In Figure 3.7 (a) the ramp begins at $10 \mathrm{~s}$ and ends at $15 \mathrm{~s}$ with MAXR $=10 \mathrm{mi} / \mathrm{h}(14.67 \mathrm{ft} / \mathrm{s})$. In Figure $3.7(\mathrm{~b})$ the gust component begins at $10 \mathrm{~s}$ and ends at $15 \mathrm{~s}\left(\mathrm{~T}_{G}=5 \mathrm{~s}\right)$ with $M A X G=10 \mathrm{mi} / \mathrm{h}(14.67 \mathrm{ft} / \mathrm{s})$.

Figure 3.8 shows some typical results of the wind model simulation that incorporate random noise. The top figure (a) shows a base wind of $30 \mathrm{mi} / \mathrm{h}(44 \mathrm{ft} / \mathrm{s})$ with the random component superimposed. The bottom figure (b) shows base, ramp, gust components, and random noise. In each case the random noise spectrum was oomputod with $\Delta \omega=0.5$. Similar plots are obtained with $\Delta \omega=2.0$.

Statistics computed for the random components for $\Delta \omega=2.0$ are given in Table 3.1. Those statistios are typical of those observed in many runs and show a standard deviation of $2.28 \mathrm{ft} / \mathrm{s}(1.56 \mathrm{mi} / \mathrm{h})$. 

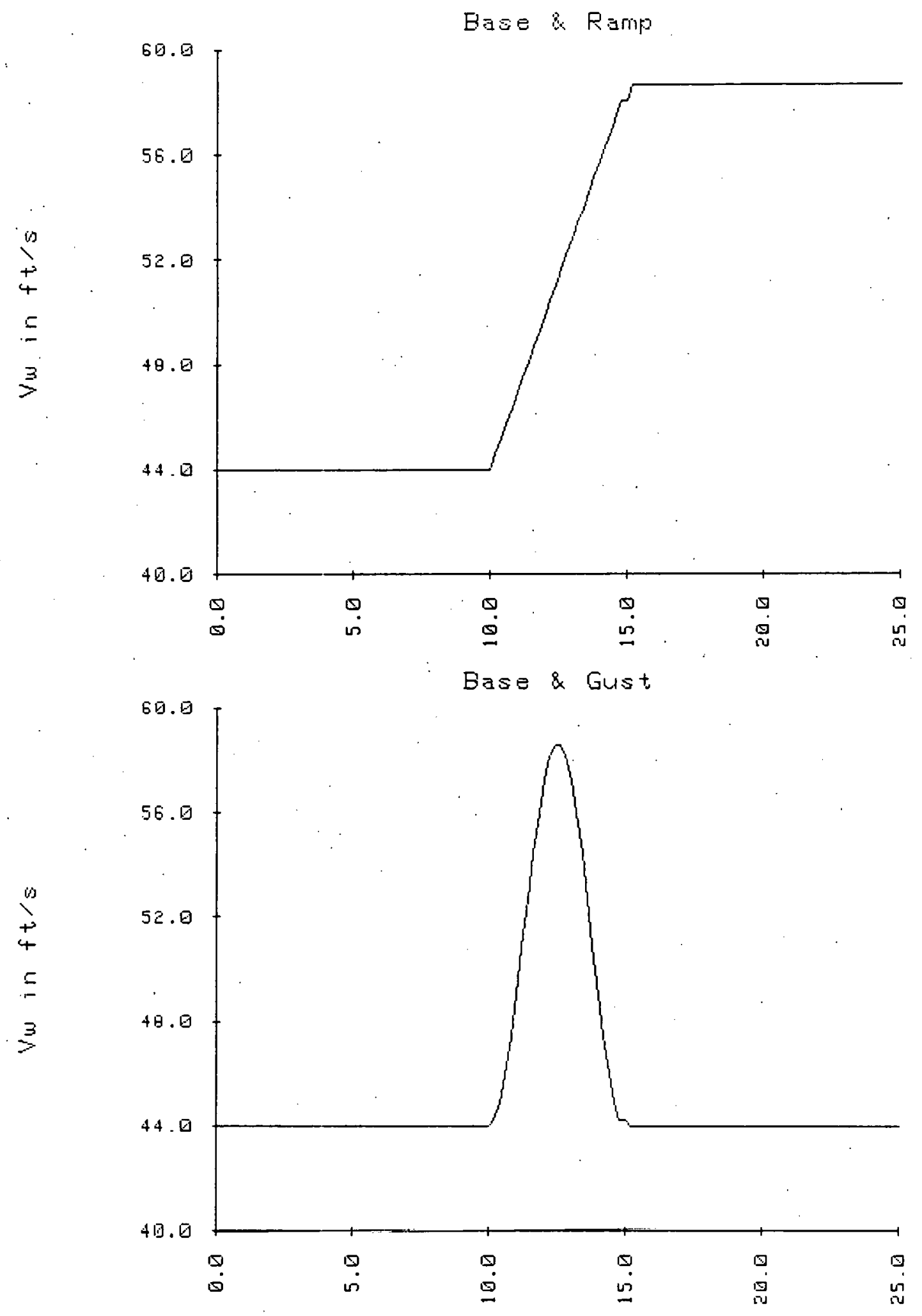

Time in Second

Figure 3.7 Wind Model Simulation with $V_{W B}=30 \mathrm{mi} / \mathrm{h}(44 \mathrm{ft} / \mathrm{s})$ 

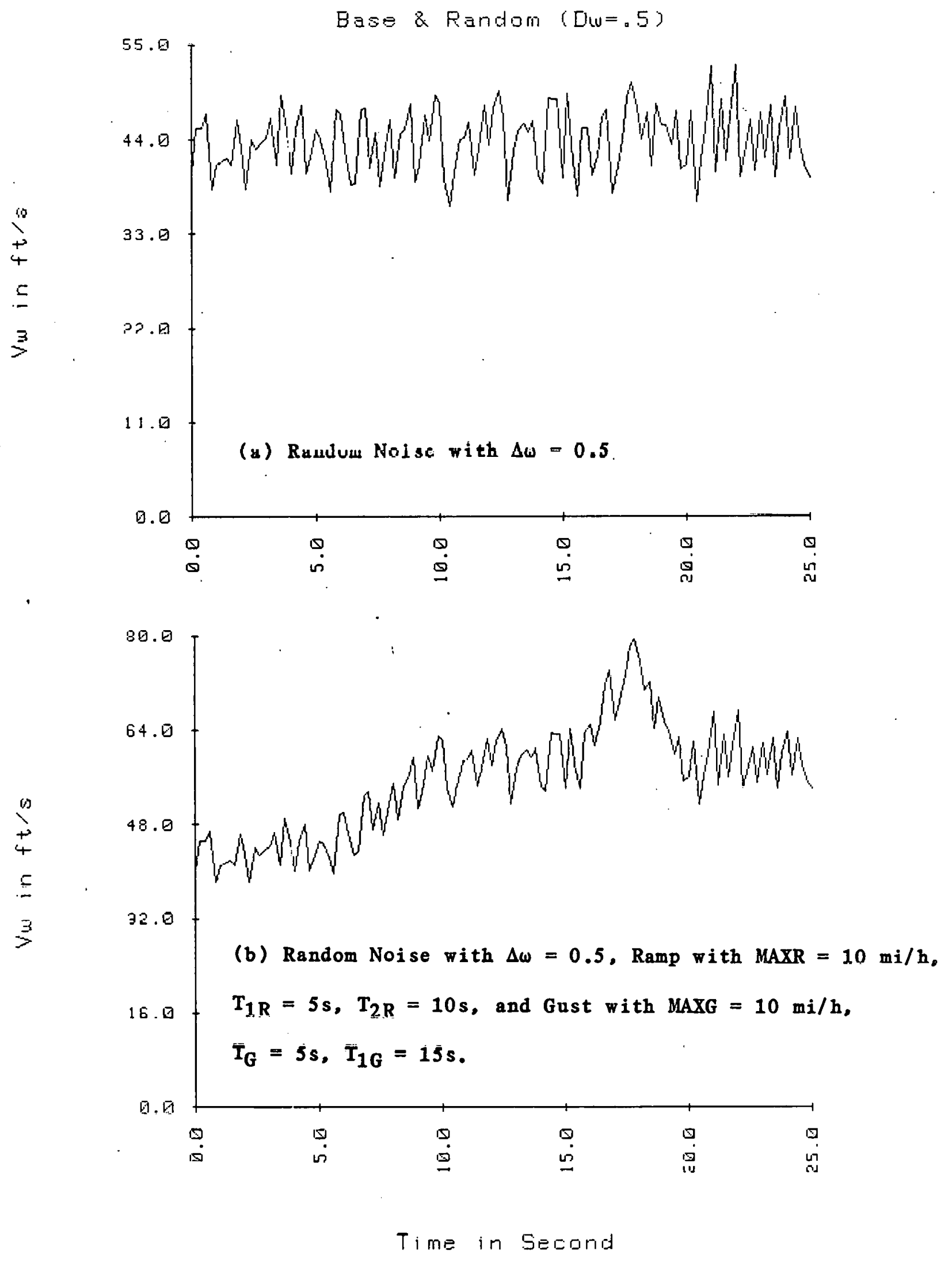

Figure 3.8 Wind Model Simulation with $V_{W B}=30 \mathrm{mi} / \mathrm{h}(44 \mathrm{ft} / \mathrm{s})$ 
Similar results were obtained with a range of $\Delta \omega$ from 0.5 to 2.0 , using $\mathrm{N}=50$. Figure 3.9 shows a histogram of the random noise components, taken over 125. samples.

Table 3.1 Statistics of Random Noise Component of Wind Computed for $N=50, \Delta \omega=2.0$

BASIC STATISTICS

$\begin{array}{lrrrrr}\text { VARIABLE } & \text { \# OBSERVATIONS } & \text { \# MISS. VALUES } & \text { SUM } & \text { MEAN } \\ \text { Vw in } \mathrm{ft} / \mathrm{s} & 126 & 0 & -.72884 & -.00578\end{array}$

$\begin{array}{lrrrr} & & & \\ \text { VARIABLE : } & \text { VARIANCE } & \text { STANDARD DEV. } & \text { SKEFNESS } & \text { COEF OF } \\ \text { VW in } \mathrm{ft} / \mathrm{s} & 5.21165 & 2.28290 & .00857 & -.51996\end{array}$

\begin{tabular}{lrrrr} 
& & & & \\
VARIABLE & COEF VARIATION & OF THE MEAN & $90 \%$ CONFIDENCE & INTERVAL ON \\
Vw in $\mathrm{ft} / \mathrm{s}$ & 39466.34613 & .20338 & -.34288 & LIMIT .33131 \\
& & & & \\
\hline
\end{tabular}

ORDER STATISTICS

$\begin{array}{llrrr}\text { VARIABLE } & \text { MAXIMUM } & \text { MINIMUM } & \text { RANGE } & \text { MIDRANGE } \\ \mathrm{Vw} \text { in } \mathrm{ft} / \mathrm{s} & 5.50392 & -5.18974 & 10.69365 & .15709\end{array}$

\subsection{Modu1ar Mode1 for Digita1 Simu1ation}

Figure 3.1 shows the block diagram of the wind turbine-generator system, modified to meet the modular modeling structures of the stability program ETMSTAB, shown in Figure 1.2. The wind turbine model is also modified to meet restrictions imposed by parameter limitations in ETMSTAB. 


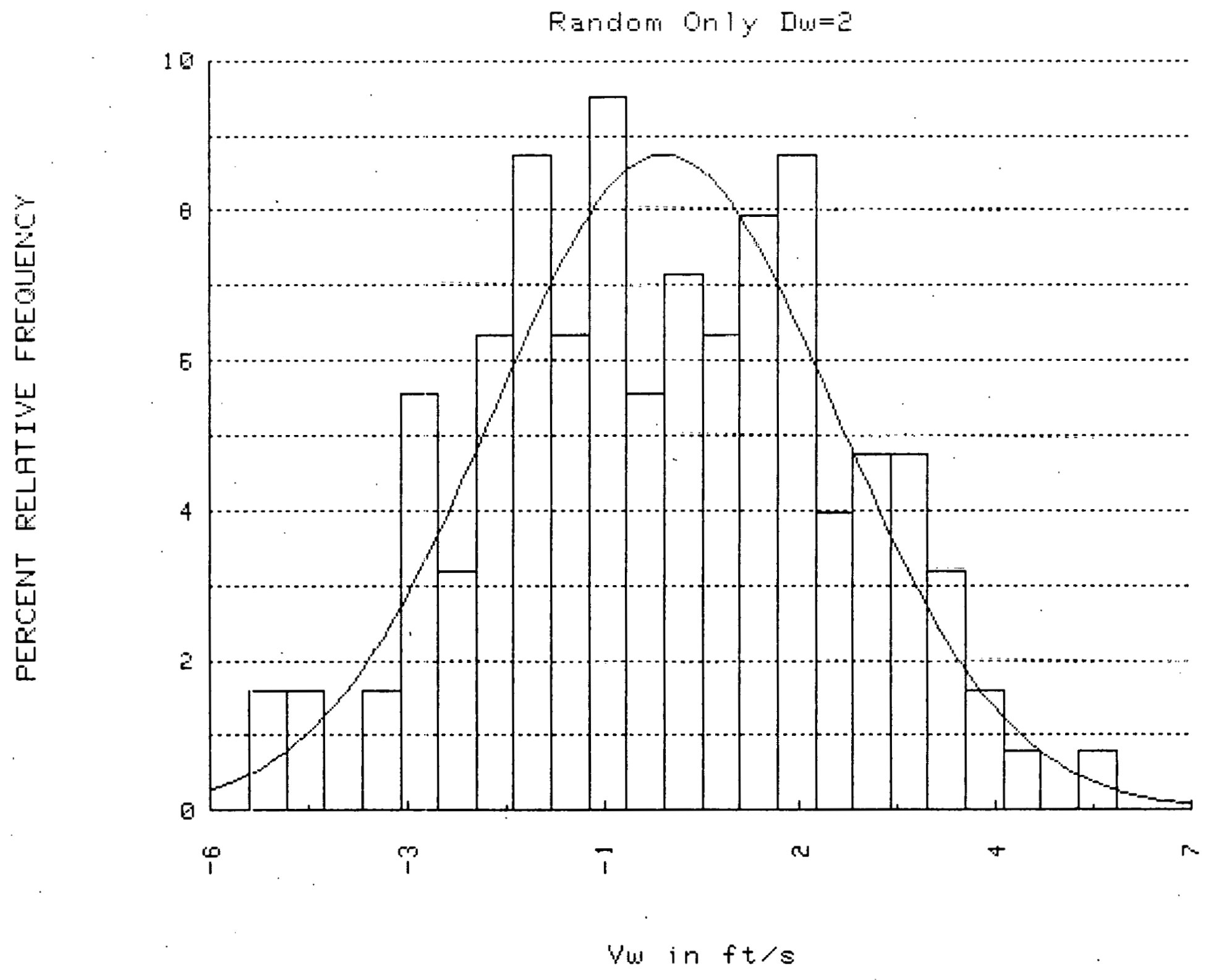

Figure 3.9 Histogram of Random Noise Component with $\Delta \omega=2.0 \mathrm{rad} / \mathrm{s}$. 
One restriction of the digital program is the scaling of variables. All computation assumes models to be normalized to a 100 MVA base, with speeds computed in radians per second and time in seconds. This requires a normalization of the turbine generator output $P_{W}$ to a 100 MVA base. Feedback from the system is similariy normalized. Major modeling accomodations are discussed below. Reference is to Figure 3.1.

The wind model was constructed by adding a special function module to provide $V_{W}$ in mi/h given the parameters of the four wind components. This special module provided an input to the $\gamma$-block, which is represented by a module available in the program.

The blade dynamics mode1, shown in Figure 3.1 , is modified to incorporate all constants into one parameter $T_{W C O N}$. This parameter also normalizes the output $P_{W}$ to a per unit value. In doing this, the intermediate variable $c_{p}$ is modified by a constant scale factor to a new variable $\hat{c}_{p}$. A special model module is then constructed to compute

$$
\hat{C}_{p}=\frac{T_{W C O N}}{2}\left(\gamma-0.022 \beta^{2}-5.6\right) e^{-0.17 \gamma}
$$

Other model requiremens are met by use of standard modeling modules, provided by the program, with the sole exception of the mode switch. This function is described mathematically by the equation

$$
x=\left\{\begin{array}{lll}
0 & \text { if } \sigma_{2} \leqq v_{c} \\
\sigma_{1} & \text { if } \sigma_{2}>v_{c}
\end{array}\right.
$$

where 


$$
\begin{aligned}
& x=\text { output } \\
& \mathrm{U}_{1}=\text { input } 1 \text { (from speed and power error) } \\
& \left.\mathrm{U}_{2}=\text { input } 2 \text { (from average } V_{W}\right)=V_{W B}+V_{W G}+V_{W R} \\
& V_{c}=V W C U T
\end{aligned}
$$

The parameter VWCUT is the pitch control cutoff wind velocity and must be input as a control parameter. The equation (3.11) is also constructed as a special modeling module.

The notch filter requires special handing as a digital filter design, but this is accomplished using standard model modules. The program implements a technique described by Cadzow [20]. The partioular filter required here is a special case of the function

$$
x=\frac{s^{2}+a s+b}{s^{2}+c s+d} u
$$

where, in our case, $c=10 a$ and $b=d$. This permits a simplification of Cadzow's filter to the form shown in Figure 3.10 , where we let

$$
\begin{aligned}
& \text { AFILT }=a-0=-\rho_{a} \\
& \text { BFILT }=-b \\
& \text { CFILT }=-c
\end{aligned}
$$

These three parameters axe iuput paramotere to the program.

The program has a basic 1imitation of 22 parameters that can be specified for a governor-turbine mode1. These parameters, and their values, are shown in Table 3.2. All other parameters required for the simulation, 14 in al1, were incorporated as parameters for spocial modeling modules. These parameters are given in Tuble 3.3 . 


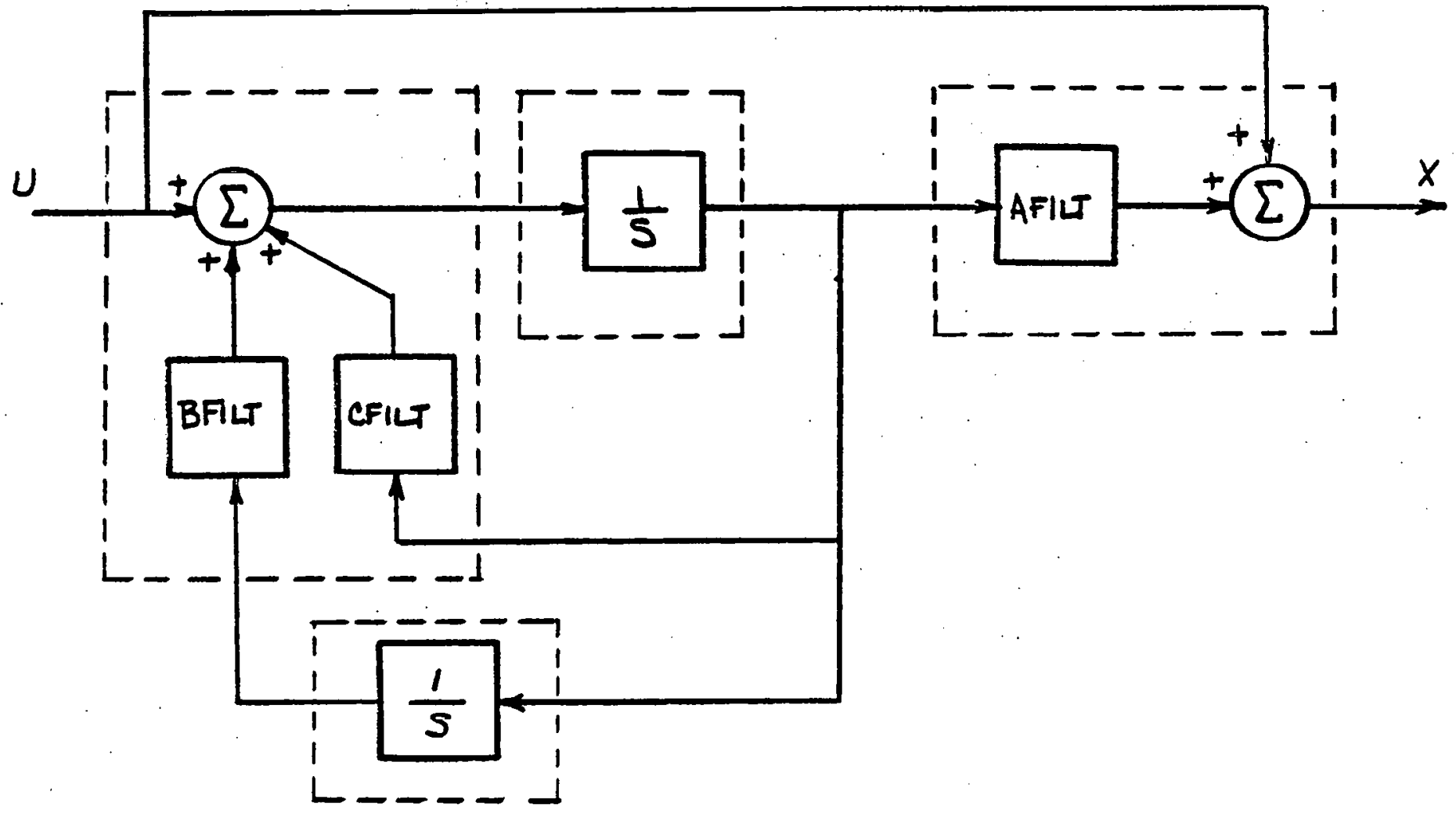

Figure 3.10 Digital Implementation of the Notch Filter 
Table 3.2 Wind Governor-Turbine Parameters

No

1

2

3

4

5

6

7

8

9

10

11

12

13

14

15

16

17

18

19

20

21

22
Parameter

KS

K1

K2

K3

VWCUT

AILT

BFILT

CFILT

K4

PZ.

RLMIN

RLMAX

BMIN

BMAX

DB

JB

KBH

DBH

DII

JH

KGH

EGH
Value

0.00487

370.0

15.0

4.0

28.0

$-0.338$

$-13.5$

$-0.375$

6.28

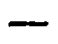

$-10.0$

10.0

0.0

34.0

$6.782 \mathrm{E}-5$

$4.852 \mathrm{E}-1$

$1.275 \mathrm{E}-1$

$4.340 \mathrm{E}-1$

8.206E-5

$1.296 \mathrm{E}-2$

2.102E-1

$1.356 \mathrm{E}-2$
Units

pn

$\operatorname{deg} /(\mathrm{rad} / \mathrm{s})$

deg/paMW

deg-s/puMW

$\mathrm{mi} / \mathrm{h}$

pa

pu

put

pa

pa

deg/s

$\mathrm{dcg} / \mathrm{s}$

deg

deg

$\mathrm{pa} /(\mathrm{rad} / \mathrm{s})$

$s^{2}$

pu/rad

$\mathrm{pa} /(\mathrm{Iad} / \mathrm{s})$

$\mathrm{pa} /(\mathrm{rad} / 6)$

$s^{2}$

pa/rad

$\mathrm{pa} /(\mathrm{rad} / \mathrm{s})$ 
Table 3.3 Special Model Parameters

\begin{tabular}{|c|c|c|c|}
\hline Module & Parameter & Va1ue & Units \\
\hline Speed $\operatorname{Ref}$ & $\omega_{B 0}$ & 1.8379 & $\mathrm{rad} / \mathrm{s}$ \\
\hline Wind & $\mathbf{K B}$ & user selected & $\mathrm{mi} / \mathrm{h}$ \\
\hline$\cdots$ & MAXG & $\cdots$ & $\mathrm{mi} / \mathrm{h}$ \\
\hline$\cdots$ & $\mathbf{T I G}$ & " & s \\
\hline , & TG & $\cdots$ & $\mathbf{s}$ \\
\hline$\cdots$ & MAXR & 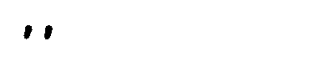 & $\mathrm{mi} / \mathrm{h}$ \\
\hline 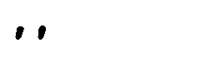 & T1R & & s \\
\hline 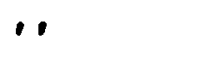 & T2R & ' & s \\
\hline 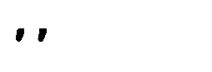 & $\mathbf{K N}$ & , & $\mathrm{mi} / \mathrm{h}$ \\
\hline . & MU & $\cdots$ & $f t / s$ \\
\hline , & F & 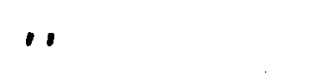 & $f t$ \\
\hline . & DELW & , & $\mathrm{rad} / \mathrm{s}$ \\
\hline Blade & TWCON & $6.5155 \mathrm{E}-6$ & $\mathrm{pu} \cdot \mathrm{h} / \mathrm{mi} \cdot \mathrm{s}$ \\
\hline Rating & PMAXWT & 3.125 & MVA \\
\hline
\end{tabular}




\subsection{ETMSTAB Simulation of the Wind Generator}

Computer simulations of the wind turbine were run using the familiar 9 bas test system shown in Figures 3.11. The wind generator was added to bus 3 and scheduled to generate $2 \%$ of the schedule 85 MW, or 1.7 MW. The steam unit is therefore backed off to $83.3 \mathrm{MW}$. A 1 arge number of test runs were made in this configuration to check ont the various wind model features.

Table 3.4 summarizes the computer runs that were plotted for this ieport. In all oasos where a random noise component is present. indicated by an $X$ in Table 3.4, the noise parameters were $\Delta \omega=2.0, F=$ $2000, K_{N}=0.004$

Results are shown in Figares $3.12-3.21$. In each figure, three results are plotted; the wind velocity, the blade pitch angle, and the turbine mechanical power. Comments on these simulated results follow.

Tab1e 3.4 Summary of Computer Runs of the Nine Bus Test System. All Wind Values in mi/h.

$\begin{array}{lccccc}\text { Run } & \text { Base } & \text { Ramp } & \text { Gust } & \text { Noise } & \text { Figure } \\ \text { WT01 } & 30 & 5 & - & - & 3.12 \\ \text { WT02 } & 30 & - & 5 & - & 3.13 \\ \text { WT03 } & 30 & - & - & \text { X } & 3.14 \\ \text { WT04 } & 25 & 5 & - & - & 3.15 \\ \text { WT05 } & 25 & - & 5 & - & 3.16 \\ \text { WT06 } & 25 & - & - & \text { X } & 3.17 \\ \text { WI07 } & 30 & 5 & - & X & 3.18 \\ \text { WT08 } & 30 & 0 & 5 & \text { X } & 3.19 \\ \text { WT09 } & 30 & -5 & - & X & 3.20 \\ \text { WT10 } & 30 & - & -5 & X & 3.21\end{array}$

Runs WTO1 - 03, shown In Figures 3.12-14, illustrate the cffect of each wind component. Many variations of these runs were tried, from very short gusts and steep ramps to slower variations. Varions noise parameters were al so tested. All runs verify that the model performs as dictated by the theory. 

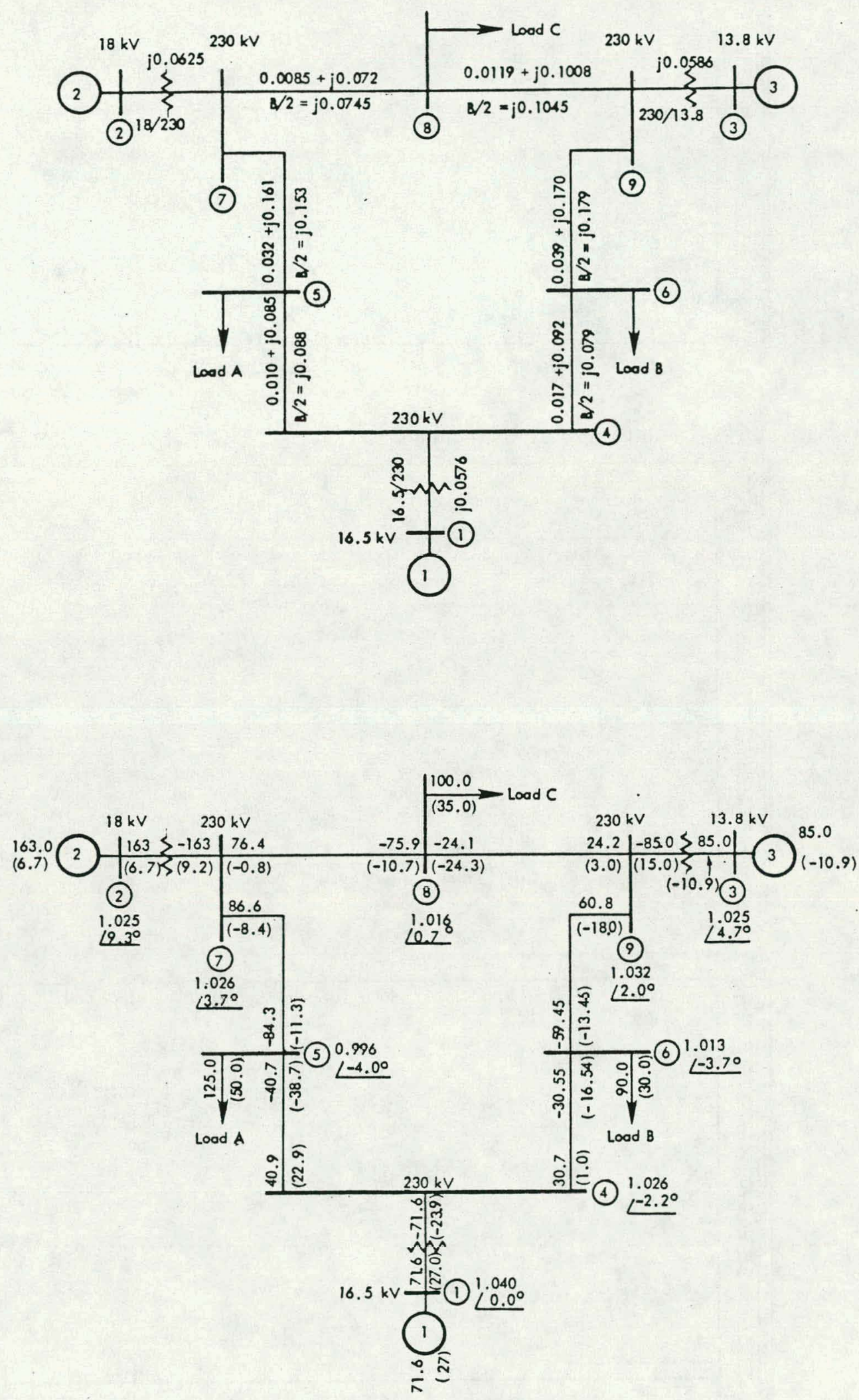

Figure 3.11 Nine Bus Test System; Top: Impedance Diagram,

Bottom: Initial Conditions 

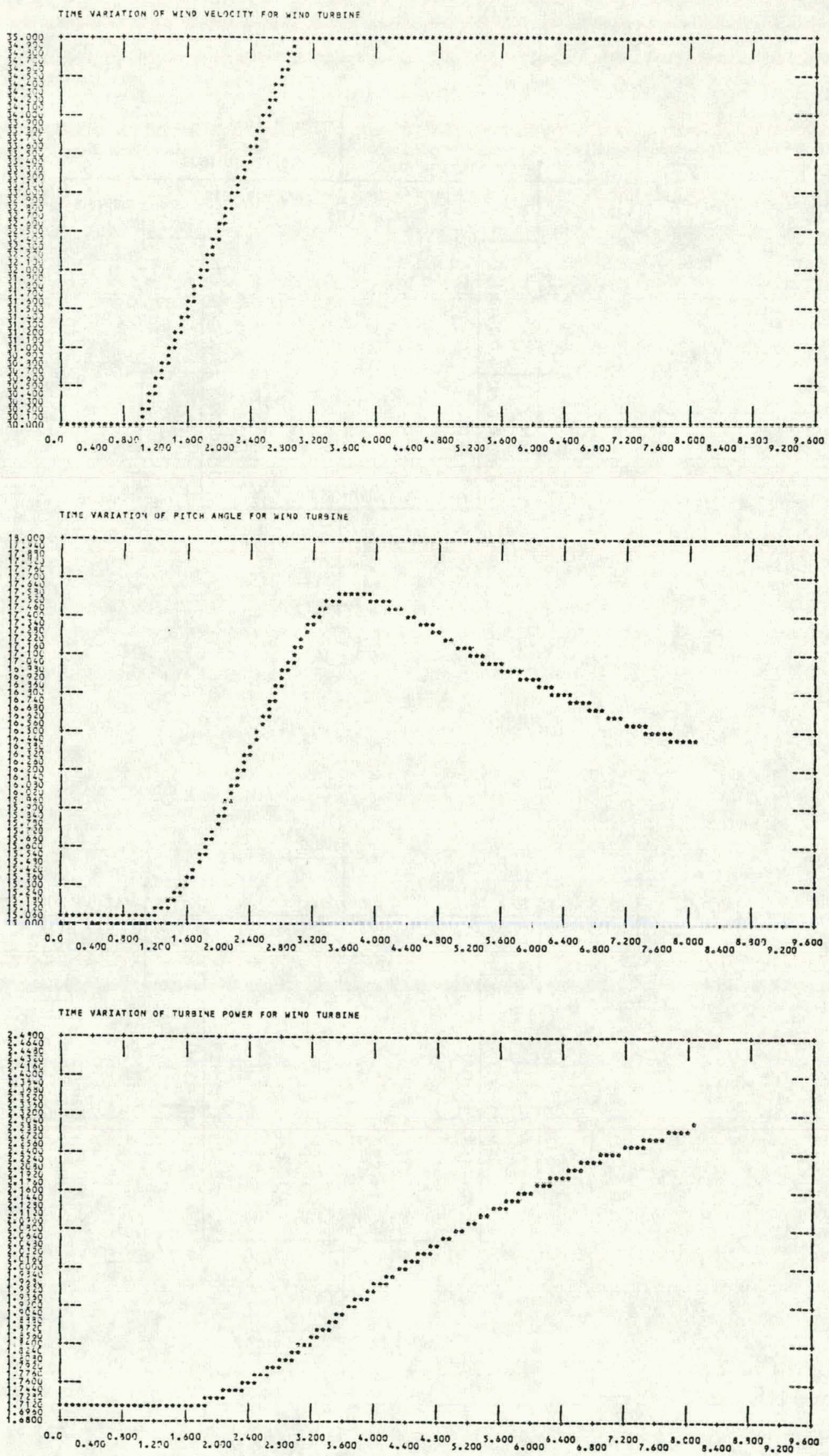

Figure 3.12 Wind Turbine Performance for Case WT01 


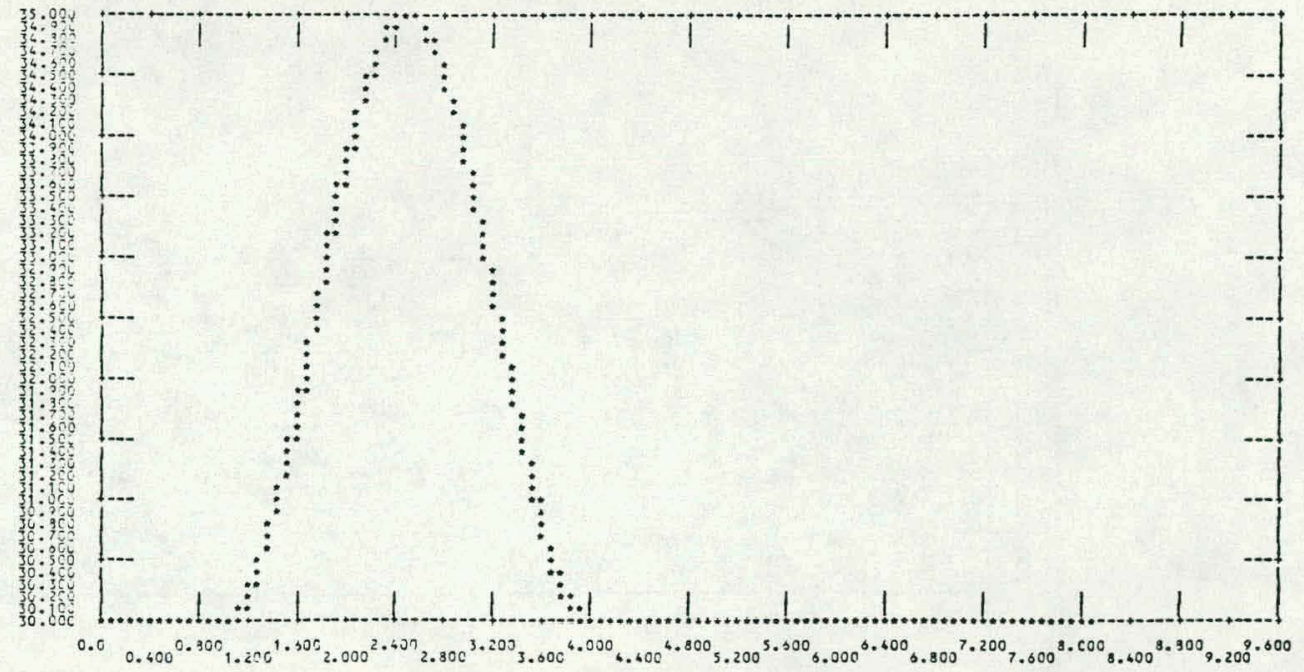

TIYE VARTATION OF PITCH AYGLE FOR WINO TURBINE

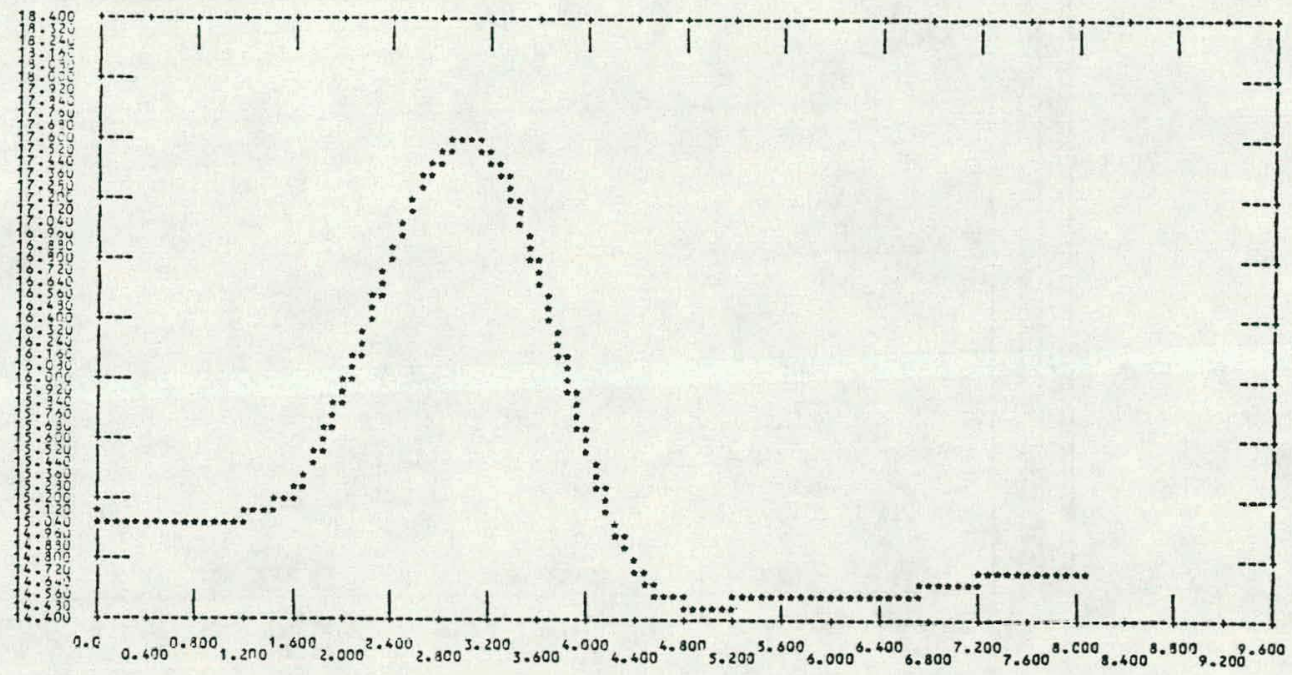

TTME VARIATION QE TUROLIE POWER FOR WINO TURBINE

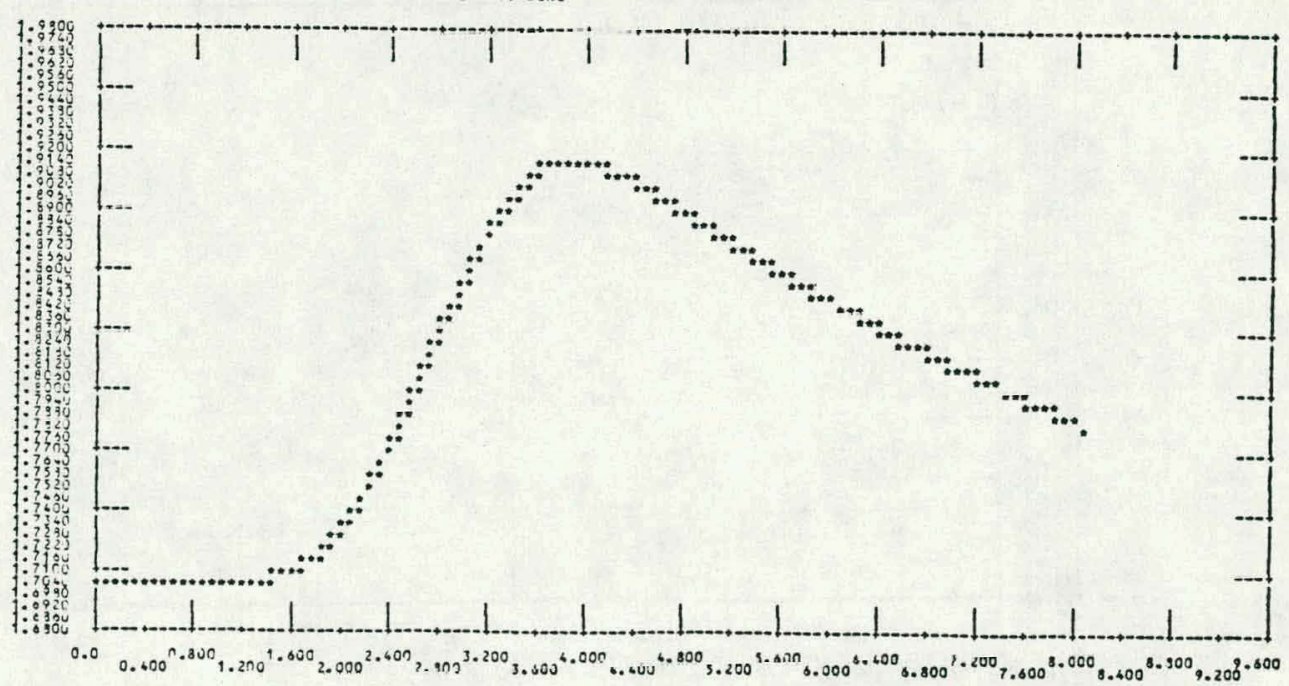

Figure 3.13

Wind Turbine Performance for Case WT02 
TIME VARIATION OF WIND VELOCITY FOR YIMO TURBIME

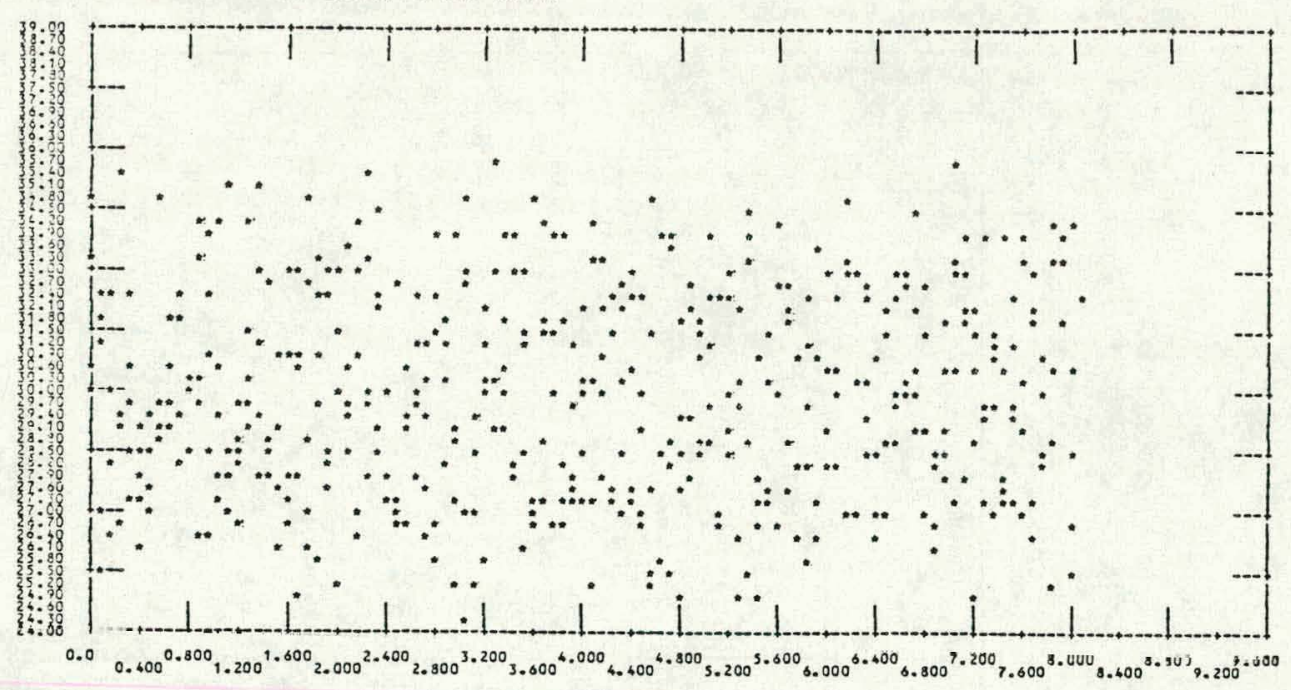

TIME VARTATION OF PITCH ANGLE FOR WINO TURBIME

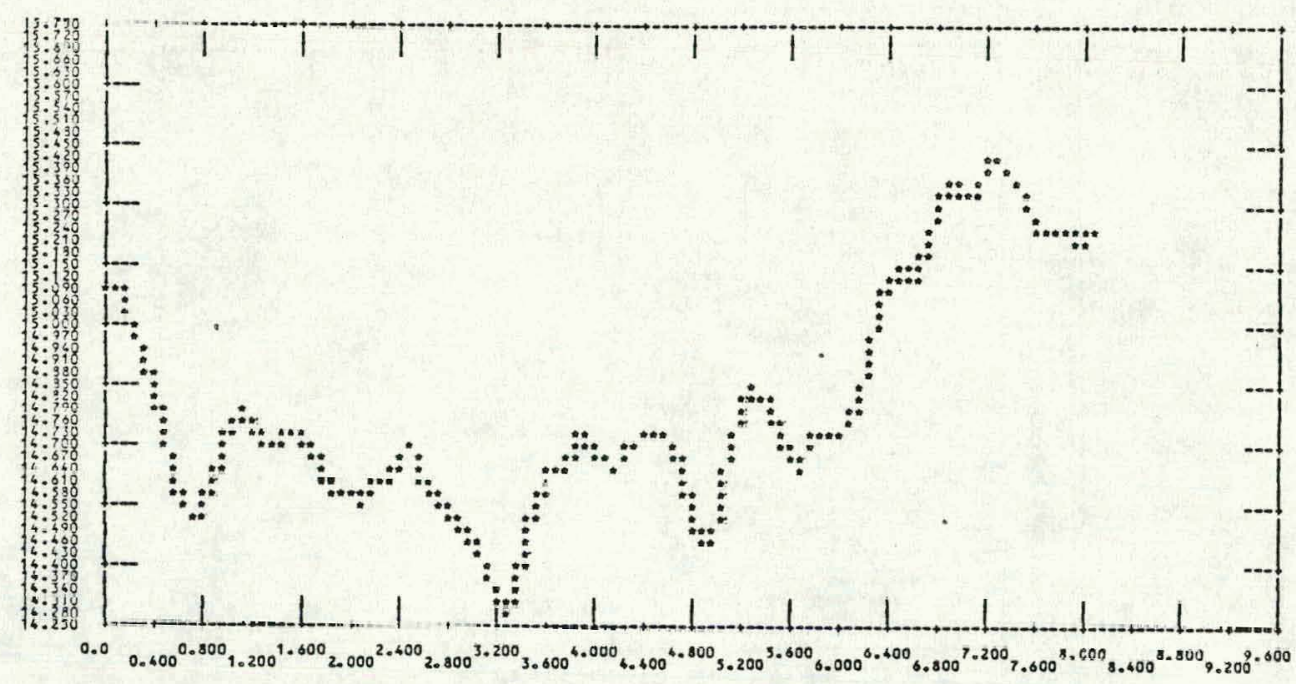

TIME VARIATION OF TURGIME POUER FOR UINO TURAINE

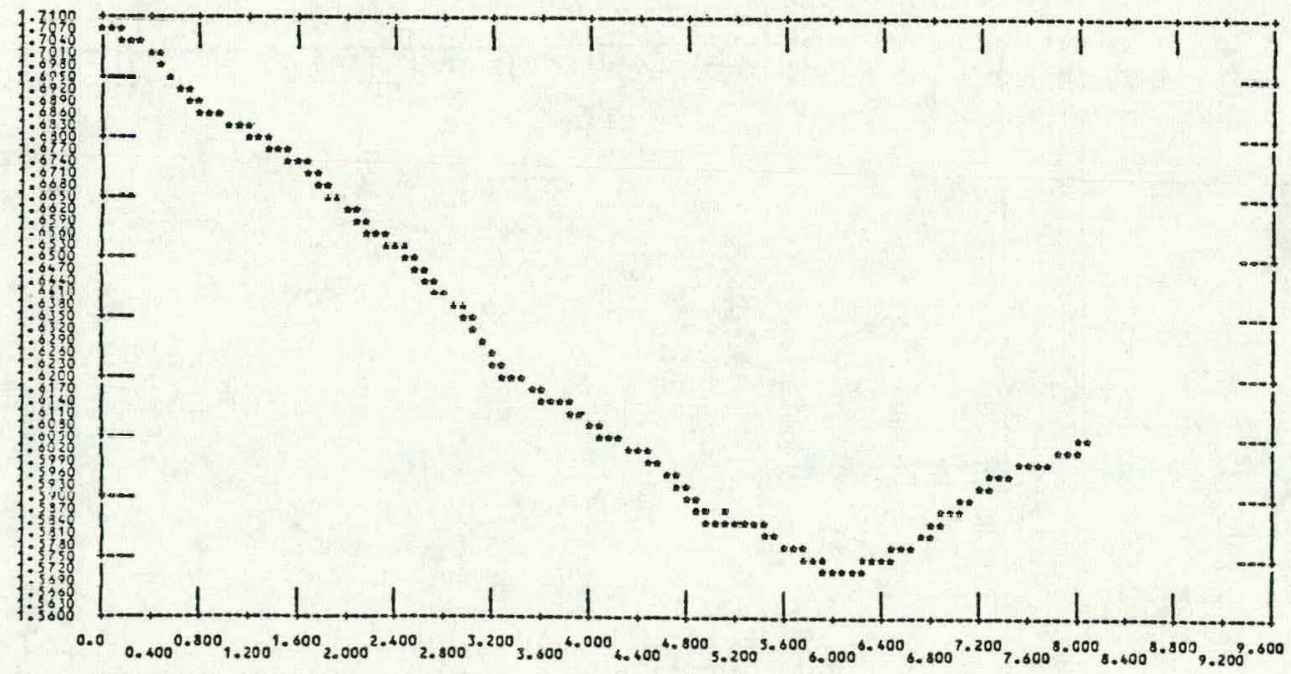

Figure 3.14 Wind Turbine Performance for Case WT03 
TIME VARTATION OF HIND VELOCITY FOR HINO TURBIME

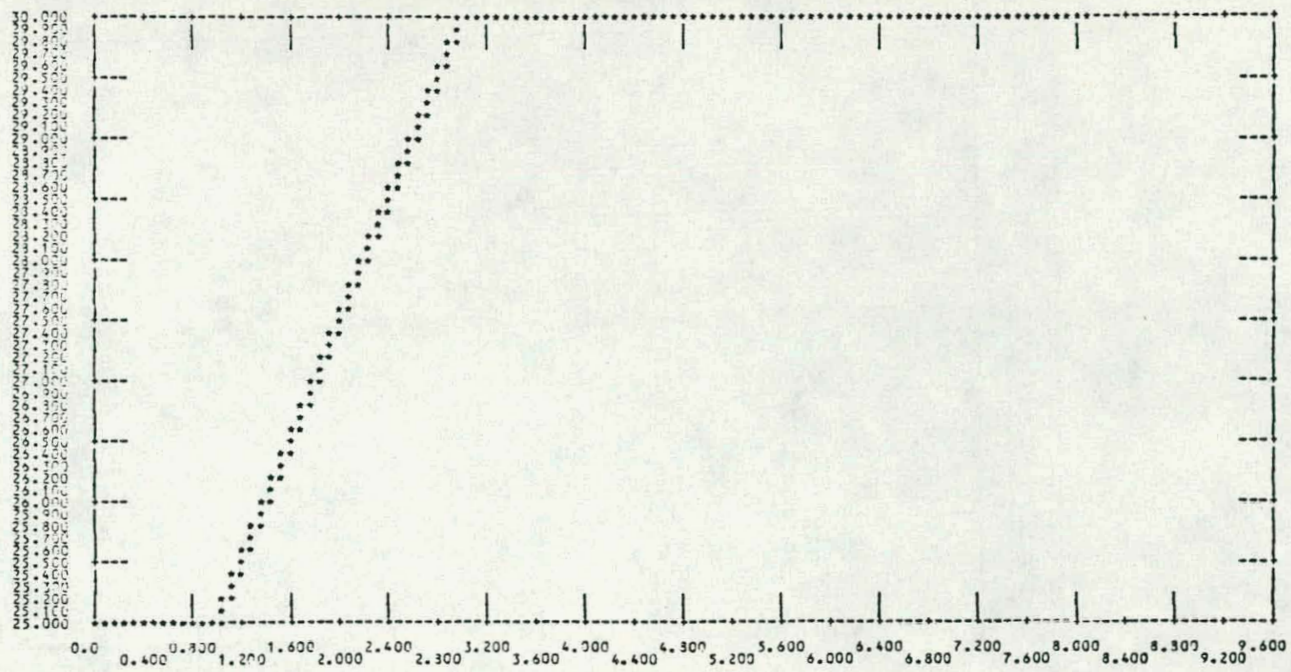

THES VARTATION OF PITCH ANGLE FOR WINO TURGINE

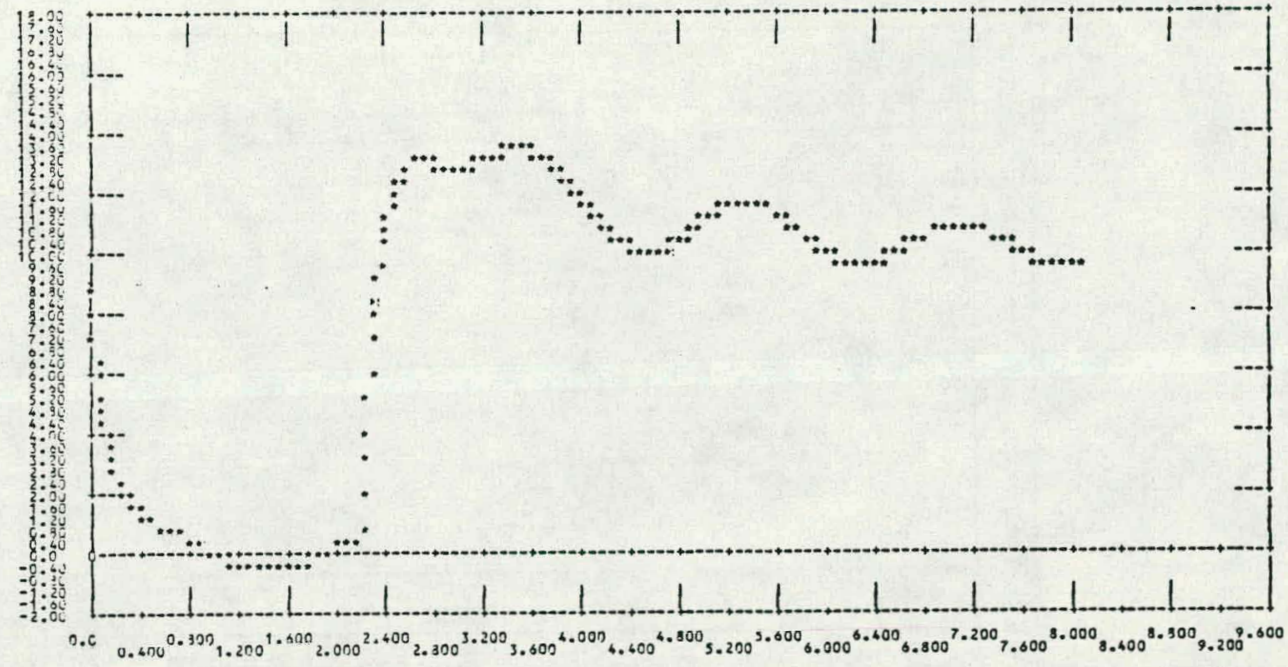

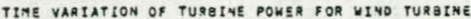

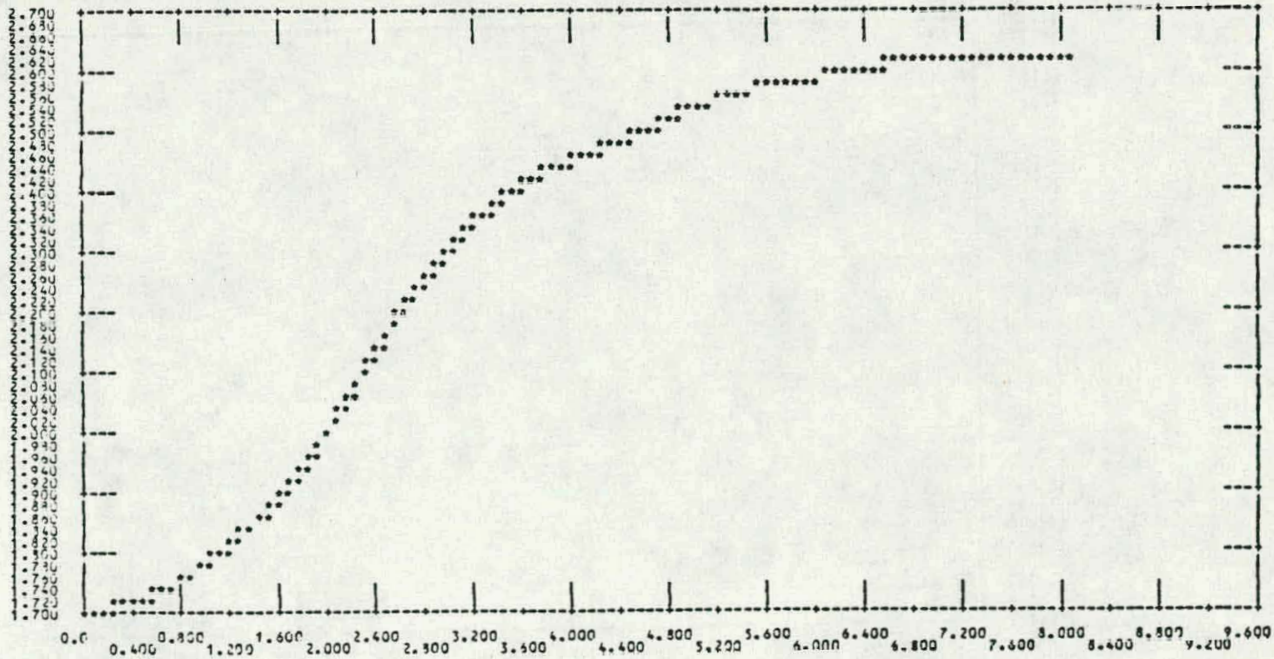

Figure 3.15 Wind Turbine Performance for Case WTn4 
TIME VADIATEON OF UEHO VELOCITY FOR WEMO TURAEYE

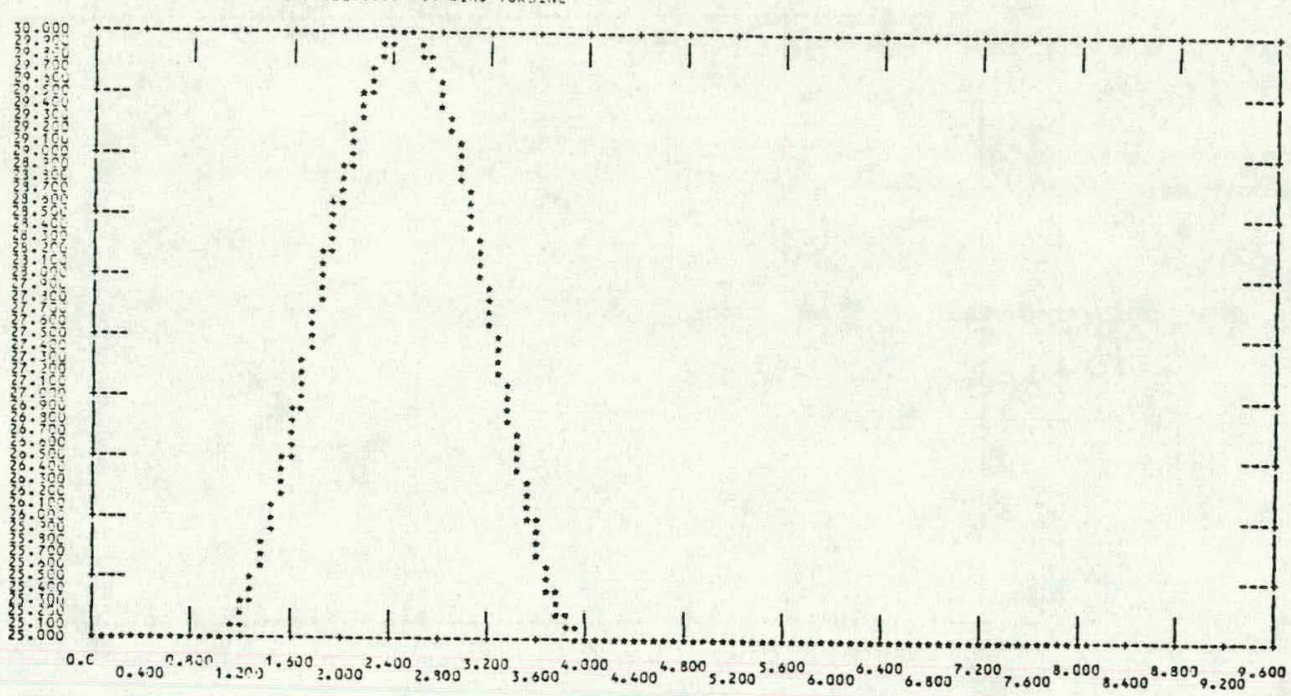

TTE YARTATIOH DF PITCH AVGLE FOR WIMO TURATME

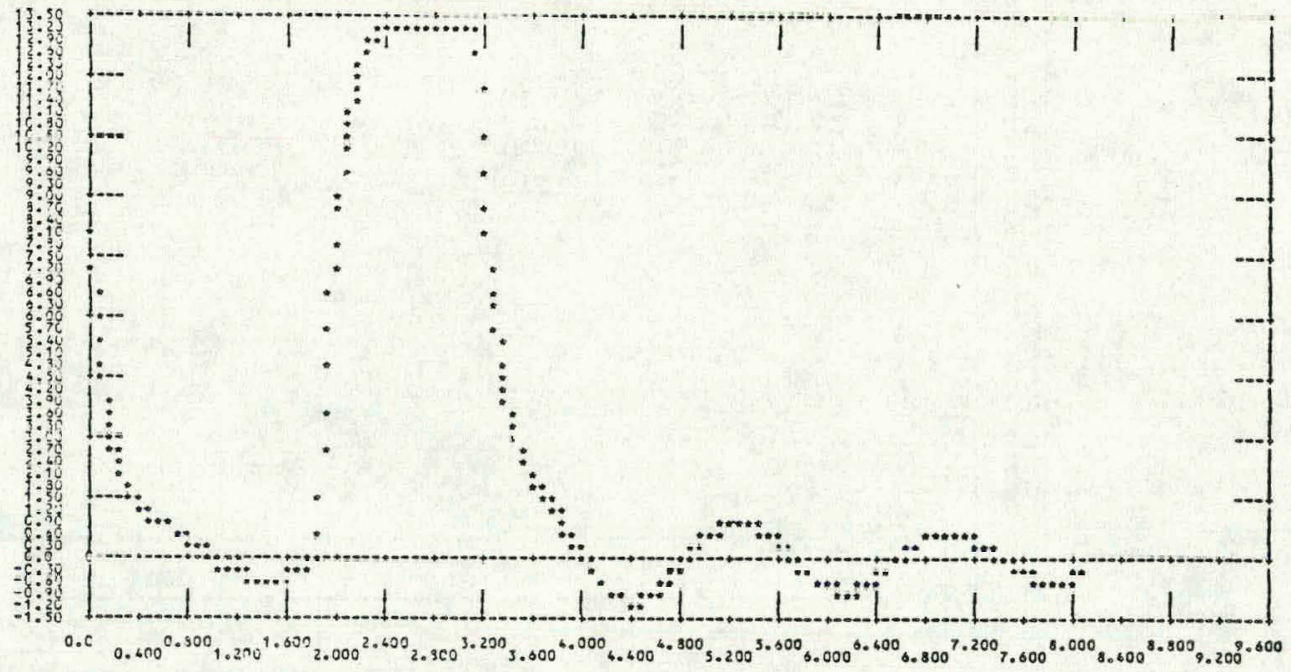

TIME YARIATION OE TURaTVE POUER F OR LIYD TURYINE

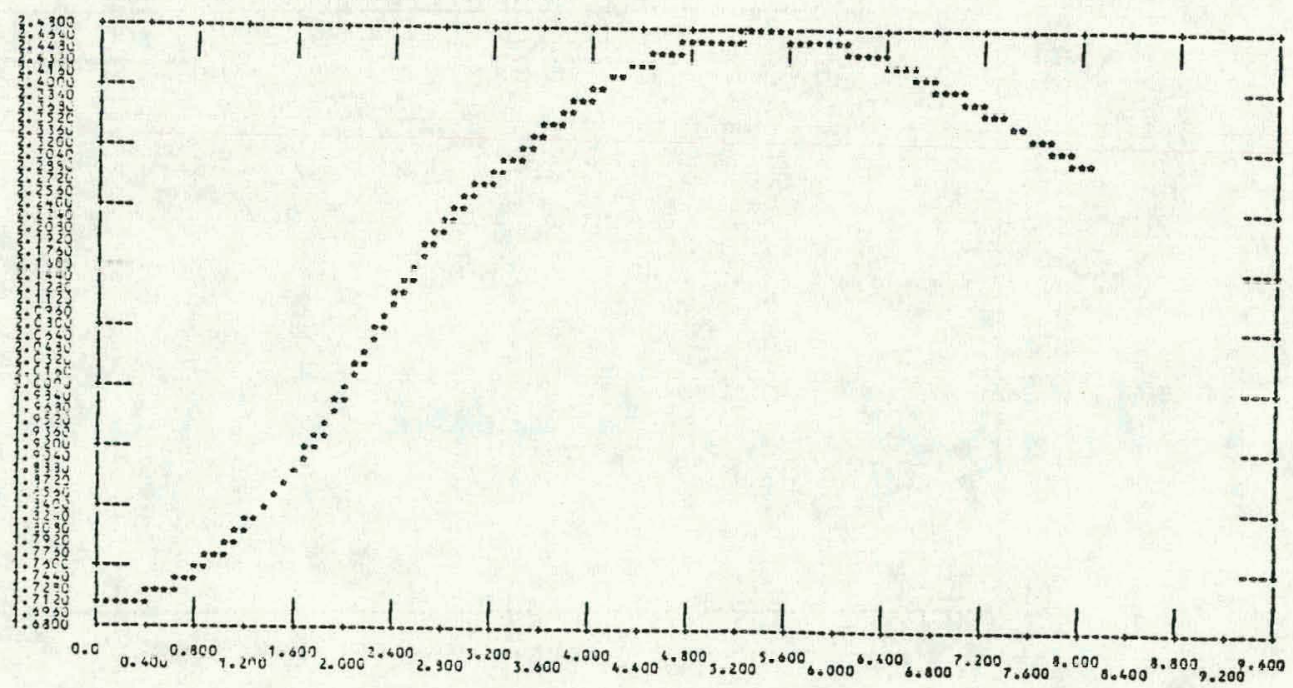

Figure 3.16 Wind Turbine Performance for Case WT05 
TIME VARLATION OF WINO VELOCLTY F.JP WINO TURELME

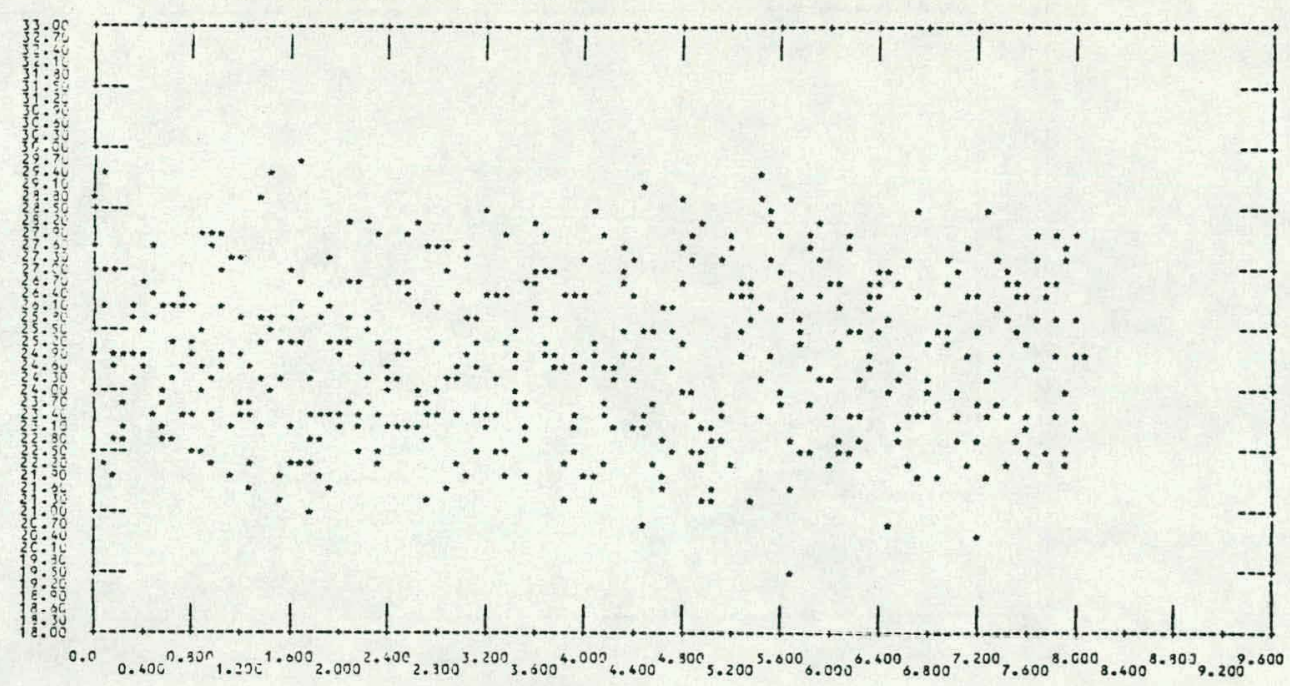

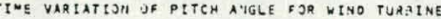

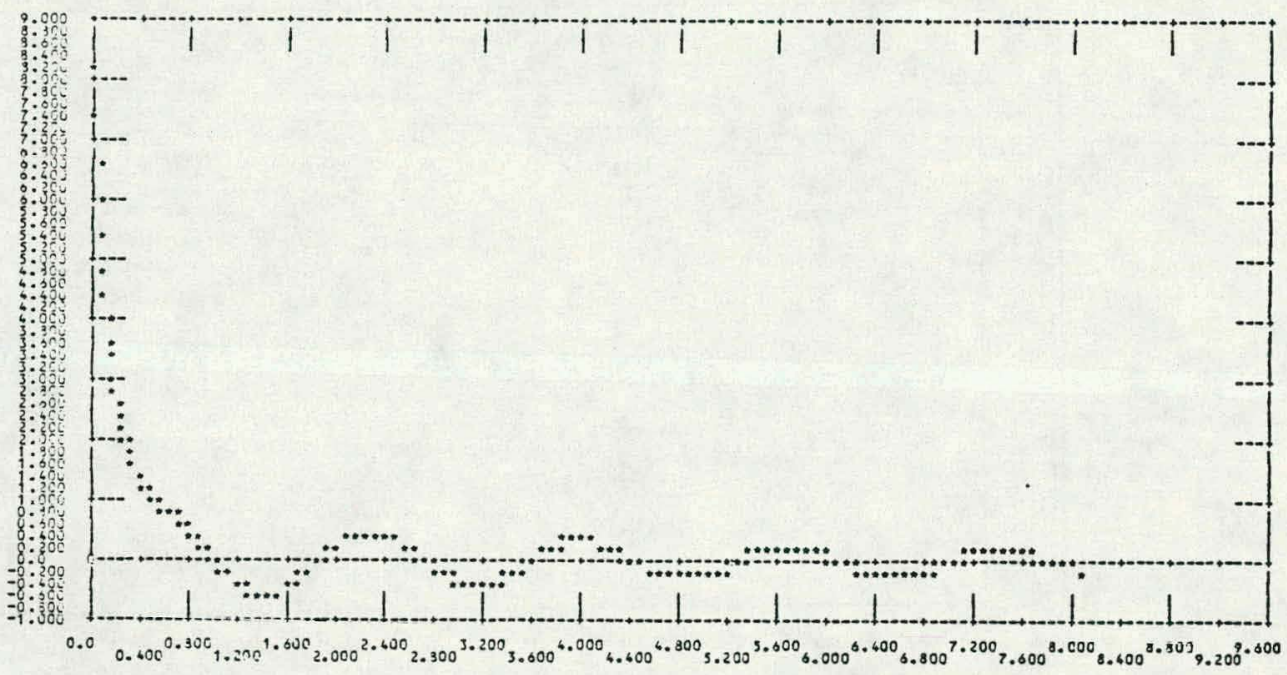

TIME VARIATION OF TURAINE POUER FOR WINO TURgENE

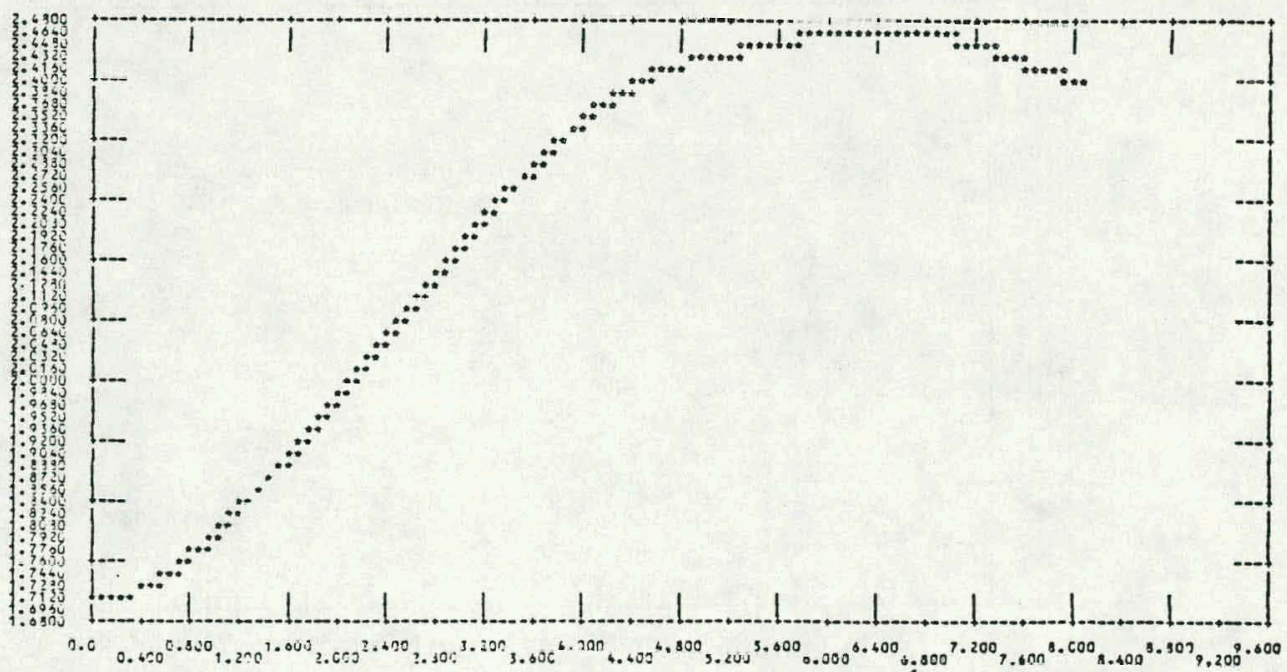

Figure 3.17 Wind Turbine Performance for Case WTO6 
TIME VARIATION OF WEAO VELOCTTY FOR WINO TUASTHE

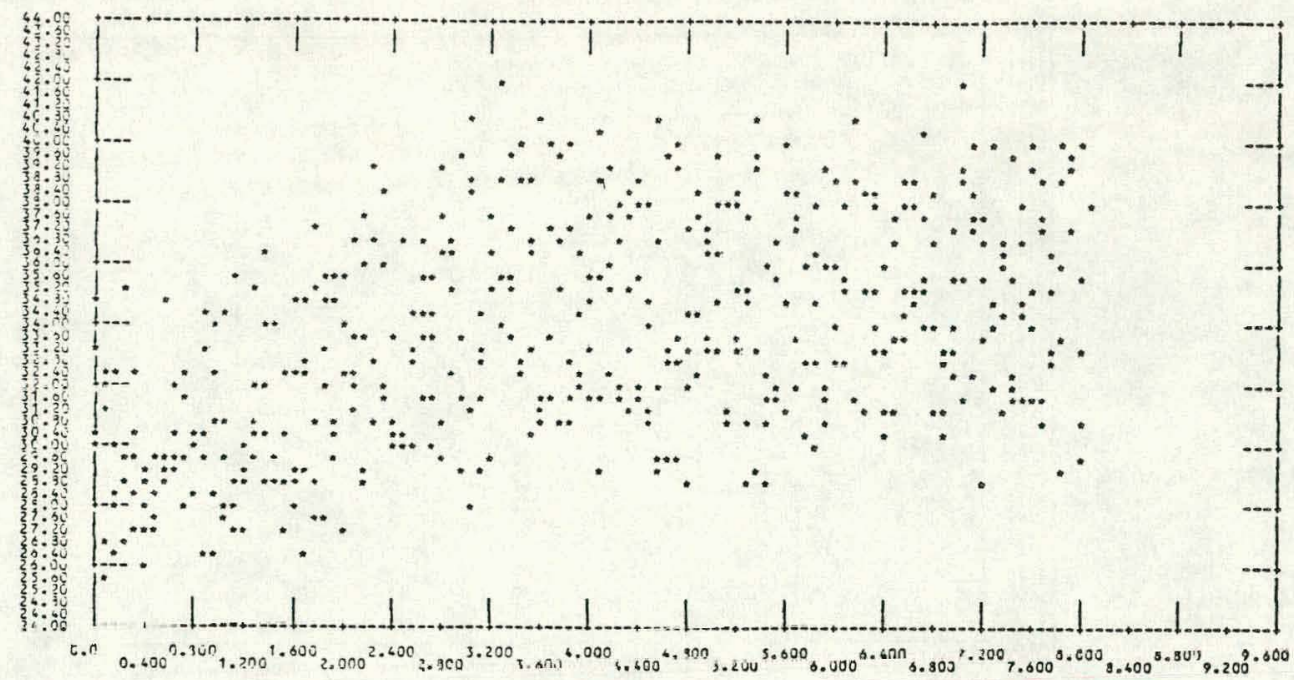

TIME VARIATIOY OS PITCM AHGLE SOR WINO TURYIM

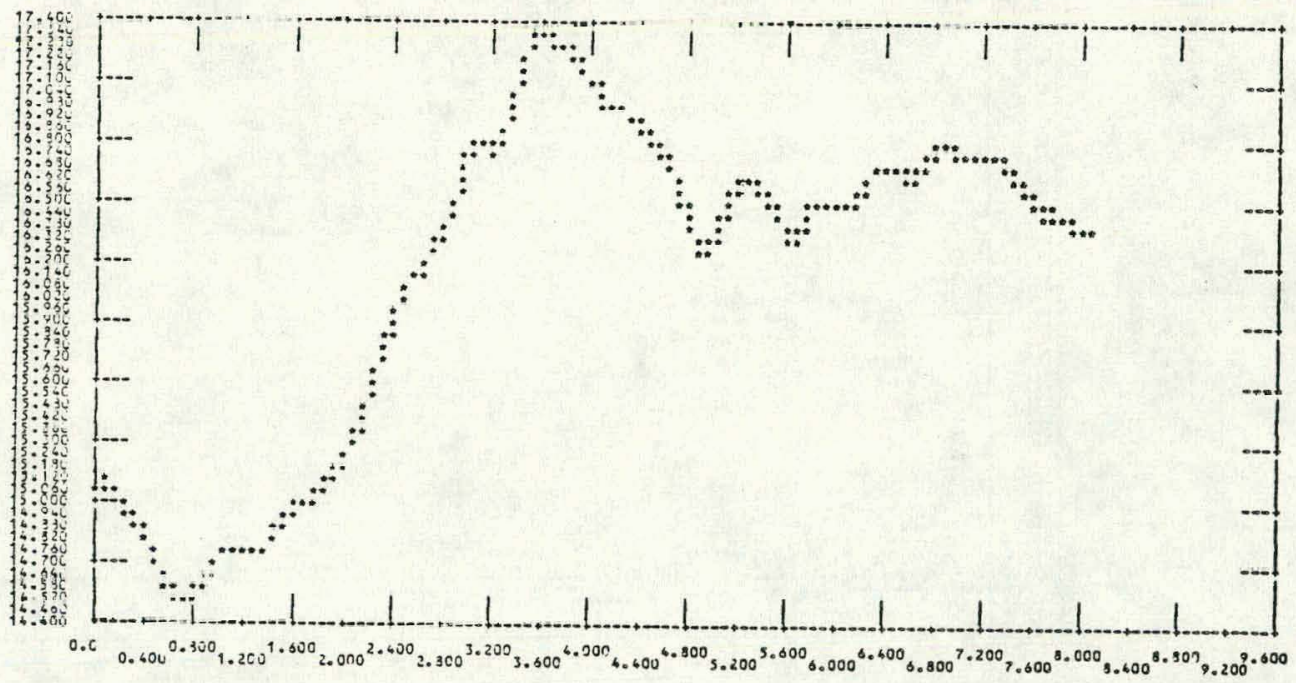

TIME VARIATION OF TURETNE POWER FOR WINO TUREINE

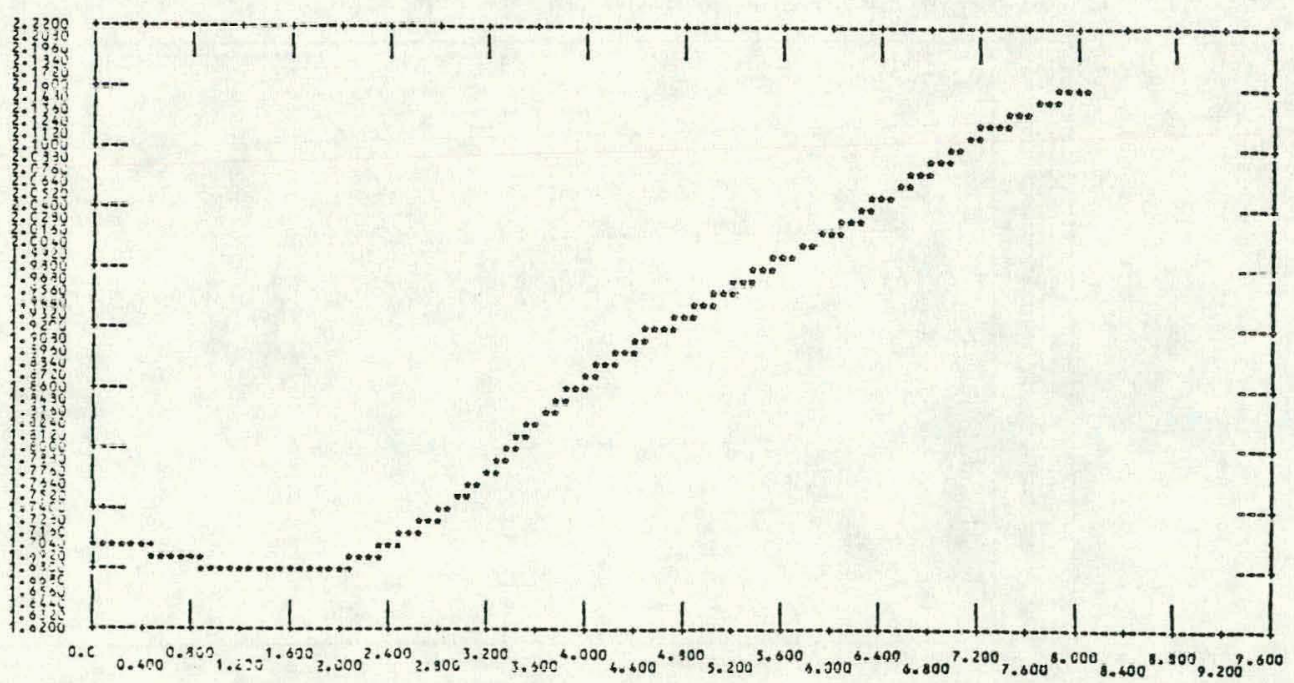

Figure 3.18 Wind Turbine Performance for Case WT07 


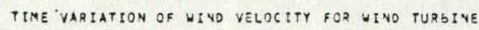

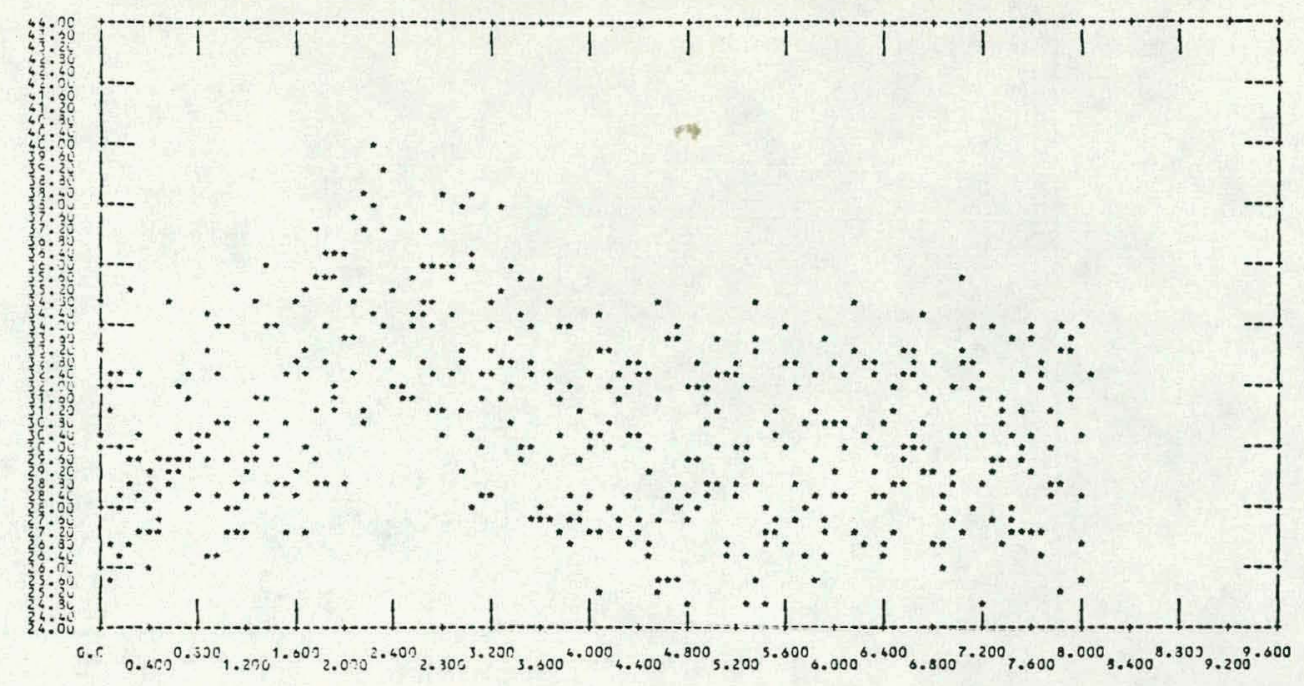

TIME VARTATION OF PITEH AHGLE FOR HINO TURALNE

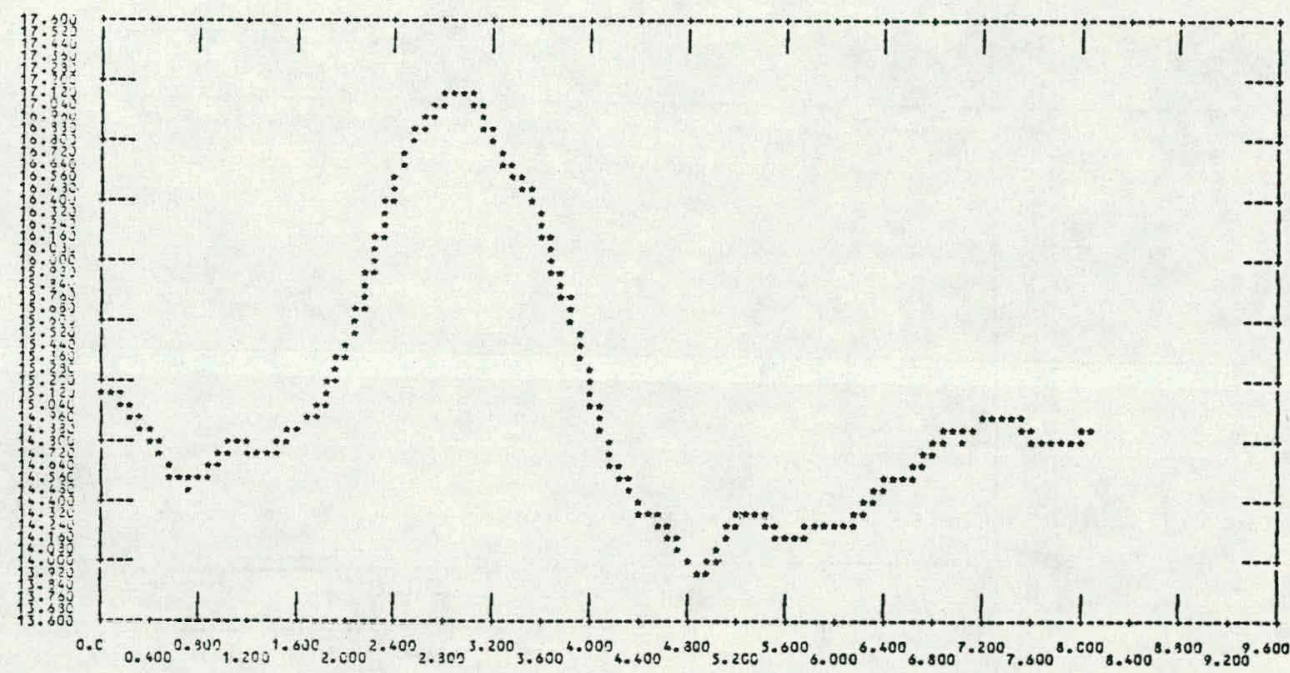

TIME VARLATION OE TURgINE POKER SOR WINO TURJINE

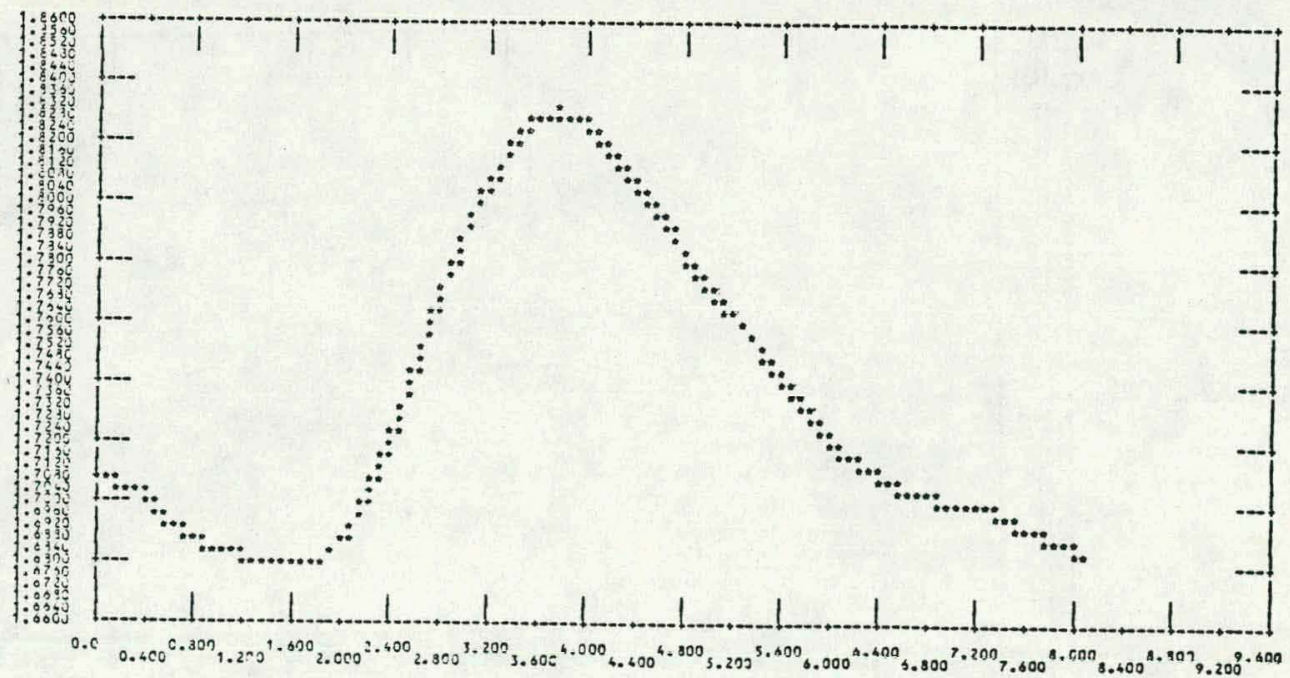

Figure 3.19 Wind Turbine Performance for Case WT08 

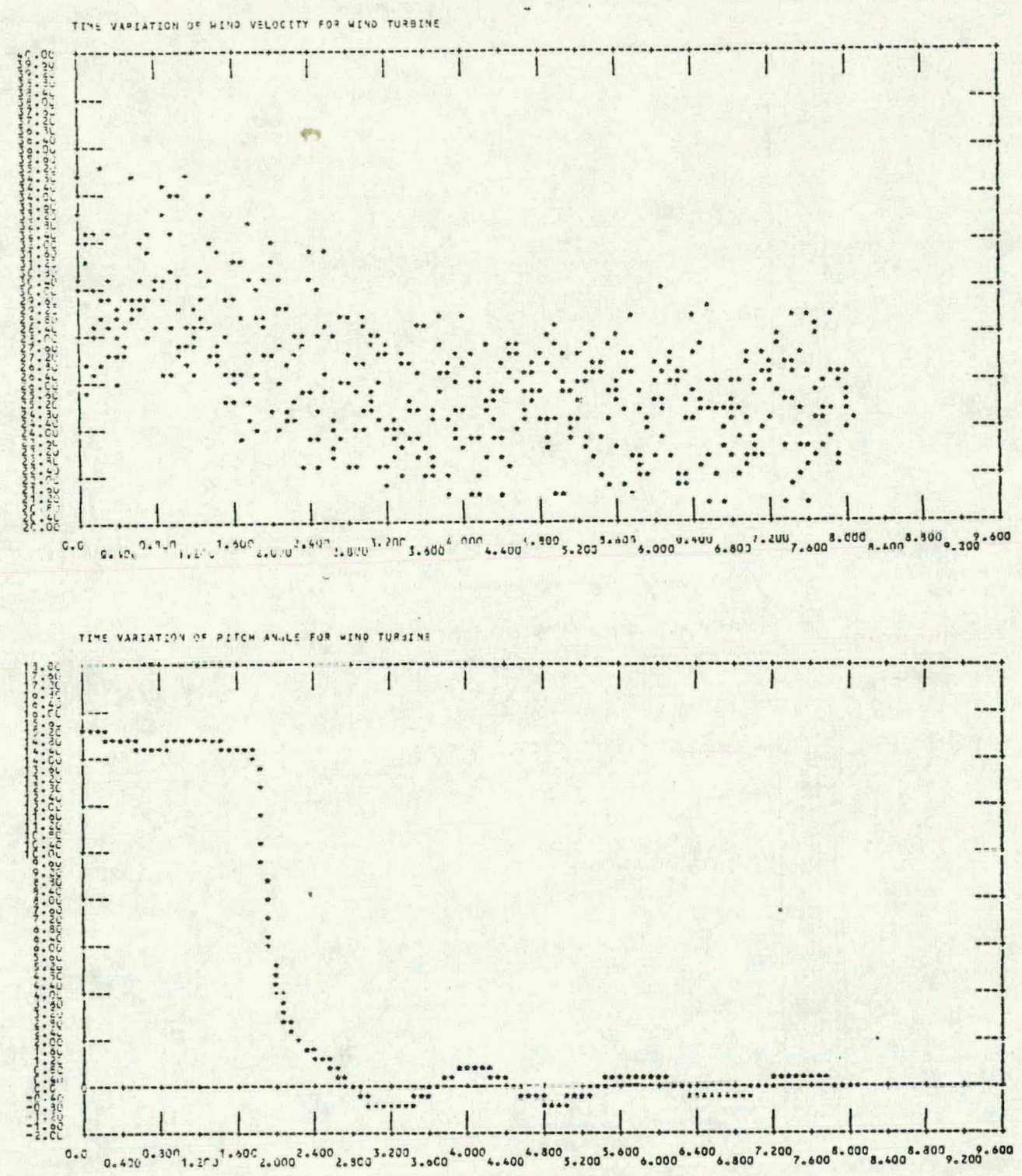

TIME VARIAT:ON OE TUAJ:VE POWER FOP WINO TURGTYE

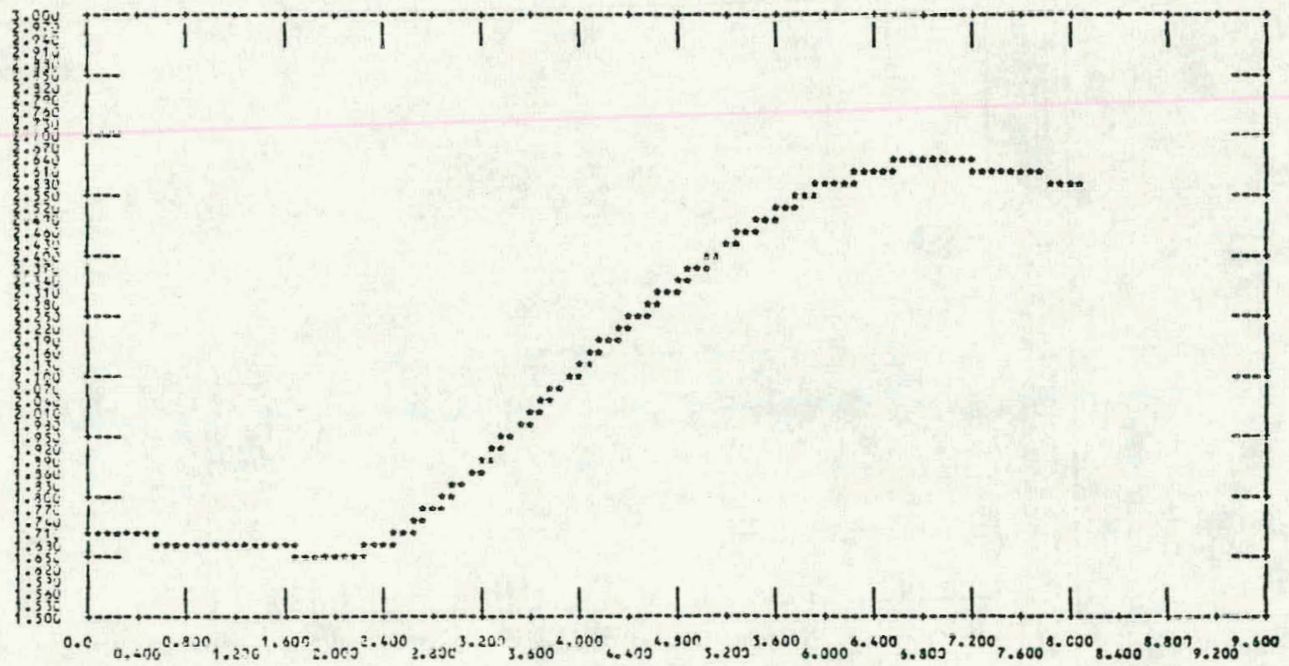

Figure 3.20 Wind Turbine Performance for Case WT09 


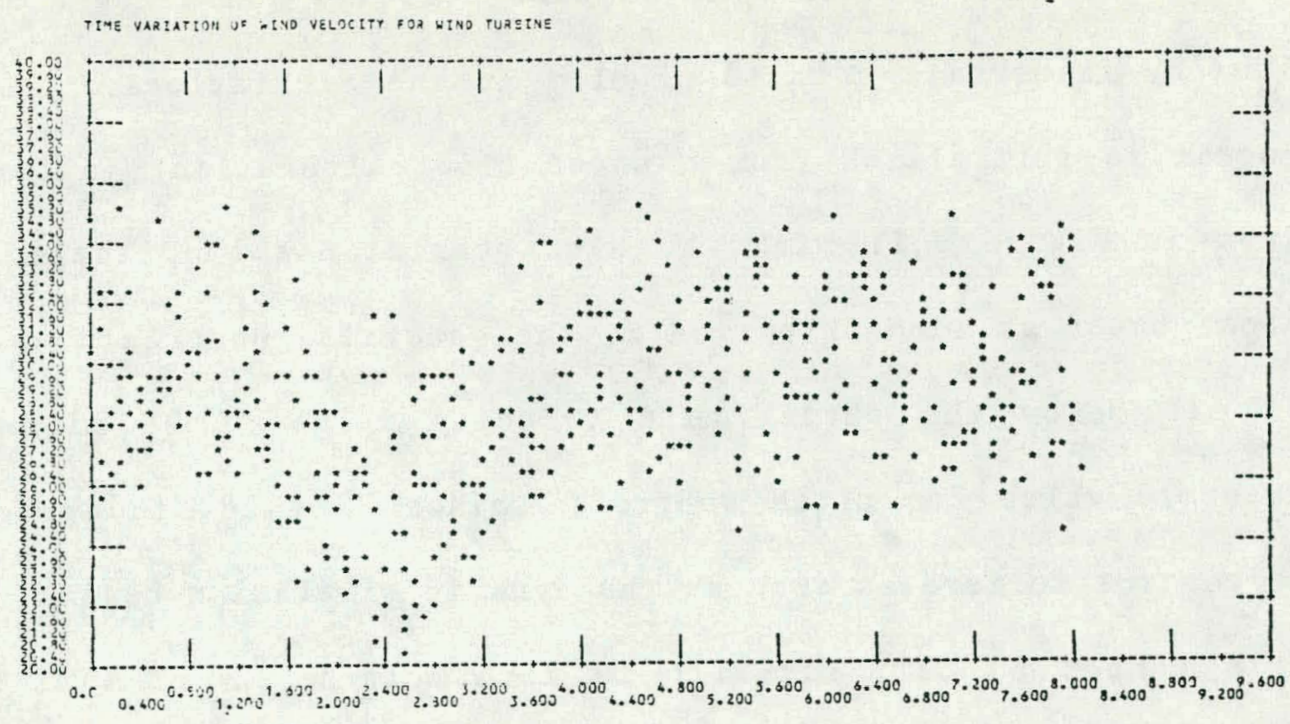

TIME YAATATIOM OF PETCH ATULE FOR WIVO TURJENE

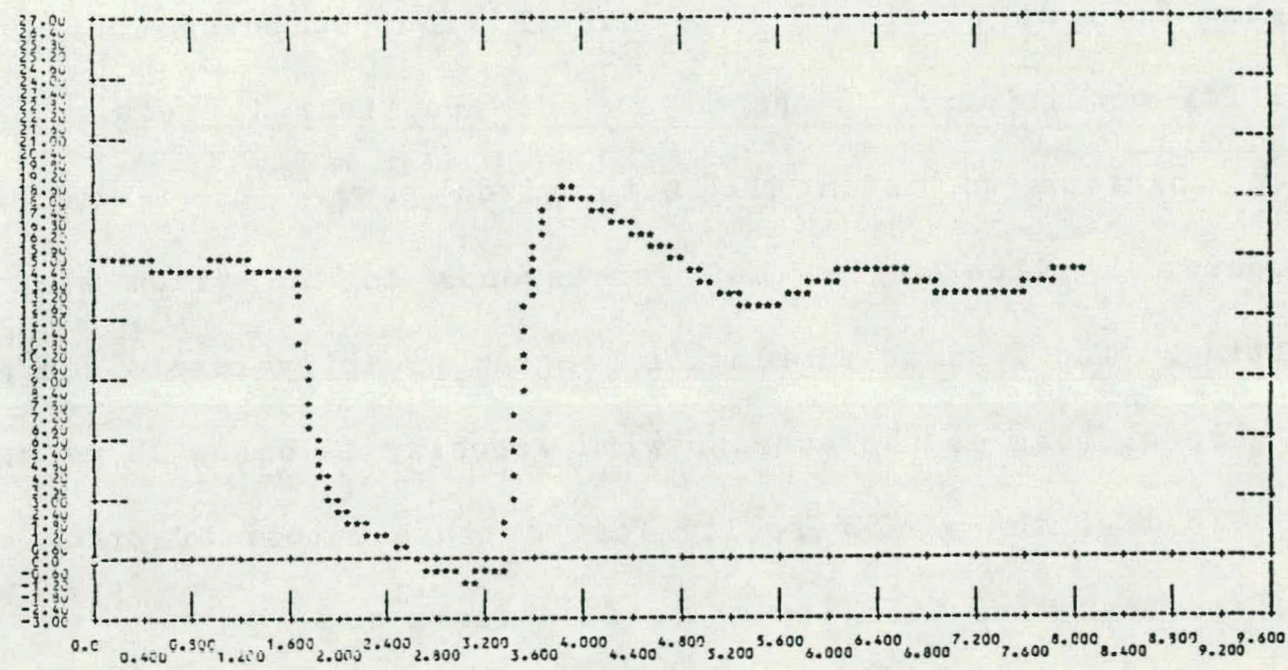

TIME VAPTATION OF TURBTYE POHER FOR WIYO TURSTMS

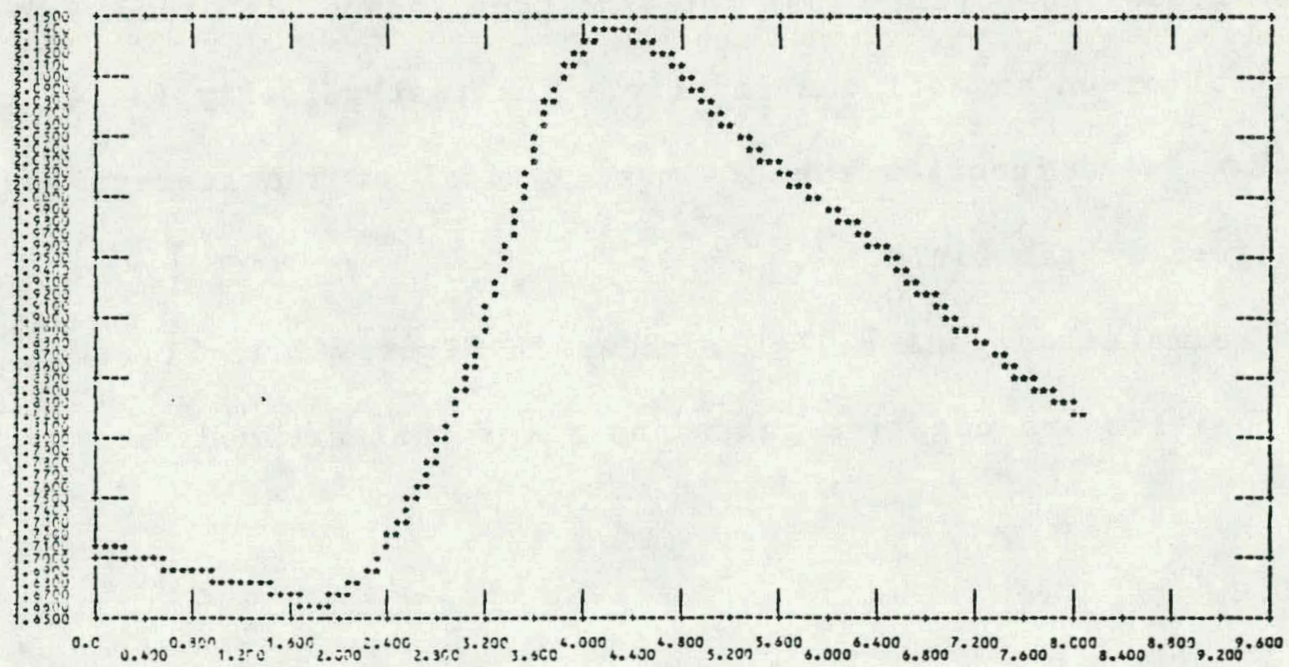

Figure 3.21 Wind Turbine Performance for Case WT10 
Runs WT04 - 06, shown in Figures 3.15-17, and using a base wind of $25 \mathrm{mi} / \mathrm{h}$, illustrate a basic problem in the simulations. The stability program is initialized from a power flow calculation, in our case that given in Figure 3.11 with the wind generator set initially to 1.7 MW output power as a contribution to the generated power at bus 3 . Now 25 $\mathrm{mi} / \mathrm{h}$ is below the cutoff wind velocity value of $28 \mathrm{mi} / \mathrm{h}$ used as a threshold value for pitch control. Since $V_{W}<28$, the program resets the control to zero as soon as the dynamic simulation begins. The pitch angle cannot be set initially to zero because $25 \mathrm{mi} / \mathrm{h}$ at zero pitch gives a turbine output from Figure 3.3 , of about $2.2 \mathrm{MW}$. But this output power would vin1ate the initial conditions. Since it is not practical to require a new power flow solution to match the zero pitch power, the stability program computes a pitch angle that corresponds to the given wind and power setting. The dynamic simulation program promptly resets the pitch ang1e to zero as 1 ong as the average wind velocity is below $28 \mathrm{mi} / \mathrm{h}$.

To test the wind velocity for possible cutoff of pitch contro1, an average test wind volocity is used, defined as

$$
\mathrm{V}_{\text {TEST }}=\mathrm{V}_{\mathrm{WB}}+\mathrm{V}_{\mathrm{WG}}+\mathrm{V}_{\mathrm{WR}}
$$

The noise component was not included since it tends to turn the controller on and off continually. The test velocity (3.14) provides an average wind function that is more typical of the average that would be observed in the field.

Simulation runs WT07-10, shown in Figures 3.18-21, show the effect of positive and negative gusts and ramps that are modified by noise. 


\subsection{CONCLUSIONS}

The MOD-2 wind tarbine generator model developed by Purdue University has been adapted for digital transient stability simulation using the advanced EPRI stability program ETMSTAB. There are certain problems in modeling the wind turbine for digital simulation, but none that are beyond resolution. The EPRI program was capable of modeling most functions directly, and the remaining special functions were added by coding modifications. Seven subroutines required modification, with most of the changes in four subroutines. One subroutine was rewritten in its entirety. The results were satisfactory in every respect.

The production version of ETMSTAB will have features that will be of considerable value for the study of wind turbine dynamics. Where our simulation was 1 imited to a single wind generator, the utility user will often want to study a group of wind machines. This suggests two possible modes of oscillation: 1. where the entire group of wind machines swings together, or 2. where substantial intermachine oscillation takes place within the group. ETMSTAB will have the capability of forming a dynamic equivalent of the entire wind group in the former case, or of studying the intermachine osci11ation of tho latter.

Considerable effort was spent on synchronous machine modeling as a part of this project. It is believed that additional work may be warranted to develop models of machine saturation that are accurate and easy to apply. 
It was not the purpose of this study to develop a wind turbine mode1, but only to apply the model previously developed by Purdue Oniversity. Additional effort should be initiated to develop a generic wind turbine model, normalized to the size of the generator, and that can be used for a variety of different wind machines. Wind turbines will not receive serious consideration from power system planners until such models are available. 


\section{REFERENCES}

1. Dembart, Benjamin, Albert M. Erisman, Esko G. Cate, Michae1 A. Epton, and Herman Domme1. 'Power System Dynamic Analysis, Phase 1,' Fina1 Report EL-484, EPRI, Palo Al to, July 1977.

2. Cate, Esko G. and Benjamin Dembart, 'Diagnostic Program Document, EL-1104; Volume 1, User's Guide; Volume 2, Program Modification Document; and Volume 3, Diagnostic Program Listings,' EPRI, Palo Al to, June 1979 .

3. Lightfoot, et al, 'Transient-Midterm Stability Program,' EL-596 to 601 inclusive, EPRI, Pa10 A1to, June 1979.

4. Wasynczuk, O., D. T. Man, and J. P. Sullivan, 'Dynamic Behavior of a class of Wind Turbine Generators during Random Wind F1uctuations,' IEEE Paper 81WM173-4, presented at the PES Winter Meeting, Feb 1-6, 1981, At1anta.

5. Krause, P. C. and D. T. Man, 'Transient Behavior of a Class of Wind Turbine Generators During Electrical Disturbances,' IEEE Paper 81 WM 011-6, presented at the PES Winter Meeting, Feb 1-6, 1981, Atlanta.

6. Krause, P. C. and 0. Wasynczuk, 'Methods of Resynchronizing Wind Turbinc Gcnerators,' IELE Paper 81 WM 162-7, presented at the PES Winter Meeting, Feb 1-6, 1981, Atlanta.

7. Triezenberg, David M., Purdue hybrid computer wind generation simulation mode1. Private communication.

8. Anderson, P. M. and A. A. Fouad, Power System Control and Stability, Iowa State University Press, 1977. 
9. Concordia, C. and R. P. Schulz, 'Appropriate Component Representation for the Simulation of Power System Dynamics,' Symposium on Adequacy and Philosophy of Modeling: Dynamic System Performance, 1975 Winter Power Meeting, 75 CHO 970-4-PWR, pP 16-23.

10. R. P. Schulz, 'Synchronous Machine Modeling,' Ibid, pp 24-28.

11. Skvarenina, T. L., D. M. Triesenberg, and P. C. Krause, 'Effects of Neglecting Electrical Transients on Shaft Torques,' IEEE Trans, v PAS-97, n 4, July/Aug 1978, p. 1013, (paper A 78 233-9 1978WPM).

12. Krause, P. C., F. Nozari, T. L. Skvarenina, and D. W. Olive, 'The Theory of Neglecting Stator Transients,' IEEE Trans, $v$ PAS-98, Jan/Feb 1979, pp 141-145.

13. Murdock, A., III and P. C. Kranse, 'Comparison of Detailed and Simplified Power System Representations for Predicting Transient and Dynamic Stability, IEEE paper A.76 143-8, presented at the PES 1976 Winter Meeting, New York.

14. Skvarenina, Timothy Lya11, 'The Theory and Effects of Neglecting Stator and Network Transients,' Purdue University, Energy Systems Simulation Laboratory Report TR-EE 79-50, December 1979.

15. International Electrotechnical Commission, IEC Standard, 'Rotating Electrical Machine, Part 10: Conventions for descriptions of synchronous machines,' Publication 34-10, first edition, Geneva, 1975 .

16. doMc110, F. P. and L, H. Hannott, 'Validation of Synchronons Machine Mode1s and Derivation of Model Parameters from Tests,' IEEE paper 80 SM 537-1, presents at the PES summer Meeting, Ju1y 1980, Minne apo1 is. 
17. Krause, P. C. Analysis and Simulation of Wind Energy Systems, Final Report, NASA Grant NSG-3237, Purdue University. 1979.

18. Reynolds, Michael G. Stability of Wind Turbine Generators to Wind Gusts, Purdue University Report TR-EE 79-20.

19. Vaicaitis, Rimas, Masanoba Shinozaka, and Masaru Takeno. Parameters Study of Wind Loading on Structures, J. of the Structura1 Div, ASCE, Mar 1973, p 453-468.

20. Cadzow, James A. Discrete-Time Systems, Prentice-Ha11. 
THIS PAGE

\section{WAS INTENTIONALLY \\ LEFT BLANK}




\section{APPENDIX A}

\section{Simulation Results with Complete Saturation}

for a

$10 \%$ Step Change in $T_{m}$ 

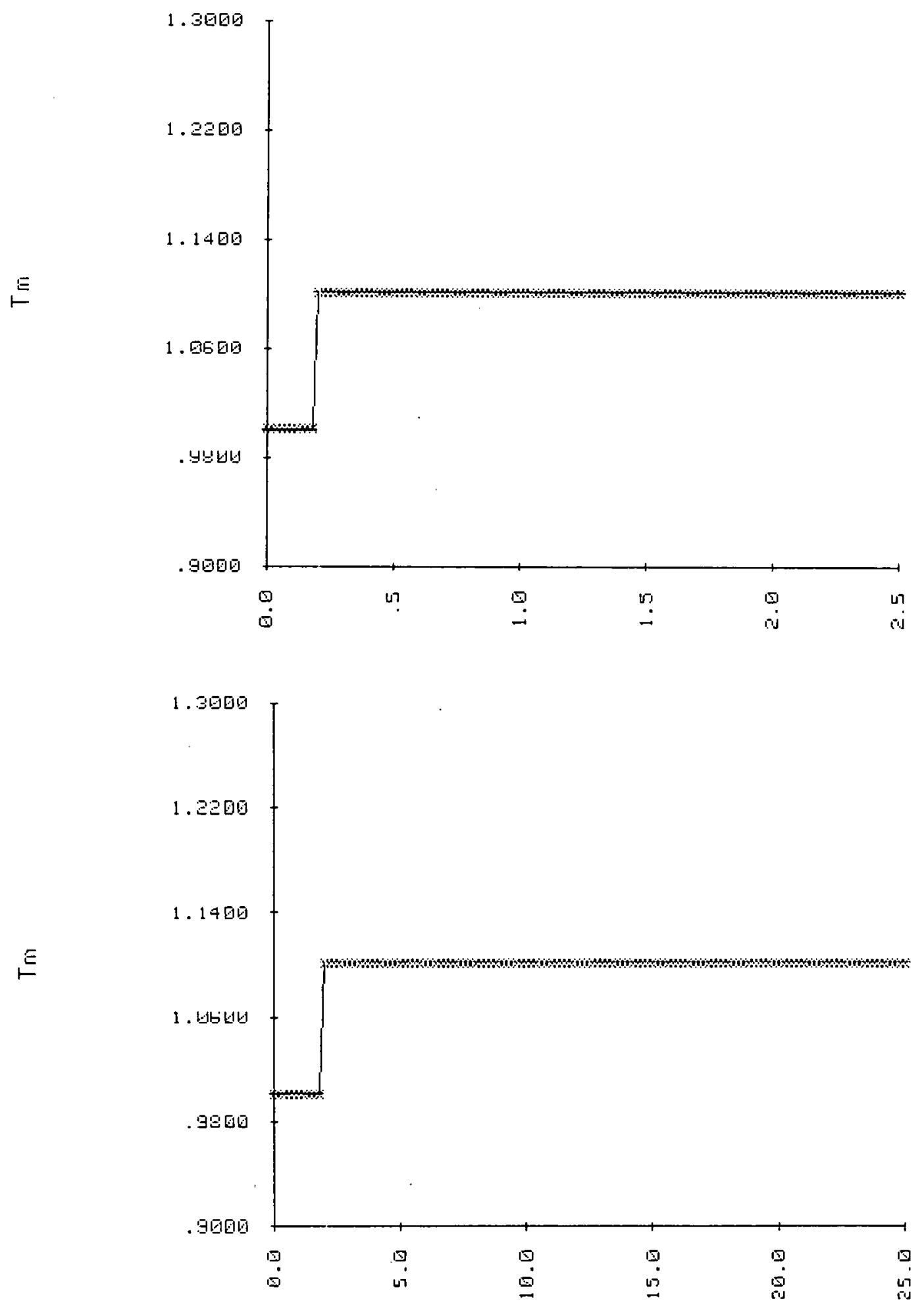

Figure A.1.a $T_{m}$ vs time in seconds, flux 1 inkage mode1 (a), step change in $T_{m}$, saturated $(*)$ and unsaturated response 

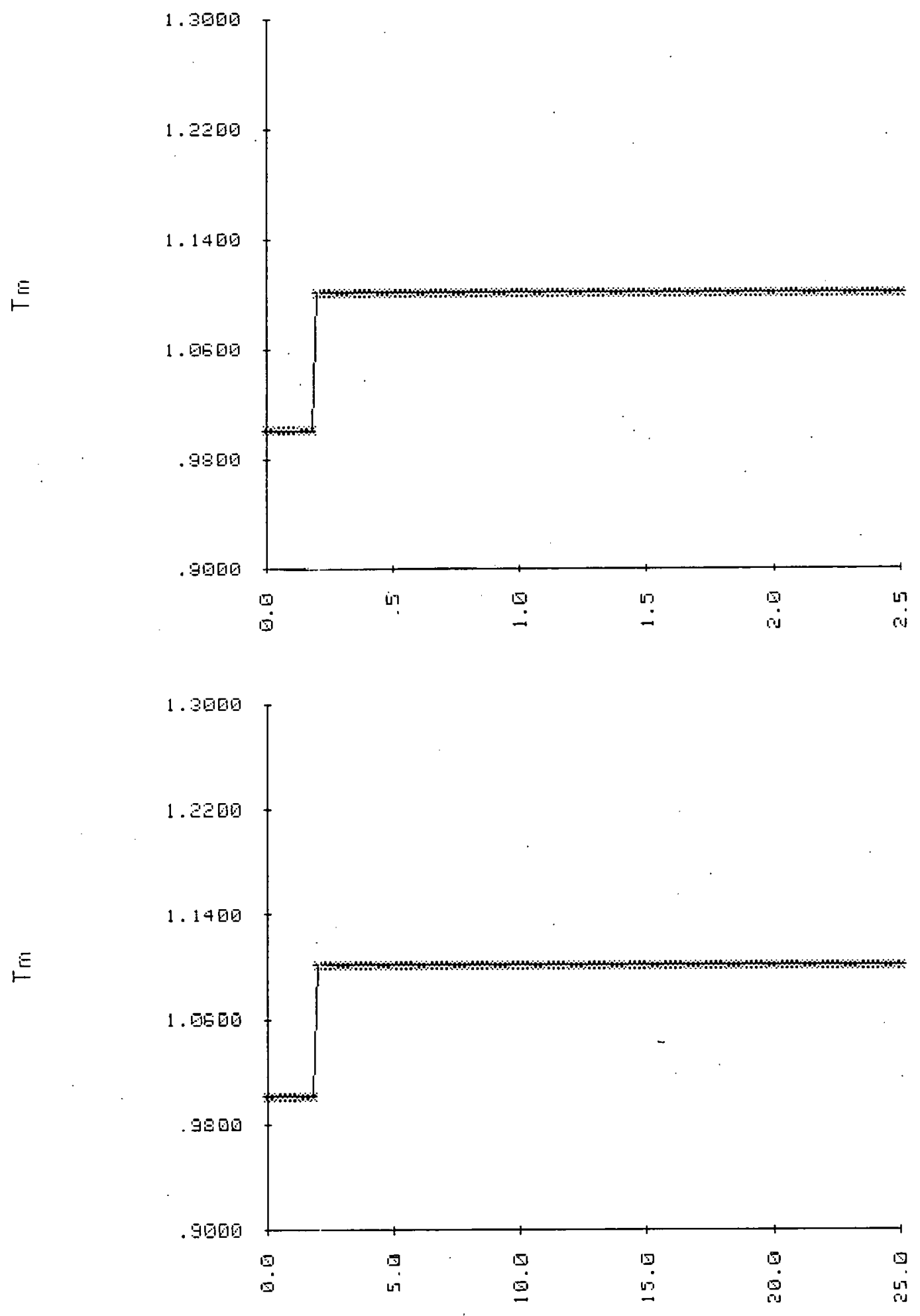

$\begin{aligned} \text { Figure A.1.b } & T_{m} \text { vs time in seconds, E' model (b), } \\ & \text { step change in } T_{m} \text {, saturated (*) and unsaturated response }\end{aligned}$ 

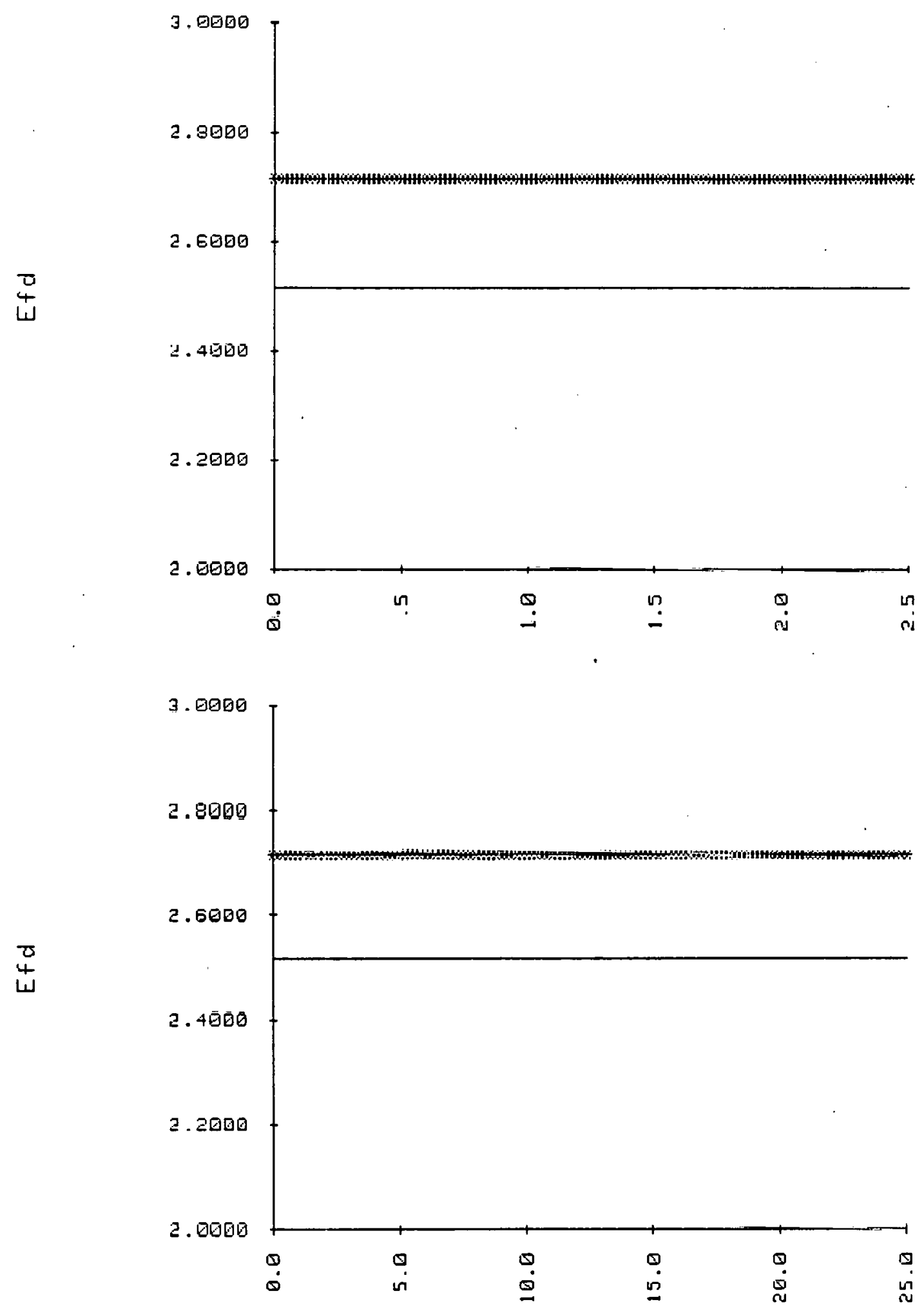

Figure A.2.a E FD vs time in seconds, f1ux 1inkage model (a), step change in $T_{m}$, saturated (*) and unsaturated response 

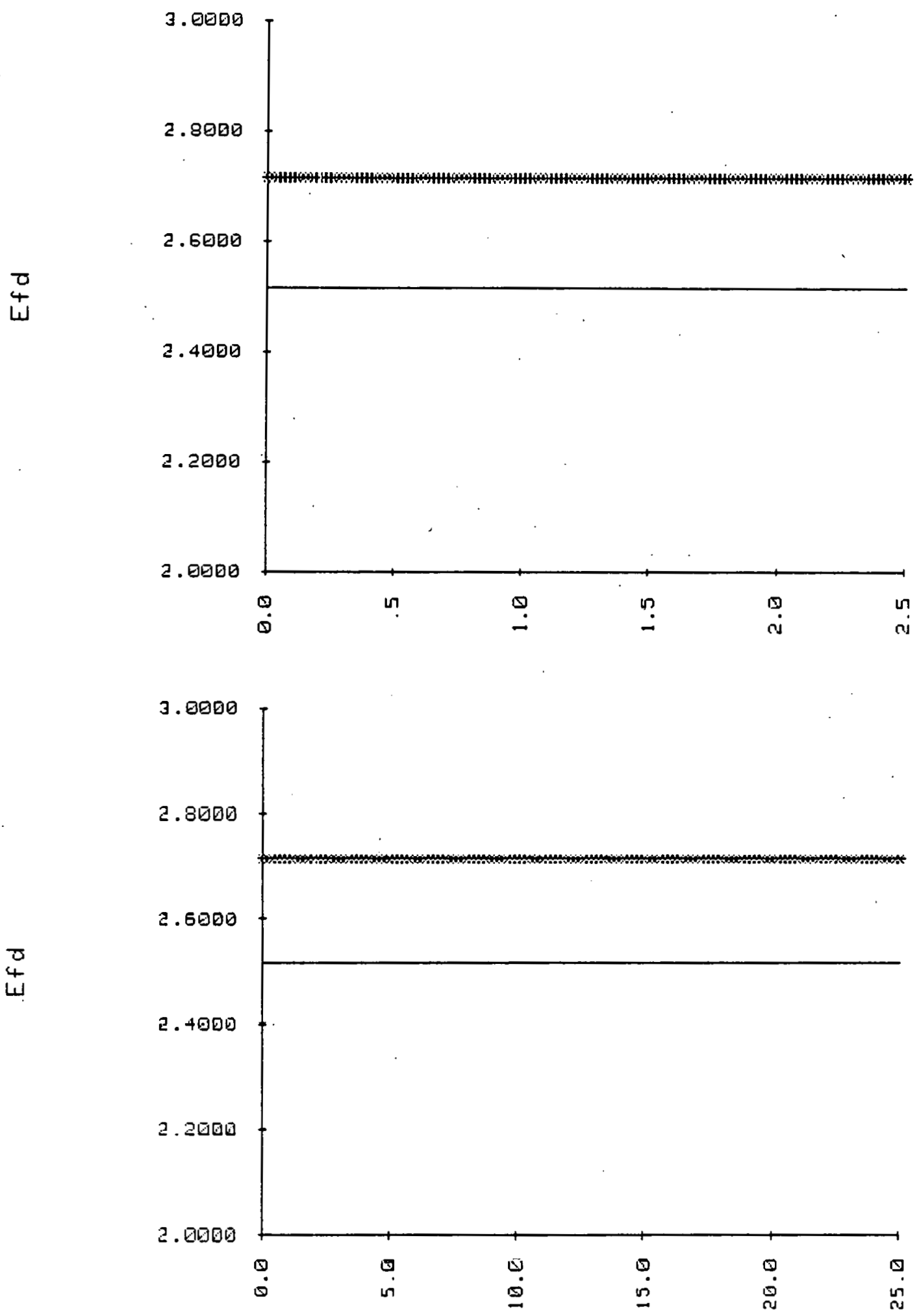

Figure A.2.b $E_{F D} \nabla s$ time in seconds, E' mode1 (b), step change in $T_{m}$, saturated (*) and unsaturated response 

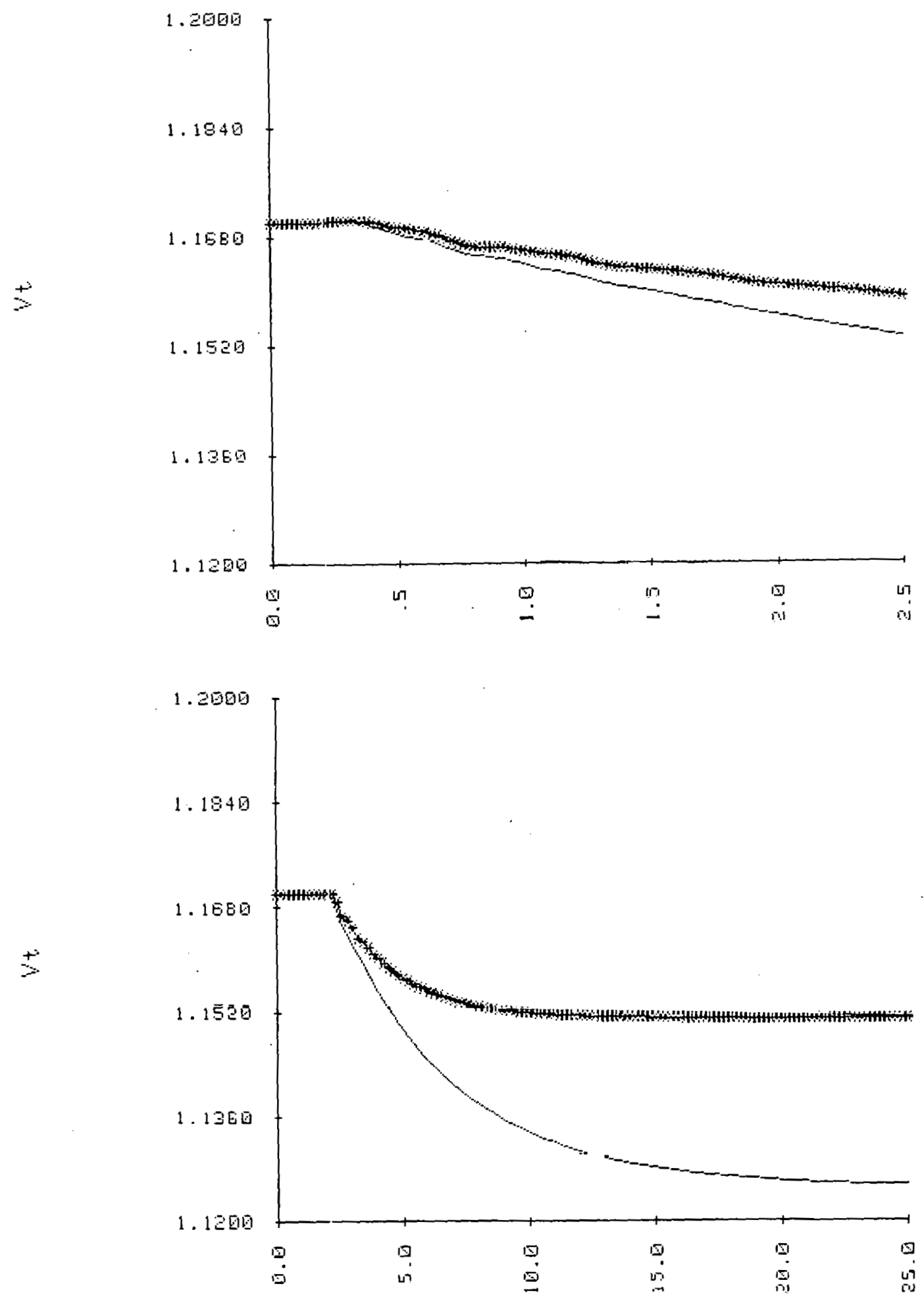

Figure A.3.a $V_{t}$ vs time in seconds, flux linkage model (a), step change in $T_{m}$, saturated (*) and unsaturated response 

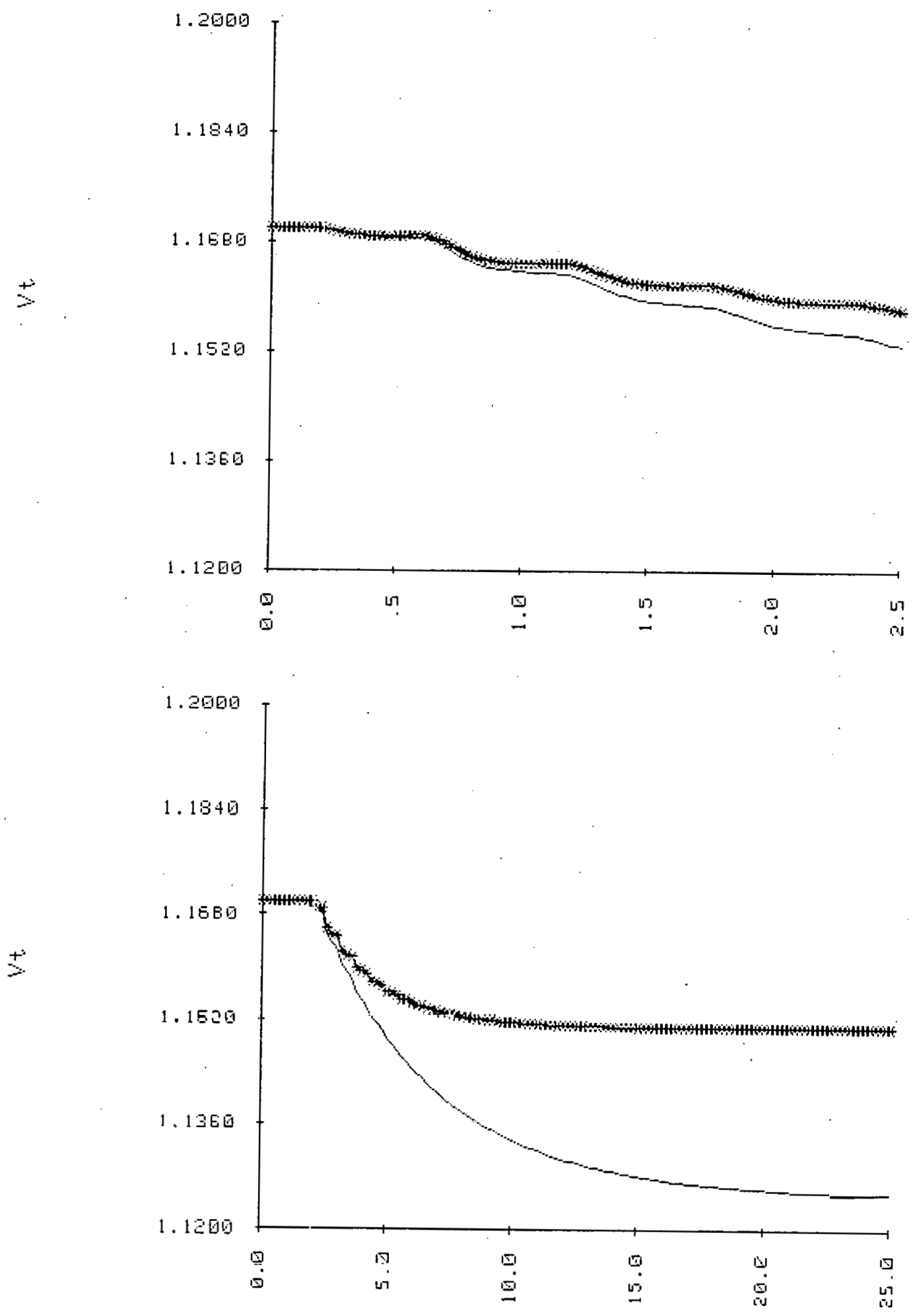

Figure A.3.b $V_{t}$ vs time in seconds, E' mode1 (b), step change in $T_{m}$, saturated (*) and unsaturated response 

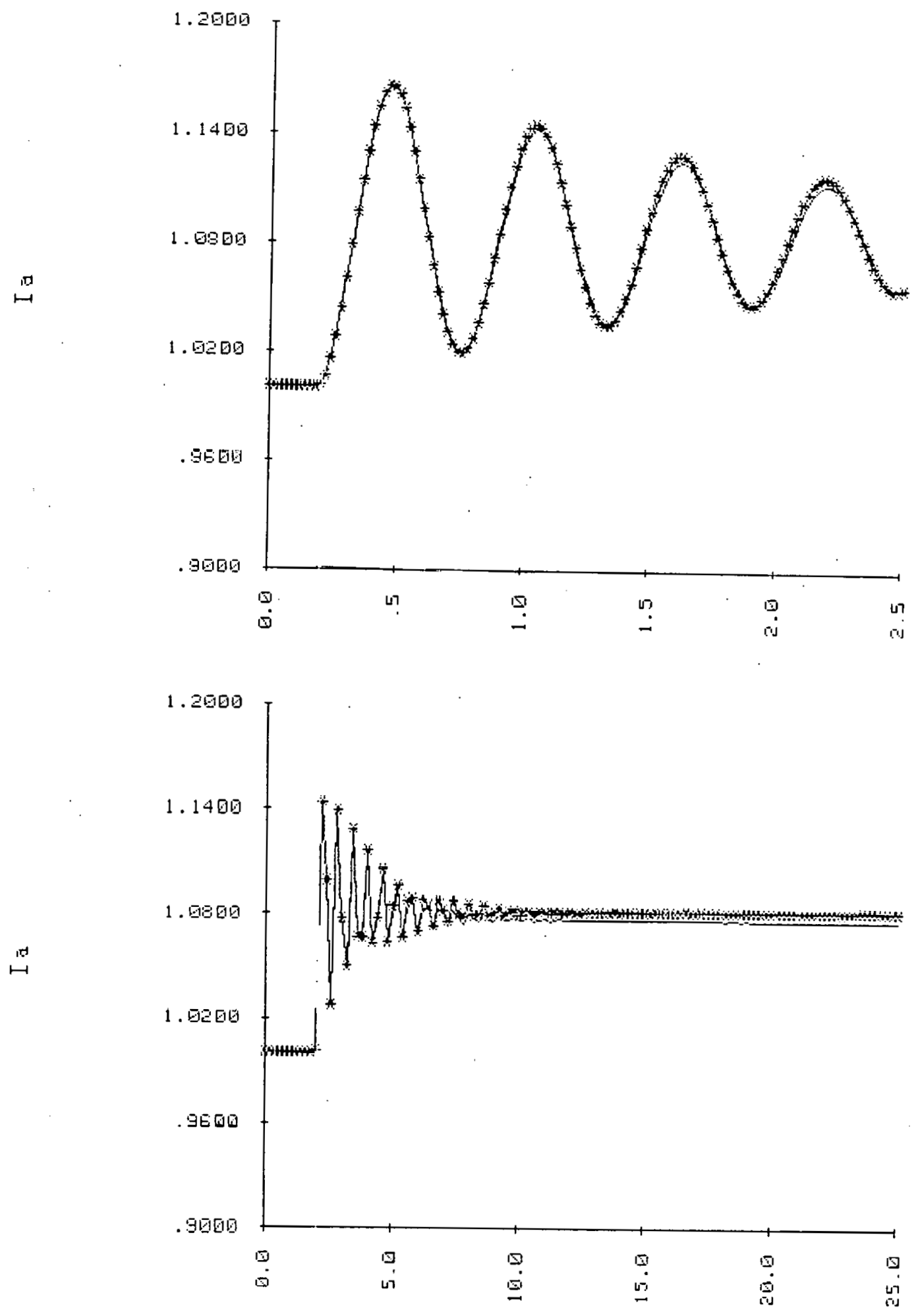

Figure A,4.a $I_{a}$ vs time in seconds, flux 1inkage mode1 (a), step change in $T_{m}$, saturated (*) and unsaturated response 

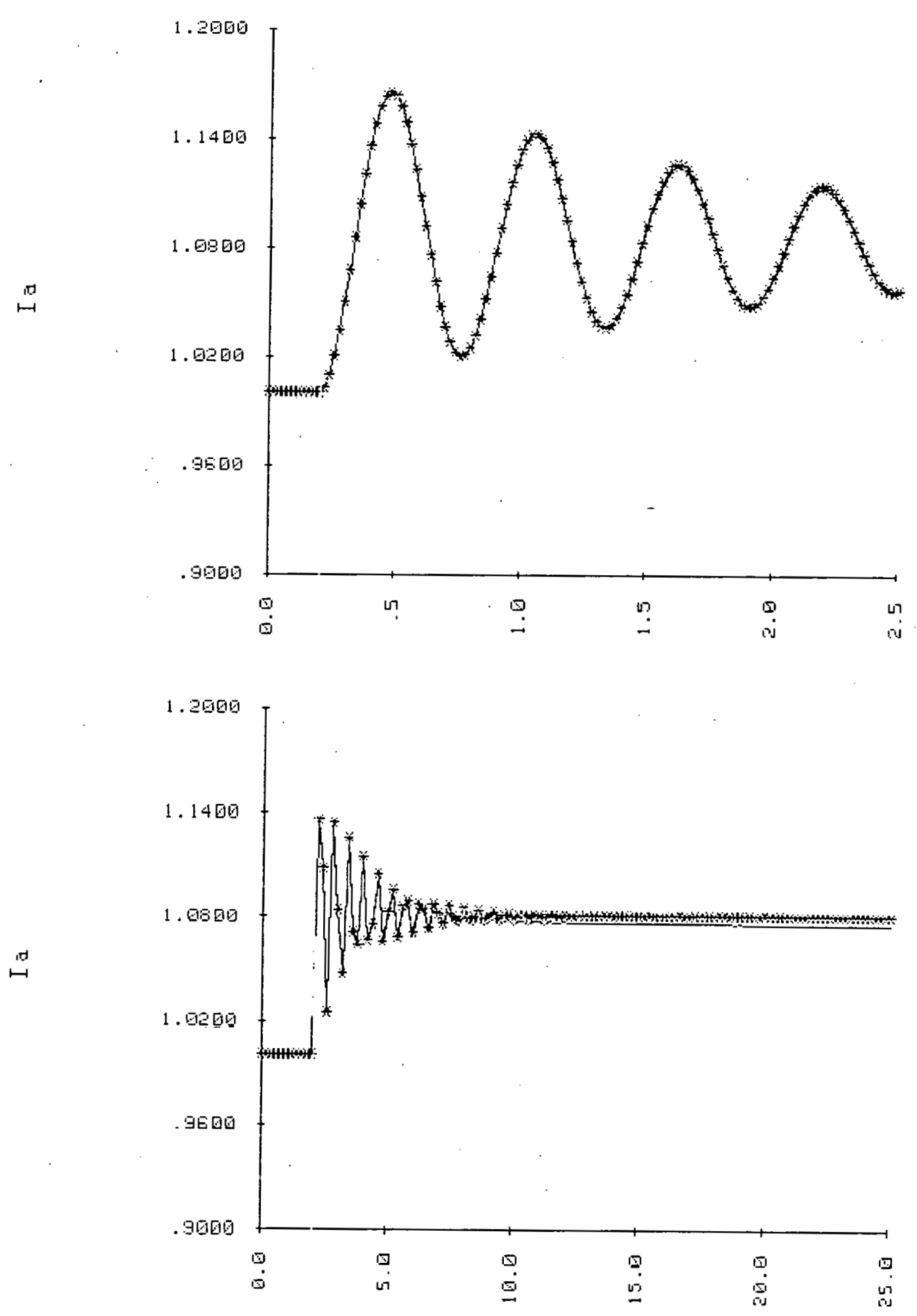

Figure A.4.b $I_{a} v s$ time in seconds, E' model (b), step change in $T_{m}$, saturated $(*)$ and unsaturated response

75 

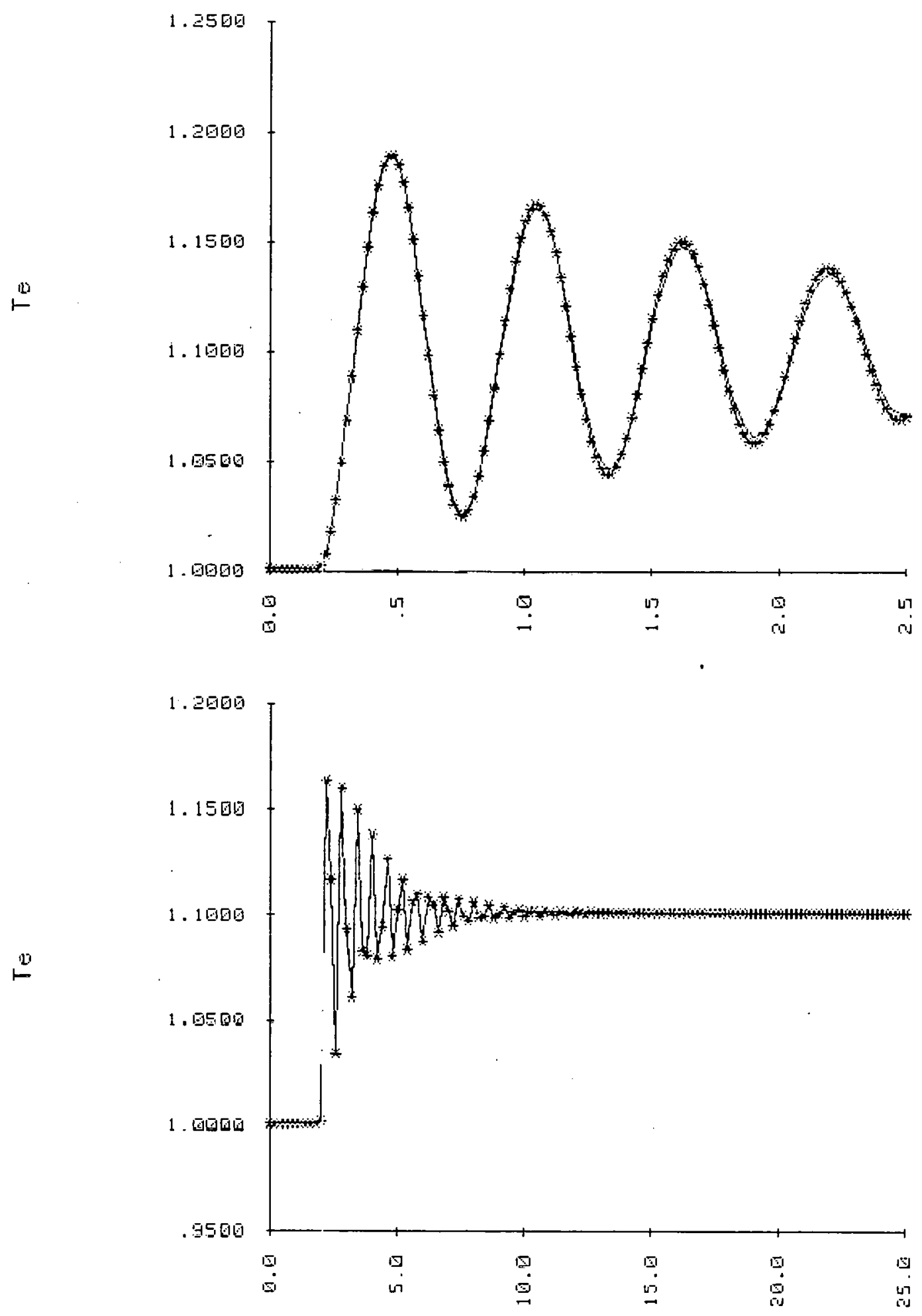

Figure A.5.a $T_{e}$ vs time in seconds, f1ux 1 inkage model (a), step change in $T_{m}$, saturated $(*)$ and unsaturated response 

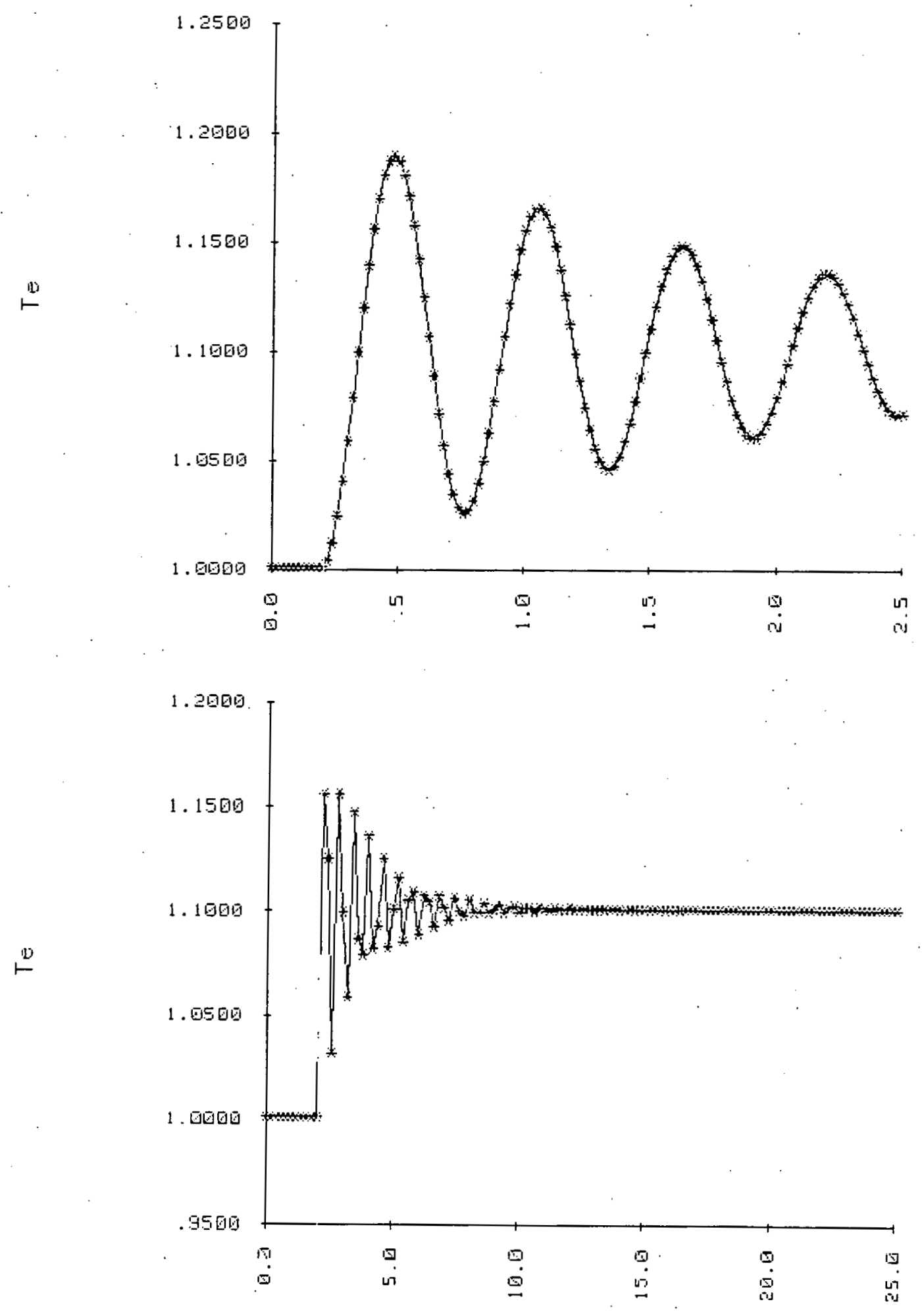

Figure A.5.b $T_{e}$ vs time in seconds, E' model (b). step change in $T_{m}$, saturated (*) and unsaturated response 

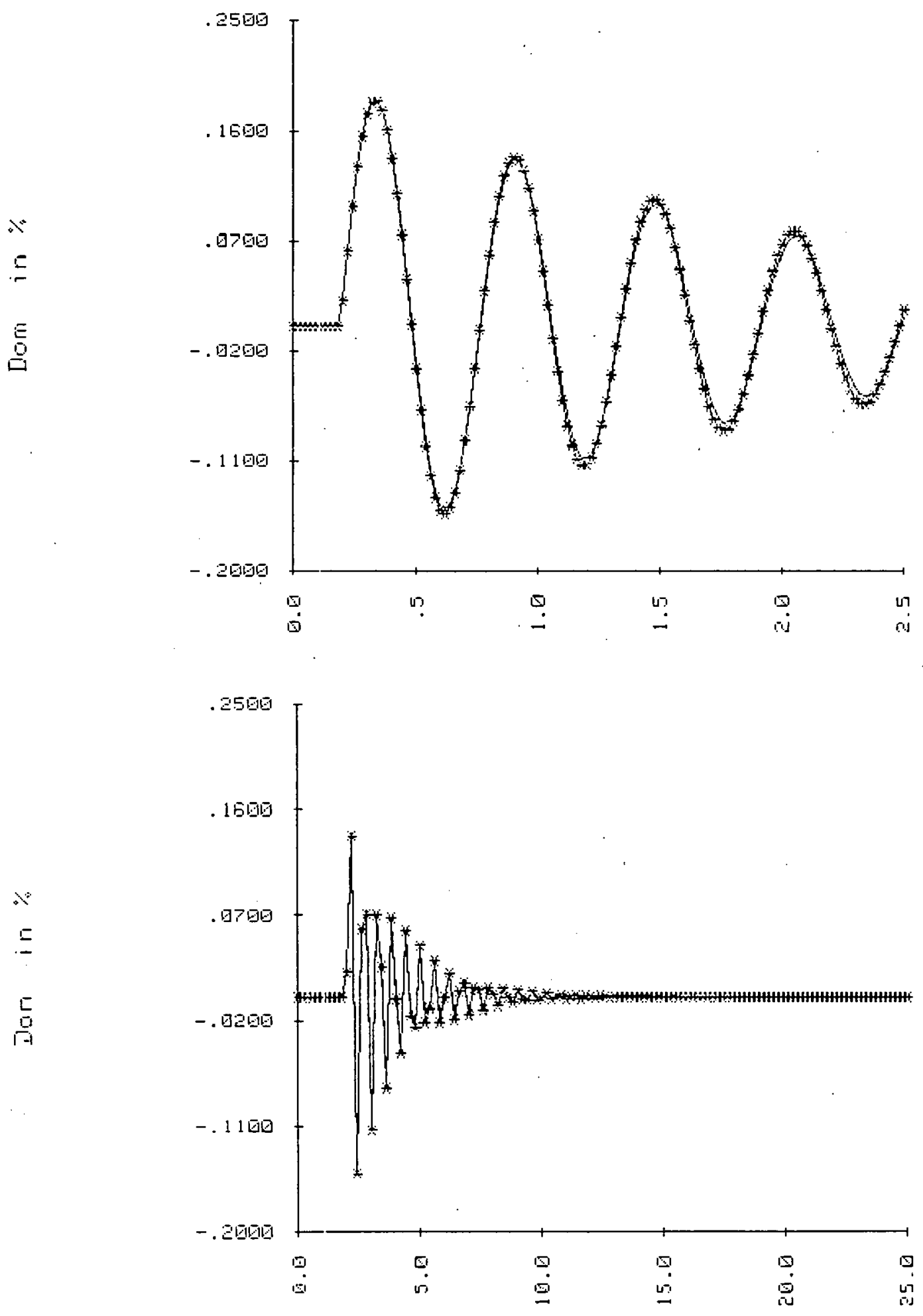

Figure A.6.a $\Delta \omega$ vs time in seconds, f1ux 1inkage mode1 (a), step change in $T_{m}$, saturated (*) and unsaturated response 

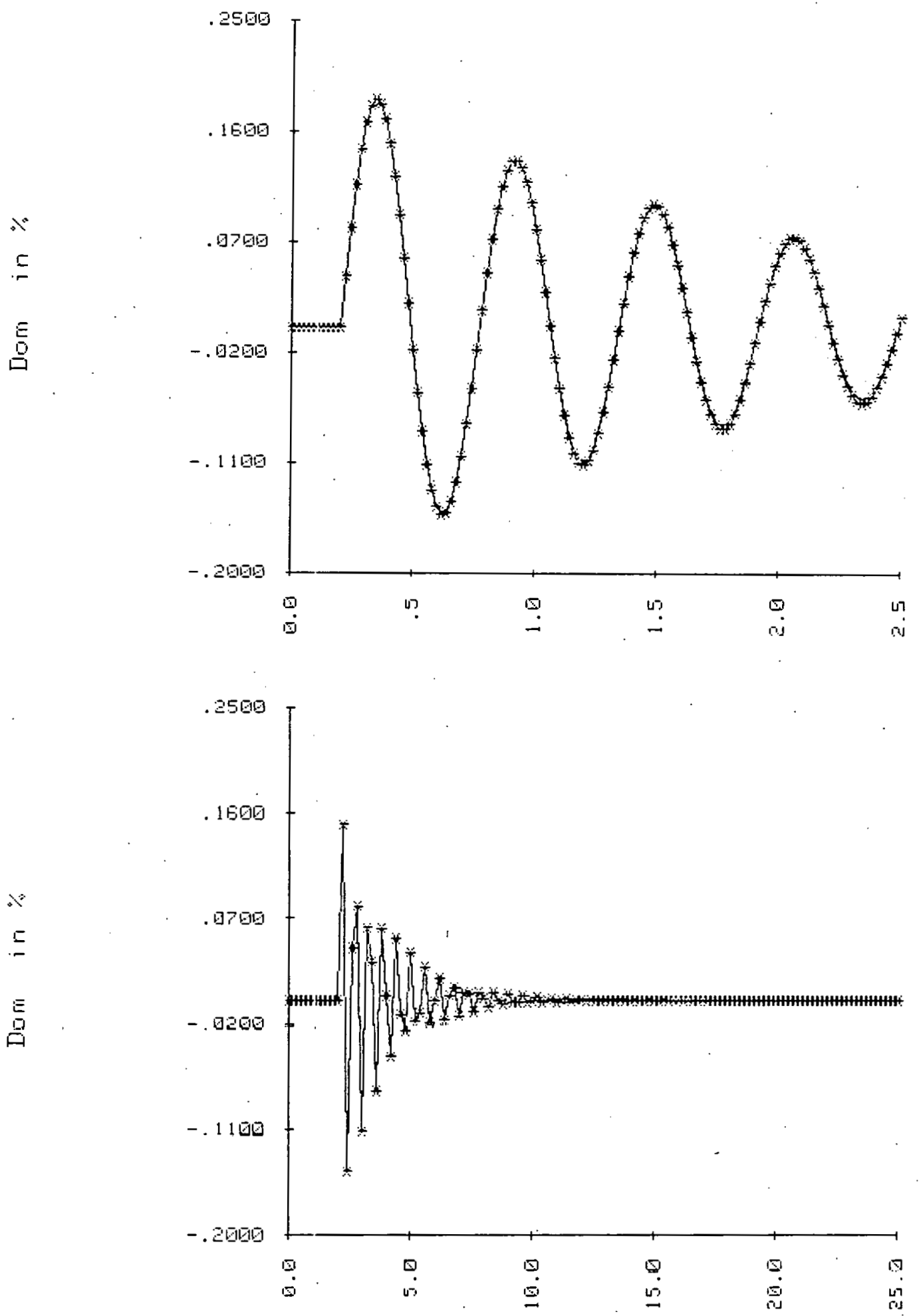

Fignre A.6.b. $\Delta \omega$ vs time in seconds, E' mode1 (b), step change in $T_{m}$, saturated (*) and unsaturated response 


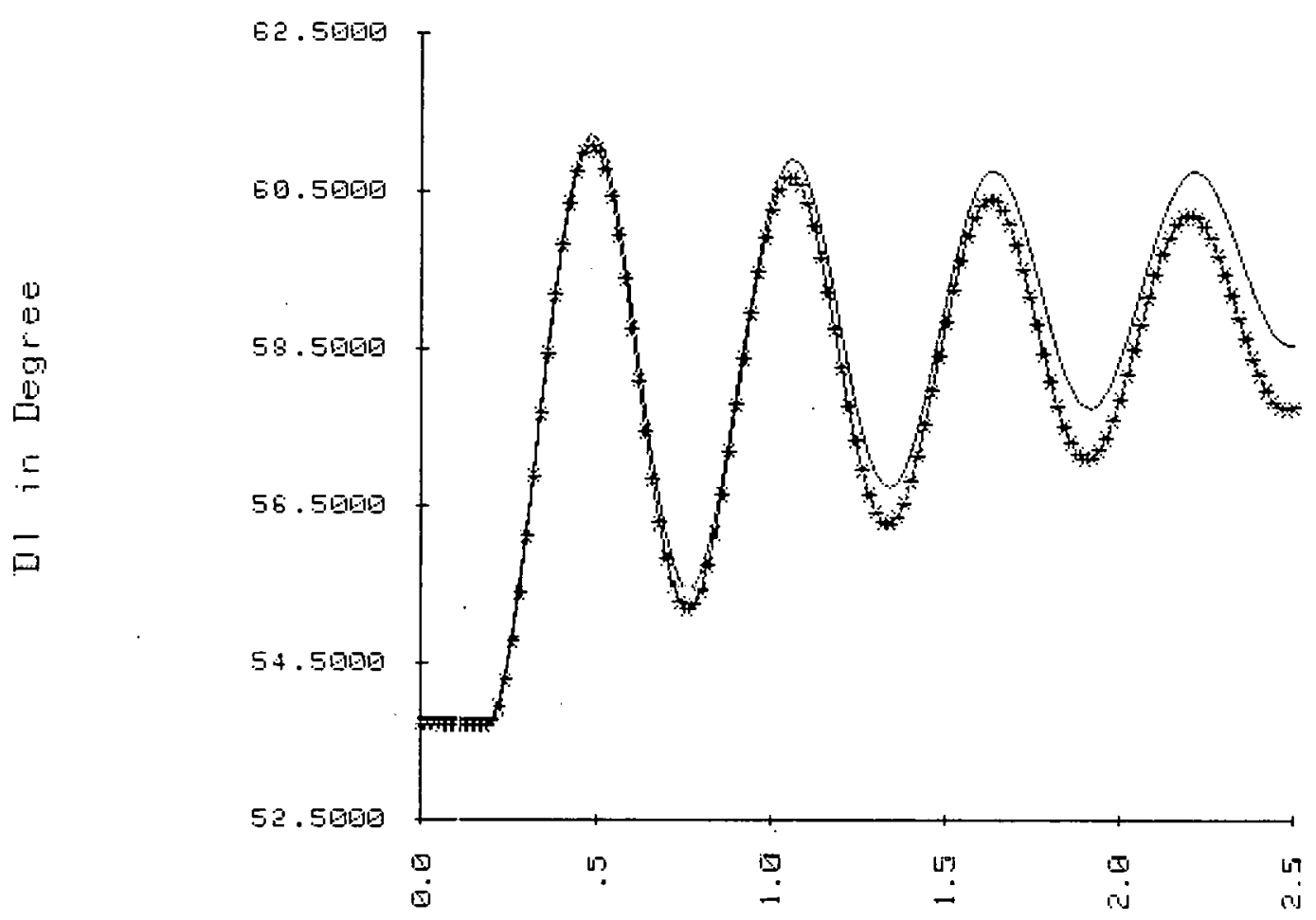

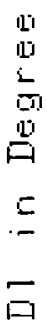

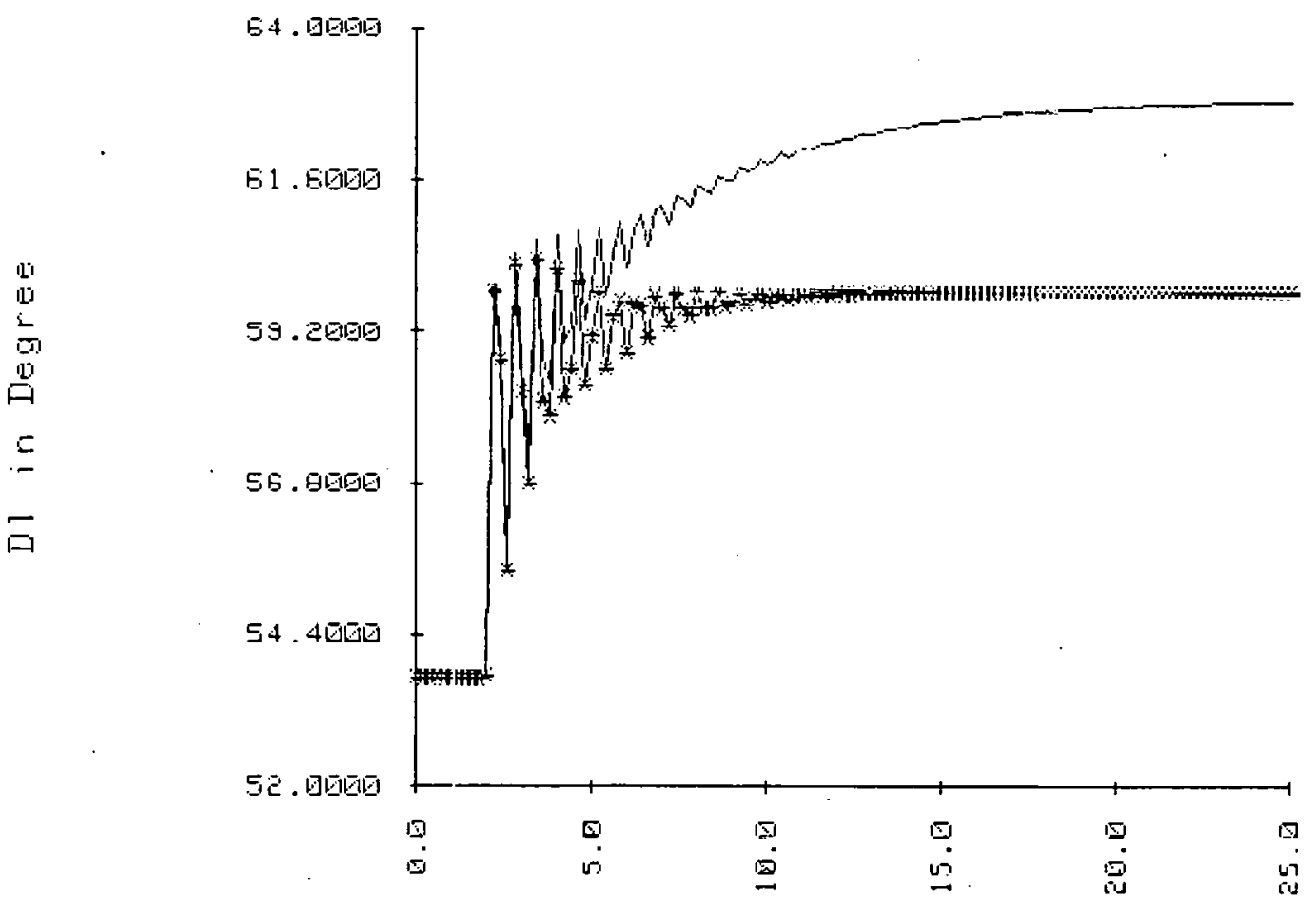

Figure A.7.a $\delta$ vs time in seconds, flux linkage model (a), step change in $T_{m}$, saturated (*) and unsaturated response 


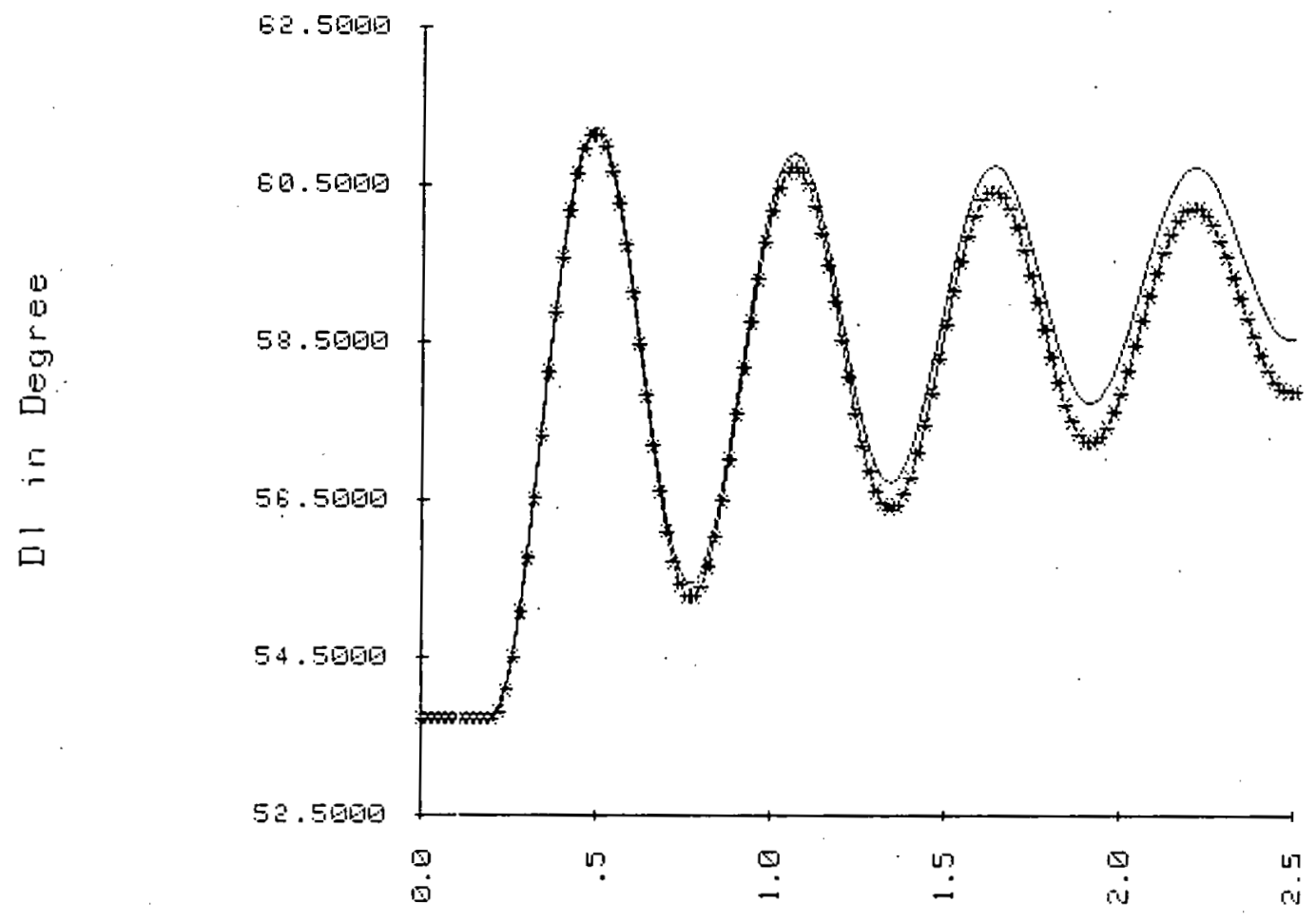

0
0
2
0
0
0
$a$
$=$
$\bar{\Xi}$

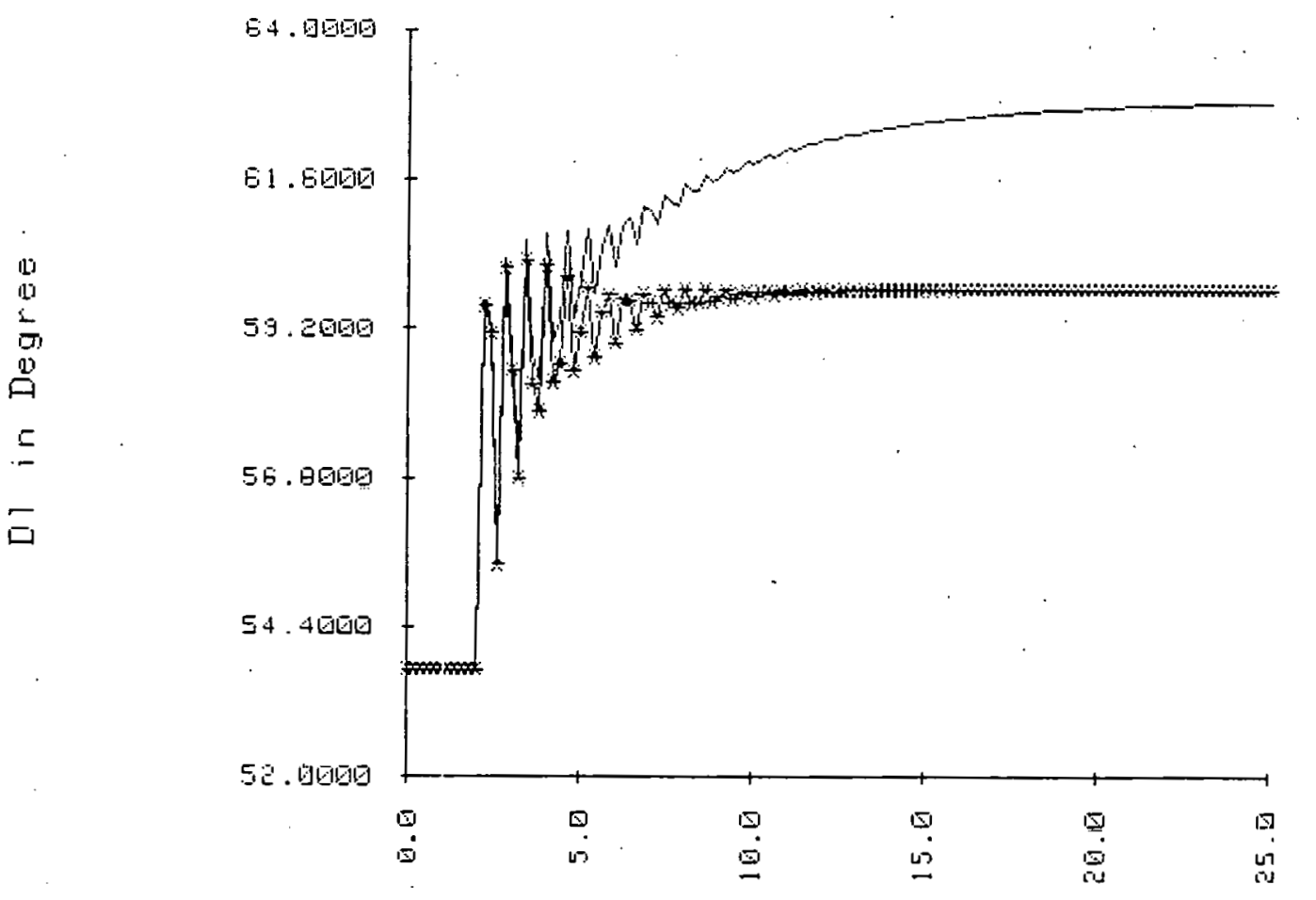

Figure A.7.b $\delta$ vs time ini seconds, E' $\operatorname{mode1}(b)$, step change in $T_{m}$, saturated (*) and unsaturated response 

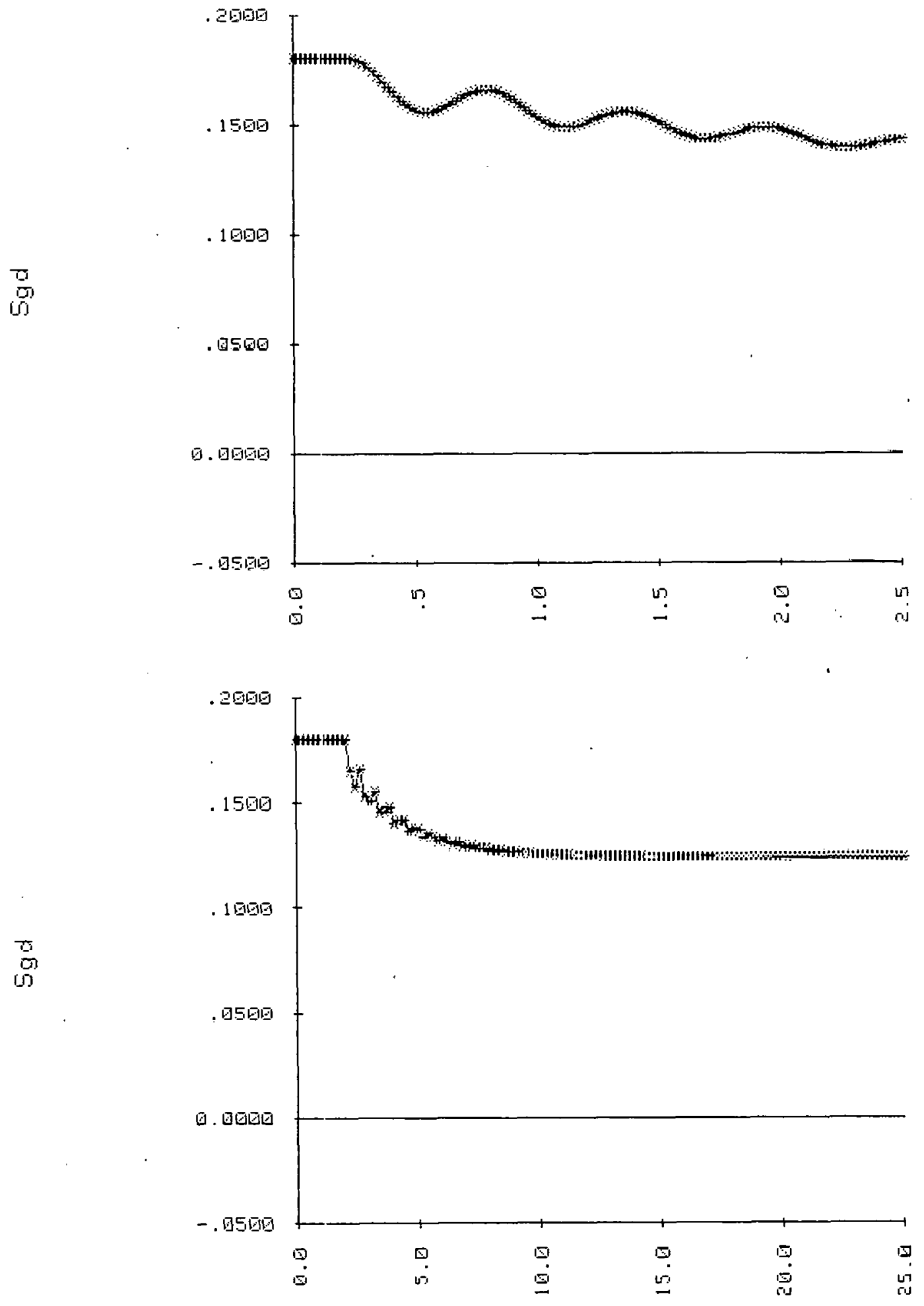

Figure A.8.a $S_{g d} v s$ time in seconds, flux linkage mode1 (a), step change in $T_{m}$, saturated (*) and unsaturated response 

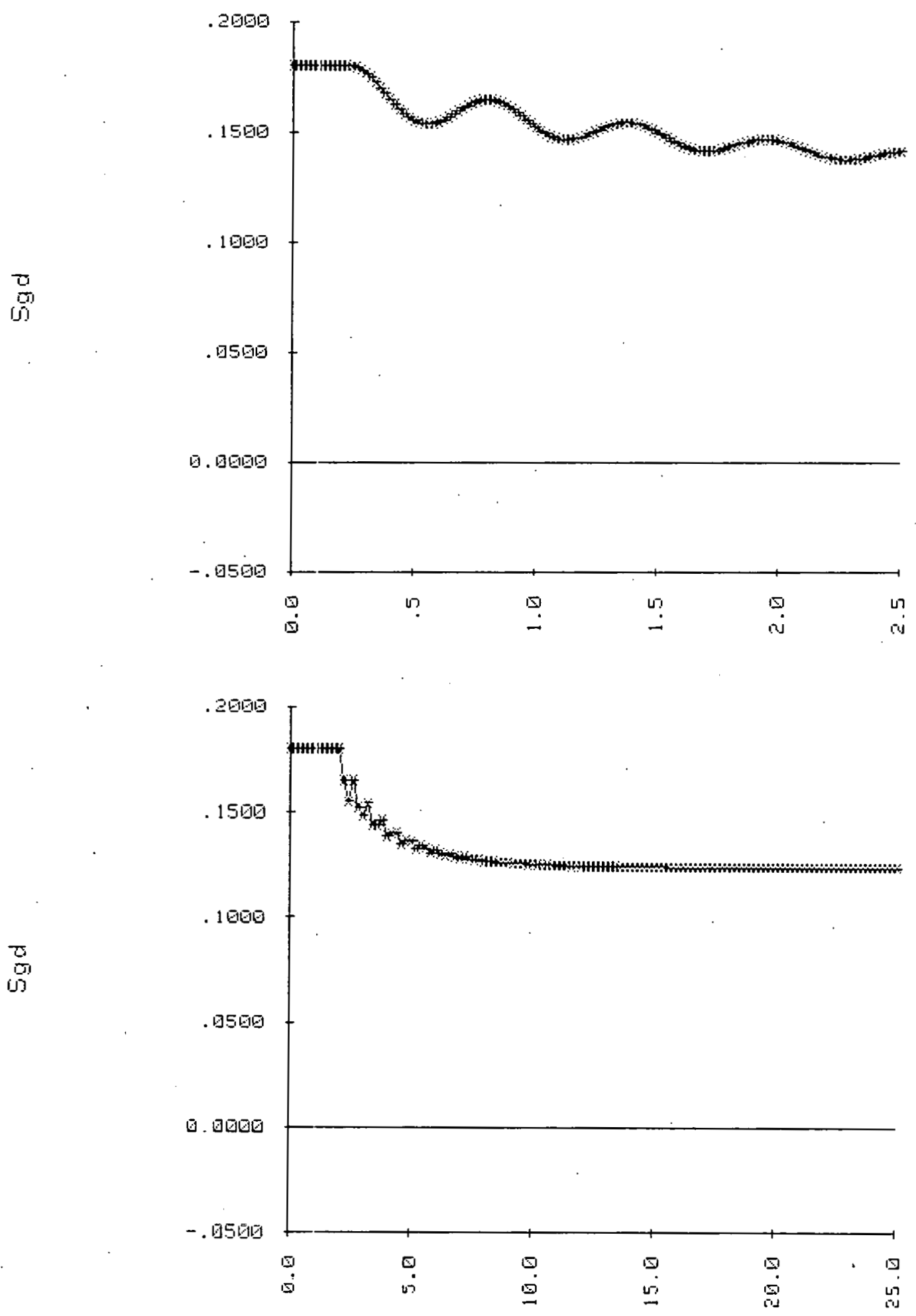

Fignre A.8.b $S_{g d}$ vs time in seconds, E' model (b), step change in $T_{m}$, saturated $(*)$ and unsaturated response 

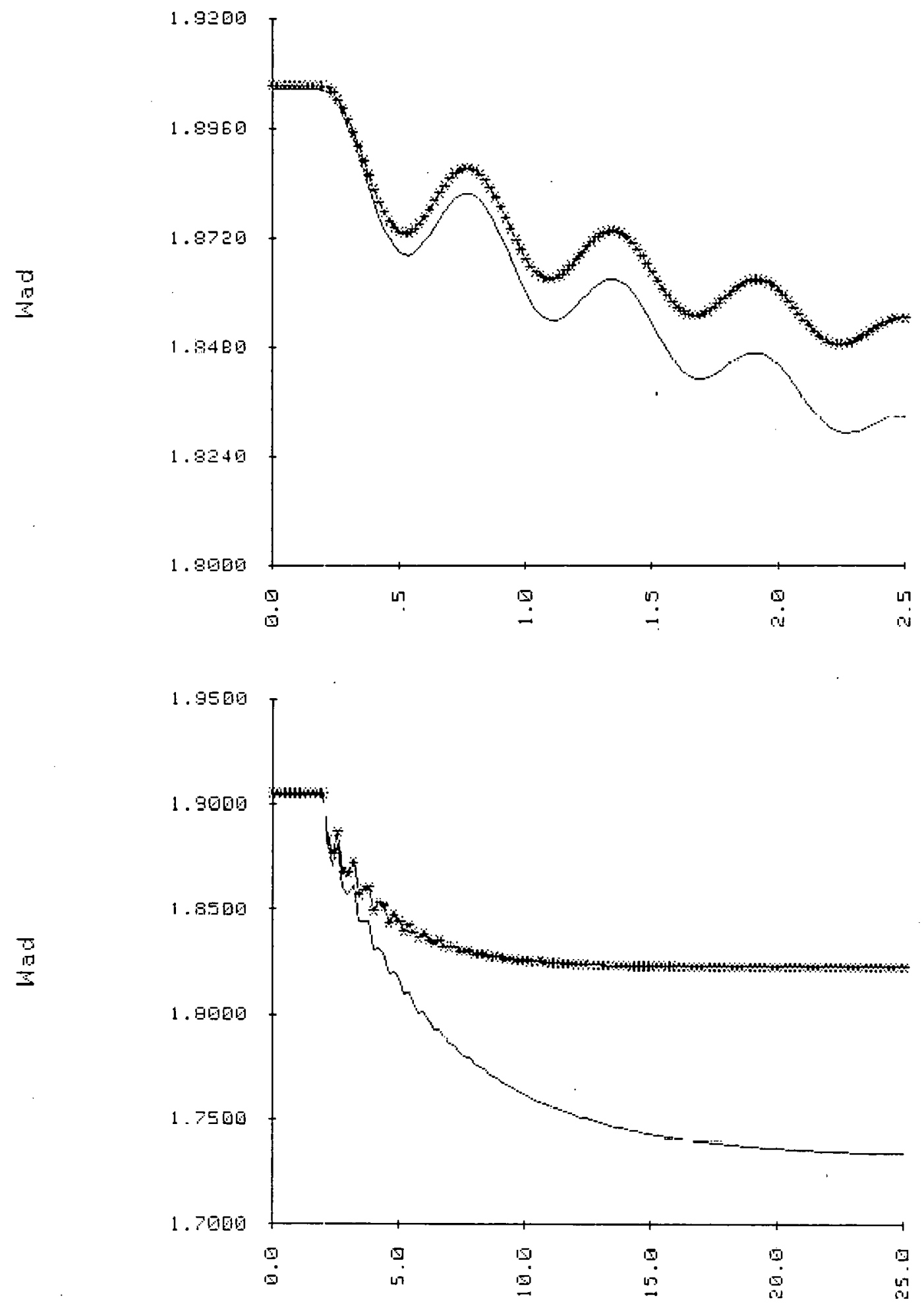

Figure A.9.a $\Psi_{A D}$ vs time in seconds, flux 1 inkage model (a), step change in $T_{m}$, saturated $(*)$ and unsaturated response 

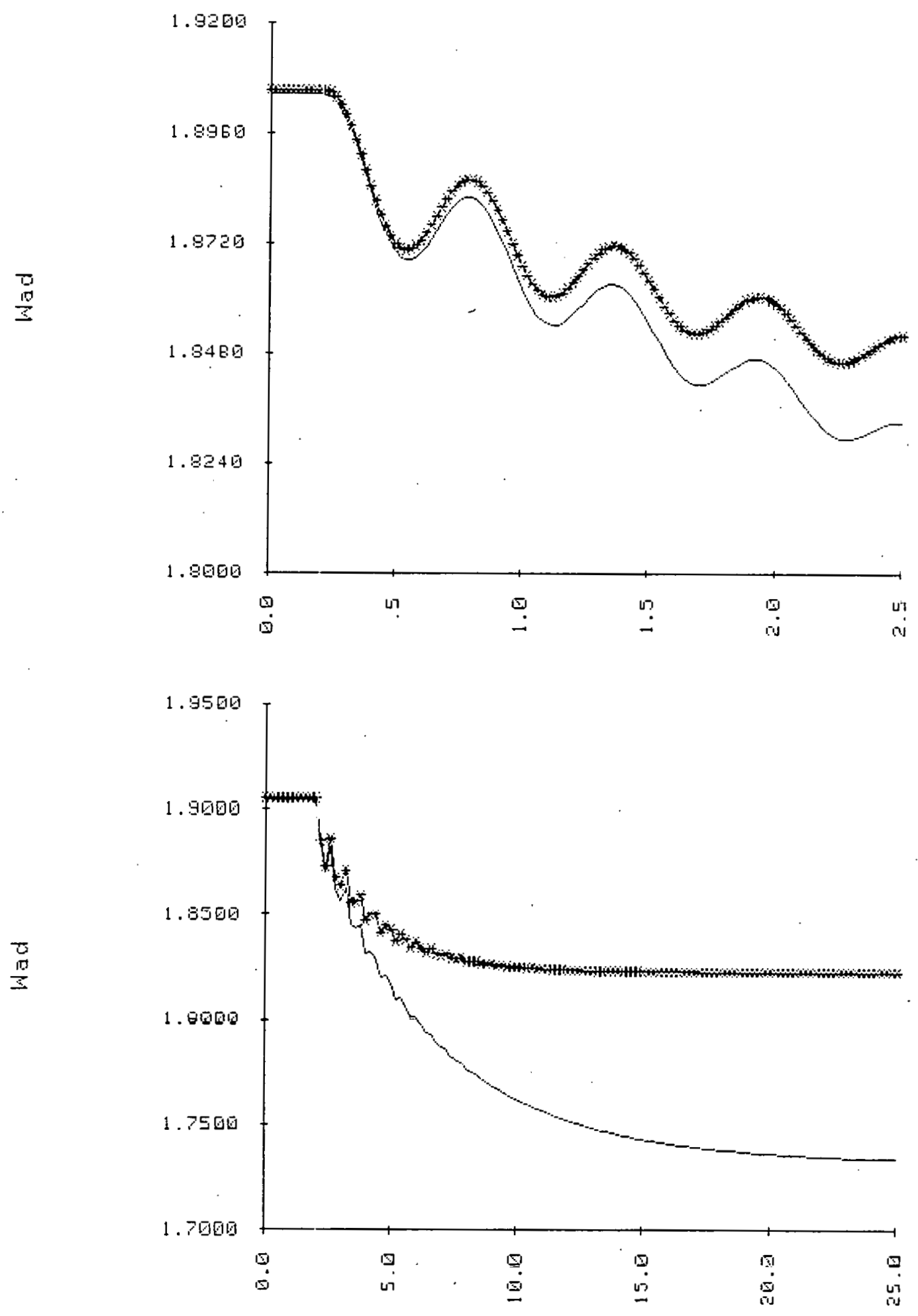

Figure A.9.b $\psi_{A D} v s$ time in seconds, E' model (b), step change in $T_{m}$, saturated $(*)$ and unsaturated response

85 

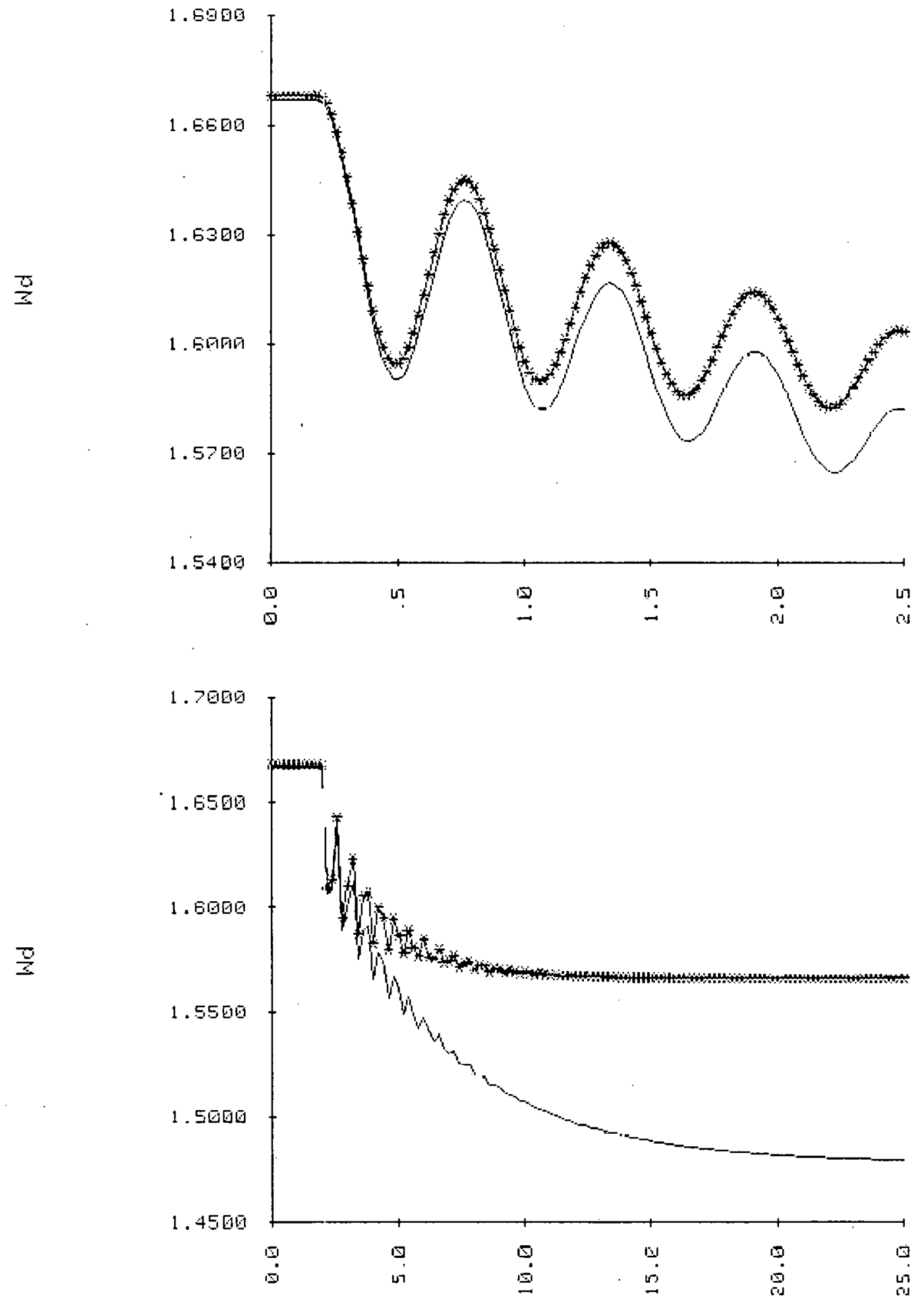

Figure A.10.a $\psi_{d}$ vs time in seconds, flux 1 inkage mode1 (a), step change in $T_{m}$, saturated (*) and unsaturated response 

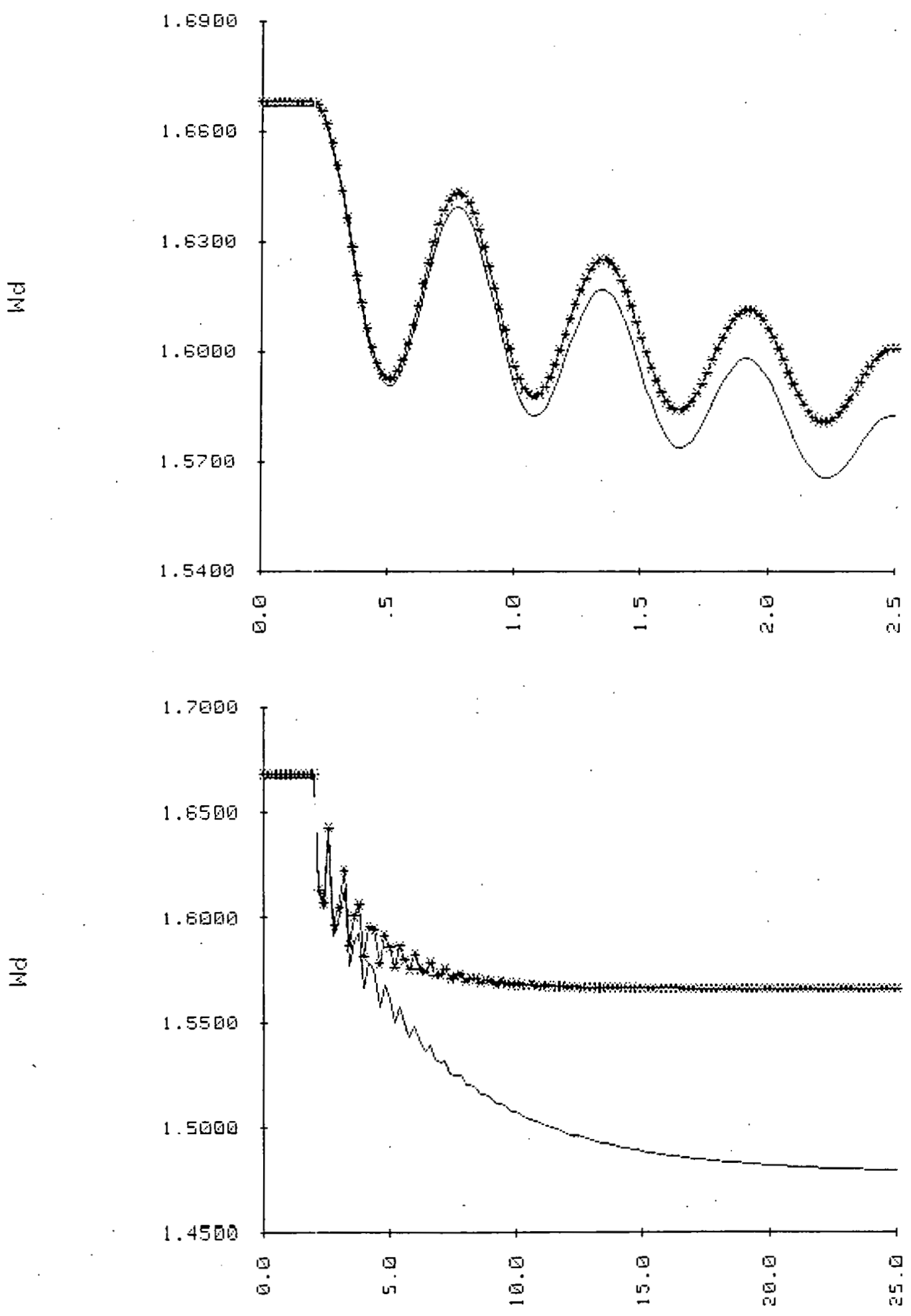

Figure A.10.b $\psi_{d}$ vs time in seconds, E' mode 1 (b), step change in $I_{m}$, saturated (*) and unsaturated response

87 

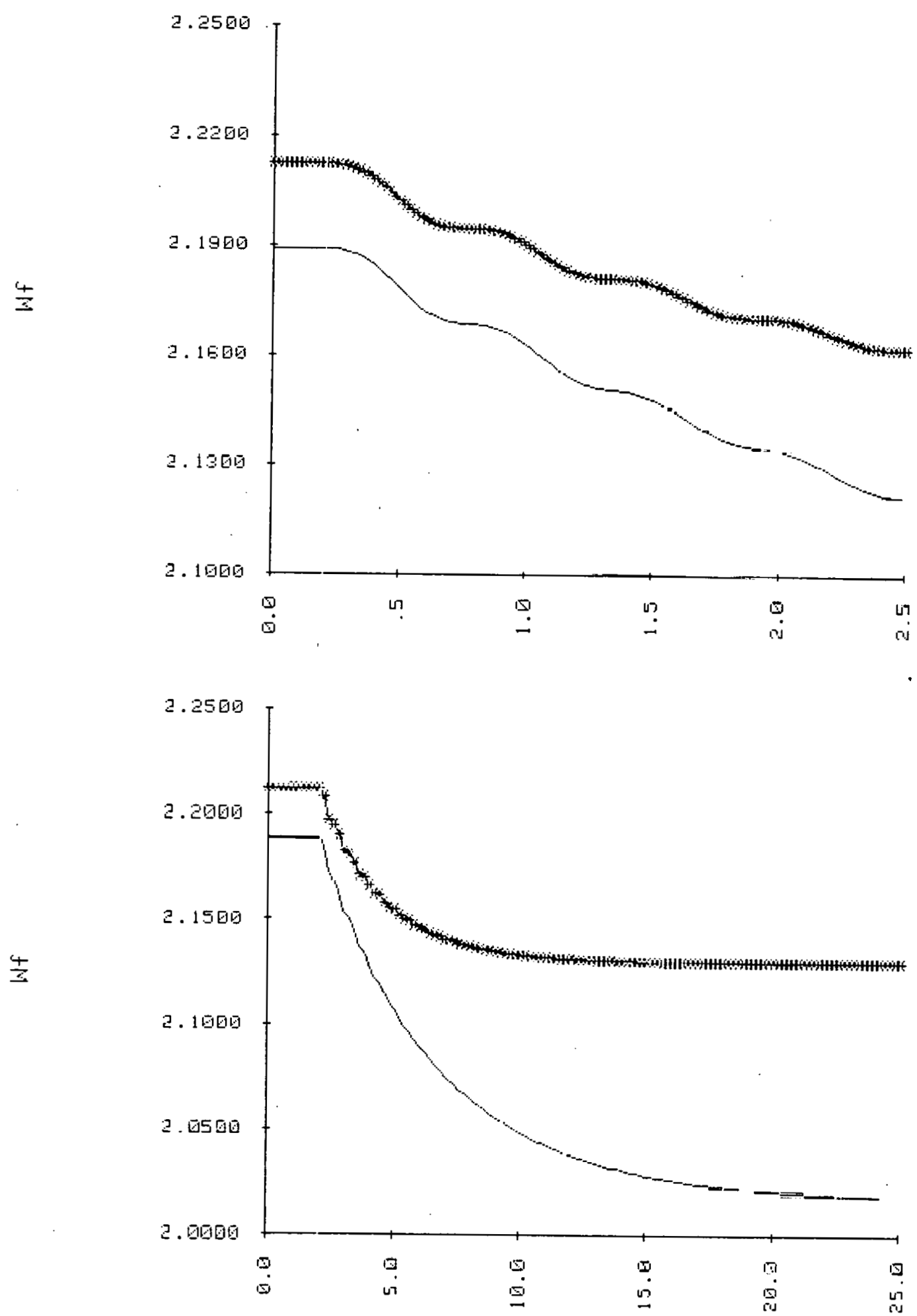

Figure A.11.a $\psi_{F}$ vs time in seconds, flux linkage mode1 (a), step change in $T_{m}$, saturated (*) and unsaturated response 

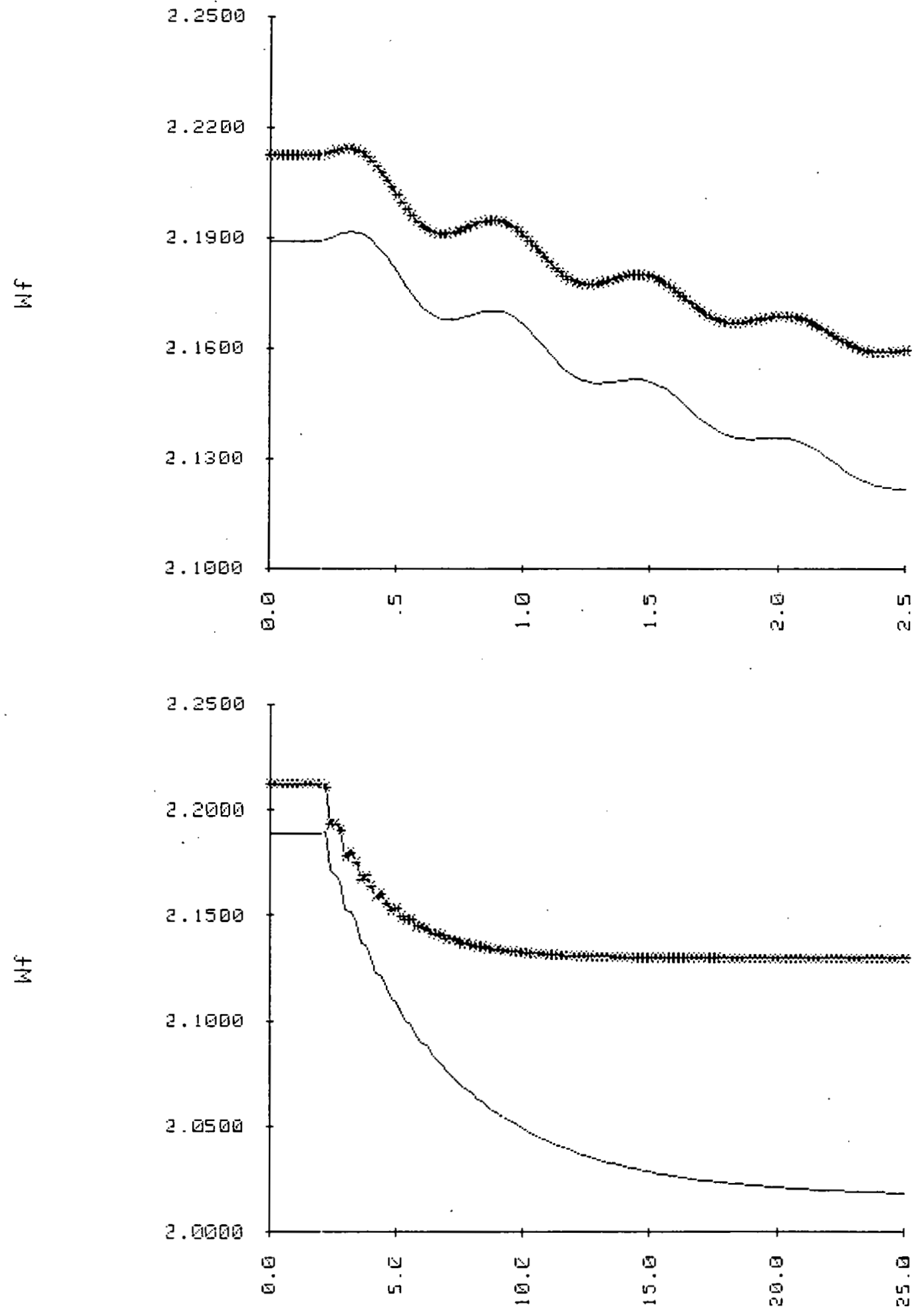

Fignre A.11.b $\psi_{F}$ s time in seconds, E' mode1 (b), step change in $T_{m}$, saturated (*) and unsaturated response 

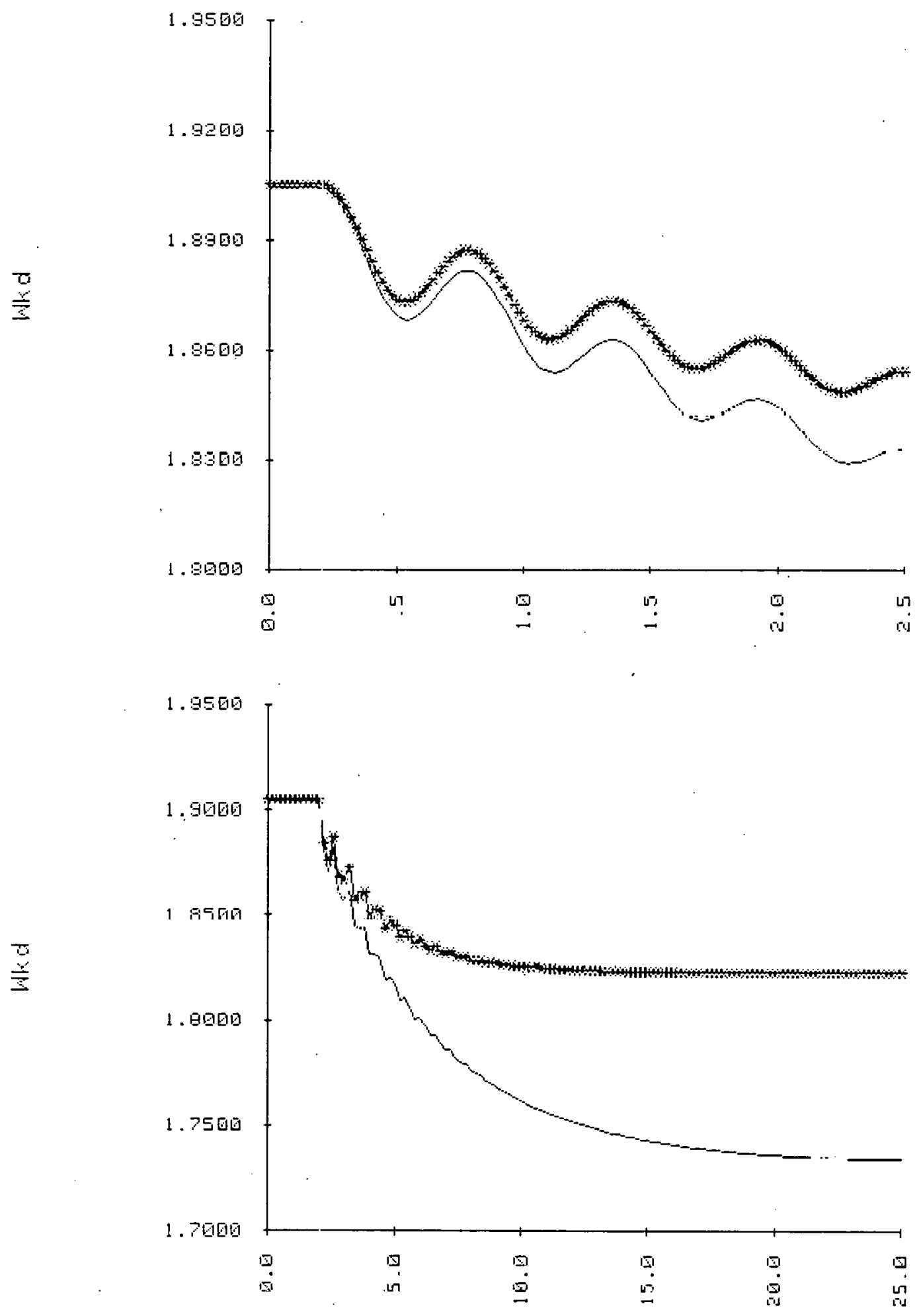

Figure A.12.a $\psi_{k d}$ vs time in seconds, flux 1inkage mode1 (a), step change in $T_{m}$, saturated (*) and unsaturated response 

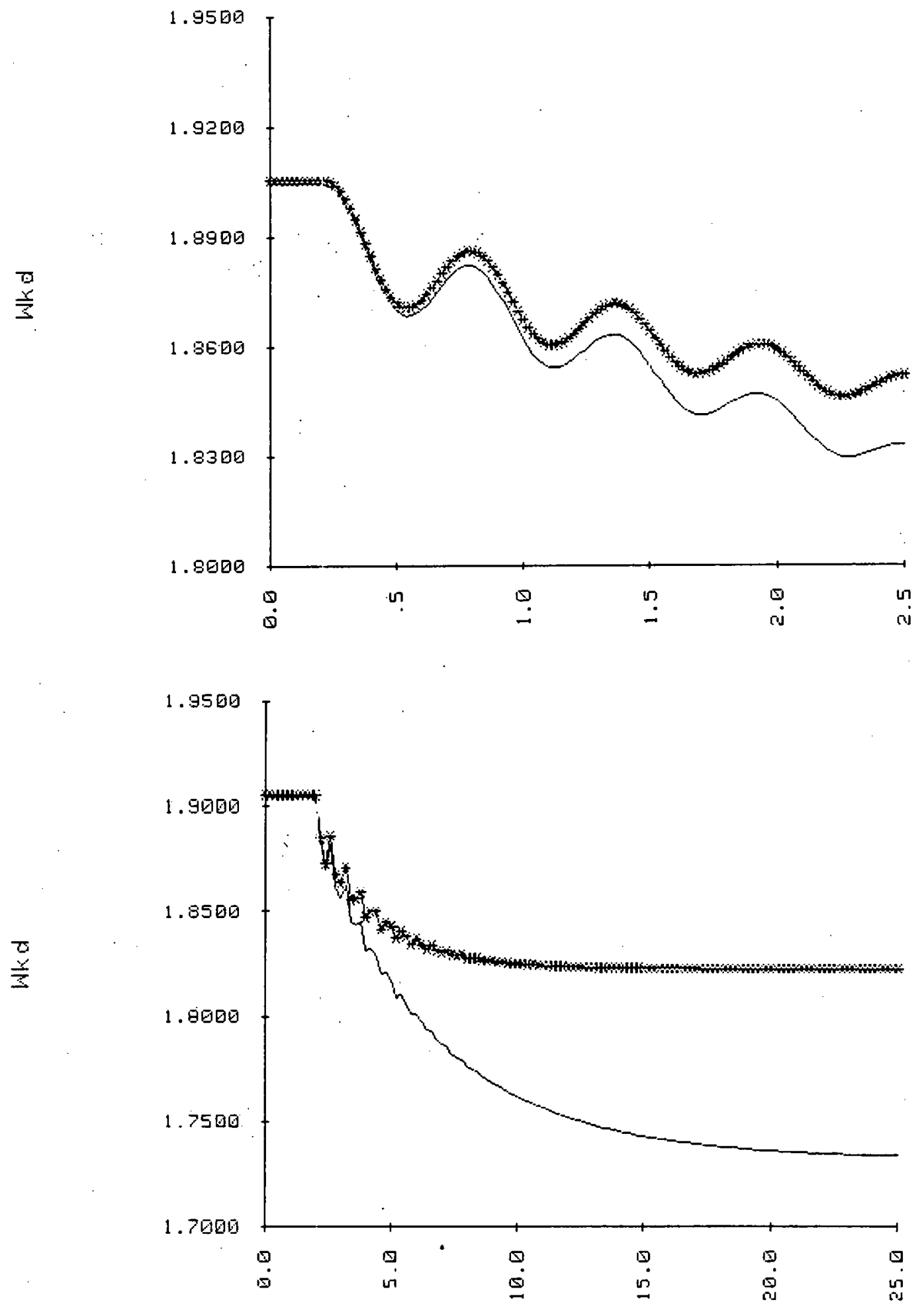

Fignre A.12.b $\psi_{k d}$ vs time in seconds. B' model (b).

step change in $T_{m}$, saturated (*) and unsaturated response 

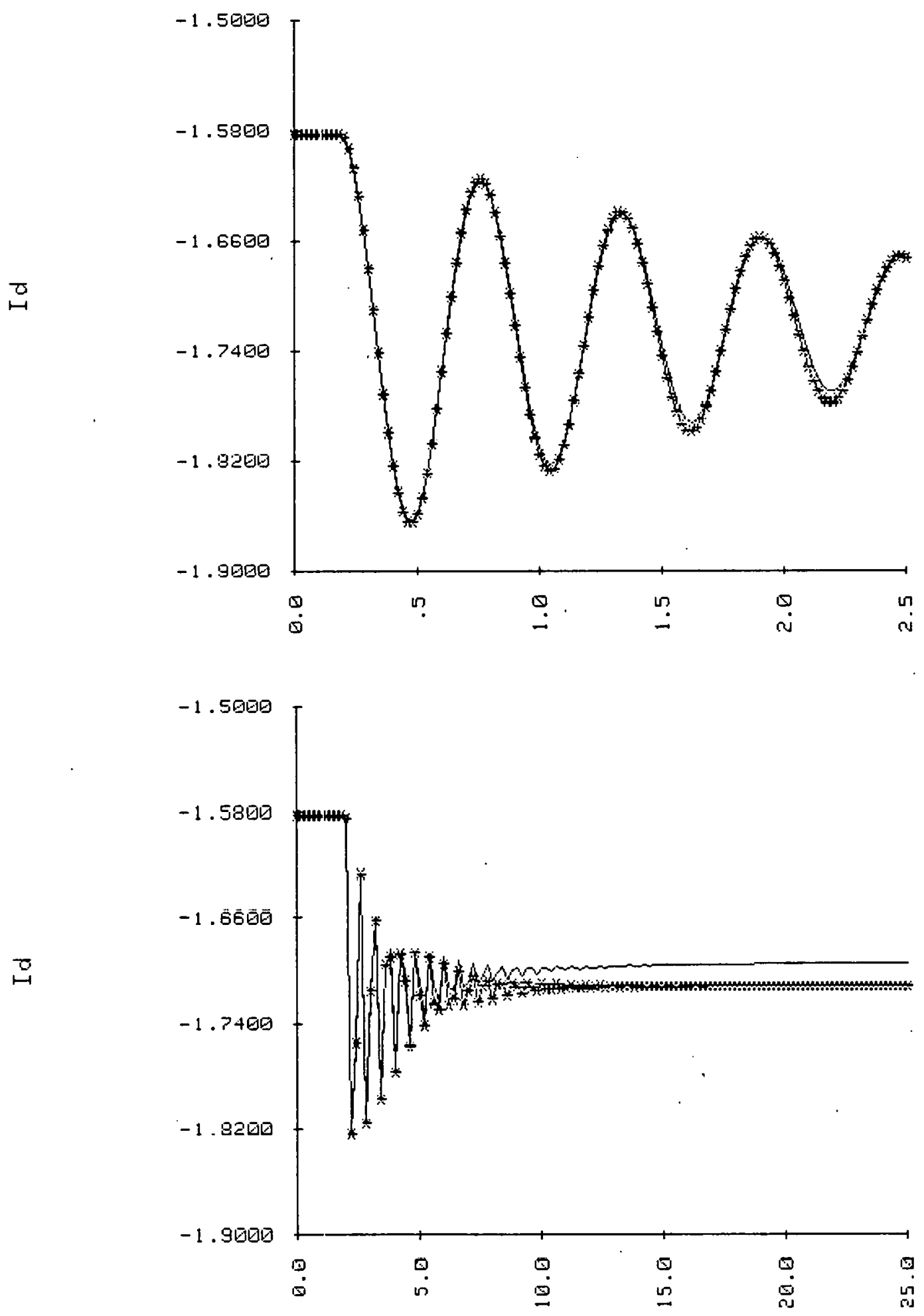

Figure A.13.a I $I_{d}$ s time in seconds, flux linkage model (a), step change in $T_{m}$, saturated (*) and unsaturated response 

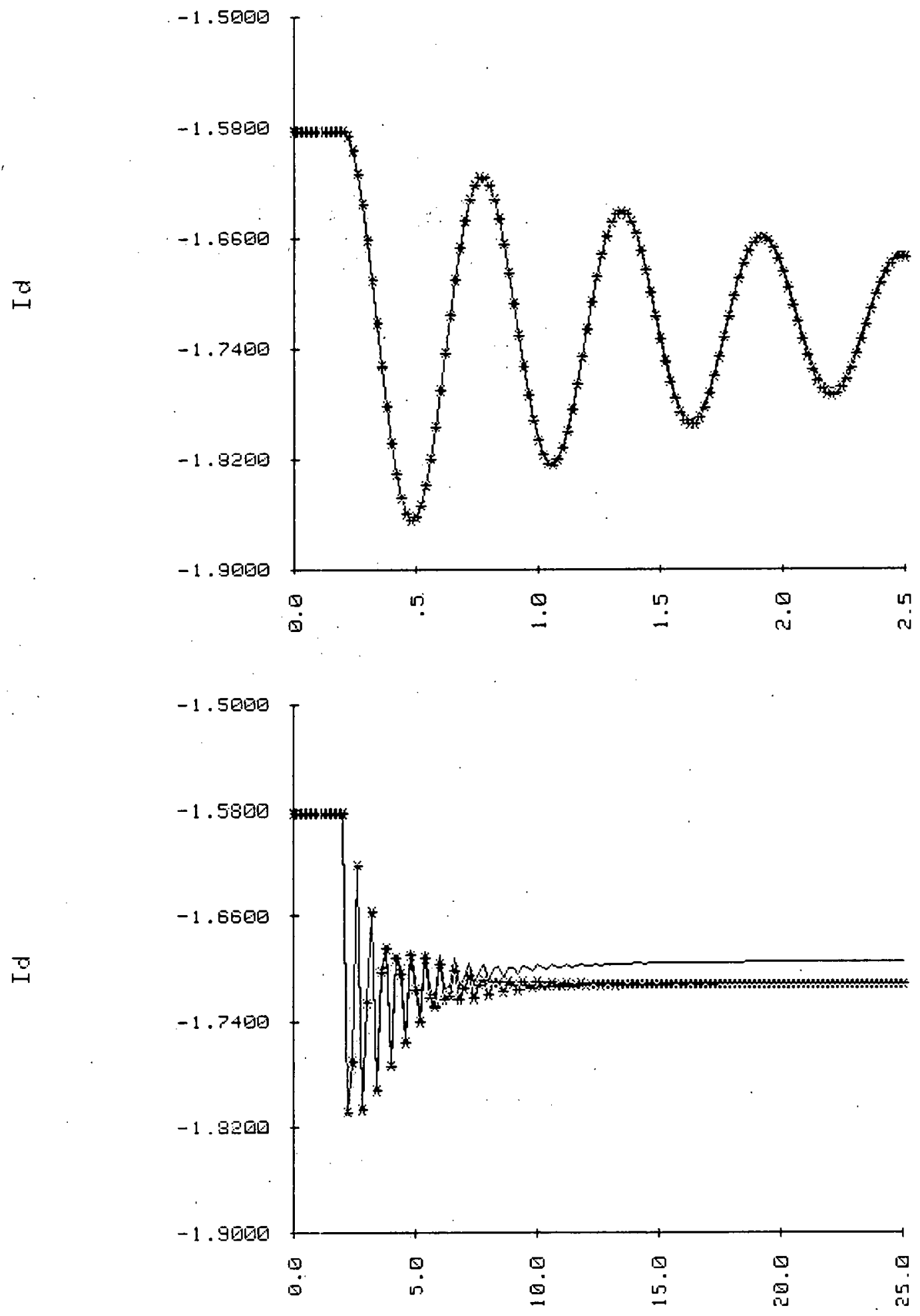

Figure A.13.b $I_{d}$ vs time in seconds, E" mode1 (b), step change in $T_{m}$, saturated (*) and unsaturated response 

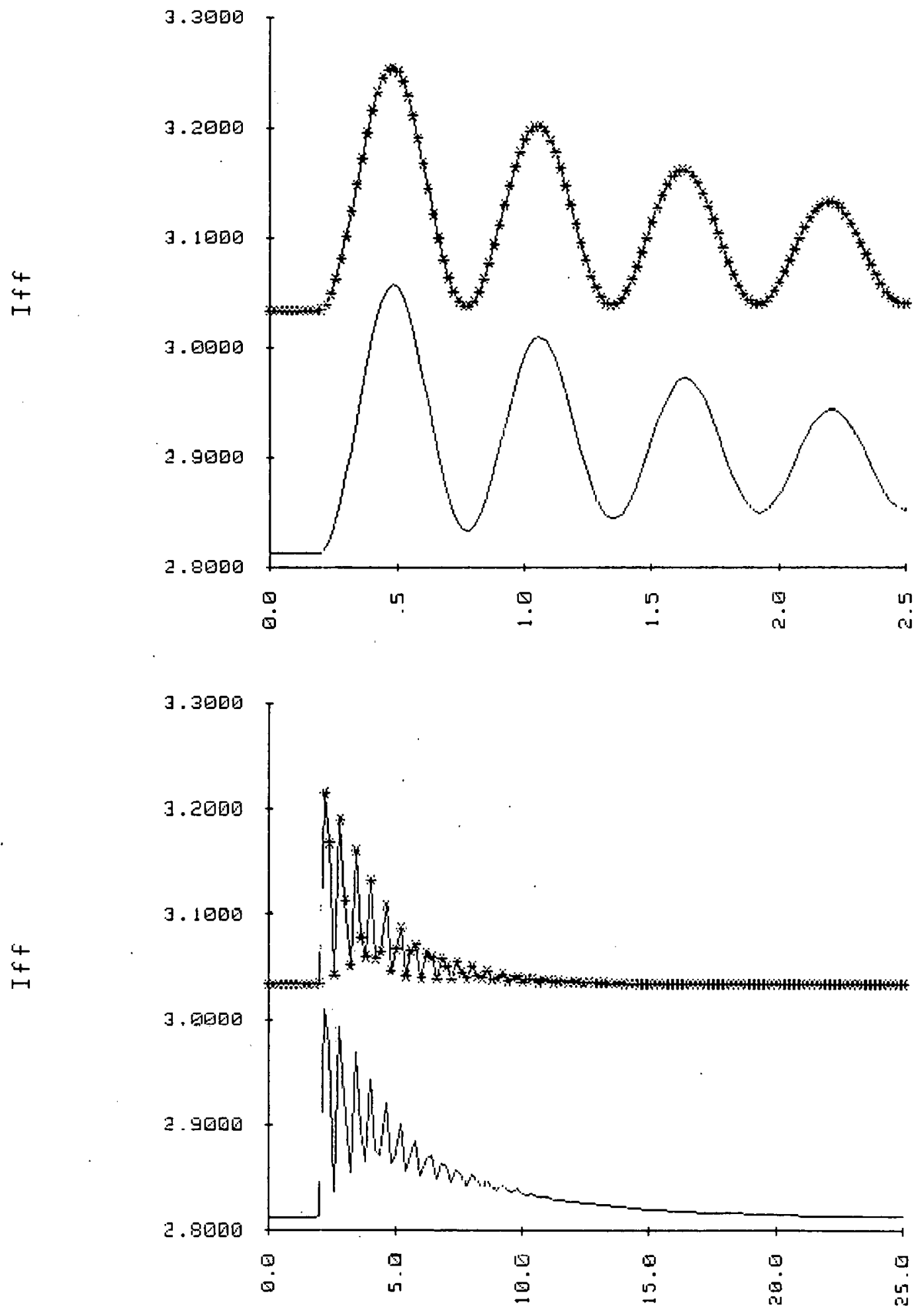

Figure A.14.a $I_{f}$ vs time in seconds, flux 1inkage mode1 (a). step change in $T_{m}$, saturated (*) and unsaturated response 

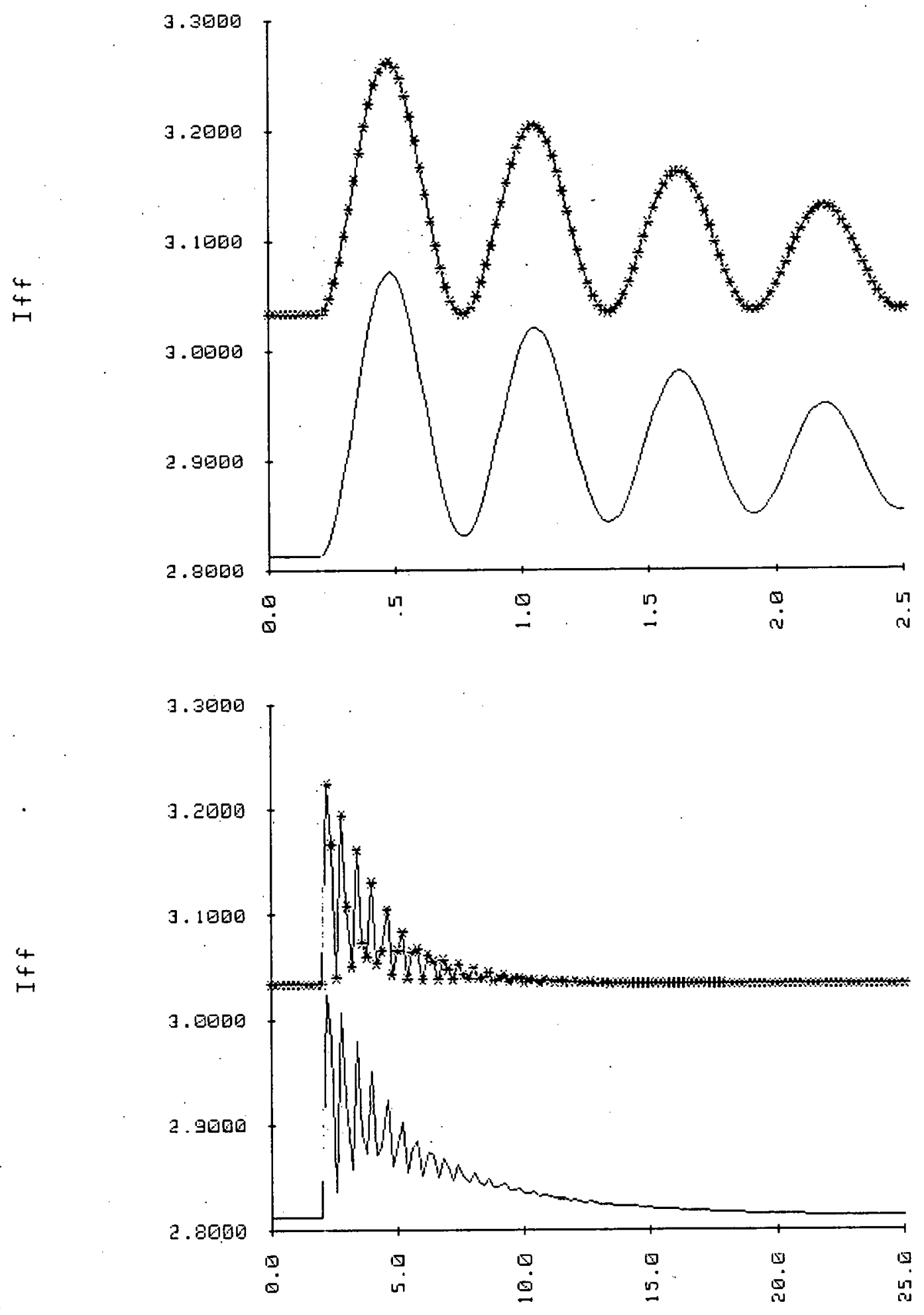

Figure A.14.b $I_{f}$ vs time in seconds, E' model (b), step change in $T_{m}$, saturated (*) and unsaturated response 

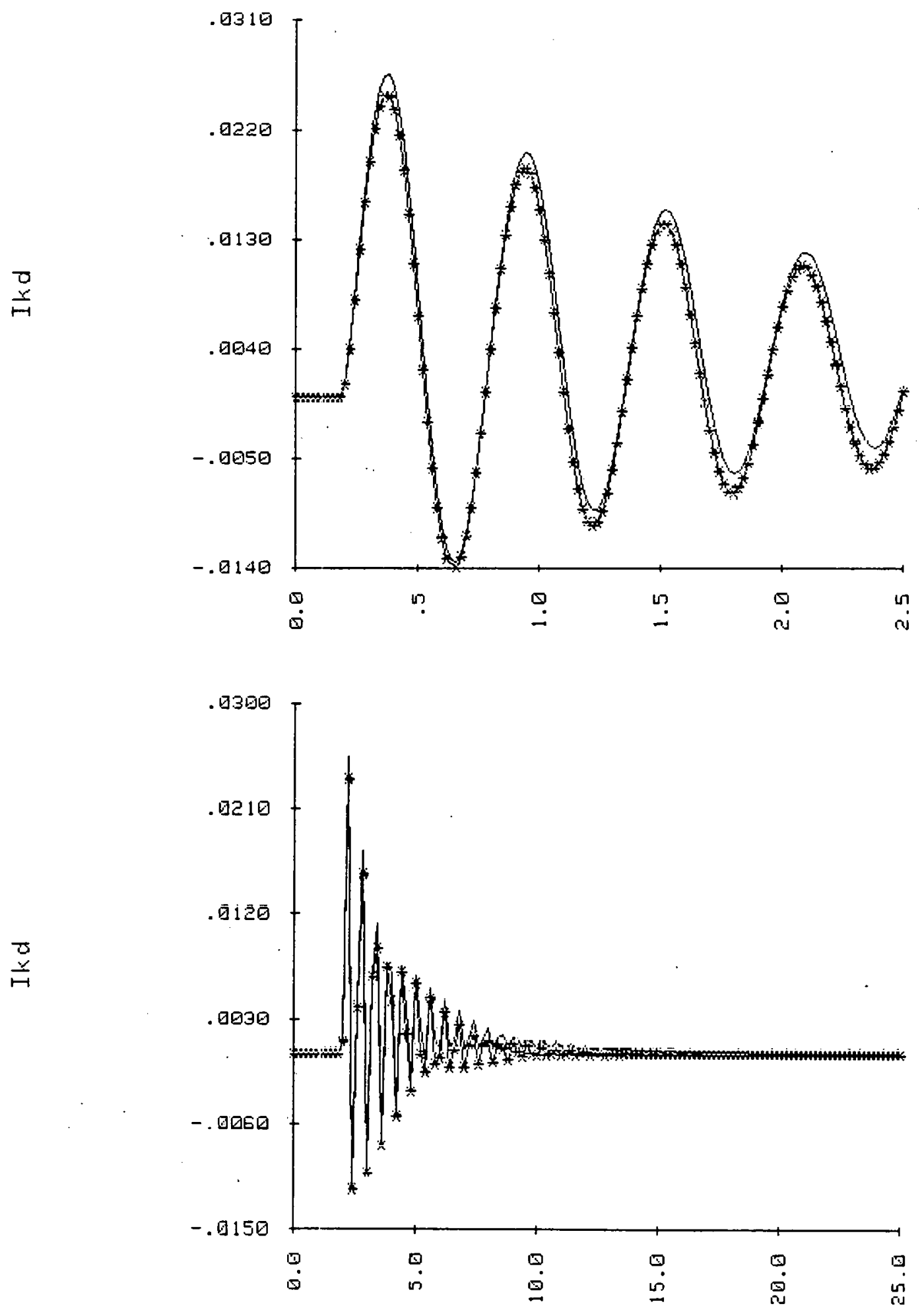

Figure A.15.a $I_{k d}$ vs time in seconds, E'" model (b), step change in $T_{m}$, saturated (*) and unsaturated response 

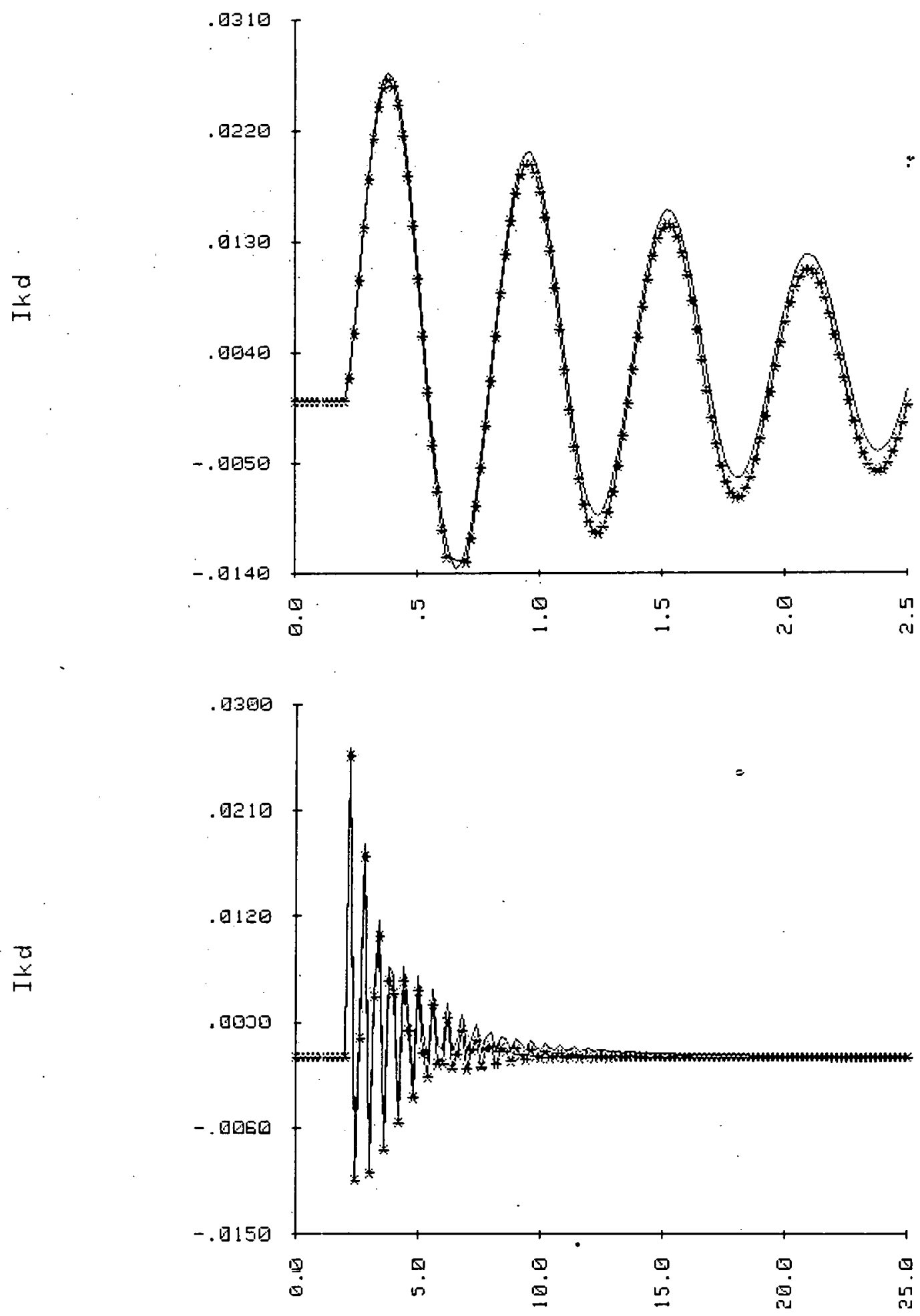

Figure A.15.b $I_{k d}$ vs time in seconds, E' model (b), step change in $T_{m}$, saturated $(*)$ and unsaturated response 

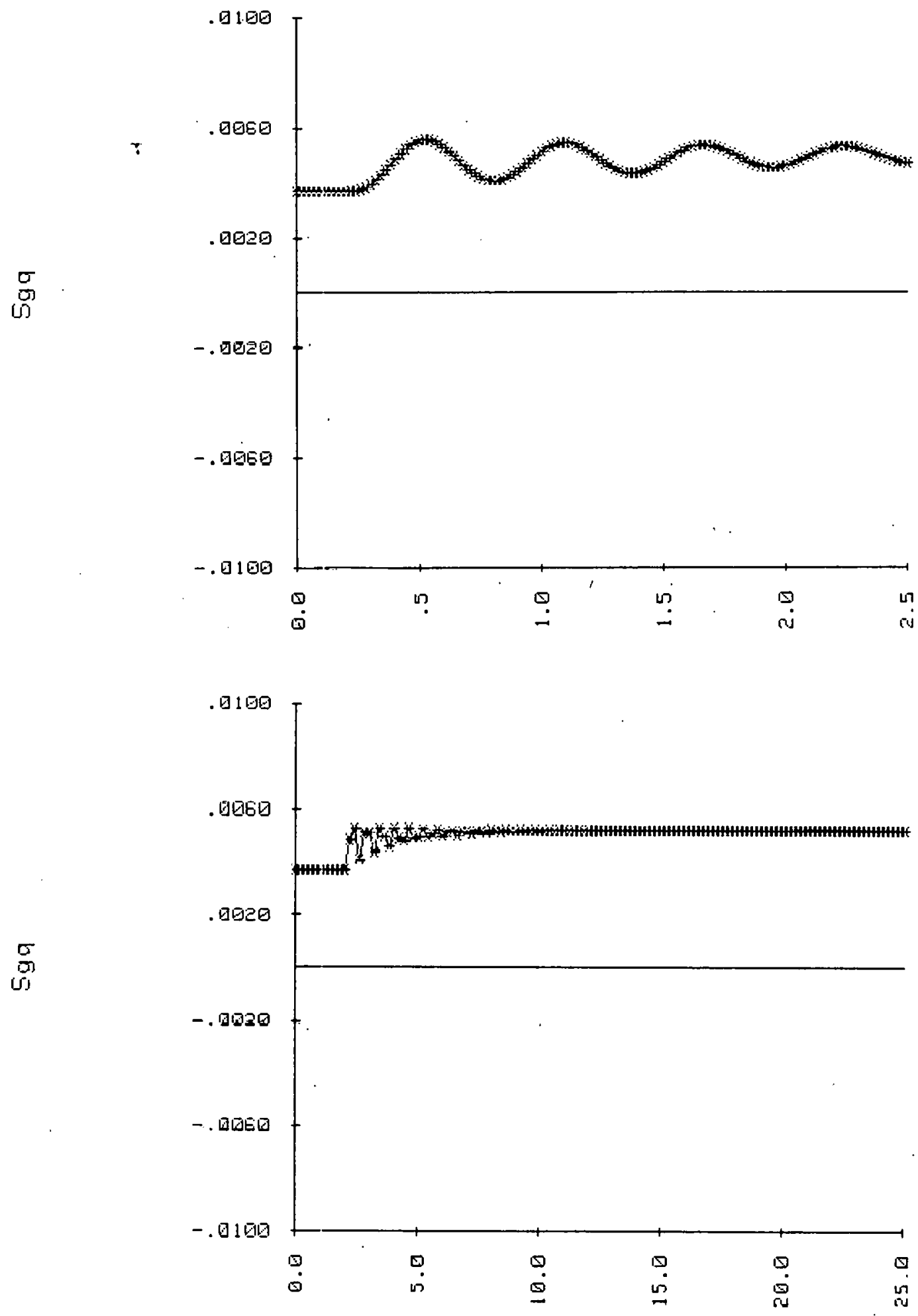

Figure A.16.a $S_{g p}$ vs time in seconds, f1ux linkage model (a), step change in $T_{m}$, saturated $(*)$ and unsaturated response 

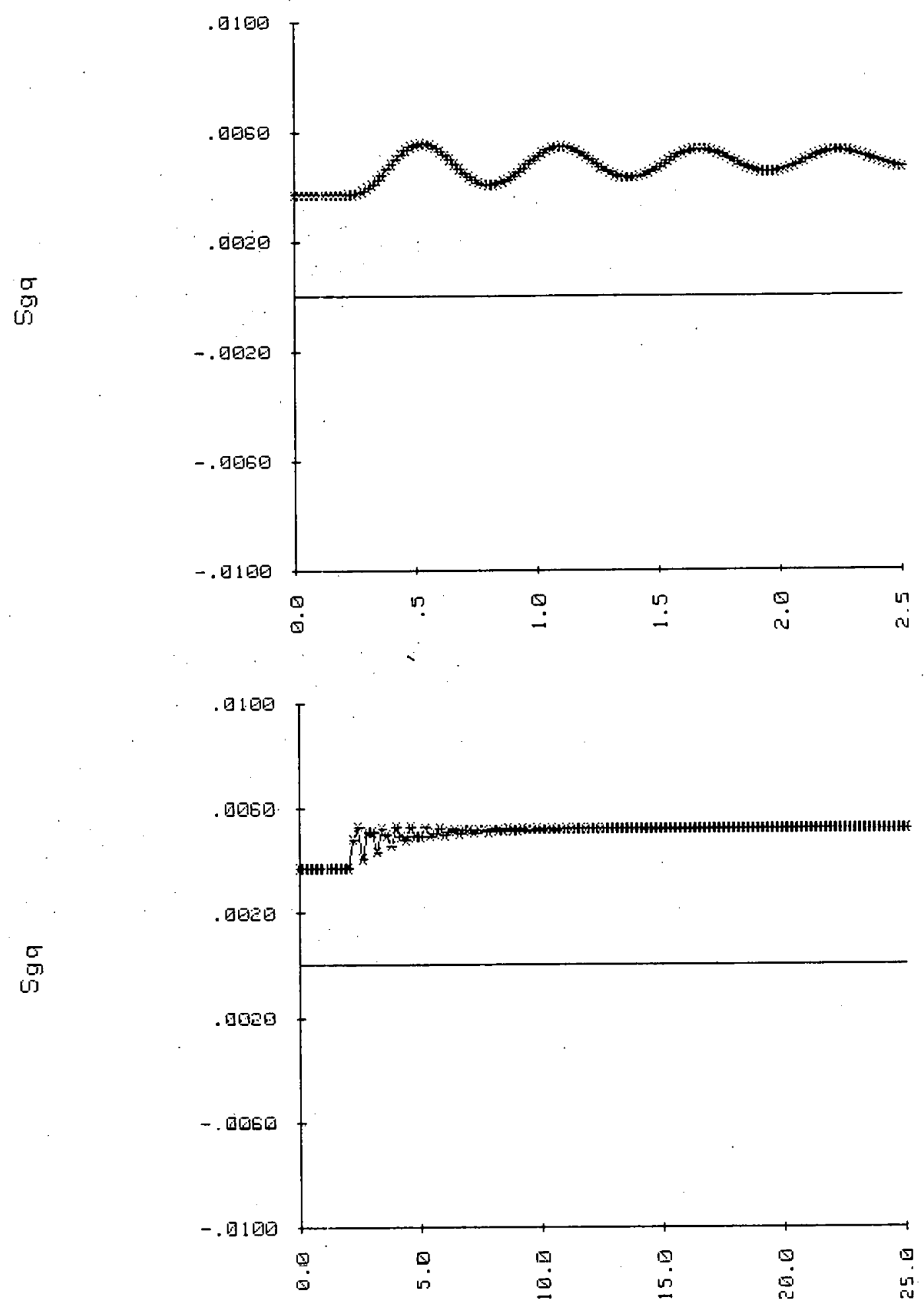

\footnotetext{
Figure A.16.b $S_{g p}$ vs time in seconds, E' model (b), step change in $T_{m}$, saturated $(*)$ and onsaturated response
} 

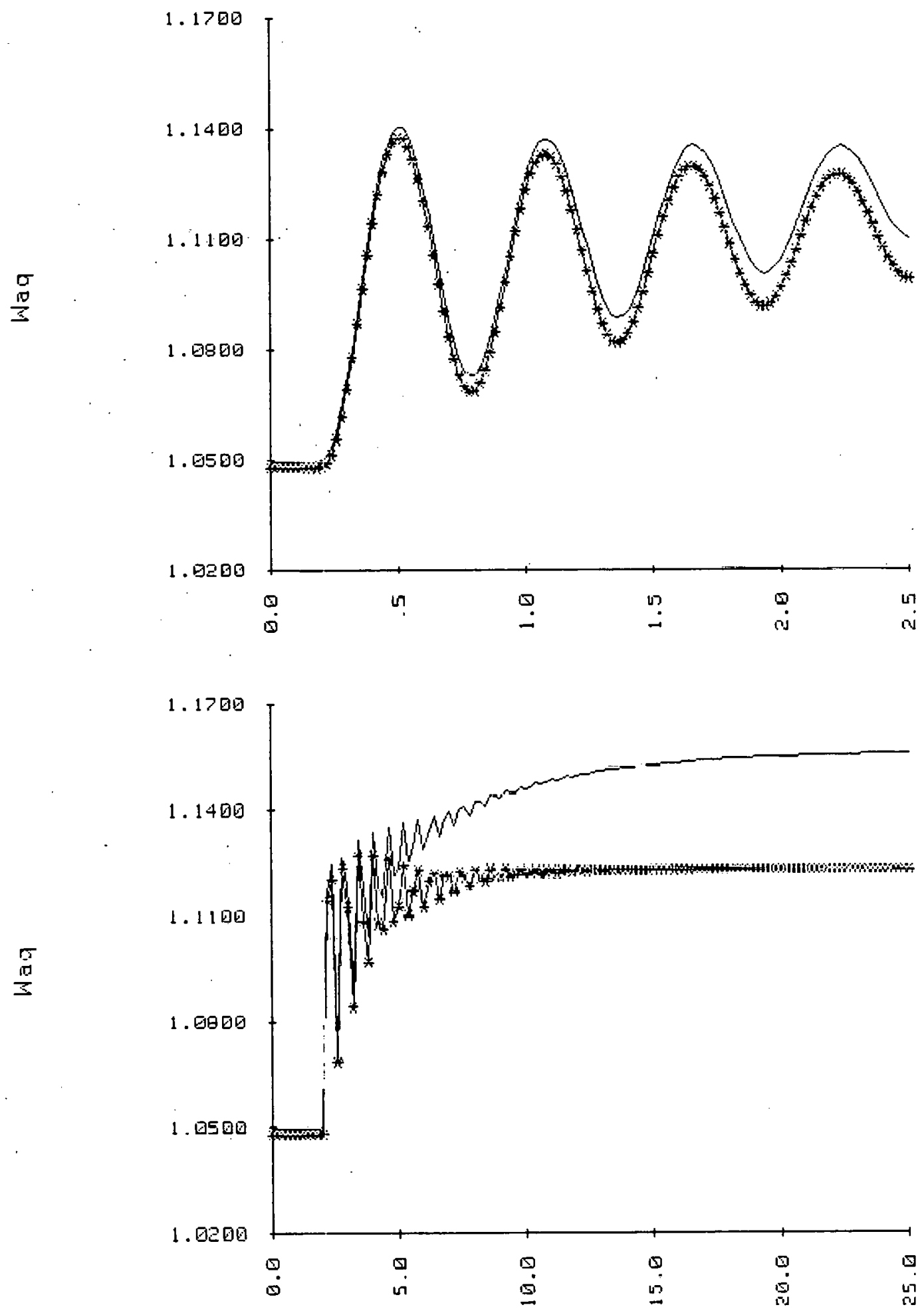

Figure A.17.a $\Psi_{A Q}$ vs time in seconds, flax 1 inkage model (a), step change in $T_{m}$, saturated (*) and unsaturated response 

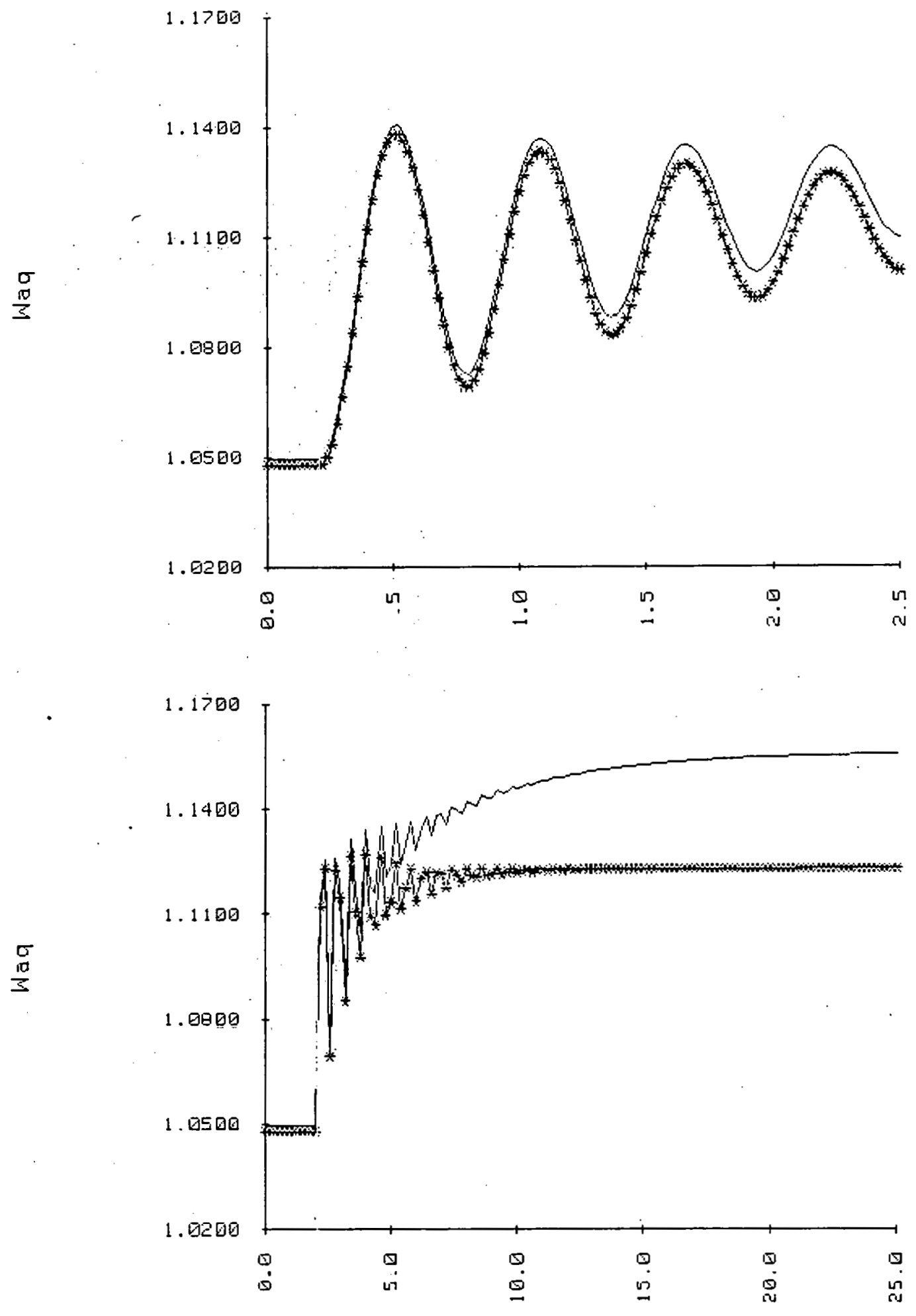

Figure A.17.b $\psi_{A Q}$ vs time in seconds, E' model (b), step change in $T_{m}$, saturated (f*) and ansaturated response 

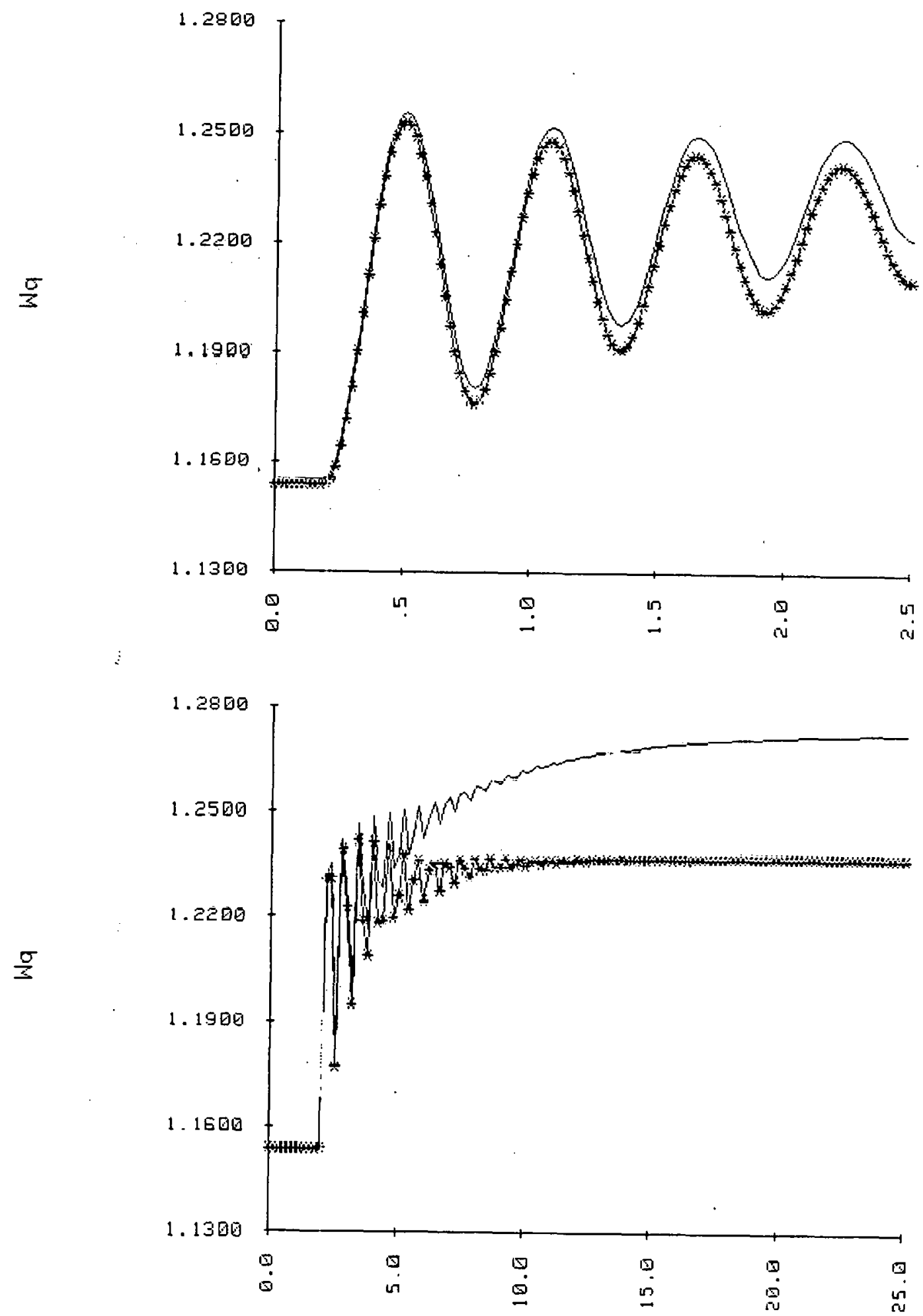

Figure A.18.a $\psi_{q}$ vs time in seconds, f1ux 1inkage model (a). step change in $T_{m}$, saturated (*) and unsaturated response 

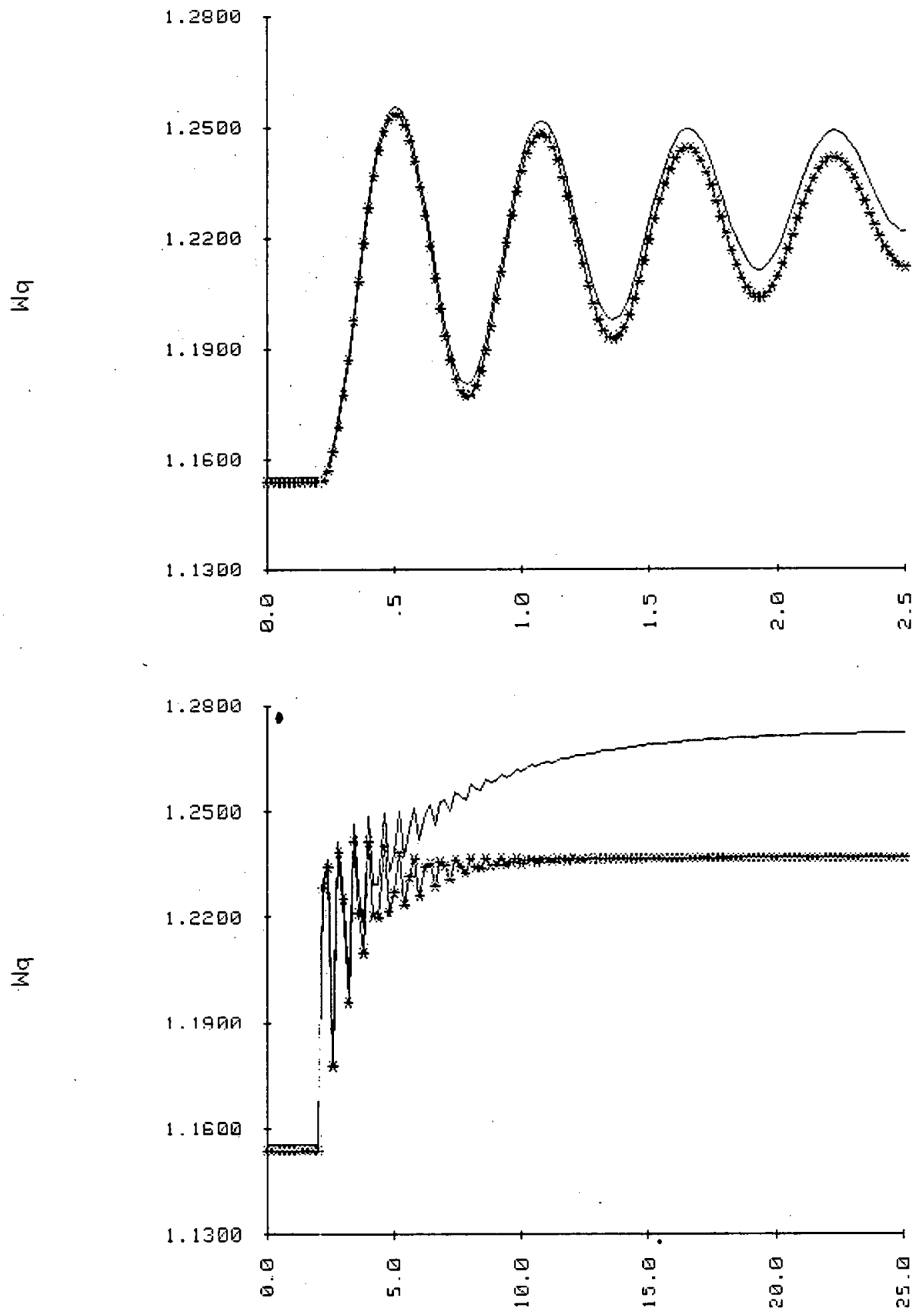

Figure A.18.b $\psi_{q}$ vs time in seconds, E' model (b), step change in $T_{m}$, saturated (*) and unsaturated response 

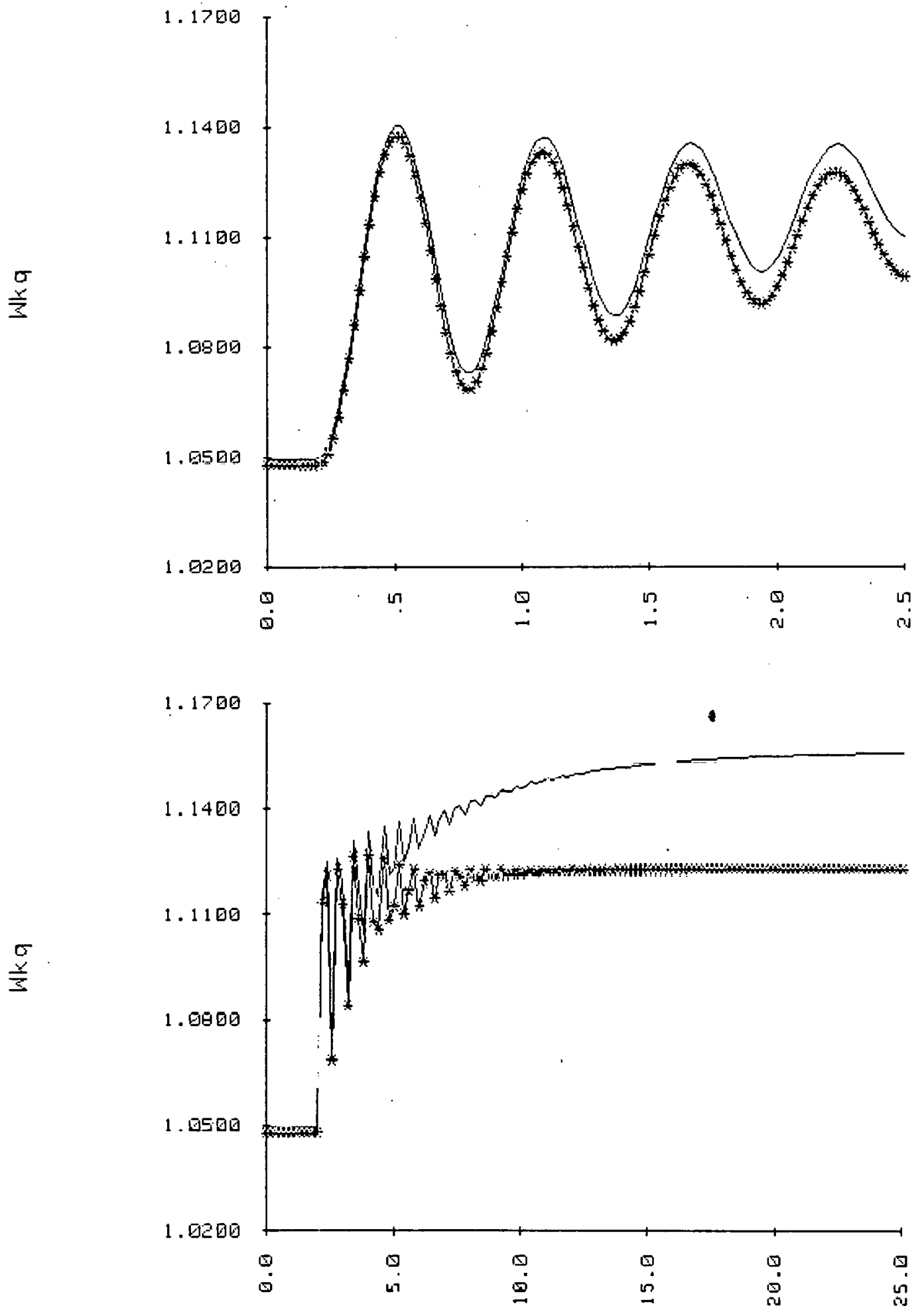

Figare A.19.a $\psi_{\mathrm{kq}}$ vs time in seconds, flux linkage model (a), step change in $T_{m}$, saturated (*) and unsaturated response 

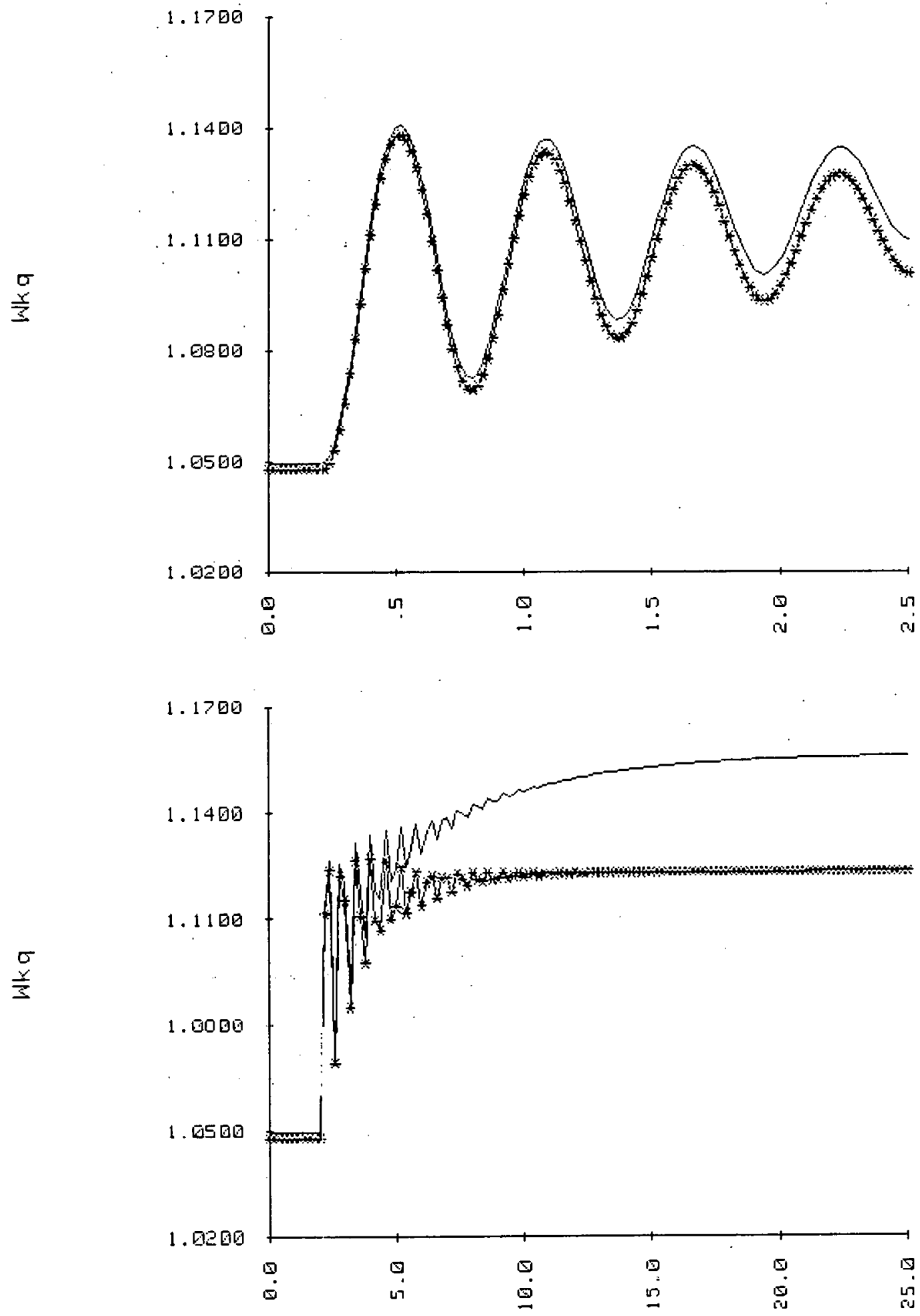

Figure A.19.b kq vs time in seconds, E'" model (b). step change in $T_{m}$, satarated (*) and unsaturated response 

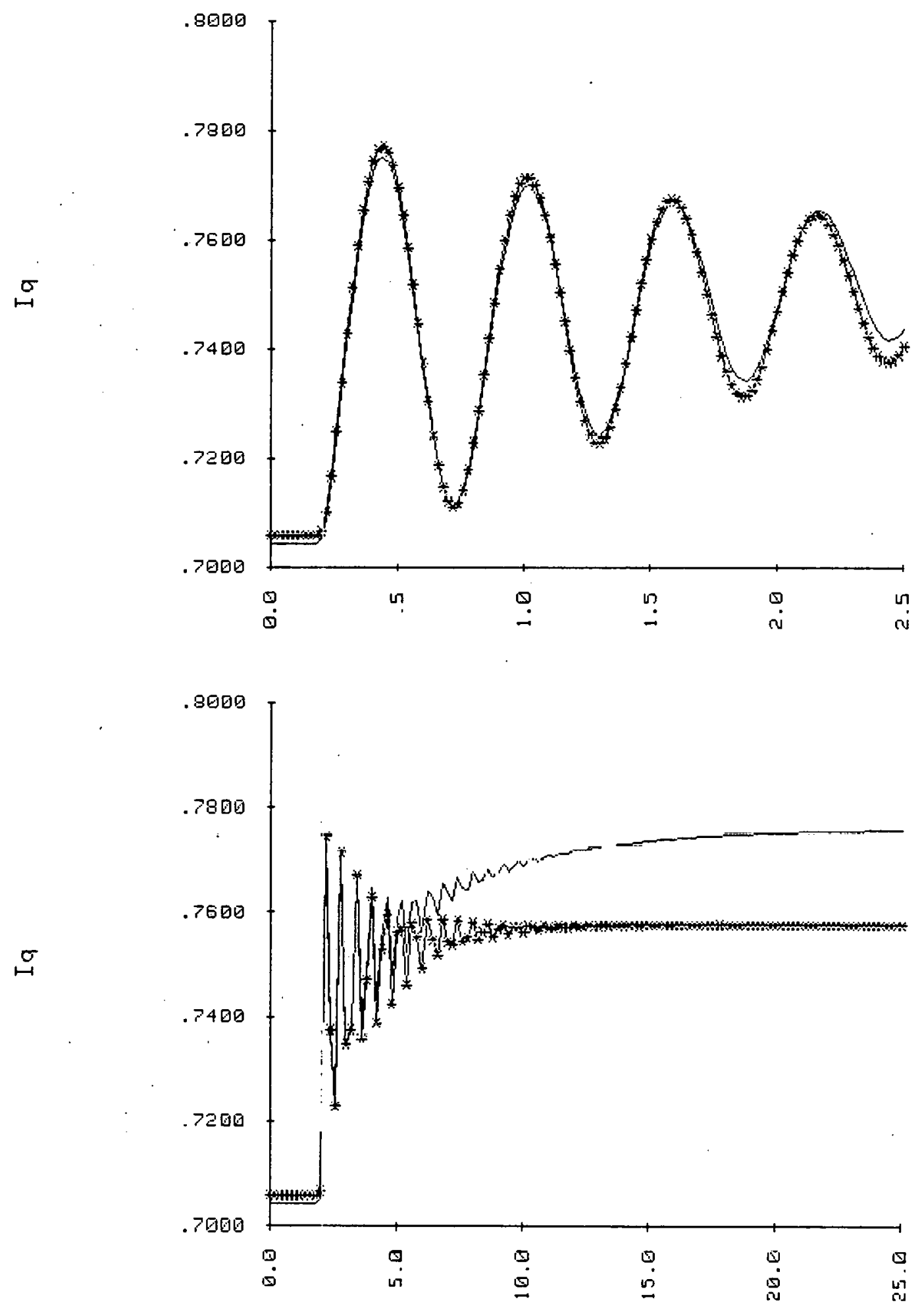

Figure A.20.a $I_{q}$ vs time in seconds, f1ax linkage model (a), step change in $T_{m}$, saturated (*) and unsaturated response 

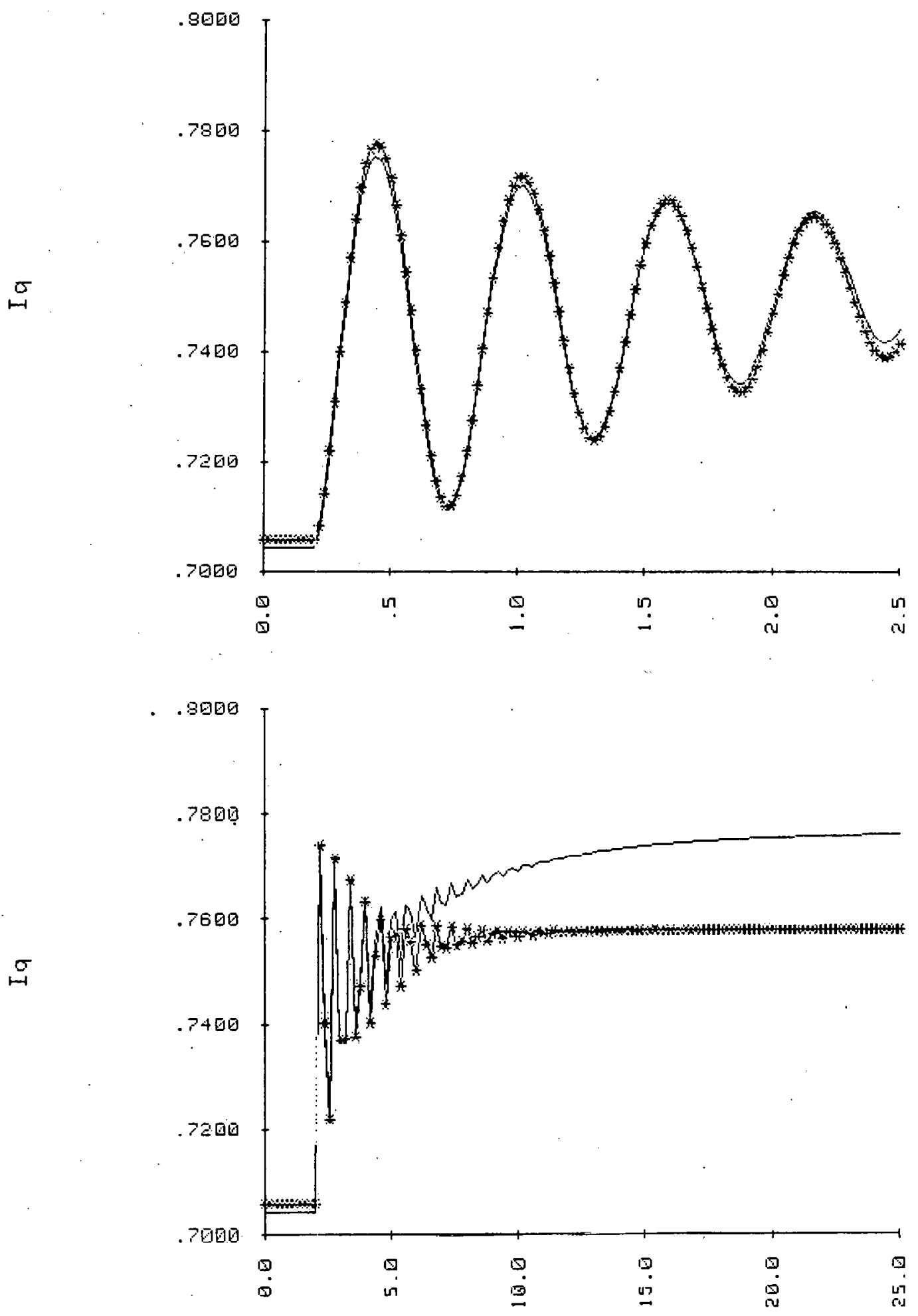

Figure A.20.b $I_{q}$ vs time in seconds, E" model (b), step change in $T_{m}$, saturated (*) and unsaturated response 

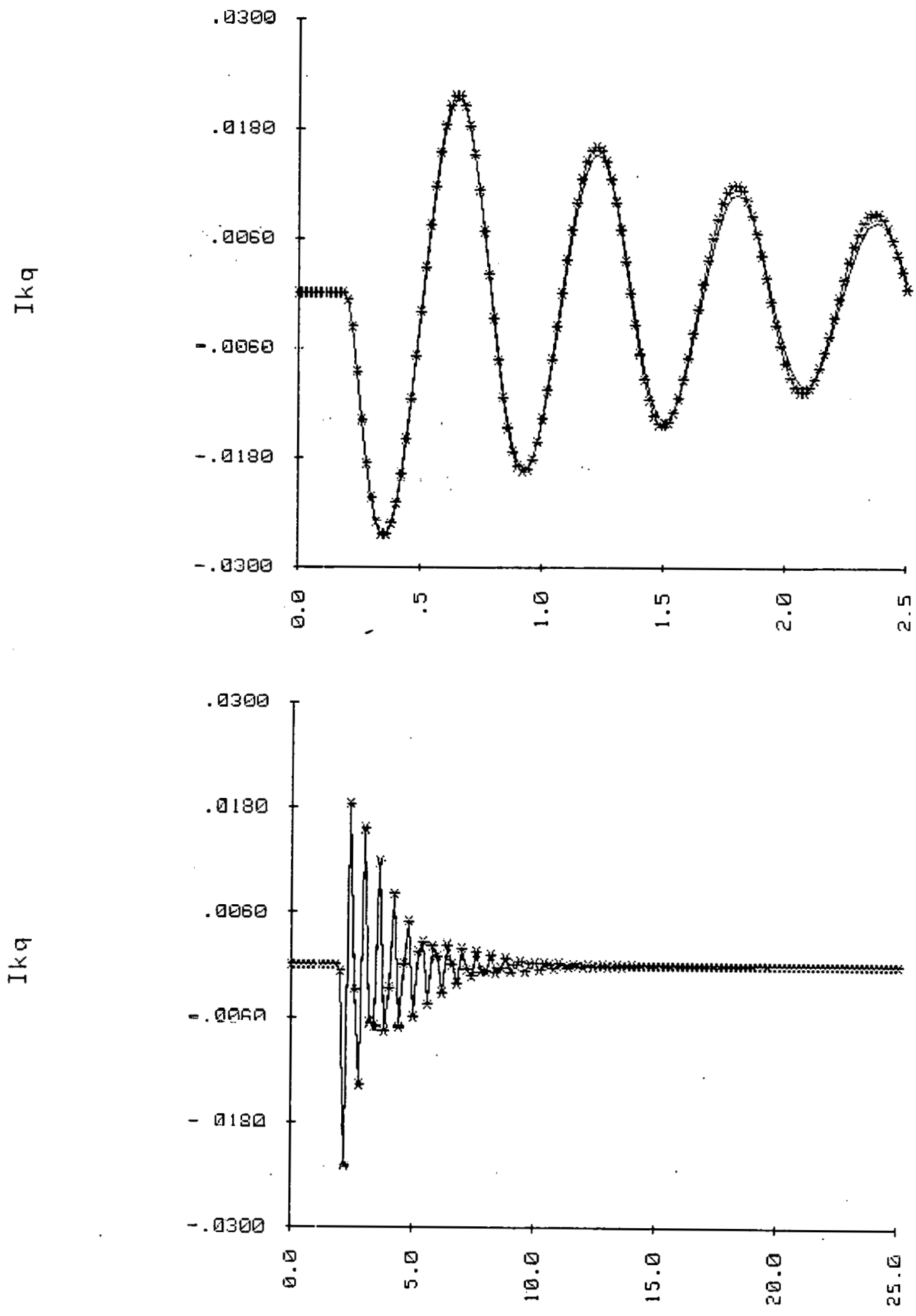

Figare A.21.a $I_{k q}$ vs time in seconds, flux 1inkage mode1 (a), stop change in $T_{m}$, saturated $(*)$ and unsaturated response 

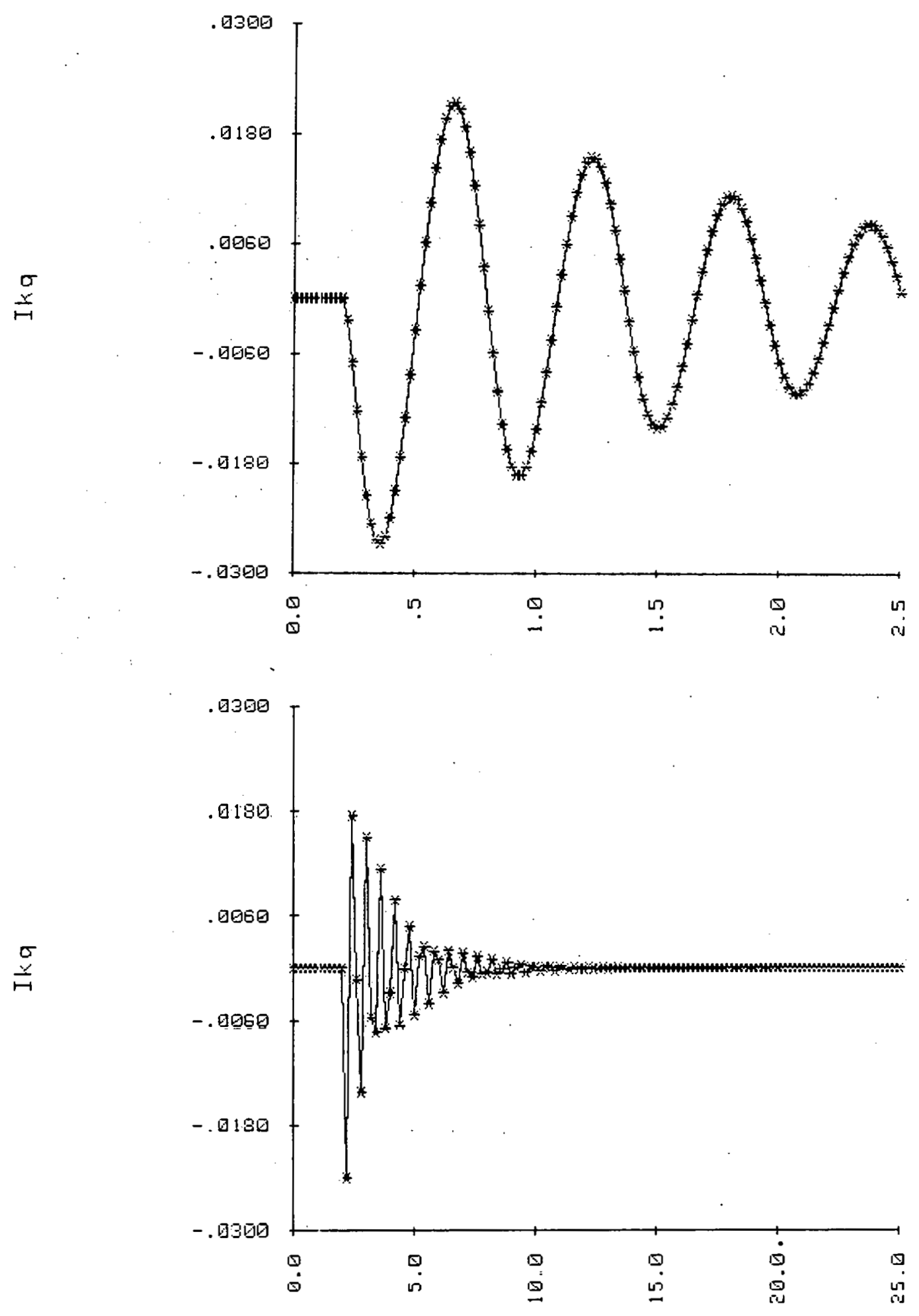

Figure A.21.b $I_{k q}$ vs time in seconds, E' mode1 (b), step change in $T_{m}$, saturated (*) and unsaturated response 


\section{THIS PAGE \\ WAS INTENTIONALLY \\ LEFT BLANK}




\section{APPENDIX B}

\section{Simulation Results with Complete Saturation}

for a

5\% Step Change in $\mathrm{E}_{\mathrm{FD}}$ 

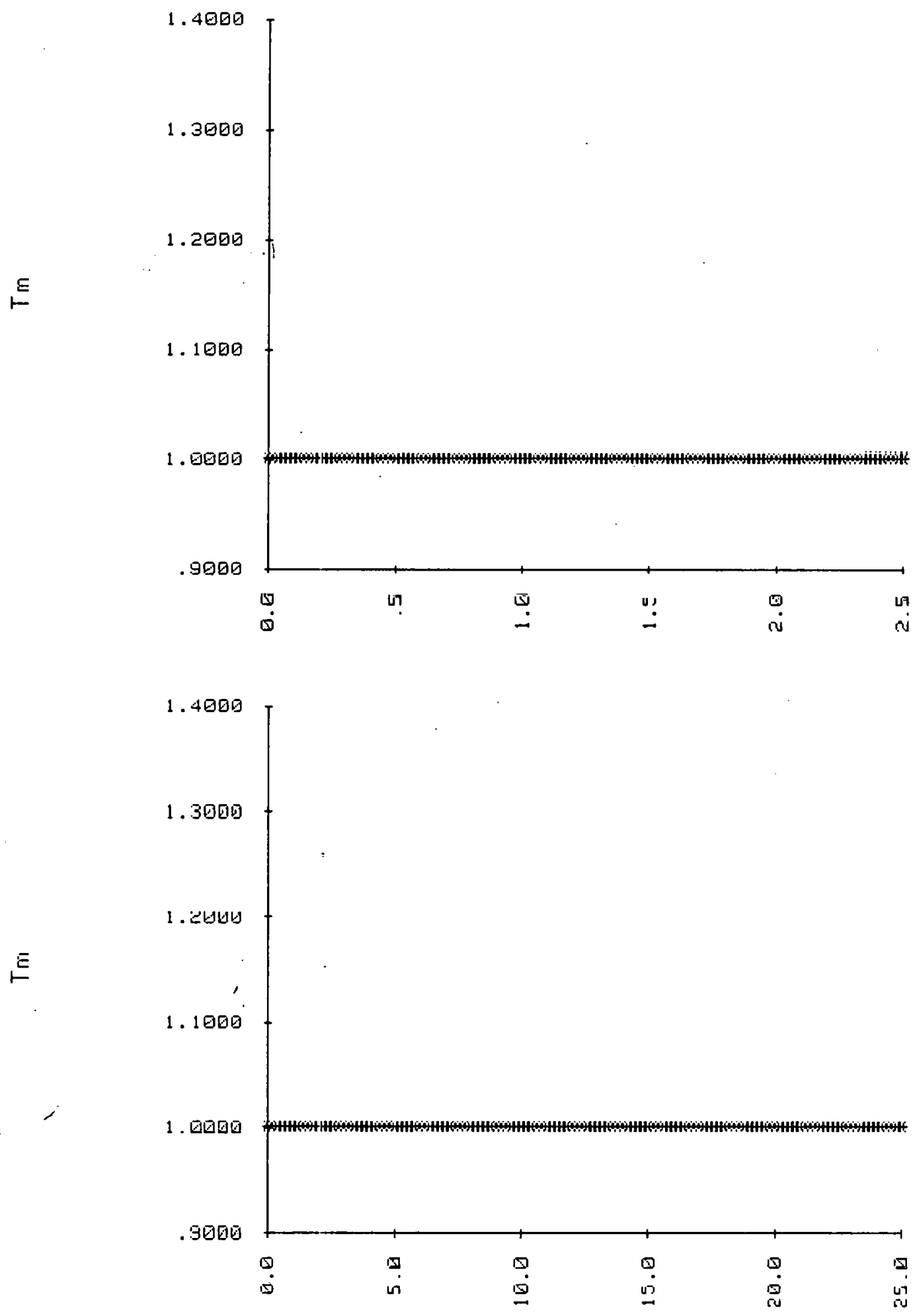

Figure B.1.a $T_{m}$ vs time in seconds, flux 1inkage model (a). step change in EFD, saturated (*) and unsaturated response 

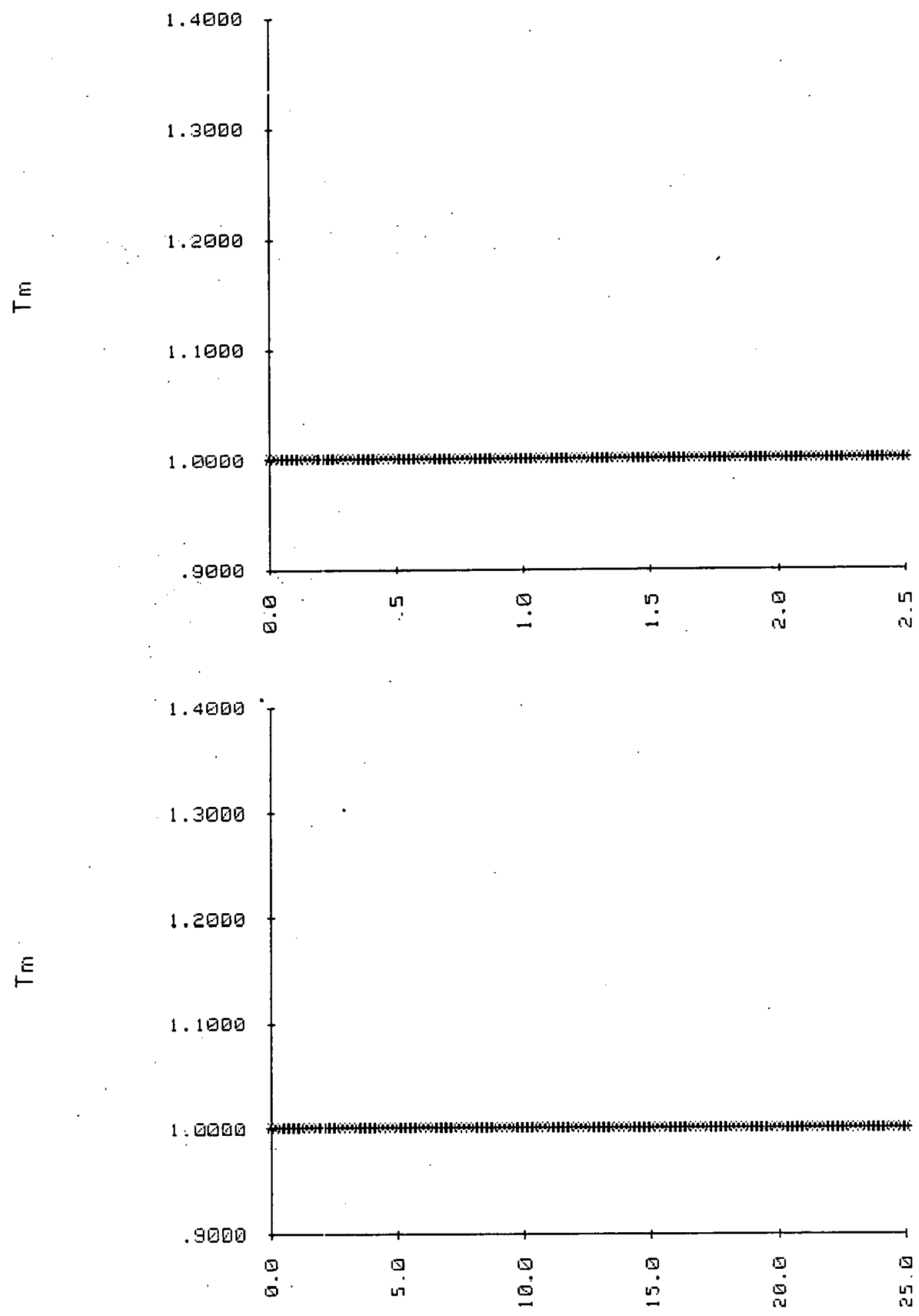

Figure B.1.b $T_{m}$ vs time in seconds, $E^{\prime \prime} \operatorname{model}(b)$, step change in EFD, saturated (*) and unsaturated response 

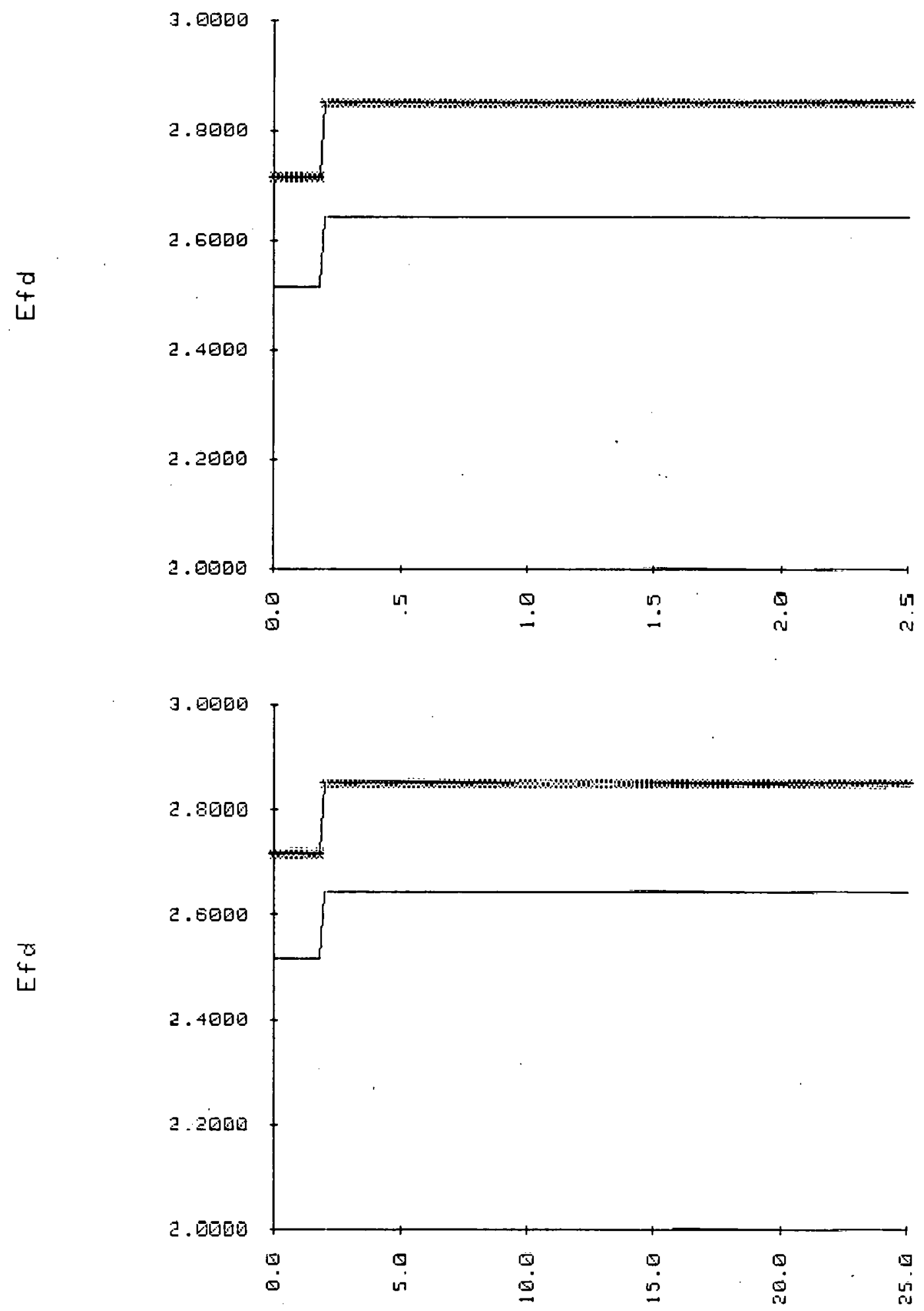

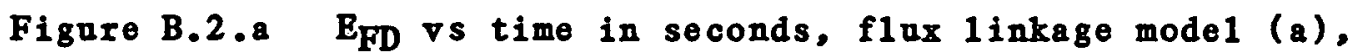
step change in EFD, saturated (*) and unsaturated response 

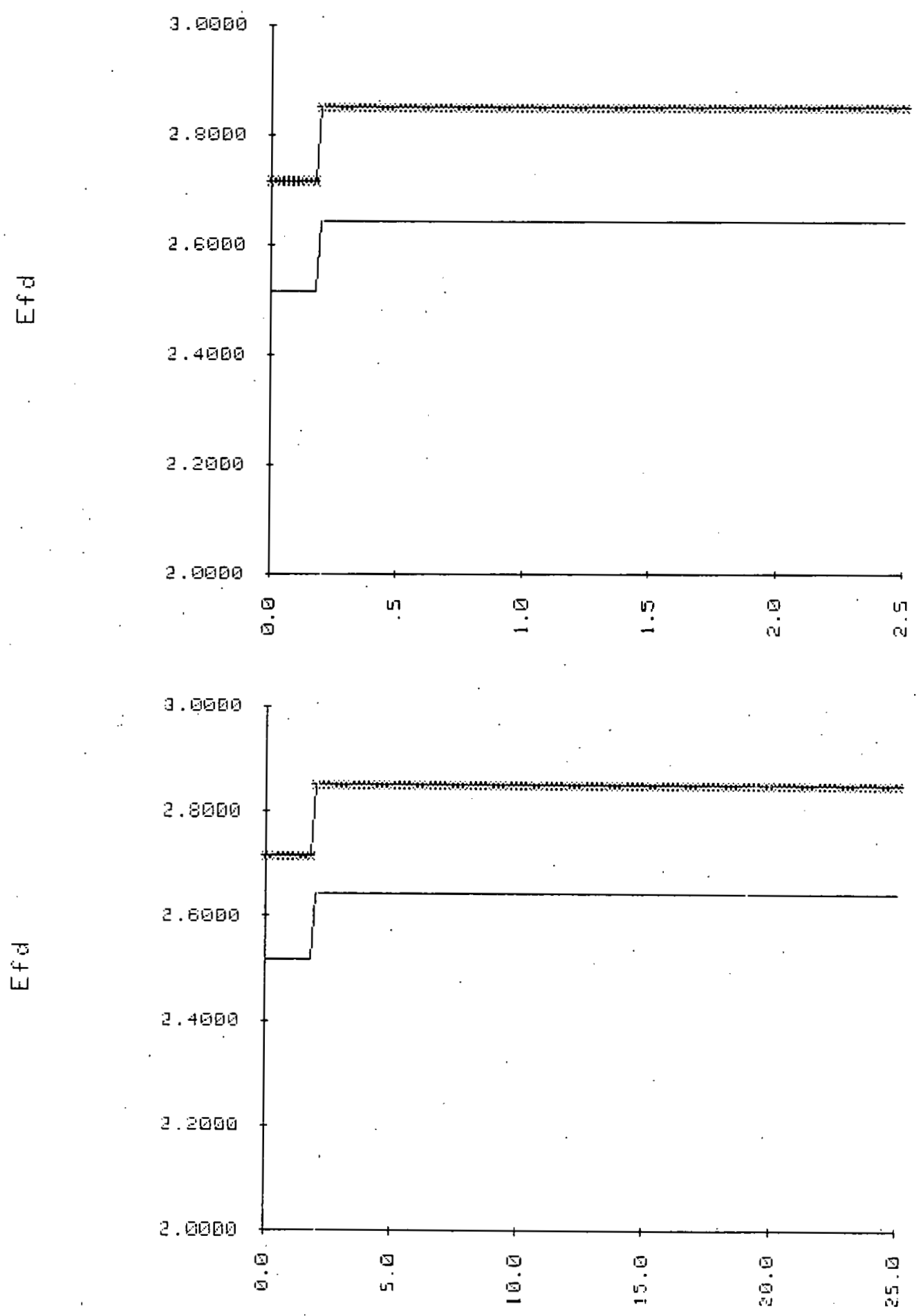

Figure B.2.b E ED vs time in seconds, E' mode1 (b), step change in EFD, saturated (*) and unsaturated response 

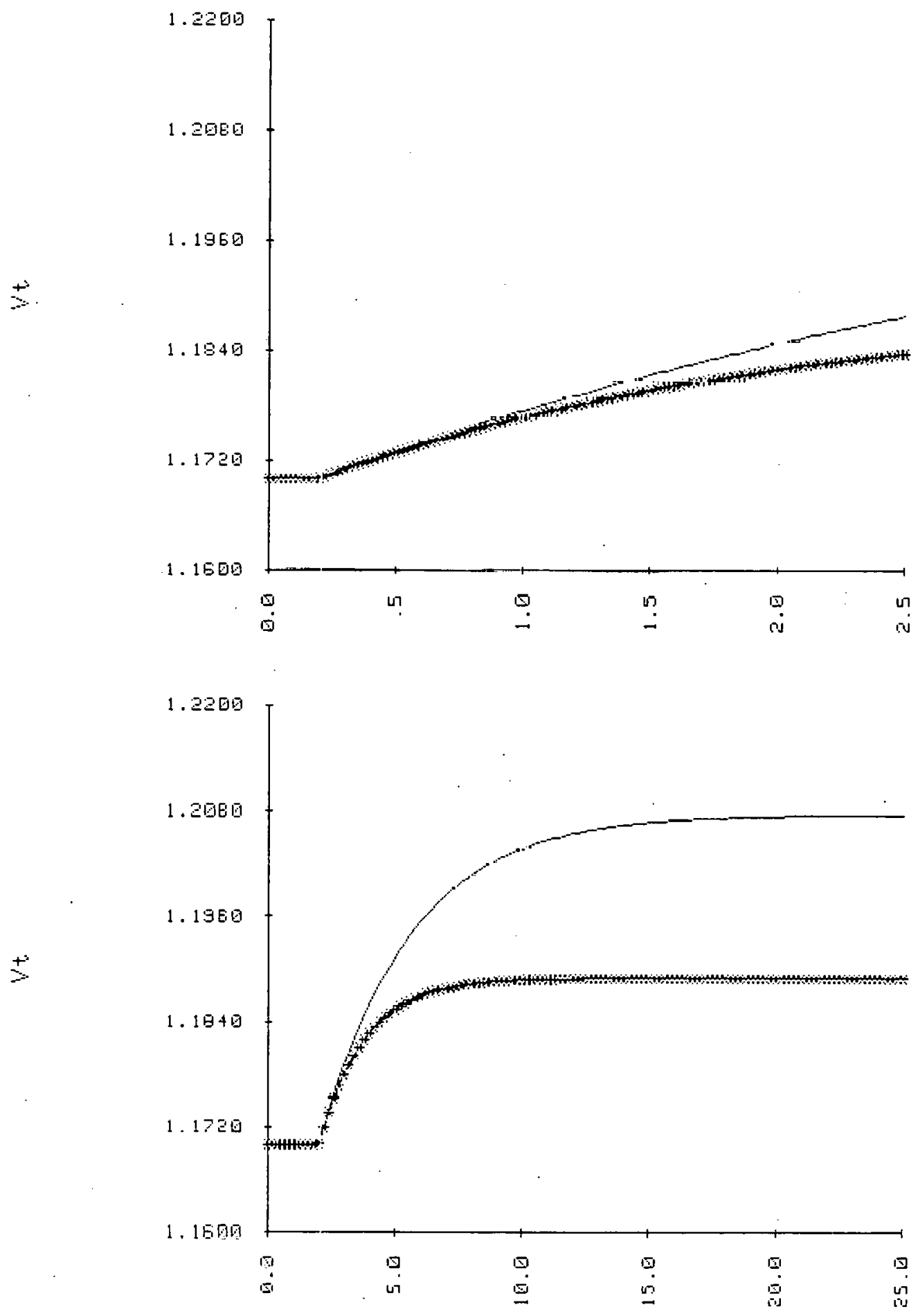

Figure B.3.a $V_{t}$ vs time in seconds, flux linkage model (a), step change in EFD, saturated (*) and unsaturated response 

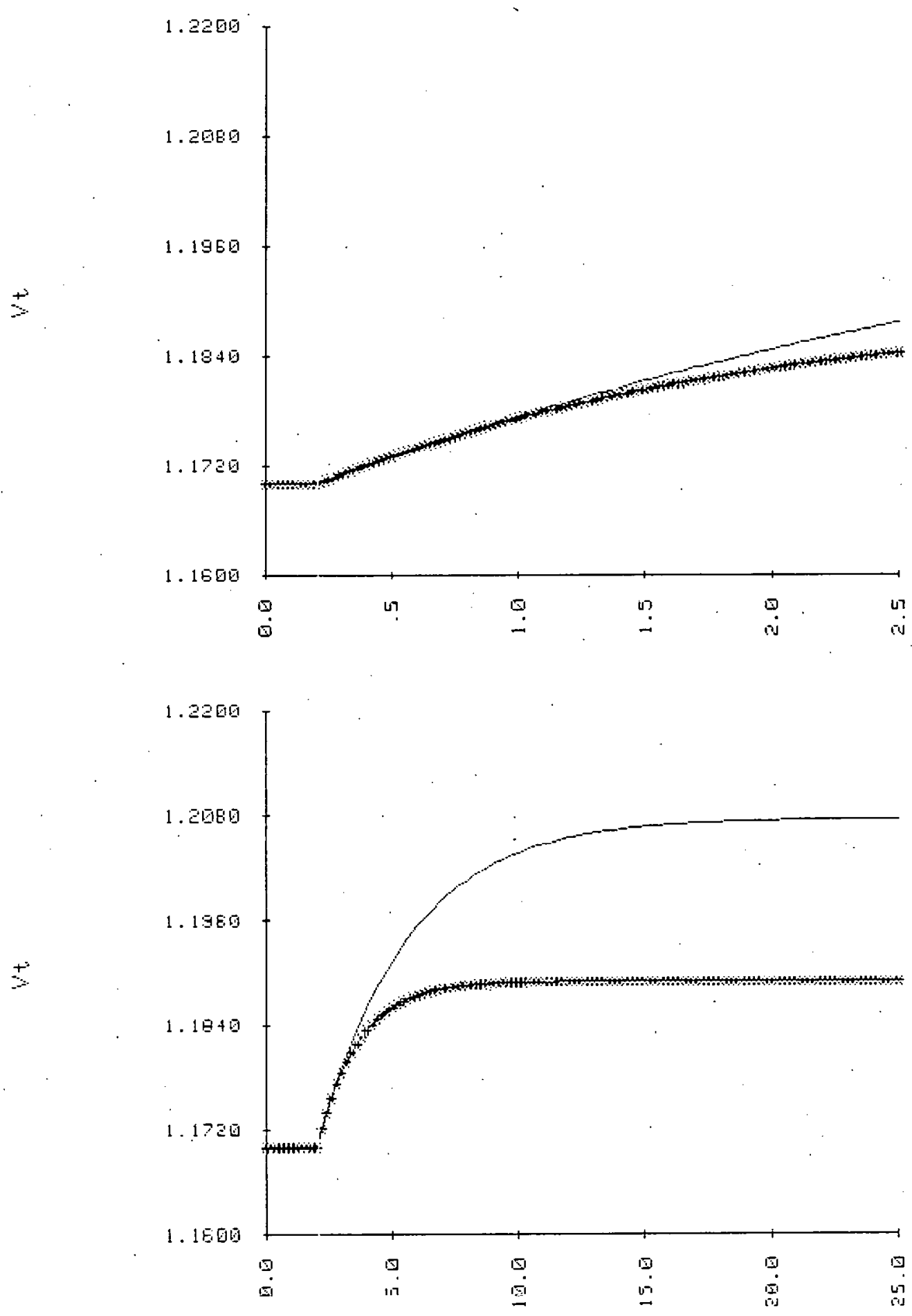

Figure B.3.b $V_{t}$ vs time in seconds, E'" mode1 (b), step change in EFD, saturated $(*)$ and unsaturated response 

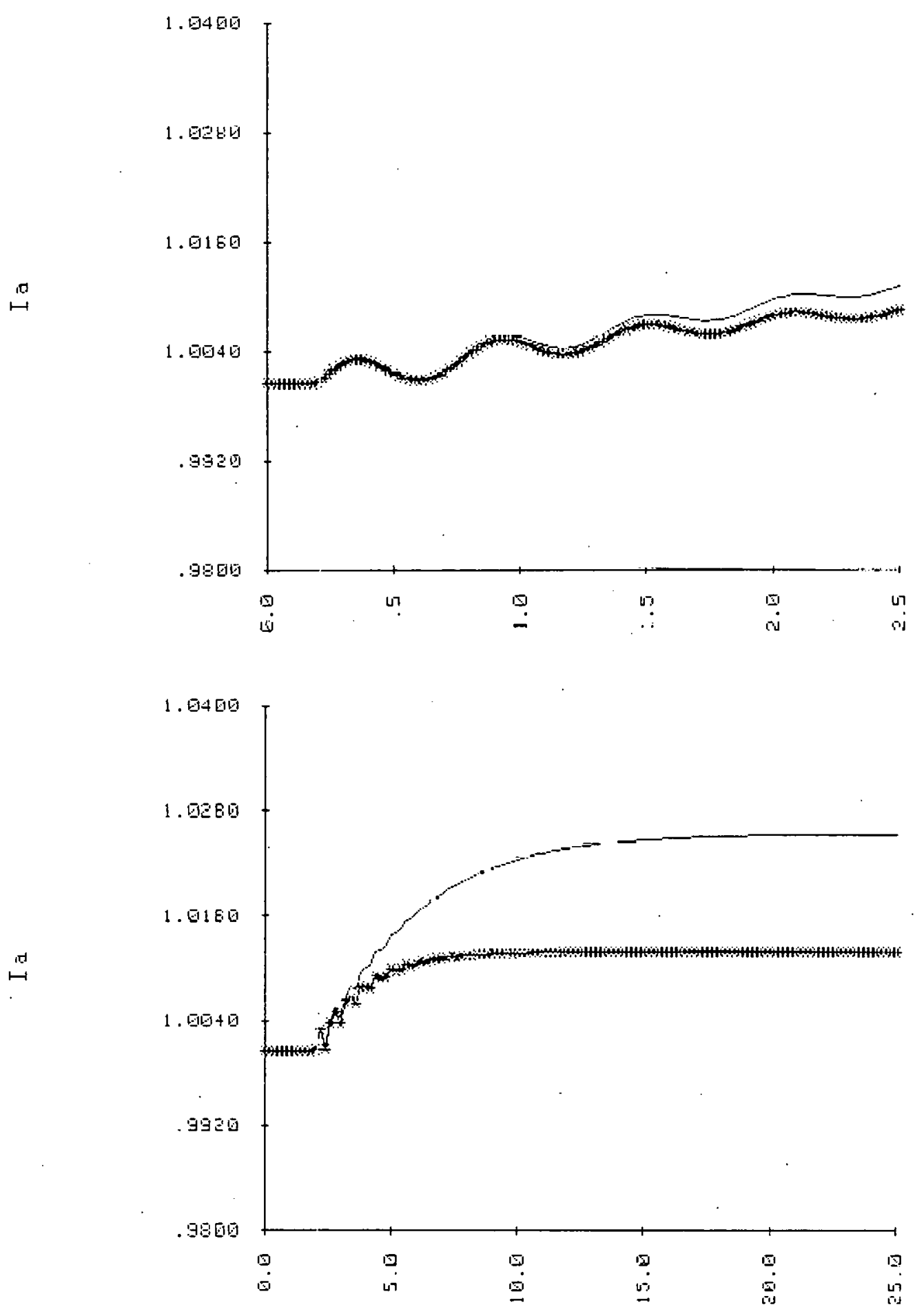

Figure B.4.a $I_{a}$ vs time in seconds, flux linkage mode1 (a), step change in EFD, saturated (*) and unsaturated response 

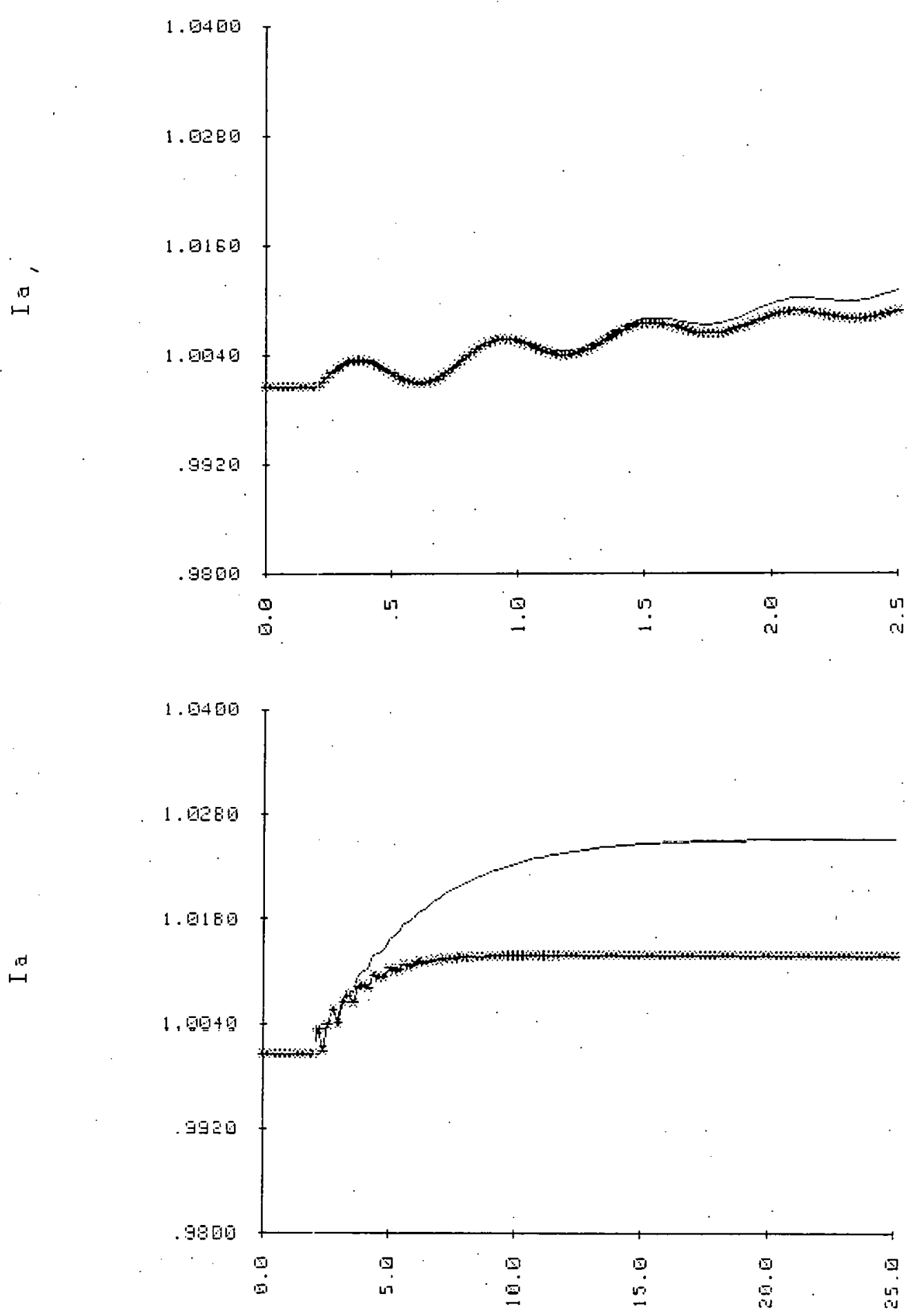

Figure B.4.b $I_{a}$ vs time in seconds, E' mode1 (b), step change in EFD, saturated (*) and unsaturated response 

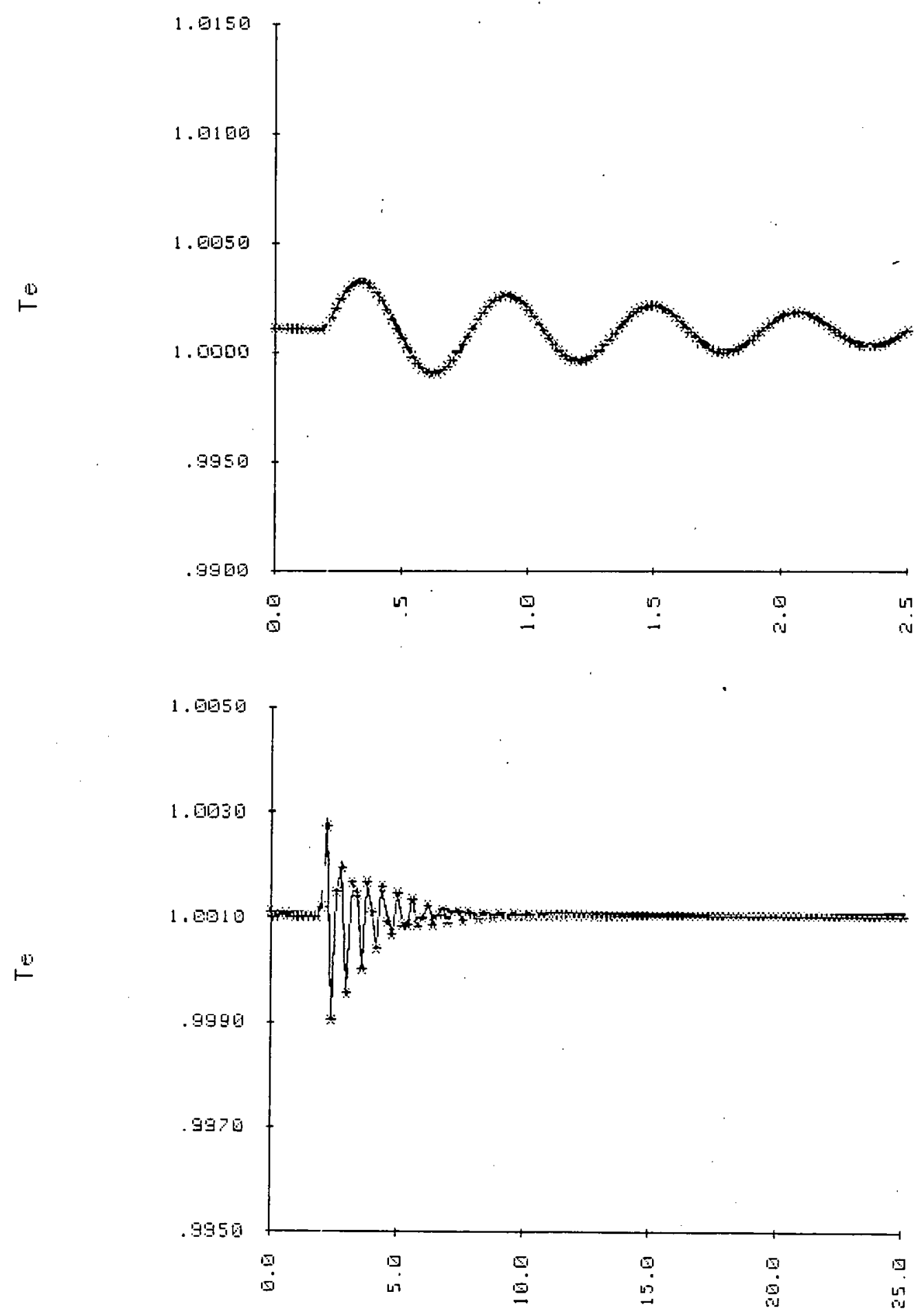

Figure B.5.a $T_{e}$ vs time in seconds, flux linkage model (a), step change in EFD, saturated (*) and unsaturated response 

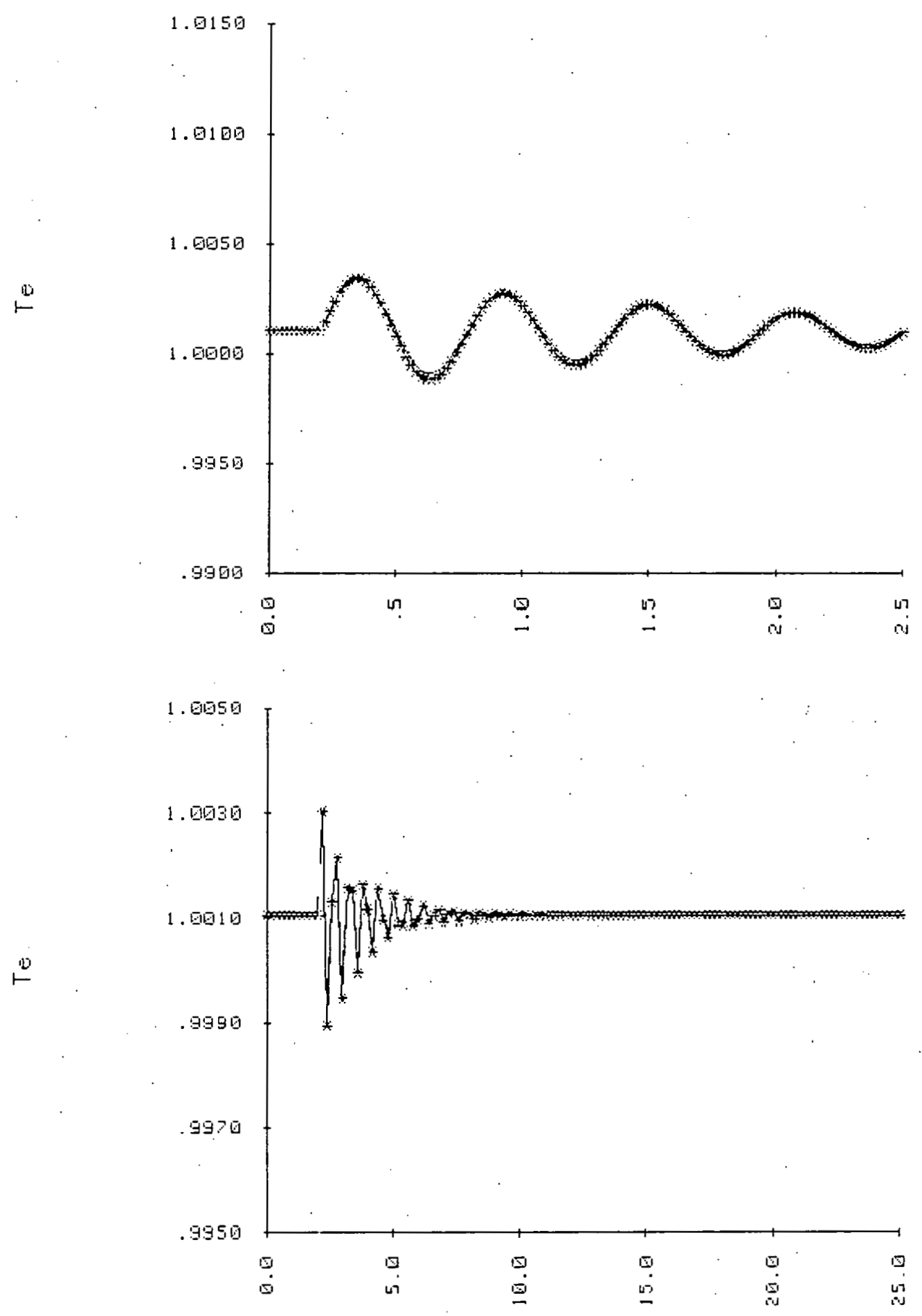

Figure B.5.b $T_{e} v s$ time in seconds, E' mode1 (b), step change in EFD, saturated (*) and unsaturated response 

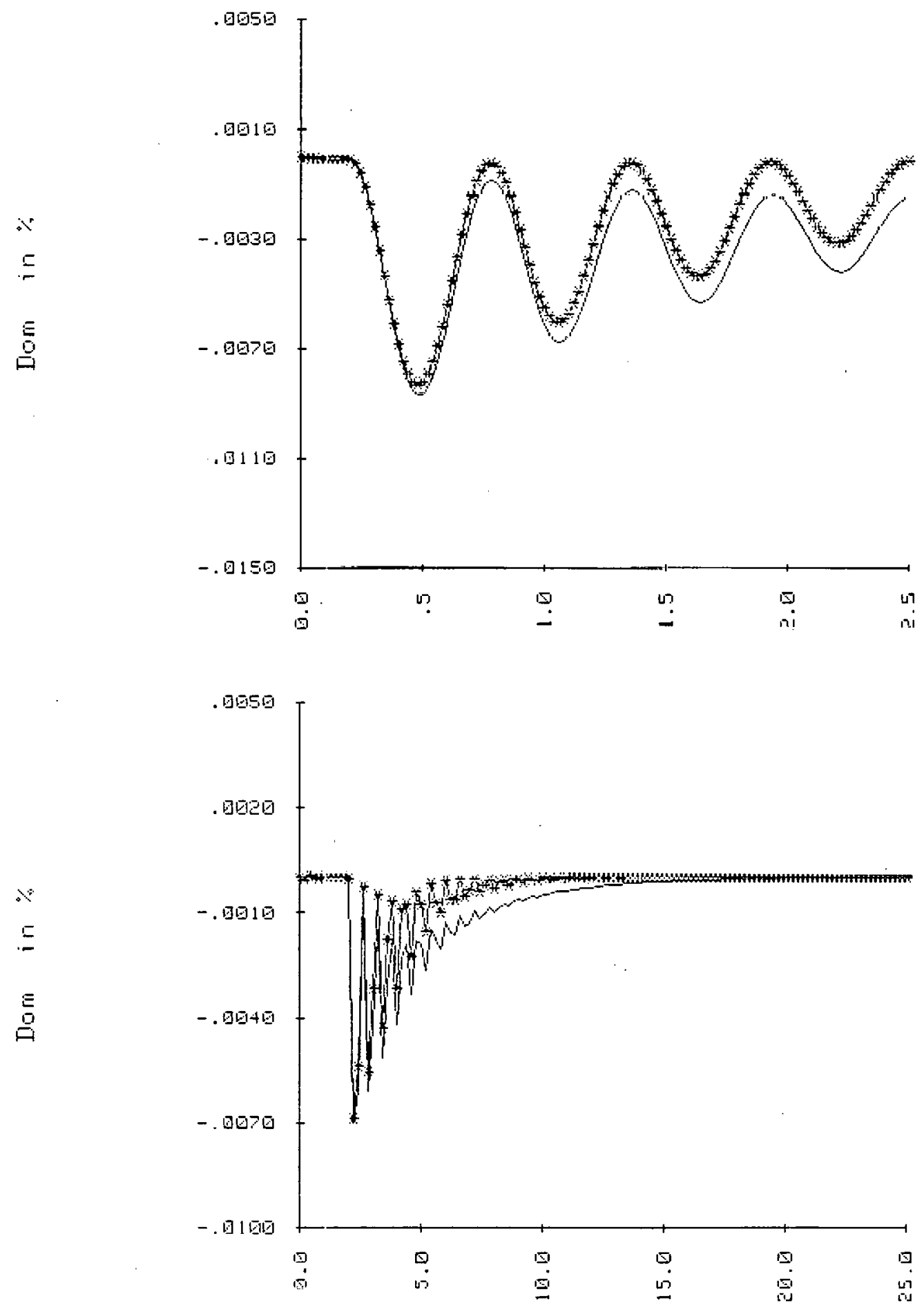

Figure B.6.a $\Delta w$ vs time in seconds, flux linkage model (a), step change in EFD, saturated $(*)$ and unsaturated response 

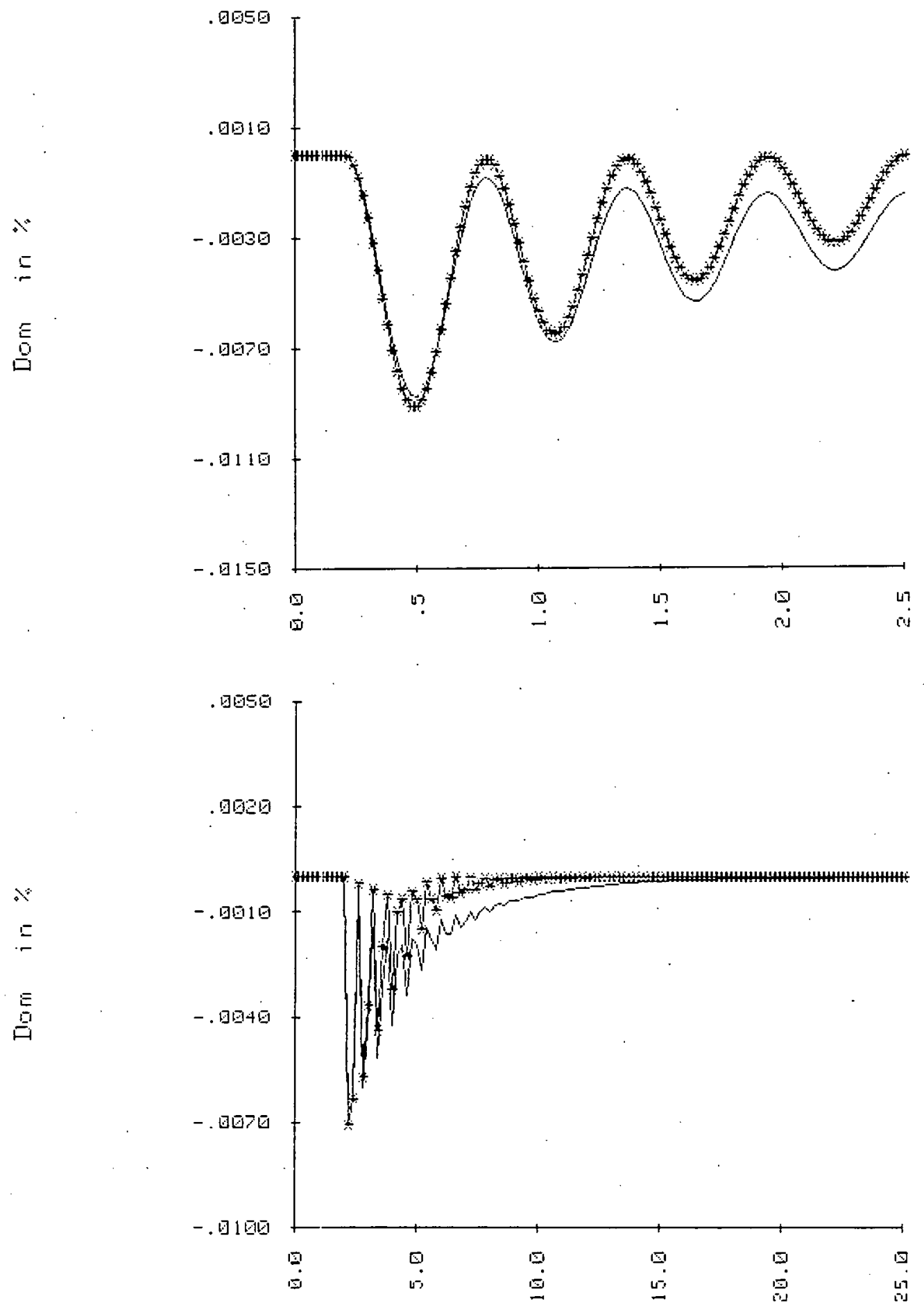

Figure B.6.b $\Delta \omega$ vs time in seconds, E' mode1 (b), step change in EFD, saturated (*) and unsaturated response 

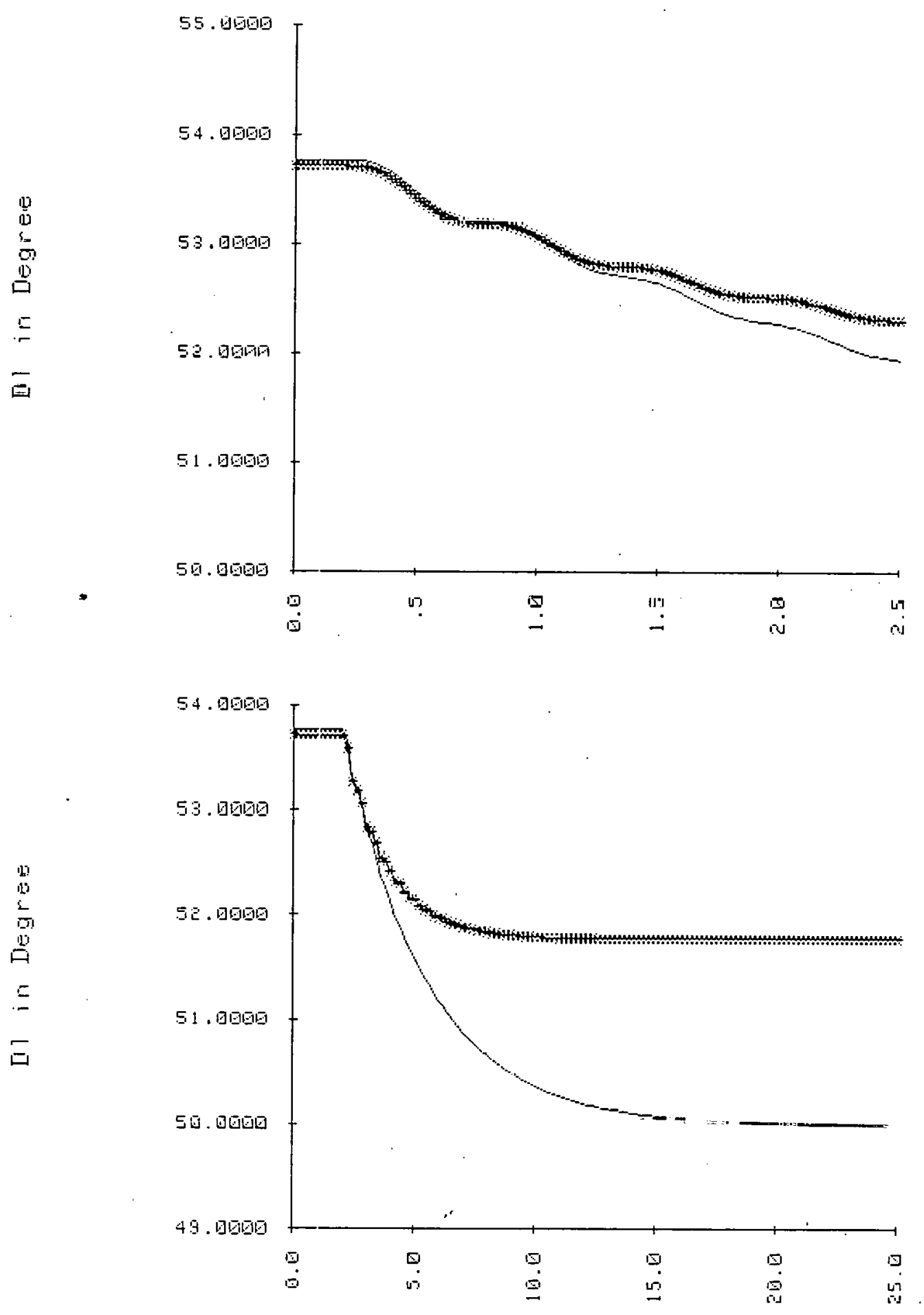

Figure B.7.a $\delta$ vs time in seconds, flux 1 inkage model (a), step change in EFD, saturated (*) and unsaturated response 


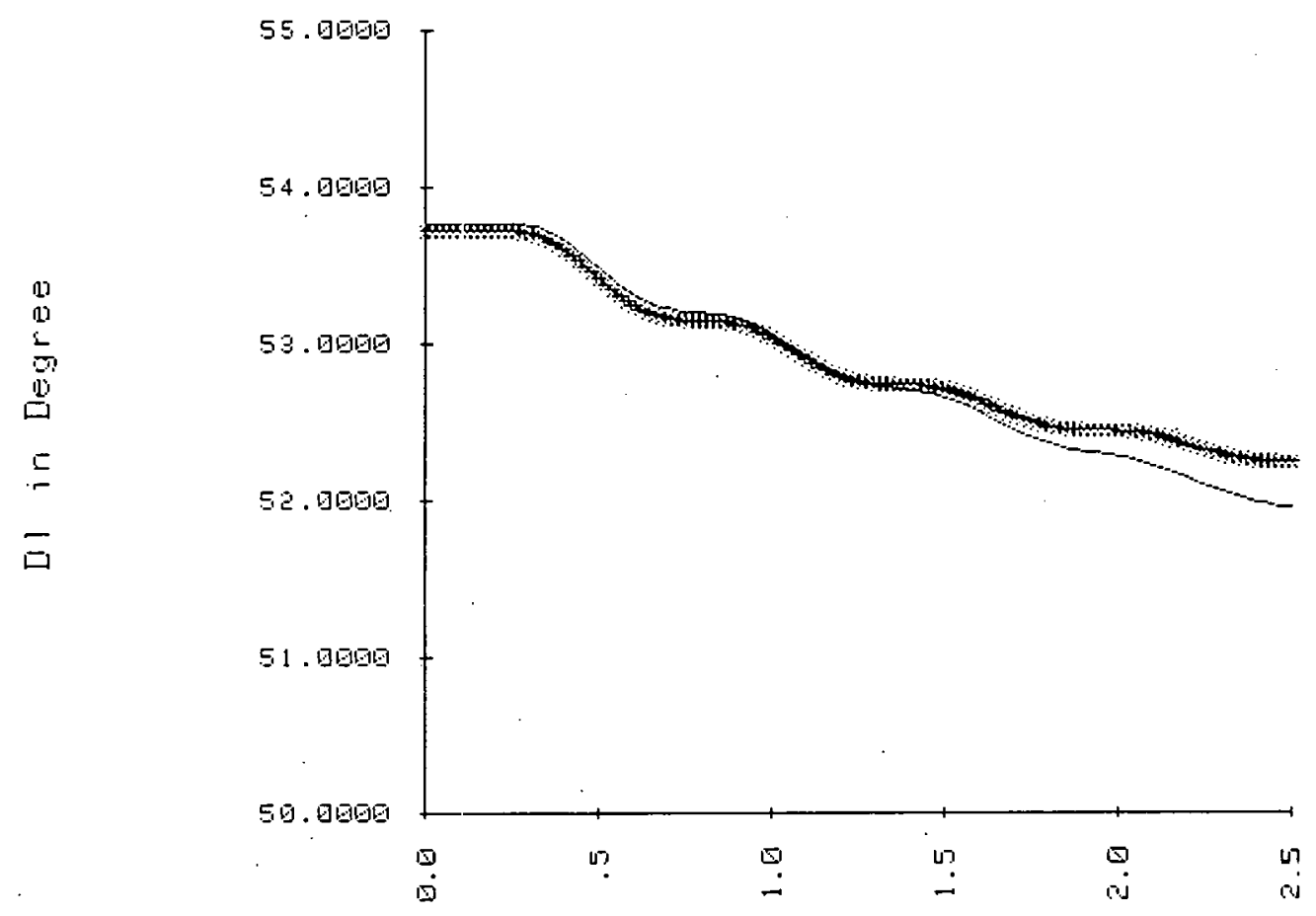

10
10
$\vdots$
0
$⿱ 10$
$\Xi$
$\Xi$
$\Xi$

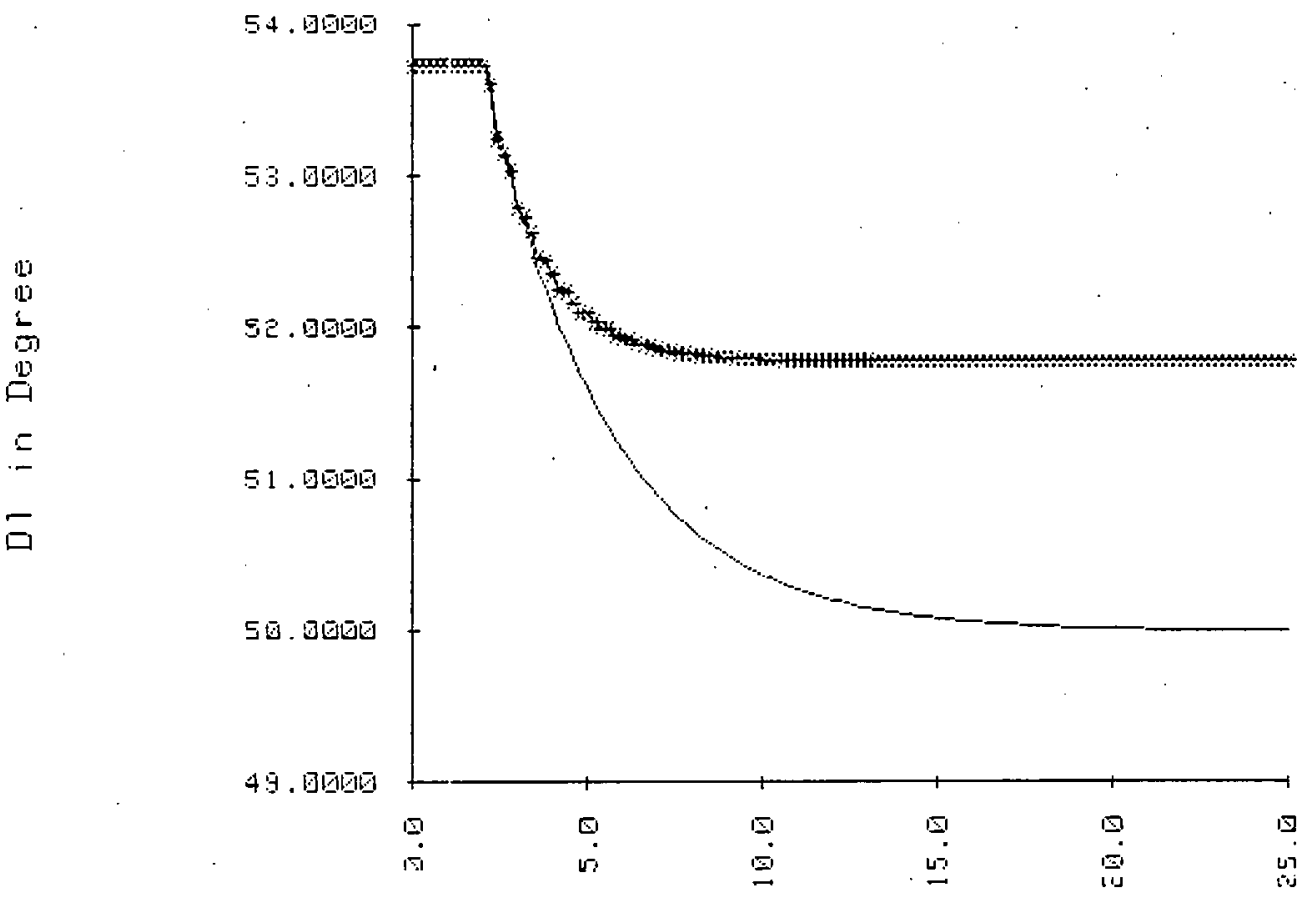

Figure B.7.b $\delta$ vs time ini seconds, E' mode1 (b), step change in EFD, saturated (*) and unsaturated response 

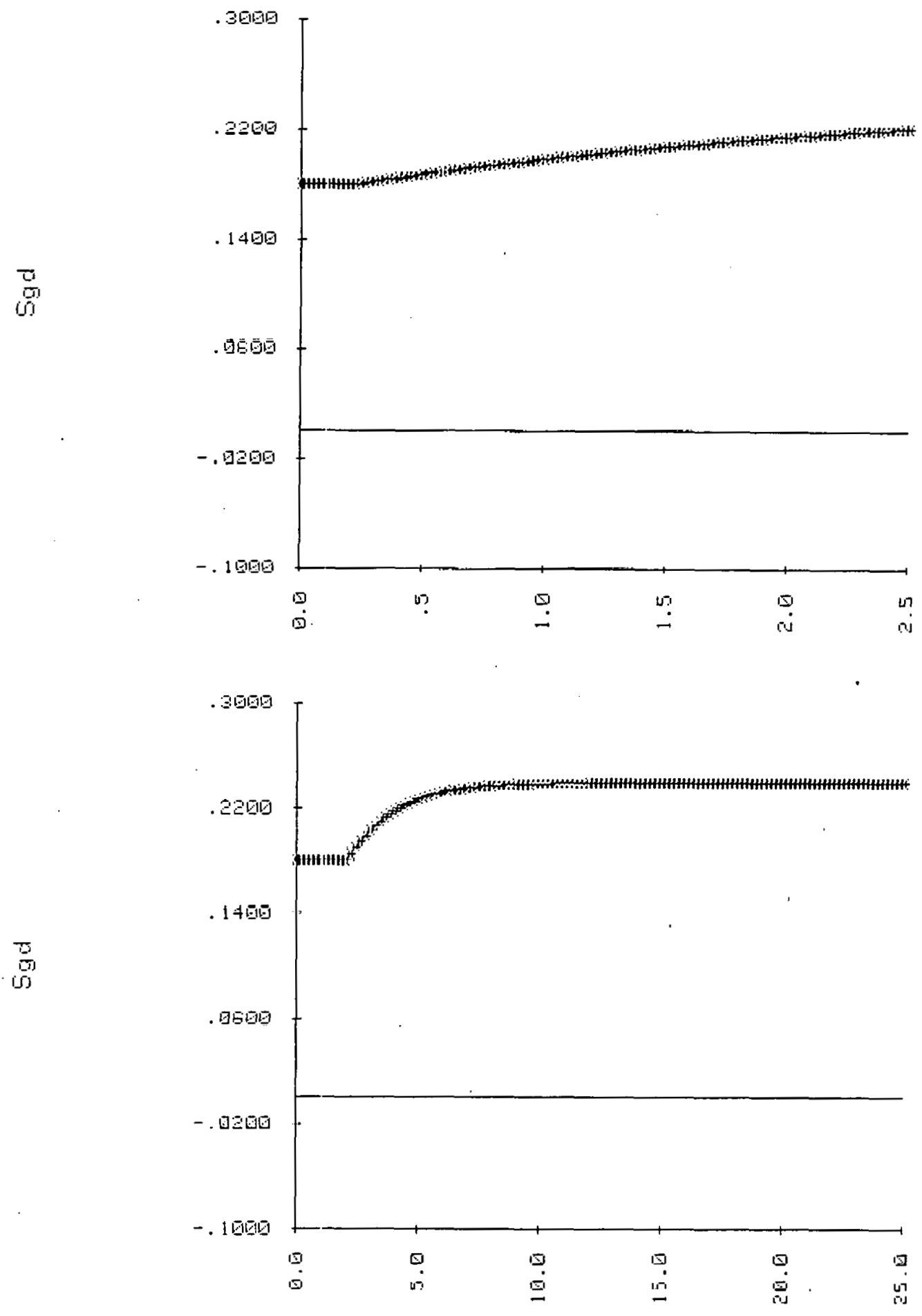

Figure B.8.a $\mathrm{S}_{\text {gd }}$ vs time in seconds, flux 1inkage model (a), step change in EFD, saturated (*) and unsaturated response 

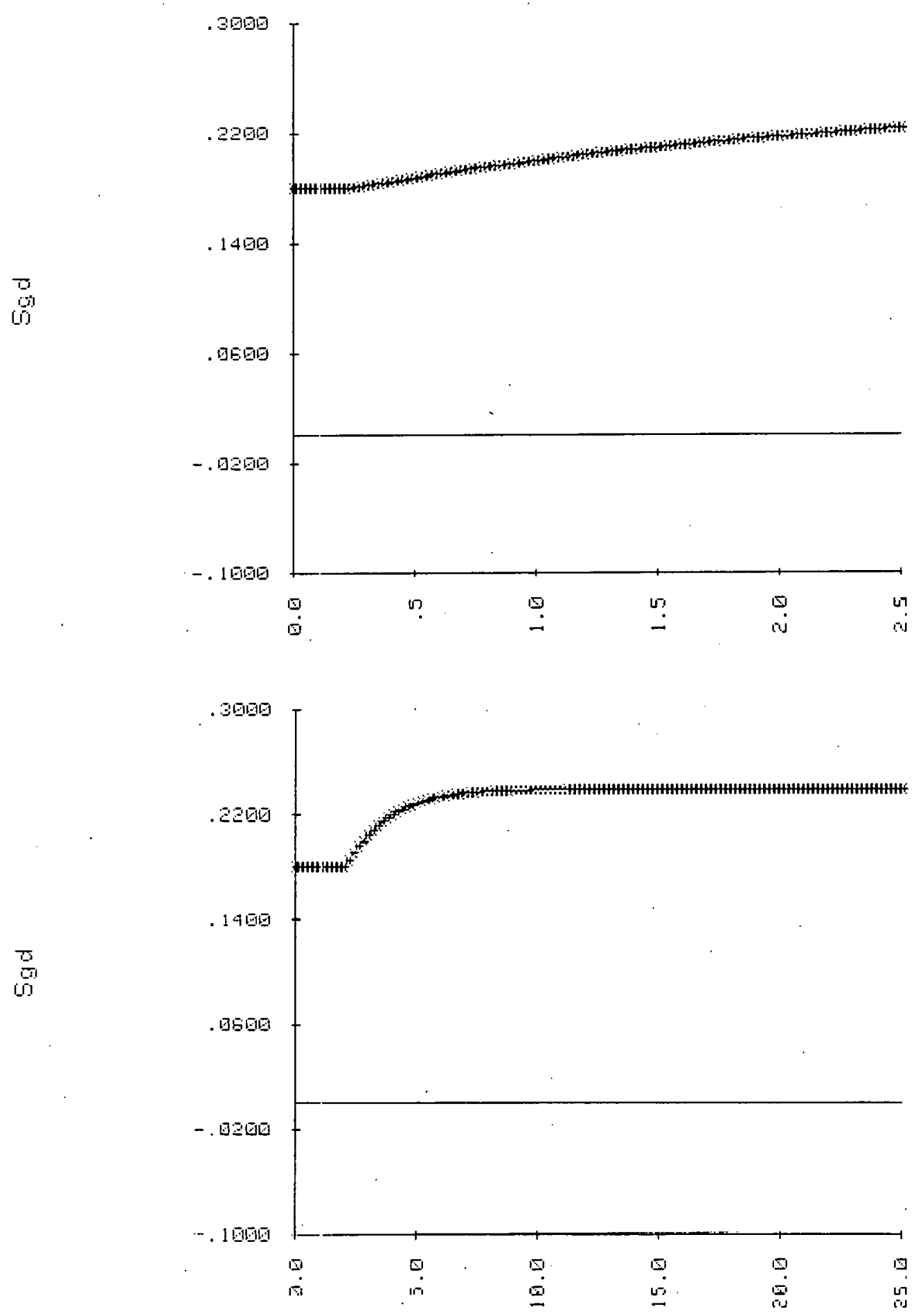

Figure B.8.b $S_{\text {gd }}$ Vs time in seconds, E' mode1 (b),
step change in EFD; saturated (*) and unsaturated response 

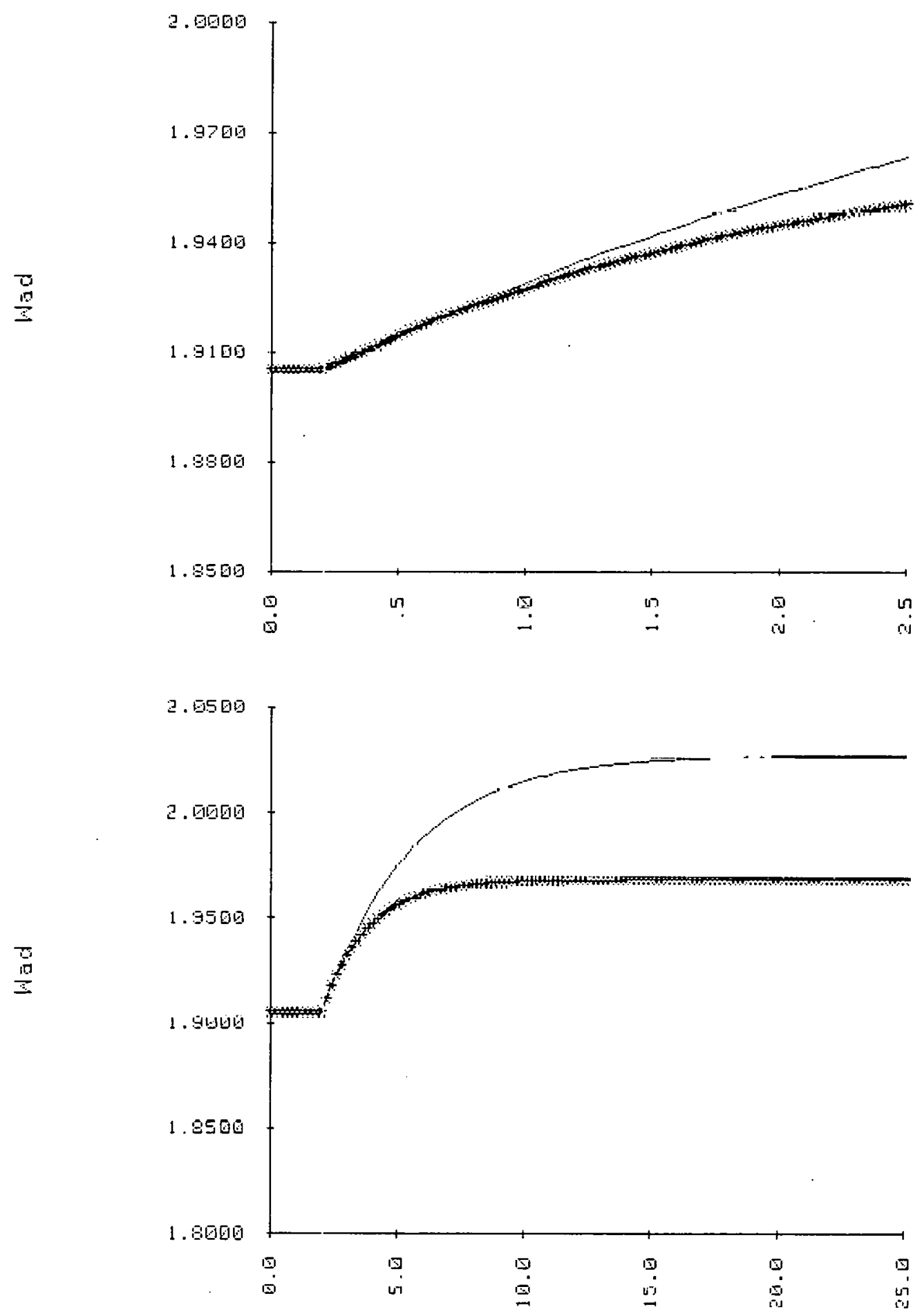

Figure B.9.a $\psi_{\text {AD }}$ vs time in seconds, flux 1 inkage model (a), step change in EFD, saturated (*) and unsaturated response 

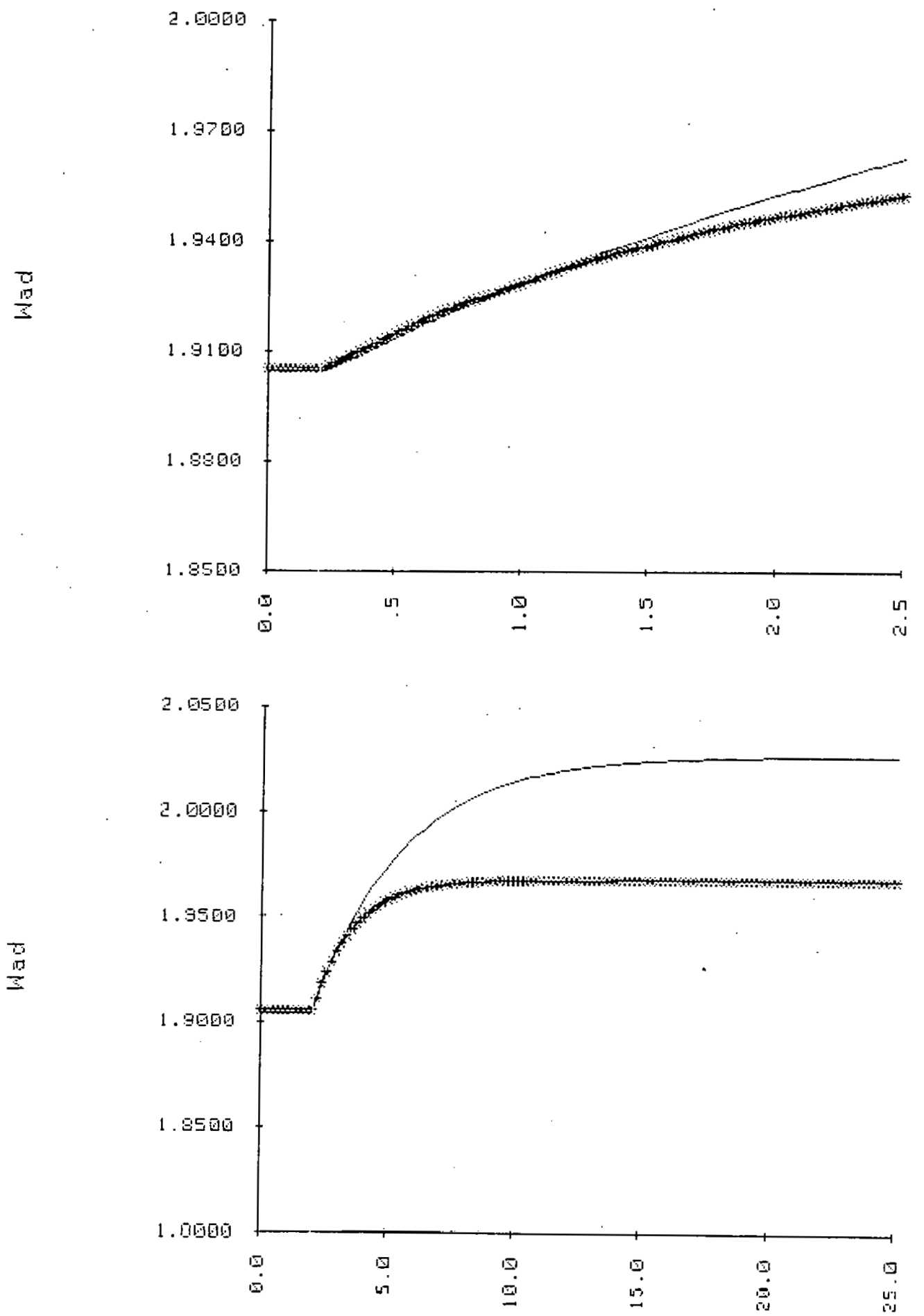

Figure B.9.b $\psi_{\mathrm{AD}} \mathrm{vs}$ time in seconds, $\mathrm{E}^{\prime \prime} \operatorname{mode} 1$ (b), step change in EFD, saturated (*) and unsaturated response 

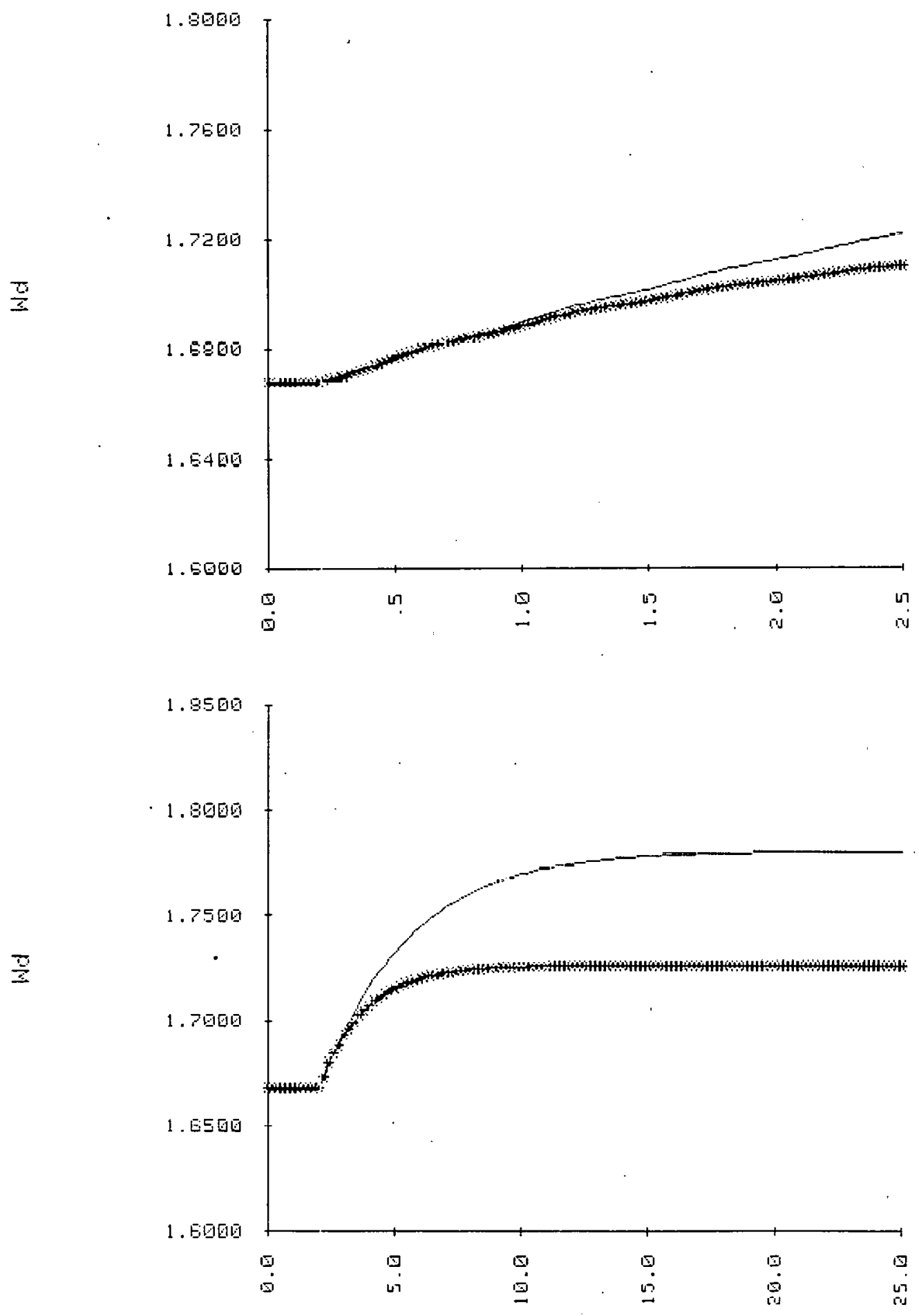

Figure B.10.a $\psi_{d}$ vs time in seconds, flux linkage mode1 (a), step change in EFD, saturated (*) and unsaturated response 

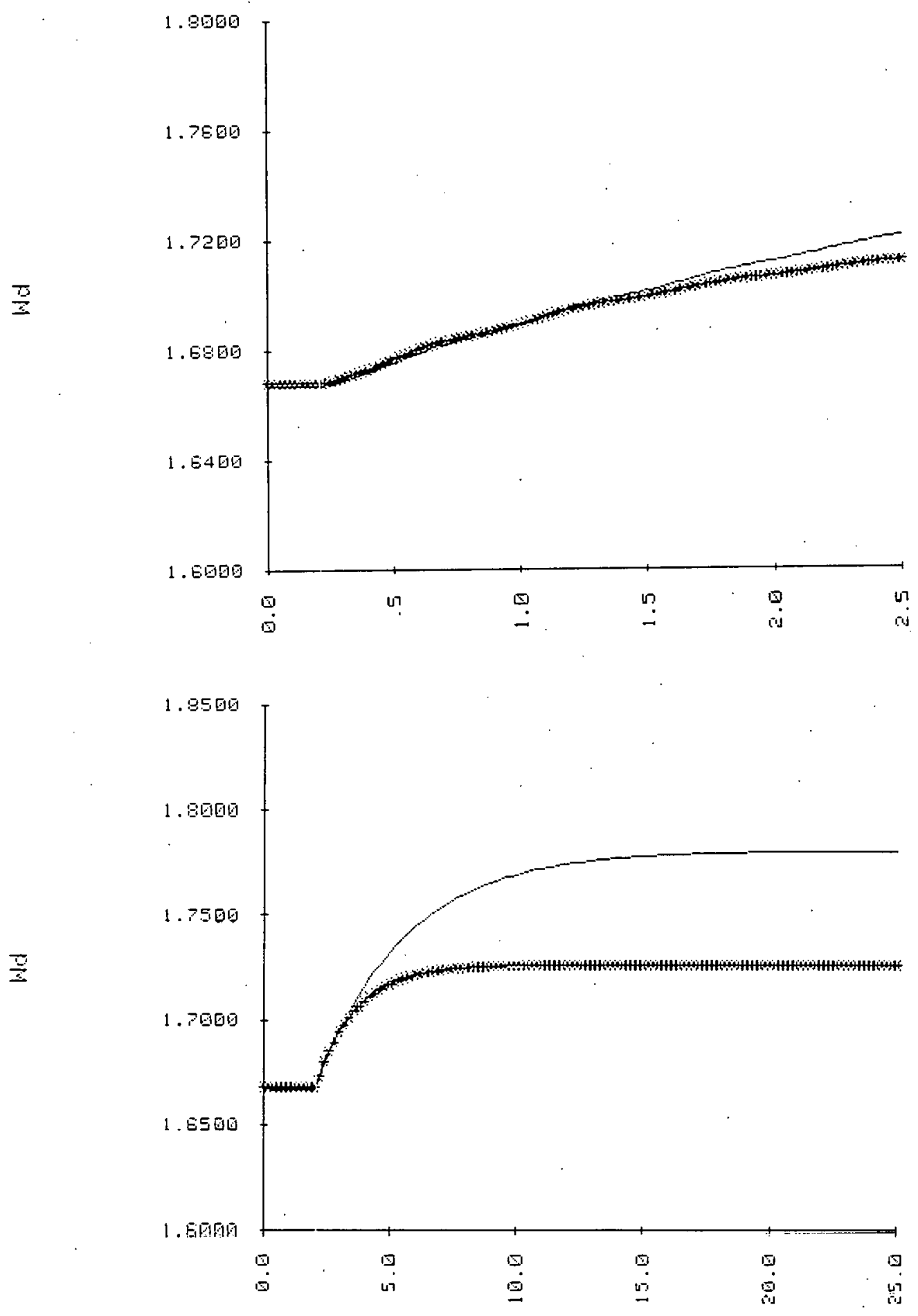

Figure B.10.b $\psi_{d}$ vs time in seconds, E' model (b), step change in EFD, saturated (*) and unsaturated response 

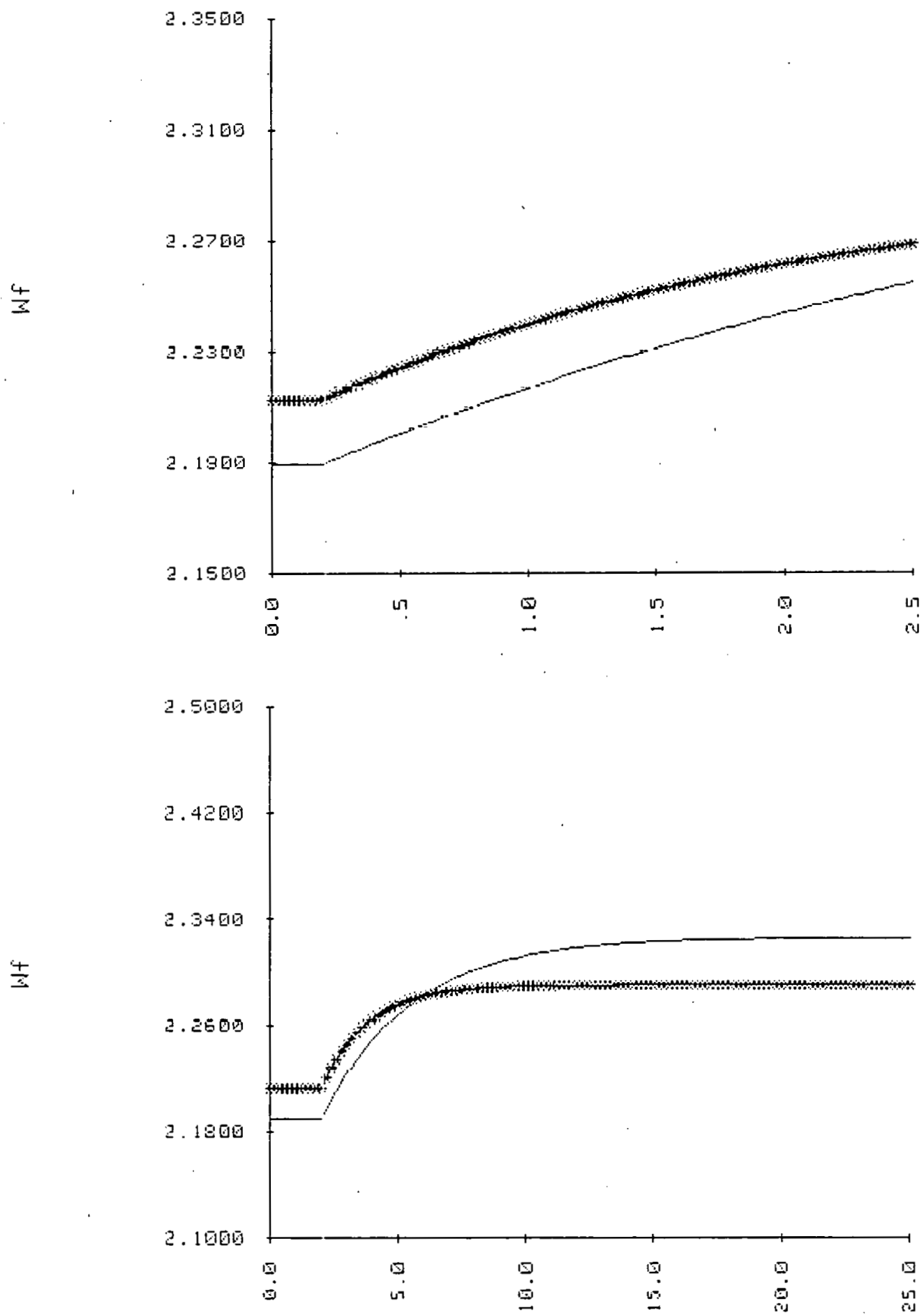

Figure B.11.a $\psi_{F}$ vs time in seconds, flux 1 inkage model (a). step change in EFD, saturated (*) and unsaturated response 

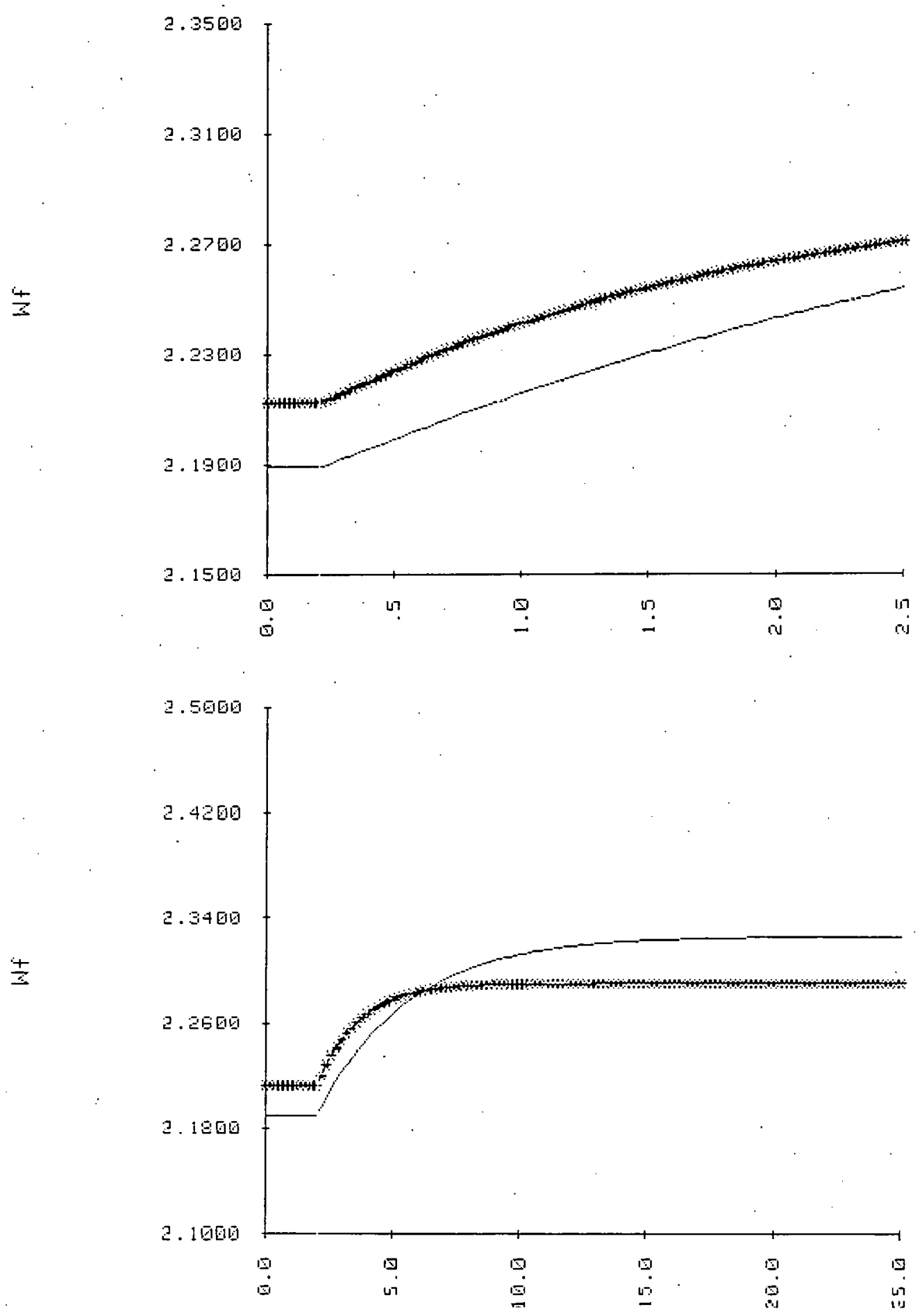

Figure B.11.b $\psi_{F}$ vs time in seconds, E' model (b), step change in EFD, saturated (*) and unsaturated response 

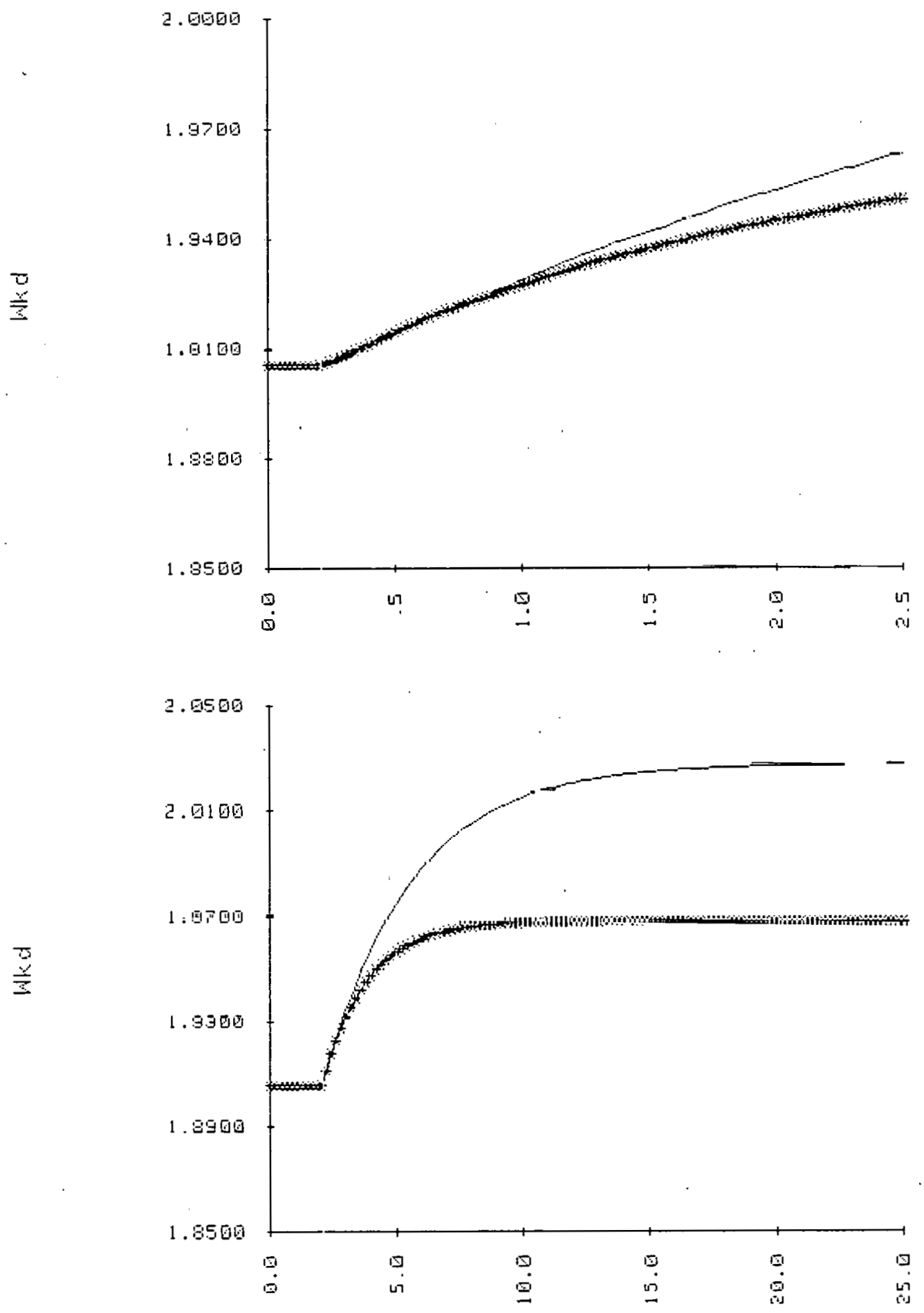

Figure B.12.a $\psi_{\text {kd }}$ vs time in seconds, flux linkage model (a), step change in EFD, saturated (*) and unsaturated response 

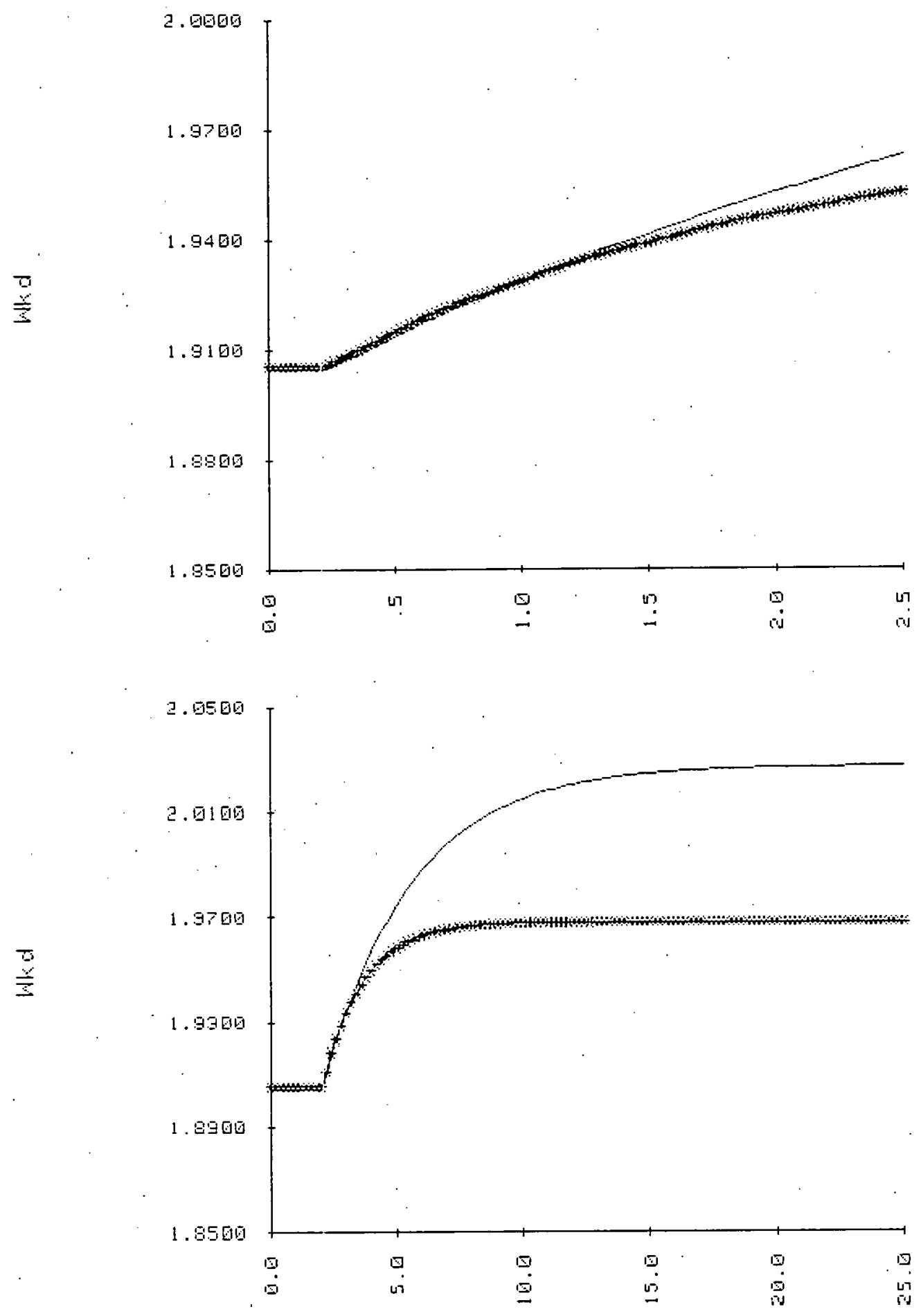

Figure B.12.b $\psi_{k d} v s$ time in seconds, E' $\operatorname{mode1}(b)$,

step change in EFD, saturated (*) and unsaturated response 

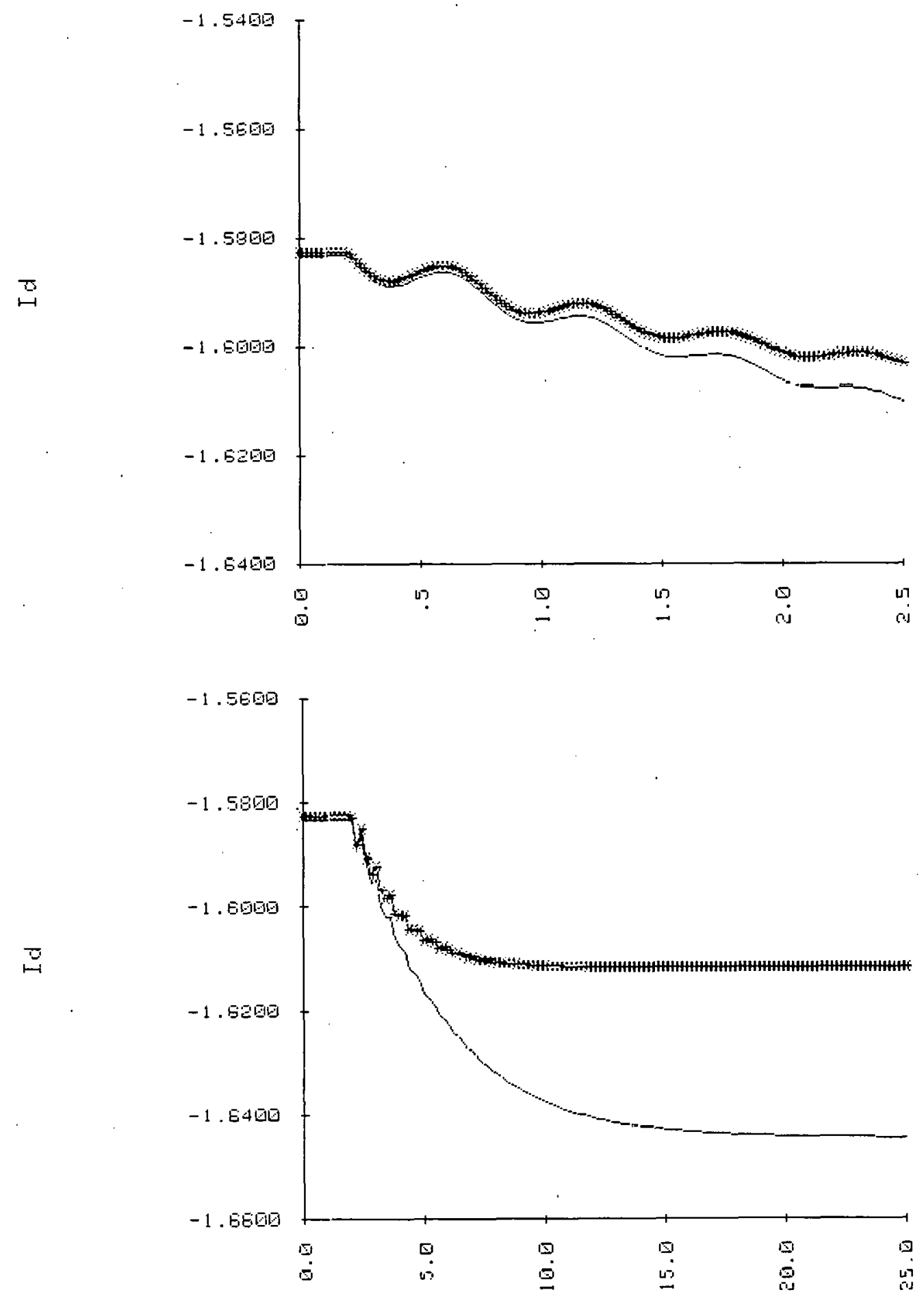

Figure B.13.a $I_{d}$ vs time in seconds, flux 1 inkage model (a), step change in EFD, saturated (*) and unsaturated response 

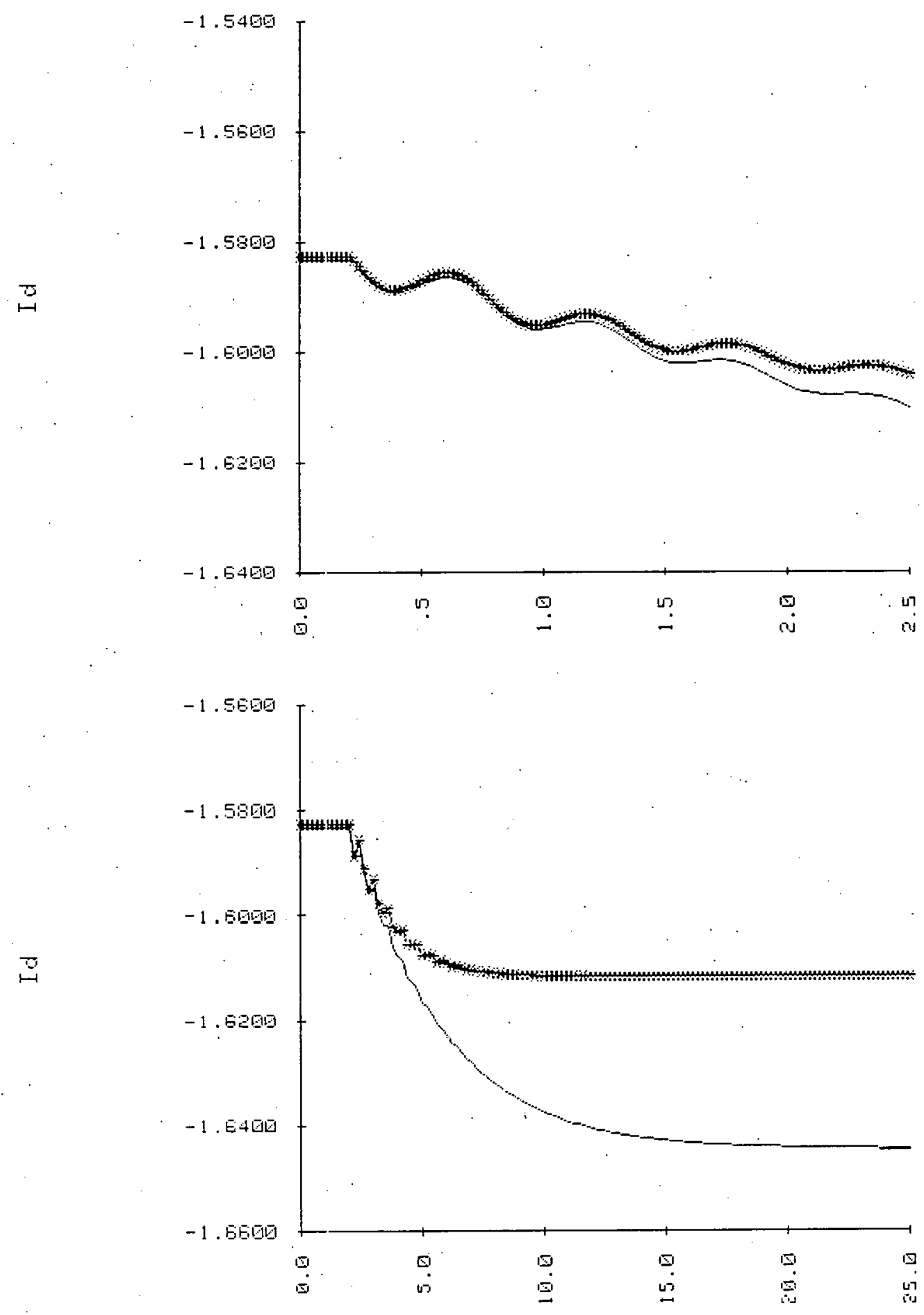

Figure B.13.b $I_{d}$ vs time in seconds, E'" model (b), step change in EFD, saturated (*) and unsaturated response 

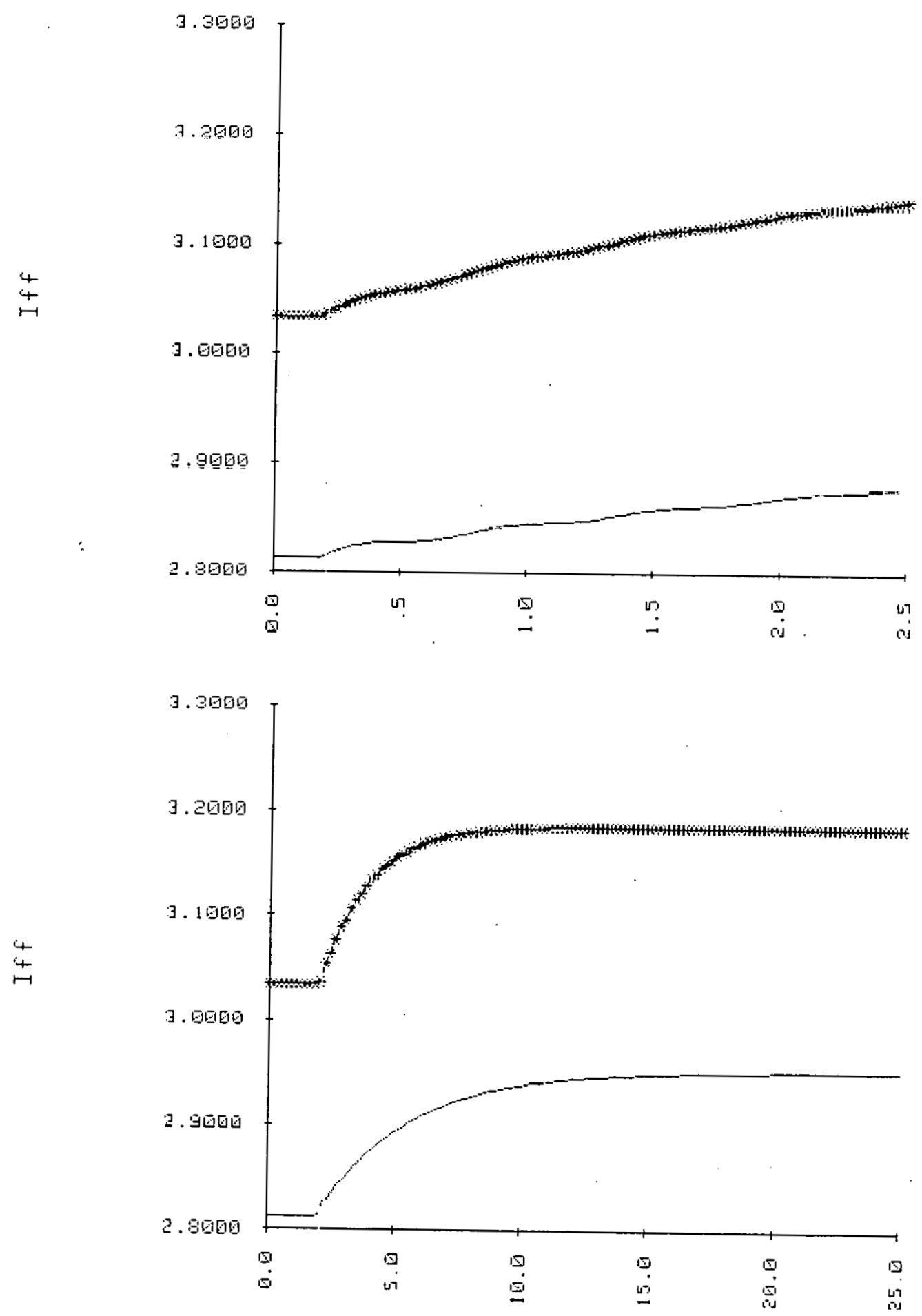

Figure B.14.a If vs time in seconds, flux 1 inkage mode1 (a), step change in EFD, saturated (*) and nnsaturated response 

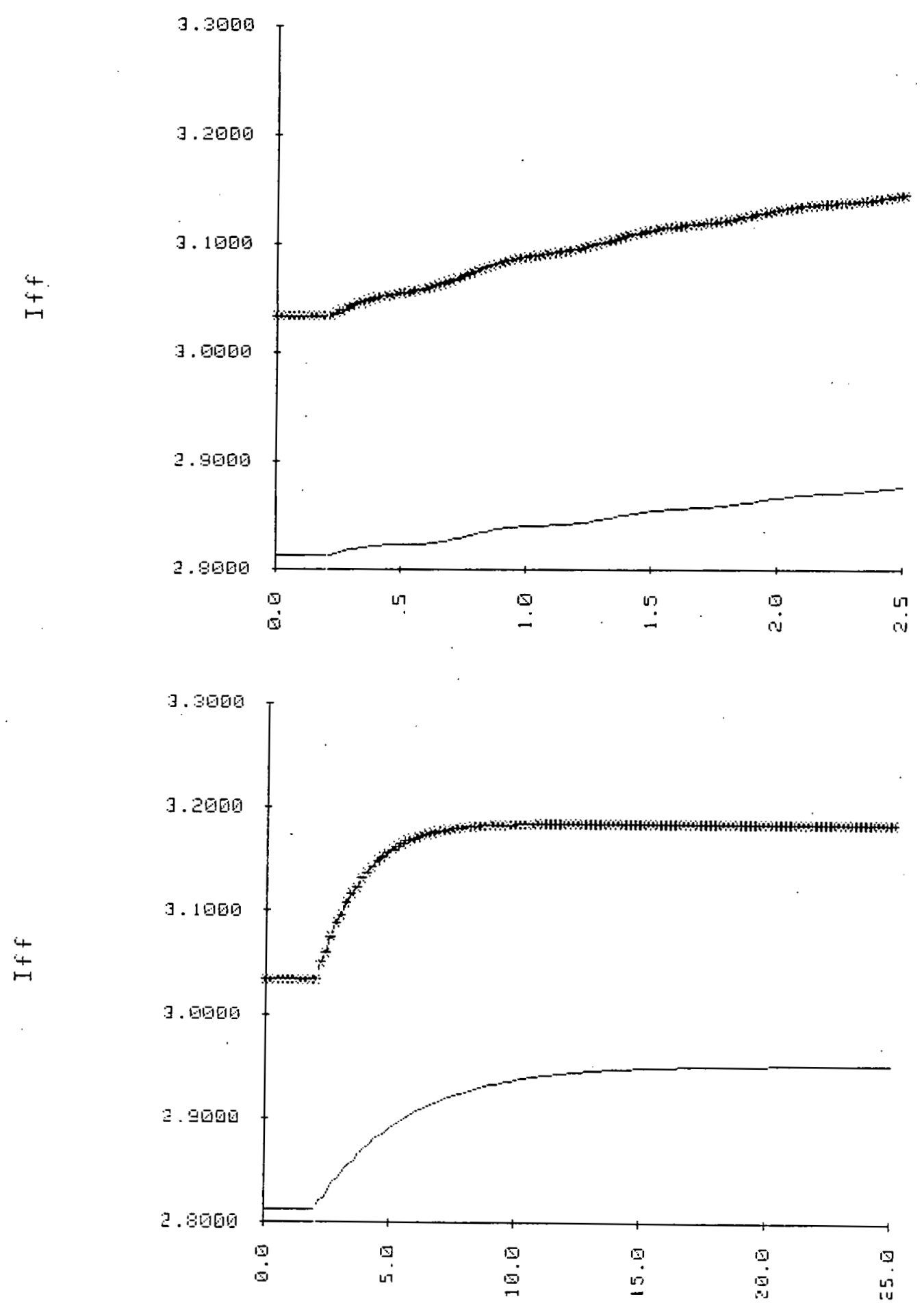

Figure B.14.b If vs time in seconds, E' mode1 (b), step change in EFD, saturated (*) and unsaturated response 

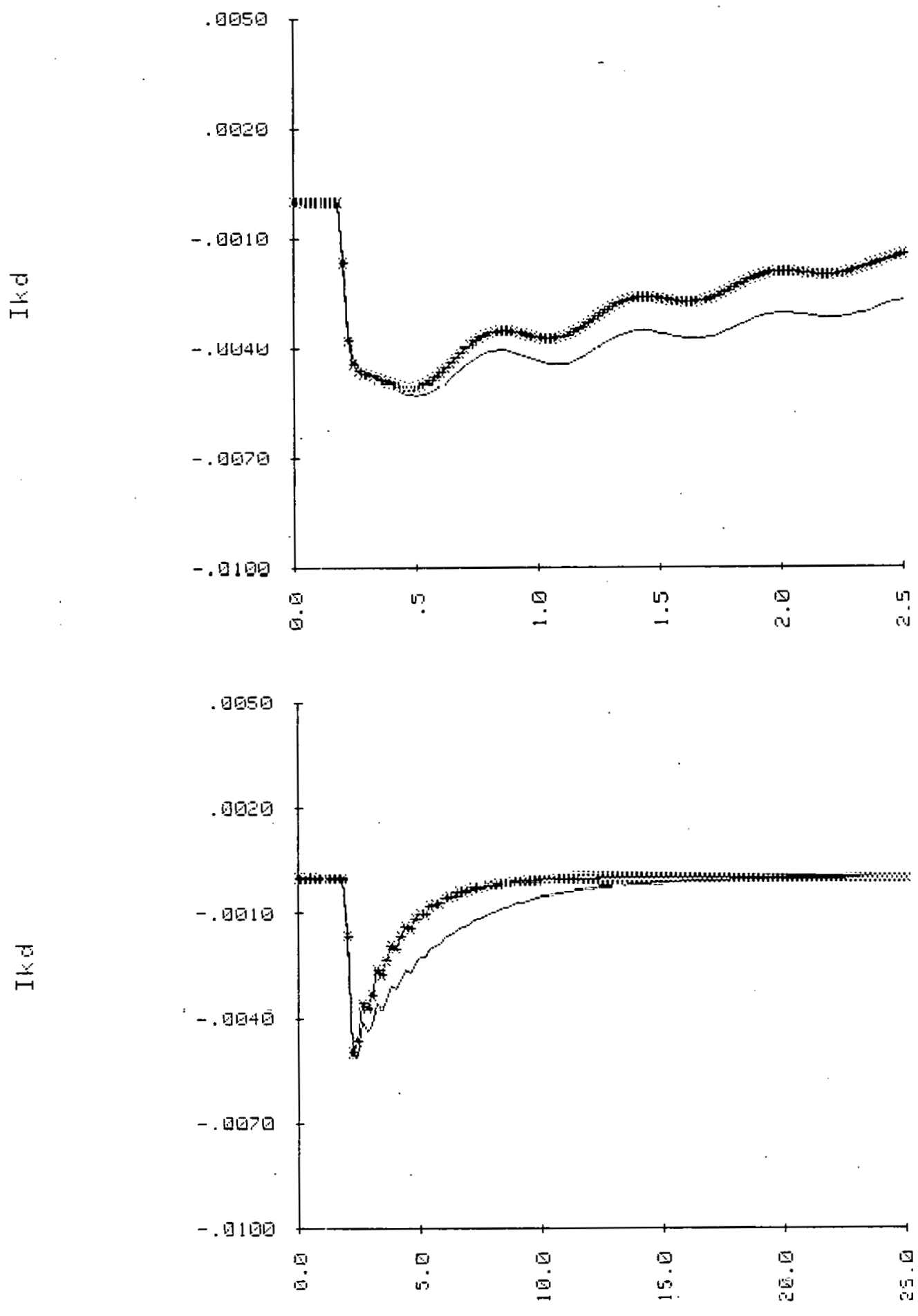

Figure B.15.a $I_{k d} v s$ time in seconds, E' mode1 (b), step change in EFD, saturated (*) and unsaturated response 


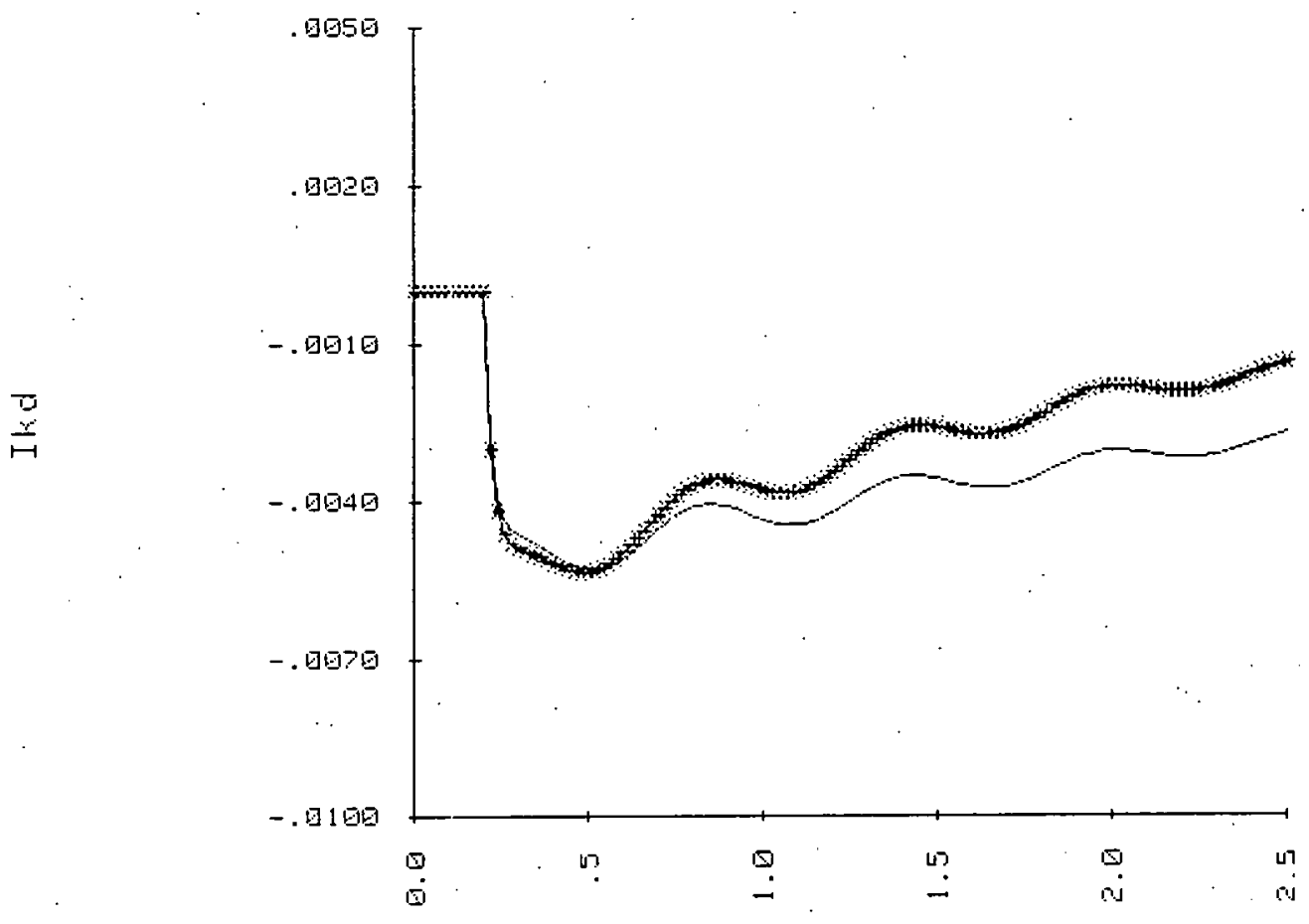

$\stackrel{\square}{\square}$

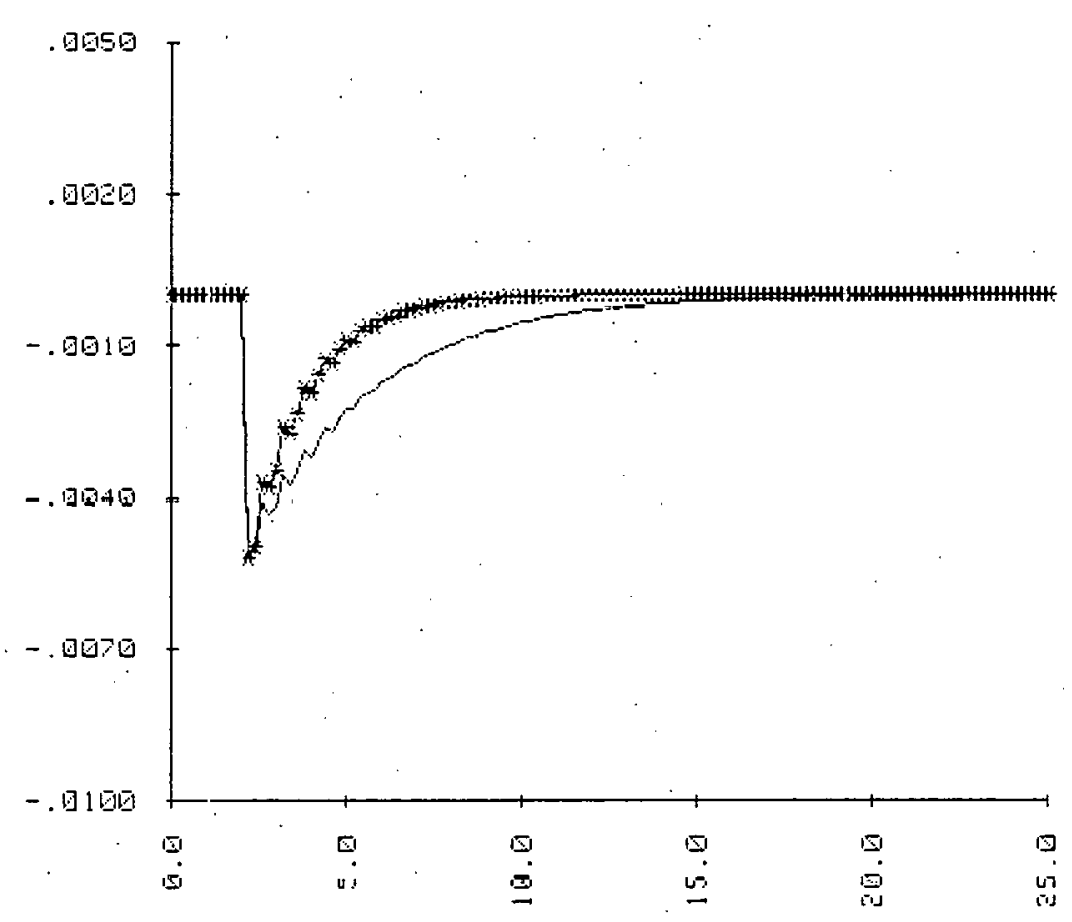

Figure B.15.b $I_{k d} v s$ time in seconds, E' model (b), step change in EFD, saturated (*) and unsaturated response 

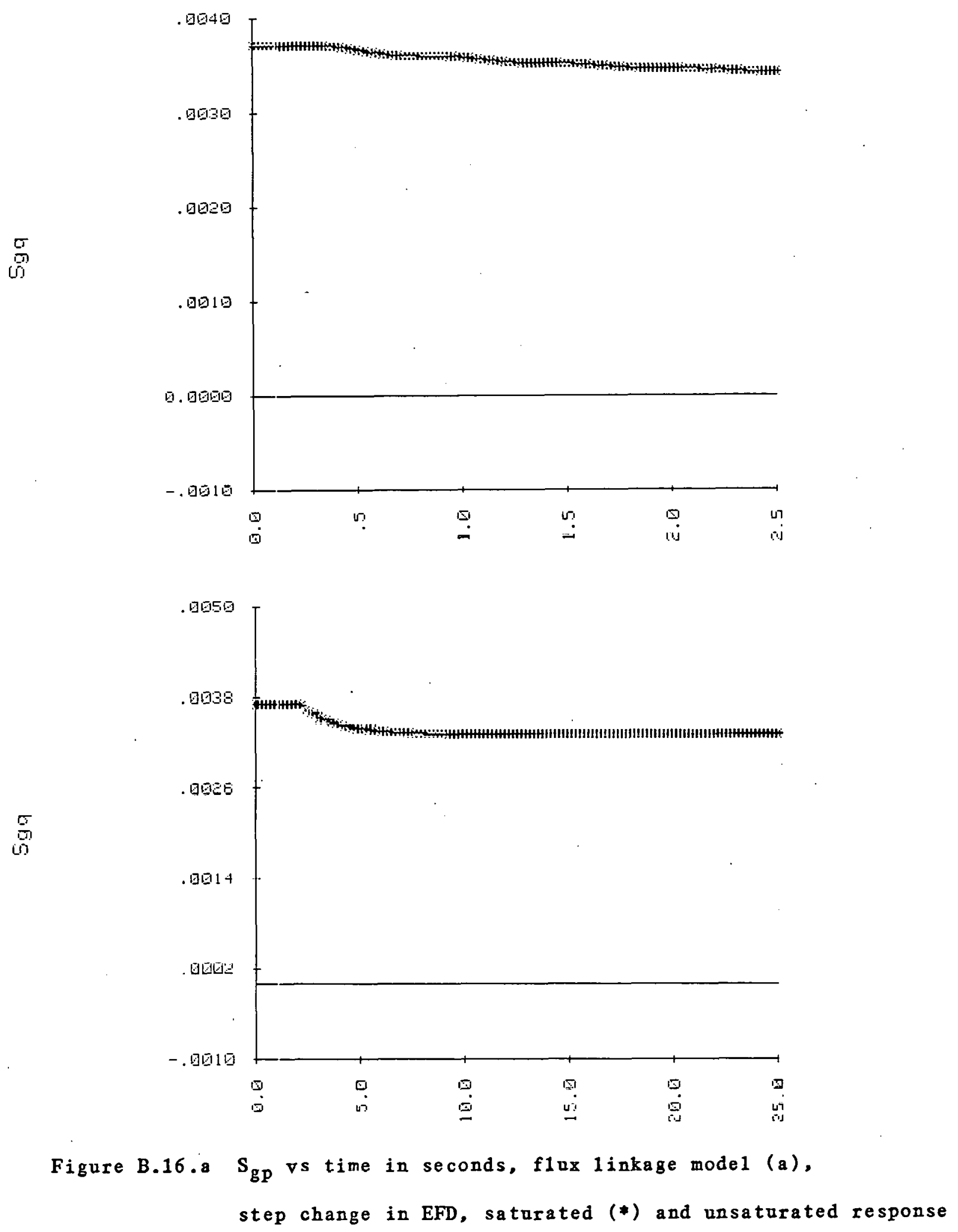

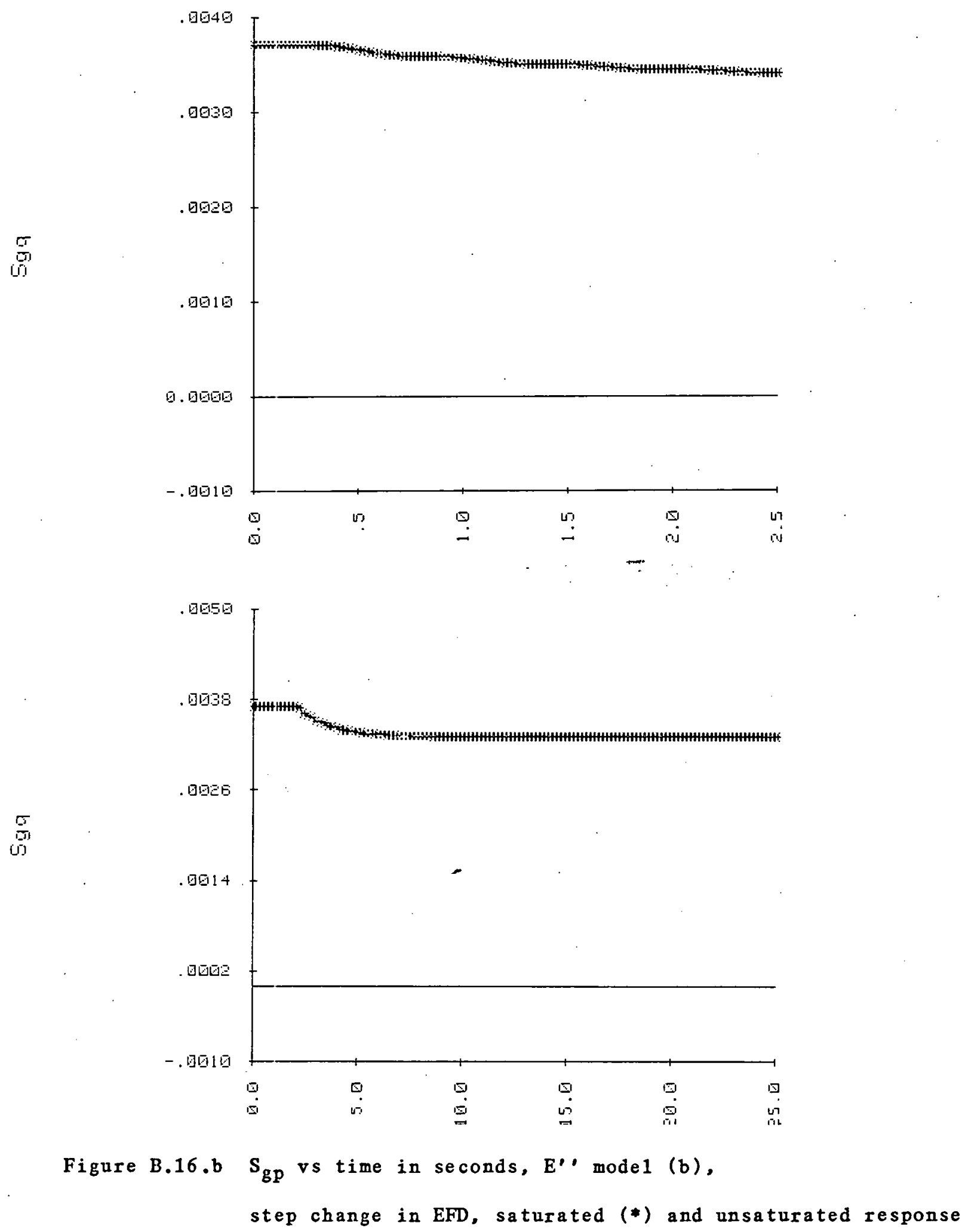

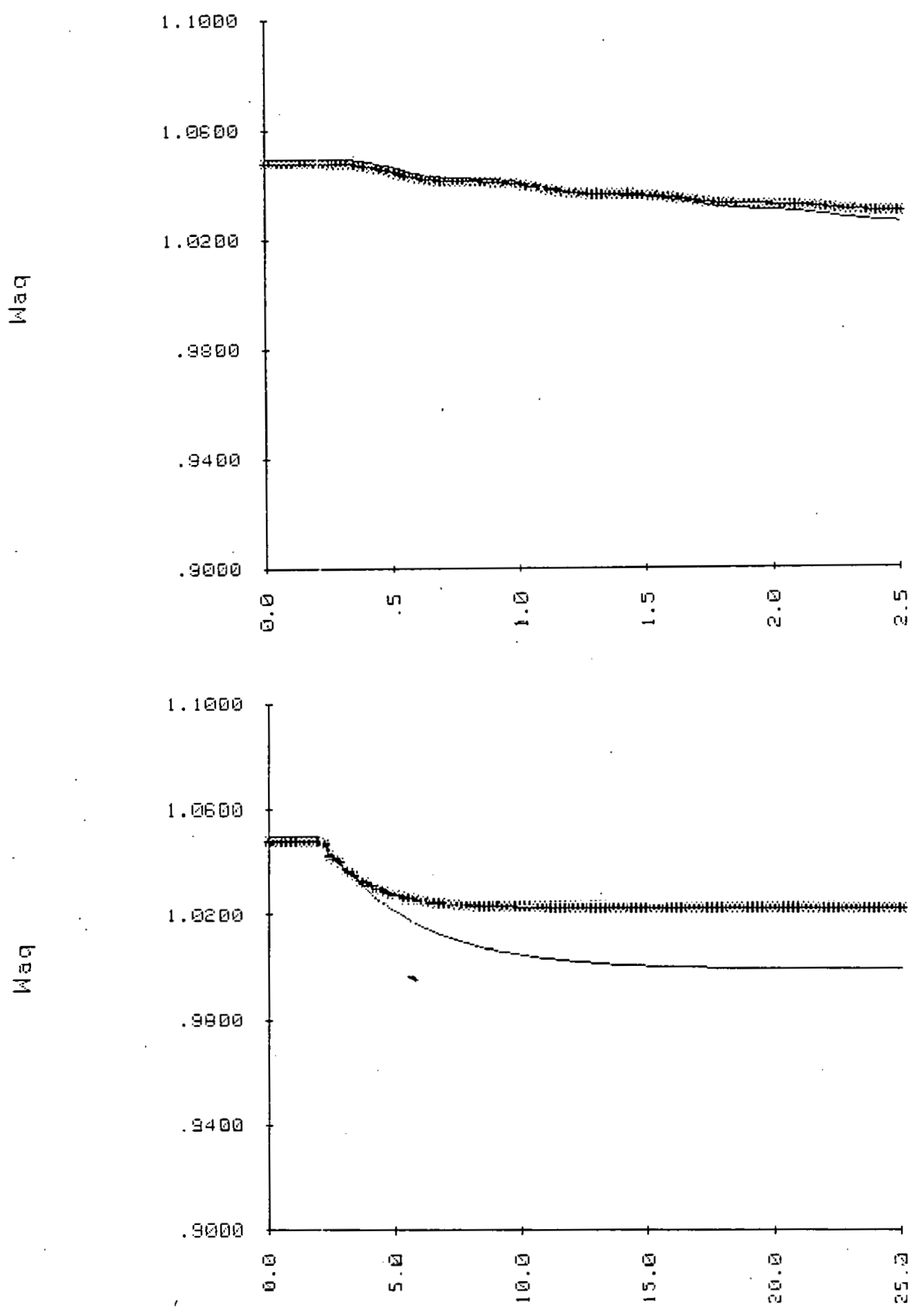

Figure B.17.a $\Psi_{A Q}$ vs time in seconds, flux 1 inkage model (a), step change in EFD, saturated (*) and unsaturated response 

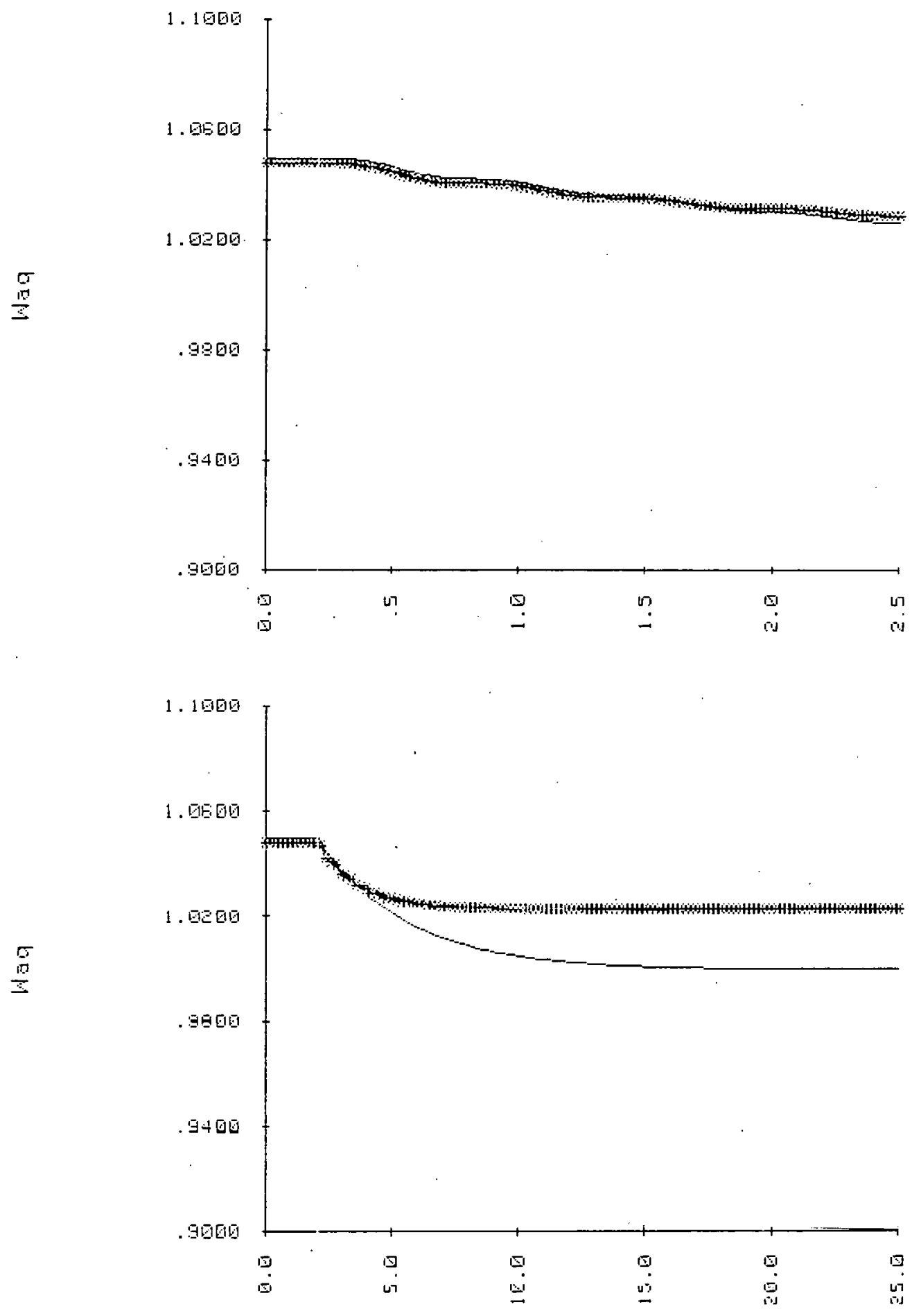

Figure B.17.b $\Psi_{A Q}$ vs time in seconds, $E^{\prime \prime} \operatorname{model}(\mathrm{b})$,

step change in EFD, saturated (*) and unsaturated response 

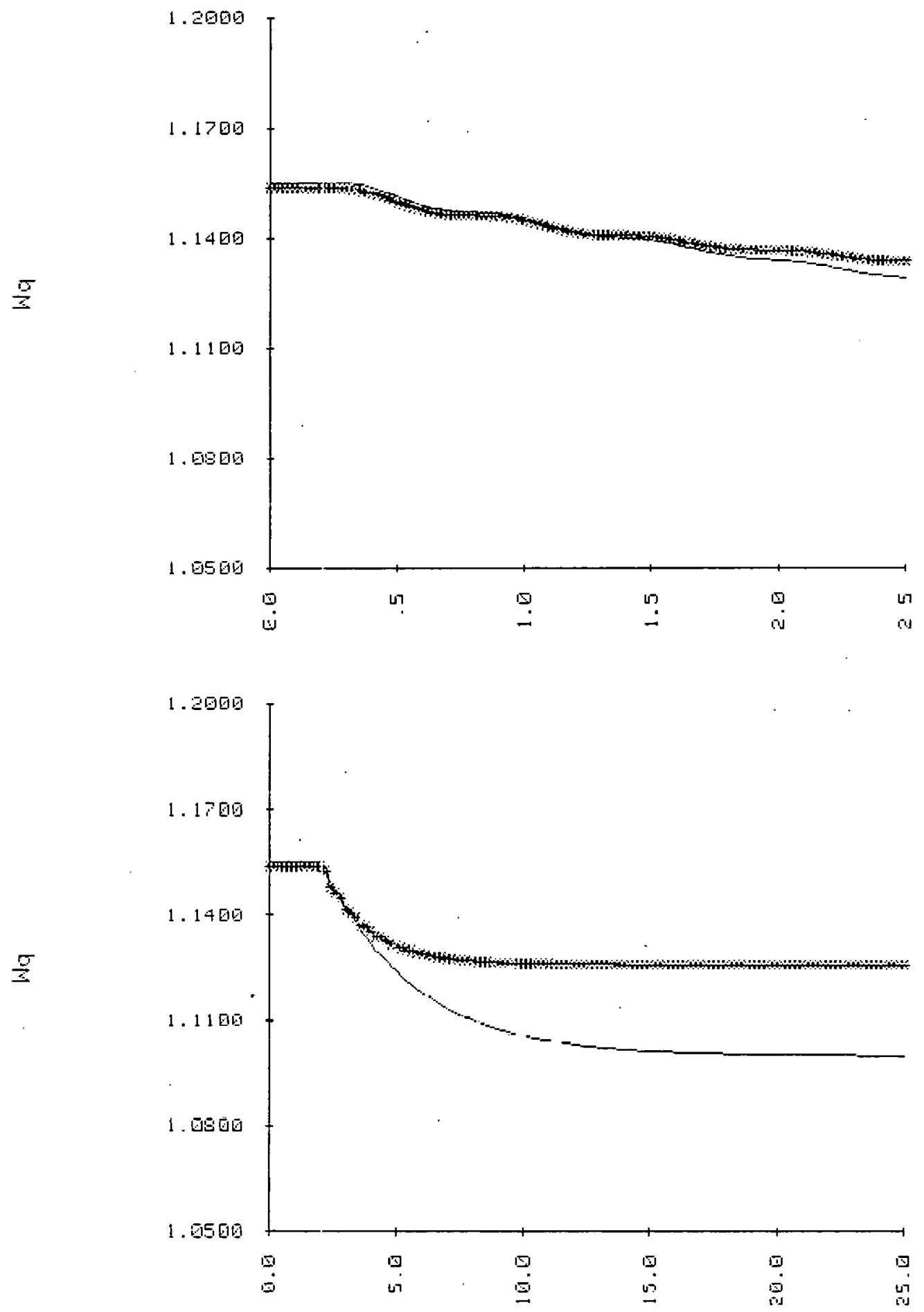

Figure B.18.a $\psi_{q}$ vs time in seconds, flux 1 inkage mode1 (a), step change in EFD, saturated (*) and unsaturated response 

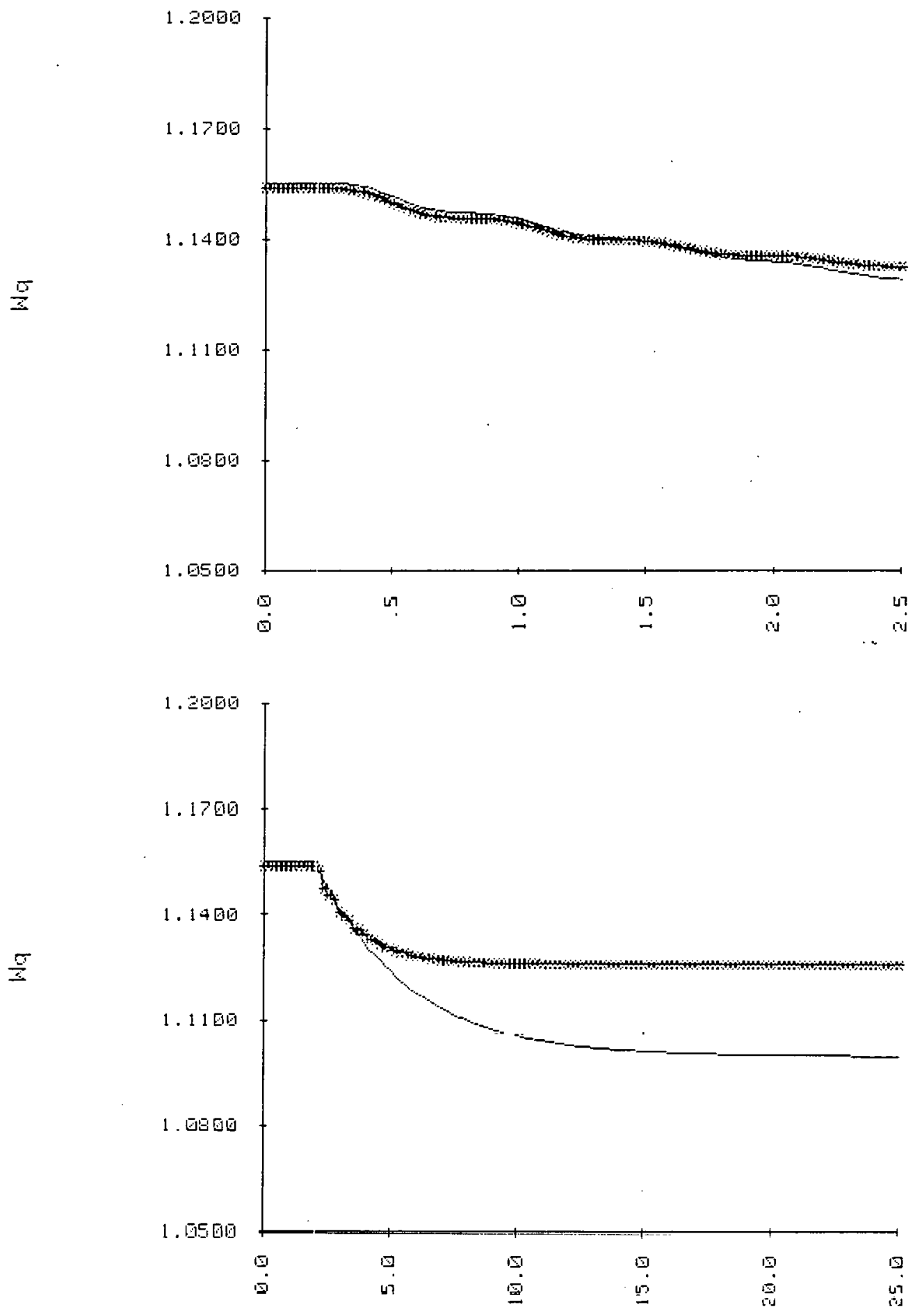

Figure B.18.b $\psi_{q}$ vs time in seconds, E' model (b), step change in EFD, saturated (*) and unsaturated response 

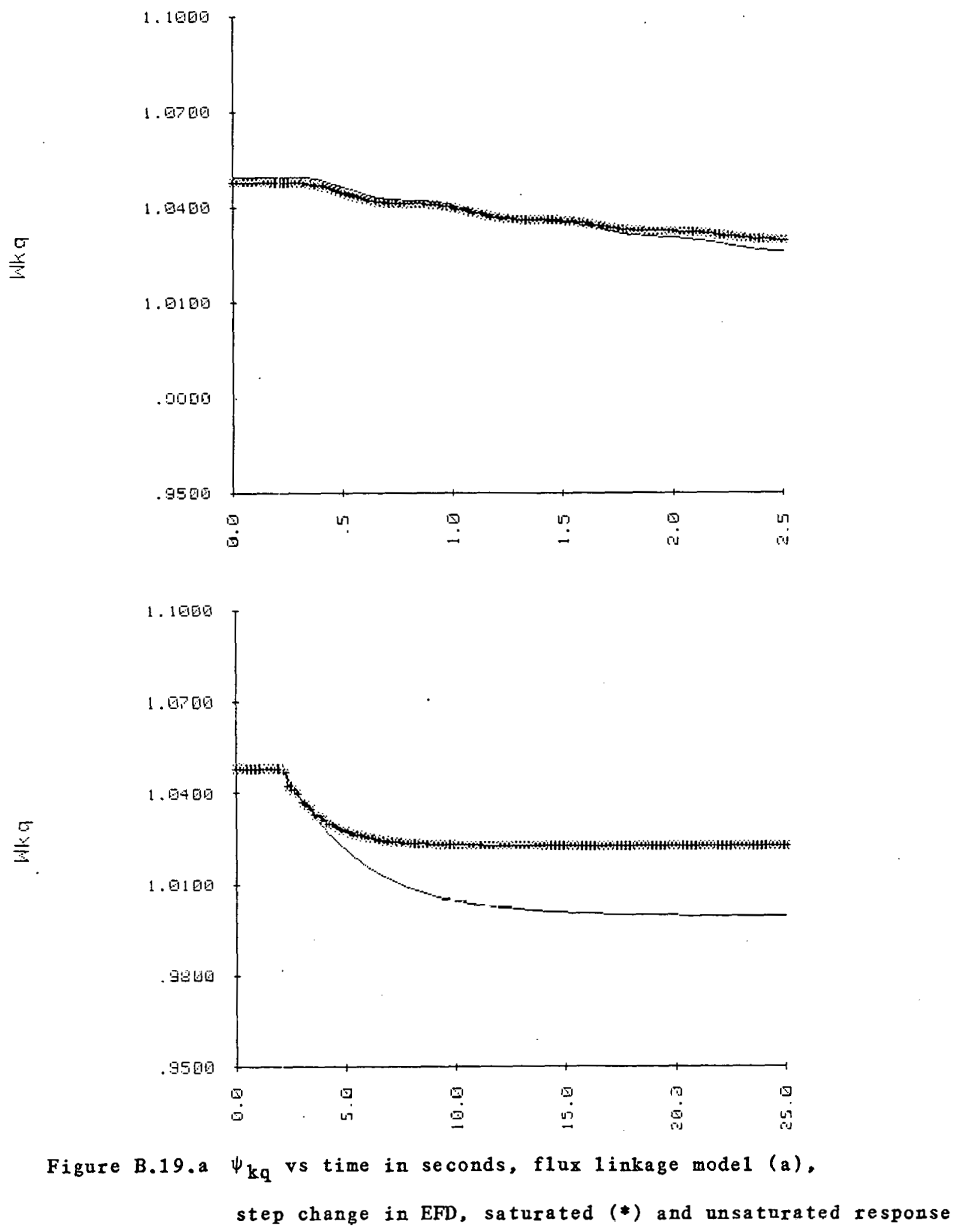

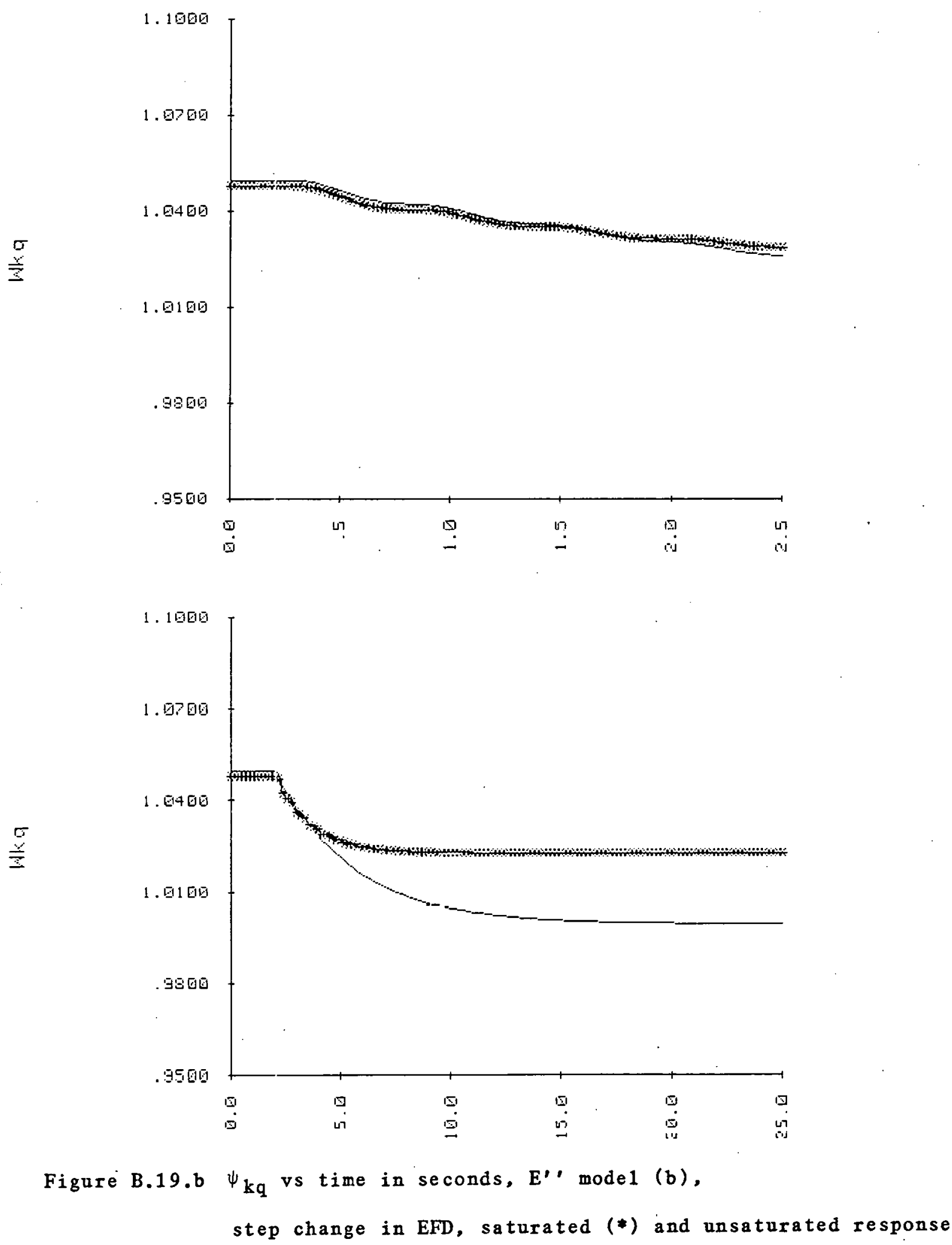

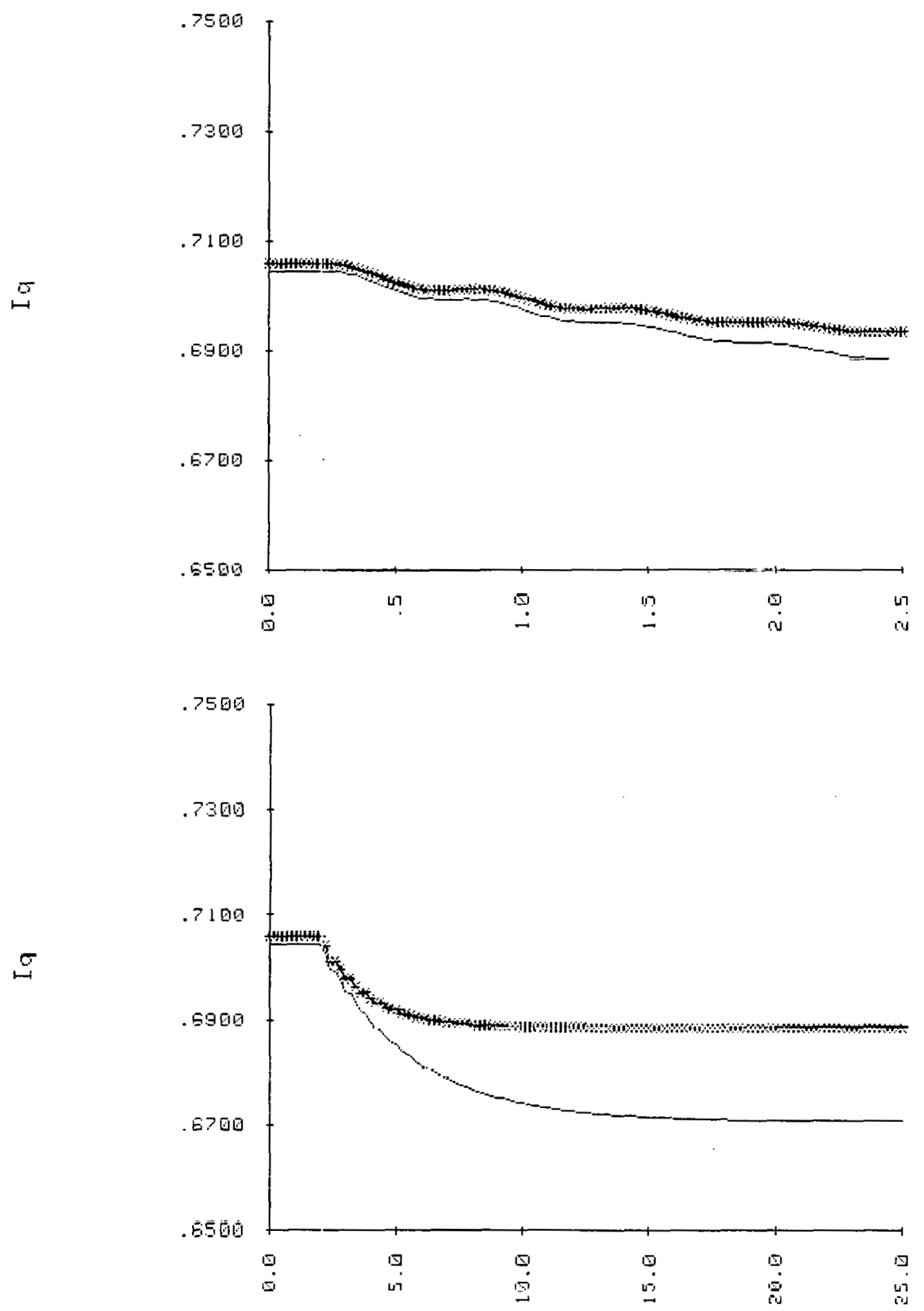

Figure B.20.a $I_{q}$ vs time in seconds, flux 1 inkage mode1 (a). step change in EFD, saturated (*) and unsaturated response 

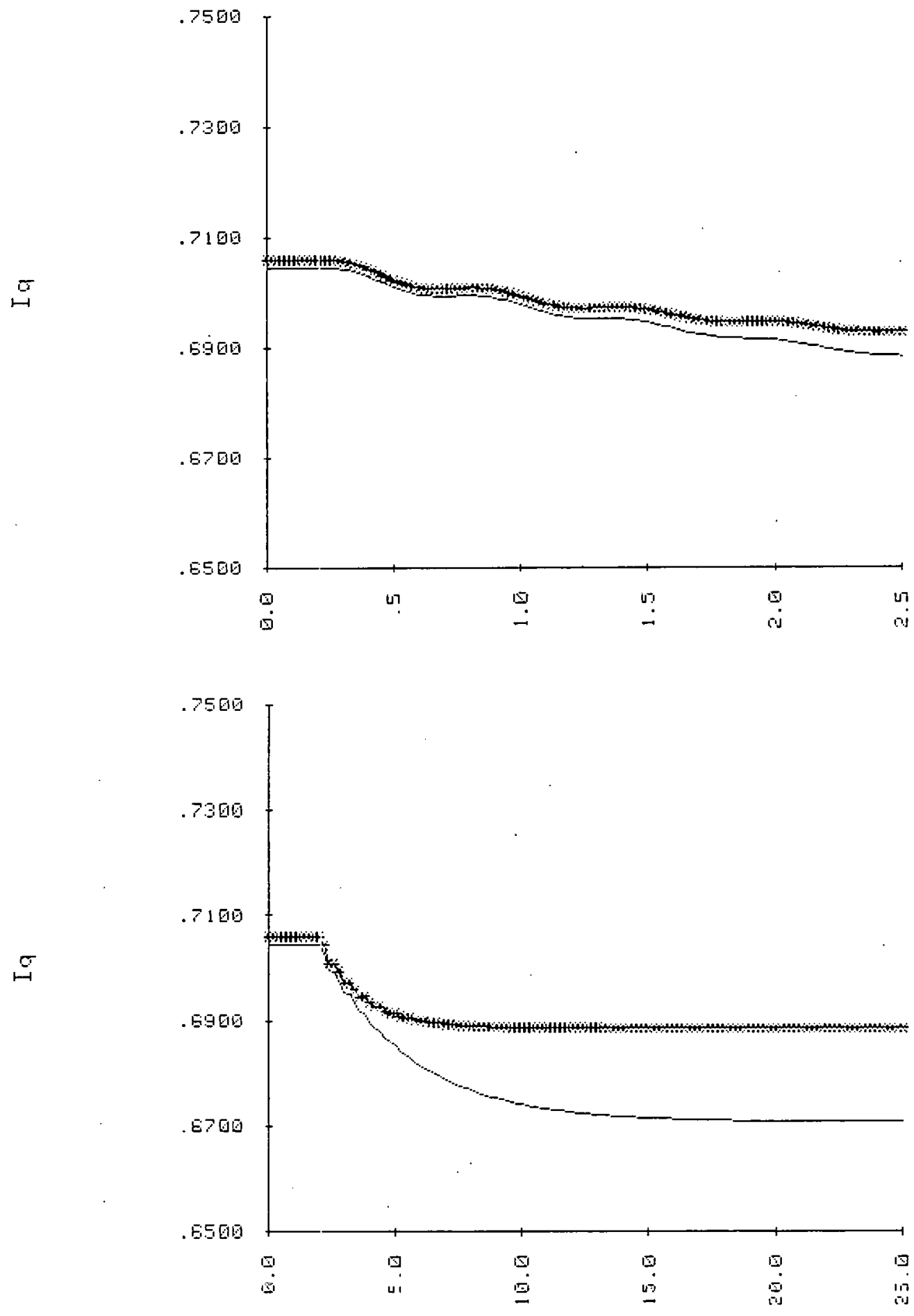

Figure B.20.b $I_{q}$ vs time in seconds, E' $\operatorname{mode1}(b)$, step change in EFT, saturated (*) and unsaturated response 

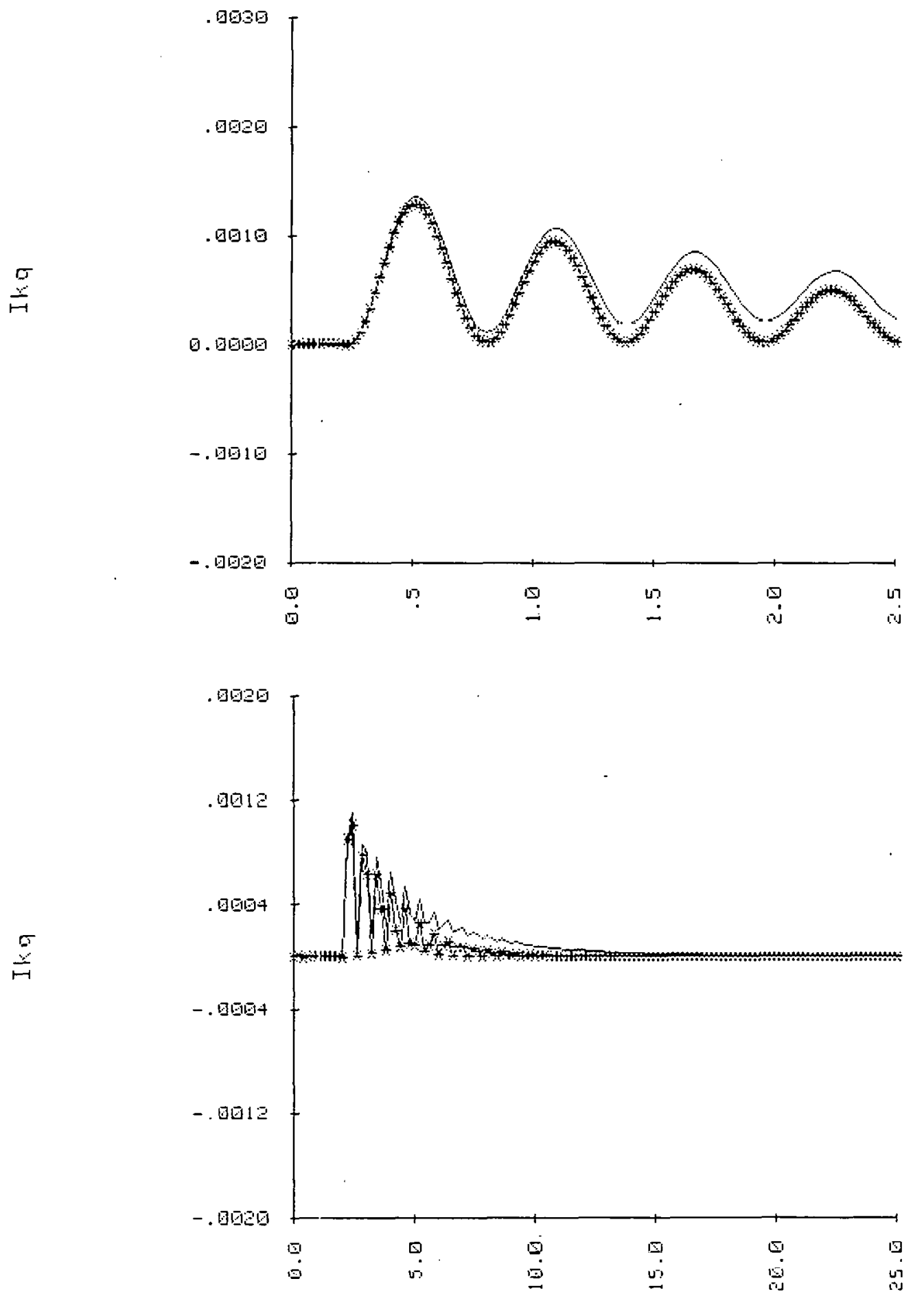

Figure B.21.a $I_{k q}$ vs time in seconds, flux linkage mode1 (a), step change in EFD, saturated (*) and unsaturated response 

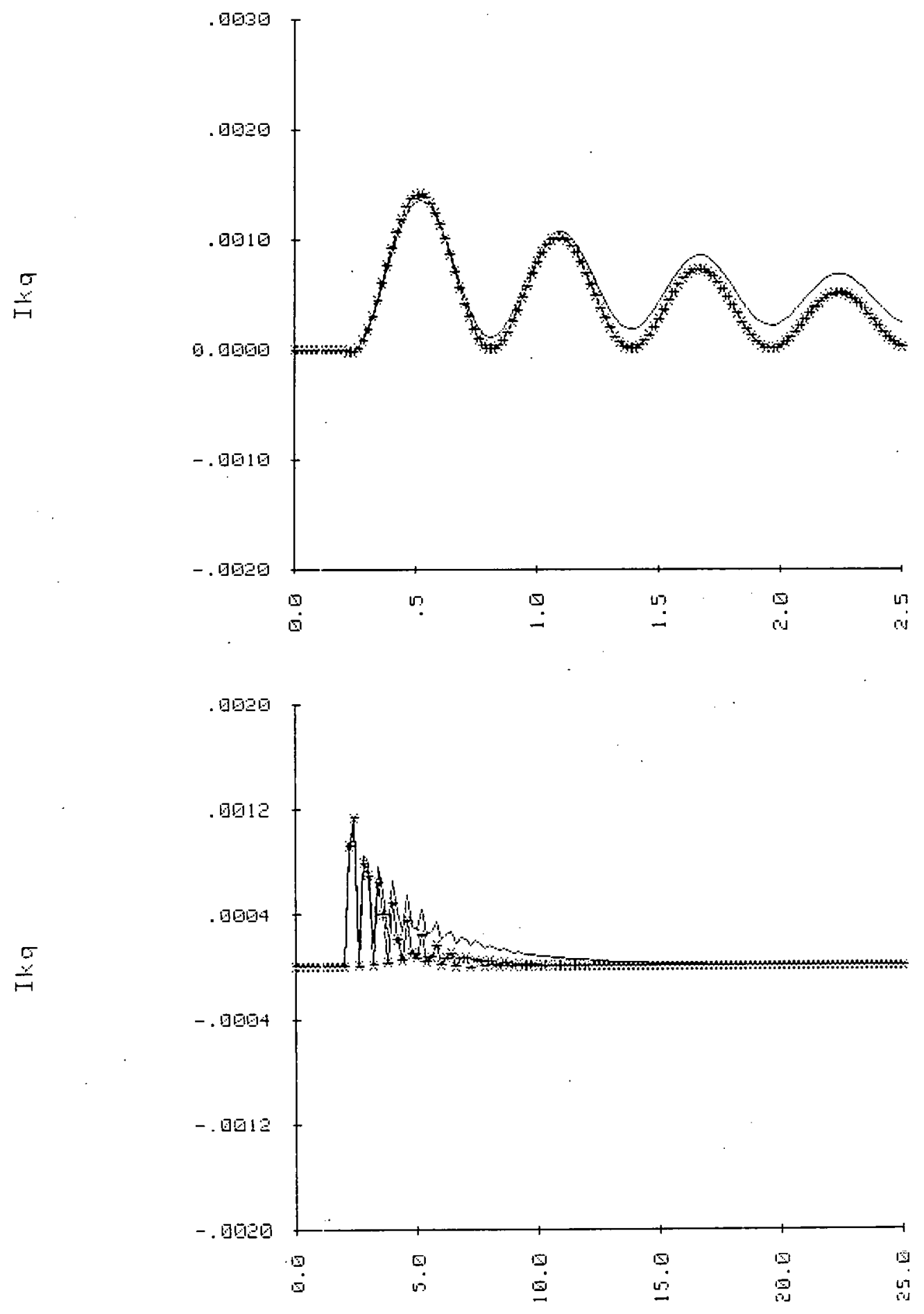

$\begin{aligned} \text { Figure B.21.b } & I_{k q} \text { vs time in seconds, E' mode1 (b), } \\ & \text { step change in EFD, saturated (*) and unsaturated response }\end{aligned}$ 


\section{THIS PAGE}

\section{WAS INTENTIONALLY \\ LEFT BLANK}


APPENDIX C

Simulation Results for the Flux Linkage Mode1

Comparing Full Saturation

to

Partial Saturation

with

Constant $\mathrm{L}_{\mathrm{MD}}$ and $\mathrm{L}_{\mathrm{MQ}}$ 

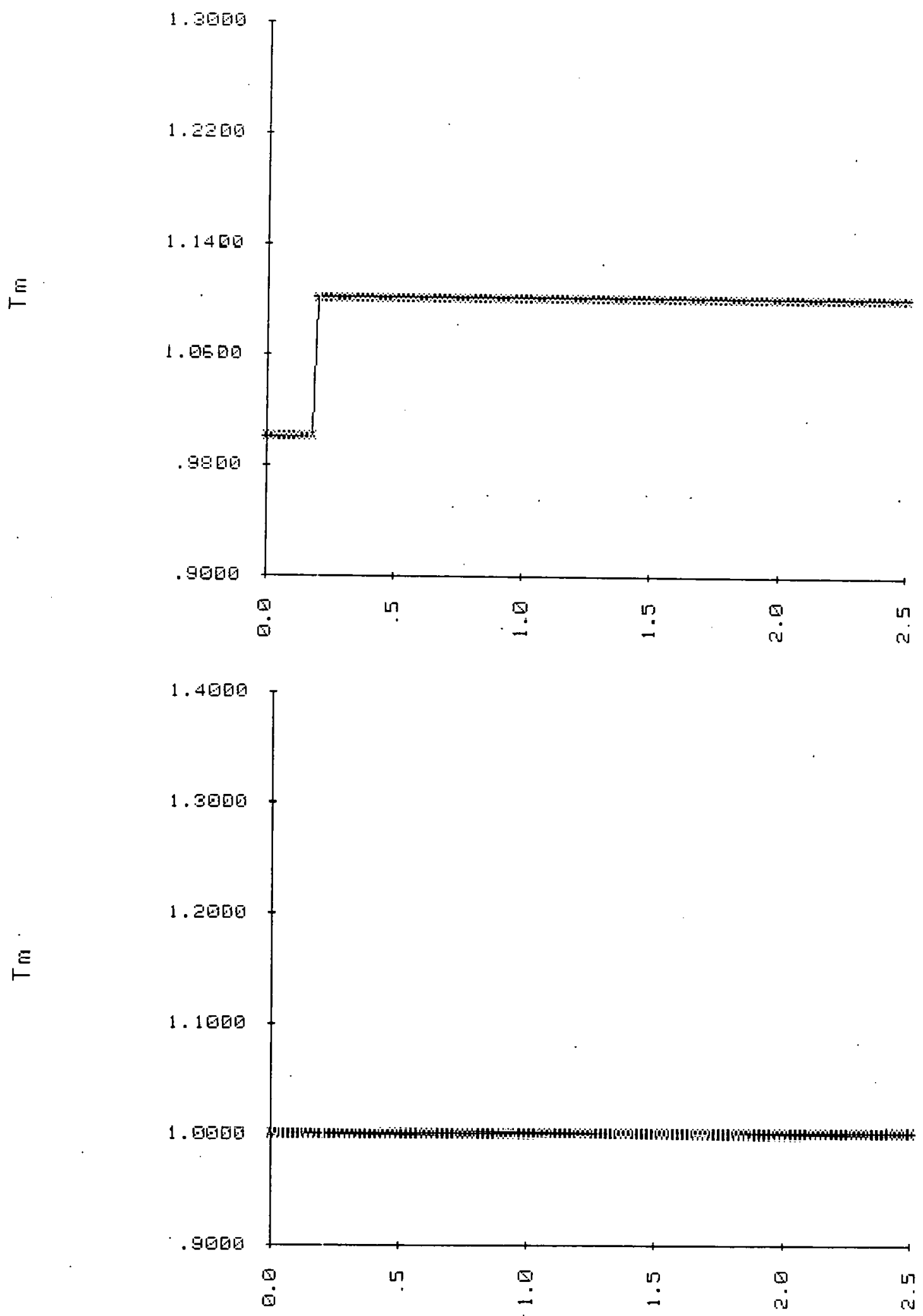

Figure C.1 $T_{m}$ vs time in seconds, Simplified F1ux Linkage Mode1, Top: $16 \%$ Change in $\mathrm{T}_{\mathrm{m}}$, Bottom: $5 \%$ Change in $\mathrm{E}_{\mathrm{FD}}$ 

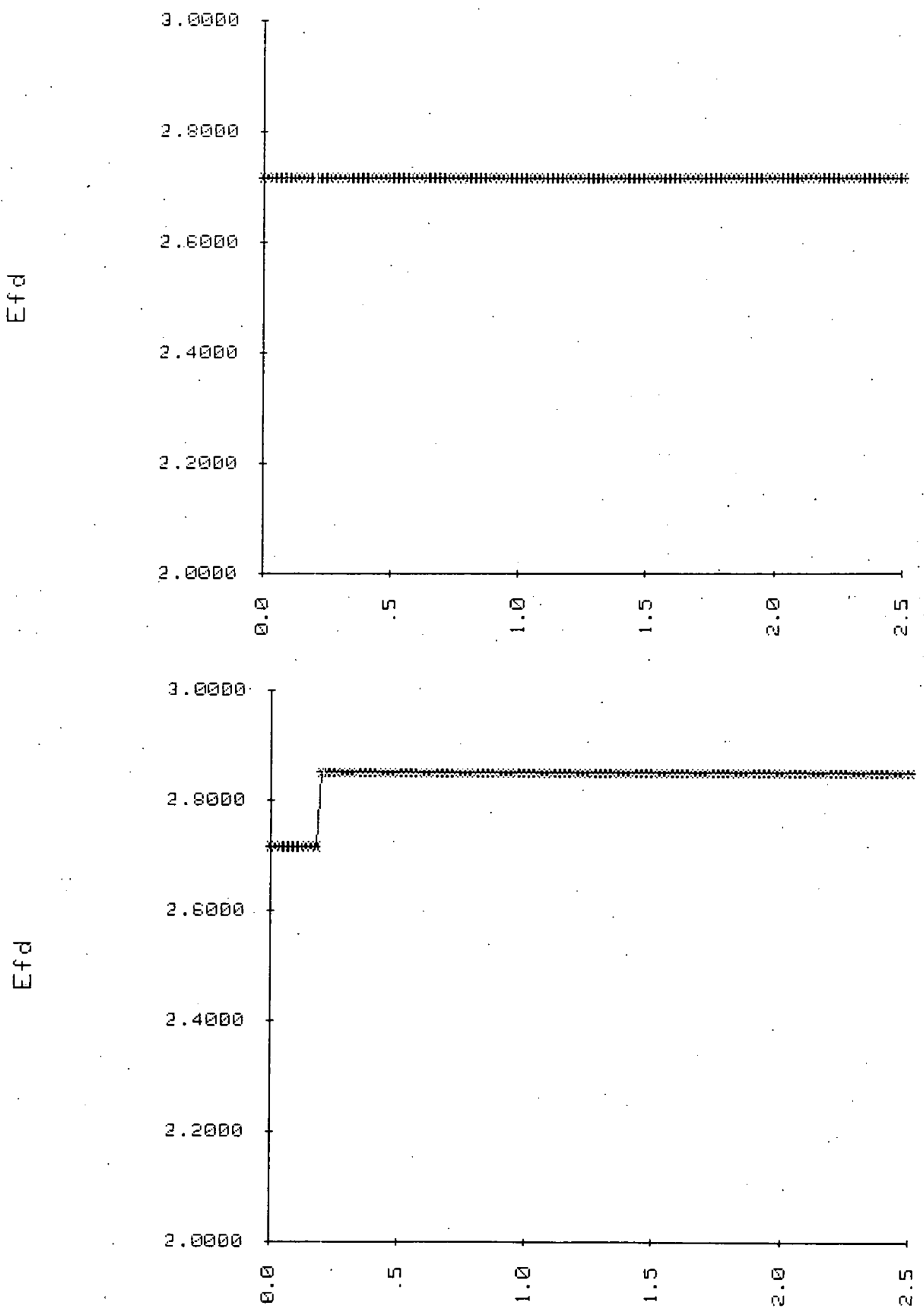

Figure C.2 E 2 Fs time in seconds, Simplified F1ux Linkage Mode1, Top: $10 \%$ Change in $\mathrm{T}_{\mathrm{m}}$, Bottom: $5 \%$ Change in $\mathrm{E}_{\mathrm{FD}}$ 

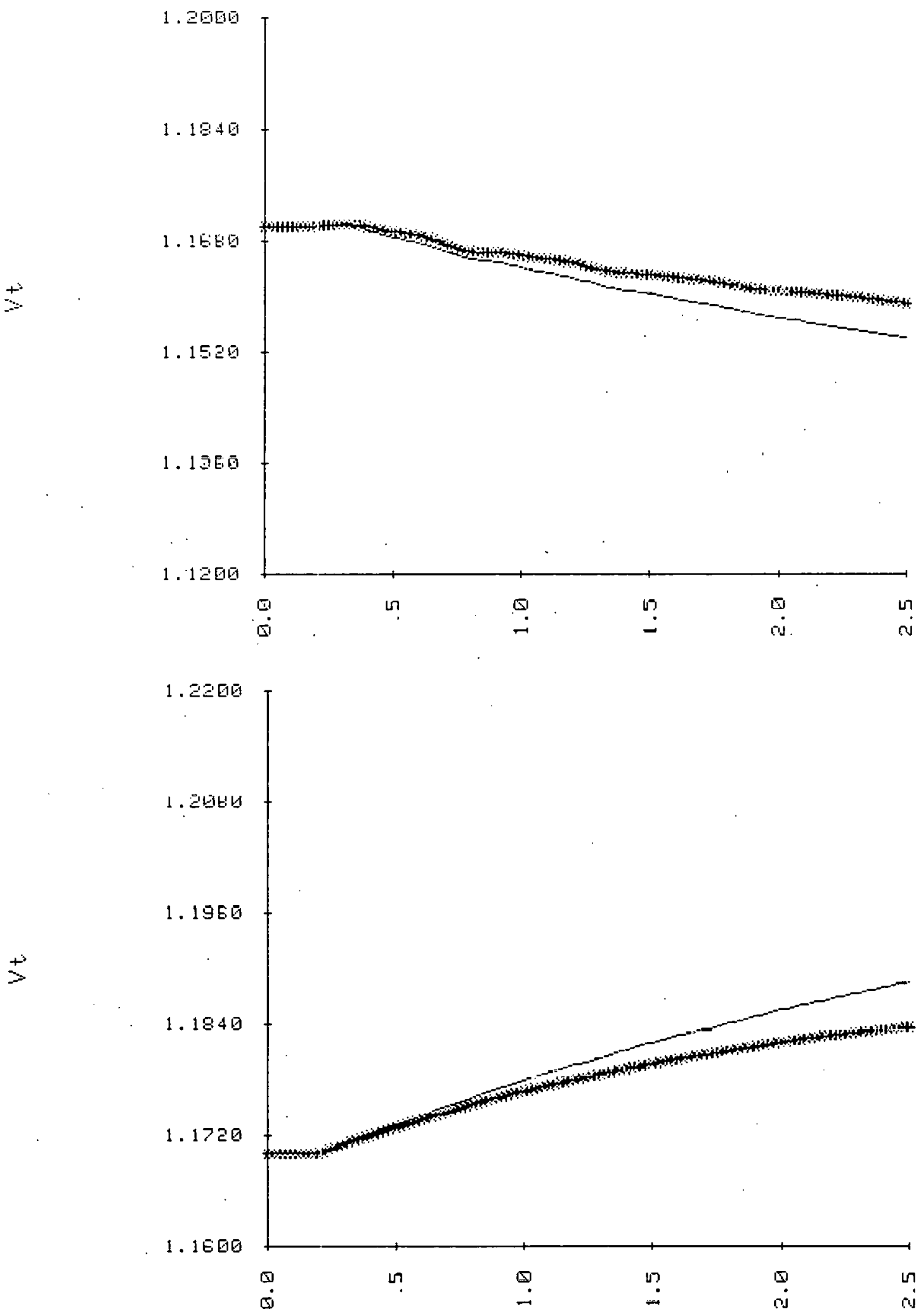

Figure C.3 $V_{t}$ vs time in seconds, Simplified F1ux Linkage Mode1, Top: 10\% Change in $T_{m}$, Bottom: $5 \%$ Change in $E_{F D}$ 

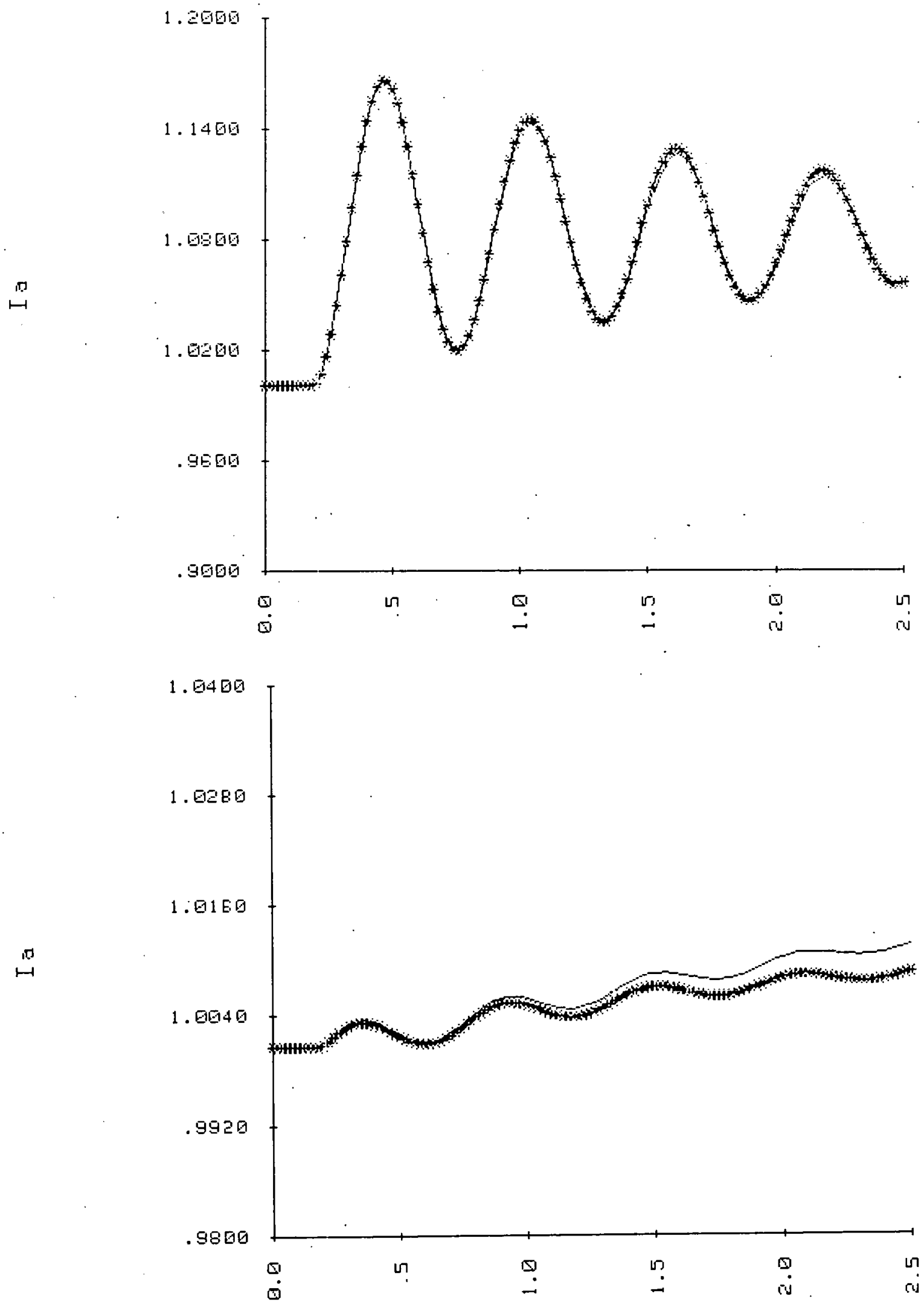

Figure C.4 $I_{a}$ vs time in seconds, Simplified F1ux Linkage Model, Top: 10\% Change in $T_{m}$, Bottom: $5 \%$ Change in $E_{F D}$ 
$\stackrel{\text { 出 }}{\leftarrow}$
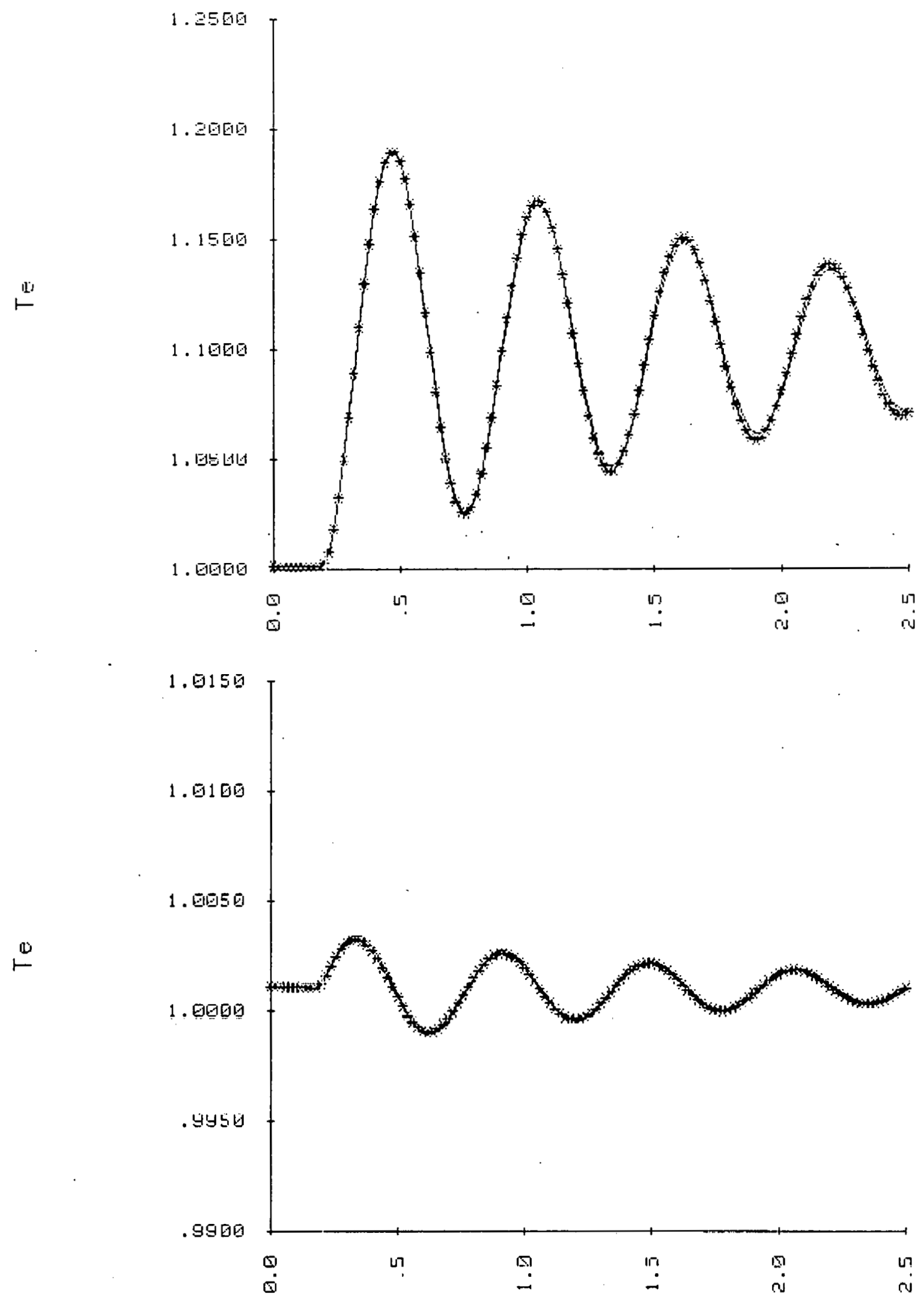

Figure C.5 $T_{e}$ vs time in seconds, Simplified F1ux Linkage Model, Top: 10\% Change in $\mathrm{T}_{\mathrm{m}}$, Bottom: $5 \%$ Change in $\mathrm{E}_{\mathrm{FD}}$ 

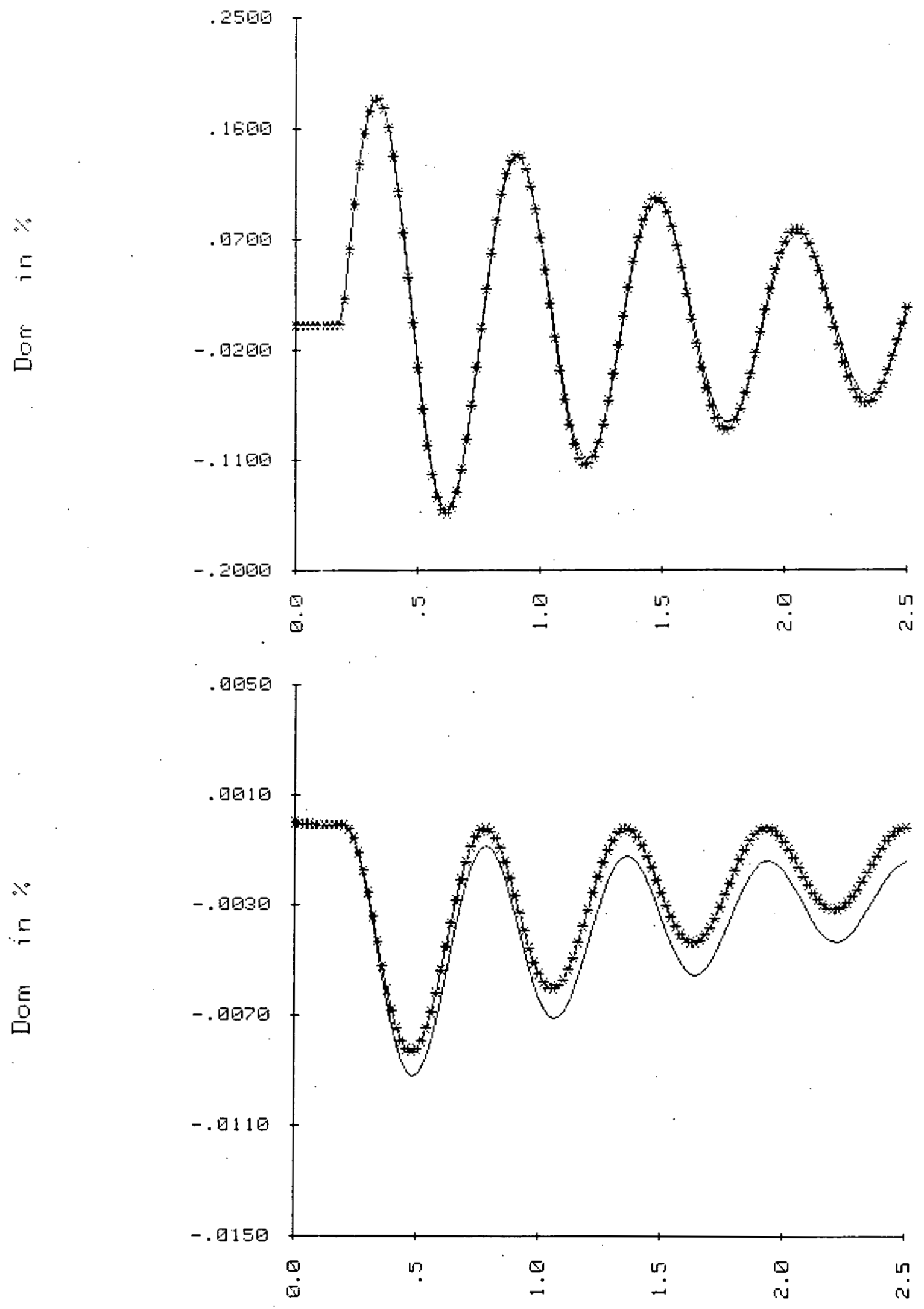

Figure C.6 $\quad \Delta \omega$ vs time in seconds, Simplified F1ux Linkage Model, Top: 10\% Change in $\mathrm{T}_{\mathrm{m}}$, Bottom: 5\% Change in $\mathrm{E}_{\mathrm{FD}}$ 


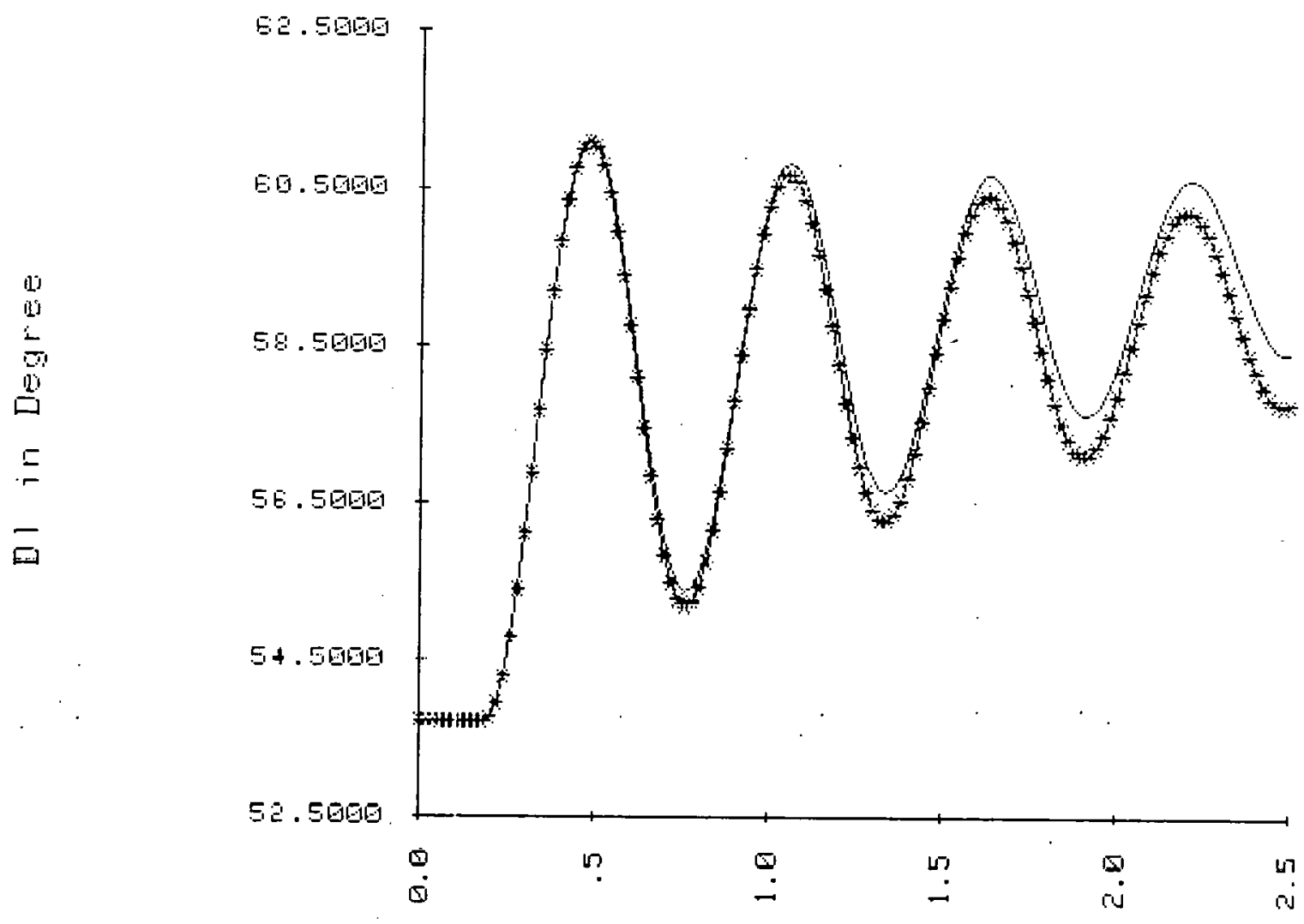

0
0
$\vdots$
0
0
0
$=$
$\square$
$\square$

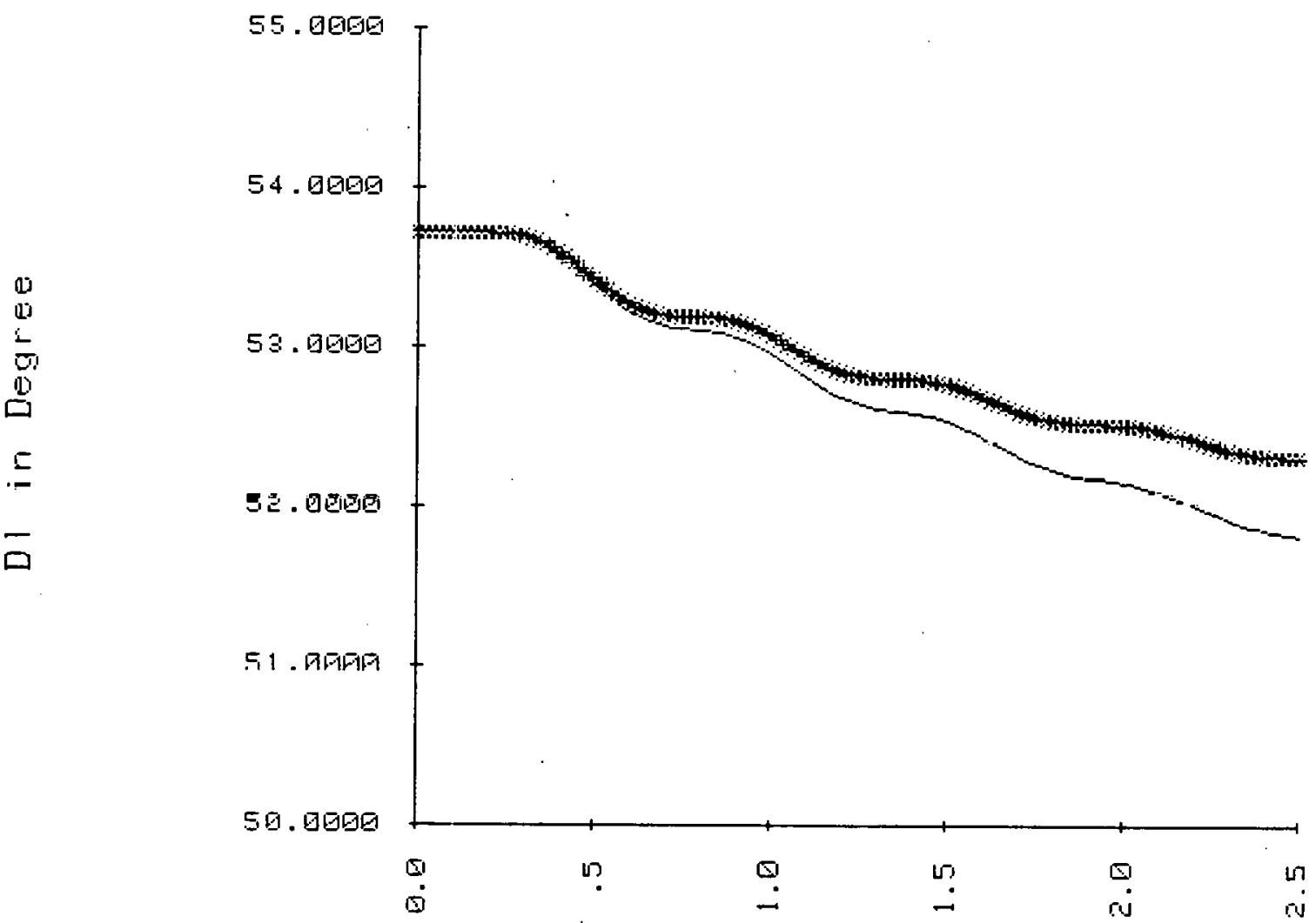

Figure C.7 $\delta$ vs time in seconds, Simplified F1ux Linkage Model, Top: $10 \%$ Change in $\mathrm{T}_{\mathrm{m}}$, Bottom: $5 \%$ Change in $\mathrm{E}_{\mathrm{FD}}$ 


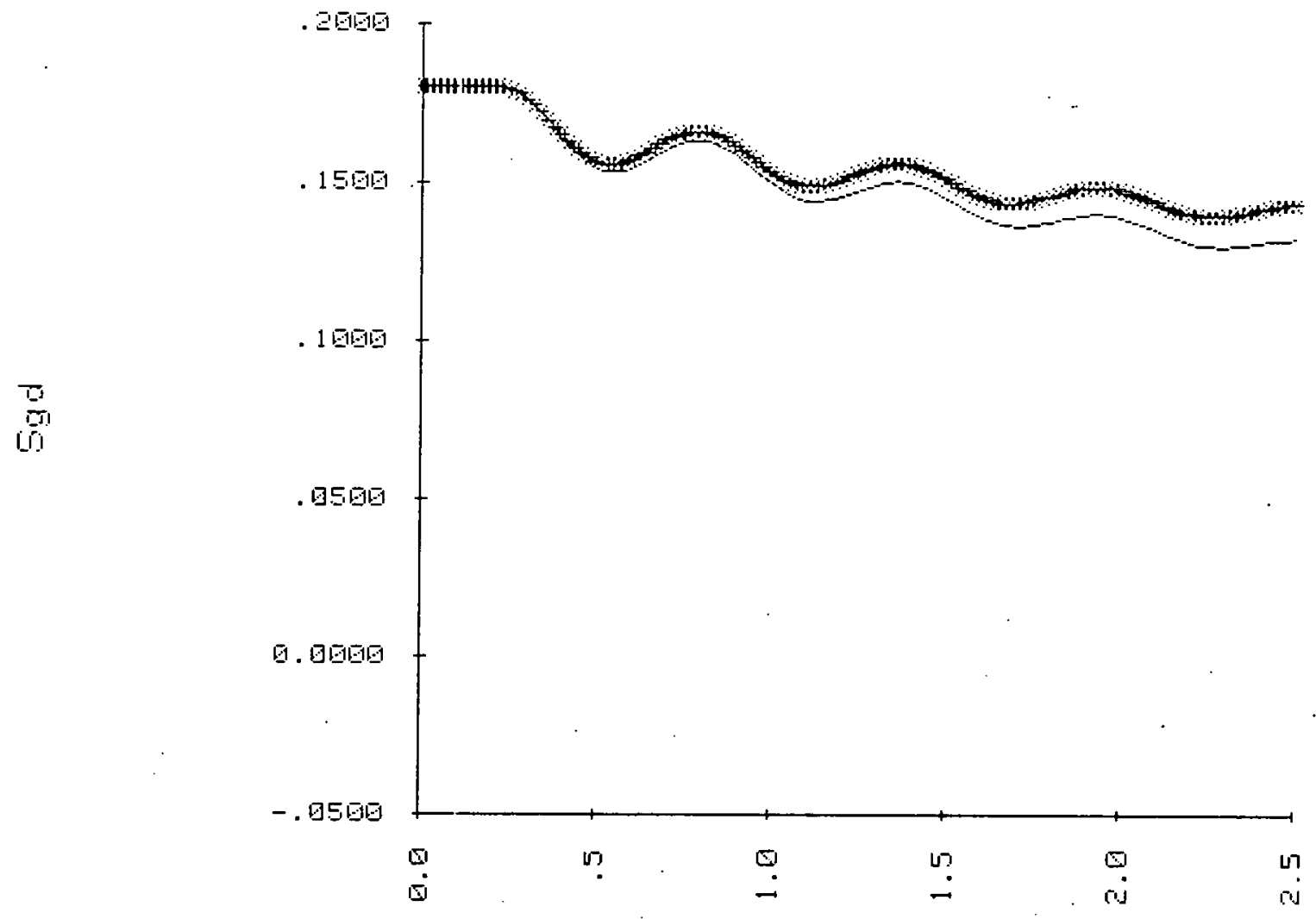

$(0)$

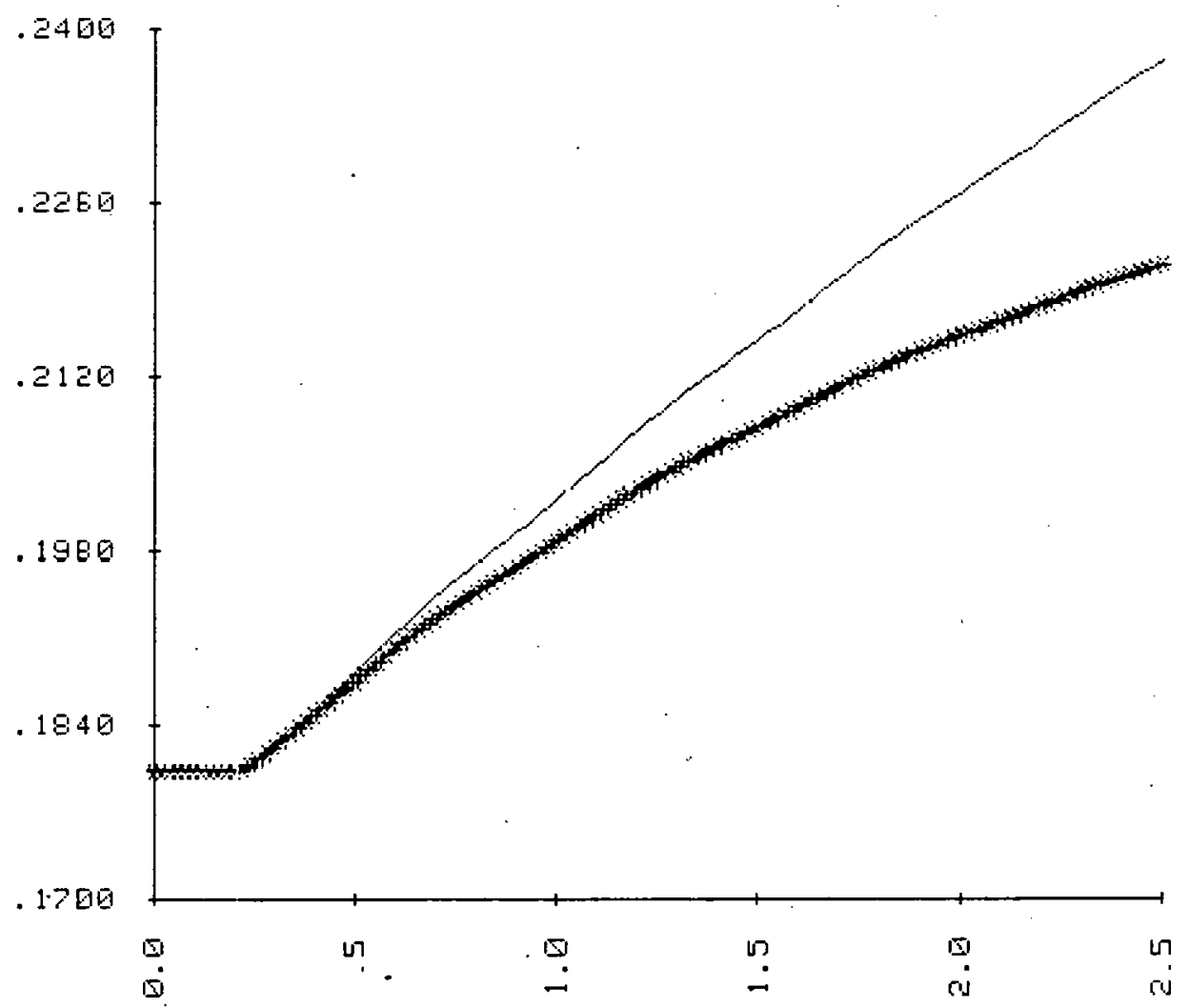

Figure C.8 $S_{G D}$ vs time in seconds, Simplified F1nx Linkage Model, Top: $10 \%$ Change in $\mathrm{T}_{\mathrm{m}}$, Bottom: $5 \%$ Change in $\mathrm{E}_{\mathrm{FD}}$ 

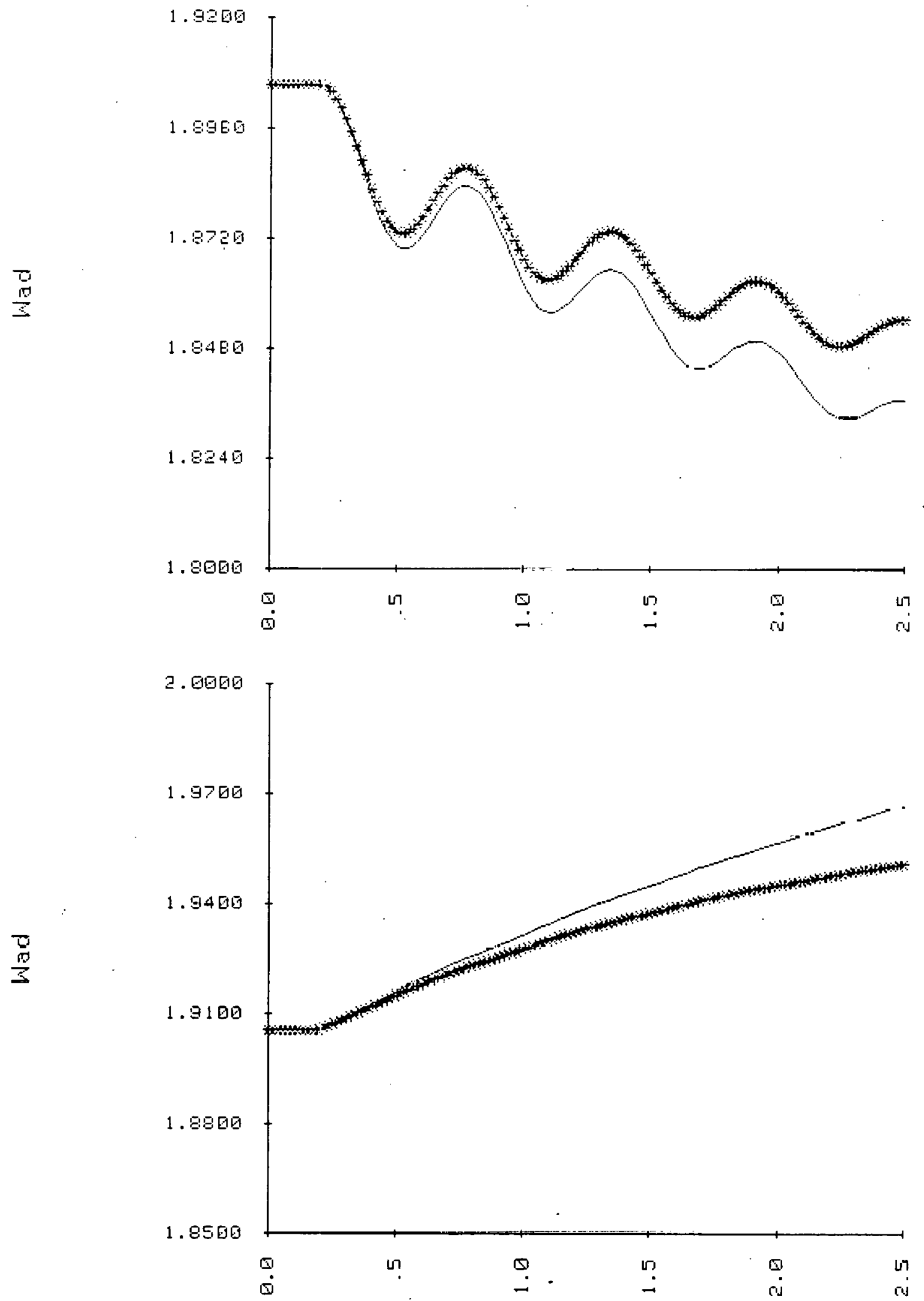

Figure C.9 $\psi_{\text {AD }}$ vs time in seconds, Simplified F1ux Linkage Model, Top: 10\% Change in $\mathrm{T}_{\mathrm{m}}$. Bottom: $5 \%$ Change in $\mathrm{E}_{\mathrm{FD}}$ 

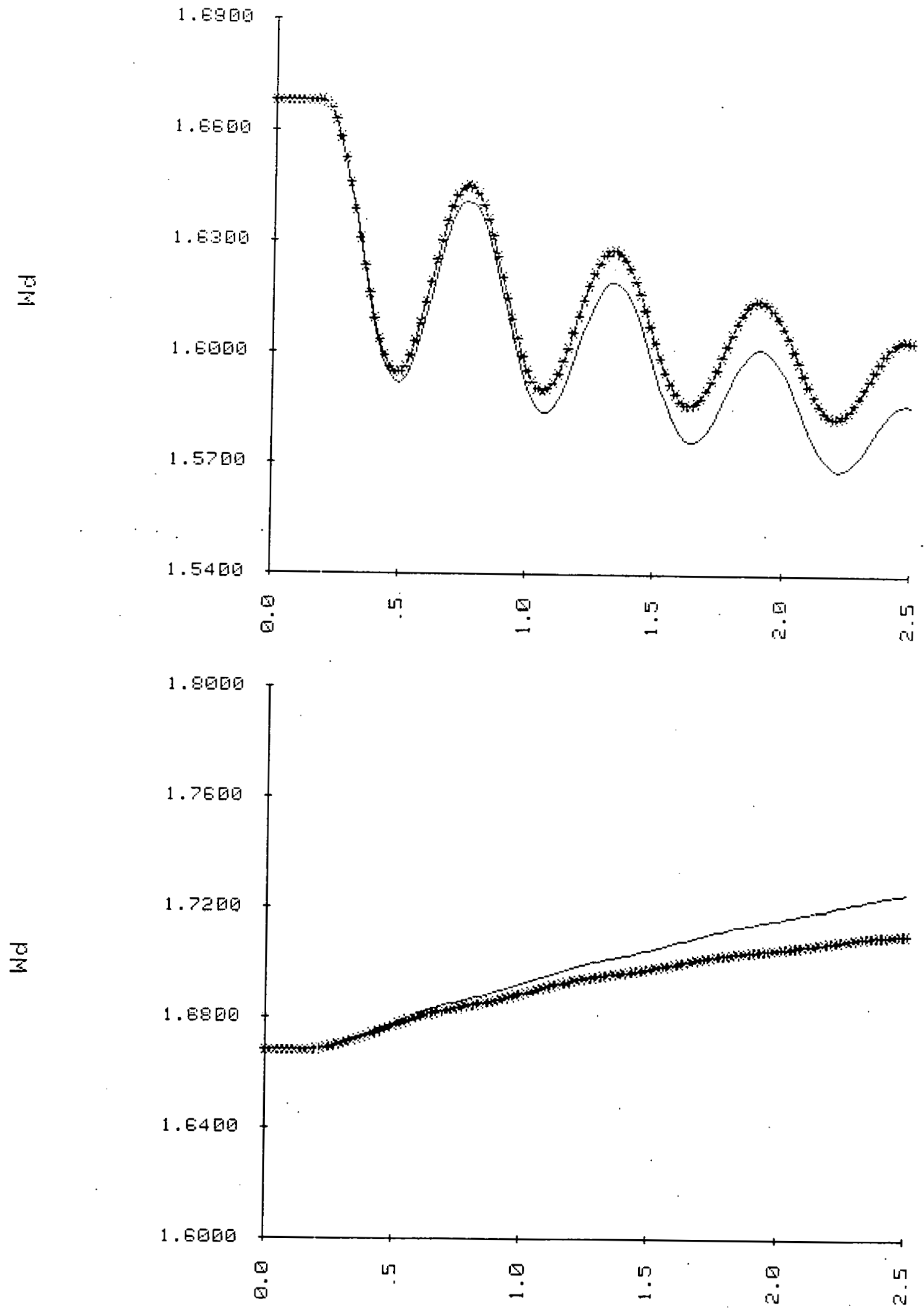

Figure C.10 $\psi_{d}$ vs time in seconds, Simplified Flux Linkage Model, Top: $10 \%$ Change in $T_{\text {mI }}$, Bottom: $5 \%$ Change in EFD 

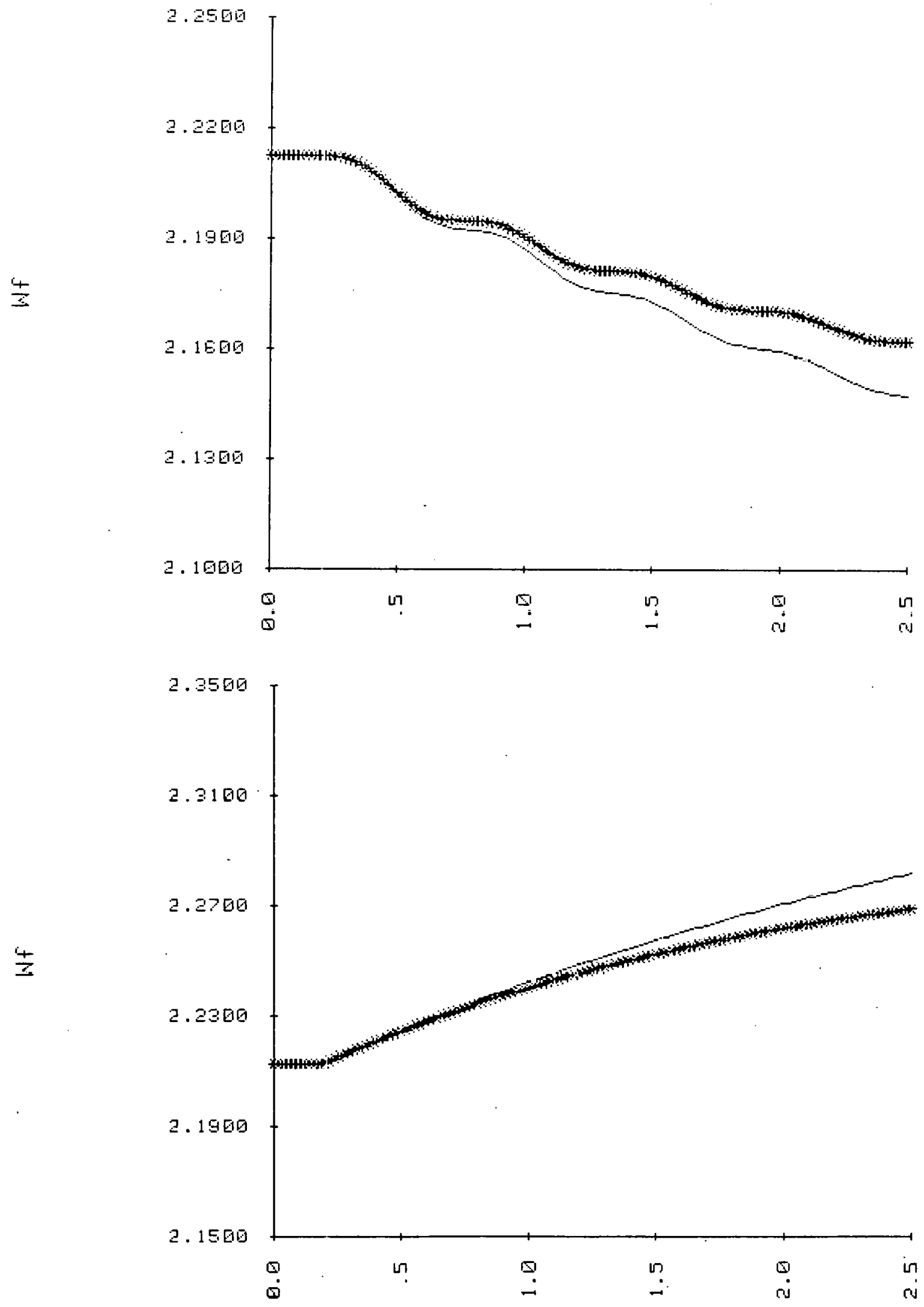

Figure C.11 $\psi_{F}$ vs time in seconds, Simplified Flux Linkage Model, Top: 10\% Change in $T_{m}$, Bottom: $5 \%$ Change in $\mathrm{E}_{\mathrm{FD}}$ 

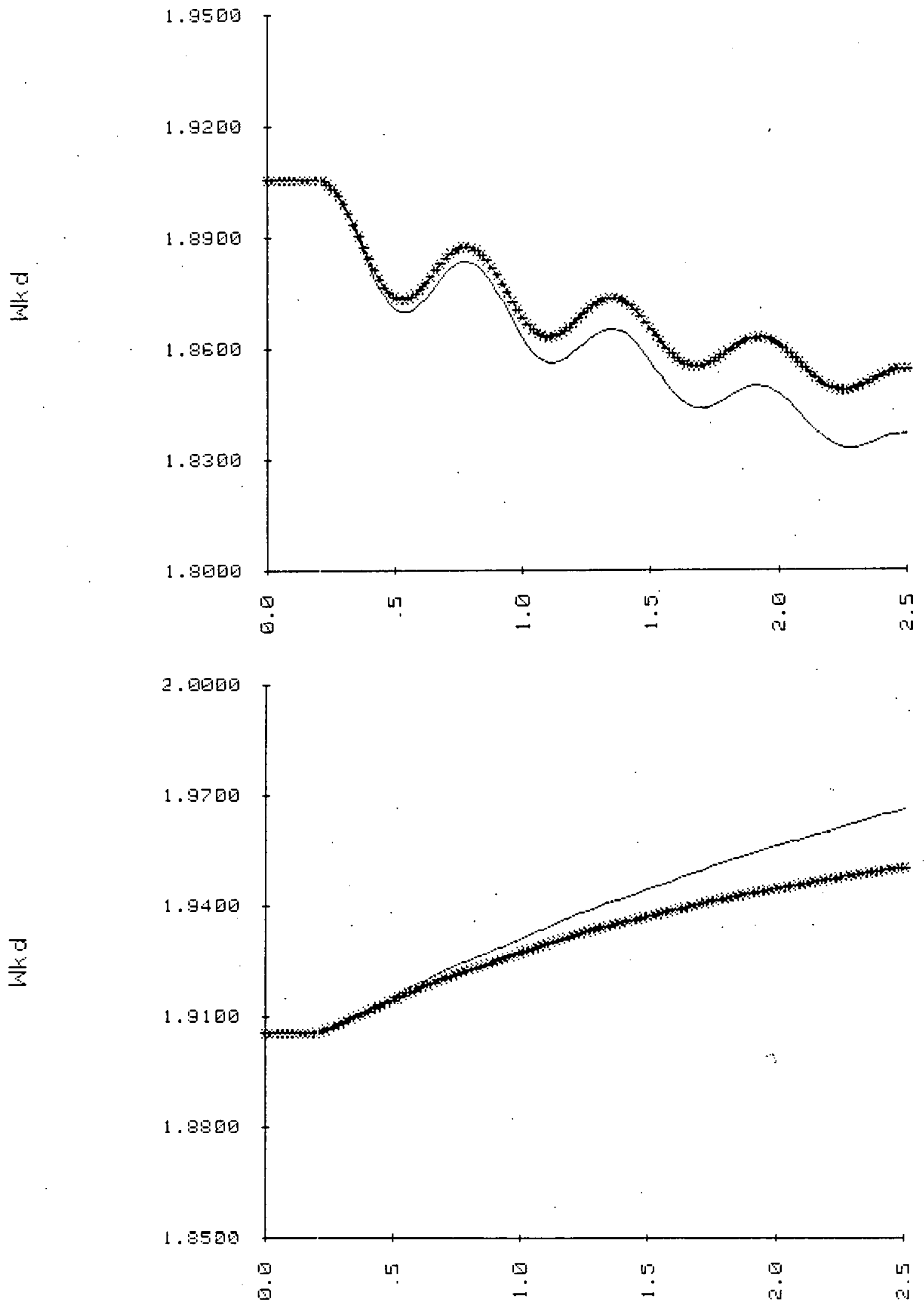

Figure C.12 $\psi_{k d}$ vs time in seconds, Simplified Flux Linkage Model, Top: $10 \%$ Change in $T_{m}$, Bottom: $5 \%$ Change in $E_{F D}$ 

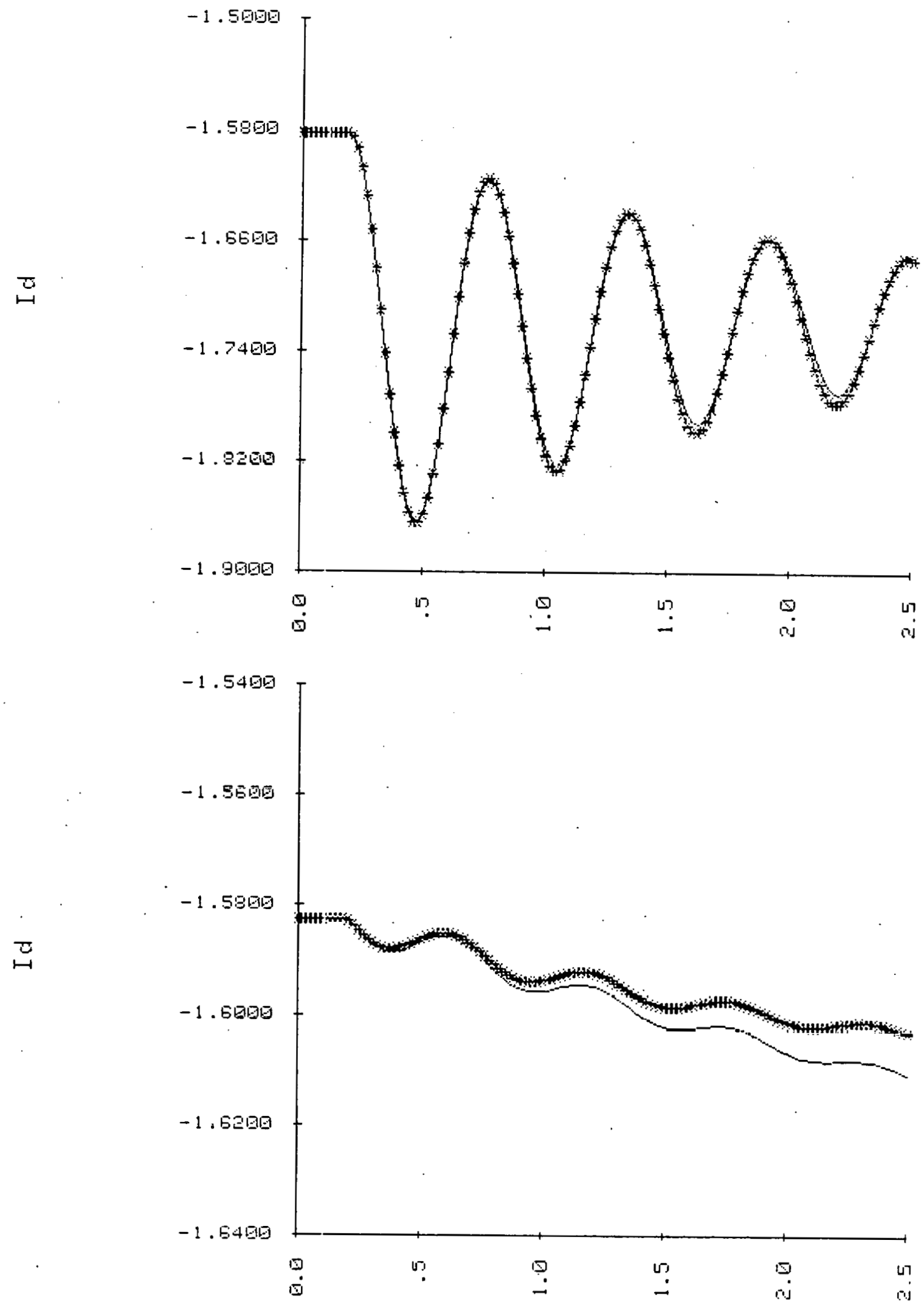

Figure C.13 $I_{d}$ vs time in seconds, Simp1ified Flux Linkage Mode1, Top: 10\% Change in $T_{m}$, Bottom: $5 \%$ Change in $E_{F D}$ 

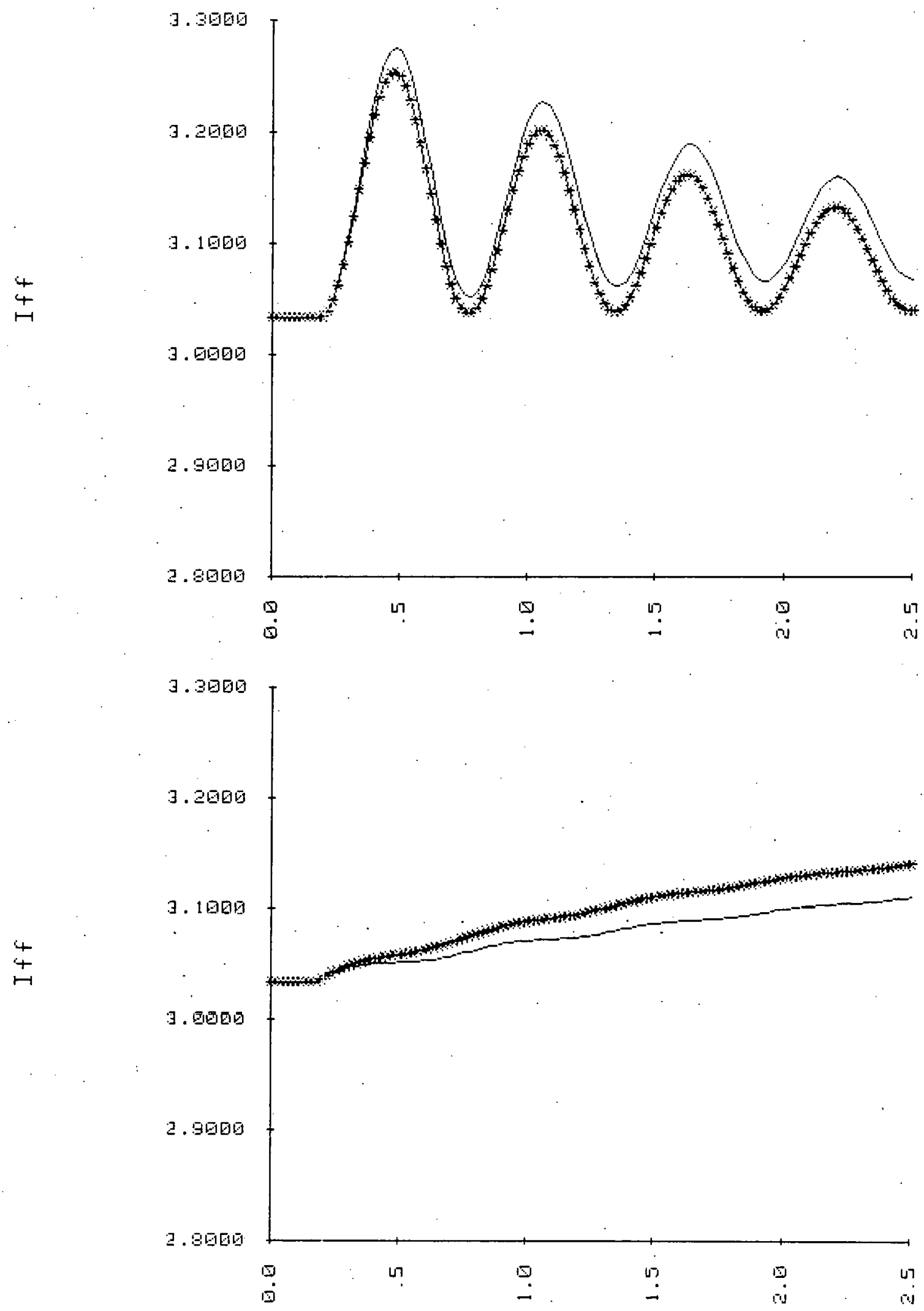

Figure C.14. IF vs time in seconds, Simplified F1ux Linkage Mode1, Top: 10\% Change in $\mathrm{T}_{\mathrm{m}}$, Bottom: $5 \%$ Change in $\mathrm{E}_{\mathrm{FD}}$ 

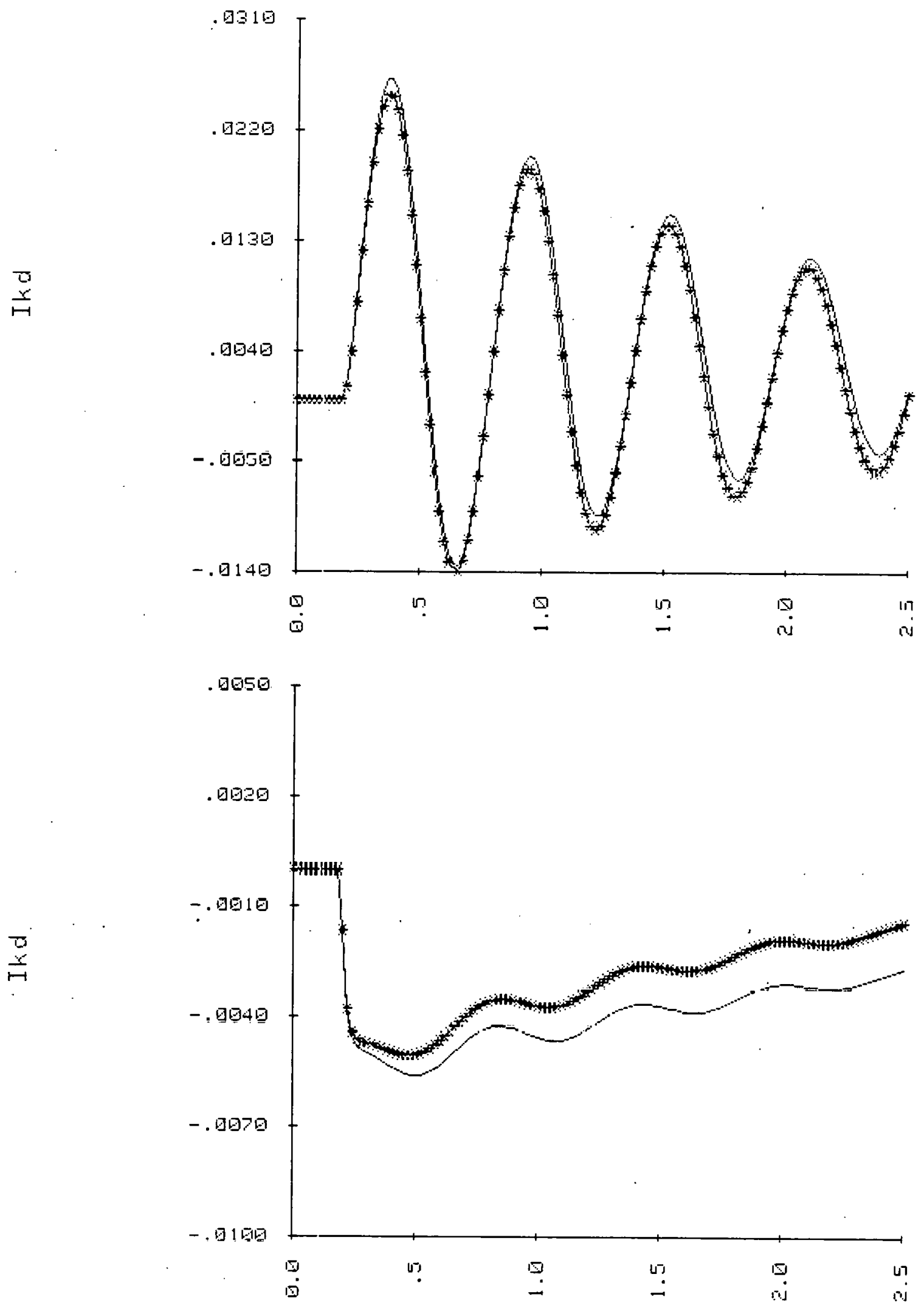

Figure C.15 $I_{k d} v s$ time in seconds, Simplified Flux Linkage Model,

Top: 10\% Change in $T_{m}$, Bottom: $5 \%$ Change in $\mathrm{E}_{\mathrm{FD}}$

170 

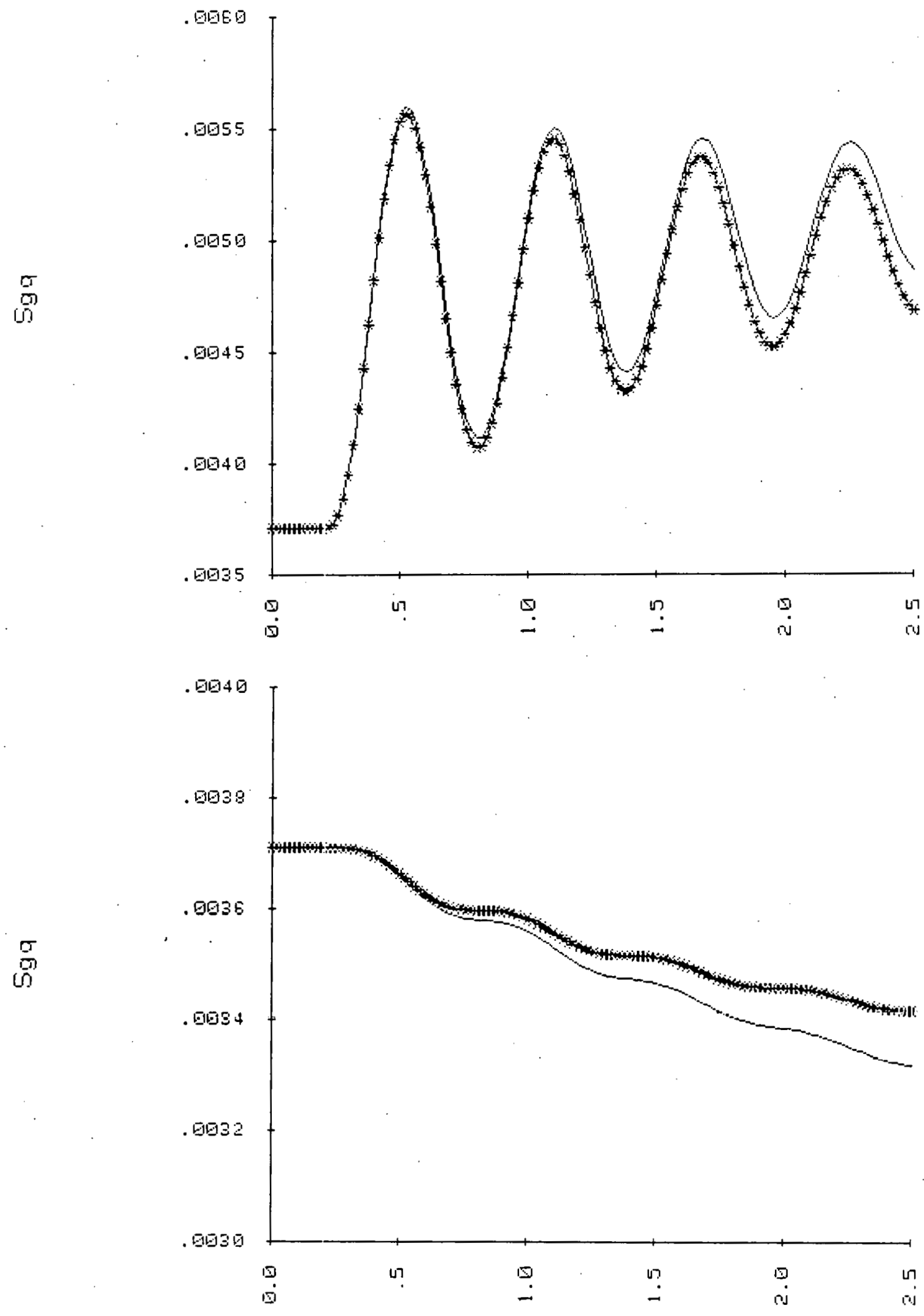

Figure C.16 S $S_{\text {Gq }}$ vs time in seconds, Simplified F1ux Linkage Model, Top: $10 \%$ Change in $\mathrm{T}_{\mathrm{m}}$, Bottom: $5 \%$ Change in $\mathrm{E}_{\mathrm{FD}}$ 

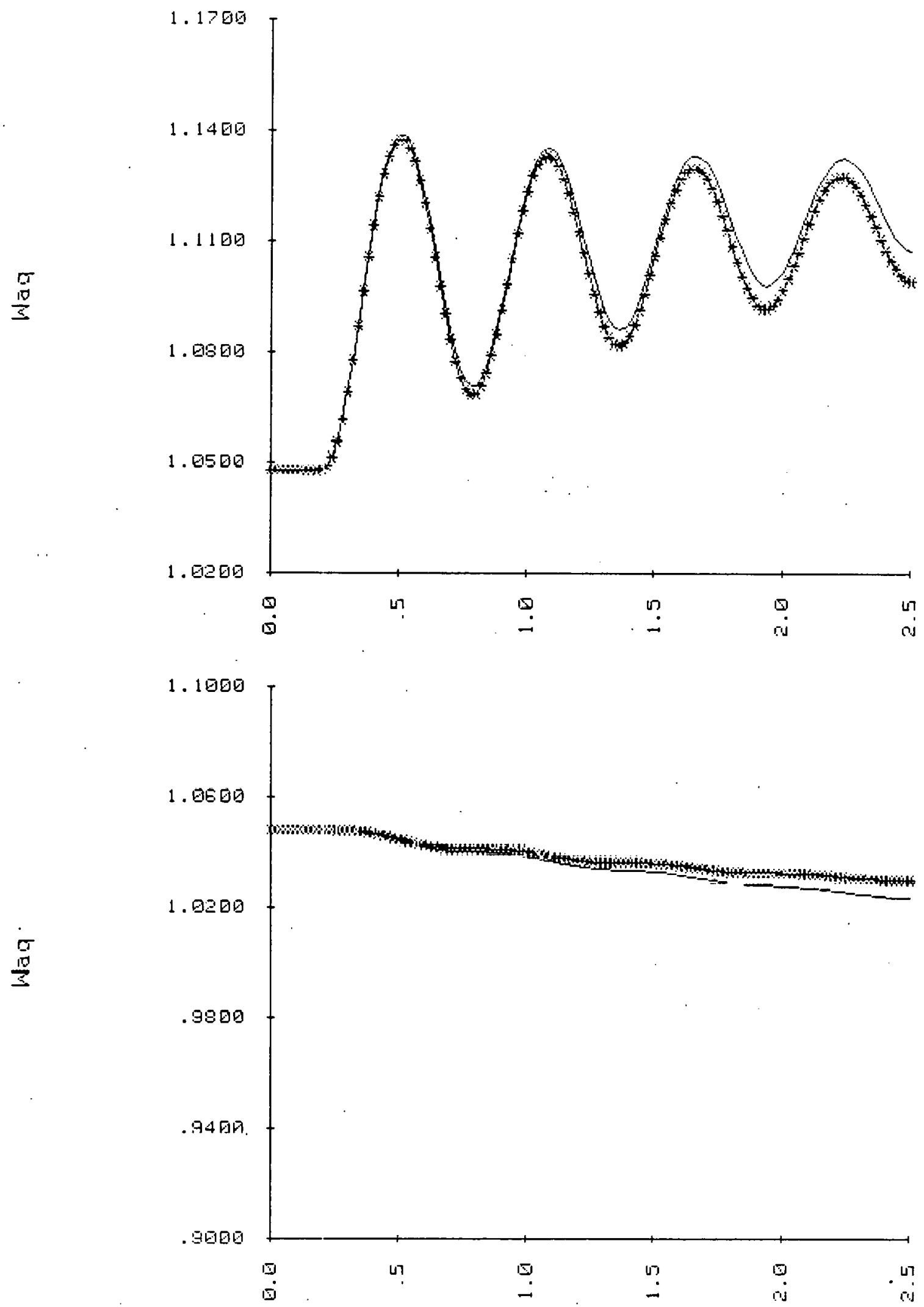

Figure C.17 $\Psi_{A Q}$ vs time in seconds, Simp1ified F1ux Linkage Mode1, Top: 10\% Change in $T_{m}$, Bottom: $5 \%$ Change in $E_{F D}$ 

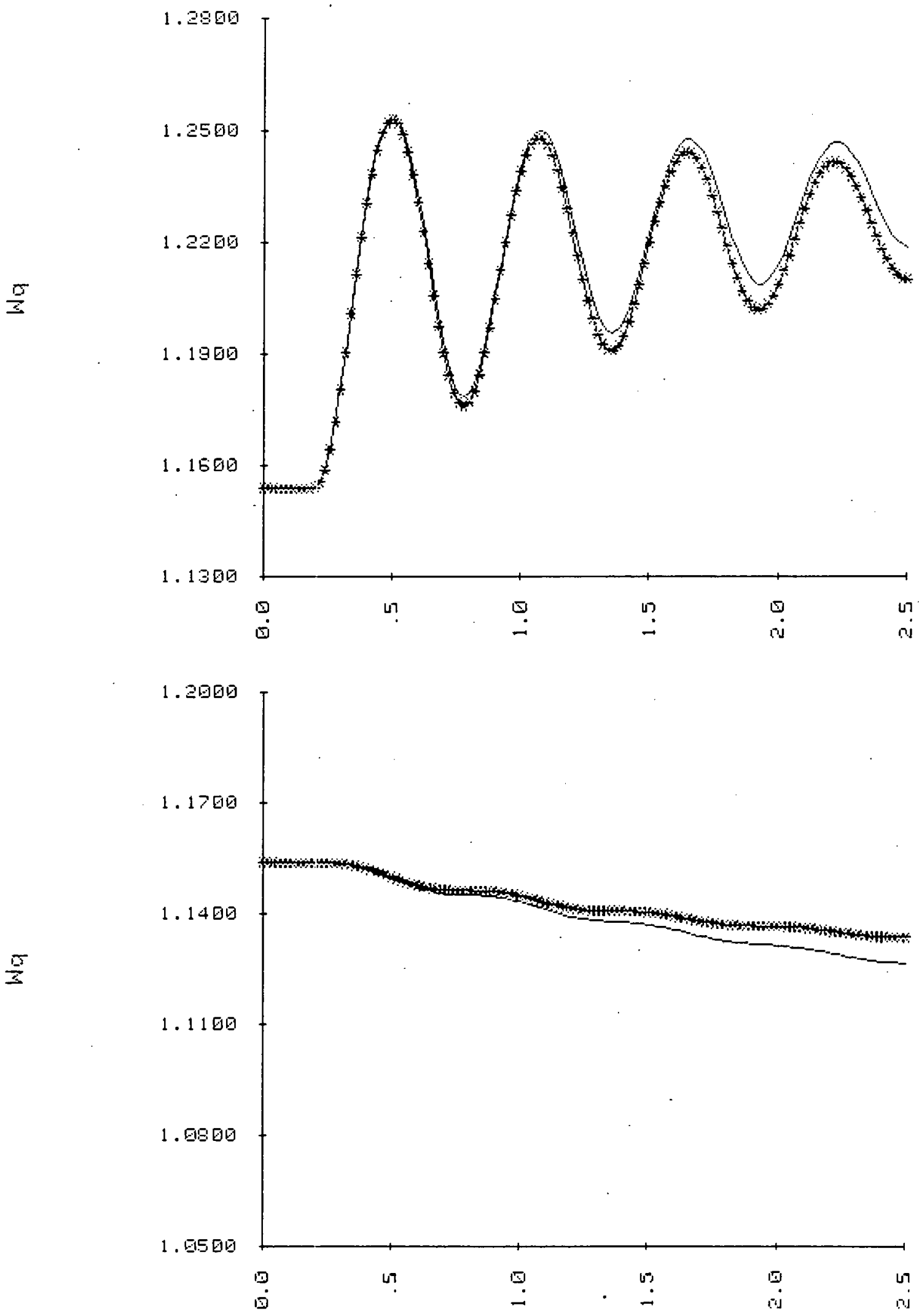

Figure C.18 $\psi_{\mathrm{q}}$ $\nabla \mathrm{s}$ time in seconds, Simplified F1ux Linkage Model, Top: $10 \%$ Change in $\mathrm{T}_{\mathrm{m}}$, Bottom: $5 \%$ Change in $\mathrm{E}_{\mathrm{FD}}$ 

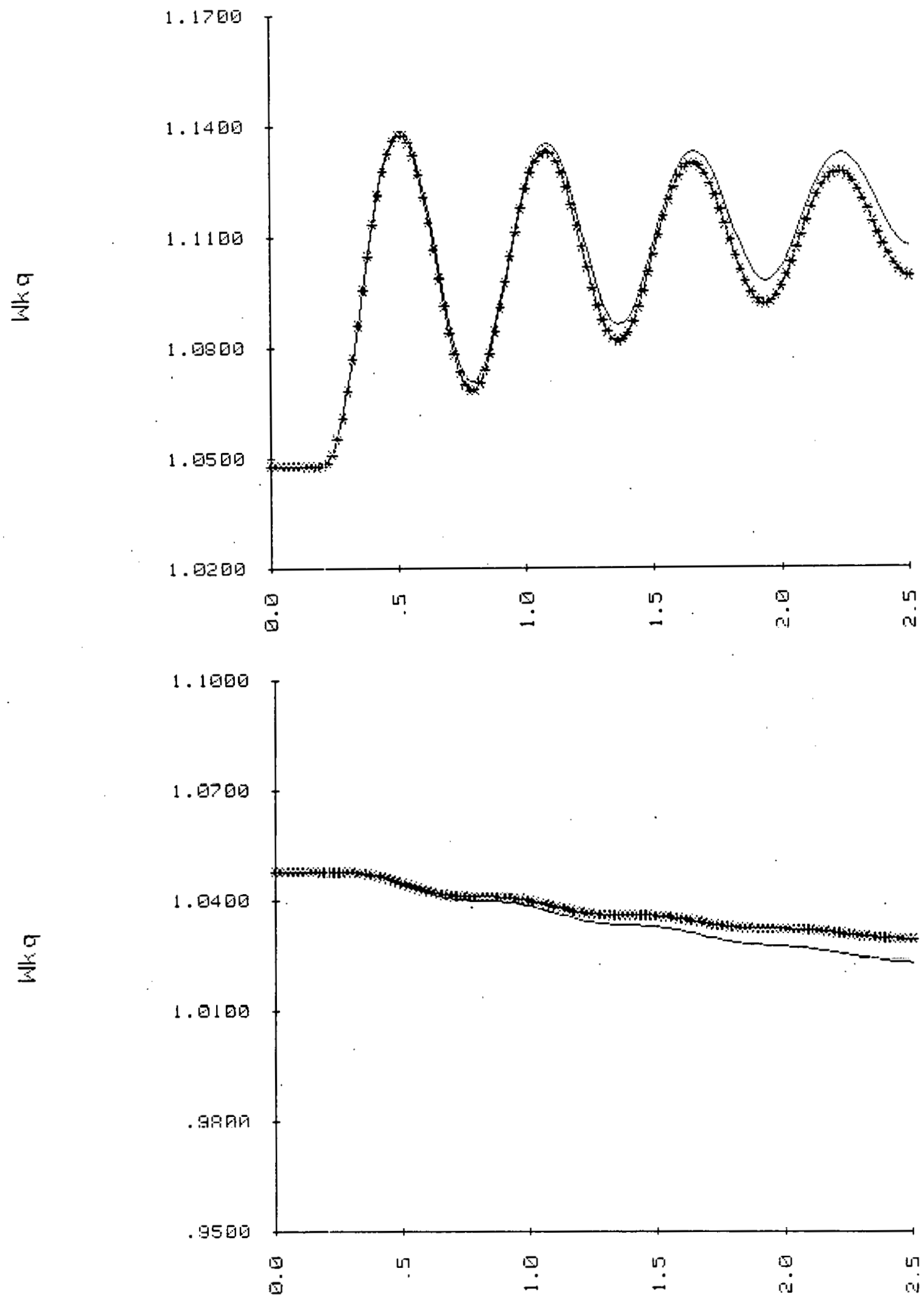

Figure C.19 $\psi_{\mathrm{kq}}$ vs time in seconds, Simplified F1ux Linkage Model, Top: $10 \%$ Change in $T_{m}$, Bottom: $5 \%$ Change in $E_{F D}$ 

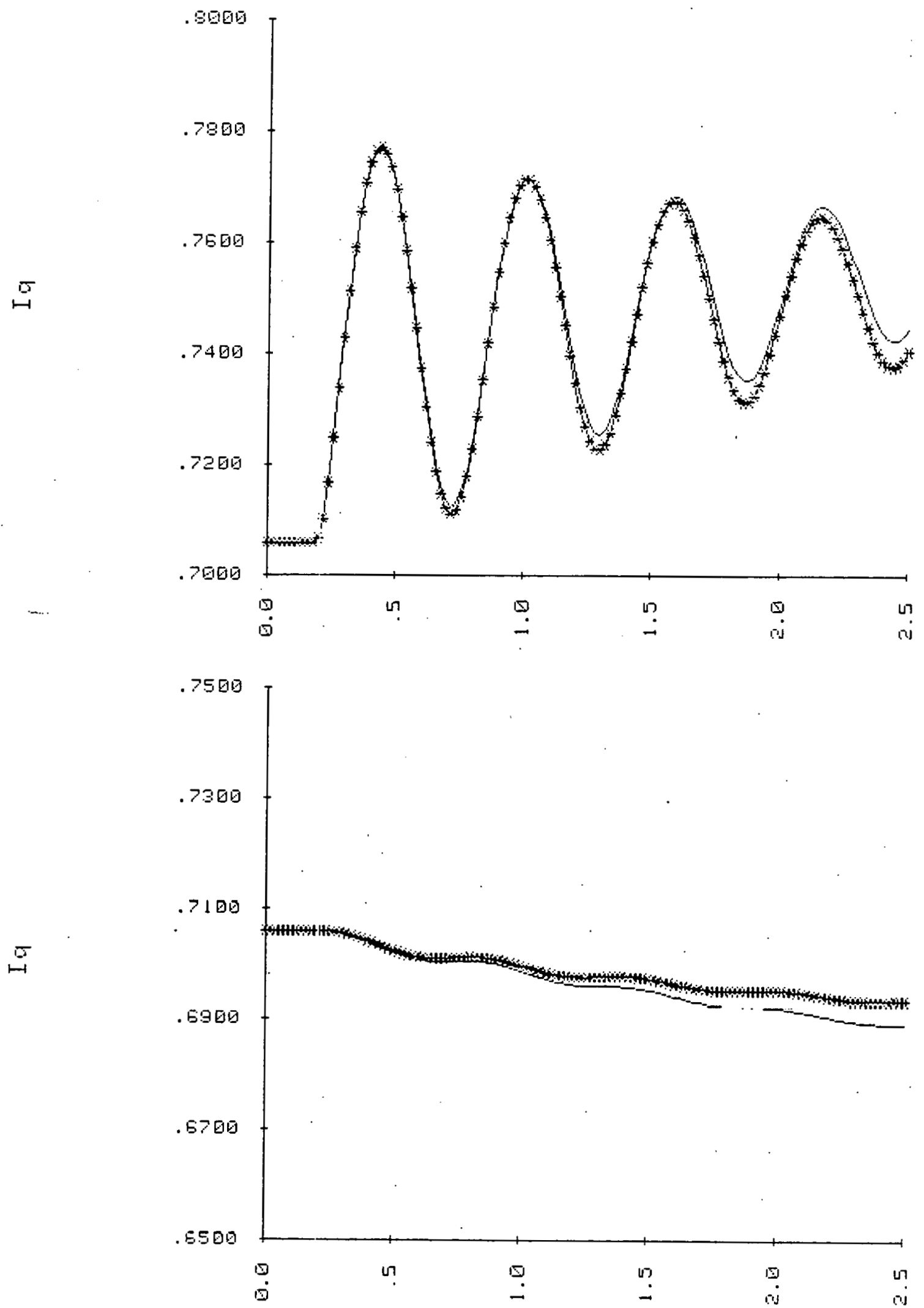

Figure C.20 $I_{q}$ vs time in seconds, Simplified Flux Linkage Model, Top: 10\% Change in $T_{m}$. Bottom: $5 \%$ Change in $E_{F D}$ 

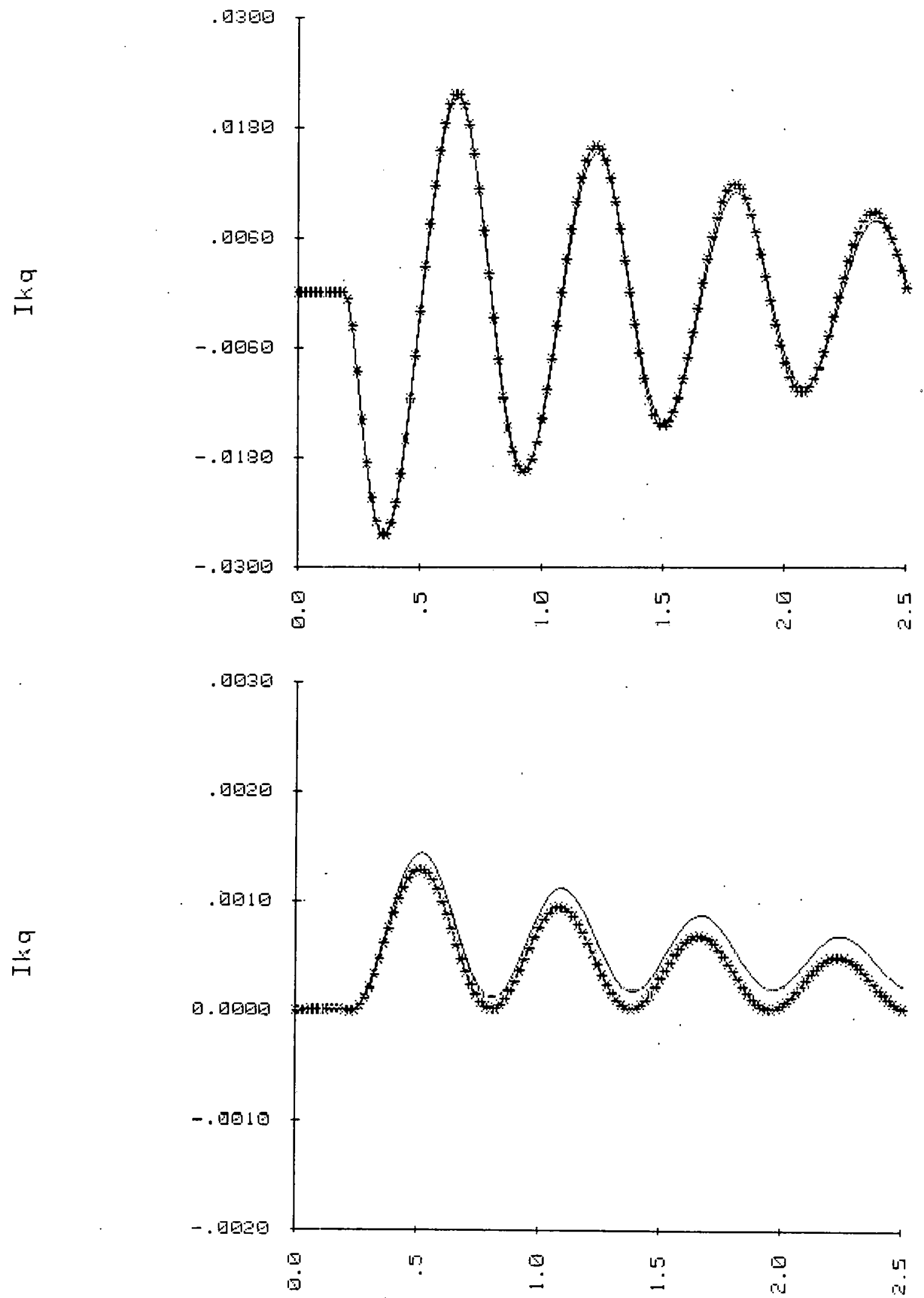

Figure C.21 $I_{k q}$ vs time in seconds, Simplified Flux Linkage Model,

Top: $10 \%$ Change in $\mathrm{T}_{\mathrm{m}}$, Bottom: $5 \%$ Change in $\mathrm{E}_{\mathrm{FD}}$ 


\title{
APPENDIX D
}

\author{
Simulation Results Comparing \\ Flux Linkage and E"' Models \\ with the \\ E' Model only Partially Saturated
}



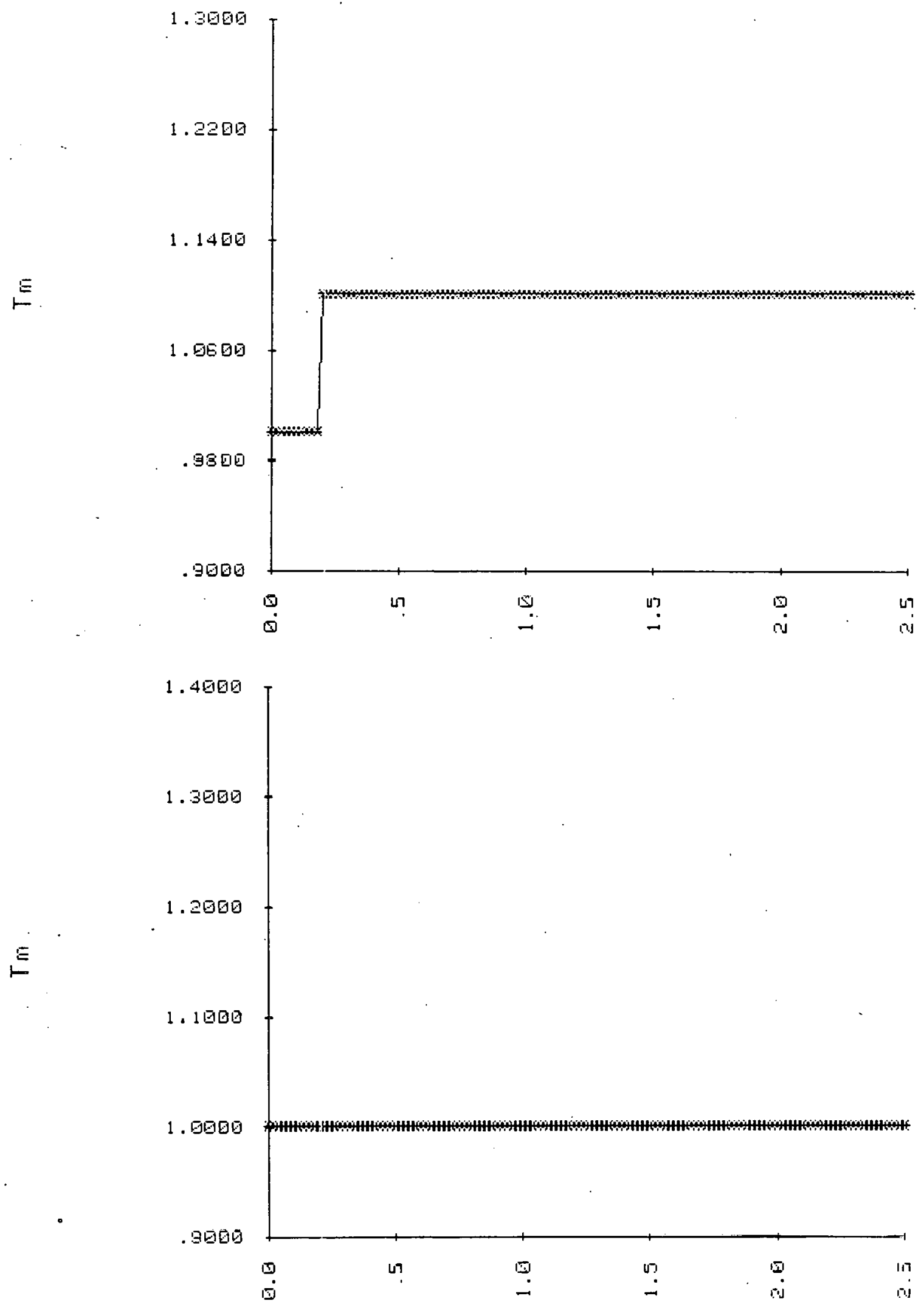

Figure D.1 $T_{m}$ vs time in seconds, Simplified E' Model,

Top: 10\% Change in $\mathrm{T}_{\mathrm{m}}$, Bottom: $5 \%$ Change in $\mathrm{E}_{\mathrm{FD}}$ 

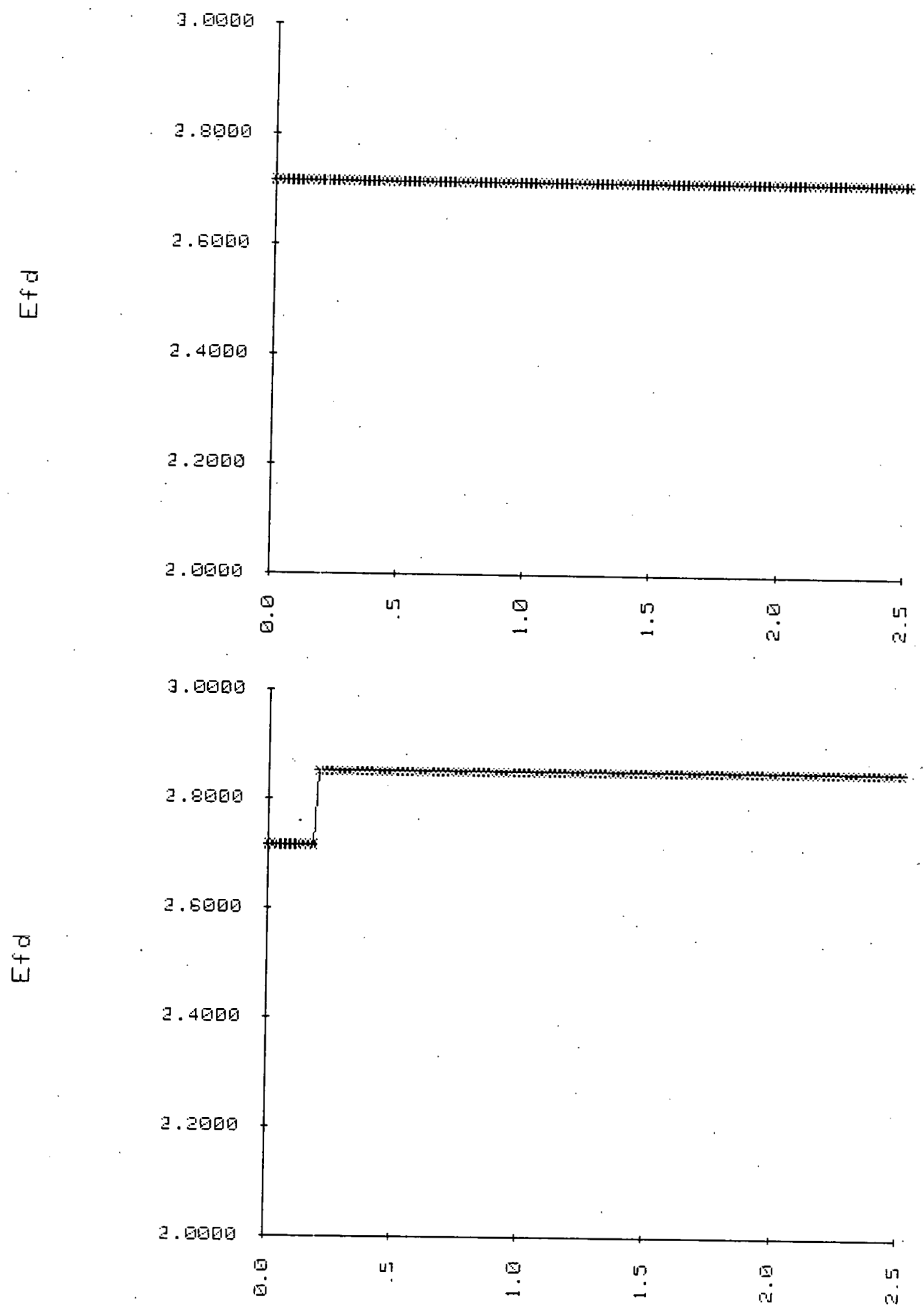

Figure D.2 $E_{F D}$ vs time in seconds, Simp1ified E'" Mode1, Top: $10 \%$ Change in $\mathrm{T}_{\mathrm{m}}$, Bottom: $5 \%$ Change in $\mathrm{E}_{\mathrm{FD}}$ 

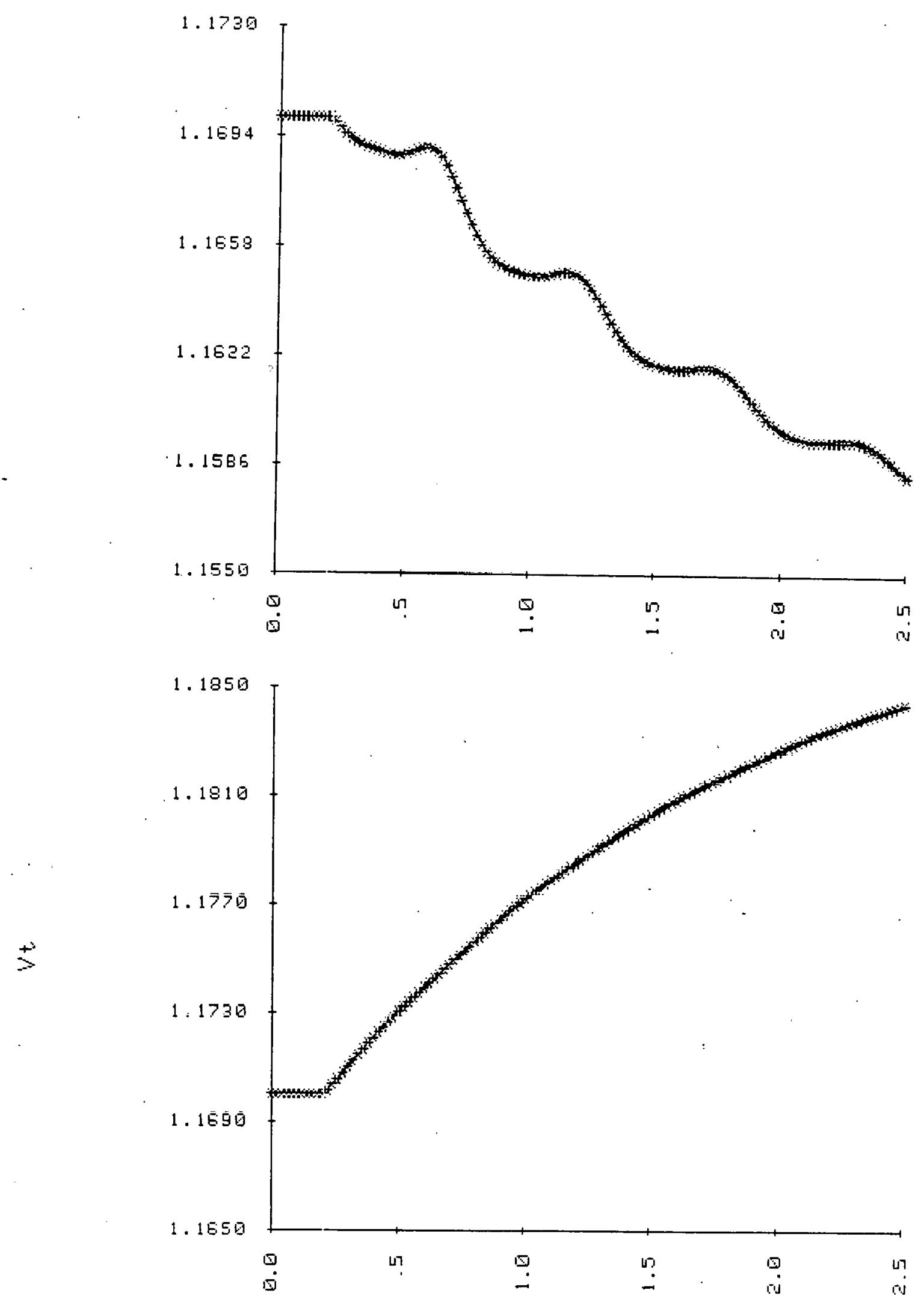

Figure D.3 $V_{t}$ vs time in seconds, Simplified E' Model,

Top: 10\% Change in $T_{m}$, Bottom: 5\% Change in $E_{F D}$ 

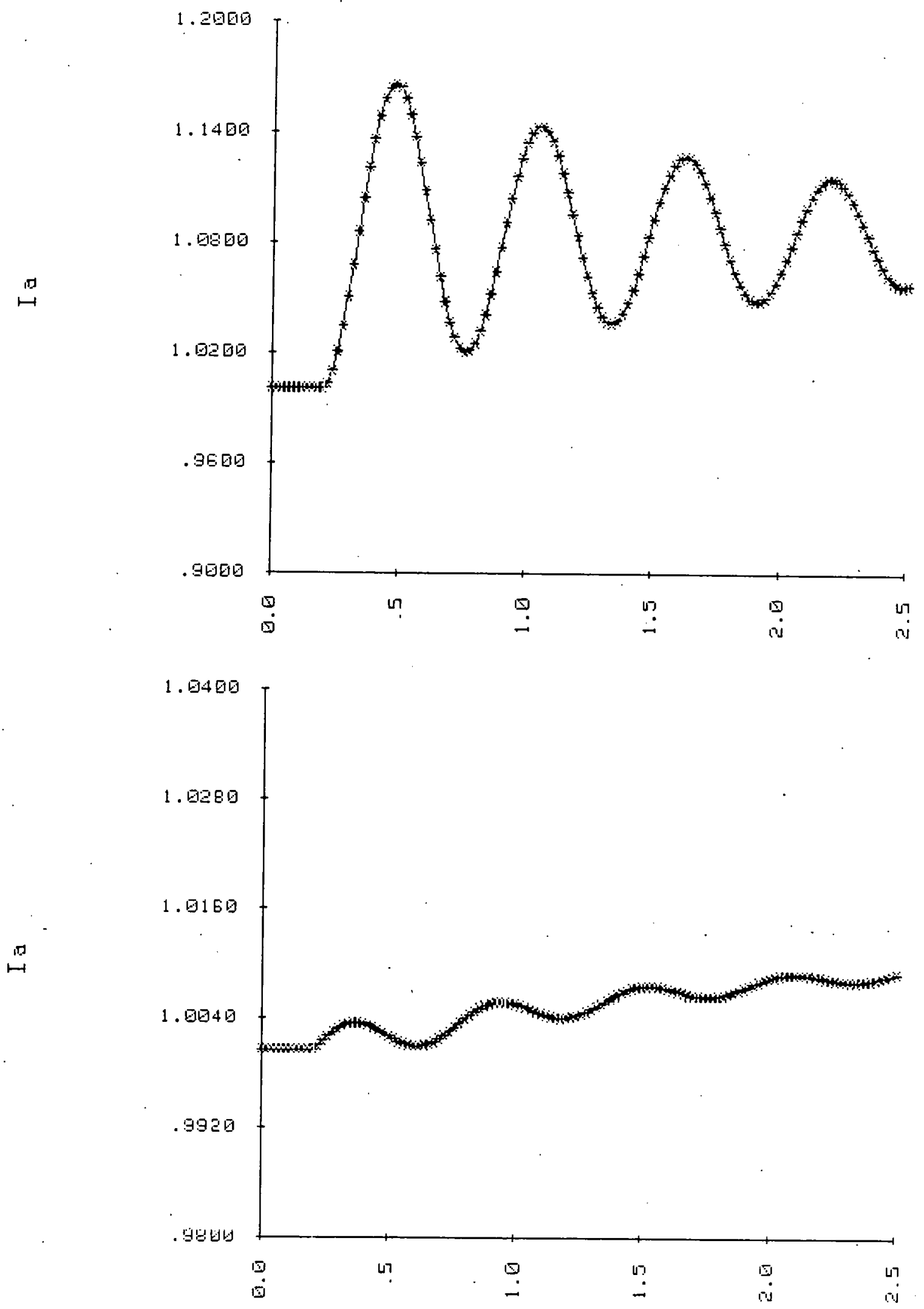

Figure D.4 $I_{a}$ vs time in seconds, Simplified E'"Mode1,

Top: 10\% Change in $\mathrm{T}_{\mathrm{m}}$, Bottom: $5 \%$ Change in $\mathrm{E}_{\mathrm{FD}}$ 
$\stackrel{11}{\vdash}$

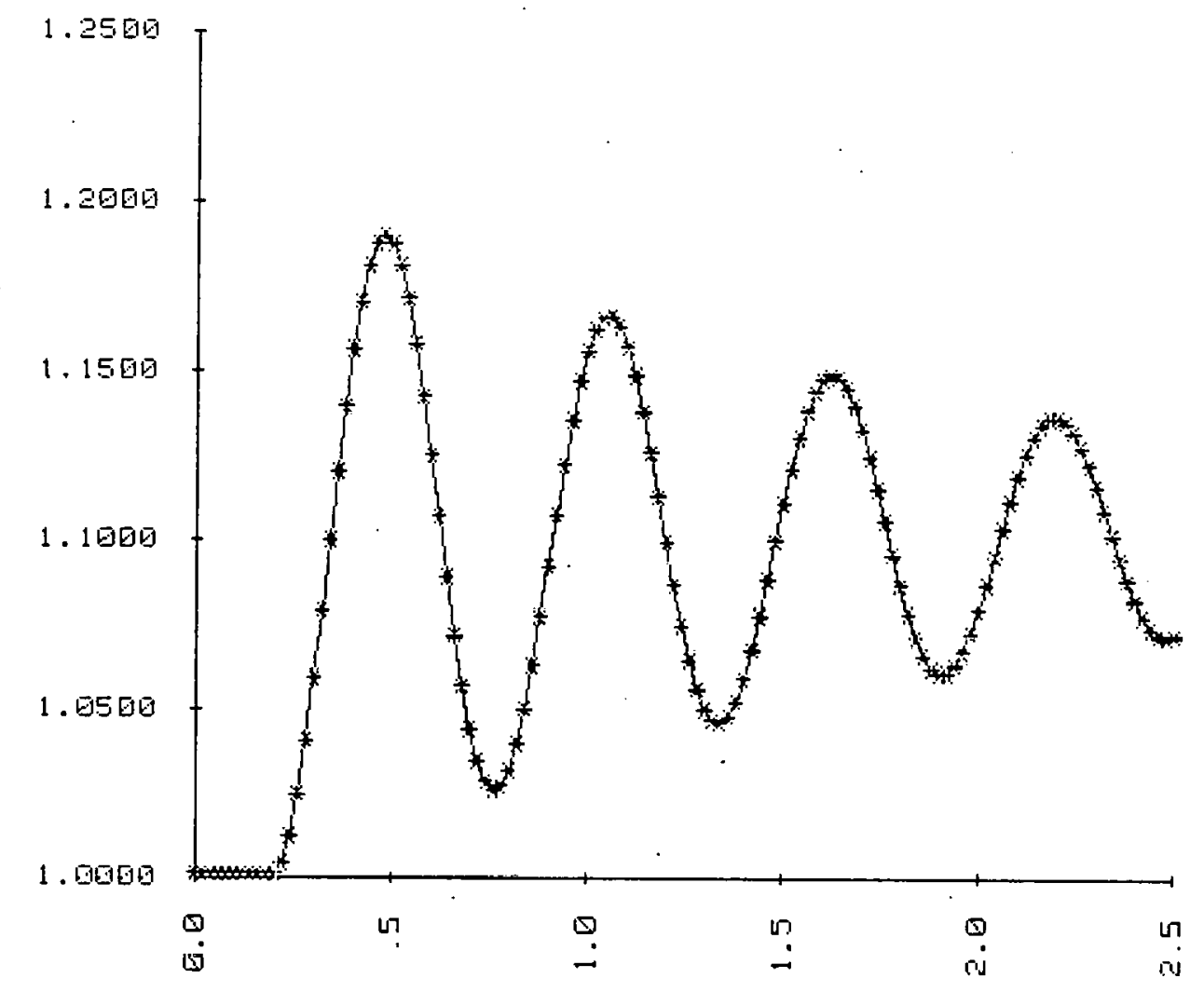

$\stackrel{12}{-}$

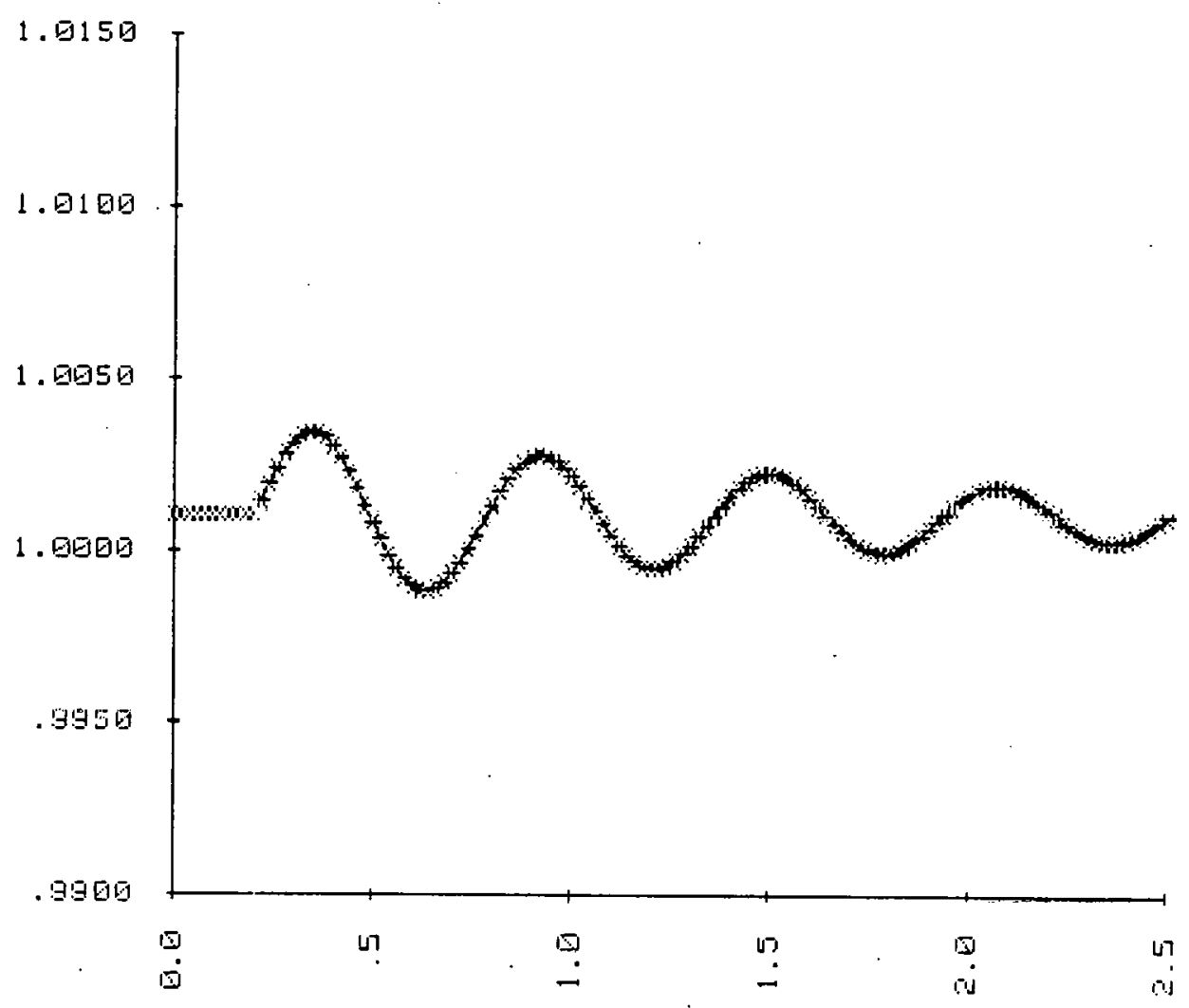

Figure D.5 $T_{e}$ vs time in seconds, Simplified E'' Mode1,

Top: $10 \%$ Change in $\mathrm{T}_{\mathrm{m}}$. Bottom: $5 \%$ Change in $\mathrm{E}_{\mathrm{FD}}$ 

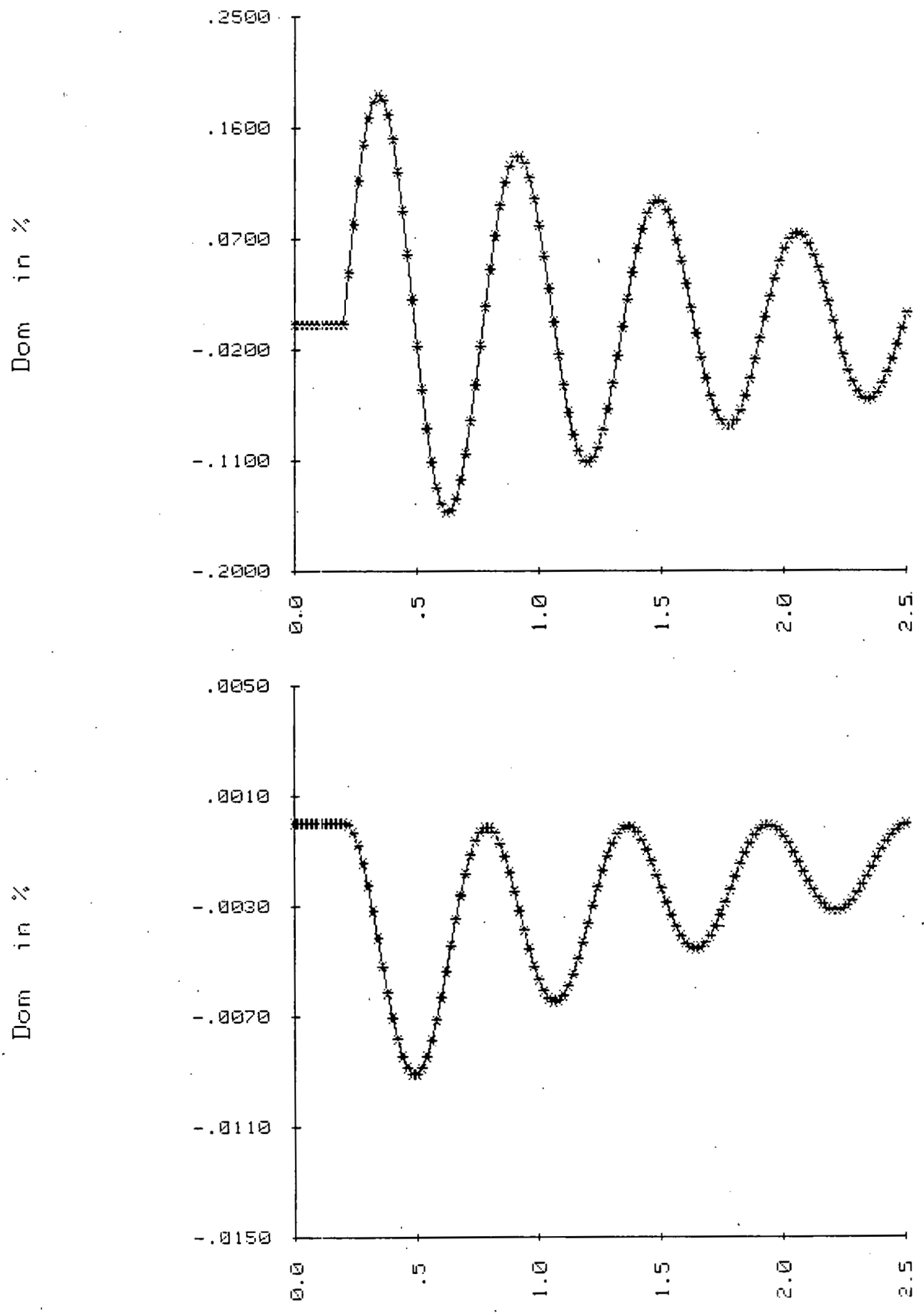

Figure D.6 $\Delta \omega$ vs time in seconds, Simplified E' Mode1,

Top: $10 \%$ Change in $T_{m}$, Bottom: $5 \%$ Change in $E_{F D}$ 


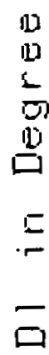
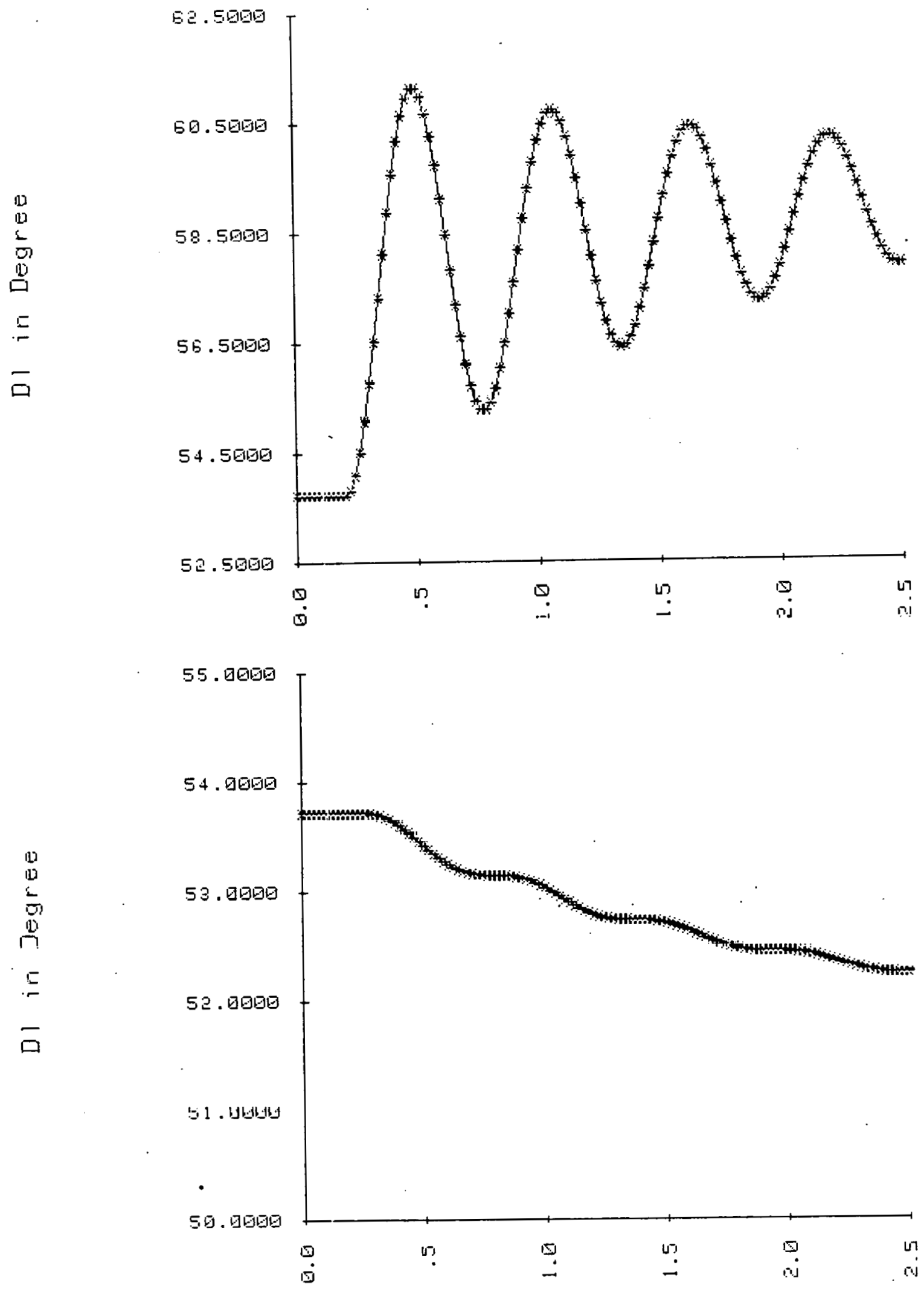

Figure D.7 $\delta$ vs time in seconds, Simplified E'" Mode1, Top: $10 \%$ Change in $\mathrm{T}_{\mathrm{m}}$, Bottom: $5 \%$ Change in $\mathrm{E}_{\mathrm{FD}}$ 


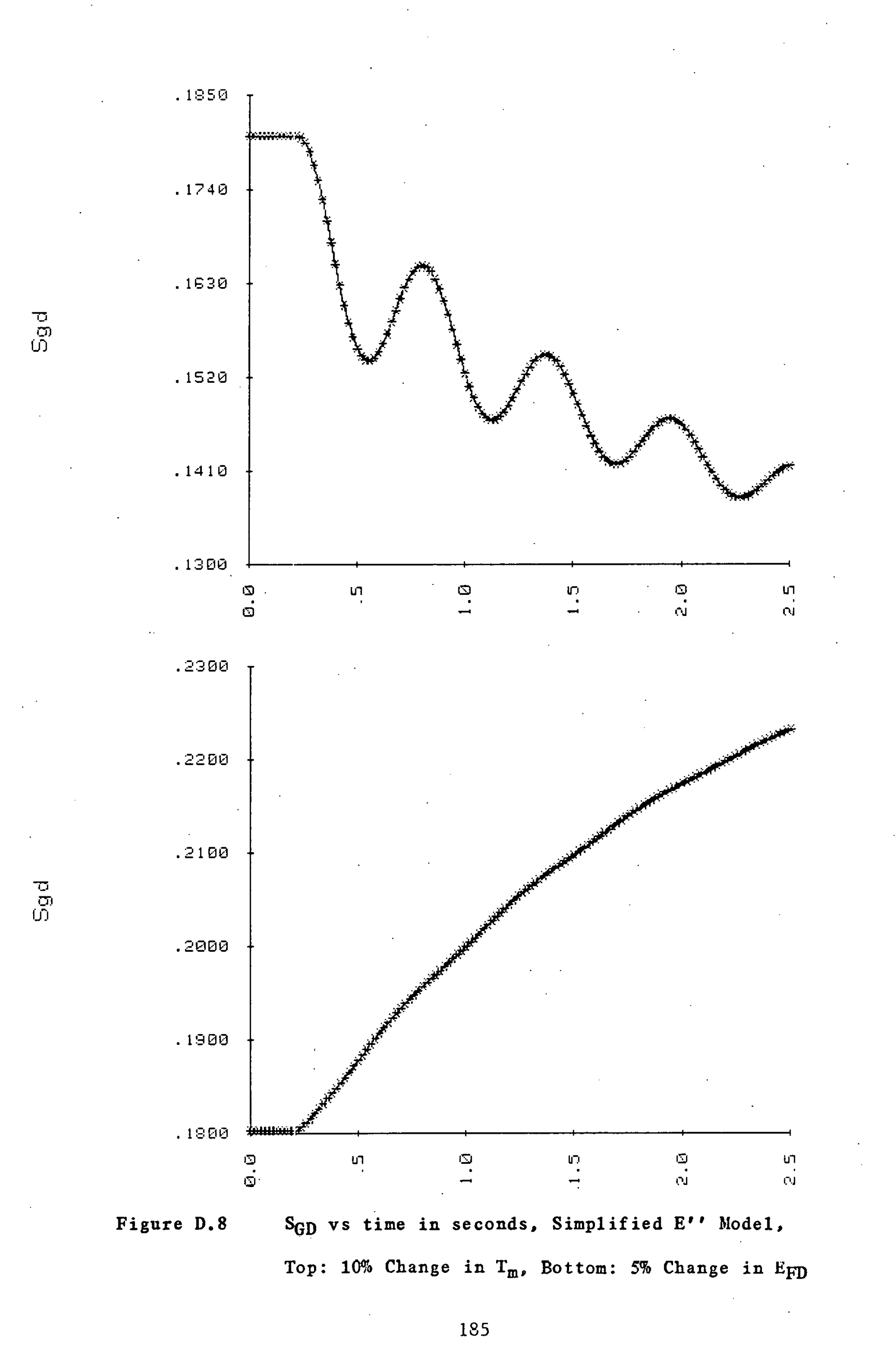



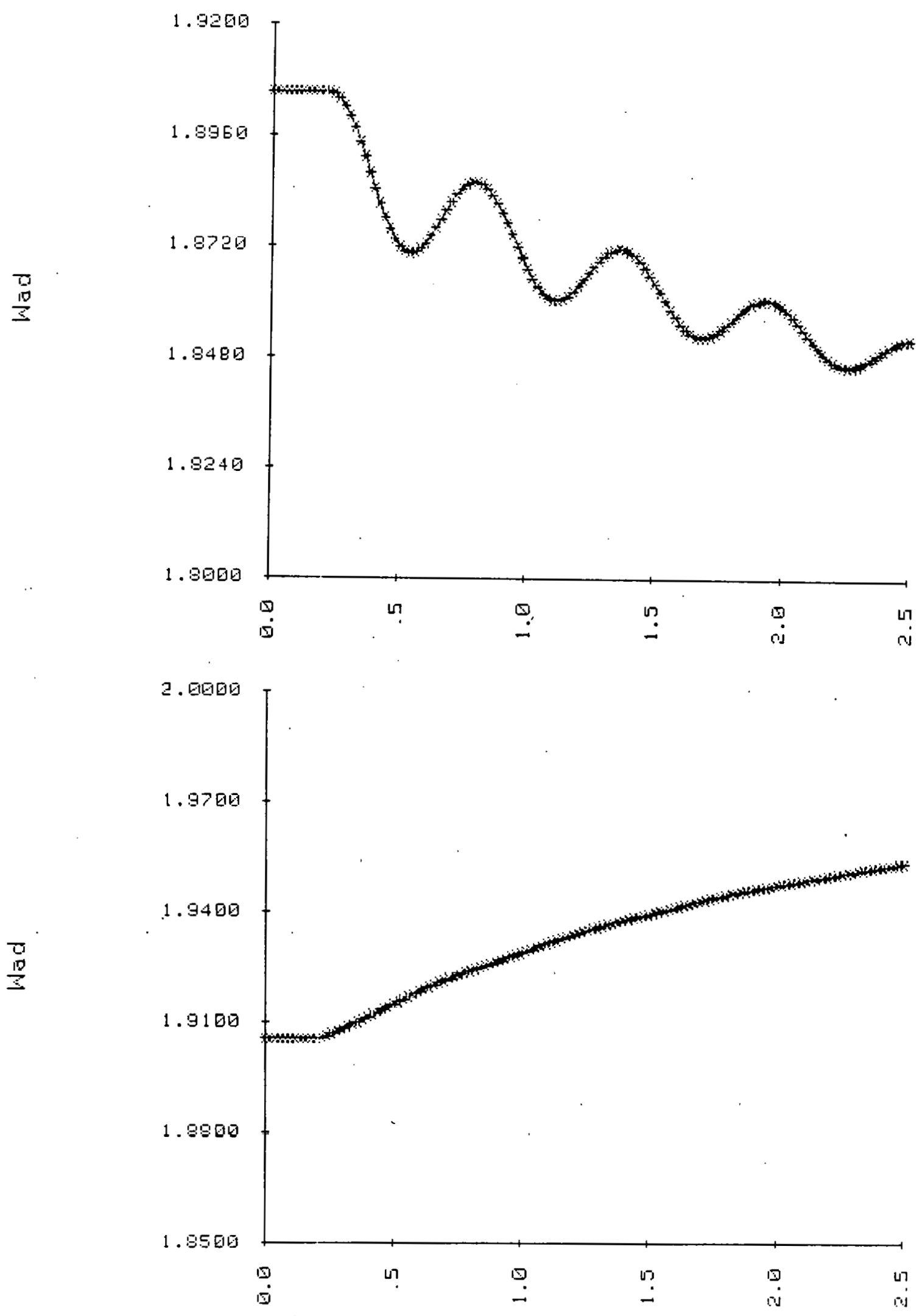

Figure D.9. $\Psi_{A D}$ vs time in seconds, Simplified E" Model, Top: 10\% Change in $T_{m}$, Bottom: 5\% Change in E FD

186 

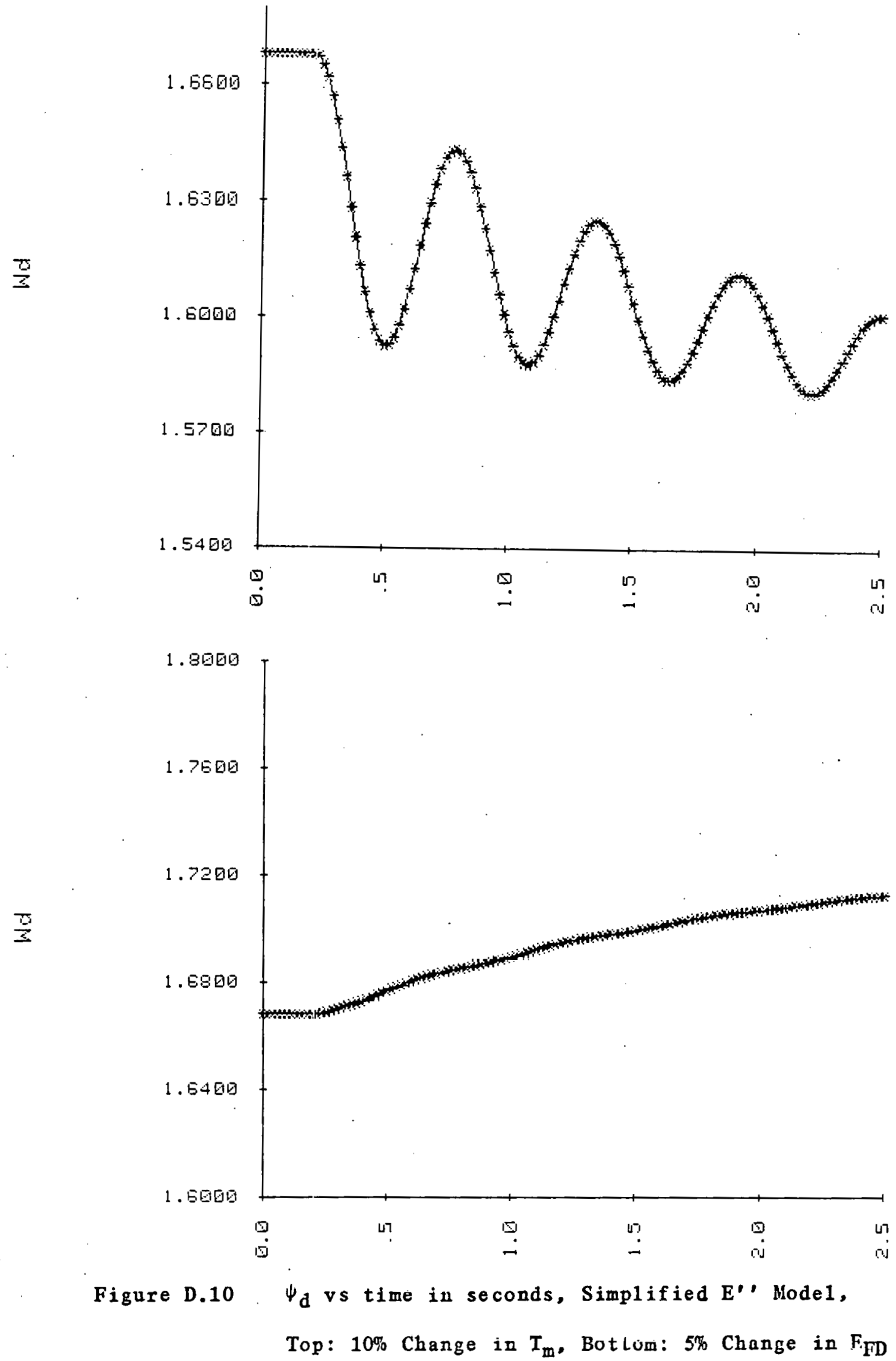

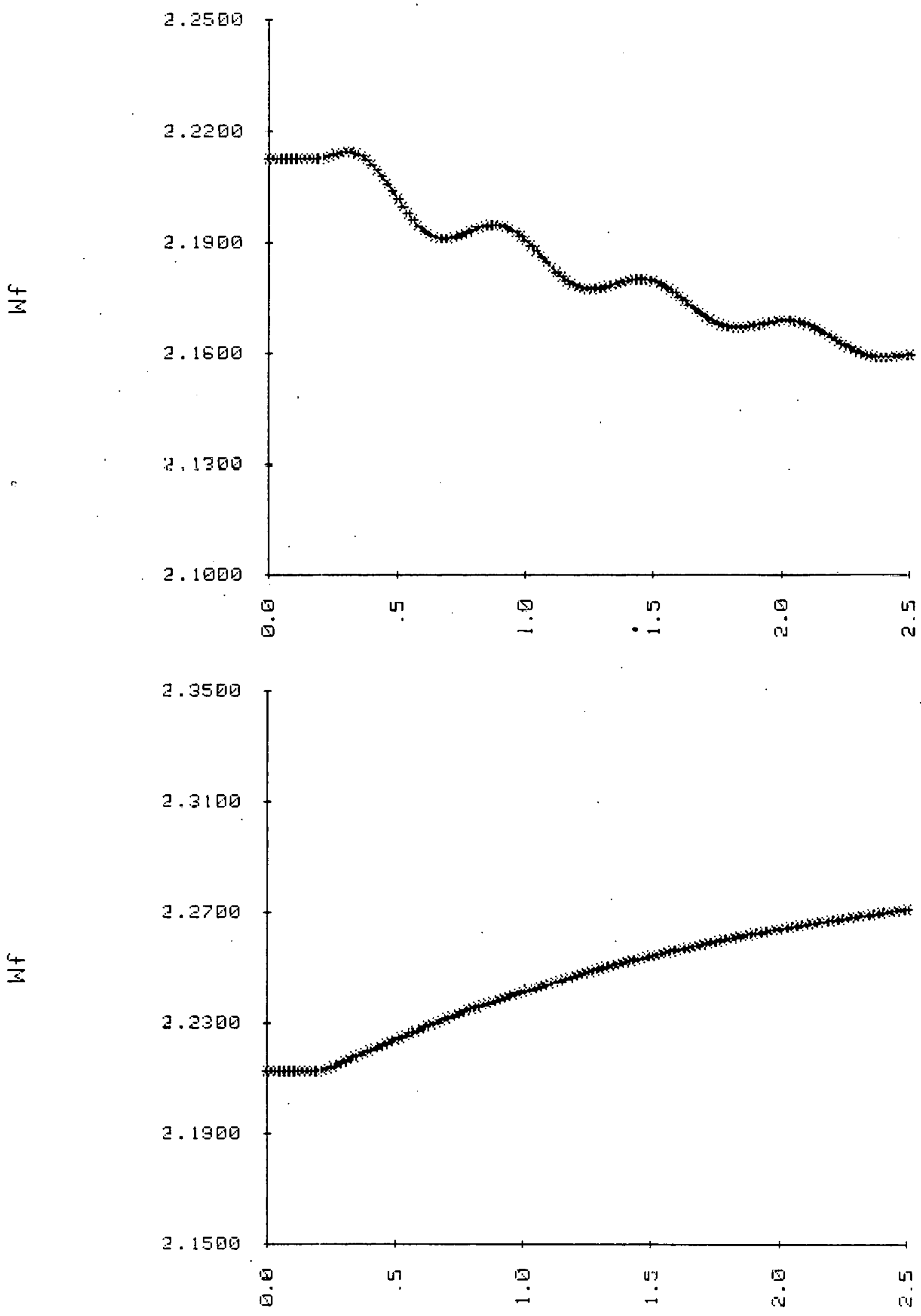

Figure D.11 $\Psi_{F}$ vs time in seconds, Simplified E' Model,

Top: 10\% Change in $\mathrm{T}_{\mathrm{m}}$, Bottom: $5 \%$ Change in $\mathrm{E}_{\mathrm{FD}}$

188 

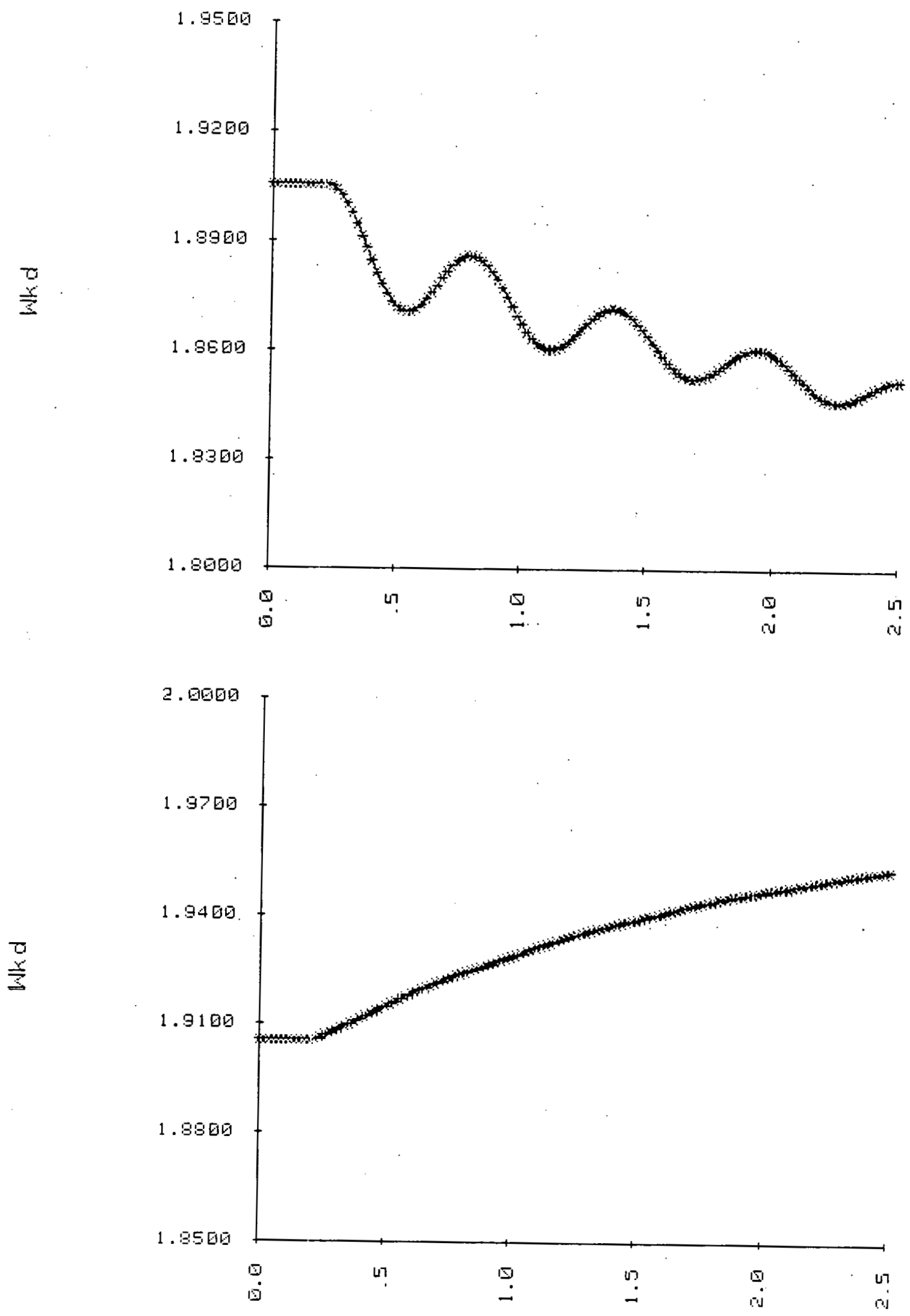

Figure D.12 $\Psi_{k d}$ Vs time in seconds, Simplified E' Mode 1, Top: 10\% Change in $T_{m}$, Bottom: $5 \%$ Change in $E_{F D}$

189 


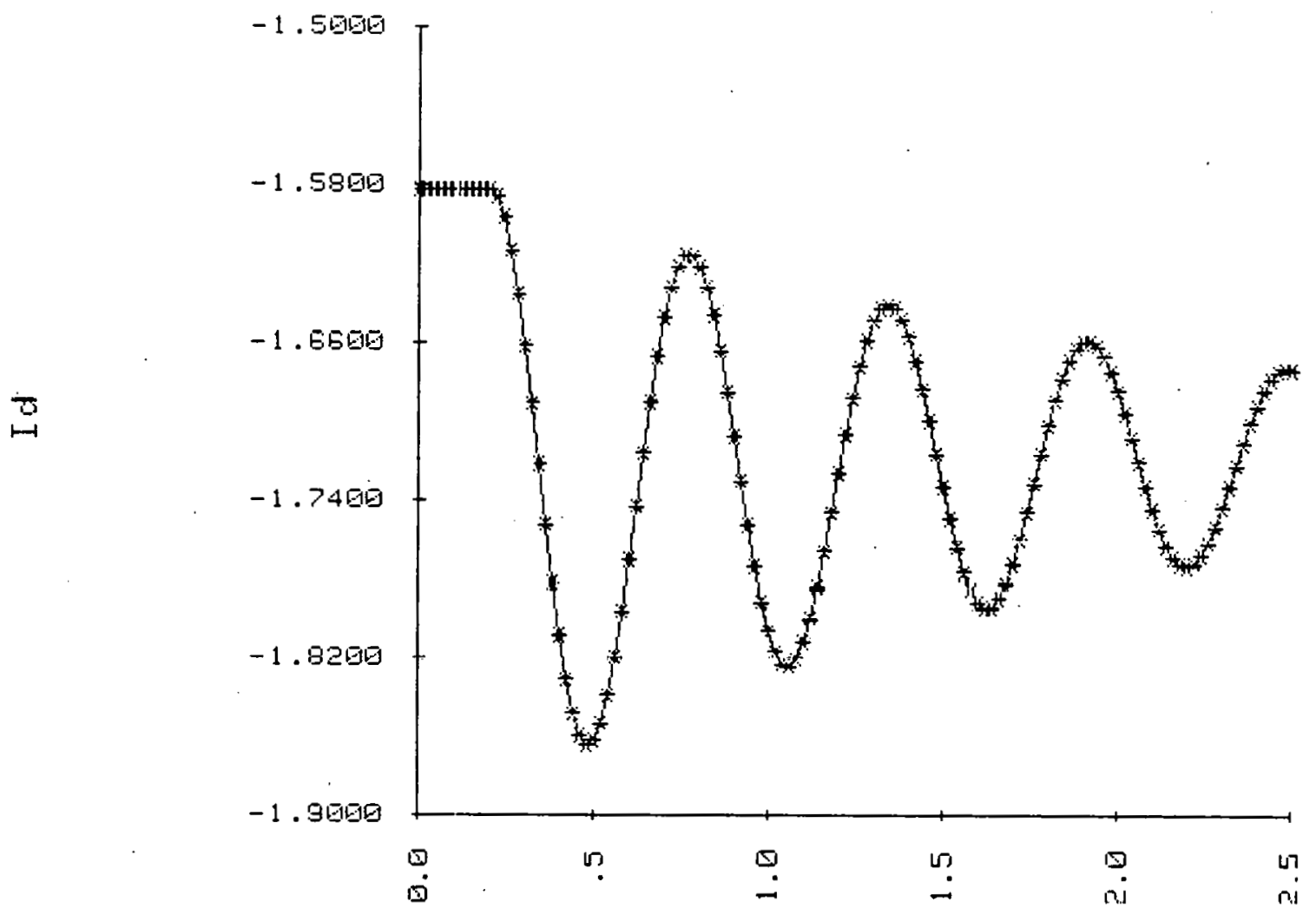

품

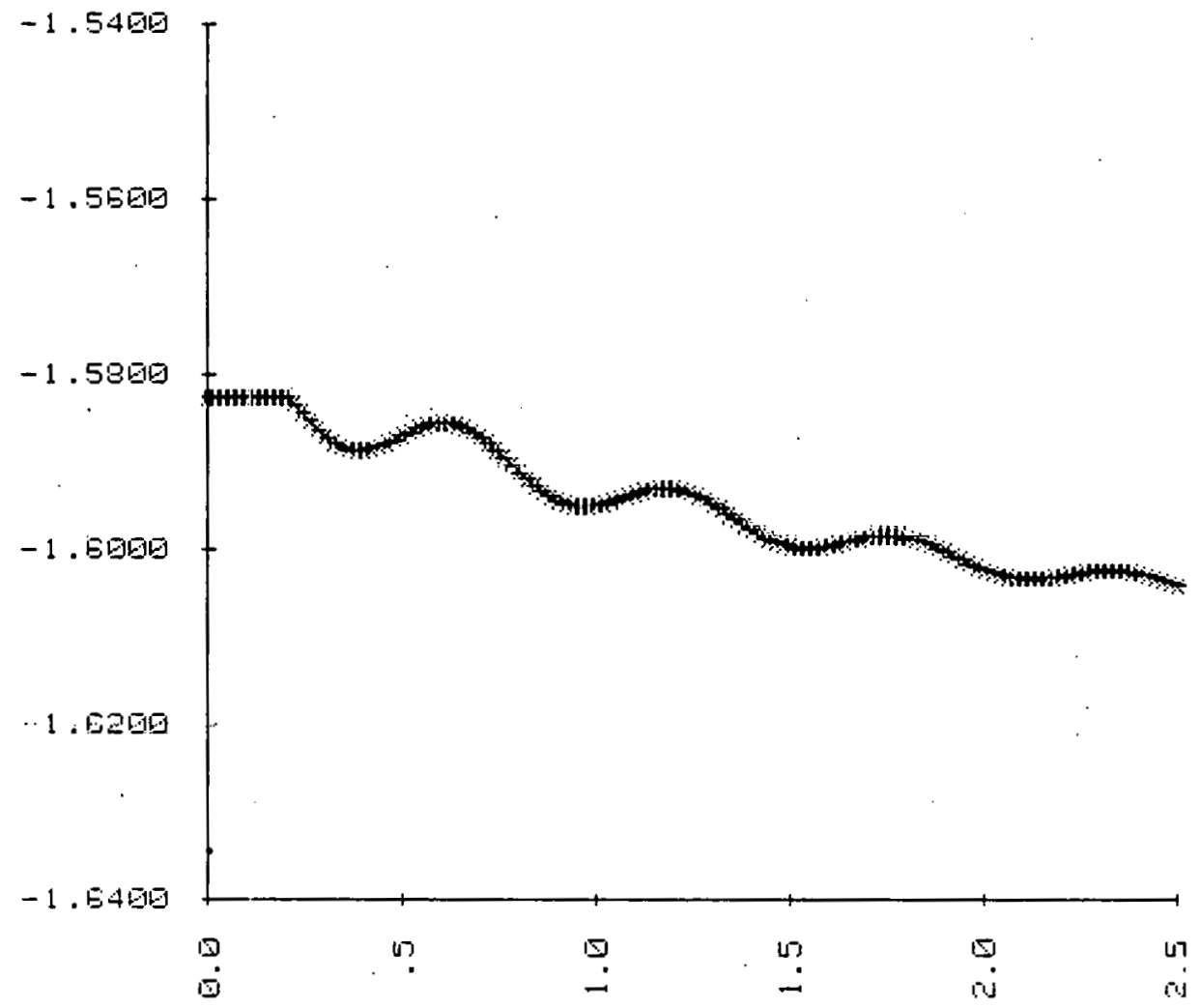

Figure D.13 I I vs time in seconds, Simplified E''Mode1, Top: $10 \%$ Change in $\mathrm{T}_{\mathrm{m}}$, Bottom: $5 \%$ Change in $\mathrm{E}_{\mathrm{FD}}$ 

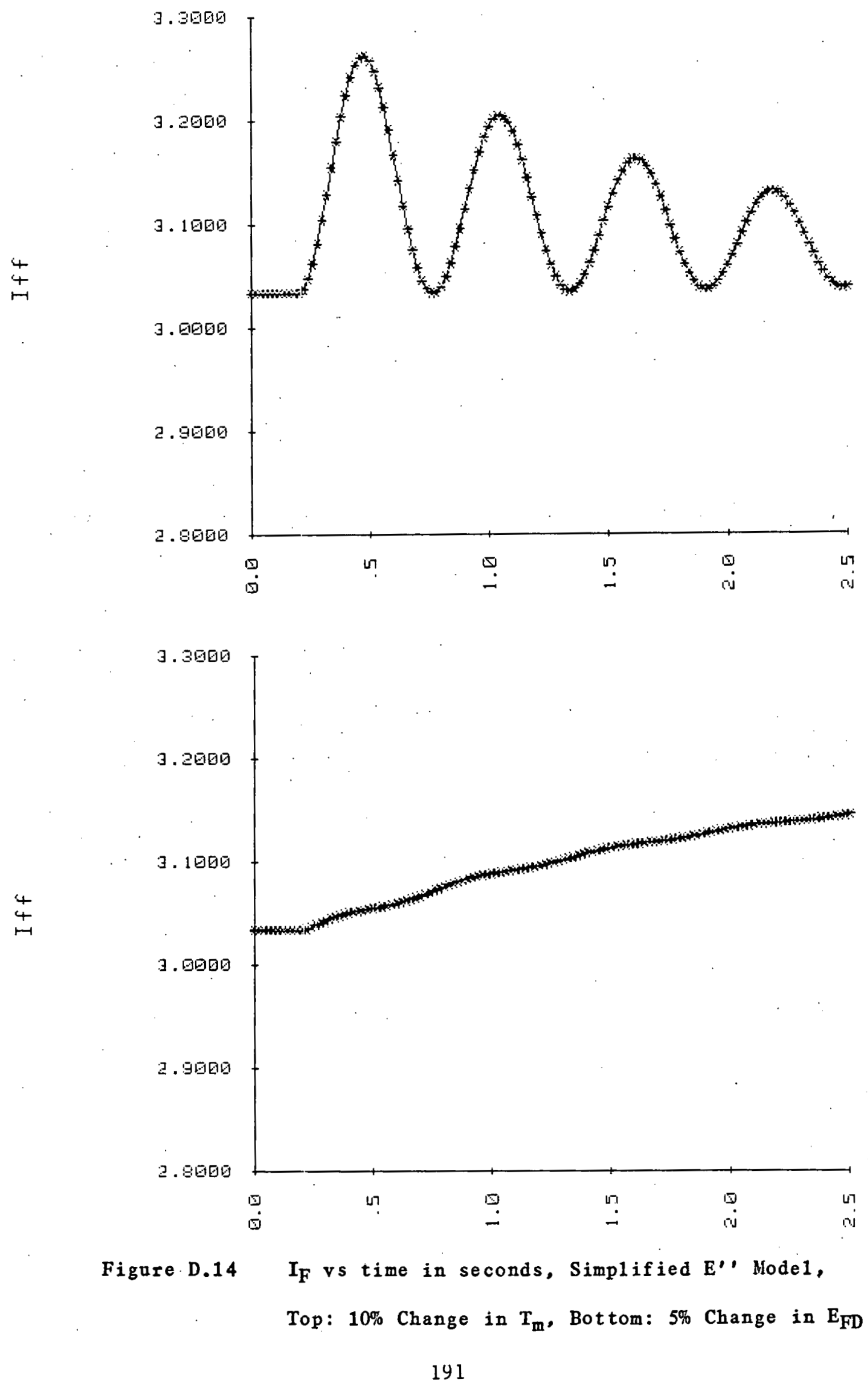

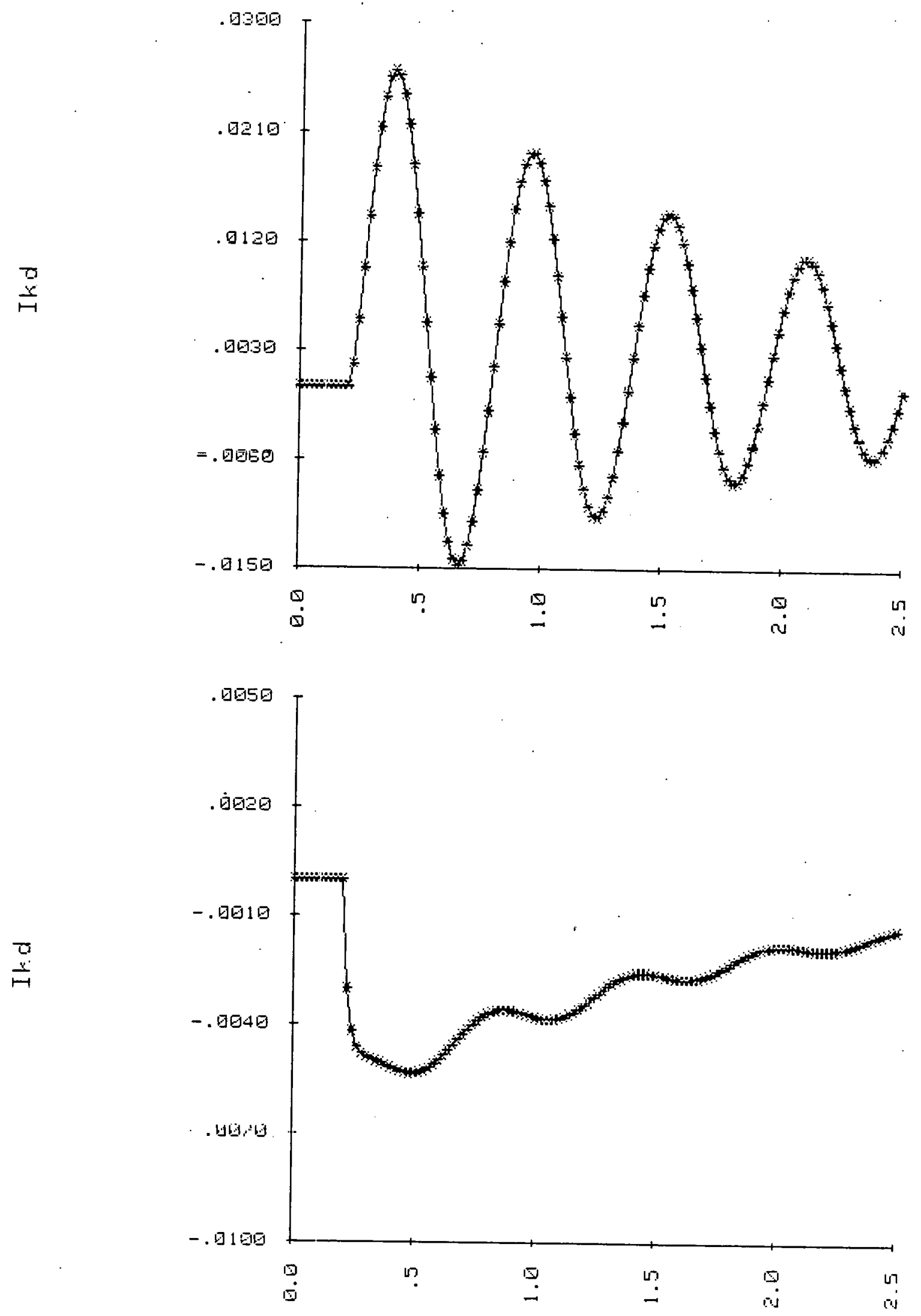

Figure D.15 $I_{k d} \nabla s$ time in seconds, Simplified E' Mode1,

Top: 109 Change in $T_{m}$, Bottom: 5\% Change in $E_{F D}$ 

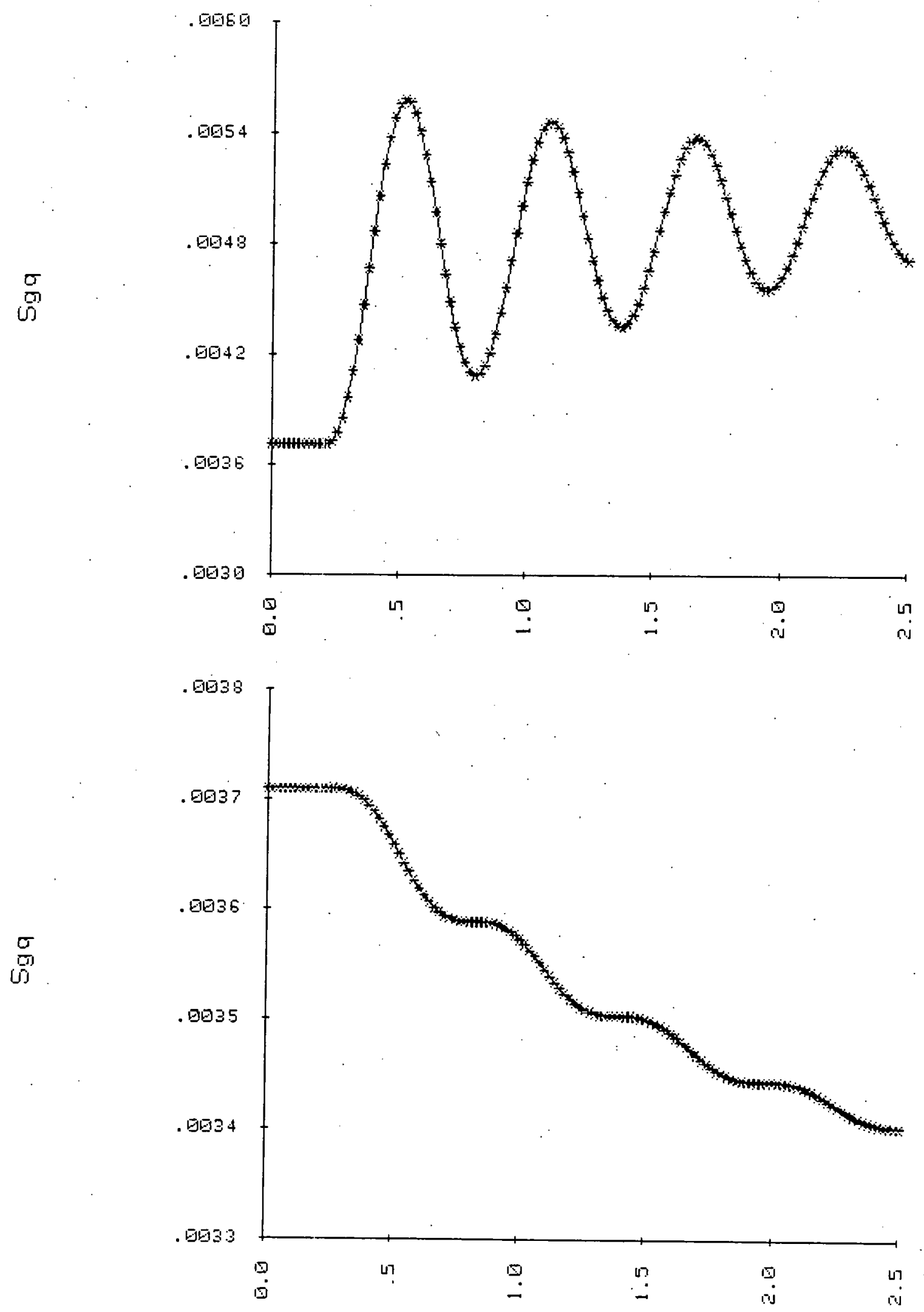

Figure D.16 $S_{G Q}$ vs time in seconds, Simplified E' Model,

Top: 10\% Change in $T_{m}$, Bottom: $5 \%$ Change in $\mathrm{E}_{\mathrm{FD}}$ 

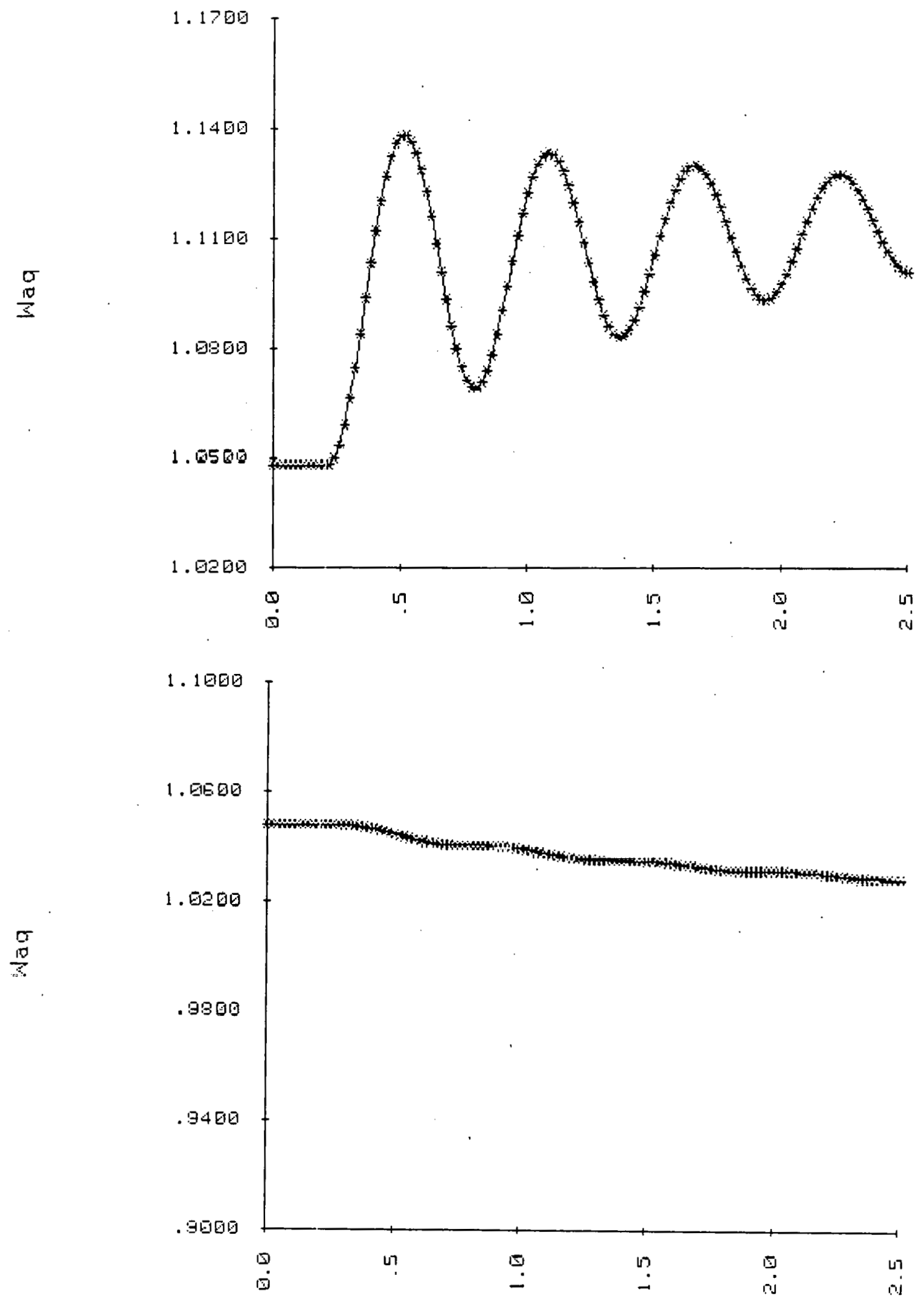

Figure D.17 $\psi_{A Q}$ vs time in seconds, Simplified E'' Mode1,

Top: $10 \%$ Change in $\mathrm{T}_{\mathrm{m}}$, Bottom: $5 \%$ Change in $\mathrm{E}_{\mathrm{FD}}$ 

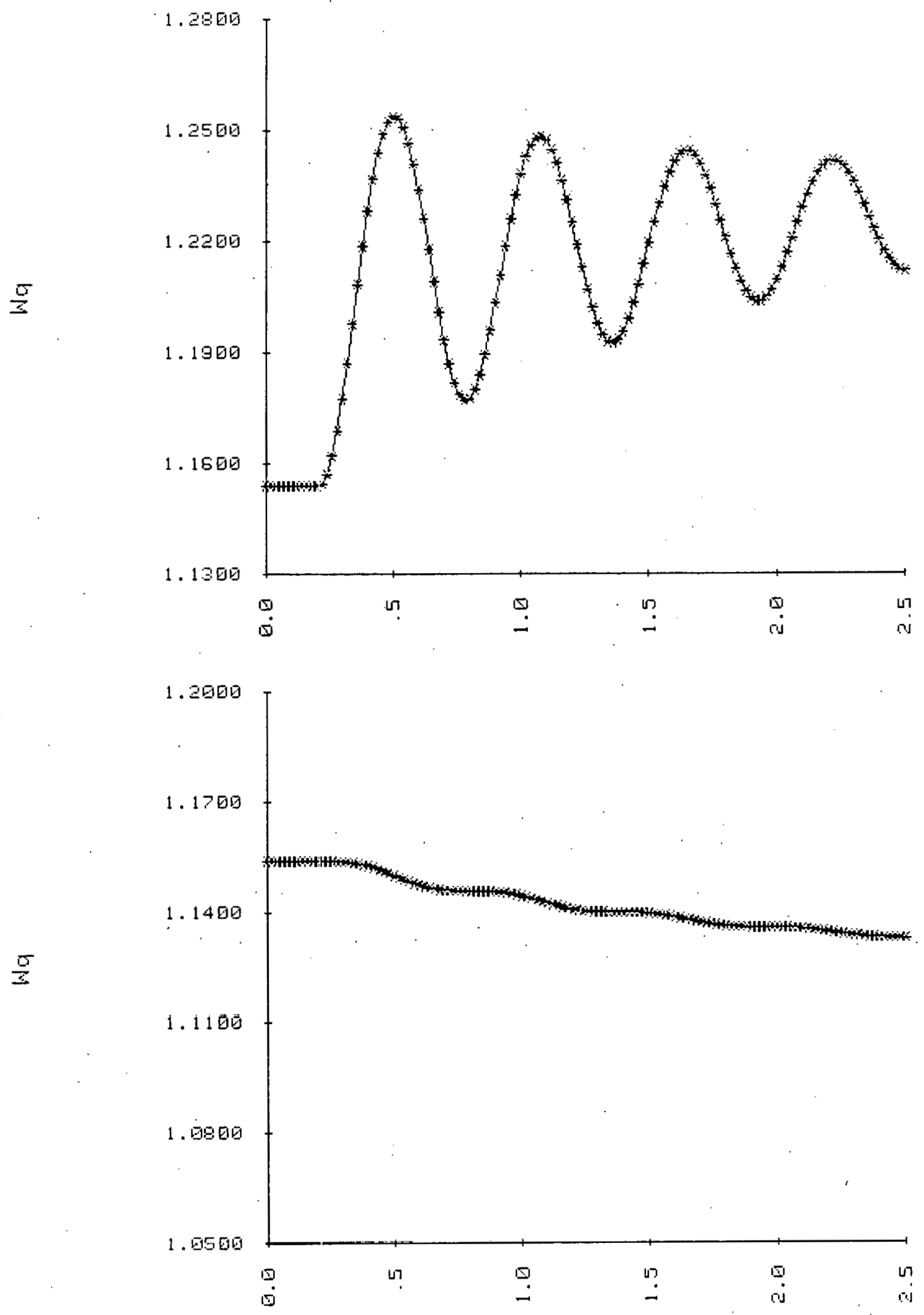

Figure D.18 $\psi_{q}$ vs time in seconds, Simplified E" Model,

Top: $10 \%$ Change in $\mathrm{T}_{\mathrm{m}}$, Bottom: 5\% Changc in $\mathrm{E}_{\mathrm{FU}}$ 

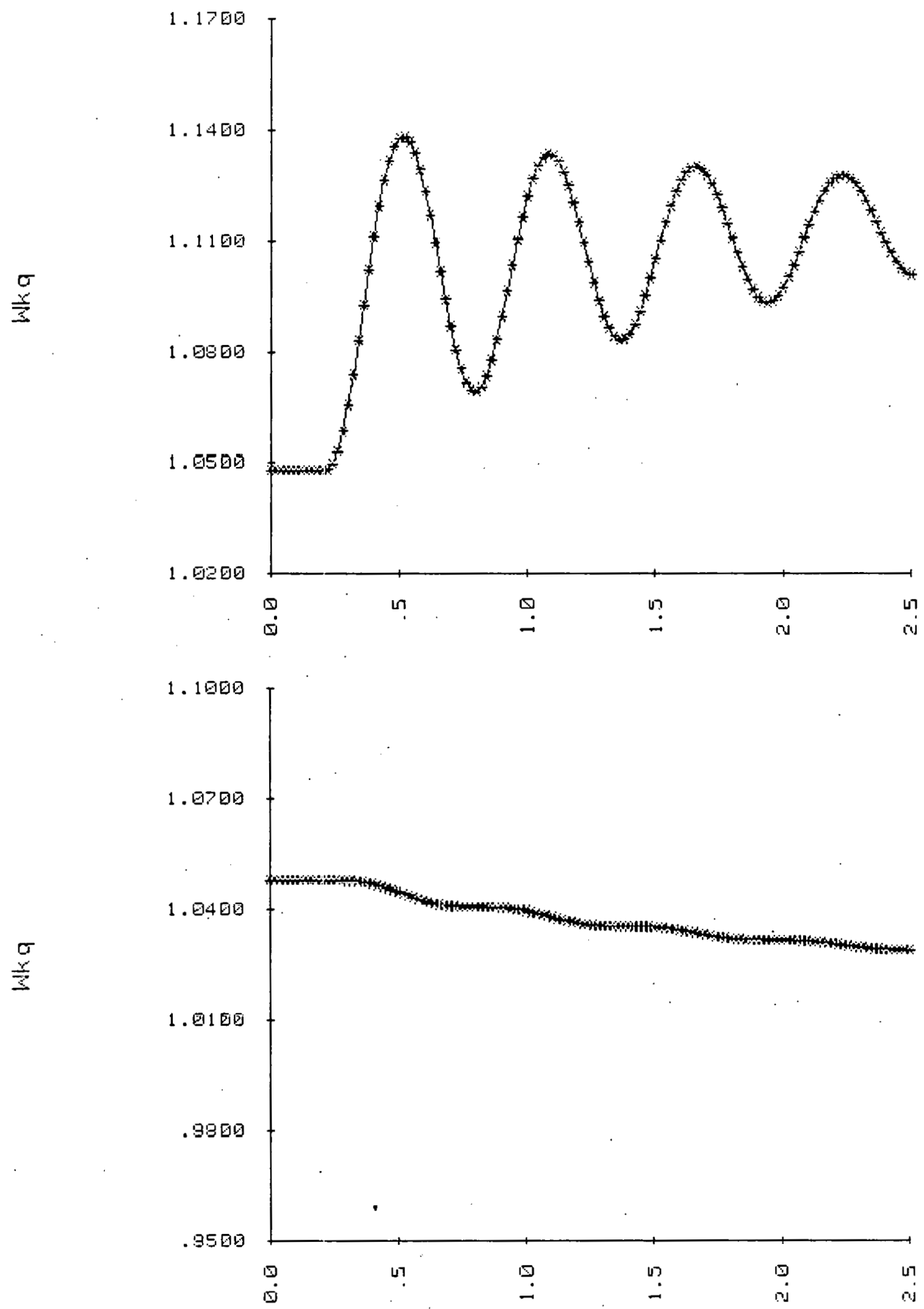

Fignre D.19 $\psi_{\mathrm{kq}}$ vs time in seconds, Simplified E' Mode1,

Top: 10\% Change in $T_{m}$, Bottom: 5\% Change in $E_{F D}$ 

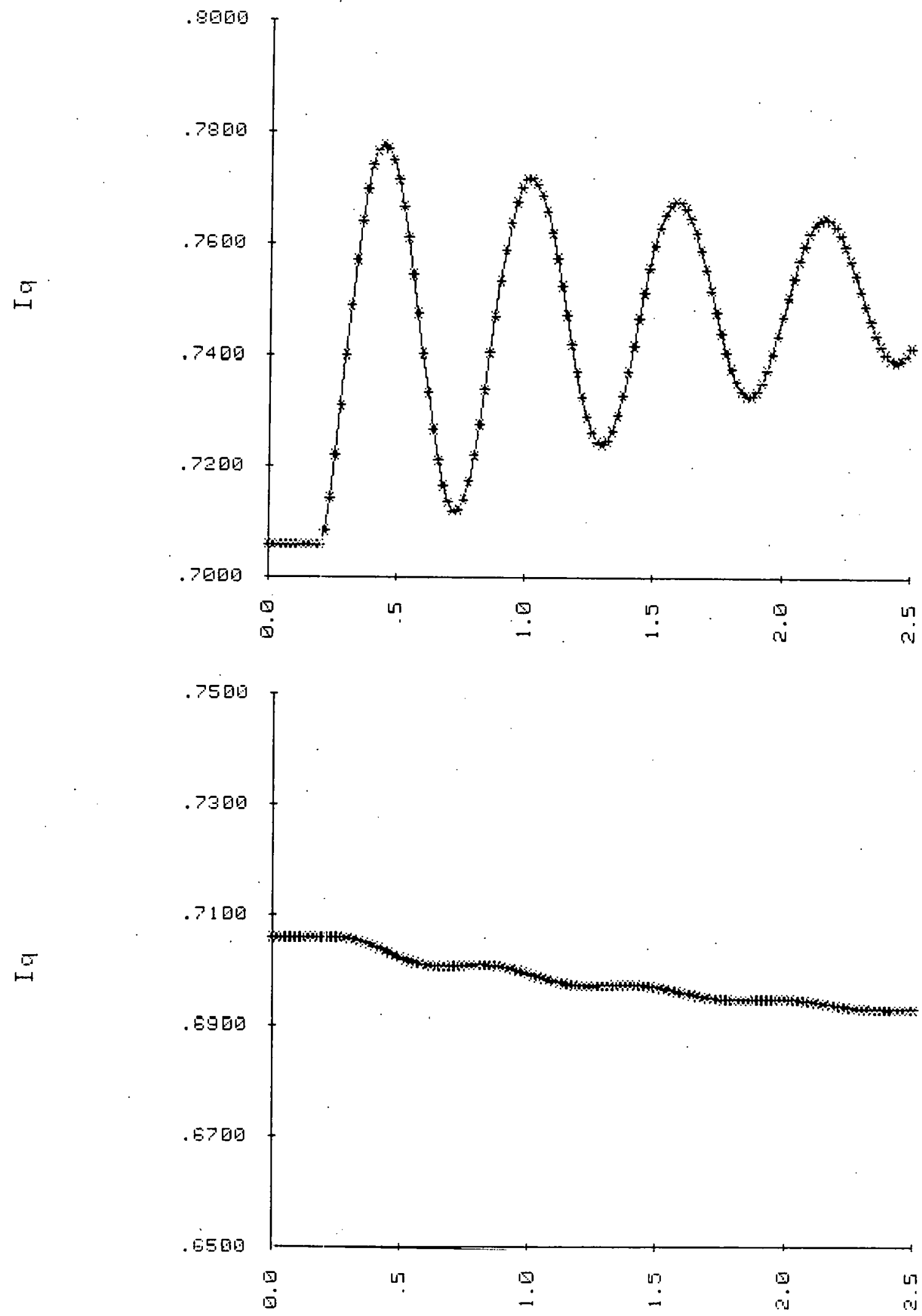

Figure D.20 $I_{q}$ vs time in seconds, Simplified E' Mode1,

Top: $10 \%$ Change in $T_{m}$, Bottom: $5 \%$ Change in $E_{F D}$ 
$\stackrel{\square}{\check{F}}$

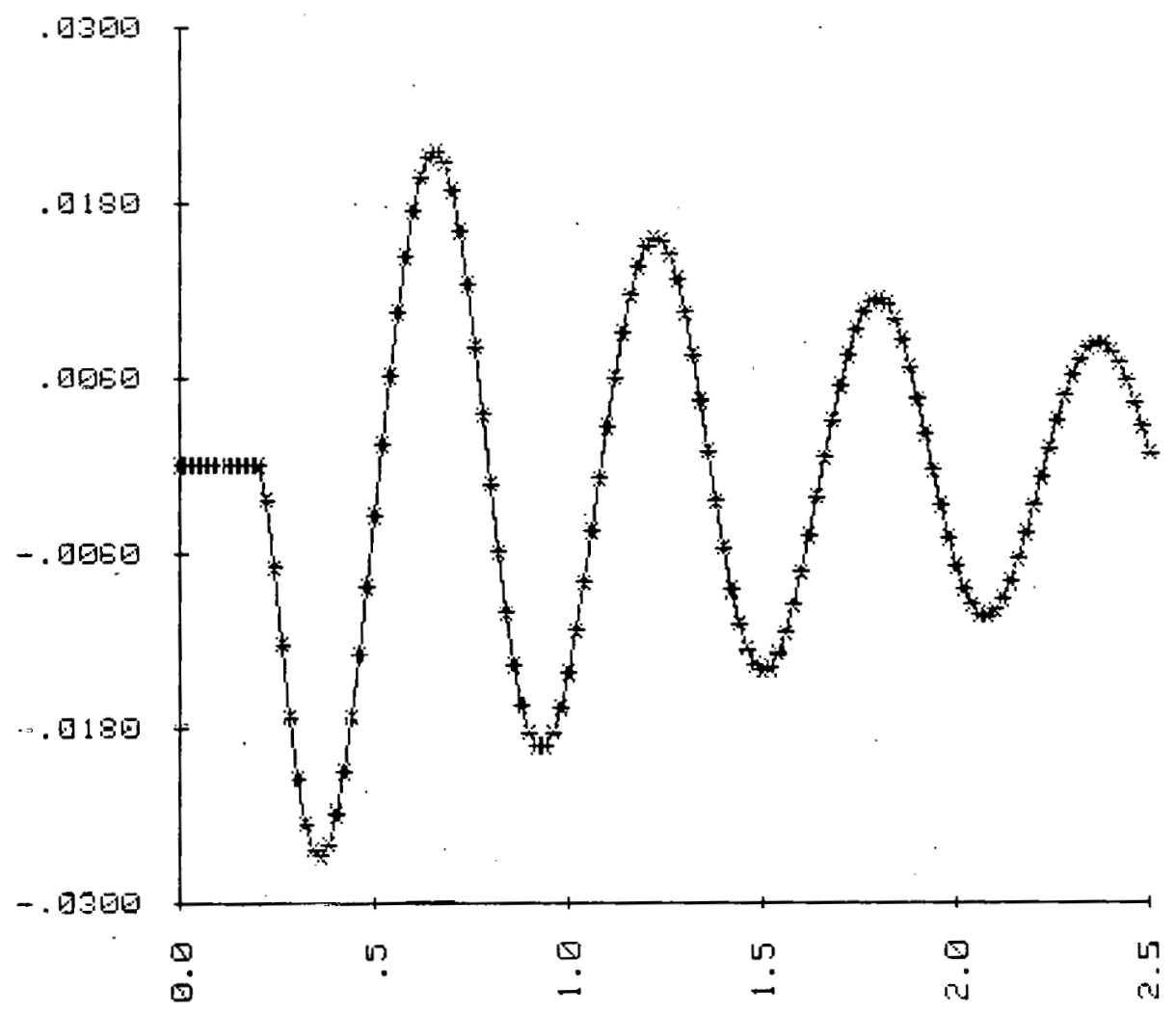

$\frac{\square}{\mathscr{r}}$

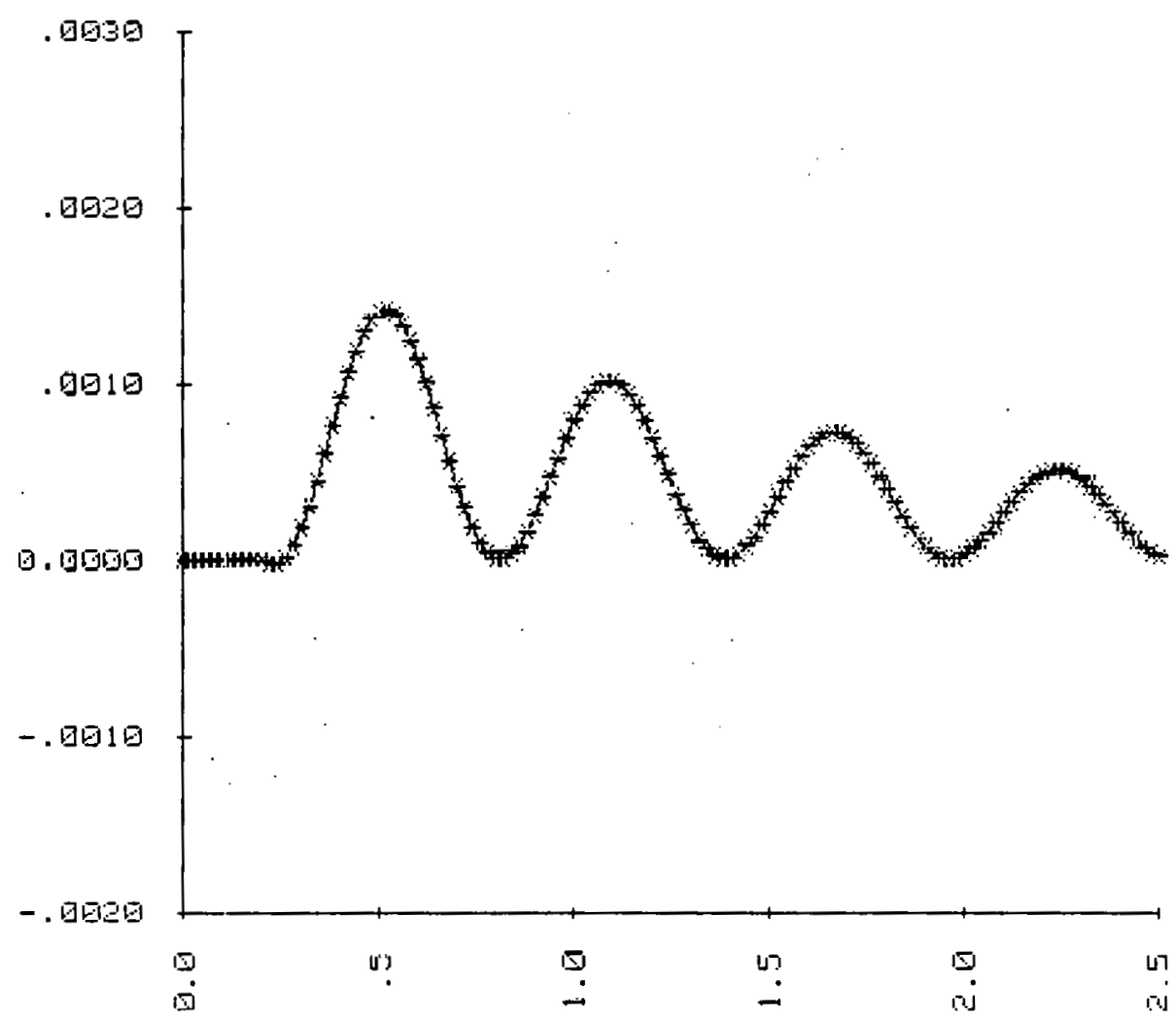

Figure D.21 $I_{\mathrm{kq}}$ vs time in seconds, Simplified E' Mode1,

Top: 10\% Change in $\mathrm{T}_{\mathrm{m}}$, Bottom: $5 \%$ Change in $\mathrm{E}_{\mathrm{FD}}$ 
APPENDIX E

Statistical Analysis of Differences

in

Simulated Results 


\section{THIS PAGE \\ WAS INTENTIONALLY \\ LEFT BLANK}


The graphical statistical analyses of results presented here are of two types: histograms and normal probability plots. All results are for differences between time domain simulations. Simulation results are identified by letter code, using the coding scheme of Table E.1. Data for analysis is provided by subtracting, point by point, the time domain simulation results, with 126 such poitns retained for analysis.

Comparisons are provided for ten cases, as shown in Table E.2. For each case 1isted, two statistical analysis graphs are provided: a histogram and a normal probability plot.

The histogram plots the relative frequency of eight classes vs the class intervals. C1ass frequency is determined by summing the total number of measurements in a given class or ce11. Relative frequency is this class frequency divided by 126 , the total population. Each histogram is overlaid by a best fit of the data to a normal distribution.

The normal probability plot is tho second graphical aid provided. These graphs show the actual errors (differences) plotted vs the percent of values that fall below a given absissa value. If this plot is a straight 1 ine then the data comes from a normal distribution.

\section{General Comments on Statistical Graphs}

The statistical difference between the flux 1 inkage and E' models, for the unsaturated case, is given in Figure E1. The differences are generally very smali and are non-gaussian. Nearly all errors are clustered around zero, and are small. 
Table E.1 Coding of Simulation Rans

\section{Code}

EA

EB

A

B

C

D
Mode 1

F1ux Linkage

E'

F1ux Linkage

$E^{\prime \prime}$

F1ux Linkage

E' '
Saturation

Unsaturated Case

Unsaturated Case

Complete: $\mathrm{L}_{\mathrm{AD}}$ and $\mathrm{L}_{\mathrm{AQ}}$

Complete: A11 L's, $T^{\prime} s$, and $K^{\prime} s$

Only $\psi_{A D}$ and $\psi_{A Q}$, constant $L^{\prime} s$

Only $L_{d}, x_{x d}, K_{d}, L_{q}$, and $T_{d o}^{\prime}$ 
Table E.2 Comparison Sets for Statistical Analysis

$\begin{array}{lllll}\text { Code } & \text { Designation } & \text { Disturbance } & \text { Table } & \text { Figure } \\ \text { EAEBTC } & \text { EA-EB } & T_{m} & \text { E3 a } & \text { E1 a } \\ \text { EAEBVC } & \text { EA-EB } & E_{F D} & \text { E3b } & \text { E1b } \\ \text { ABTC } & \text { A-B } & T_{m} & \text { E4 a } & \text { E2 a } \\ \text { ABVC } & \text { A-B } & E_{F D} & \text { E4b } & \text { E2b } \\ \text { AEATC } & \text { A-EA } & T_{m} & \text { E5 a } & \text { E3 a } \\ \text { AEAVC } & \text { A-EA } & E_{F D} & \text { E5b } & \text { E3b } \\ \text { ACTC } & \text { A-C } & T_{m} & \text { E6 } a & \text { E4 a } \\ \text { ACVC } & \text { A-C } & E_{F D} & \text { E6b } & \text { E4b } \\ \text { ADTC } & \text { A-D } & T_{m} & \text { E7 } a & \text { E5 a } \\ \text { ADVC } & \text { A-D } & E_{F D} & \text { E7b } & \text { E5b }\end{array}$


enough to be considered negligible. A statistical summary of errors in a11 variables is given in Tables E3a and E3b, for $T_{m}$ and $E_{F D}$ disturbances, respectively. Note that the standard deviation in all variables is very small and considered well within acceptable tolerance. The statistical errors between fully saturated flux linkage and E' fully saturated mode1s (A and $B$, respectfully) are given in Figure E2 and in Tables $\mathrm{E} 4 \mathrm{a}$ and $\mathrm{E} 4 \mathrm{~b}$. These errors are in about the same range as for the unsaturated case and show only slightly larger standard deviation. The results are clearly from a normal distribution. The accuracy is clearly acceptable, or, stated another way, the models are statistically equivalent.

A comparison of the saturated flux linkage model and the same model with no saturation (A-EA) is shown in Figure E3 and in Tables E5a and E5b. The errors here are much greater and are generally not gausian. Some of the results are surprising. Certain variables, such as $T_{e}$, are affected very little by saturation and show very little change in standard deviation or standard error. Other variables are greatly affected by saturation, such as torque angle, and therefore show much greater error. These statistics are displayed simply to show an approximate worst case in saturation analysis. and will be used only for comparison. The offoot of caturation io aloo oloarly dioplayod in tho time domain plots of Appendices A-D.

Figure E4 and Tables E6 compare the saturated f1ux 1inkage mode1 (A) against the same model with simplified saturation (C). These results are disappointing and indicate tho nood for a difforont approach. The statistics here are only slightly better than the comparison against an unsaturated model. 
The final comparison is for the $E^{\prime \prime}$ model with saturation applied only to the five parameters that are most sensitive to change in $\mathrm{L}_{\mathrm{AD}}$ and $\mathrm{L}_{\mathrm{AQ}}$. These results are shown in Figure E5 and Tab1e E7. These statistics indicate that this model (D) performs a1most exactly the same as the more detailed saturation model (B). Errors are almost identical to the more detailed case and are very sma11. Most errors plotted are nearly guasian. 

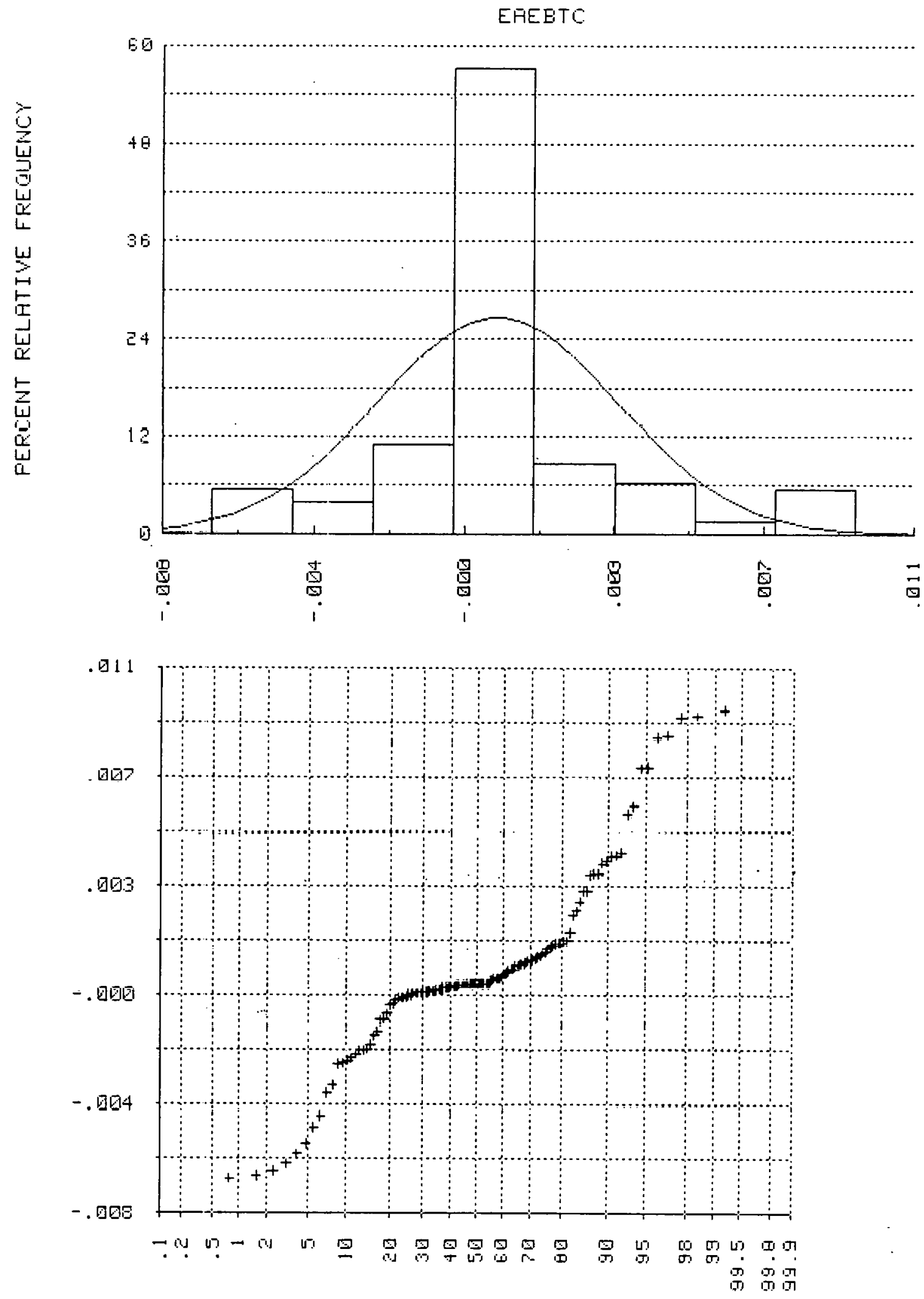

PERCENT UNDER

NOFMAL FROBAEILITY FLOT

Figure E.1.a.1 Statistical Plots of EA-EB for a $T_{m}$ Disturbance,

Data for $T_{e} \quad 206$ 

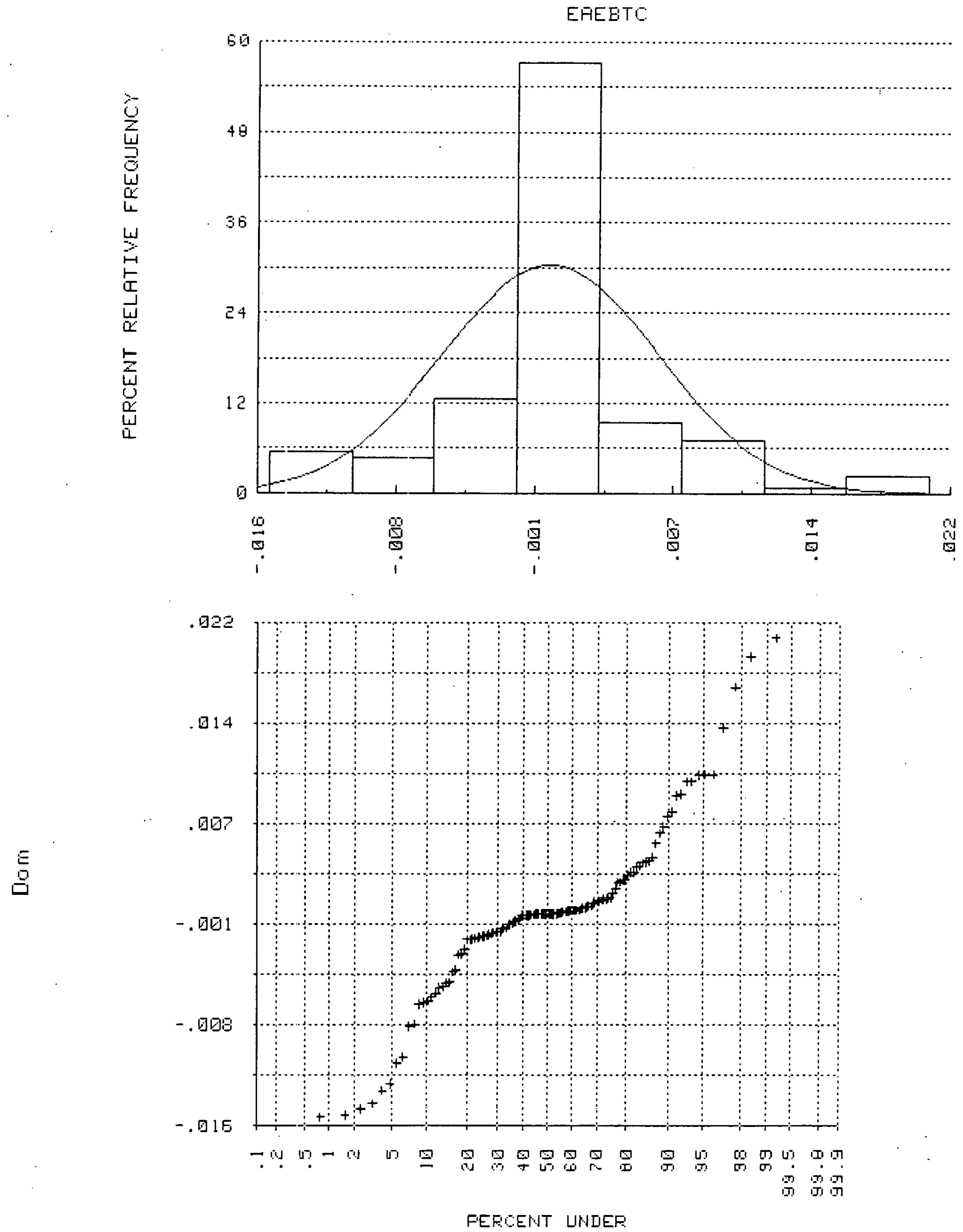

NOFML PFOEAEILITY FLOT

Figure E.1.a.2 Statistical Plots of EA-EB for a $T_{m}$ Disturbance,

Data for $\Delta \omega$ 


\section{EAEETE}
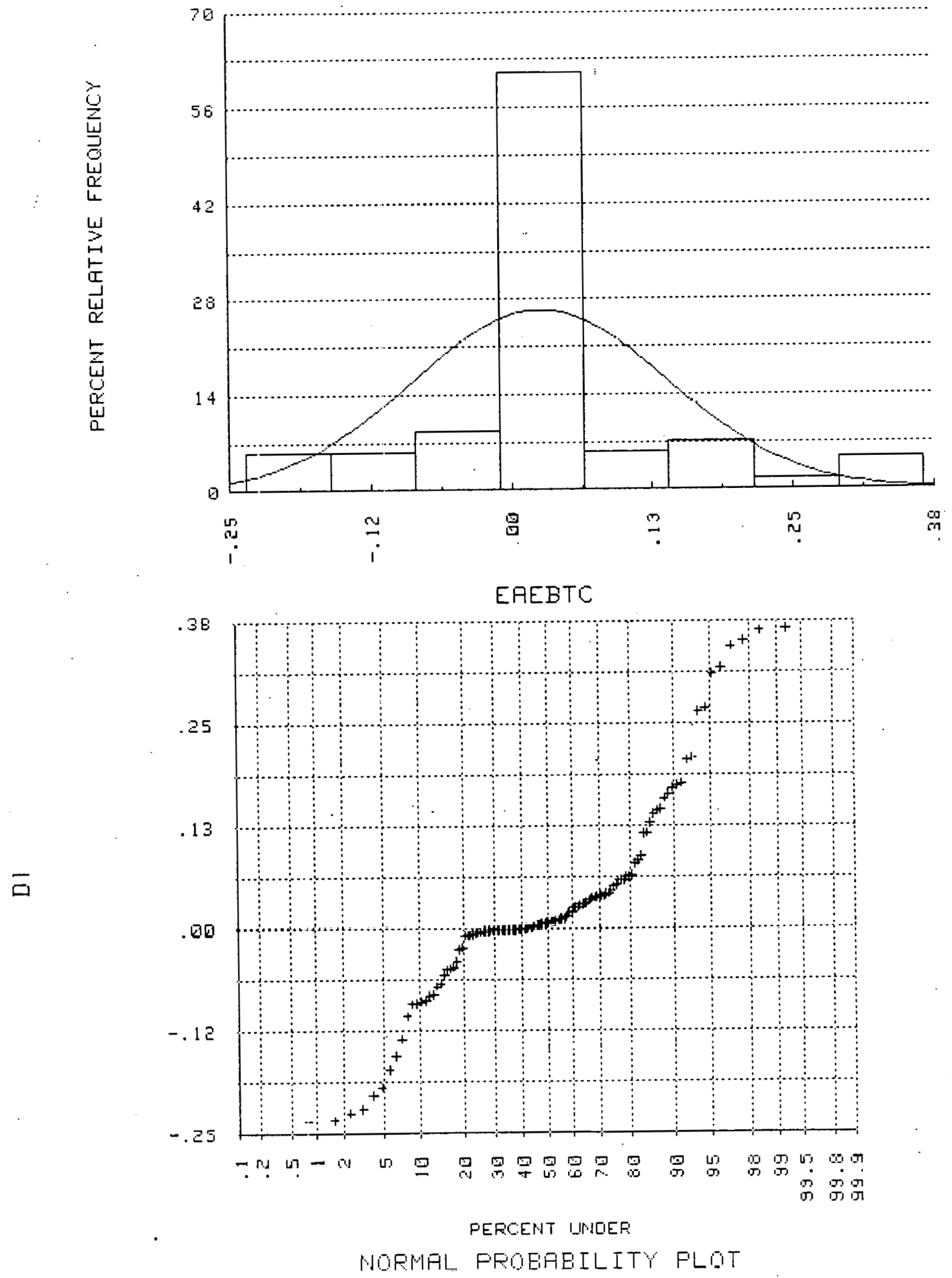

Figure E.1.a.3 Statistical Plots of EA-EB for a $T_{m}$ Disturbance. 

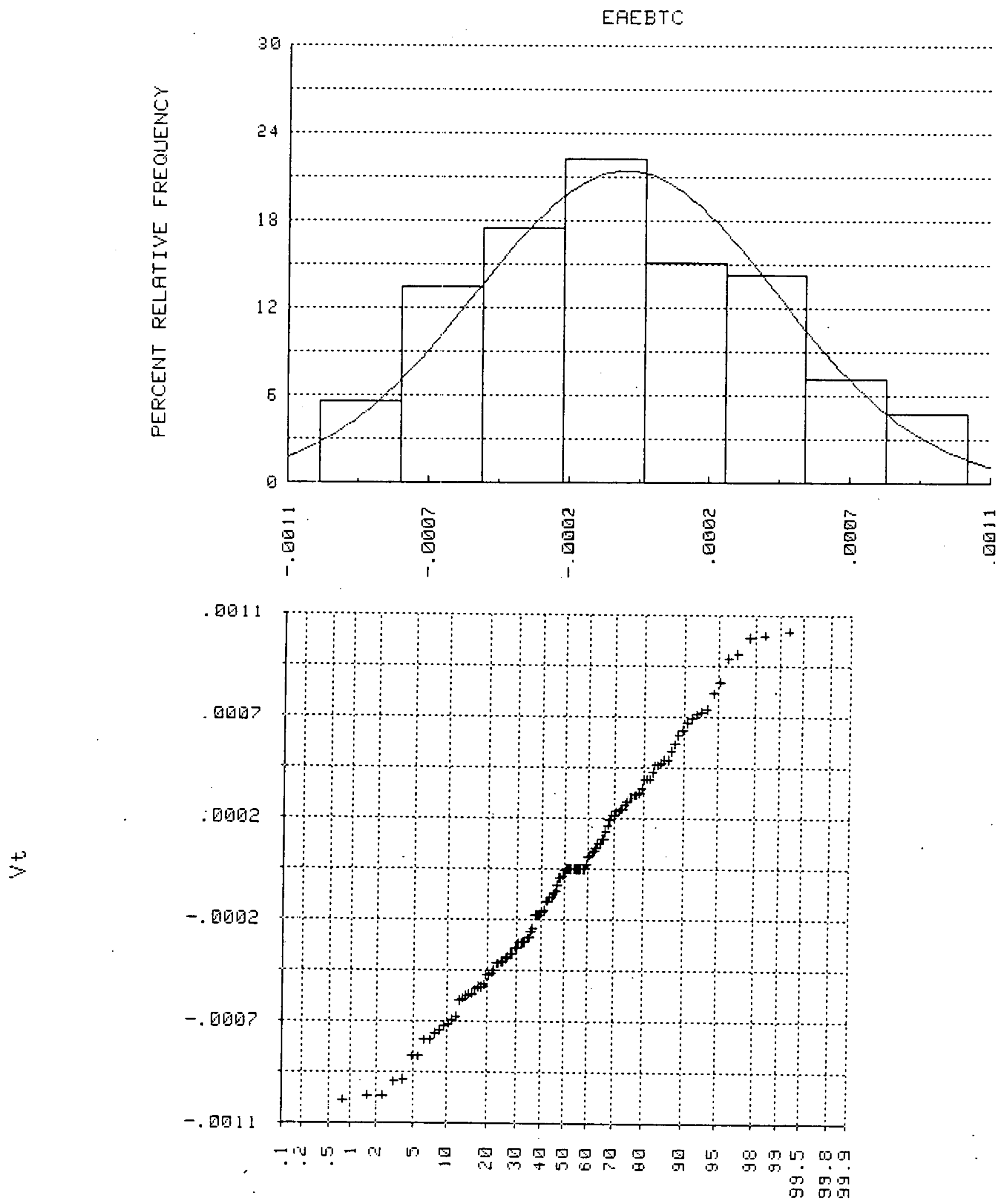

$$
\begin{gathered}
\text { PERCENT INIEER } \\
\text { MOPMAL FROEAEILITY FLOT }
\end{gathered}
$$

Figure E.1.a.4 Statistical P1ots of EA-EB for a $T_{m}$ Disturbance, 
EREEYC
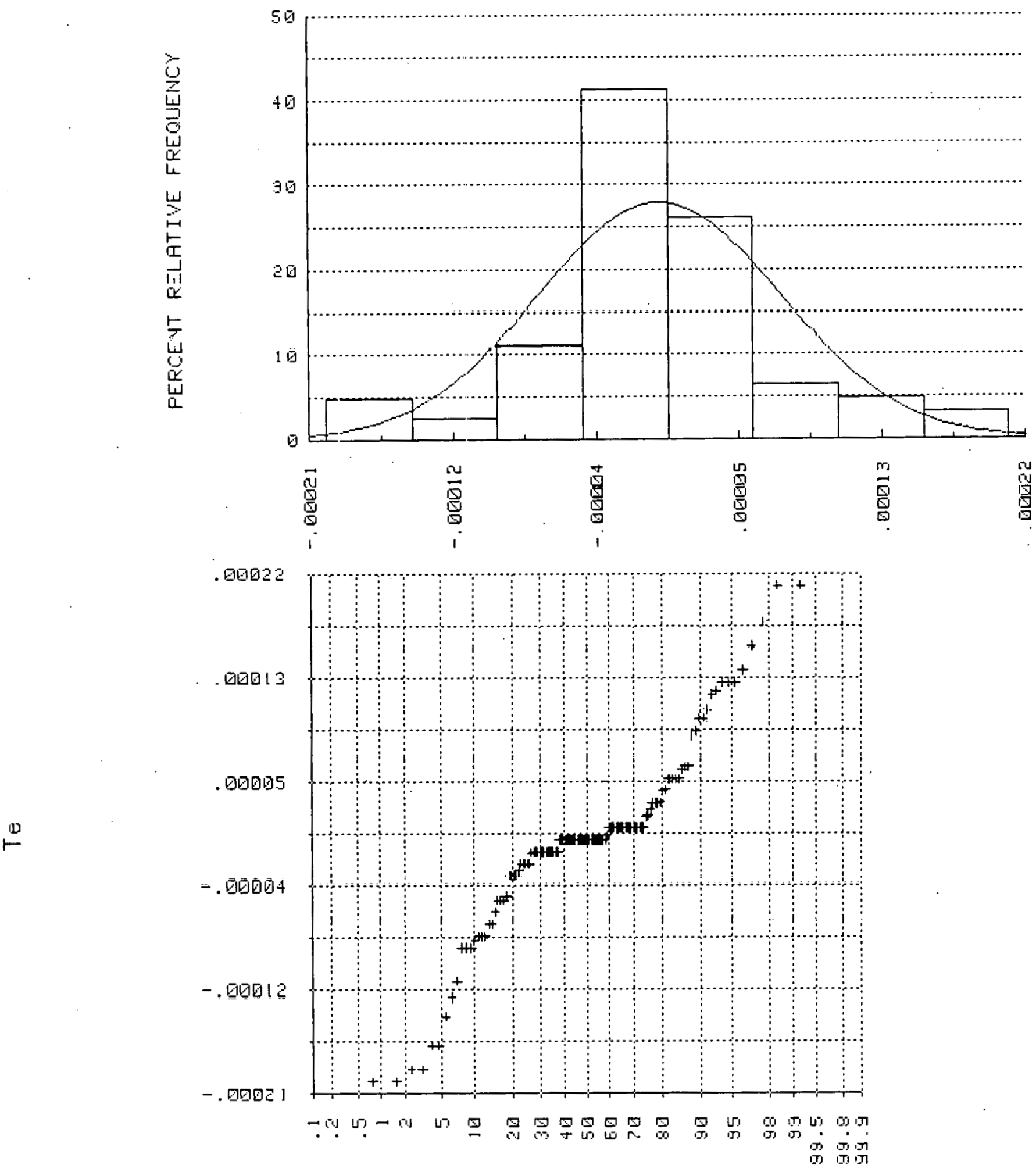

PERCENT LNNDER

NOFMAL FFOEAEILITY FLOT

Figuro E.1.b.1 Statistical P1ots of EA-EB for a EFD Disturbance,

Data for $\mathrm{T}_{e}$ 

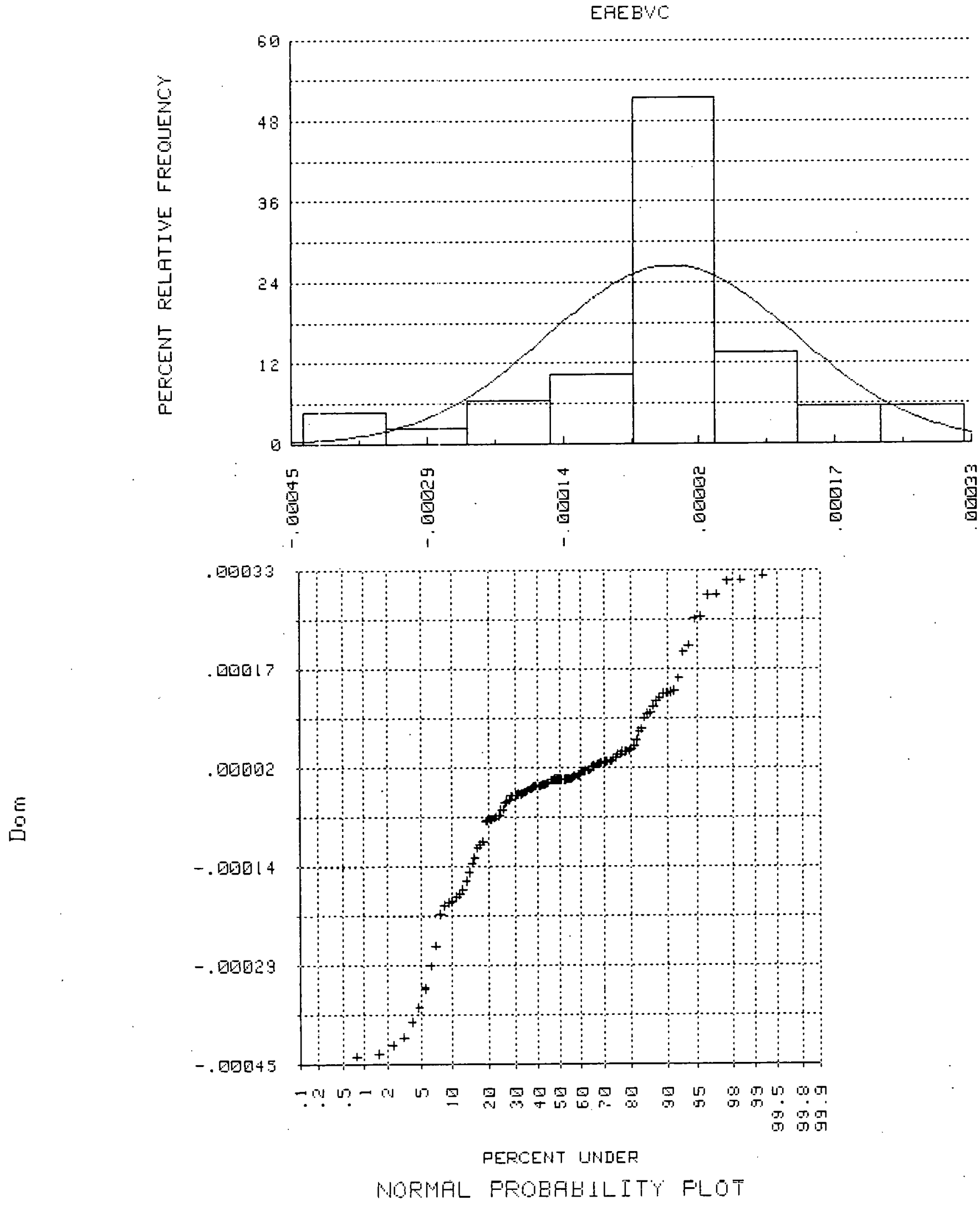

Figure E.1.b.2 Statistical Plots of EA-EB for a $E_{F D}$ Disturbance, 
EAEEYC
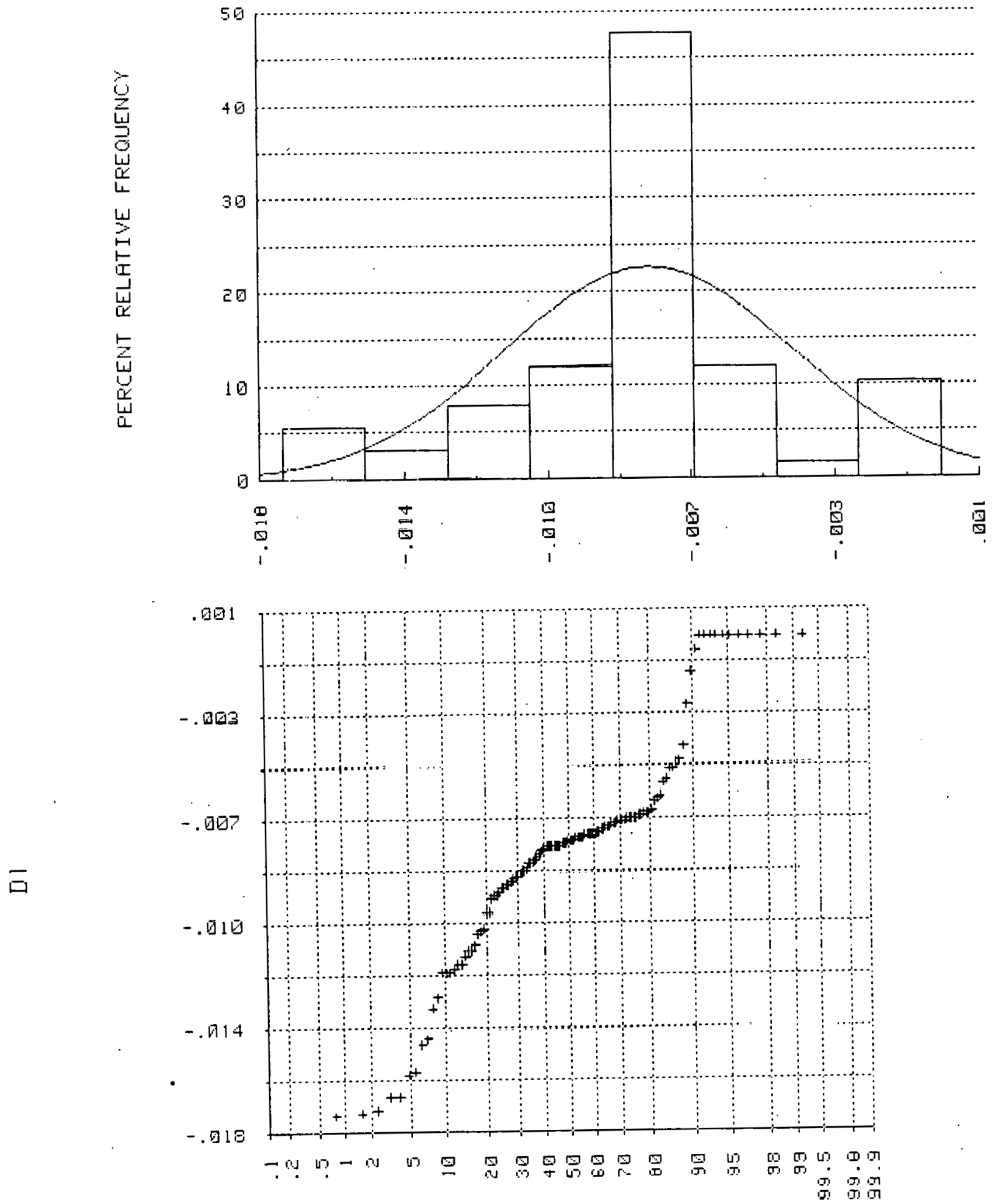

FERCENT LINLER

NOFMAL FROEAEILITY FLOT

Figure E.1.b.3 Statistical Plots of EA-EB for a EFD Disturbance, 

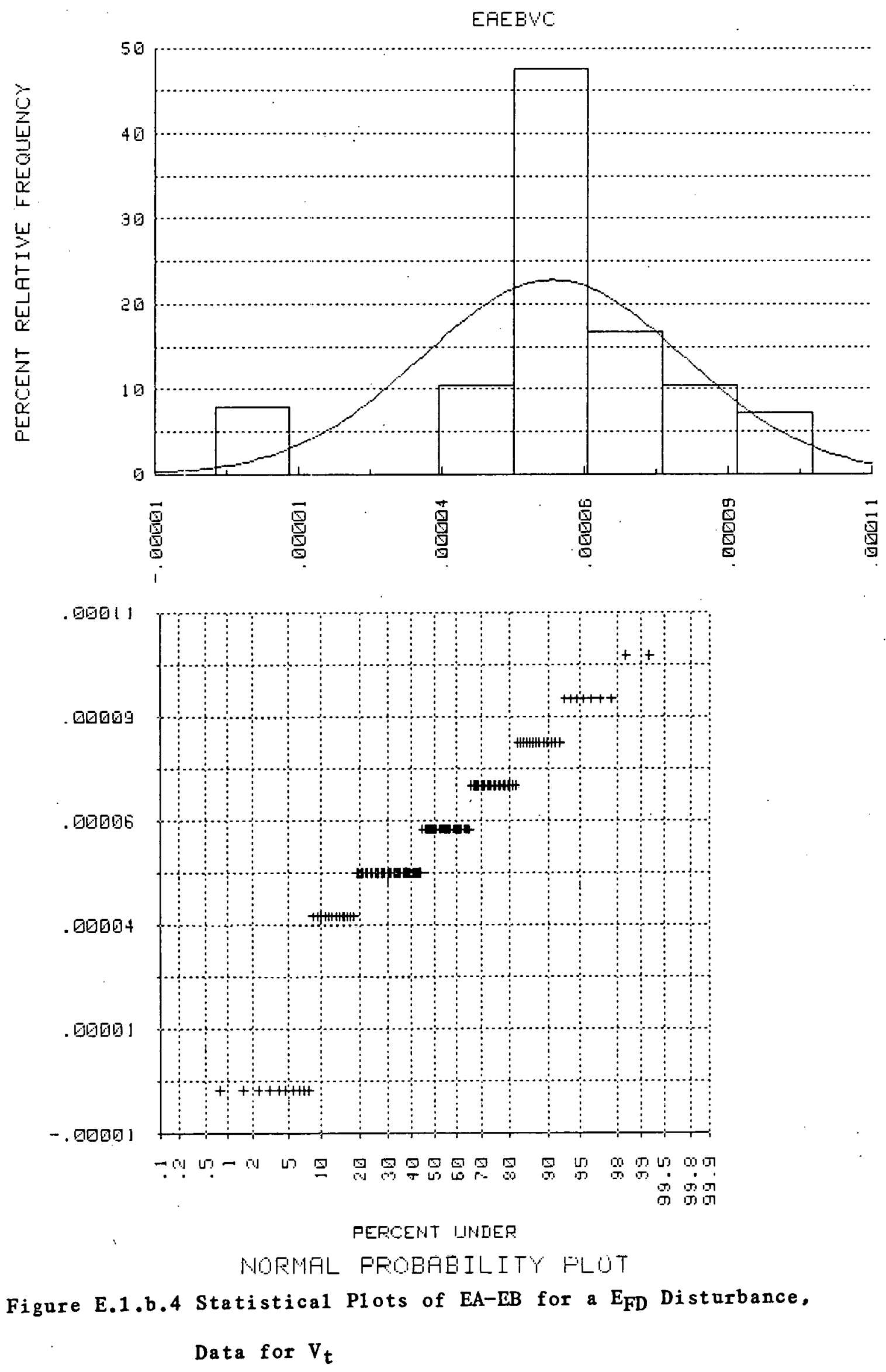
Table E.3a Statistical Analysis of the Difference between Flux

\section{Linkage and E'' hodels, Unsaturated Case, \\ Step Change in $\mathrm{T}_{\mathrm{m}}$}

\begin{tabular}{|c|c|c|}
\hline HAFI $\overline{H E L E}$ & WAFIAHE:E & :TAUIIAFI IIEU。 \\
\hline$y t$ & $=01060$ & .06197 \\
\hline$T: E$ & $=$ 6061 & .6056 \\
\hline Thin & $=$ 10日64 & . 6159 \\
\hline II 1 & .61395 & $.1143 E$ \\
\hline 忹日可 & .69060 & . \\
\hline 怰 & - 10600 & .80199 \\
\hline$\omega f^{\circ}$ & 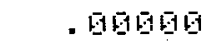 & .90158 \\
\hline Wt: $\square$ & - DEEG & .60659 \\
\hline H.三马 & .90600 & . 01006 \\
\hline 197 & . 010000 & - 615695 \\
\hline 叫: & .69600 & . 90150 \\
\hline
\end{tabular}

\begin{tabular}{|c|c|}
\hline DOEF DF & DOEF IIF \\
\hline GEEWHES & FUFTOSIS \\
\hline . $14 E \overline{6}$ & -.51540 \\
\hline . 8964 & 1.5.540 \\
\hline .9791 & 2.4347 \\
\hline .72475 & 1. 876 \\
\hline-.59785 & .2978 \\
\hline - . FOEA & . 7 日9 \\
\hline - . 46回可 & - . 6193 \\
\hline 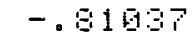 & $1.694 \mathrm{E}$ \\
\hline 1. 15424 & 2.1769 \\
\hline 1. & 2.19510 \\
\hline 1. 14455 & 2.1444 \\
\hline
\end{tabular}

\section{HFFI I FELE}

ist.

$T=$

IIIII

[I]

H.

H.

U. $f$

H.

月.

49

[1.: 9

\author{
EDEF WHFI ITT IOH \\ 1658.5989 \\ 769.86929 \\ 209499562 \\ 485.4594 \\ 156.3015 \\ 25.5. \\ 151.2975 \\ 139.6282 \\ 311 . \\ छ1日. 1972 \\ 311.9428
}

STAHIIAFII EFEOIIE:

DF THE MEHH

- DES014

- 5657

- 6165:

. 61919

. 01019

. 96918

.00014

. 10105

- 960108

- 0060

- 01060
$96 \approx$ EDHF IIEHIE IHTEFYAL OH MESH LIIUEF: LIVIIT

- . 96011

- . 96962

- . G650

- 11111

- 605

- . 01107

- . 0128 .

- . 1061

- 60115

. 0 国正

. 90615
UFF'EF: LI IIT

- 16010

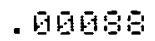

. 60691

.8445

- . 5655

- . 66548

- . 0151

- . 5094

- 1004

96044

.09641

DFIIEF: БTHT I GT IL:

\begin{tabular}{|c|c|c|c|c|}
\hline 'AF: IAELE & PIFYI INU & 们IHINIIN & FEHEE & MI IIFAHFE \\
\hline 'yl. & .90103 & - . 버년 & - 10263 & .00602 \\
\hline$T \fallingdotseq$ & .6957 & $=51879$ & . & . 90135 \\
\hline IVGii & - 6268 & -.01530 & . 03619 & .60273 \\
\hline II 1 & . 37626 & 一. . & . 50550 & .60745 \\
\hline$H \equiv d$ & .00151 & - . 16950 & . 01504 & -. 60191 \\
\hline Wa & .00849 & - DEE & . 019969 & - . 60136 \\
\hline 日十 & . $\overline{14} 174$ & -.6475 & . 1055 & .618151 \\
\hline Wh: 日 & - 501979 & -.6821 & .00296 & - . 01066 \\
\hline 14.19 & $=601$ & -.05147 & .06445 & .09077 \\
\hline 以马 & . 9535 & - 80185 & - 96560 & - 010685 \\
\hline 1.1:日 & . 60900 & -.05147 & .09647 & . $6067 \%$ \\
\hline
\end{tabular}


Tab1e E.3b Statistical Analysis of the Difference between Flux

\section{Linkage and E'' Mode1s, Unsaturated Case,}

\section{Step Change in $E_{F D}$}

\begin{tabular}{|c|c|c|}
\hline UFA IAELE & UAFI IFHEE & STAHIIAEII IEU. \\
\hline$y t$ & $=06060$ & . 00602 \\
\hline$T E$ & .96969 & .09607 \\
\hline Irom & .90100 & .00014 \\
\hline [11] & .9061 & .00384 \\
\hline 时可 & . 9101019 & . 01615 \\
\hline Wa & - 9016日e & . $60161 \mathrm{E}$ \\
\hline Wf & - 101969 & - 61029 \\
\hline He日. & . 60606 & . 515019 \\
\hline H. & - 6196日 & .01004 \\
\hline Wa & .90900 & .0606 \\
\hline H:1:口 & . 06060 & . 1560 \\
\hline
\end{tabular}

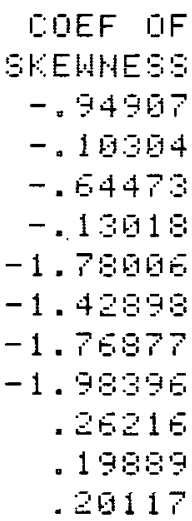

DOEF DF

KIIFTOISIS

1.3843

1. 68437

1. 90521

.79189

3. 18987

2.50905

3.69014

3. 75206

. 76986

.89476

.67172

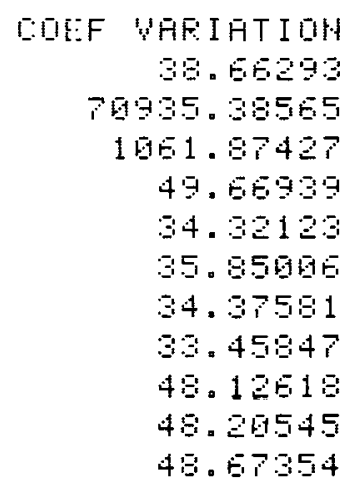

STAHIHFII EFEOAF GF THE NERH . . 60日6 1 - 96061 - 616 - 1601 - 6061 - 6010 . 10101 - 6 回日6 - 60906 . 900 日9
$96 \%$ DOHFIIIEHCE IHTEFUAL DH MEAH LIWEF: LINIT . 01005

- . 01001

-. $696 \overline{6}$

- . 69829

.60643

. 10042

- 60679

- 9605

- . 01019

- 0 日e日g

- 9606
IIFFEF: LINIT - 960 - 0001 - 6001

-. 9616 - 60164 - 96017

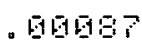
- Q16E27

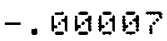

- . g日ger - . 1907

DIFIEF: BTHTIST ILS

Y

\begin{tabular}{|c|c|c|c|c|}
\hline 'YFF I I & MA\% I MUP & MIHIMUN & FEH HIEE & MI DFEHLE \\
\hline ' $y$ 't & . 601010 & 9.006日0 & - 06010 & .80605 \\
\hline$T E$ & . 0601 & - . 19日20 & . 60 国4 & . 回国回 \\
\hline Ilom & . 10632 & - . 10日4 4 & . 09675 & - D日EGE \\
\hline III & 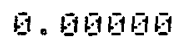 & -.81740 & .51745 & -.00870 \\
\hline ل1. & . 01065 & 口. & . 0065 & . 1963 \\
\hline W & - 10976 & 日. 国国国 & 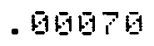 & . 10日5: \\
\hline Wh & . 50113 & 9.06日6 & .65113 & . 965 \\
\hline Wht: a & .00637 & 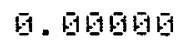 & - 01037 & . 回日19 \\
\hline 月.引日 & 日. & $-.0001 E$ & . 901016 & - . D国国 \\
\hline 约 & .00861 & 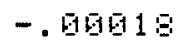 & . 6巨E19 & -.06069 \\
\hline |.1: 9 & G，因可国 & - . G日E & . 01016 & -.9606 \\
\hline
\end{tabular}




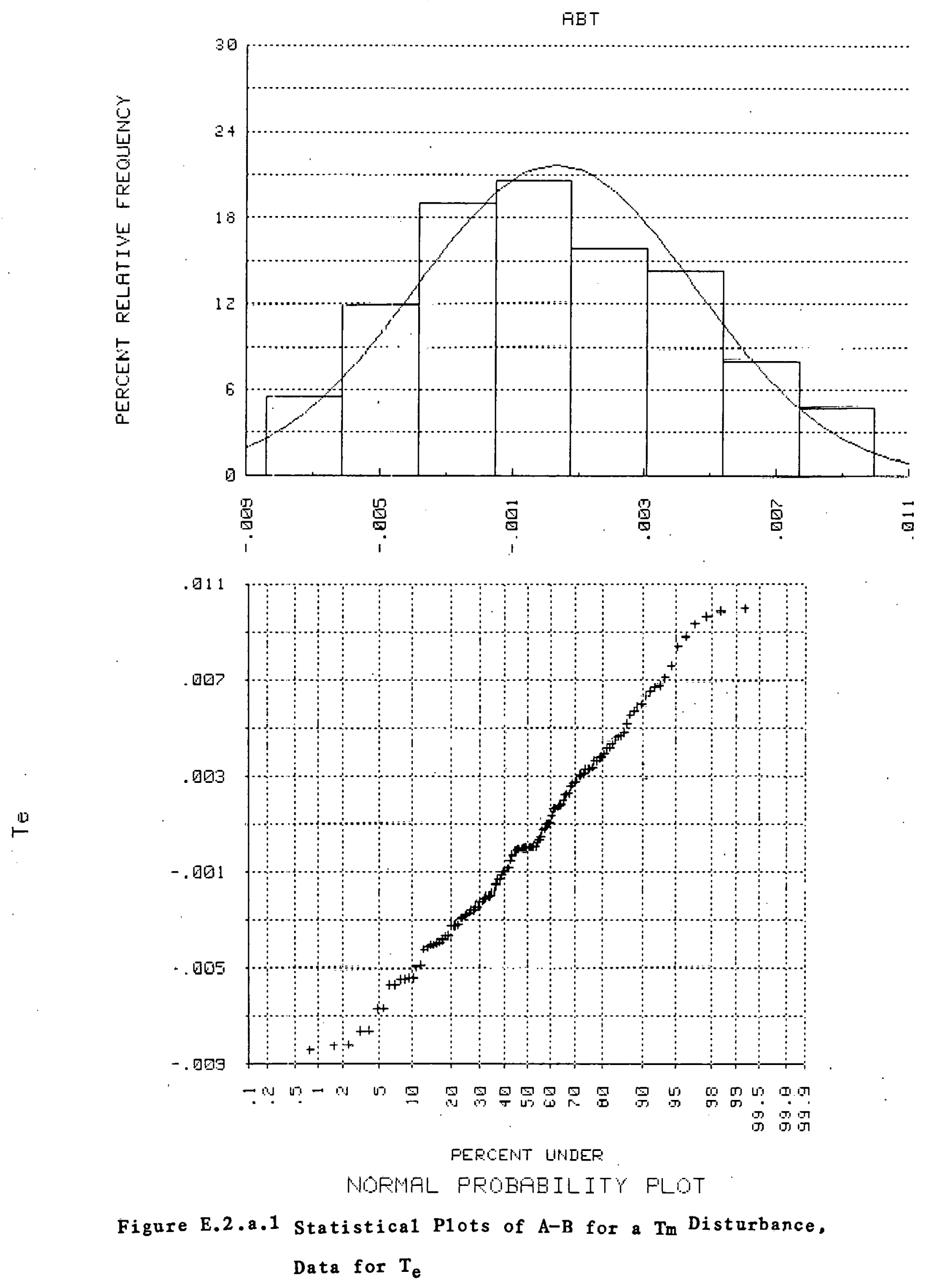




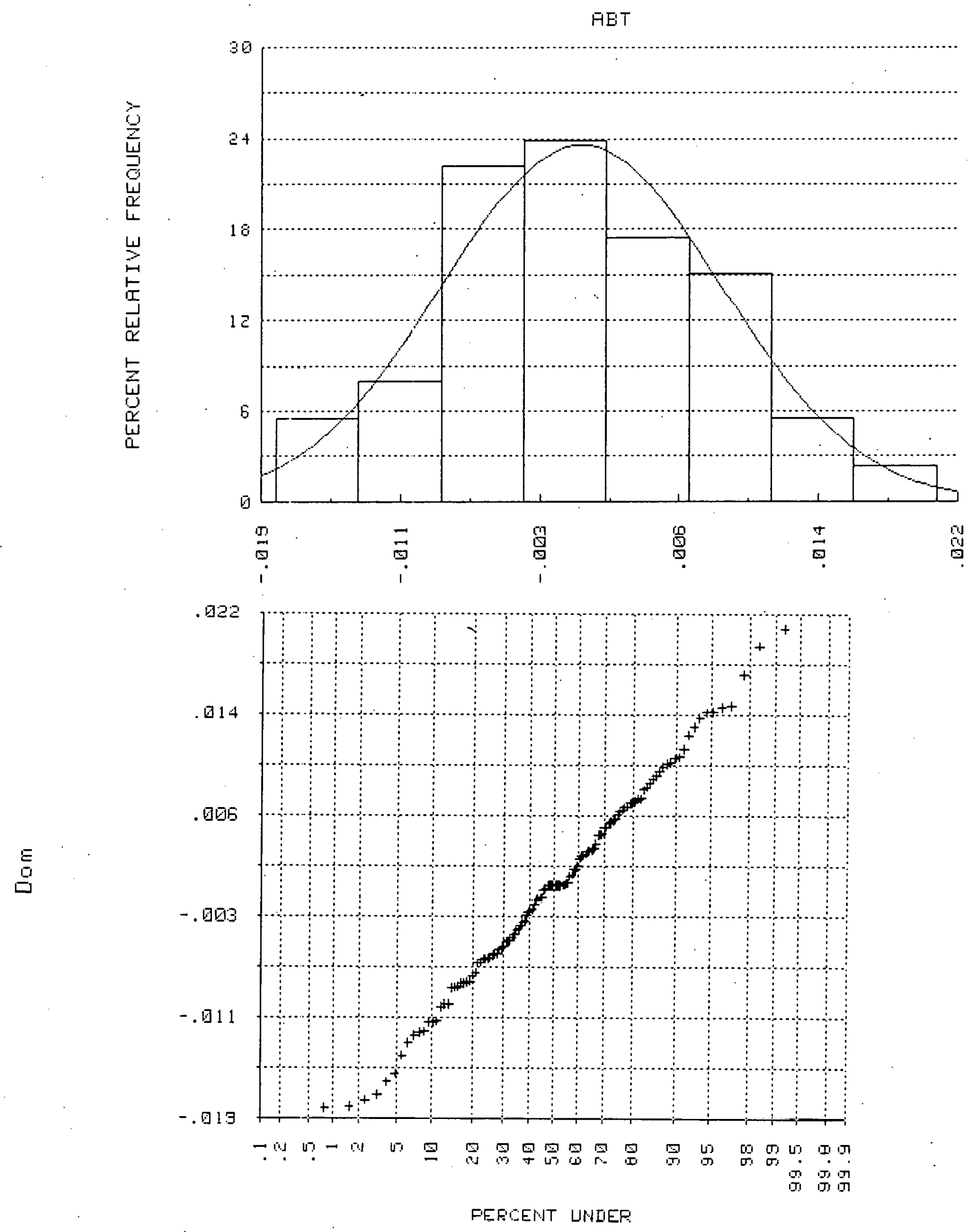

NOFMAL FROEAEILITY FLOT

Figure E.2.a.2 Statistical Plots of A-B for a Tm Disturbance,

Data for $\Delta \omega$ 


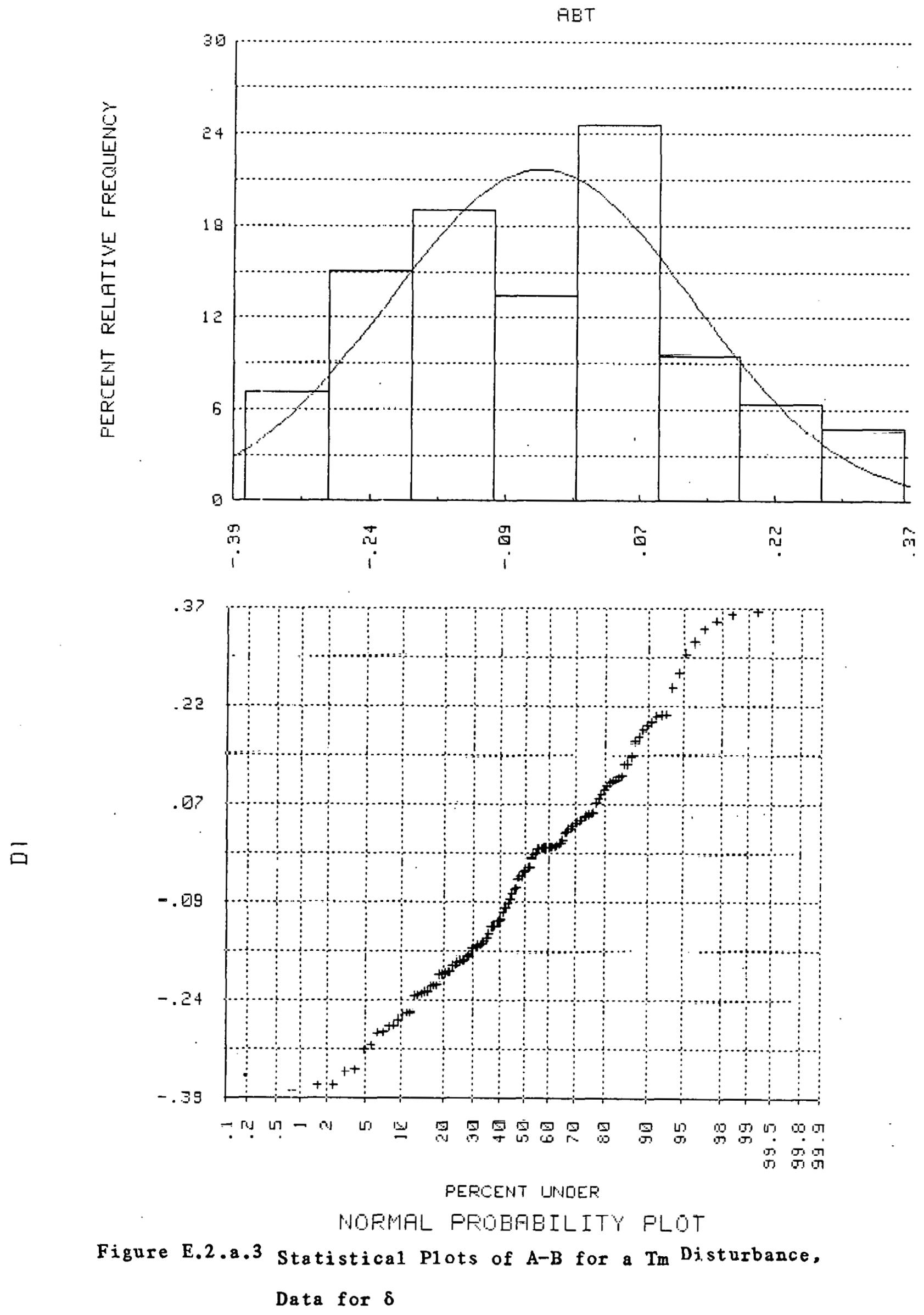




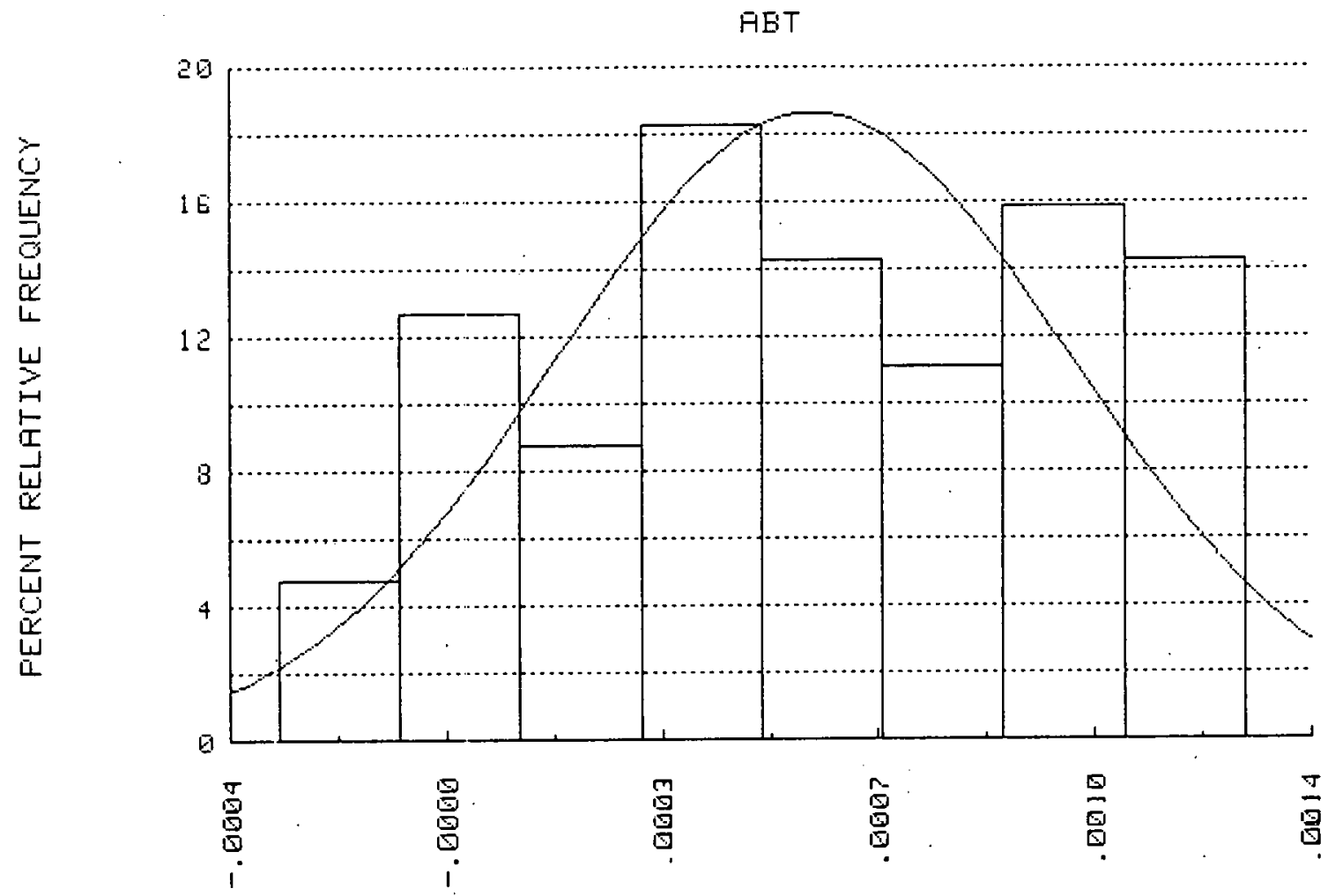

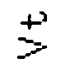

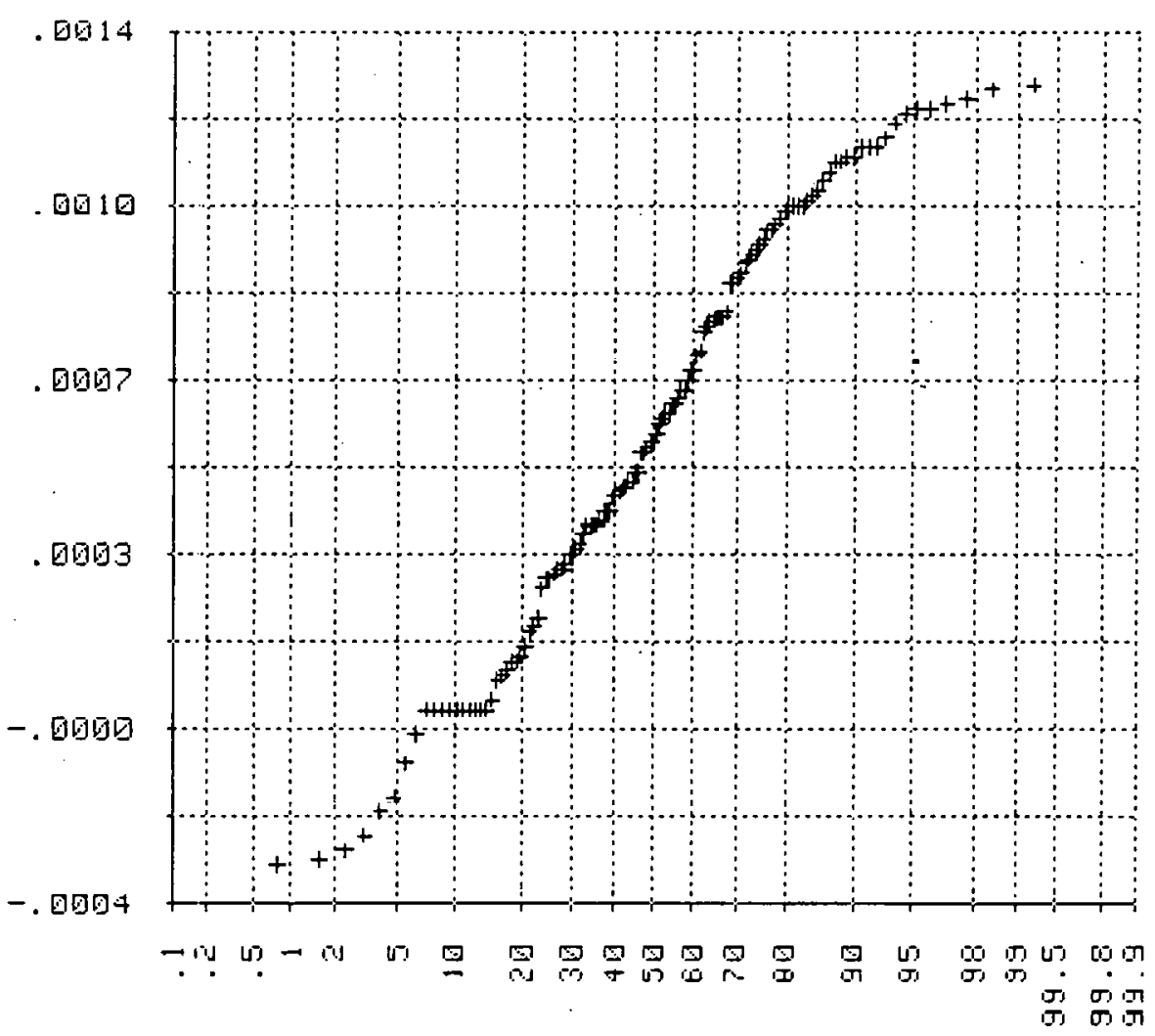

FEFEENT INIDEF

NORMAL PROEAEILITY PLOT

Figure E.2.a.4 Statistical Plots of A-B for a Tm Disturbance,

Data for $v_{t}$ 


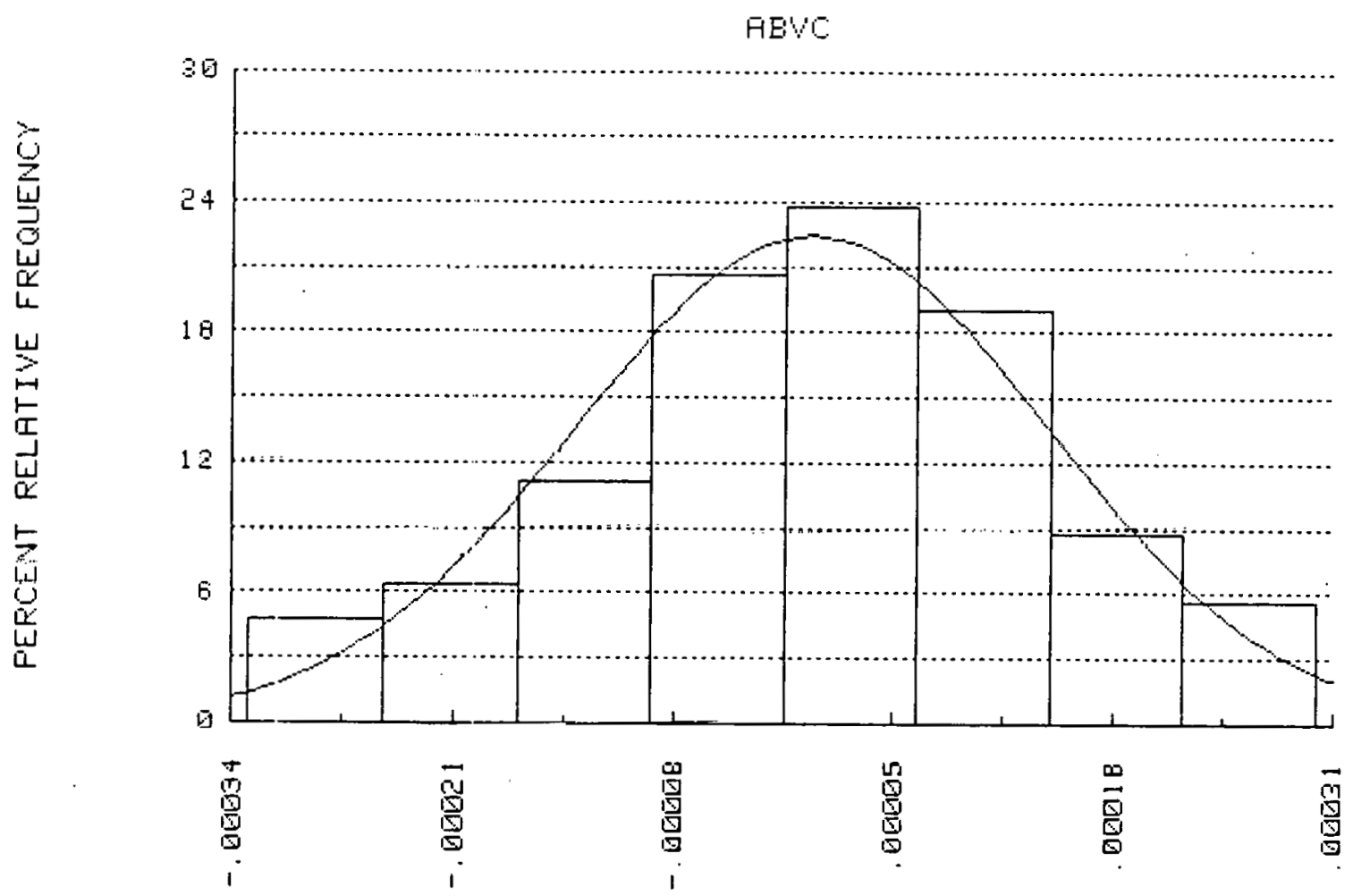

1

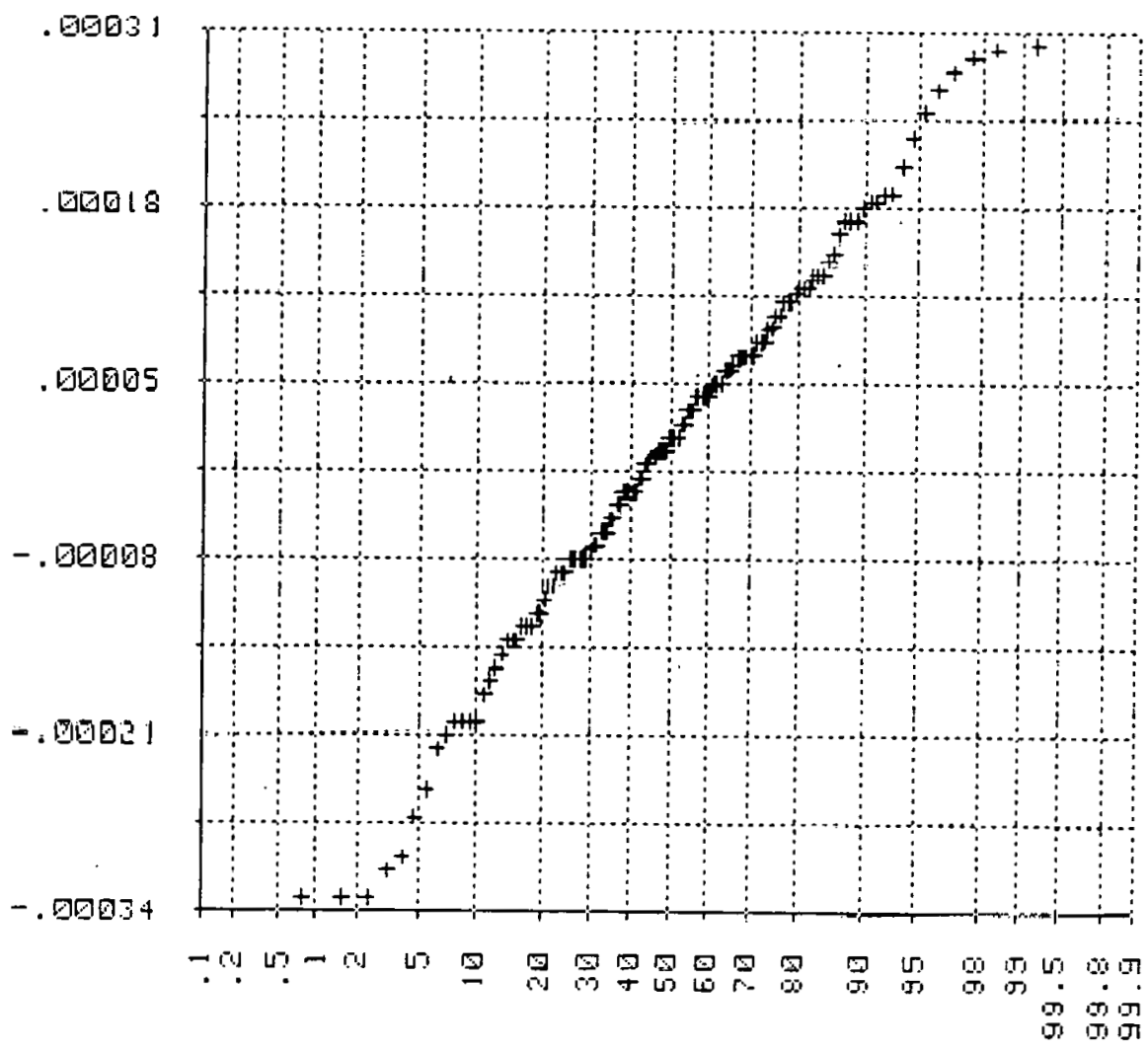

PERCENT IJNDER
NOFMAL FFOBAEILITY FLOT

Figure E.2.b.1 Statistical P1ots of A-B for a EFD Disturbance,

Data for $T_{e}$ 


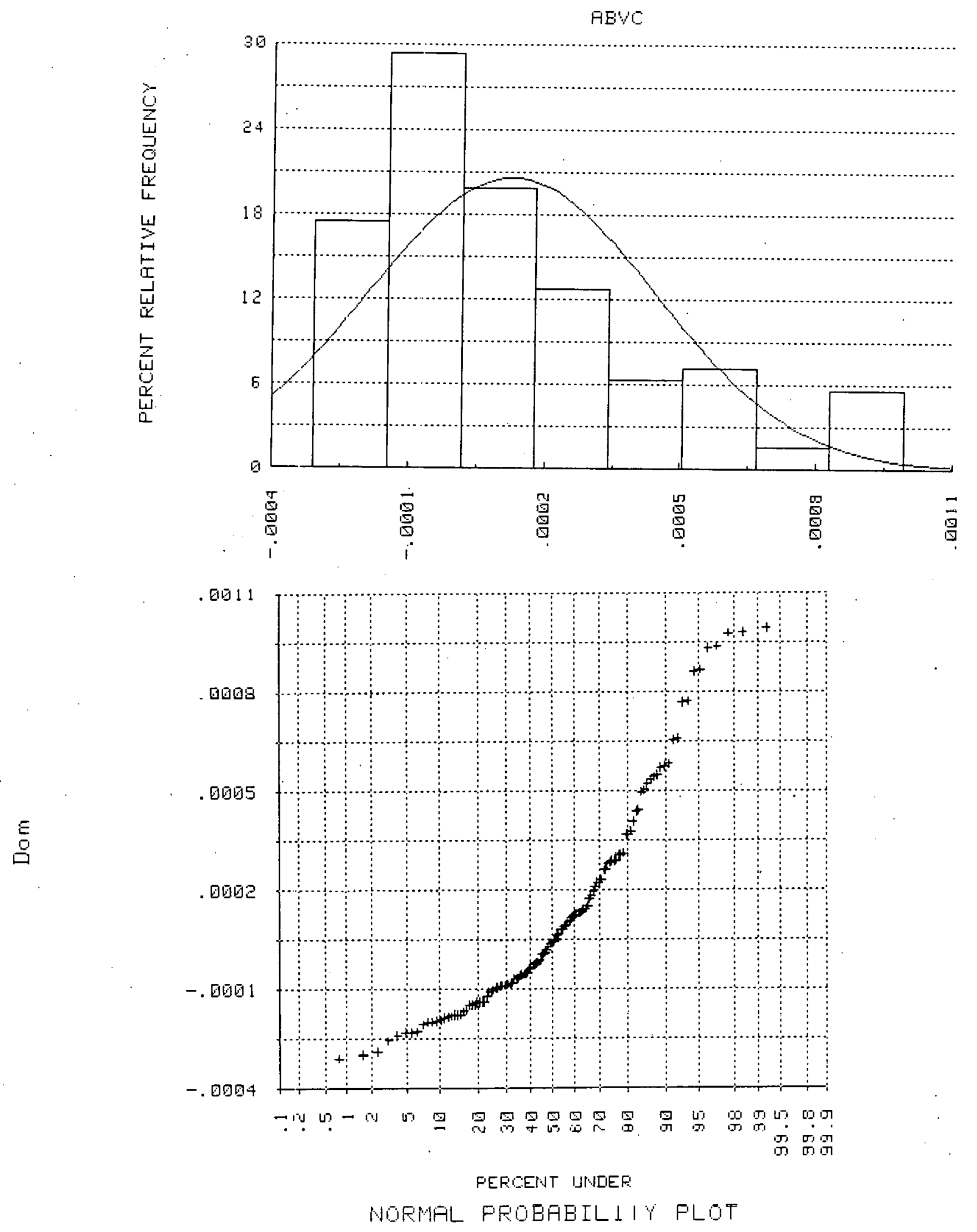

Figure E.2.b.2 Statistical P1ots of A-B for a $E_{F D}$ Disturbance,

Data for $\Delta \omega$ 

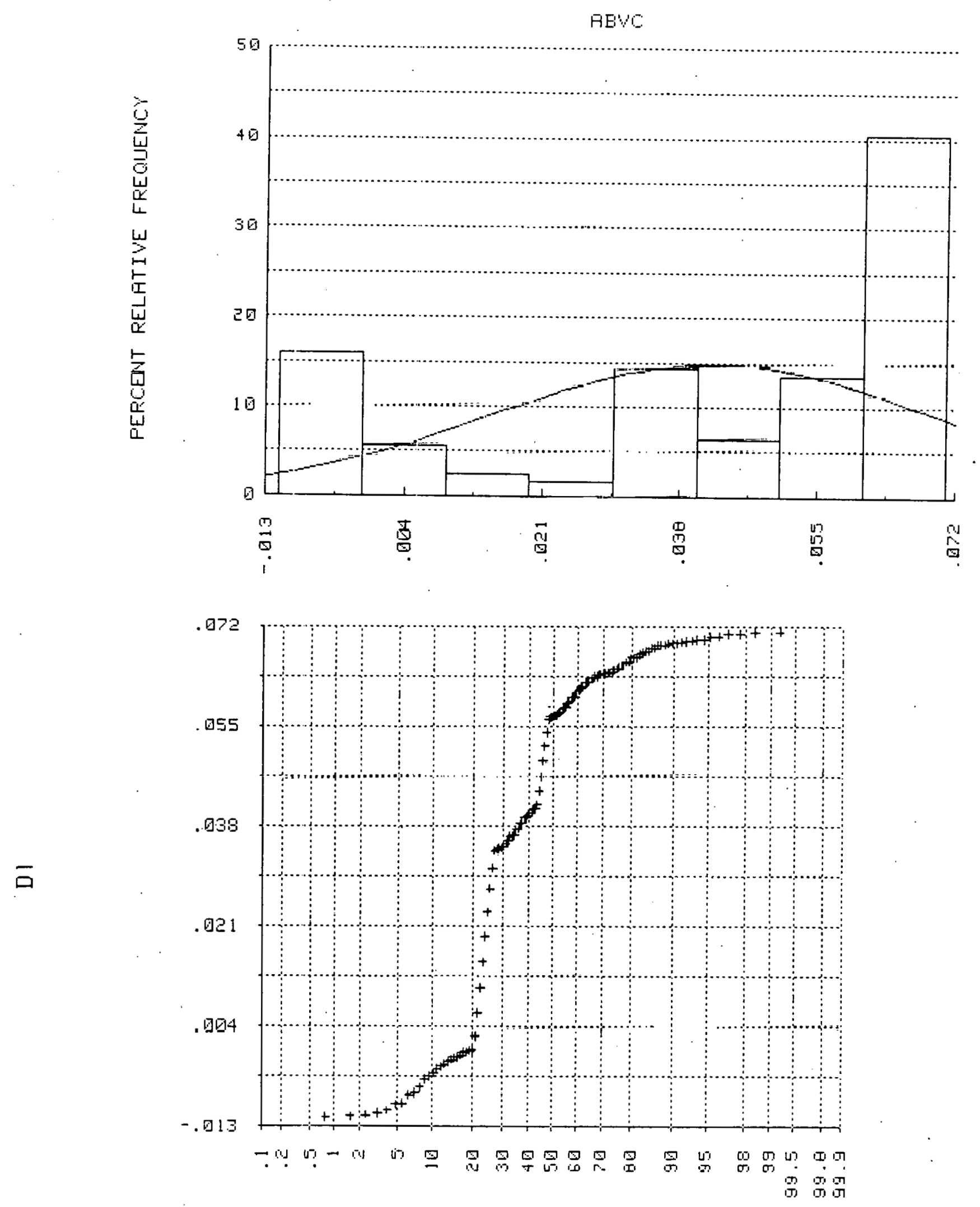

FERCENT LINIEF:

NOFMAL FROBEEILITY FLOT

Figure E.2.b.3 Statistical Plots of A-B for a $E_{F D}$ Disturbance,

Data for $\delta$ 


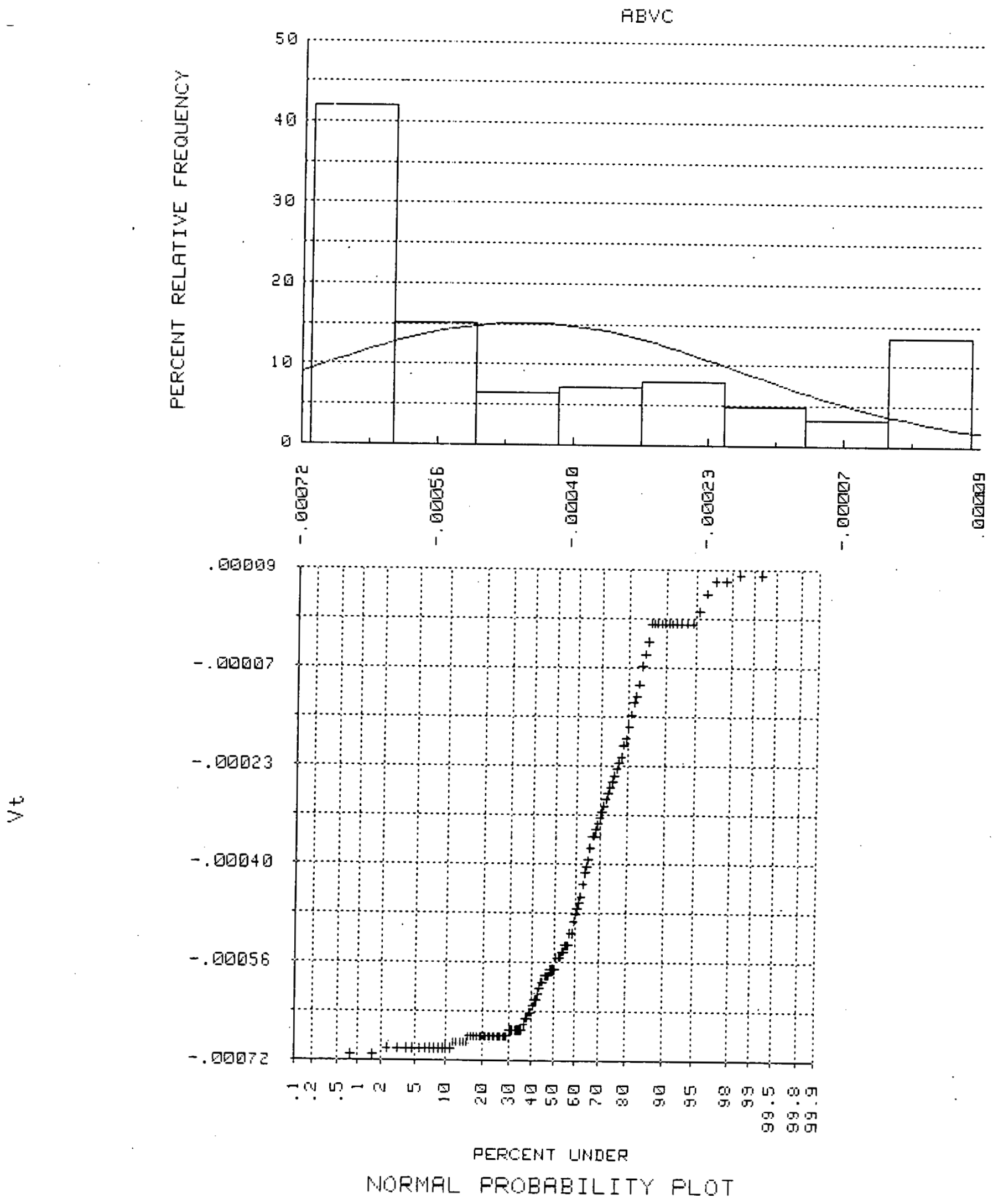

Figure E.2.b.4 Statistical P1ots of A-B for a $E_{F D}$ Disturbance,

Data for $V_{t}$ 
Table E.4a Statistical Analysis of the Difference between F1ux

\section{Linkage and E' Models, Complete Saturation,}

\section{Step Change in $\mathrm{T}_{\mathrm{m}}$}

\begin{tabular}{|c|c|c|c|c|}
\hline & & & IIIEF IIF. & EIEF DF \\
\hline "AF' I HELE & UFE: I HHEE & GTHHIIAFI IIE' & GHEWHE: & HUFTOEIS \\
\hline$y+$ & $=$ G010日 & $=$ - 1040 & -.14242 & -1.05925 \\
\hline$T \equiv$ & - 96962 & - 96423 & .17241 & -.44924 \\
\hline Ilgrit & - 960日7 & .6092 & $.84: 1$ & -2989 \\
\hline II 1 & - 1295 & .17553 & .90152 & -.3065 \\
\hline 以.引日 & - 0010日 & . $018 \mathrm{E}$ & -.56796 & -.51778 \\
\hline W & - 1061 & . 0025 & -.35144 & $-.48 E$ \\
\hline 45 & - $\overline{19} 6 \overline{16} \overline{1}$ & -51919 & -.48653 & -.5476 \\
\hline HI: & . & .60195 & .71491 & -476 \\
\hline 月三日 & 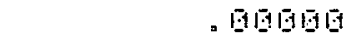 & .07138 & .4534 & -.12501 \\
\hline 49 & 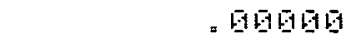 & .69153 & .4593 & -.11925 \\
\hline 1.15: & 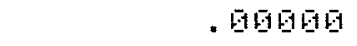 & - E1E 195 & $.402 E$ & -.12820 \\
\hline--- & 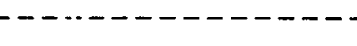 & --------------- & - - - - - - - - - - - & - --------------- \\
\hline & & STAPIIAFI EFFOF & $\because 6 \%$ COHF IIEHEE & IHTERUAL DH MEAH \\
\hline "AFI I AELE & DEEF UAFIATIDH & DIF THE MEAH & LUHEF: LIHIT & UIF'EF LIII T \\
\hline$y t$ & 75.12954 & . 90604 & . 10651 & . 9605 \\
\hline TE & 1491.91844 & - 90996 & - . 00632 & - 66095 \\
\hline Il Diii & 45699728 & - 10078 & - . 19145 & . 60194 \\
\hline III & 34.7960 & .61519 & -.67194 & -.5257 \\
\hline W: & 109.51555 & . 90015 & .61928 & .96175 \\
\hline W曰 & 209.75E13 & . 1505 & . 5064 & $.9617:$ \\
\hline Wf & 124.23425 & .90015 & . 61913 & .90158 \\
\hline Wh: & $7 \because .7671$ & . 60611 & . 0151 & .00193 \\
\hline W.玉口 & 251.4455 & . 19012 & -.06075 & - . -10日9 \\
\hline 敞口 & 256.65574 & - 501414 & -.95054 & - . 101089 \\
\hline Whiti & 2561.4520 & .9512 & - . 196175 & -61015 \\
\hline
\end{tabular}

DERER: STHTISTIS:

\begin{tabular}{|c|c|c|c|c|}
\hline$\forall \bar{H} F_{T}^{\prime} T \overline{H F}$ & WF天 THUN & 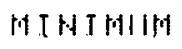 & Fin & HI IIFAHAEE \\
\hline 'yt & .06129 & - . & . 0161 & . 61649 \\
\hline$T E$ & .06997 & - . DES42 & .01889 & . 96078 \\
\hline IlDin & .62675 & $-.01 \Xi 1 E$ & .03891 & .96130 \\
\hline II 1 & .36461 & - . 378 & .741 .30 & - . QDE5 \\
\hline 以.三曰 & .96416 & - . & . 9605 & . \\
\hline W日 & $=068 \mathrm{~B}$ & - . 65.50 & .01198 & . 90649 \\
\hline$w t^{\prime}$ & .56451 & -.60317 & . 19768 & .60607 \\
\hline 1.1:日 & - 51539 & - . & .06471 & .05164 \\
\hline W. $=7$ & .00295 & -.00313 & - 6日EG & -.00009 \\
\hline H口 & - 1098 & -.65347 & - G曰E & - . 01069 \\
\hline 바: 日 & .00294 & -.06312 & .69696 & - . 06869 \\
\hline
\end{tabular}


Table E.4b Statistical Analysis of the Difference between Flux

Linkage and E" llodels, Complete Saturation,

Step Change in $\mathrm{E}_{\mathrm{FD}}$

\begin{tabular}{|c|c|c|c|c|}
\hline & & & 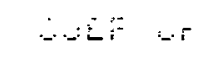 & $\because \because \quad \square F$ \\
\hline VAFI I ELE & VARE I HHIEE & STAHIARI IIEU. & SFEHHESS & KUETOSIS \\
\hline$Y^{t}$ & .616010 & . 01902 & .79307 & -.85525 \\
\hline$T E$ & $=016061$ & . 90914 & -20265 & -.15131 \\
\hline Inom & .06096 & 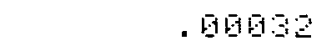 & 1.86780 & .47457 \\
\hline II 1 & $=96977$ & . 92781 & -.78932 & -.99179 \\
\hline H. Bu & .60606 & - 9009 & .6594 & -1.07597 \\
\hline Ho & .60090 & .01694 & - EEEGG & -1.0 .525 \\
\hline Wf & . 96969 & $.0011 E$ & .59965 & -1.0792 \\
\hline 朋:日 & - 90106 & .06087 & .71729 & $-1 \cdot 02230$ \\
\hline 月झ口 & - & .06030 & -.75650 & -.95121 \\
\hline H口 & . 96060 & .90640 & -.7556 & -.93507 \\
\hline Wh: & $=9000$ & .90635 & -.74771 & -.90801 \\
\hline
\end{tabular}

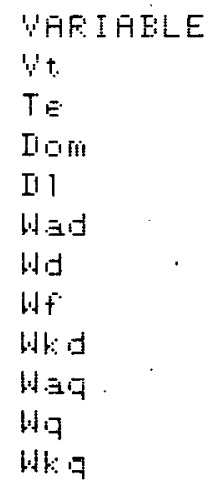

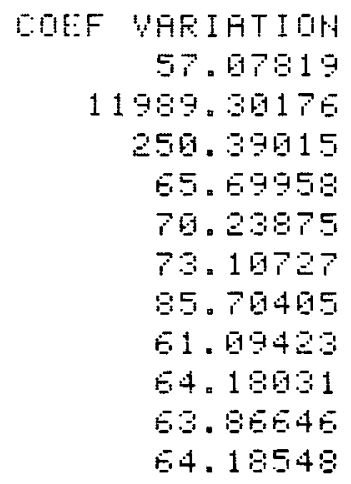

STAHIIAFII EFFOIF:

DF THE MEAH

.06062

. 01061

.01060

.06248

. Q6日69

.

.06010

.

. 00603

.0064

. 80109
96 $\%$ COHF I DEHCE IHTEFUAL DH WEAH LDWEF: LIMIT

$-.09649$

$-.06062$

.00618

.03822

$-.09140$

$-.09127$

$-.015152$

$-.010155$

- 01061

. 0065

. 00951
UFFEF: LIMIT

$-.06942$

. 0 日962

. 00017

.0454

$-.06114$

$-.09162$

$-.06118$

$-.61129$

. 010日e

- 01068

- 06日e 1

DFIEF: STATISTIDS

\begin{tabular}{|c|c|c|c|c|}
\hline YAFE I AELE & WHESIMUNA & 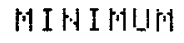 & FEH HILE & WI IFEA \\
\hline$w_{t}$ & - 6906日 & -. 96971 & - 6日979 & - . 61982 \\
\hline$T E$ & - 50696 & -.016103 & - 96160 & -.610192 \\
\hline IIGIi & $=61099$ & -.00101 & . 90136 & . 69014 \\
\hline III & $=6716$ & -.01150 & - 0250 & - 6995 \\
\hline H. & $=96949$ & - . & . 9626.5 & $=516194$ \\
\hline Ha & - 101647 & -.00199 & . 01246 & -.01078 \\
\hline $4 f$ & - 90100 & - . 06258 & .0035 & - . 019079 \\
\hline 胜: & - 010025 & - . 10224 & .01249 & - . 019106 \\
\hline W: & .00693 & -.01012 & .09165 & .010941 \\
\hline W曰 & .00103 & -.06012 & .016115 & .00048 \\
\hline $14: 9$ & .04093 & -.00011 & . 90104 & $=00041$ \\
\hline
\end{tabular}




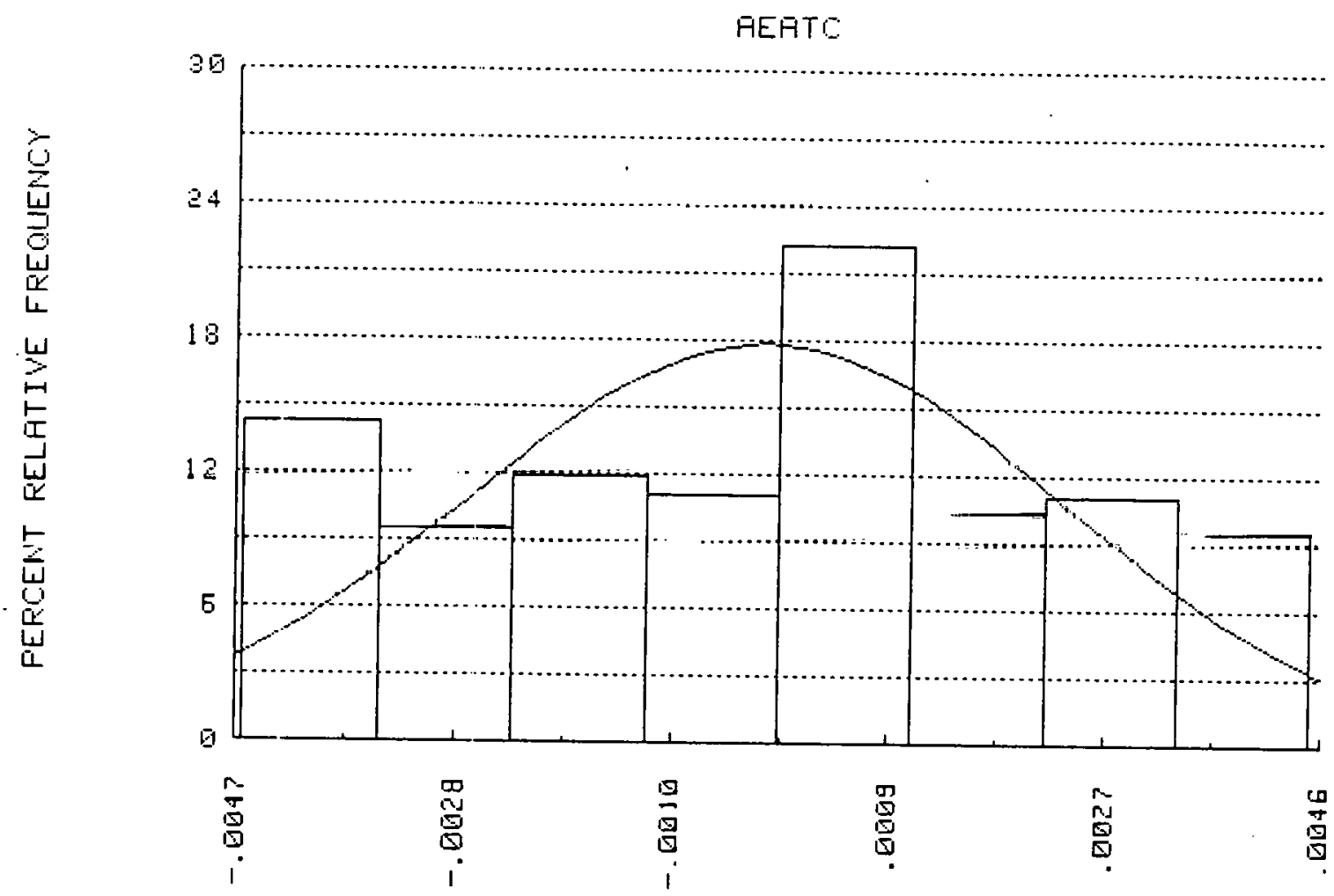

$\stackrel{n 17}{\mapsto}$

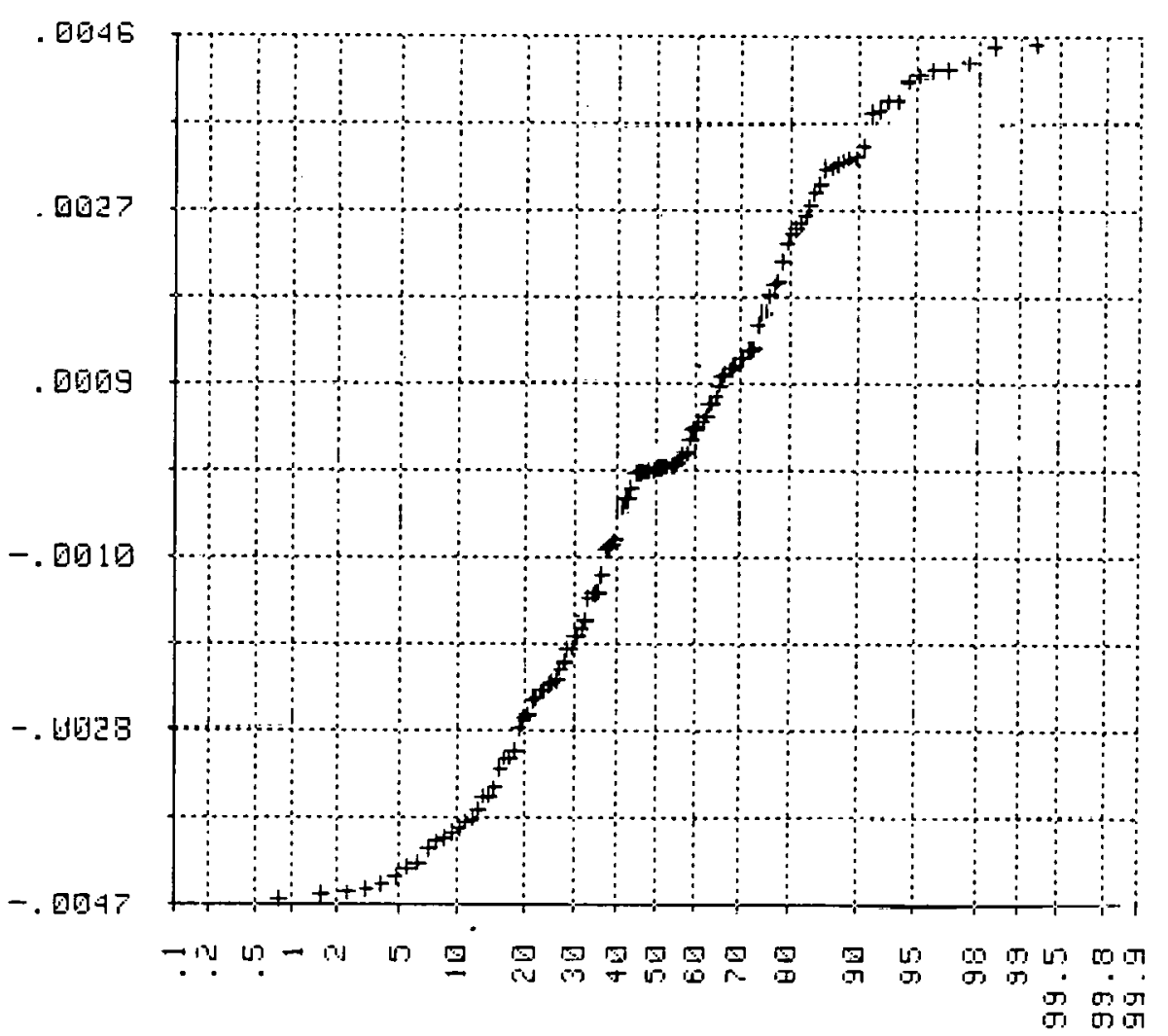

PERCENT INUER

NOFMAL FPOEAEILITY FLOT

Figure E.3.a.1 Statistical P1ots of A-EA for a $T_{m}$ Disturbance,

Data for $T_{e}$ 


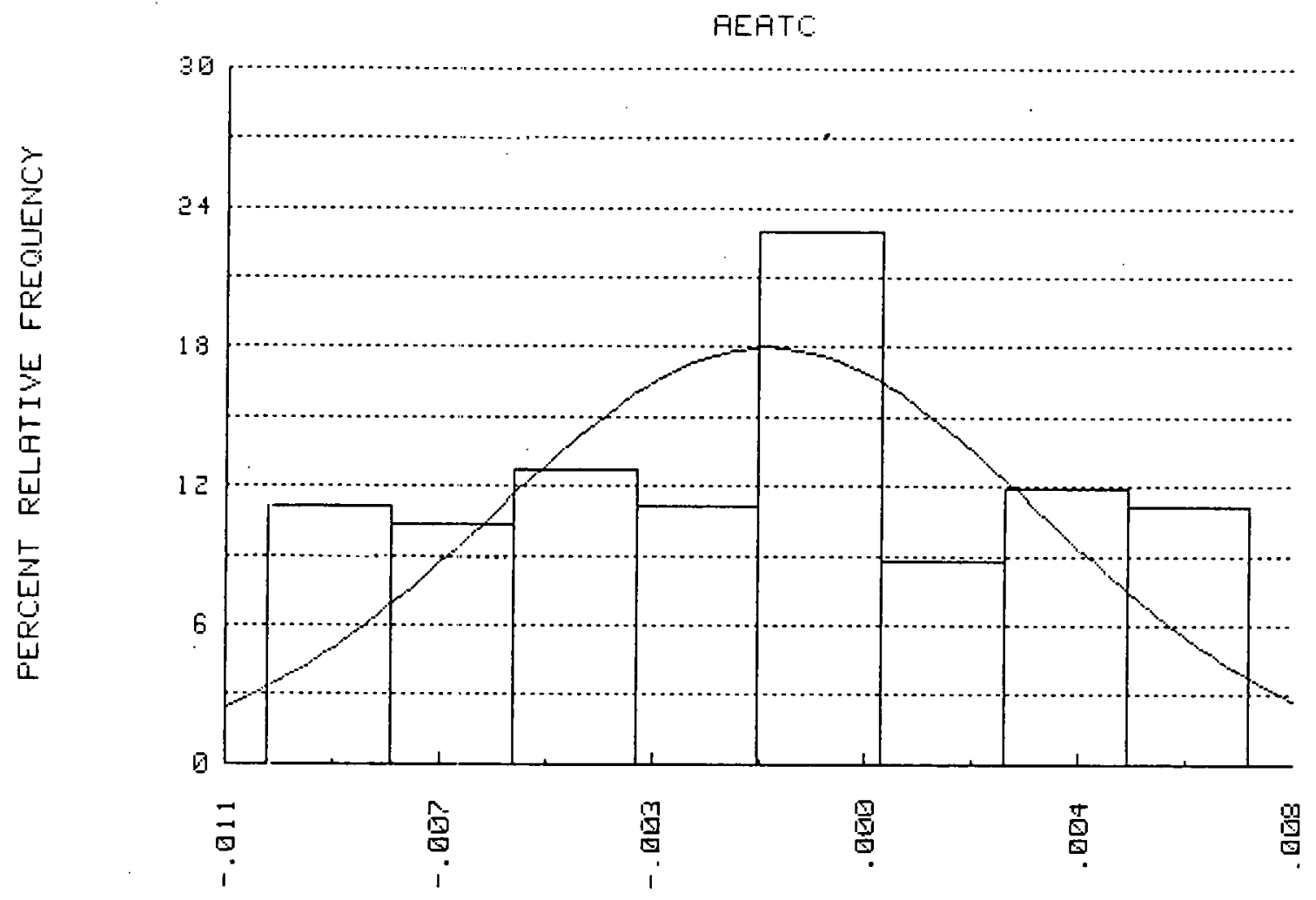

E

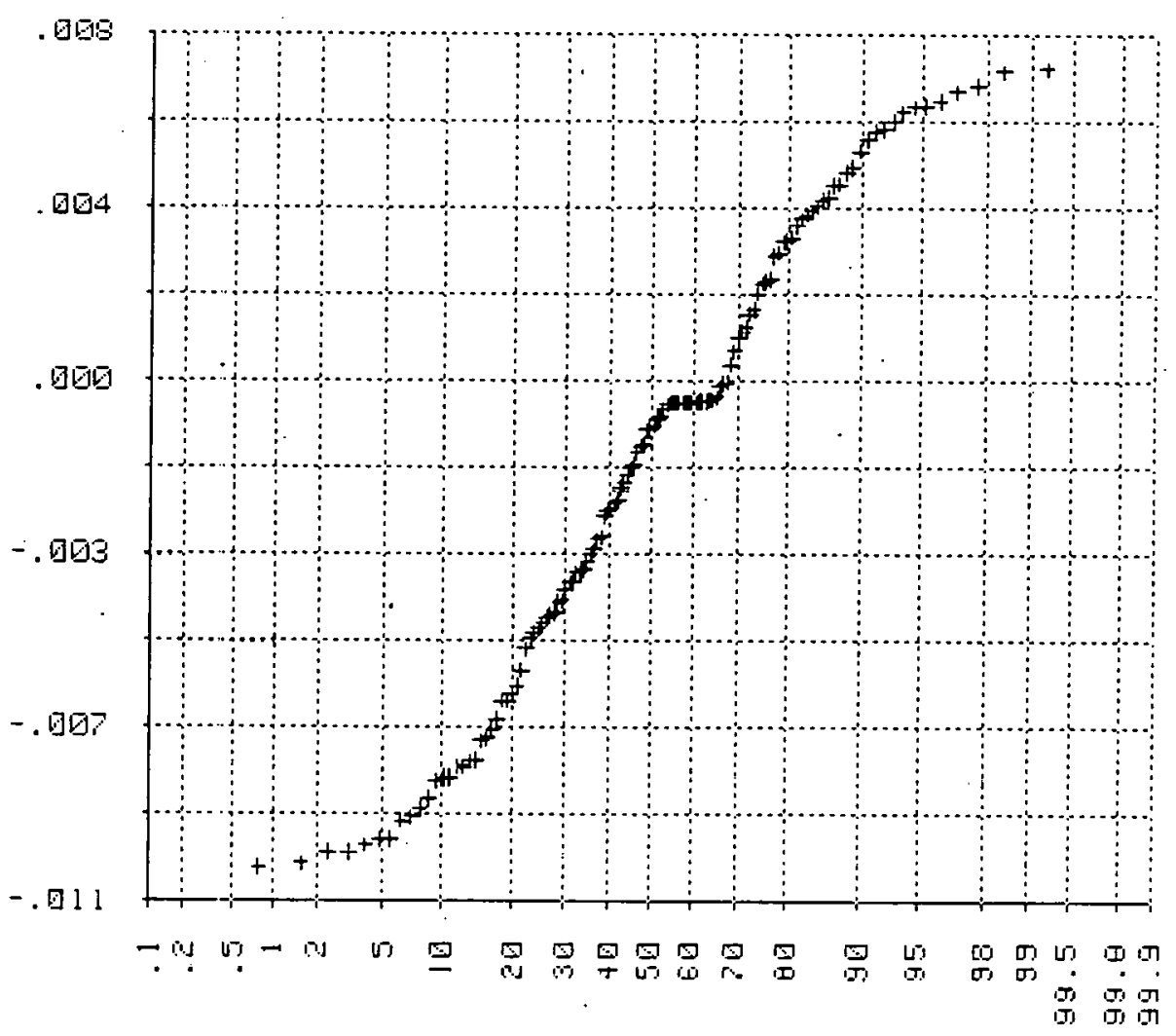

FEFCENT LINDER:

NOFMHL FROBHEILITY FLOT

Figure E.3.a.2 Statistical Plots of A-EA for a $T_{m}$ Disturbance,

Data for $\Delta \omega$ 

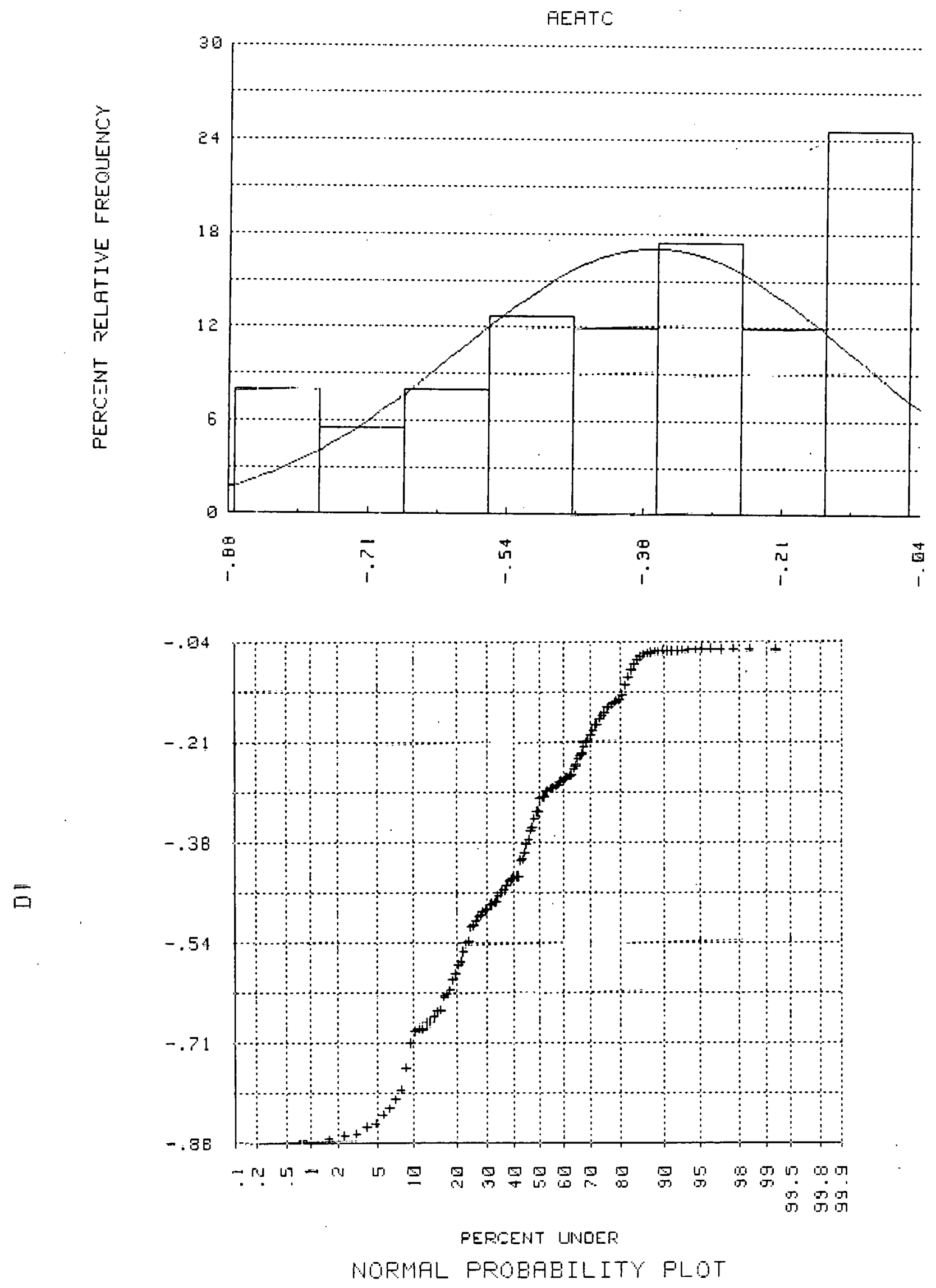

Figure E.3.a.3 Statistical P1ots of A-EA for a $T_{m}$ Disturbance,

Data for $\delta$ 

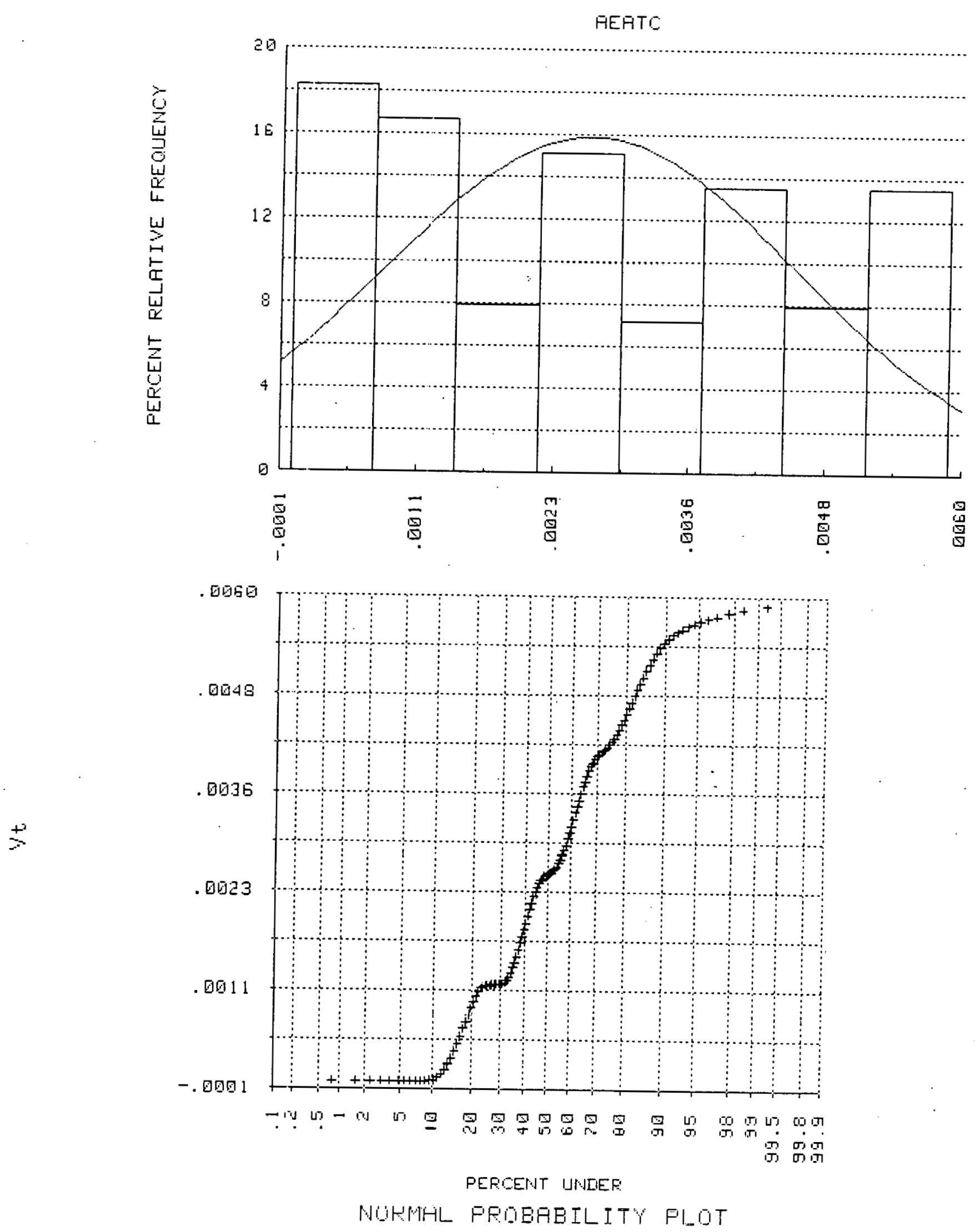

Figure E.3.a.4 Statistical Plots of A-EA for a $T_{m}$ Disturbance,

Data for $V_{t}$ 
REFVC
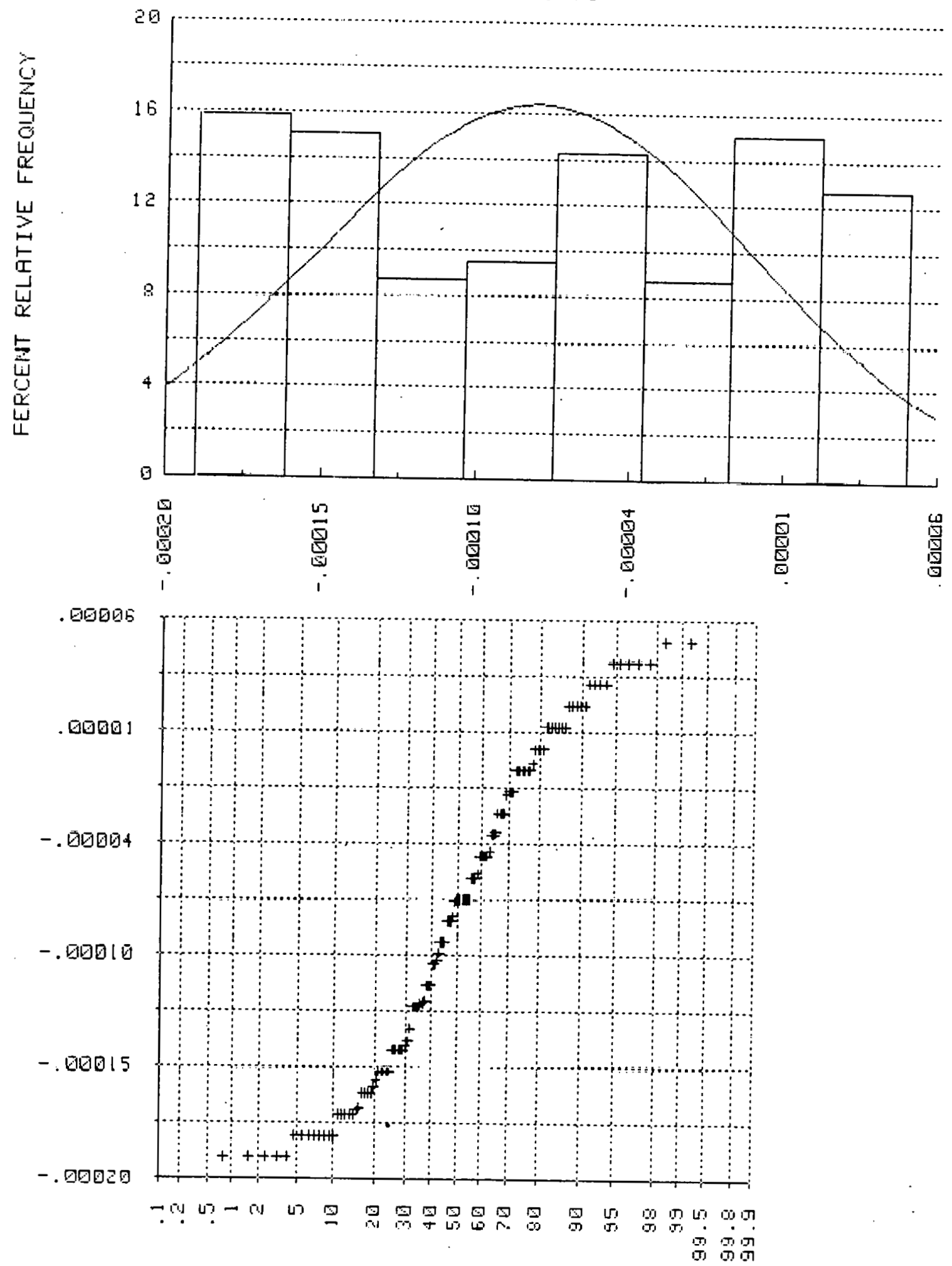

PEFCENT IJNDER

NOFMFL FFOEREILITY FLOT

Figure E.3.b.1 Statistical P1ots of A-EA for a EFD Disturbance,

$$
\text { Data for } T_{e}
$$




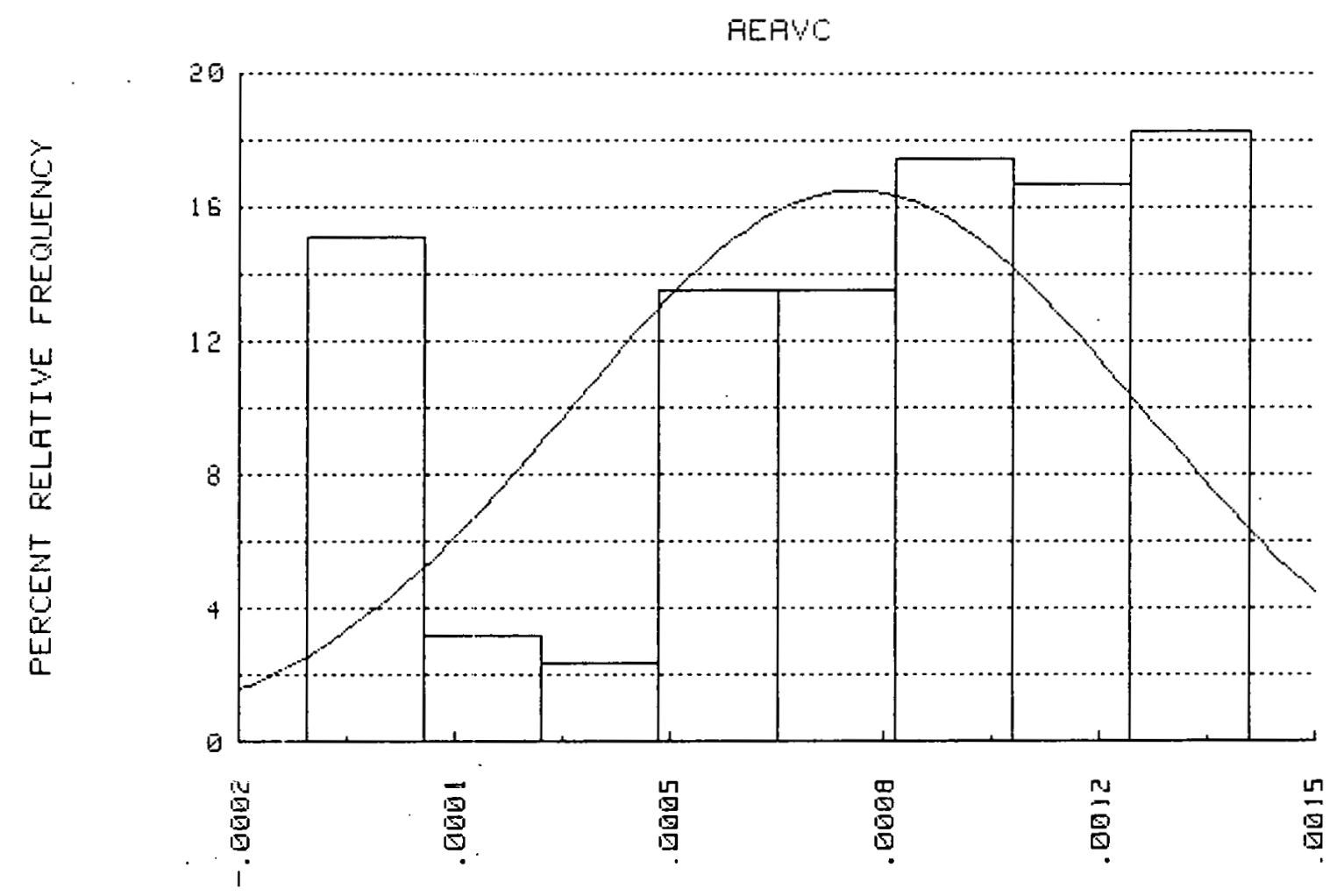

E

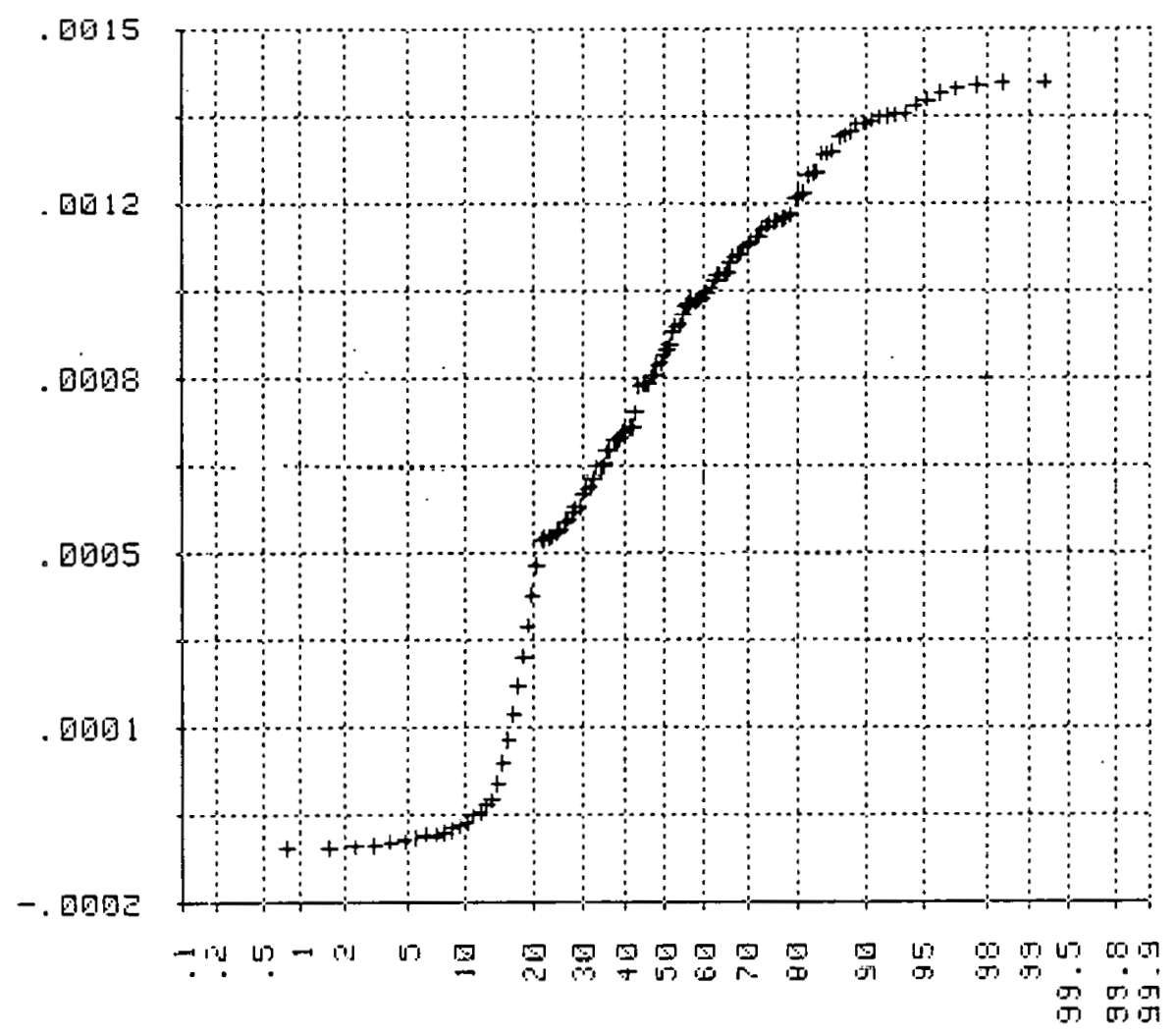

PERICENT INLER

NORMFL FROEAEILITY FLOT

Figure E.3.b.2 Statistical P1ots of A-EA for a $E_{F D}$ Disturbance,

Data for $\Delta \omega$ 
AEFYC
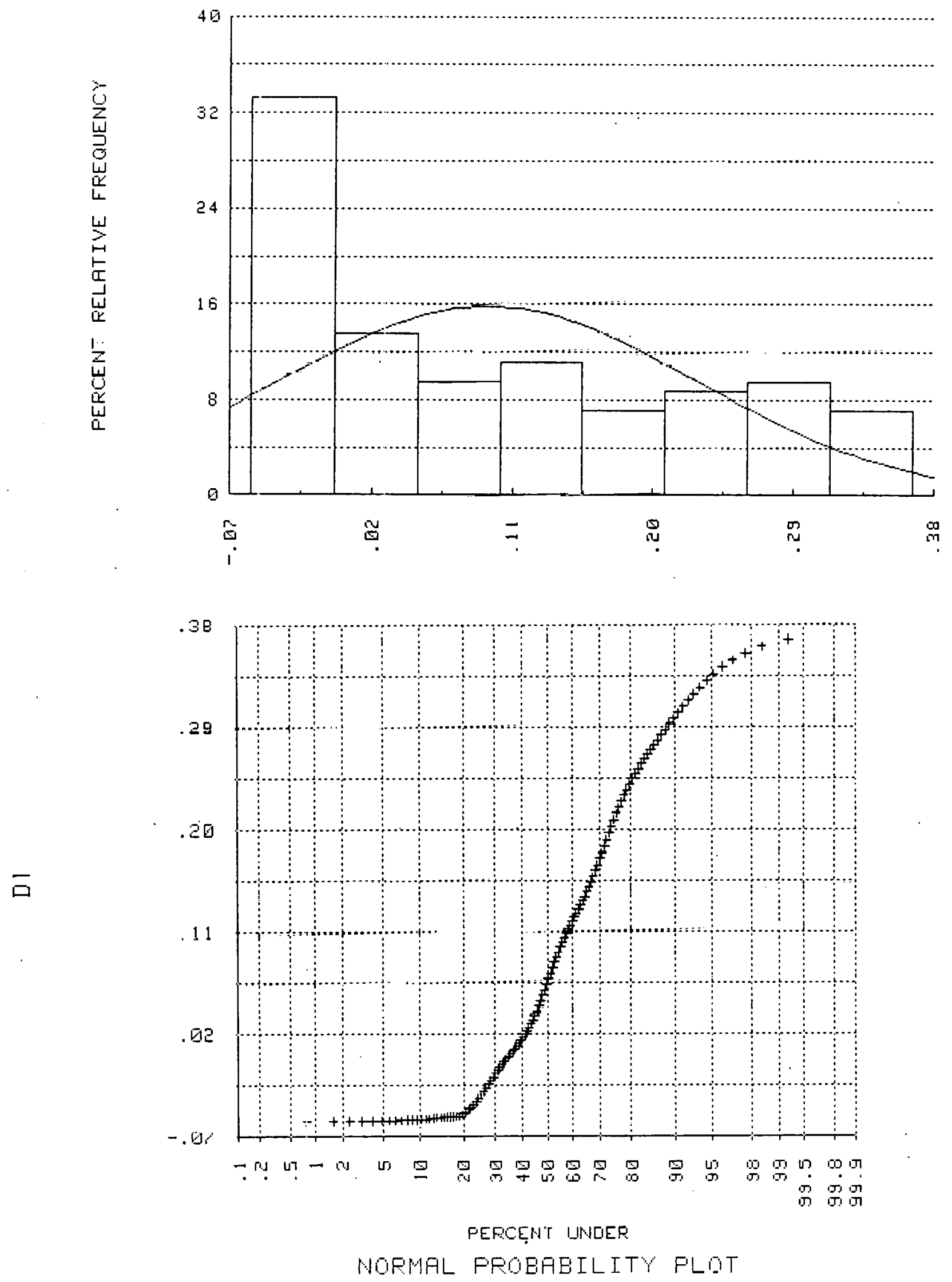

Figure E.3.b.3 Statistica1 P1ots of A-EA for a $E_{F D}$ Disturbance, Data for $\delta$ 


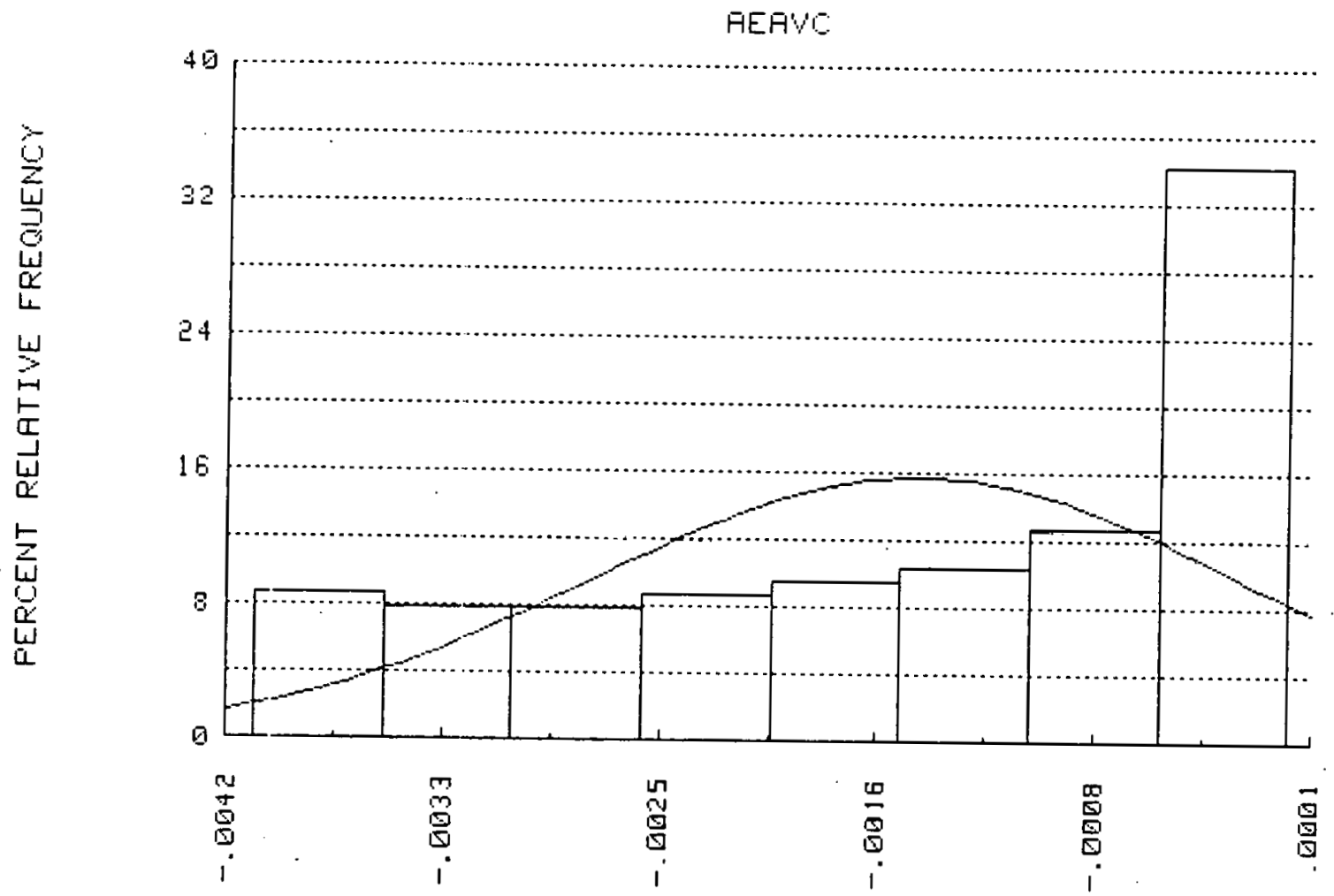

$\stackrel{+}{2}$

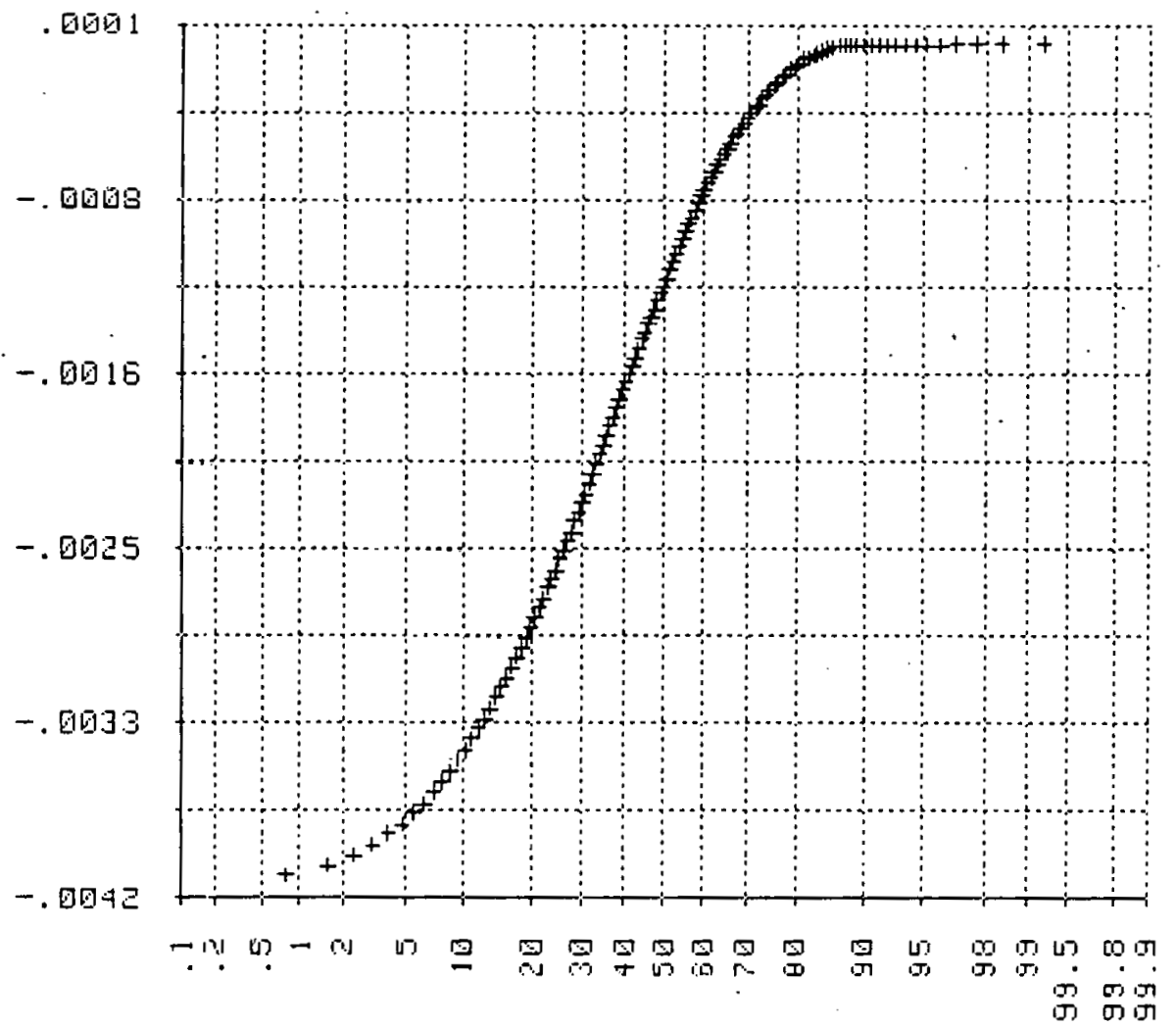

FEFICENT IJMEE:

NORMFL FFOEBILITY FLOT

Figure E.3.b.4 Statistical Plots of A-EA for a $E_{F D}$ Disturbanco,

Data for $V_{t}$

233 
Table E.5a Statistical Analysis of the Difference between

the Saturated (A) and Unsaturated (EA) F1ux

Linkage Hode1, Step Change in $T_{m}$

\begin{tabular}{|c|c|c|c|c|}
\hline & & & EUEF DF & IIIEF IIF \\
\hline VAFIAELE & WHE I AHCE & STAHIAAEII IEV. & SKEHHESS & RURTQSIS \\
\hline$y^{t}$ & . 801010 & .019185 & .13024 & $-1.21 \geqslant 1$ \\
\hline$T=$ & $=00901$ & .9625 & .91178 & -.95086 \\
\hline Iom & .00902 & .00455 & $-.0912 i$ & -.95188 \\
\hline IIT & .05760 & .240101 & -.44591 & $-.7 \sin$ \\
\hline W:三十 & .65144 & .016159 & .13986 & -1.15229 \\
\hline 虰 & $=96104$ & $=0962$ & .26168 & -1.0630 \\
\hline$W f$ & . 010169 & .09546 & .31947 & -1.19476 \\
\hline He日 & $=$ 16164 & 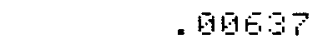 & .14315 & -1.15312 \\
\hline U.玉口 & 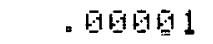 & .01075 & $-.414 \%$ & -.74498 \\
\hline 4 口 & .601501 & .96197 & -.44646 & -.4005 \\
\hline H:: & . 6616日1 & . 96276 & -.415 .57 & -.74389 \\
\hline
\end{tabular}

\begin{tabular}{|c|c|}
\hline WFE I AELE & COEF UAFIATTOHA \\
\hline$y t$ & E. 969 \\
\hline$T E$ & 1393.9596 \\
\hline Ilgii & 956.51952 \\
\hline II 1 & 65.7932 \\
\hline H. & 52.1129 \\
\hline Ha & 82.295 \\
\hline$H F$ & 18. ब叫 \\
\hline Wh: & $E 2.371$ \\
\hline H. & 50.5946 \\
\hline 147 & 54.9499 \\
\hline W: & 50.6045 \\
\hline
\end{tabular}

STAPIIAFI EFEOAF:

DF THE MEFH

. 601615

. 01028

. 61048

.02138

. 60155

.00056

.00949

.

.00105

.61627

. 버너널도
9E $\%$ EDHFT TIEHEE IHTEFUAL OH HEFH LQWER LIMIT

.519239

$-.016956$

$-.06269$

$-.46928$

.0695

.06913

. 52946

.01629

$-.05587$

$-.60958$

- . 9658
UFF'ER LIMIT

.08294

. 0019

- . 010654

- . 32940

. 1129

.61699

. 0161

.01117

$-.06565$

- . 60567

$-.00565$

DEIIEF: STATISTILE

\begin{tabular}{|c|c|c|c|c|}
\hline YAFI I AELE & 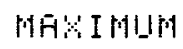 & 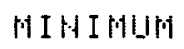 & FEHALE & MI IIFEHHEE \\
\hline$y t$ & .8058 & 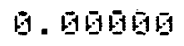 & .00598 & . 1094 \\
\hline$T E$ & .61451 & -.65454 & .09915 & - . 90107 \\
\hline Iliorio & . 0679 & -.81日2E & $.8174 y$ & -.615151 \\
\hline III & - . $652=0$ & -.97896 & .8216 & $-.4 E 365$ \\
\hline W.三丁 & .6175 & - 01695 & - 02680 & .91135 \\
\hline W与 & .62172 & .96165 & . 02607 & .01139 \\
\hline $4 f^{\circ}$ & $.9467 \%$ & .62397 & .01740 & - 1920 \\
\hline 111:日 & . 92173 & . 96995 & .9367 & .81154 \\
\hline 40.99 & - . 19174 & -.01145 & .61971 & - . DQEBD \\
\hline H口 & - . 19159 & - . 01207 & .01955 & - . Q6日80 \\
\hline 141: 口 & - . 16174 & -.01144 & .06976 & - . 06059 \\
\hline
\end{tabular}


Table E.5b Statistical Analysis of the Difference between

the Saturated (A) and Unsaturated (EA) Finx

Linkage Mode1, Step Change in $\mathrm{E}_{\mathrm{FD}}$

\begin{tabular}{|c|c|c|c|c|}
\hline & & & COEF OF & COEF GIF \\
\hline GAEI IAELE & WHE I HHCE & STHHIAFII IEU. & SKEWHESE & KUFTOSIS \\
\hline$y t$ & - 01616 & .00136 & -.49512 & -1.09120 \\
\hline$T E$ & - G日E耳百 & . 616067 & .0306 & -1.2906 \\
\hline Iingin & .96960 & .06045 & -.02892 & -.08674 \\
\hline III & $.917 P E$ & .1300 & .47515 & -1.11431 \\
\hline पㅔㅓㅁ & . 01692 & .90456 & -.46564 & -1.19250 \\
\hline 昍 & . 61612 & .06460 & $-.4 \vdots 114$ & -1.1974 \\
\hline Wf & 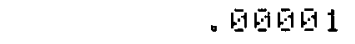 & .96312 & -.96194 & -.72211 \\
\hline bl: & . 19692 & . 016428 & -.49114 & -1.69776 \\
\hline H. $\equiv$ & . DEDEg & . Q1617E & .49301 & -1.69814 \\
\hline 明 & .01609 & .00193 & .49279 & -1.019787 \\
\hline W. & - $00 \overline{06}$ & .09175 & .45355 & -1.0996 \\
\hline & & STFHIAFI EFEOE & $90 \%$ COHF I IIEHCE & IHTEFUAL DN MEAH \\
\hline VAPIAELE & DOEF UAFIATI DHA & OF THE MEFH & LOWEF: LINIT & UFFEF: LIMIT \\
\hline$y t$ & 89.91576 & - 961日2 & -.0165 & -.60120 \\
\hline$T E$ & 95.30879 & . D16 E161 & - . 0101609 & -.00107 \\
\hline I曰 ঢй & 58.21097 & . 96104 & . 01071 & . 96194 \\
\hline II 1 & 140.93967 & $.011 \Xi 7$ & .07459 & .11425 \\
\hline W.at & $111.2423 \mathrm{E}$ & .06038 & -.00450 & -.01903 \\
\hline Wa & 116.94416 & .90030 & -.00401 & -.01023 \\
\hline$W f$ & 14.96900 & .00620 & .02049 & . 0141 \\
\hline Wh: 寸 & 111.78926 & .06130 & -.00446 & -.00320 \\
\hline W:日 & 1009.78950 & . 00618 & -.010109 & .00943 \\
\hline 屾 & 331.80420 & .01617 & 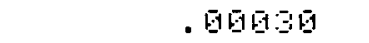 & .00987 \\
\hline HN: 口 & 1026.65779 & . 961616 & - . 161619 & . 61963 \\
\hline
\end{tabular}

DFIIEF: STATISTIES

\begin{tabular}{|c|c|c|c|c|}
\hline UAFI I AELE & WH:S IMU⿴囗十⺝ & MIHIMU⿴囗十⺝刂 & RANIEE & M I IFEFHILE \\
\hline$y$ t. & . 96901 & - . 96409 & .09410 & - - 60204 \\
\hline$T E$ & - 90605 & -.00619 & - 96024 & - . 96967 \\
\hline In & .96140 & -.09099 & .09149 & - GEGES \\
\hline I 1 & .3600 & -.95870 & .42306 & .15480 \\
\hline 以:a寸 & .80181 & -.61250 & .91559 & -.01979 \\
\hline Hब & .00112 & -.01151 & . 112E3 & - . 90520 \\
\hline$W t$ & . 0239 & .01389 & .91909 & .91094 \\
\hline 明: d & . 601616 & -.01251 & .61351 & - . 0158 \\
\hline 的辈口 & - 01978 & -.00180 & .00558 & . 90999 \\
\hline 149 & .56454 & -.56159 & . 96013 & .96148 \\
\hline Wl: & .00377 & -.96196 & .965 .57 & . 90995 \\
\hline
\end{tabular}




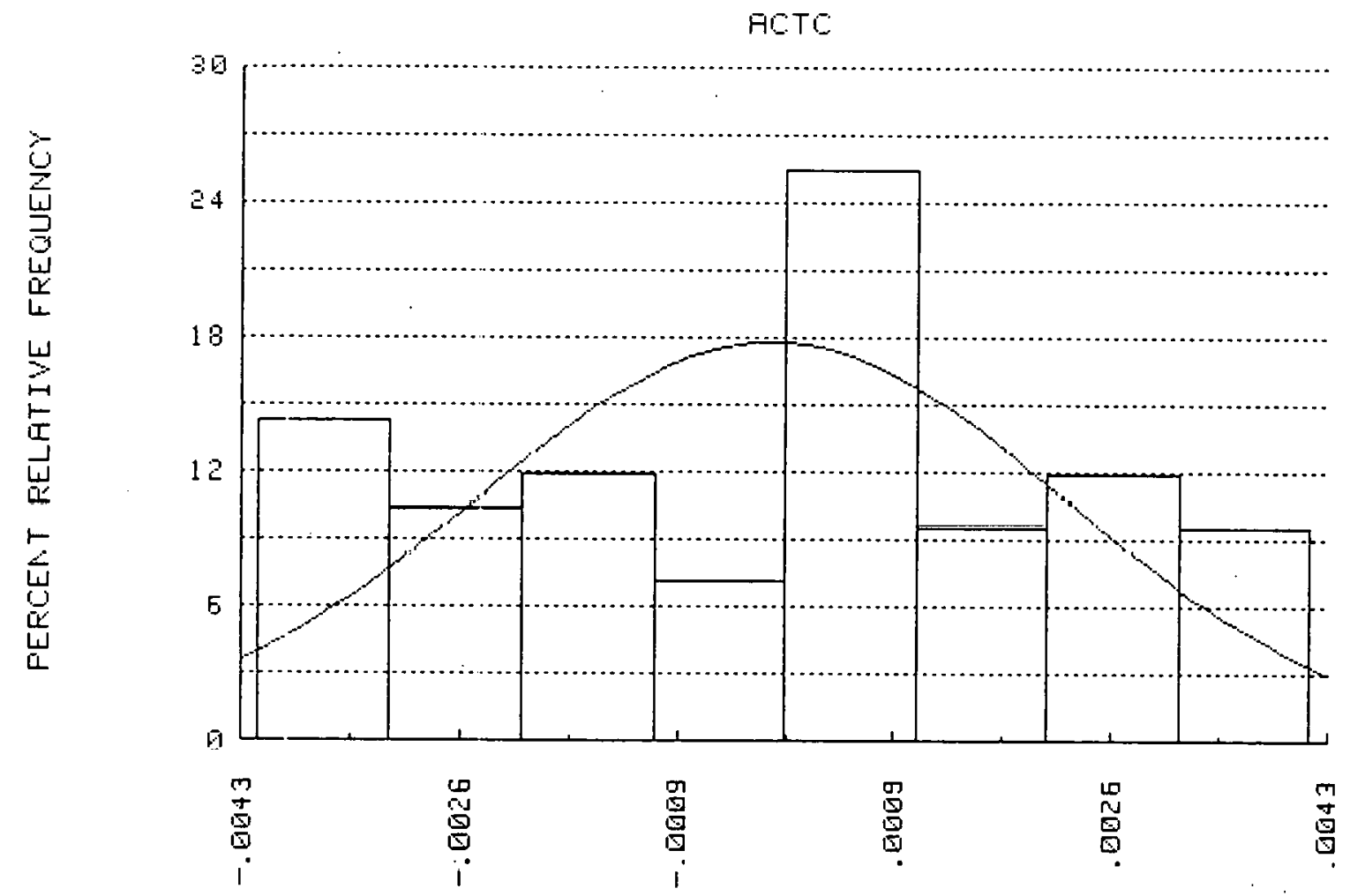

$\stackrel{120}{\leftarrow}$

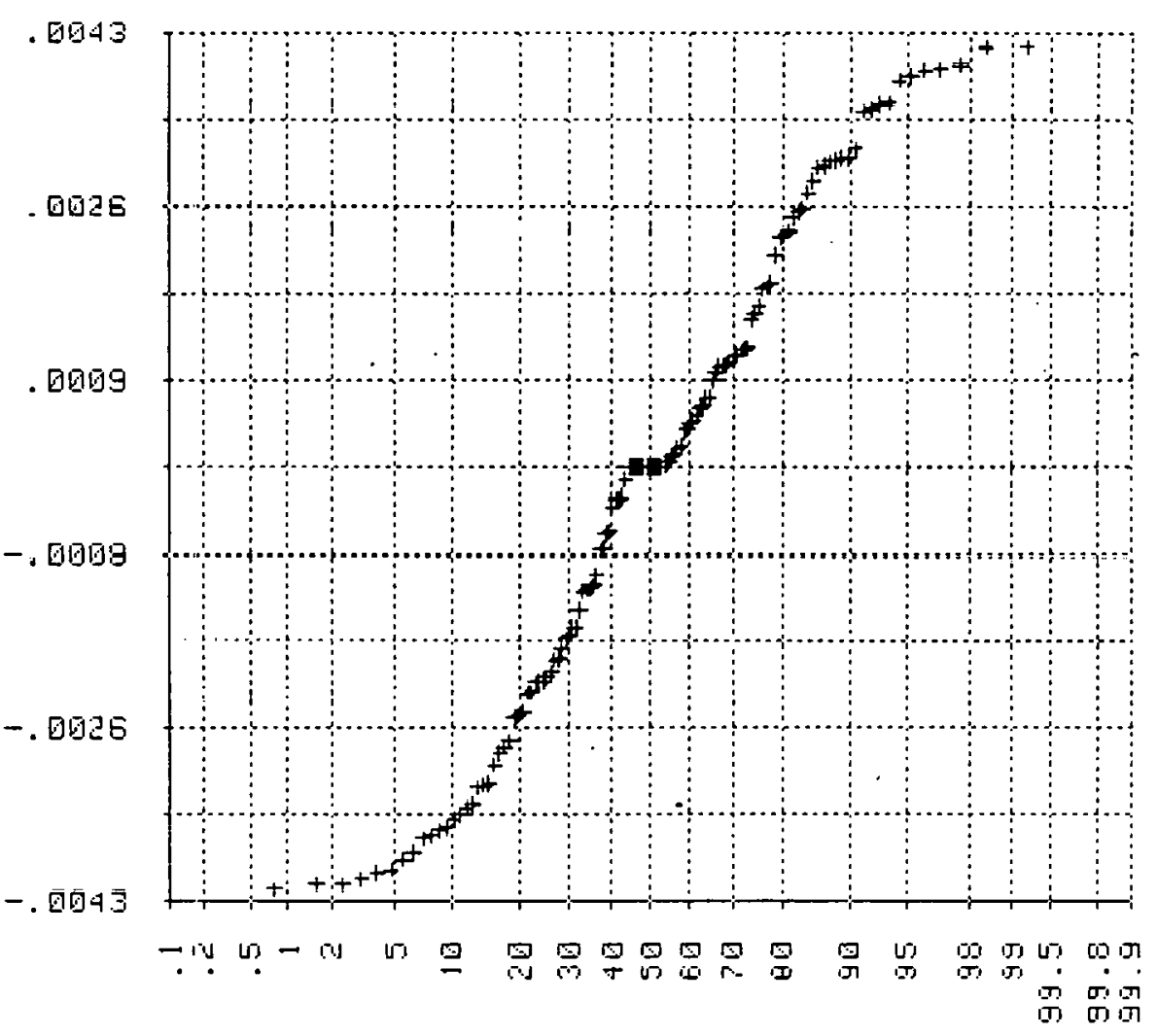

PEFICENT INIDEF:

NOFMAL FROBAEILITY FLOT

Figure E.4.a.1 Statistical Plots of $A-C$ for a $T_{m}$ Disturbance,

Data for $T_{e}$ 


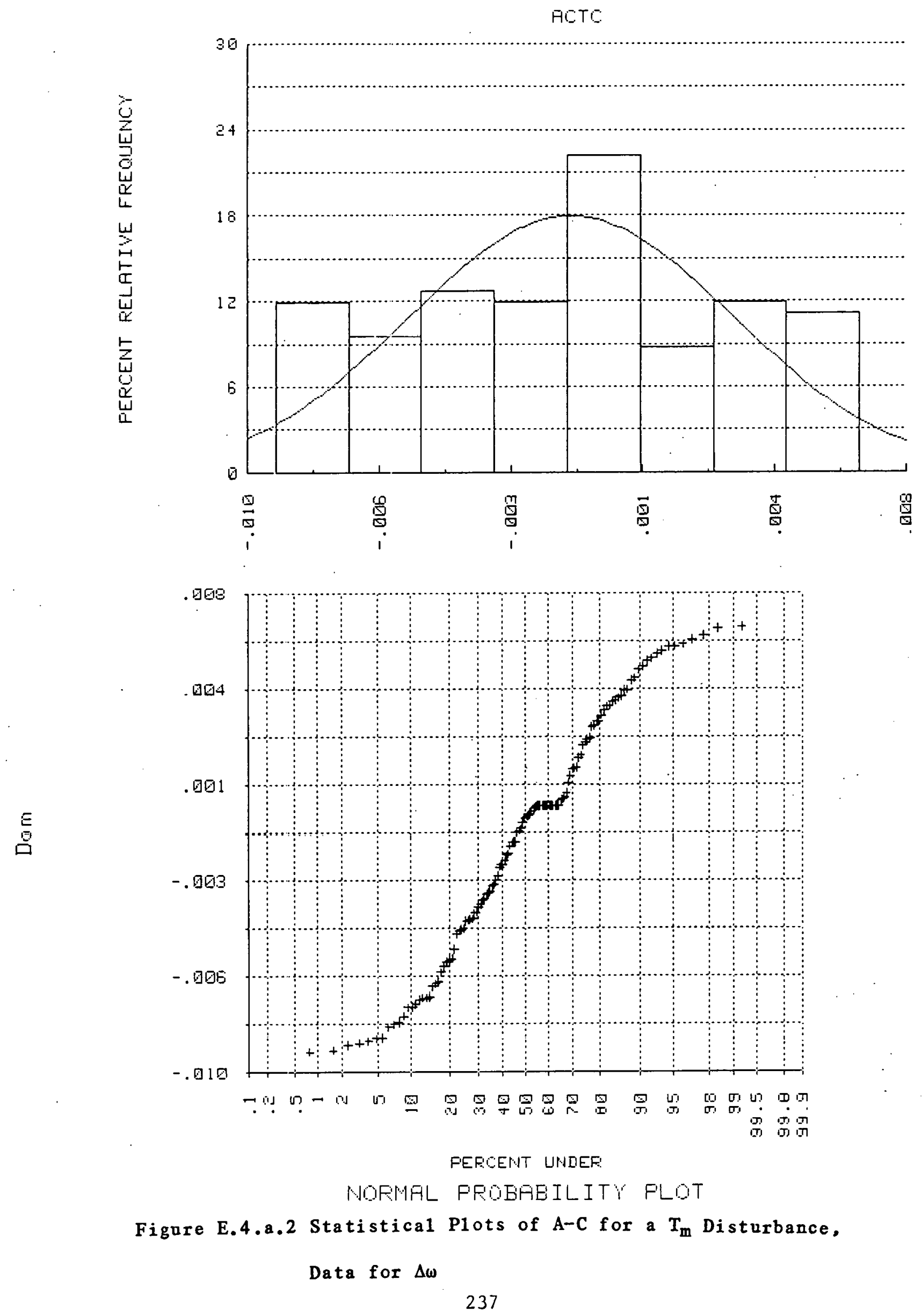



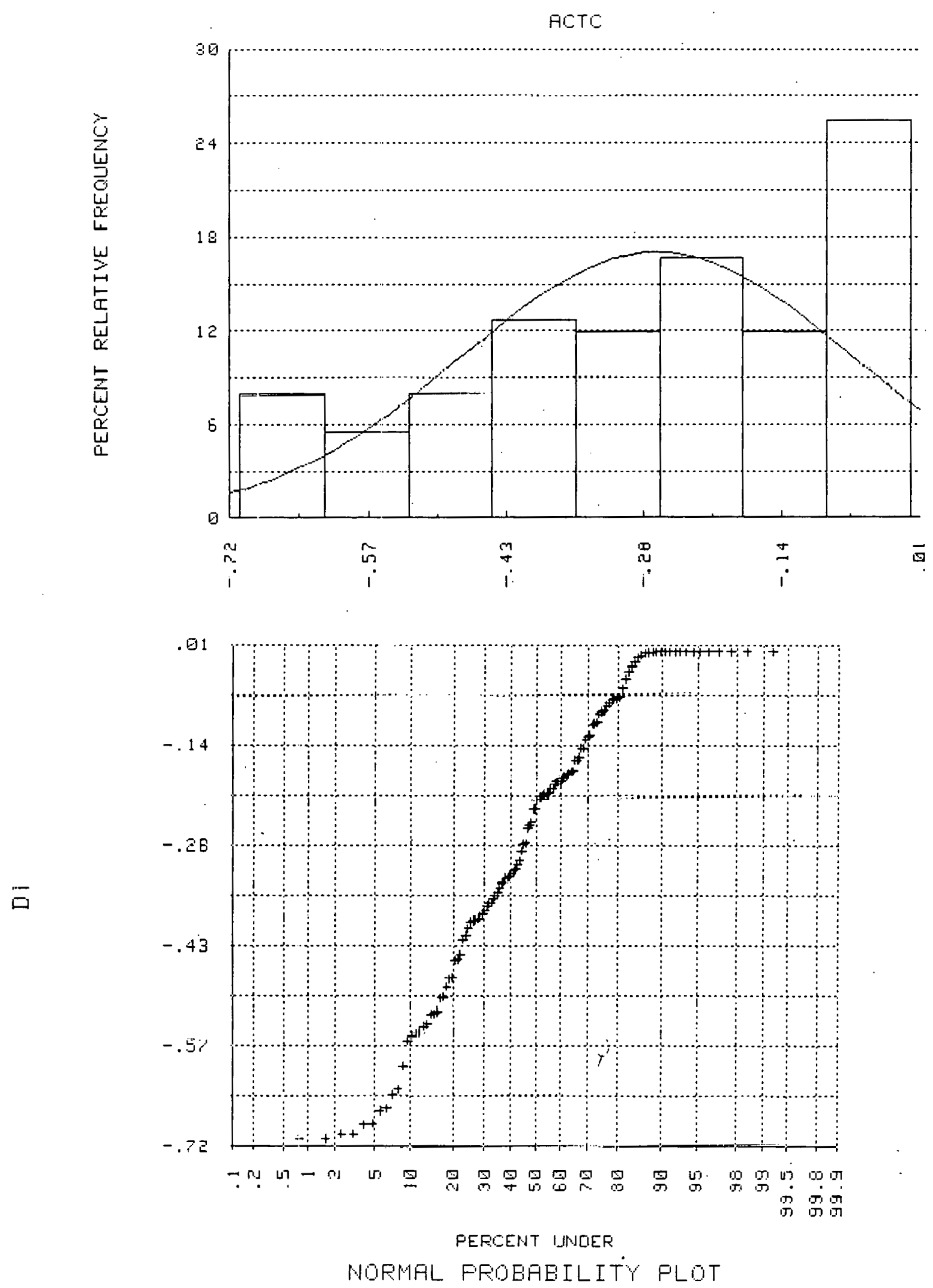

Figure E.4.a.3 Statistica1 P1ots of A-C for a $T_{m}$ Disturbance,

Data for $\delta$ 

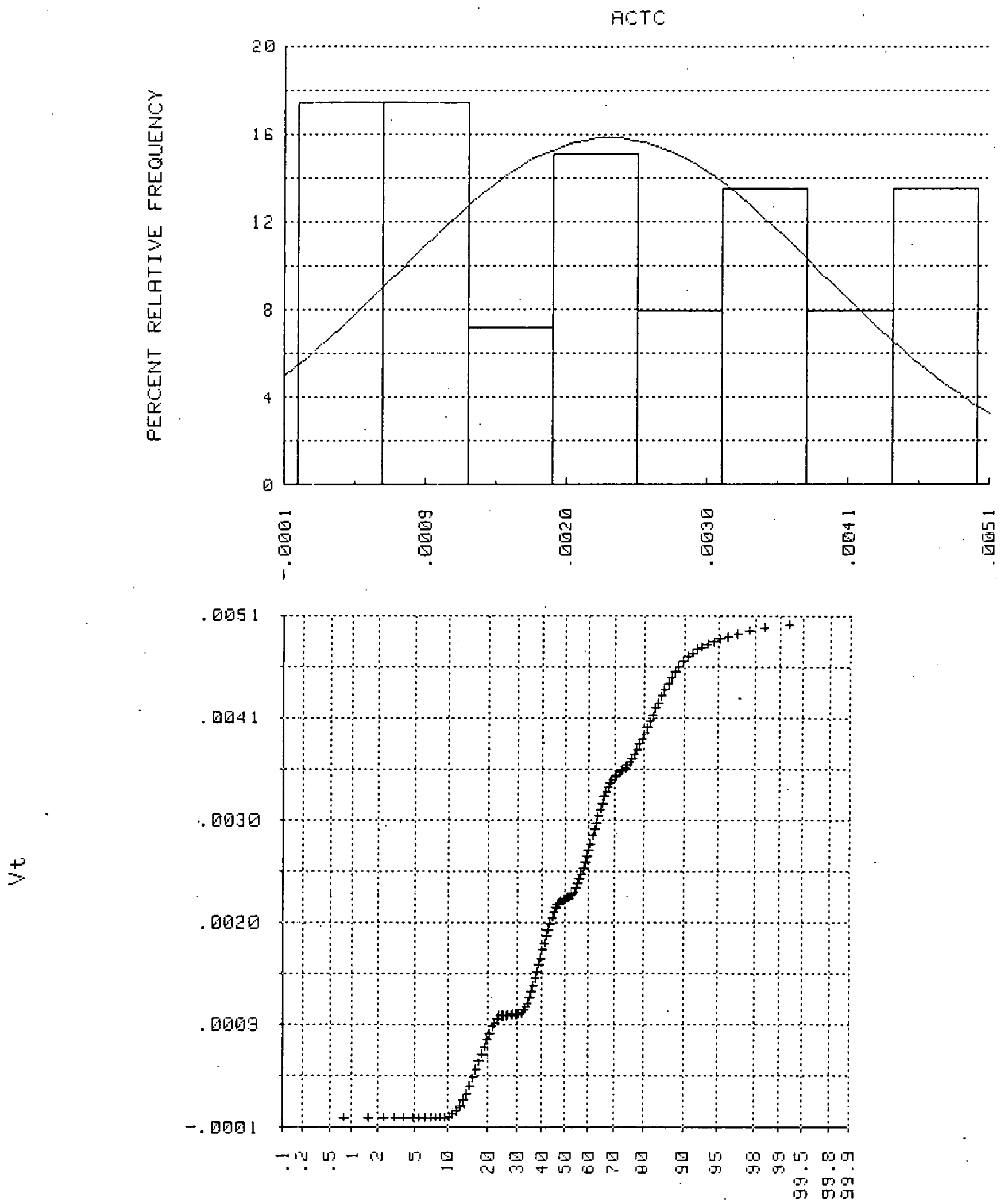

PERCENT IJMIER

NOFMFL FFOEAEILITY FLOT

Figure E.4.a.4 Statistical Plots of A-C for a $T_{m}$ Disturbance,

Data for $v_{t}$ 


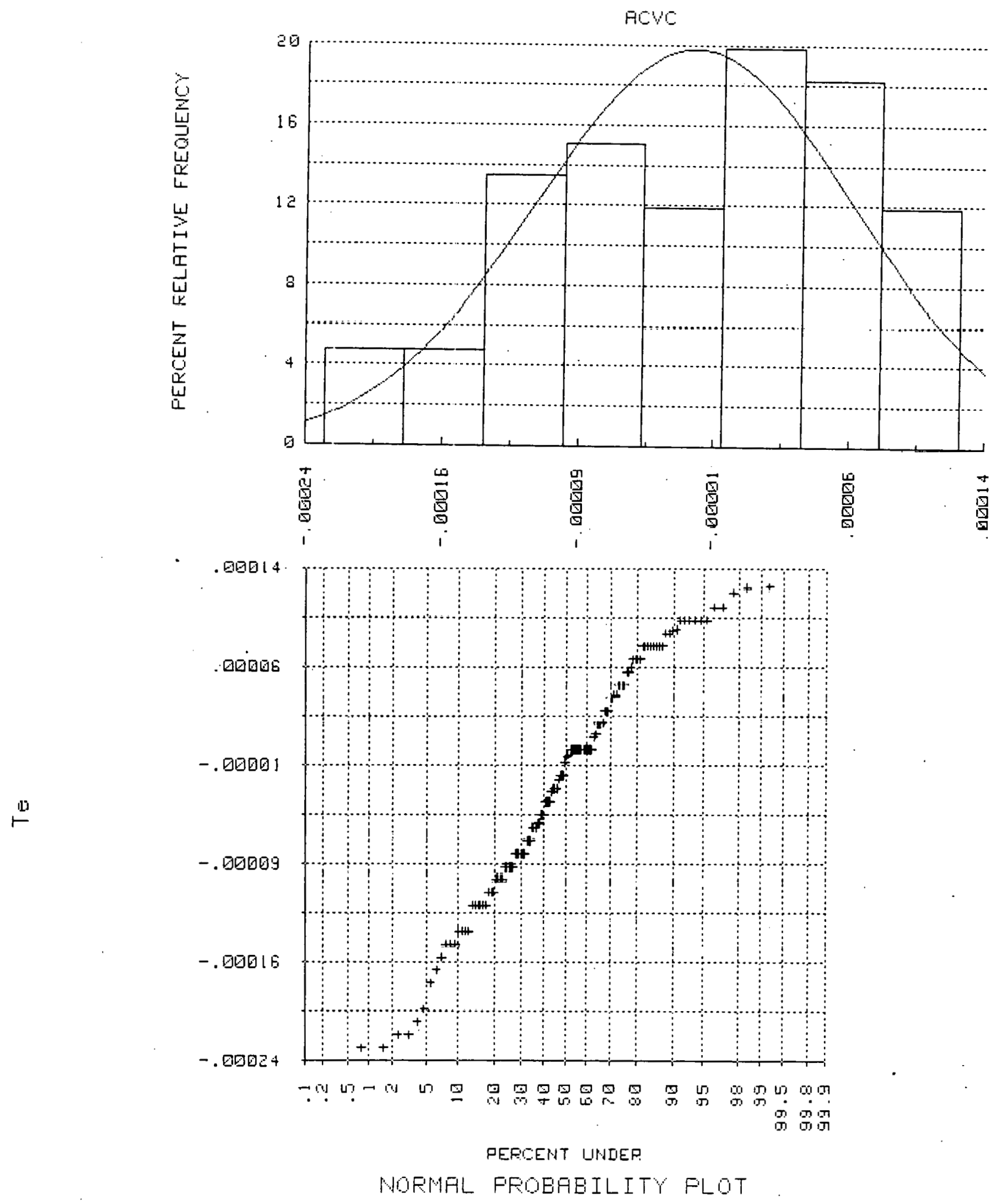

Figure E.4.b.1 Statistical Plots of A-C for a $E_{F D}$ Disturbance,

Data for $T_{e}$ 


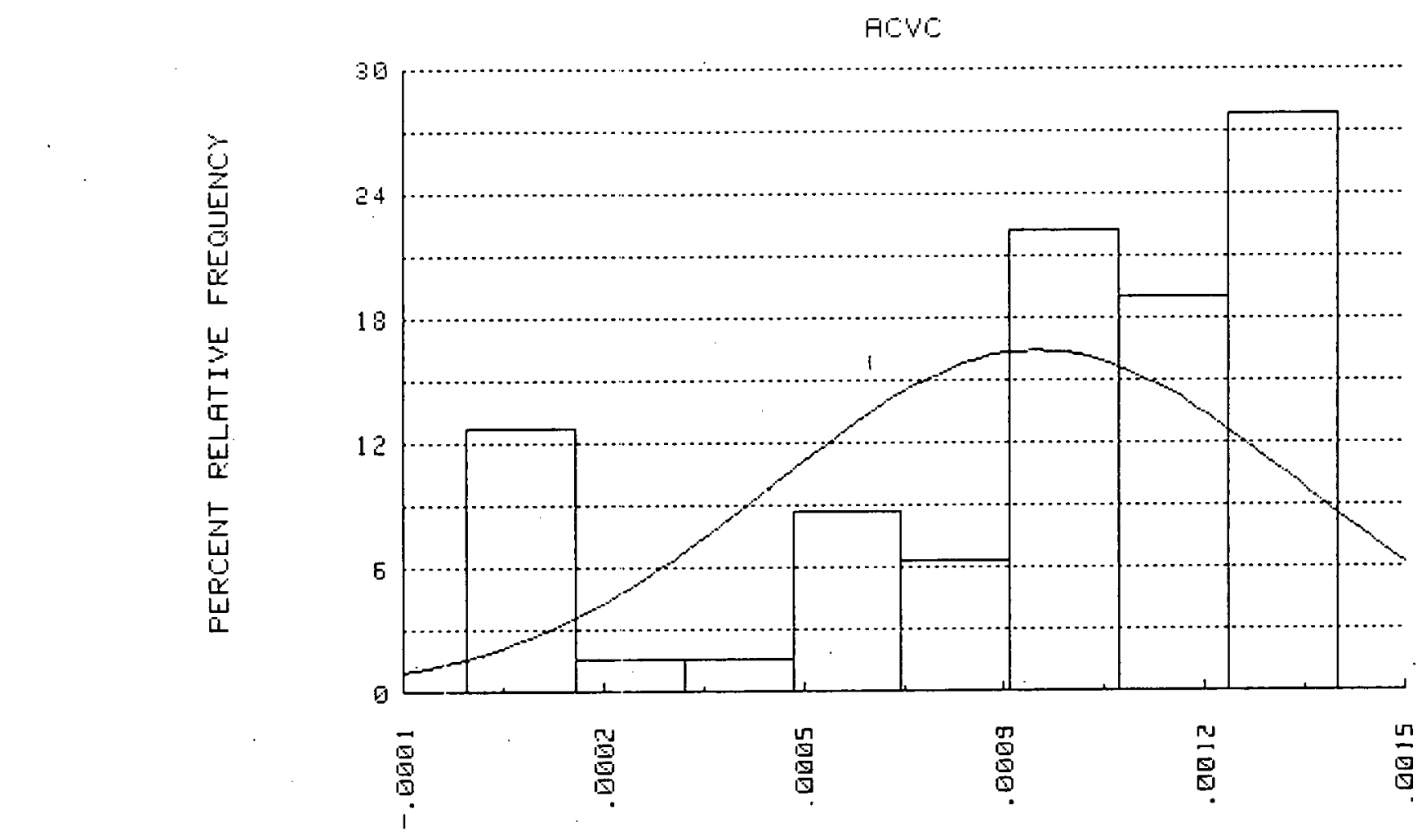

E

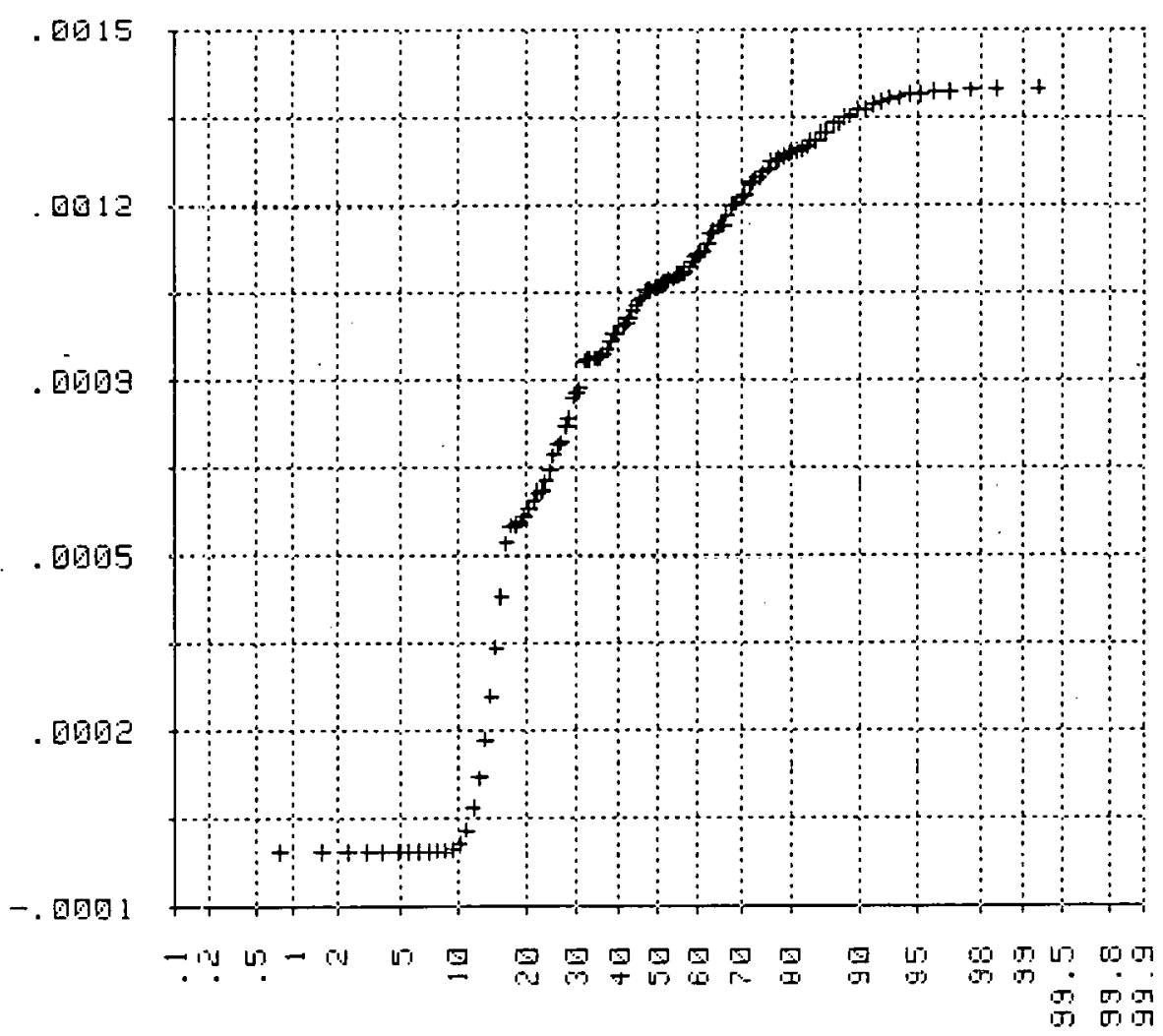

PERTENT INIIEE

NOFMAL FFOEAEILITY FLOT

Figure E.4.b.2 Statistical Plots of A-C for a $E_{F D}$ Disturbance,

Data for $\Delta \omega$ 

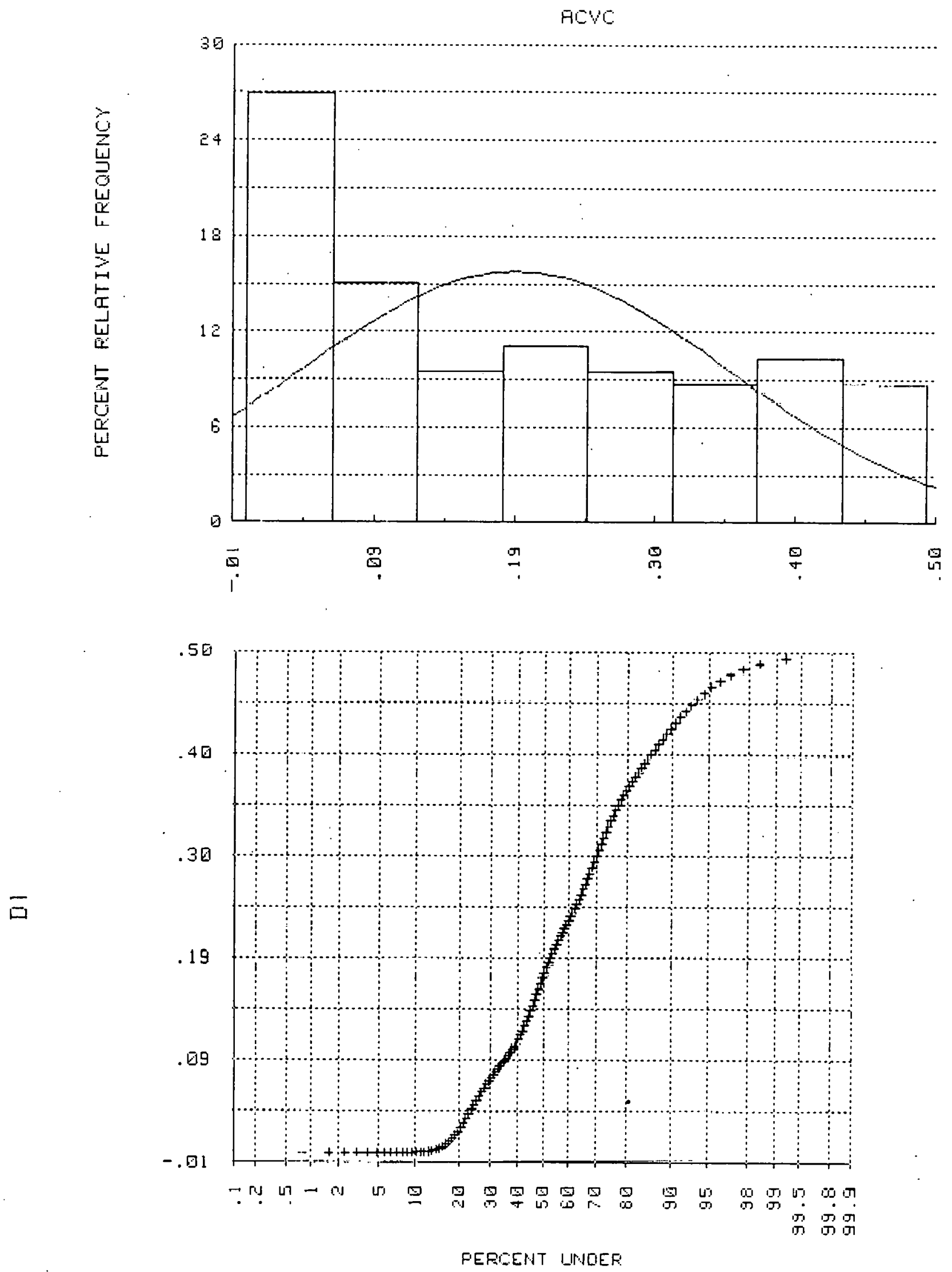

NOFMAL FFOEAEILITY PLOT

Figure E.4.b.3 Statistical Plots of A-C for a EFD Disturbance,

Data for $\delta$ 
ACVO
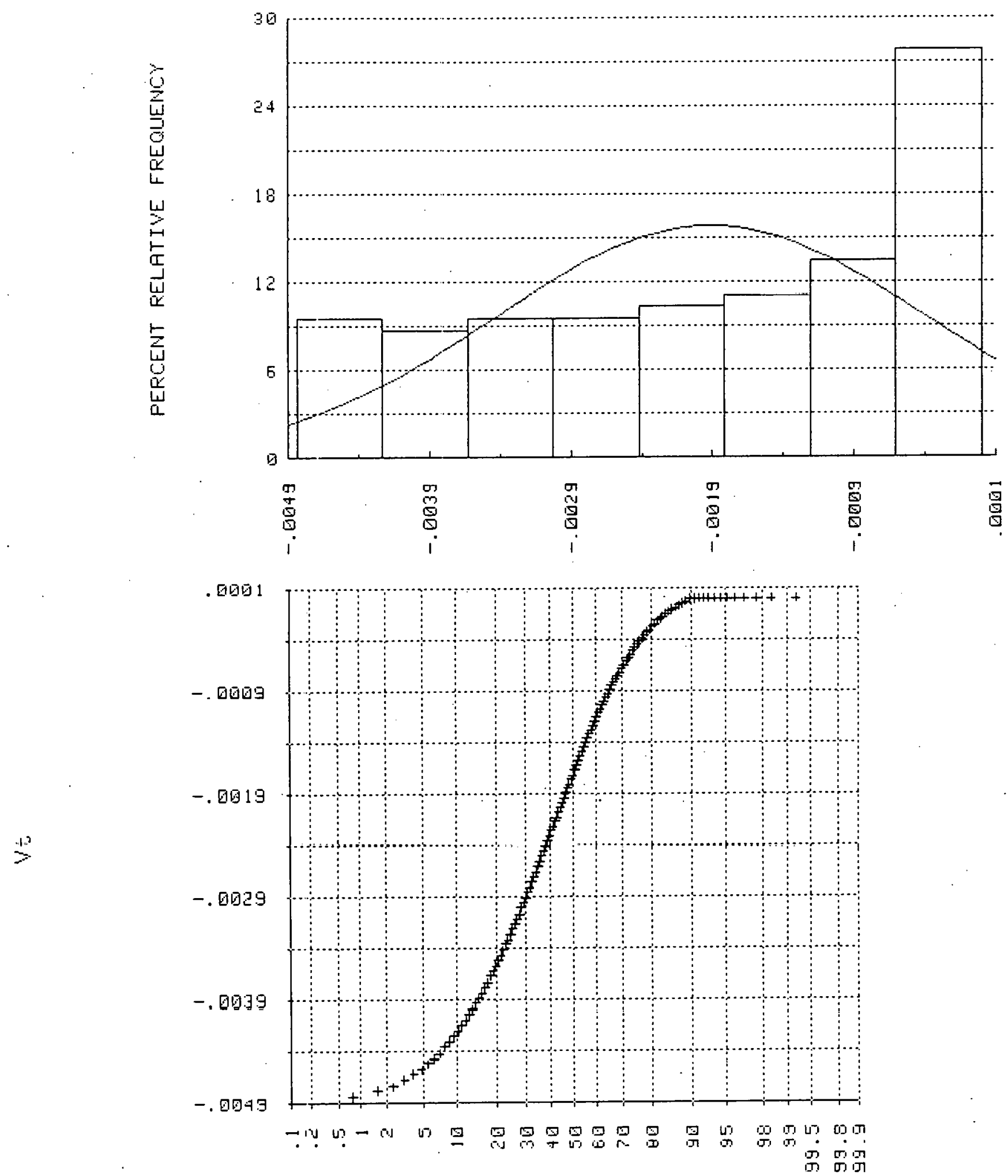

FERCEMT UNDER
MOFMAL. FFIGABEILITY FLOT

Figure E.4.b.4 Statistical Plots of A-C for a $E_{F D}$ Disturbance,

Data for $v_{t}$ 
Tab1e E.6a Statistical Analysis of the Difference between

the F1ux Linkage Mode1 when Fully Saturated and

Partially Saturated, Step Change in $\mathrm{T}_{\mathrm{m}}$

\begin{tabular}{|c|c|}
\hline $\bar{H}_{1,1 ; 1: 2}$ & 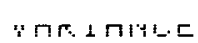 \\
\hline t. & $=$ E1960 \\
\hline$T E$ & - E10日1 \\
\hline Inom & $=010012$ \\
\hline II 1 & .94317 \\
\hline$W=1$ & 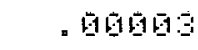 \\
\hline W日 & - 61006 \\
\hline Wf & . 01962 \\
\hline 快:日 & - 96013 \\
\hline W三曰 & . 90151 \\
\hline$W_{\square}$ & ，国国是 \\
\hline ㅂ. 1: 口 & - 96101 \\
\hline
\end{tabular}

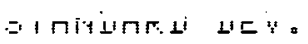

- 610

- 169

. 61648

2677

.60545

- 6055

. 1045

. 01543

. 1024

. 0 日es

. 11241
郋

$\Rightarrow$ rasitcas

- 118

.61425

- $678 \mathrm{~g}$

$-.4456$

- 12202

.18989

.3643

. 12517

$-.4558$

$-.4365$

- 40155

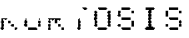

$-1.21715$

$-.95995$

- . 95891

- .7964

$-1.1509$

$-1.6669$

$-1.2057$

$-1.15 .569$

$-.7455$

- . 7527

- . 74485

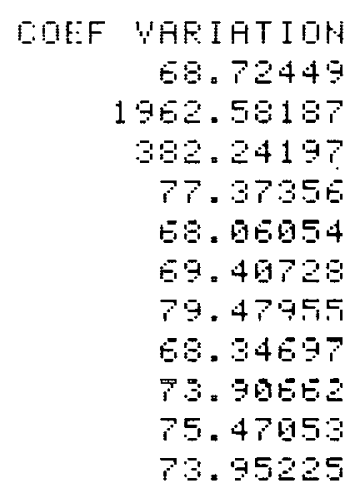

STHHTHFEI EFEOE:

DF THE MEHH

. G019 14

.8651

.

.91851

. 16949

. 96948

- 15642

. 16048

- 00021

- 61625

- 16021
$90 \%$ DOHF IIEHHE IHTEFUAL DH MEHH LDWEF: LIMIT - 0028

- .

- . 10182

$-.29926$

- 646

. 01582

- 60518

. 60715

- . by

- . 01989

- . 9691
IIFF'EF: LIPIT

. 6025

- 960

- .0151

- . 2785

. 01881

- 065

- 0105

. 96975

- . 6929

- . 0631

- . 69296

DEIEF STHTISTIES

\begin{tabular}{|c|c|c|c|c|}
\hline WAFIAELE & 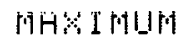 & 的IHI问边 & FHEHE & WI IFAHEE \\
\hline$y+$ & .6551 & 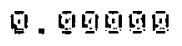 & . 01051 & . \\
\hline$T E$ & . Q64 $41 E$ &.$- \overline{1648}$ & - 60034 & - - 96061 \\
\hline Il Dri & . 므든 & - . 10924 & .61596 & -.00126 \\
\hline III & Q日. & - .7098 & . 7日92日 & $-.34 E$ \\
\hline 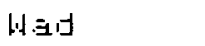 & .91778 & 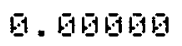 & .91776 & - 101905 \\
\hline H. & $.017 E 5$ & - . 国可1 & $.917 E$ & - 9 G日Ea \\
\hline$W F$ & .01484 & 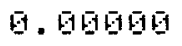 & .01484 & .0672 \\
\hline Wh: if & $.917 \mathrm{E}$ & 6. 56.069 & .61765 & - 9604 \\
\hline 1․ㅡㅁ & Q. & - - DEG4E & . 6084 & - . 16428 \\
\hline 19 & 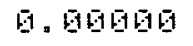 & - . 15919 & .08919 & - . E1450 \\
\hline 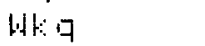 & 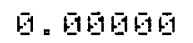 & - DEG4E & .00640 & - . E148 \\
\hline
\end{tabular}


Tabie. E.6b Statistical Analysis of the Difference between

F1ux Linkage Model when Fully Saturated and

Partially Saturated, Step Change in $\mathrm{E}_{\mathrm{FD}}$

\begin{tabular}{|c|c|c|c|c|c|c|}
\hline & & & & & COEEF DF & DUEF DF \\
\hline WHF I HELE & & WAF I AHIEE & STAHIAFEI IIEU. & & SKEWHESE & KUET TOSIS \\
\hline$y t$ & & . 01060 & . 9615\% & & -.39823 & -1.19841 \\
\hline$T E$ & & 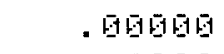 & . 06069 & & -.92284 & -.70549 \\
\hline Il gini & & 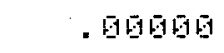 & . DES42 & & -1.05544 & .0405 \\
\hline II] & & .0243 & .15597 & & .51559 & -1.21149 \\
\hline Wad & & .00603 & .0550 & & - . 92909 & -1.20509 \\
\hline 㟊与 & & .90062 & .96467 & & - . 2098 & -1.20900 \\
\hline Hf & & .00002 & . 9646 & & -.5069 & -1.65073 \\
\hline 베: $d$ & & - 1960 & $.695 \mathrm{i}$ & & -.93943 & $-1.204 E 2$ \\
\hline 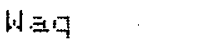 & & 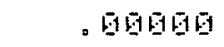 & - 9020 & & .9354 & -1.20154 \\
\hline W & & - GEGE1 & . 61527 & & .9346 & -1.20117 \\
\hline Wh: & & - EDEE & . 6020 & & .9368 & -1.26224 \\
\hline & & & STAHIIAFI EFEOE & 96 & $\because$ EOHF I IIEHEE & IHTEFUAL OHA MEFH \\
\hline UAFE I AELEE & EDEF & UFE I I T I OH & DF THE MEAH & & LDWEF LIFIT & UFFEF: LIMIT \\
\hline$y t$ & & 79.78198 & . .01014 & & -.90214 & -.60189 \\
\hline$T E$ & & 979.74573 & .00601 & & -.0161964 & -.06061 \\
\hline Ilomiin & & 46.30300 & . ब010日4 & & .01685 & .06997 \\
\hline II 1 & & 80.25647 & .91396 & & $.171 \Xi 1$ & .21737 \\
\hline H三日 & & 79.72360 & $=01645$ & & -.019795 & - . 01557 \\
\hline WG & & 79.72495 & .06042 & & - . 10654 & -.09517 \\
\hline$\omega f$ & & 91.56199 & - 10600 & & -.01956 & -.06305 \\
\hline Wh: & & 80.02956 & .06945 & & -.016760 & -.06552 \\
\hline W. $\equiv$ & & 81.59812 & - 90018 & & - 19222 & .01283 \\
\hline W曰 & & 81.95940 & .06020 & & .9625 & . 01512 \\
\hline WN:口 & & 81.79277 & . 91618 & & . 9622 & - 5628 \\
\hline
\end{tabular}

DFIEF STATISTILS

\begin{tabular}{|c|c|c|c|c|}
\hline WHEI I HELE & 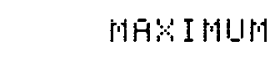 & MINIMU⿴囗十⺝ & FEAHIE & MI IIEAHE \\
\hline$y$ t. & Q. 960日日 & -.06454 & .00484 & -.06242 \\
\hline$T E$ & . 06013 & - . 10023 & .06006 & - - 5161615 \\
\hline InGm & $=90139$ & 日. 00060 & .6109 & - 91678 \\
\hline III & .49500 & 日. 0 日0 & .49860 & .24806 \\
\hline W.三丁 & 日.90100 & -.01592 & .61592 & -. 90798 \\
\hline Wh & 0. 90606 & -.01477 & 91477 & - . 01739 \\
\hline Wf & 9. 06000 & -.01287 & .01287 & - . 01544 \\
\hline Wt: & 0. 06060 & -.01585 & .01585 & -.06793 \\
\hline H三马 & . 90652 & E. 010060 & .65652 & - 61920 \\
\hline$H_{\square}$ & .60718 & 里. 90000 & $=867$ & $=96959$ \\
\hline H. & .00652 & 可. 000060 & - $90 \mathrm{E} 2$ & .06325 \\
\hline
\end{tabular}




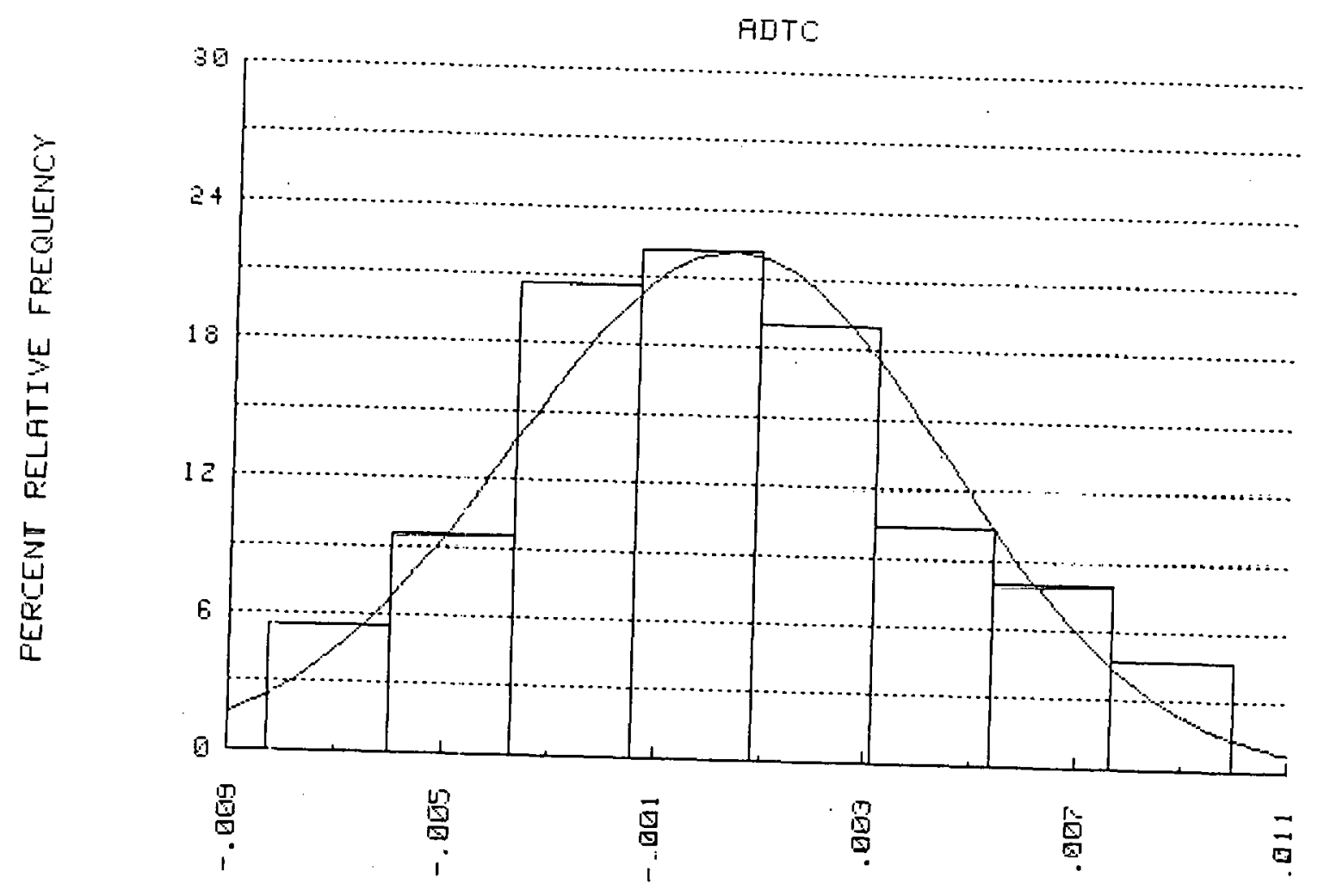

$\stackrel{112}{1-}$

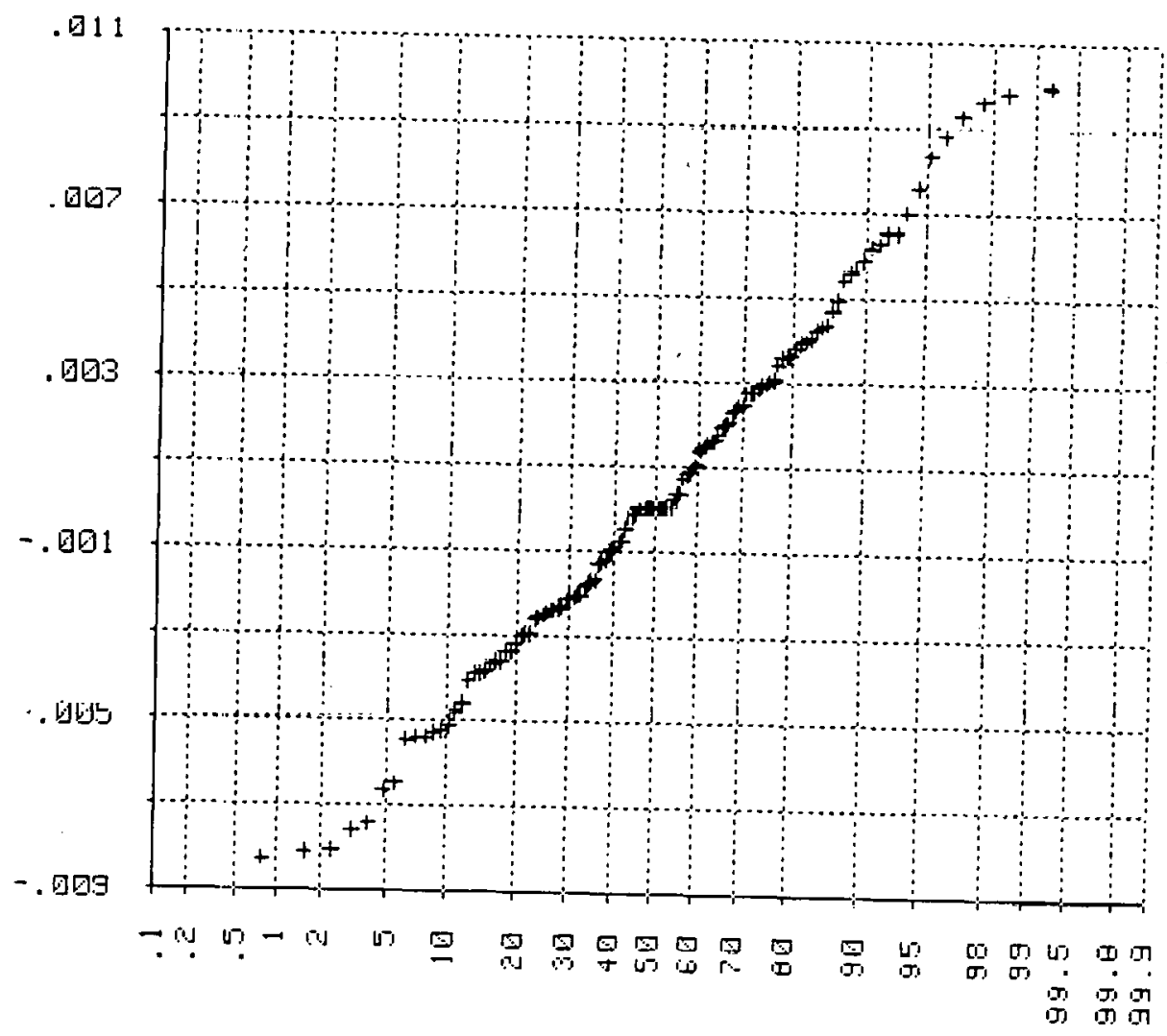

FERCENT UNDEF:

NORMAL PROBABILITY FLOT

Figure E.5.a.1 Statistical P1ots of A-D for a $T_{m}$ Disturbance,

Data for $T_{e}$ 

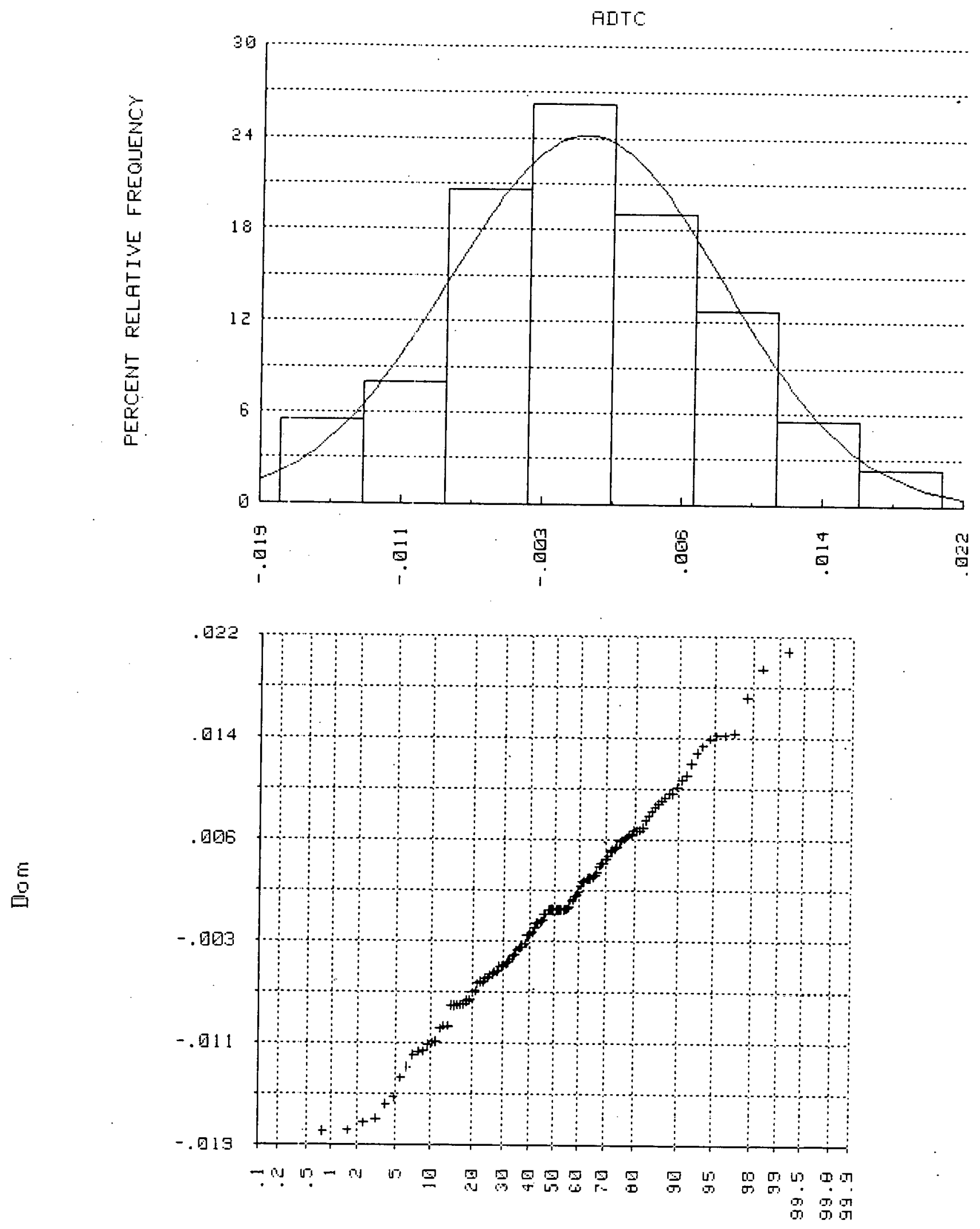

FEPCENT LINIIER

$$
\text { NOPMAL FFOEAEILITY FLOT }
$$

Figure E.5.a.2 Statistical P1ots of A-D for a $T_{m}$ Disturbance,

Data for $\Delta \omega$ 

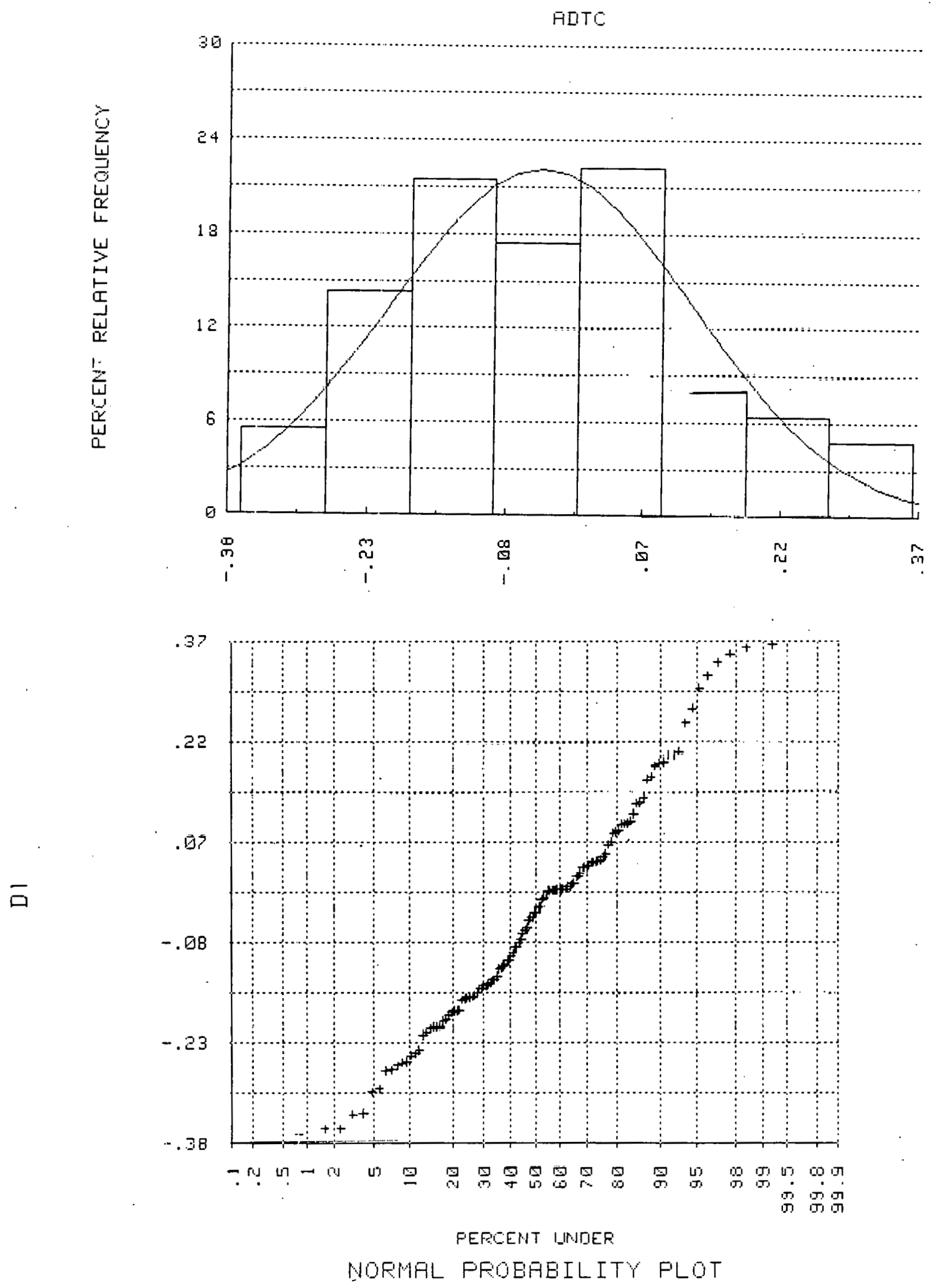

Figure E.5.a.3 Statistical P1ots of A-D for a $T_{m}$ Disturbance. Data for $\delta$ 

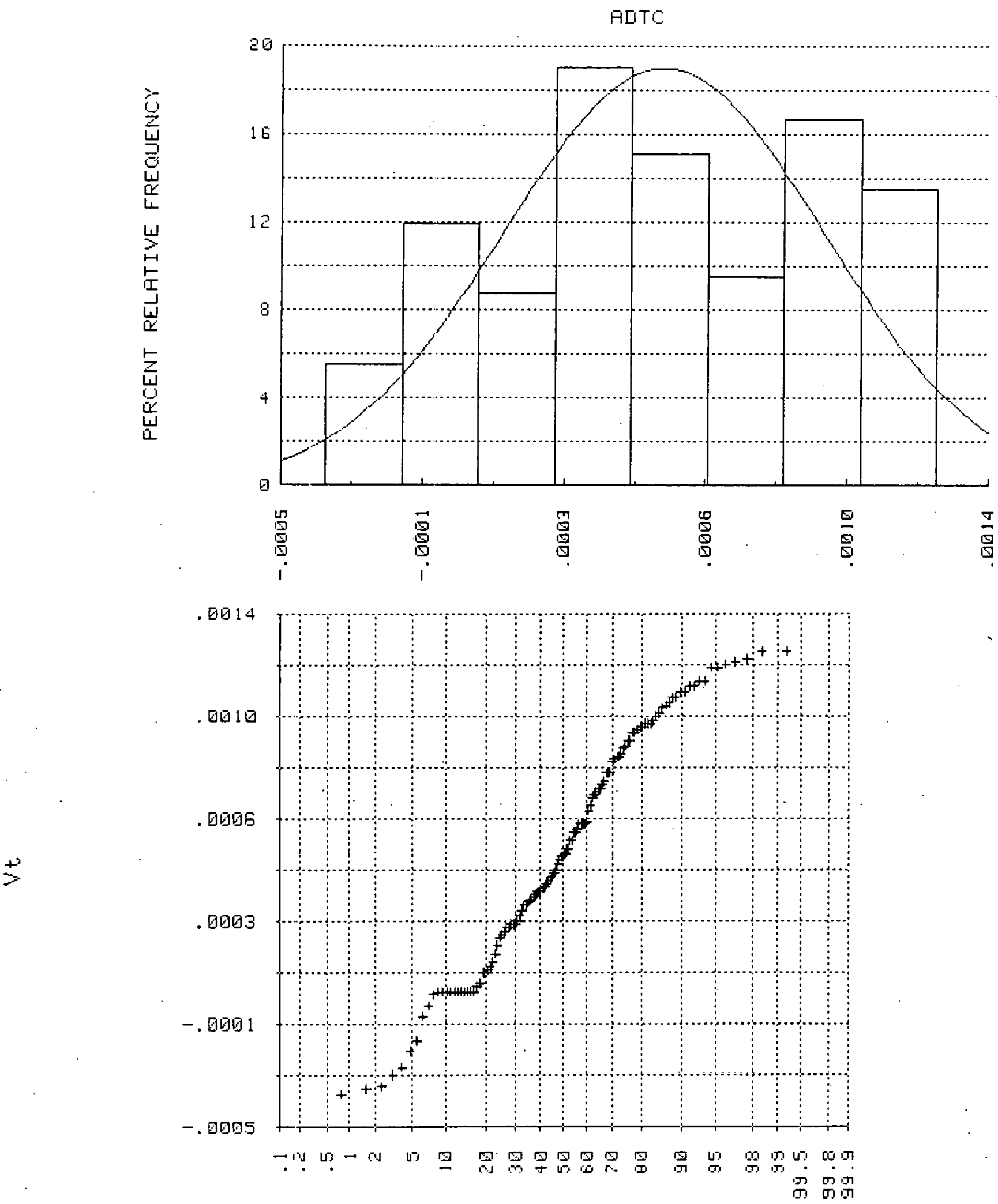

PEPEENT UPLIER

NORMFL PROEAEILITY PLOT

Figure E.5.a.4 Statistical Plots of A-D for a $T_{m}$ Disturbance,

Data for $v_{t}$ 


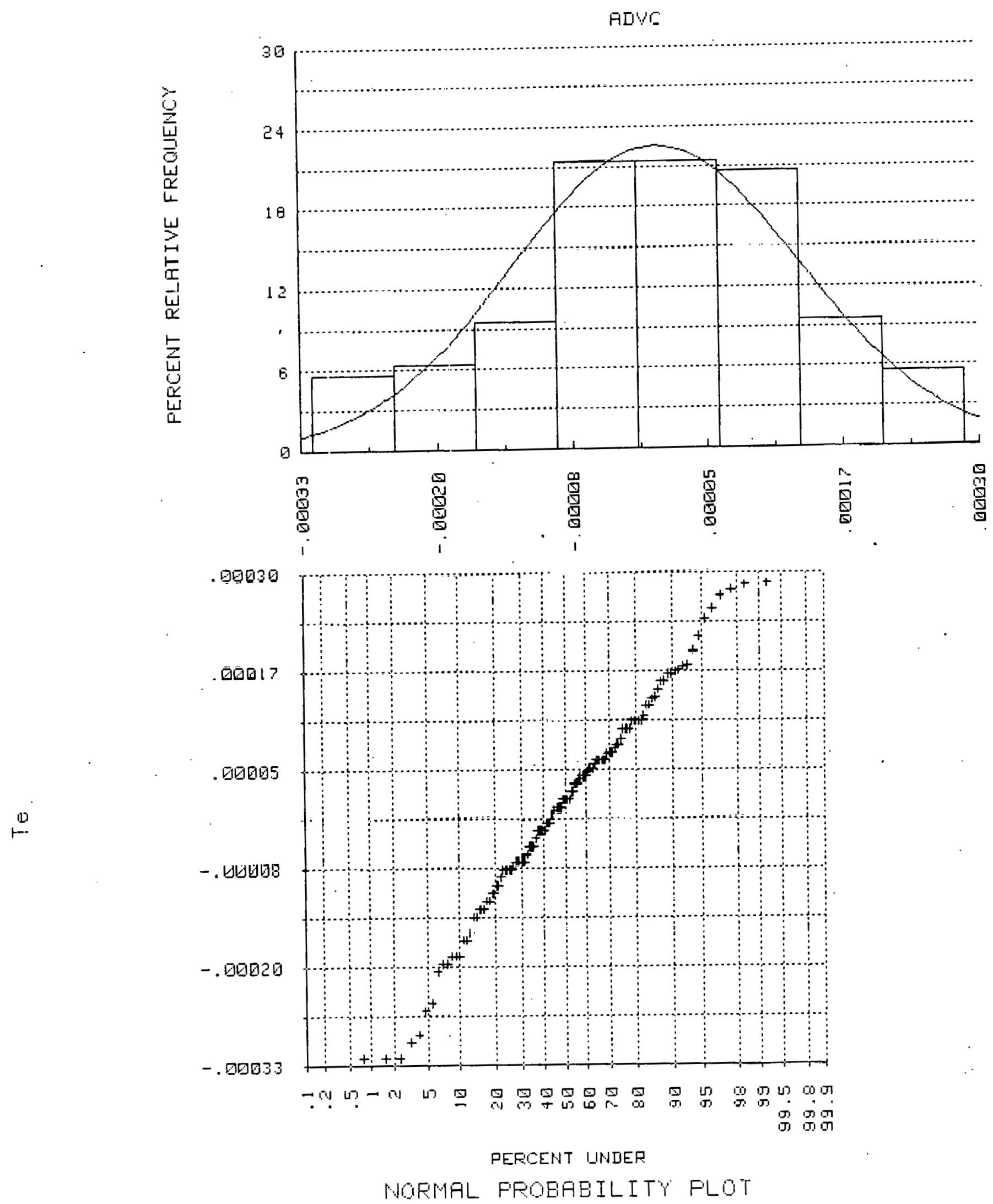

Figure E.5.b.1 Statistical Plots of A-D for a $E_{F D}$ Disturbance,

Data for $T_{e}$ 


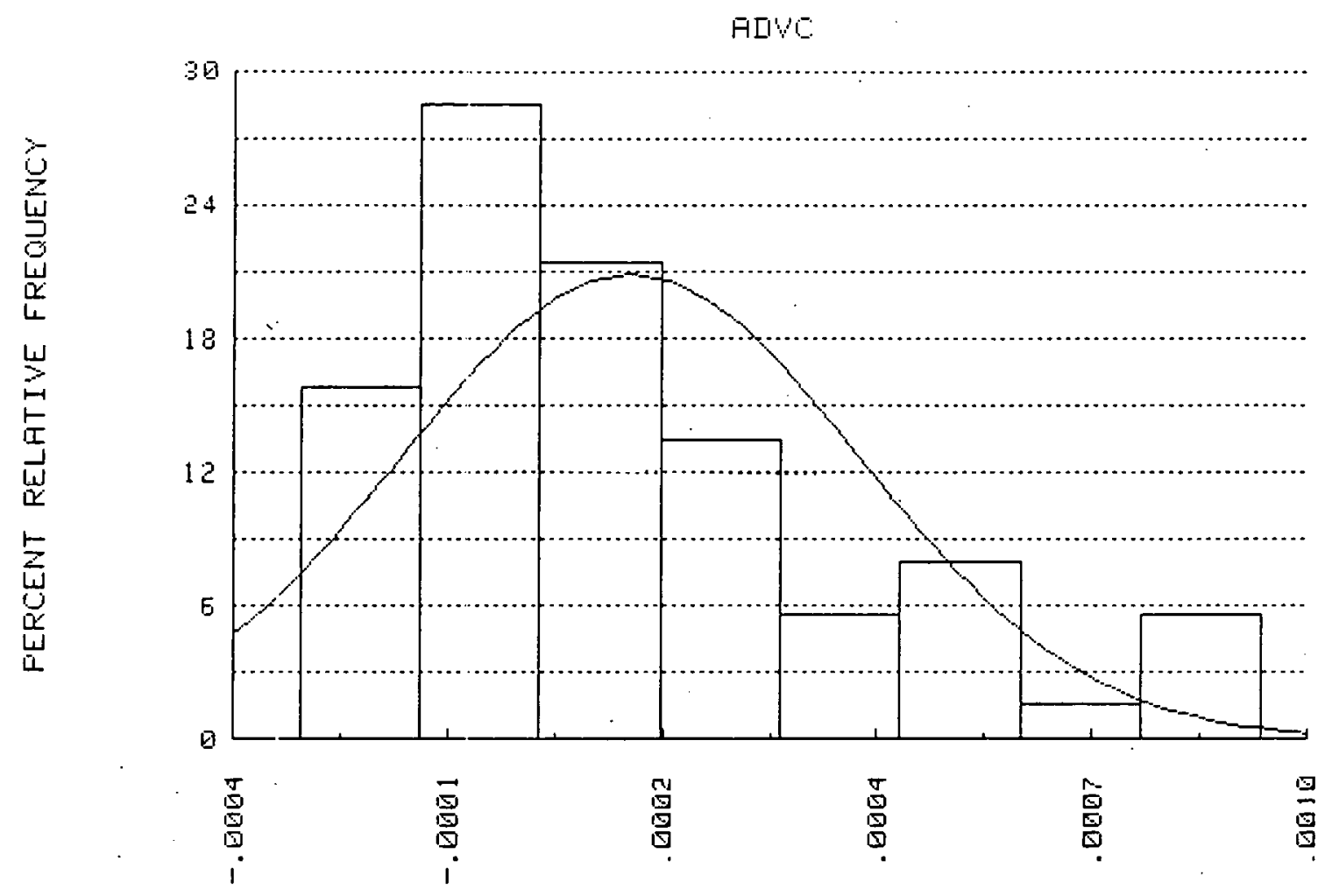

$\stackrel{\Xi}{\Xi}$

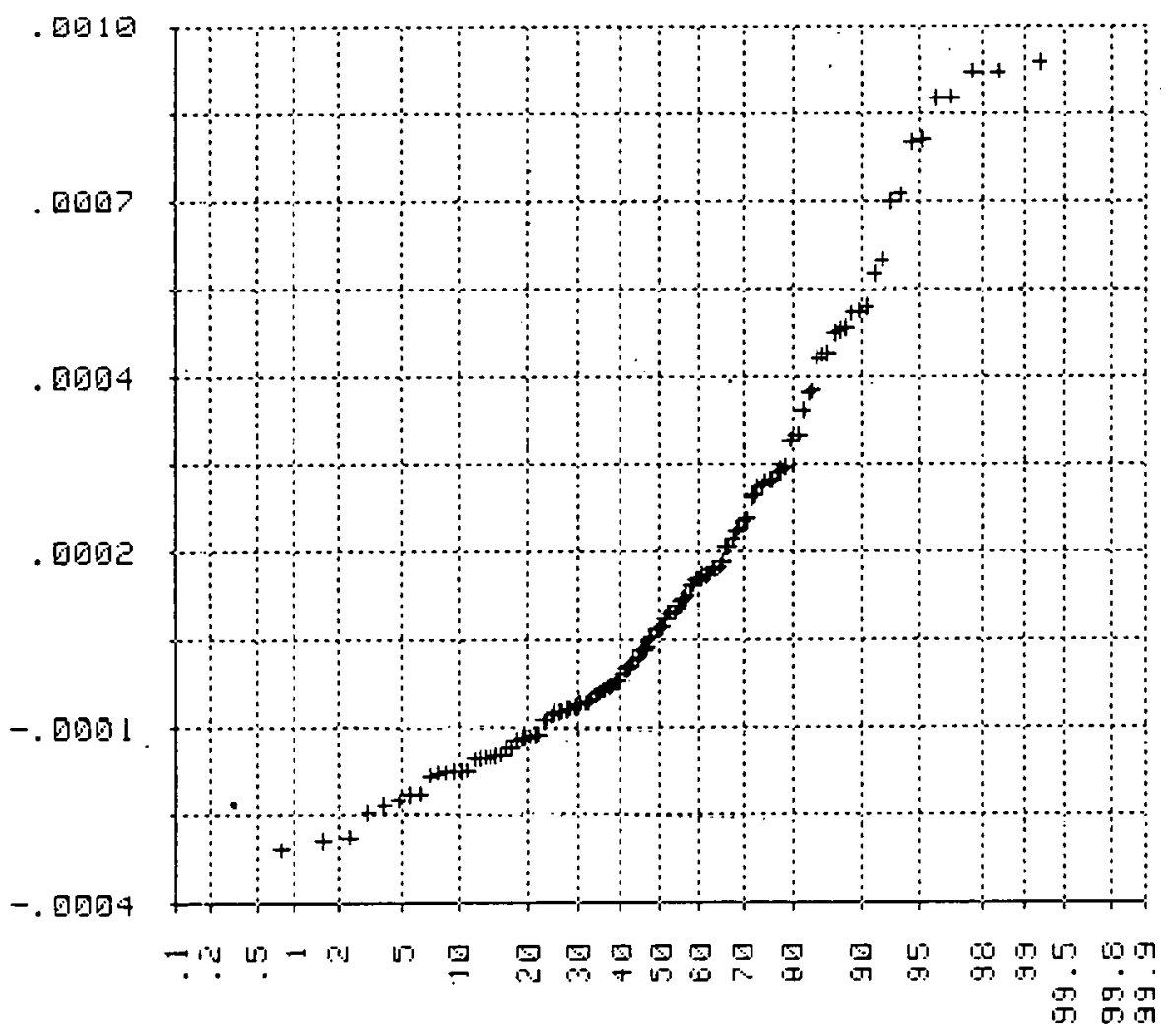

FEFCENT INNIEE

NOFMEL FPOBAEILITY FLOT

Figurie E.5.b.2 Statistical P1ots of A-D for a $E_{F D}$ Disturbance, 

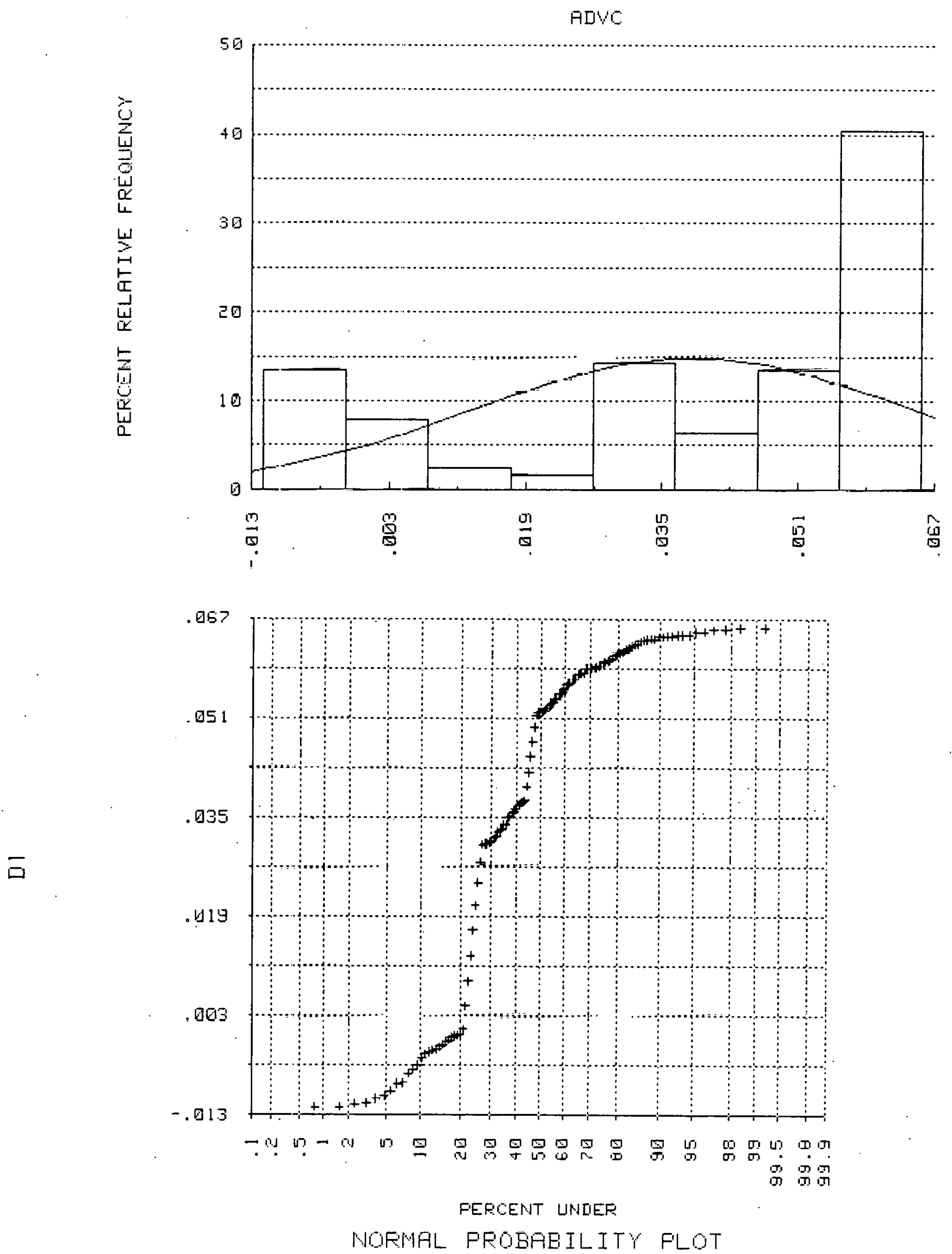

Figure E.5.b.3 Statistical P1ots of A-D for a $E_{F D}$ Disturbance,

Data for $\delta$ 

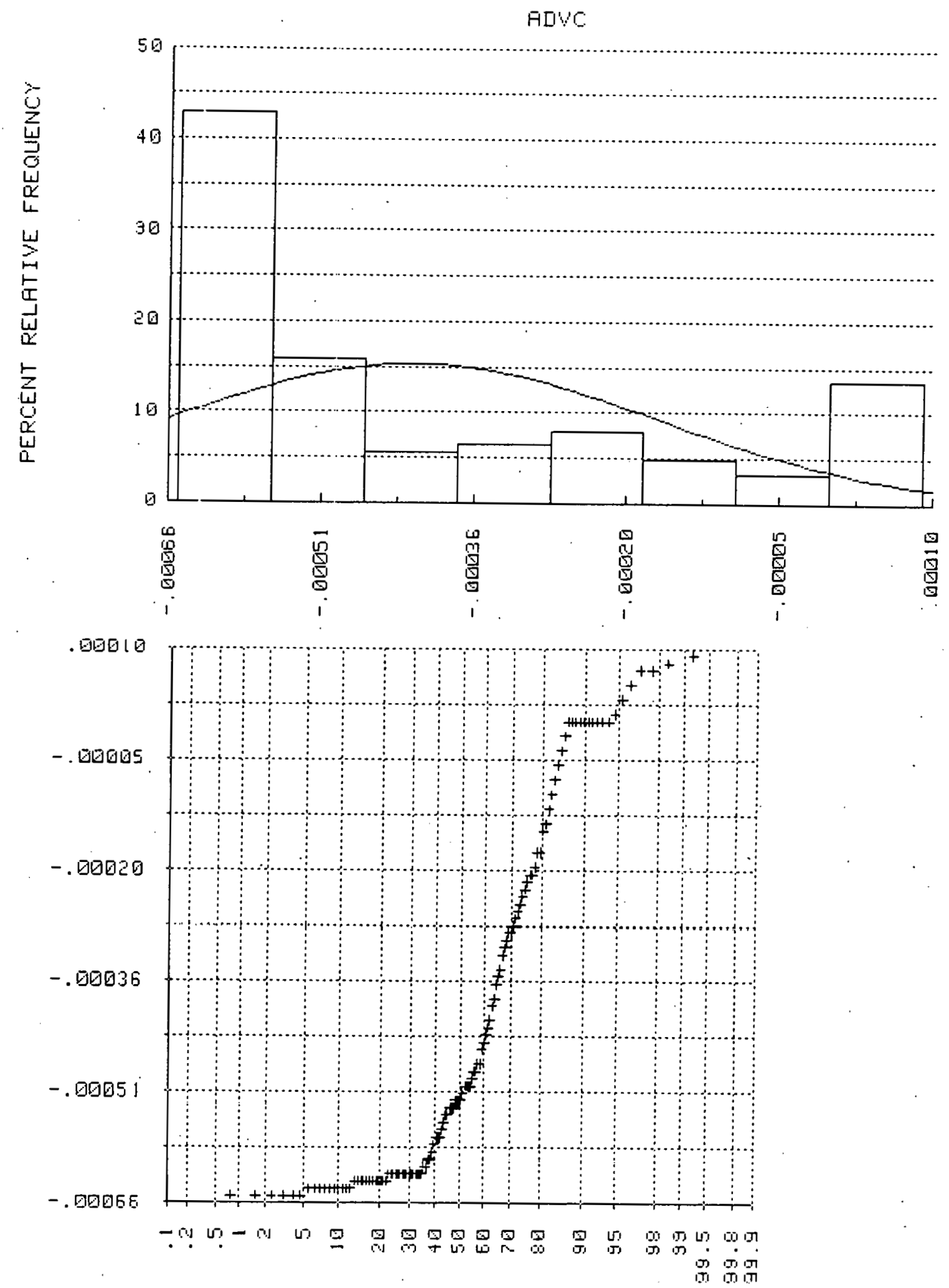

PEFICENT INUER
MPMFL FFOEHEILITY FLOT

Figure E.5.b.4 Statistical Plots of A-D for a $E_{F D}$ Disturbance,

Data for $V_{t}$ 
Table E.7a Statistical Analysis of the Difference between

the F1ux Linkage (Saturated) Model and the E'' Model

with Partial Saturation, Step Change in $\mathrm{T}_{\mathrm{m}}$

\begin{tabular}{|c|c|c|c|c|}
\hline & & & GOEF IF & COEF OIF \\
\hline WAFI I HELE & YAFE I AHEE & STAHIAFII IIEY. & SKE WHESE & KUFTOSIS \\
\hline yt & . 90106日 & .06163 & -.09962 & -.99132 \\
\hline TE & - 10962 & .06416 & .26130 & -.2950 \\
\hline Itamin & - 60 日至 & . 60797 & .05457 & -.12156 \\
\hline III & . 92769 & .16450 & .34659 & -.19689 \\
\hline W引日 & .00060 & - 61日e. & -.51694 & -.45805 \\
\hline Wब & 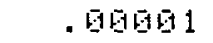 & .61927 & -.39496 & -.95744 \\
\hline$H \tilde{r}$ & $=90600$ & .6192 & -.45197 & -.52434 \\
\hline bled & - 906日6 & - 베년 & - . & -.42561 \\
\hline H.9 & 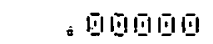 & 20 & $.4 \vec{i}+10$ & .15967 \\
\hline 悄 & 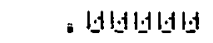 & . $101.1 \mathrm{E}$ & .49291 & $.1224 E$ \\
\hline HFa & 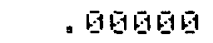 & . -610131 & .47491 & .16920 \\
\hline
\end{tabular}

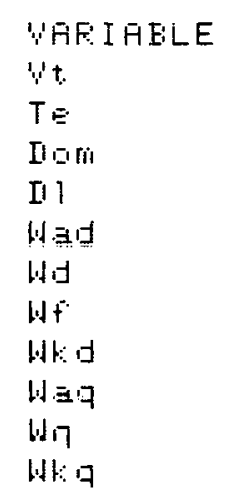

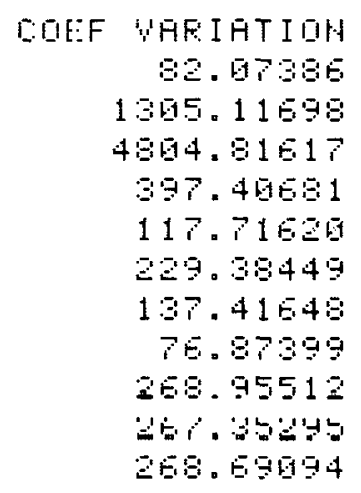

STAHIAFI EFEOE

OF THE MEHH

. 61601

. 06907

. 01067

.01406

. 0614

. 90625

. 0616

. 61011

- $\operatorname{9an} 15$

- 90913

.06012

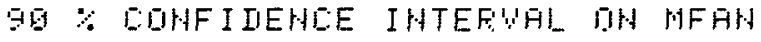
LOWEF LIMIT - 161648

$-.06029$

$-.06134$

- . 6157

.60113

. 96190

.8111

. 00138

- . मAनिF

- . QDOBE

- . 00968
IIFFEF LINIT

.00659

. 6069

.06161

$-.01711$

- 0181

. 0181

. 016

.00171

$-.06029$

- 6 - 6035

$-.06029$

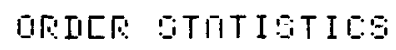

\begin{tabular}{|c|c|c|c|c|}
\hline WFF TAELE & WEXIMU⿴囗十⺝ & 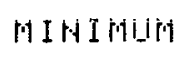 & FAH.GE & MI IIFAHEE \\
\hline Inom & 。国是再5 & 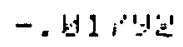 & . 610107 & .90142 \\
\hline W.E. & - 16日9 & - . 16257 & . 06E45 & . Q96E \\
\hline 虰 & - B1E⿺辶 & - . 06553 & .01177 & . 06086 \\
\hline Wi & .61427 & - . & .06752 & - 1065 \\
\hline 梳引口 & . 60295 & - . 98360 & .05595 & - - 1006: \\
\hline W曰 & . 10300 & - . -10383 & .0605 & 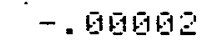 \\
\hline 小1: घ & .09295 & -.60300 & . 01555 & - . 10日0 \\
\hline
\end{tabular}


Table E.7b Statistical Analysis of the Difference between

\author{
F1ux Linkage (Saturated) Model and the E' Model \\ with Partial Saturation, Step Change in $\mathrm{E}_{\mathrm{FD}}$
}

\begin{tabular}{|c|c|c|c|c|}
\hline & & & DOEF GIF & EIIEF DF \\
\hline WFEI I AELE & WFEIAHCE & GTAHIAFI IIEY。 & SKEHHESS & KUFTOSIS \\
\hline$\because t$ & . 606日a & . 961924 & .77341 & - . 86992 \\
\hline$T E$ & - 0 日回日 & . 01018 & -2358 & -.09527 \\
\hline II 口ntit & 。910日0 & . 91600 & 1. 95132 & .46817 \\
\hline II 1 & . DEDE & .02593 & $-.77 \leq 077$ & -.89565 \\
\hline W.at & . 60 日0 & .0605 & .8479 & -1.09157 \\
\hline H. & - ब196010 & . 919678 & .5589 & -1.0505 \\
\hline$\| f$ & - ब1960 & . 9610 & .59277 & -1.05805 \\
\hline Wha & .616160 & . 96480 & .79584 & -1.0950 \\
\hline H: $:$ : & - 619615 & .90504 & -.7455 & - . 9620 \\
\hline W马 & .69696 & .66957 & -.75565 & $-.9+568$ \\
\hline 바: & .65605 & .60904 & -.73926 & -.97894 \\
\hline & & STAHIIAFI EFEOR: & $90 \%$ COHF I IESHEE & IHTEFUAL OH MEHH \\
\hline WFEIAELE & COEF UAFIATIOH & QF THE MEFH & LOHEF: LIMIT & LIFFEF LINIT \\
\hline$y t$ & 57.94022 & . 01002 & -.00045 & -. 00038 \\
\hline$T E$ & 10950.27954 & . 10001 & -.00002 & . 96019 \\
\hline [ignii & 257.17700 & .00063 & . 90607 & . D国国 \\
\hline Ii 1 & EE.971E & . 96231 & .0189 & .94255 \\
\hline wat & 72.37869 & . 018067 & -.05127 & -.9610 \\
\hline Ha & 75.55690 & . 010647 & $-.061 \mathrm{i}$ & -.06092 \\
\hline Wf & 96.27541 & .09016 & -.0180 & -. 10164 \\
\hline Wl: & 61.99793 & . 9019617 & -.09142 & -.90119 \\
\hline W.a口 & 65.1855 & . 10060 & . 01947 & .06057 \\
\hline 49 & 64.91249 & 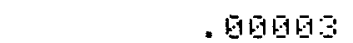 & .0005 & . Q1日EO \\
\hline HE: & 65,04129 & . 1616日3 & .01947 & . 0105.5 \\
\hline
\end{tabular}

DFIEF: STHTISTILS

\begin{tabular}{|c|c|c|c|c|}
\hline UAFI I FELE & Mค: INU⿻ & 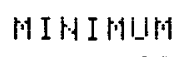 & EAHHE & 円 I IR:AHE \\
\hline$Y t$ & - 51619 & - . 95655 & . 961974 & -.01692 \\
\hline TE & .01629 & -.06632 & . 960 E1 & -.09602 \\
\hline Ingri & . 961994 & - . 60101 & . 0192 & . 01601 \\
\hline III & . 065.56 & - . $117 \mathrm{O}$ & . 67729 & .02690 \\
\hline H.EA & .06949 & -.96198 & .01247 & -.66475 \\
\hline H. & .06947 & -.90183 & . 90236 & - . \\
\hline $4 t^{\circ}$ & . 610181 & - . 003 & . 1098 & -.0008 \\
\hline H: d & - 96025 & - . 16207 & .00232 & -.0609 \\
\hline 1.:三马 & . 101986 & - - 96012 & . 06998 & - 06037 \\
\hline 怕 & .019095 & -.00913 & .00198 & .0064 \\
\hline H1:日 & . 90085 & -.00011 & .00997 & .0693 \\
\hline
\end{tabular}

